\title{
Naturalis
}

\section{Morfología del cráneo y complejo apendicular posterior de aves fororracoideas : implicancias en la dieta y modo de vida}

\section{Degrange, Federico Javier}

Doctor en Ciencias Naturales

Dirección: Tambussi, Claudia P.

Facultad de Ciencias Naturales y Museo

2012

Acceso en:

http://naturalis.fcnym.unlp.edu.ar/id/20120410001209

\section{(c) (i) () ()}

Esta obra está bajo una Licencia Creative Commons

Atribución-NoComercial-Compartirlgual 4.0 Internacional

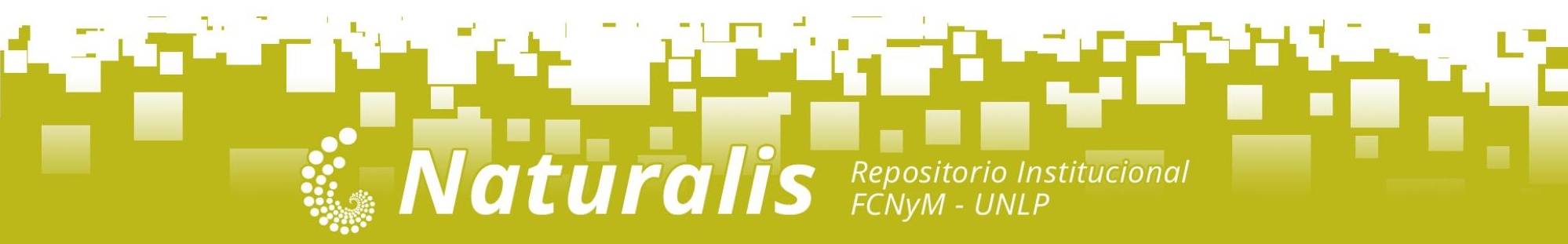




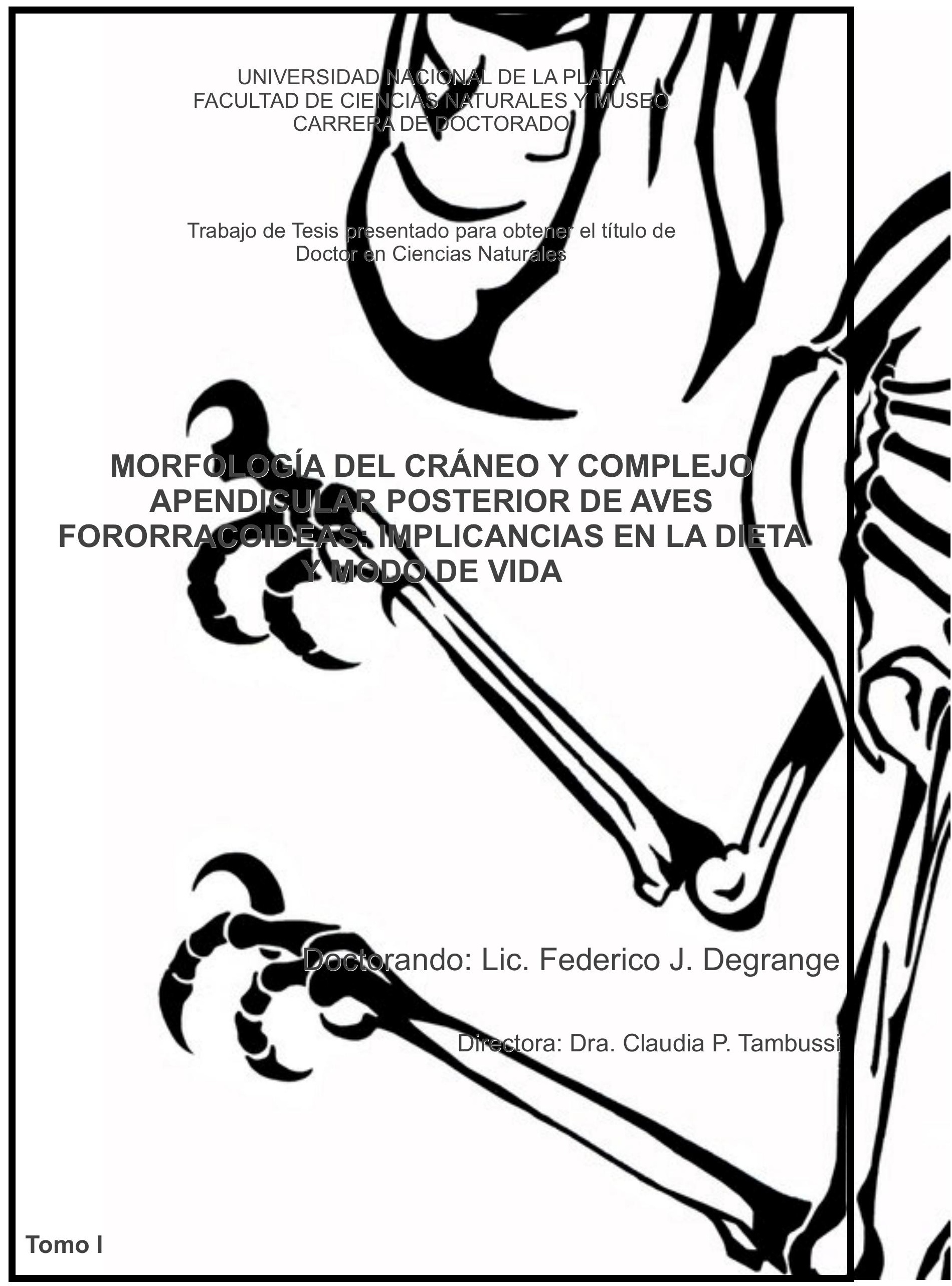


A mi abuelo Tito, quien me enseñó que los dragones SI existen!

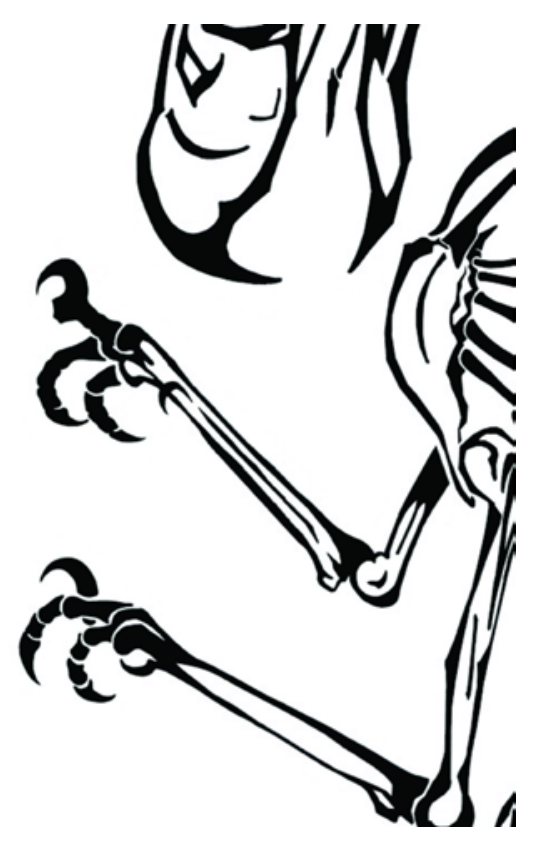




\section{Agradecimientos}

Decir (o en este caso, escribir) "gracias” siempre es más complicado de lo que parece, no por la palabra en sí, sino más bien por lo que implica cuando la decimos y la forma en la que la decimos, tratando de no dejar a nadie afuera y de que el "gracias" realmente refleje al gratitud merecida o debida. Los agradecimientos de esta tesis representaron (realmente) un esfuerzo por hacer memoria, tratando de no dejar afuera a nadie y de recordar a todos aquellos que me han ayudado a llegar a buen puerto, acompañándome no solo durante el transcurso de la tesis, sino desde antes, ya sea a través de la palabra, la compañía o el simple gesto de tomar un mate conmigo.

La razón por la cual cualquier lector puede “disfrutar" la lectura de esta tesis es culpa de todas las personas que menciono a continuación. Sin más, deseo agradecer profundamente a las siguientes personas:

A mi directora, Claudia "la jefa” Tambussi por ser una directora, una amiga, una maestra, una profesora, una guía y una consejera, por siempre permitirme opinar, escuchar y escucharme (incluso en nuestras fervorosas discusiones), por nuestras “rabietas rojas” y "rabietas amarillas" y por ser un soporte fundamental durante un período que empezó en 2002, mucho antes de pensar en una tesis, mucho antes siquiera de pensar que trabajaría en fororracos (después de todo "las Enantiornithes son fantásticas, pero los fororracos son los fororracos!!”, no?).

A mi familia: papá, mamá, Flor y Euge por su cariño, por siempre creer en mí, por apoyarme desde que a los cinco años “decidí” ser paleontólogo y por escucharme y bancarse una vida de escucharme hablar rápido, a los gritos y lo que es peor, mucho!. Sin ustedes y su apoyo, no lo hubiese logrado!.

El resto de la bochinchera familia Degrange-Suarez-Ortiz (abuelos, tíos y primos) no queda exenta de agradecimientos: gracias por fomentar mi pasión (incluso mandándome a "Tiempo de Siembra”) y gracias por tantas reuniones (bochincheras, obvio!) familiares. Han sido mi cable a tierra.

Particularmente, deseo agradecer a José Manuel Suárez (alias “el abuelo Tito”) a quien está dedicada esta tesis: groso entre los grosos si los hay!. La enseñanza más grande que me dejaste es que los dragones si existen! (después de todo luchaste toda mi infancia contra ellos!). Tardé unos cuantos años, pero finalmente creo haberlos encontrado.

A mis compañeras de laboratorio, Mariana Picasso y Clelia Mosto por su amistad, sus mates (los de Mariana son los mejores del mundo!), sus consejos y su constante y molesto recordatorio de lo que significa ser mujer.

Mucho antes de empezar con la tesis (allá por 2001), tuve la suerte de toparme con cuatro personas que siempre han estado cuando los necesité: A Diego Balseiro, Juan José Rustán, Emilia Sferco y Karen Halpern por tantas cursadas compartidas, por tantos mates, por tantos viajes juntos, por tantas luchas (ganadas y perdidas), pero fundamentalmente por seguir a mi lado después de haberme soportado durante toda nuestra formación de licenciatura (después de todo siempre seremos "el grupito de los 
5”, no? Jeje!). A Daniel Cabrera, Javier Echevarría, Leonel Acosta, Nestor Toledo, Yanina Herrera, Carolina Gandrup, Diego Fanello, Ana Carignano, Sonia Ros French, Francisco Solari Orellana, José O’gorman, Guillermo Cassini, Luciano Rasia y Soledad Gouiric por su inagotable amistad, sus consejos, su ayuda y por soportarme durante los cinco años que demandó este proyecto: sé que ha sido difícil!. A Carlita Berghoff por enseñarme a "surfear en la vida" y por demostrarme que no existen obstáculos insuperables. A Carolina Baldini, Andrea Vitalone, Leandro Fantuzzi y David Cottini por ser amigos incondicionales. A Matías Taglioretti por su amistad y compañerismo y la confianza que implica que te consideren como aquel que sabe algo acerca de algo.

A Valeria Rodrígues Capítulo por tantas noches de pizzas, tantos muñecos de fin de año y tantas tardes de mates compartidas. A Alberto Rodrígues Capítulo y Nora Gómez por su amistad, sus sabios consejos y por su ayuda totalmente desinteresada al guiarme por el mundo de la ciencia.

A Juliana Pisonero quien me bancó, soportó y aguantó durante el último recorrido, por su cariño y afecto incondicional, su paciencia y por renovar mi pasión por el dibujo.

A Agustina Martinez Azpelicueta por su amistad, sus mates, sus peleas y discusiones y por su constante ayuda en las gráficas.

A Javier Gelfo por sus charlas, sus consejos, su amistad, su casco de Boba Fett, su asistencia en los análisis filogenéticos, uso del TNT y por la lectura crítica del capítulo 5.

A Alejo Scarano por su constante e incondicional ayuda en cuestiones estadísticas.

A los chicos del laboratorio de al lado, Germán Gasaparini, Alejo Scarano, Ceci Krmpotic y Esteban Soibelzon, por su constante buena onda y predisposición.

A mi gran amigo Dave Dufeau por alojarme en su casa durante mi estadía en Athens y por todos sus consejos y ayuda en el manejo de tomografías y software.

A Marcos Cenizo por las tan interesantes discusiones que sabe crear.

A mis compañeros de la cátedra de Anatomía Comparada: Martín Ciancio, Nacho Quelas, Paula Bona, Carolina Vieytes, Darío Colautti, Leandro Alcalde, Leandro Balboni, Sabina Prado, Tomás Maiztegui y Joaquín Carreras por enseñarme como ser un mejor docente.

A Marcelo Tejedor, Sergio Vincon y Laureano González por su invitación a participar en una campaña a Santa Cruz en 2007, donde se realizó un hallazgo de Psilopterinae clave para el desarrollo de esta tesis. A Adan Tauber por facilitar el trámite de préstamo de dicho material, por permitirme consultar materiales bajo su cuidado y por "enseñarme a abrir y cerrar tranqueras".

A los Dres. Stephen Wroe y Karen Moreno por presentarme y guiarme en el fantástico mundo del análisis de elementos finitos. Particularmente, deseo agradecer al 
Dr. Wroe por financiar parte de mi viaje a Cleveland (EEUU) en 2008 para participar en la SVP, lo que me permitió además consultar material en el laboratorio del Dr.

Lawrence Witmer.

$\mathrm{Al}$ Dr. Lawrence Witmer por permitirme trabajar en su laboratorio y permitirme de forma totalmente desinteresada el acceso a los materiales bajo su resguardo, por sus charlas y por la toma de fotografías. No puedo no agradecerle por la experiencia mediática surgida a partir del trabajo de FEA en Andalgalornis.

Al Dr. Casey Holliday por la bibliografía y las charlas acerca del EPB.

Al Dr. Jorge "Nacho" Noriega por sus consejos y charlas, por su amistad, por permitirme el acceso a unos materiales bajo su resguardo y por su invitación a participar en el capítulo de Aves fósiles del libro de la Formación Santa Cruz.

A Sandra D. Chapman por las fotos suministradas de los materiales de Phorusrhacidae depositados en el British Museum.

A Guillermo López y Leopoldo Soibelzon por invitarme a participar de las campañas a su cargo.

A Washington Jones por su amistad y por demostrarme que las acciones nobles y desinteresadas son todavía moneda corriente.

A Cecilia Morgan y Rolando González-José por su asistencia incansable en cuestiones de morfometría geométrica.

A los profesores y compañeros del Paleobiology Database Instensive Summer Course: Gene Hunt, Mark Webster, Tom Olsewski, John Alroy y Pete Wagner; Annie Lagomarcino, Amelinda Webb, Aaron House, Felix Marx, Gary Motz, Fred Whiteman, Heike Mewis, Kaitlin Maguire, Katie Collins y Mark Bell, no solo por enseñarme herramientas y técnicas de avanzada, sino fundamentalmente por su amistad, las charlas, las salidas en cinco semanas de convivencia que siempre recordaré y por enseñarme que al software R hay que quererlo, no odiarlo ... Igual, todavía lo odio! (pero al menos lo uso).

A Luis Chiappe y Kimberly Page Johnson de Natural History Museum of Los Angeles County (Los Angeles), a William Simpson, Jim Holstein y Karsten Lawson del Field Museum of Natural History (Chicago); a Christopher Norris, Dan Brinkman y Marilyn Fox del Yale Peabody Museum (New Haven); a Carl Mehling de American Museum of Natural History (New York); a Alejandro Kramarz del Museo Argentino de Ciencias Naturales Bernardino Rivadavia (ciudad autónoma de Buenos Aires); a Marcelo Reguero del Museo de La Plata (La Plata) y a Alejandro Dondas y Fernando Scaglia del Museo Tradicional Lorenzo Scaglia (Mar del Plata) por permitirme y facilitarme el acceso a las colecciones que resguardan.

A Gerald Mayr por la bibliografía facilitada.

A Miguel Giardina y Leandro Alcalde por facilitarme material fresco de aves. 
Al Área Educativa y Difusión Científica del Museo de La Plata donde siempre me recibieron con los brazos abiertos y me permitieron participar de sus proyectos.

A los Dres. Eduardo P. Tonni y Silvia Ametrano por permitirme hacer del Museo de La Plata un segundo hogar.

A los Dres. Kaufman, Nicolas Nissan, Sebastian Salvarregui, Nevenka Klinar, Daniel Cagnolo y a la Srita. Miriam Risso de Investigaciones Médicas, por su asistencia en la obtención de tomografías del cráneo de fororracos. A los Dres. Raul Simonetto, Natalia Perello y Luciana Lorenzi y a las técnicas Lorena Pereyra y Rosario Quispe por su entusiasmo y ayuda en la obtención de tomografías en Ipensa (La Plata).

A CONICET por el otorgamiento de las becas de postgrado tipo I y II, las cuales subsidiaron el desarrollo de esta tesis.

A los proyectos PICT 32617, PIP 5694 y PIP 0437 por subsidiar parte de algunas de las investigaciones realizadas durante el desarrollo de la tesis.

A la Oficina de Postgrado de la Facultad de Ciencias Naturales y Museo.

A mis jurados de tesis, Jorge Noriega, Julia Desojo y Cecilia Morgan por la lectura crítica y las valiosas correcciones.

Y finalmente a ellos, a los fororracos (mis “Dragones del Cenozoico”), por dejarme estudiarlos y fascinarme con toda su magnificencia.

... espero haberlo hecho bien.

Federico “Dino” Degrange 
"...because the basic organization of the avian body is so closely associated with its adaptation for flight, a flightless birds is almost a contradiction in terms."

R.J. Raikow (1985)

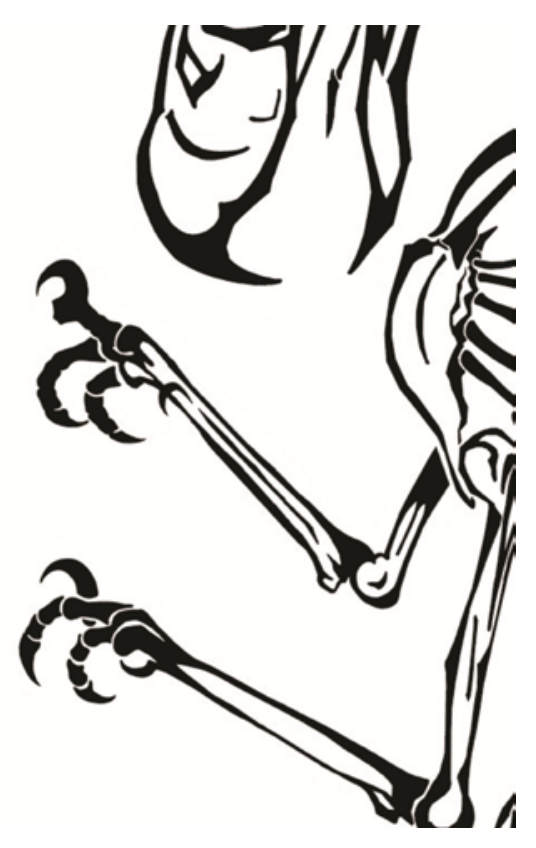


Índice general

Resumen I

Abstract IV

Capítulo1. Introducción 1

1.1 Que es un "fororraco"? 2

1.2. Generalidades acerca del marco de estudio 2

1.3. Objetivos de esta tesis 3

1.3.1. Objetivo general 4

1.3.2. Objetivos específicos 4

1.4. Hipótesis de trabajo 4

1.5. Desarrollo de la tesis 4

Capítulo 2. Antecedentes y marco teórico 6

2.1. Antecedentes 6

2.1.1. Propuestas sistemáticas previas: Los "Gruiformes" Phorusrhacidae 6

2.1.2. Los Cariamiformes Phorusrhacidae $\quad 7$

2.1.3. Los controversiales "Brontornithinae" y Paleopsilopterus 8

Brontornis burmeisteri $\quad 8$

Paleopsilopterus itaboraiensis 9

2.1.4. Distribución estratigráfica y geográfica de los Phorusrhacidae $\quad 10$

2.2. Estudios paleobiológicos previos 12

2.3. Marco teórico 13

2.3.1. Morfología funcional y el complejo forma-función 13

2.3.2. Ecomorfología y aproximaciones "Taxon free" 16

2.3.3. Módulos locomotores: bipedalismo, terrestrialidad y cursorialidad 19

Capítulo 3. Materiales $\quad 23$

3.1. Abreviaturas institucionales 23

3.2. Material estudiado 23

3.2.1. Especies fósiles $\quad 23$

A) Phorusrhacidae $\quad 23$

B) Otras aves fósiles $\quad 30$

3.2.2. Especies actuales 31

Capítulo 4: Descripción osteológica 35

4.1. Nomenclatura anatómica 35

4.2. Descripción $\quad 35$

$\begin{array}{ll}\text { 4.2.1. Generalidades del cráneo } & 35\end{array}$

4.2.2. Ossa cranii $\quad 36$

A) Región occipital $\quad 36$

B) Región parietal $\quad 37$

C) Región paraesfenoidal $\quad 37$

D) Región ótica 38

E) Ossa laterosphenoidalis $\quad 38$

F) Región frontal $\quad 38$

G) Zona flexoria craniofascialis $\quad 39$

H) Región orbital $\quad 39$ 
4.2.3. Ossa faciei

A) Fenestra antorbitalis 41

B) Os maxillare y processus maxillopalatinus

C) Pico $\quad 43$

D) Apertura nasi ossea 44

E) Ossa palati $\quad 45$

F) Arcus jugalis $\quad 46$

G) Os quadratum $\quad 47$

4.2.4 Ossa mandibulae $\quad 49$

$\begin{array}{ll}\text { 4.2.5. Morfotipos craneanos } & 50\end{array}$

A) Morfotipo I o "cráneo tipo Psilopterinae" 50

B) Morfotipo II o "cráneo tipo Terror bird"

4.2.6. Pelvis: ossa coxae $\quad 53$

4.2.7. Morfotipos pélvicos $\quad 56$

A) Morfotipo I o "pelvis tipo Psilopterinae" 56

B) Morfotipo II o "pelvis tipo Terror bird" $\quad 57$

4.2.8. Ossa membri pelvici $\quad 57$

A) Fémur $\quad 58$

B) Tibiotarso $\quad 59$

C) Fíbula $\quad 61$

D) Tarsometatarso $\quad 61$

E) Ossa digitorum pedís 63

Capítulo 5: Posición Filogenética de los Phorusrhacidae 66

5.1. Contexto filogenético 66

5.2. Análisis cladístico $\quad 67$

5.3. Resultados: Posición filogenética $\quad 68$

$\begin{array}{ll}\text { 5.4. Filogenia intrafamiliar } & 70\end{array}$

5.5. Discusión y conclusiones: Cariamiformes 71

Capítulo 6. Estimaciones de tamaño y fuerza de mordida 74

$\begin{array}{ll}\text { 6.1. Altura y postura } & 74\end{array}$

6.1.1. Resultados $\quad 75$

$\begin{array}{ll}\text { 6.2. Estimación de masa } & 75\end{array}$

$\begin{array}{lr}\text { 6.2.1. Resultados } & 80\end{array}$

$\begin{array}{ll}\text { 6.3. Tamaño } & 81\end{array}$

6.4. Fuerza de mordida de los Phorusrhacidae $\quad 82$

Capítulo 7. Miología mandibular y apendicular posterior de los fororracos $\quad 86$

7.1. La factibilidad y la importancia de reconstruir partes blandas 86

$\begin{array}{ll}\text { 7.2. Extant Phylogenetic Bracket (EPB) } & 87\end{array}$

$\begin{array}{lr}\text { 7.3. Nomenclatura anatómica } & 89\end{array}$

7.4. Reconstrucción muscular $\quad 89$

$\begin{array}{lr}\text { 7.4.1. Músculos mandibulares } & 90\end{array}$

A) M. Adductor mandibulae internus $\quad 91$

B) M. Adductor mandibulae externus $\quad 95$

C) M. Adductor mandibulae posterior $\quad 97$

D) M. Constrictor internus dorsalis $\quad 97$

E) M. Abductores $\quad 99$

7.4.2. Músculos del complejo apendicular posterior $\quad 100$ 
A) Músculos extensores de la cadera (articulación pelvis-fémur) 102

B) Músculos flexores de la cadera (articulación pelvis-fémur) 104

C) Músculos extensores de la articulación fémur-tibiotarso 105

D) Músculos flexores de la articulación fémur-tibiotarso 106

E) Músculos extensores de la articulación tibiotarso-tarsometatarso 107

F) Músculos flexores de la articulación tibiotarso-tarsometatarso 108

G) Músculos de los dedos 108

G.1) Músculos extensores de los dedos $\quad 109$

G.2) Músculos flexores de los dedos. 109

$\begin{array}{ll}\text { 7.5. Discusión y conclusiones } & 110\end{array}$

Capítulo 8. Caracterización del aparato trófico de los fororracos 115

8.1. Análisis de la quinesis en los Phorusrhacidae 116

$\begin{array}{ll}\text { 8.1.1. Quinesis aviana } & 116\end{array}$

8.1.2. Aquinesis en Phorusrhacidae 118

$\begin{array}{ll}\text { A) Anatomía } & 118\end{array}$

B) Modelo mecánico del cráneo de los fororracos $\quad 121$

$\begin{array}{lr}\text { 8.2. Análisis biomecánicos } & 122\end{array}$

8.2.1. Análisis de Elementos Finitos (FEA) 122

8.2.1.a. Introducción al FEA 122

8.2.1.b. FEA aplicada a fororracos $\quad 125$

$\begin{array}{ll}\text { Modelado } & 125\end{array}$

Análisis $\quad 126$

$\begin{array}{ll}\text { Resultados } & 128\end{array}$

8.2.2. Mecánica mandibular: brazos de momento 128

Metodología $\quad 129$

$\begin{array}{ll}\text { Resultados } & 131\end{array}$

8.3. Discusión y conclusiones $\quad 132$

$\begin{array}{ll}\text { 8.3.1. Aquinesis } & 132\end{array}$

8.3.2. Evolución de la aquinesis en los fororracos 137

$\begin{array}{ll}\text { 8.3.3. FEA } & 138\end{array}$

8.3.4. Brazos de momento 139

8.3.5. Comportamiento depredador 140

Capítulo 9. Morfometría $\quad 142$

9.1. Introducción al enfoque cuantitativo 142

9.2. Morfometría clásica: medidas $\quad 143$

9.2.1. Métodos 143

9.2.2. Análisis y resultados $\quad 146$

A) Diversidad locomotora: Gráfico ternario 146

B) Análisis de componentes principales (PCA) 147

$\begin{array}{ll}\text { Fémur } & 147\end{array}$

$\begin{array}{ll}\text { Tibiotarso } & 148\end{array}$

$\begin{array}{lr}\text { Tarsometatarso } & 149\end{array}$

$\begin{array}{lr}\text { Miembro posterior } & 150\end{array}$

$\begin{array}{lr}\text { Índices del miembro posterior } & 150\end{array}$

C) Análisis discriminantes $\quad 151$

Tarsometatarso 151

Miembro posterior $\quad 152$

9.3. Morfometría geométrica 153 
9.3.1. Método

9.3.2. Análisis y resultados

A) Cráneo

157

Neurocráneo dorsal de fororracos 157

$\begin{array}{ll}\text { Neurocráneo lateral de fororracos } & 157\end{array}$

$\begin{array}{lr}\text { Cráneo dorsal } & 158\end{array}$

$\begin{array}{lr}\text { Cráneo lateral } & 158\end{array}$

Cráneo lateral de aves carnívoras $\quad 159$

$\begin{array}{ll}\text { Esplacnocráneo } & 160\end{array}$

$\begin{array}{ll}\text { Pico } & 160\end{array}$

B) Pelvis 161

Pelvis Dorsal $\quad 161$

Pelvis Lateral 162

9.4. Discusión y conclusiones 162

9.4.1. Cráneo y diversidad trófica 162

9.4.2. Miembro posterior y locomoción 165

Hábito locomotor y uso del sustrato 165

$\begin{array}{ll}\text { Proporciones del miembro } & 167\end{array}$

PCA y análisis discriminantes 168

$\begin{array}{ll}\text { Morfometría de la pelvis } & 170\end{array}$

Capítulo 10. Conclusiones finales 173

10.1. Vuelo 173

10.2. Locomoción terrestre $\quad 175$

10.3. Relación depredador-presa y el comportamiento

$\begin{array}{lr}\text { 10.4. Ecomorfos } & 180\end{array}$

10.5. Los fororracos y la división de nichos tróficos 181

$\begin{array}{ll}\text { 10.6. Contraste de hipótesis } & 182\end{array}$

Perspectivas $\quad 186$

Referencias bibliográficas 188 


\section{Resumen}

Los Phorusrhacidae comprenden uno de los grupos de aves más característicos y diversos del Cenozoico sudamericano. Son considerados como depredadores dominantes en las cadenas tróficas durante el período de aislamiento acaecido en Sudamérica durante el Cenozoico, rol que habrían compartido con los marsupiales y cocodrilos terrestres. Su pico alto, angosto y largo terminado en gancho es un rasgo exclusivo. Sin embargo, no es su única característica peculiar. A diferencia del resto de las Neornithes, los fororracos perdieron la capacidad de flexionar el pico dorsoventralmente (una cualidad conocida como quinesis aviana). Esta inmovilidad craneana denominada aquinesis no es conocida en otras aves depredadoras y constituye sin dudas un rasgo derivado de este clado.

Se estudiaron las 19 especies consideradas originalmente como fororracos y se analizaron todos los materiales de Phorusrhacidae depositados en museos nacionales e internacionales. Aplicando técnicas modernas de morfometría geométrica y clásica, biomecánicas y reconstrucción muscular en un contexto filogenético apropiado, se realizó la descripción cuantitativa y cualitativa del diseño del cráneo (como expresión de la manera en que se adquiere y manipula el alimento) y del complejo apendicular posterior (como relevante en la locomoción). Se analizó el funcionamiento del cráneo a partir de un análisis quinético y de un análisis de elementos finitos que sentó las bases para interpretar la estrategia de caza de estos animales.

Considerando todas las líneas de evidencias puede sostenerse que el diseño del cráneo, particularmente la forma tan singular del pico y la rigidez craneana ligada a la aquinesis, son en conjunto muy apropiados para matar presas. El cráneo tiene un diseño apropiado para ejercer poderosas fuerzas de mordida y golpes verticales y precisos contra posibles presas, pero no para resistir fuerzas laterales y de torsión en tanto serían potencialmente perjudiciales. La reconstrucción muscular, la aquinesis y los análisis biomecánicos del cráneo y de la musculatura adductora mandibular de los fororracos muestran que el aparato trófico está optimizado para la fuerza a expensas de la velocidad. Se interpreta que la captura y manipulación de las presas consistiría en la abertura rápida de la boca, sometimiento a partir de golpes verticales de la cabeza, inmovilización de la presa con una fuerza de mordida poderosa evitando cualquier esfuerzo lateral o de torsión que pudiese ser ocasionado por los movimientos de la 
misma. Finalmente, desmembramiento y desgarro de la presa utilizando el gancho del pico mediante movimientos de dirección cráneocaudal (pullback).

En cuanto al complejo apendicular posterior, los fororracos poseen atributos morfológicos que pueden ser asociados inequívocamente a una locomoción cursorial: la pelvis alta y elongada postacetabularmente, con un antitrochanter muy desarrollado, el tibiotarso y tarsometatarso alargados, el alto desarrollo de las cristae cnemialis del tibiotarso, tres dígitos relativamente cortos dirigidos hacia adelante y la posición elevada de un dígito que no toma contacto con el suelo. Estas características, junto al fuerte desarrollo de la musculatura extensora, señalan el hábito locomotor terrestre y resaltan también la capacidad cursorial de estas aves. En términos de hábito de vida, los caracteres del módulo locomotor posterior indican una técnica de detección de presas mediante desplazamiento lento (caminar) y una técnica de captura basada en la persecución activa de las presas (cursorialidad). Esta última evidenciada por una alta capacidad de maniobrabilidad que los facultaba para poder perseguir a sus presas durante lapsos prolongados e incluso empleando movimientos esquivos.

La evidencia morfológica analizada en esta tesis permite discriminar dos patrones morfológicos tanto para el cráneo como para la pelvis: el tipo "psilopterino” y el tipo “terror bird”. Sin embargo, estos dos morfotipos habrían tenido un funcionamiento muy similar. Si bien el tipo “terror bird” podría considerarse como una especialización evolutiva, la forma y función de ambos complejos (trófico y apendicular) evidencian que las facultades de ambos morfotipos son la de golpear y correr respectivamente, por lo cual se infiere que el rol biológico es la adaptación a un tipo de cacería muy particular, persiguiendo y matando a picotazos. En otras palabras, todos los fororracos son similares desde el punto de vista ecomorfológico y desempeñaban el papel de activos depredadores cursoriales.

En los depredadores, la masa corporal está fuertemente ligada a la selección de la presa: cuanto mayor sea el depredador, mayor podrá ser el tamaño de sus presas potenciales. Las presas disponibles dependen de las relaciones de masa y del comportamiento tanto del depredador como de la presa, con la fuerza de mordida jugando un papel secundario. La morfología del pico de los fororracos y el alto valor de stress calculado para esfuerzos laterales parecen indicar que presas de gran tamaño podrían ser perjudiciales. En tanto las aves no pueden utilizar los miembros anteriores para manipular sus presas y sólo dependen del accionar de la cabeza, cuello y patas, puede inferirse que los fororracos consumían presas de menor tamaño que ellos mismos. 
Es posible asumir una repartición de nichos respecto al tamaño de las presas entre fororracos de diferentes tallas. Las presas más pequeñas como los roedores podrían haber sido devoradas por los Psilopterinae; los mamíferos con masas de hasta 10 o 20 kg estarían al alcance de los Patagornithinae, mientras que los de mayor masa y talla serían posibles presas de los Mesembriornithinae y Phorhusracinae que probablemente podrían perseguir y matar animales de hasta 100-130 kg. Formas de kilaje superior probablemente eran inaccesibles a los fororracos.

La ejecución de esta tesis doctoral representa una importante tentativa para unificar mejor los campos de la anatomía, la morfología funcional y la ecología y completar la información acerca de los Phorusrhacidae, pretendiendo integrar estudios funcionales, biomecánicos, ecomorfológicos y paleontológicos en un marco filogenético adecuado para evaluar hipótesis sobre el rol depredador de estas aves. 
The Phorusrhacidae comprises one of the most characteristic and diverse groups of birds of the South American Cenozoic. They are considered as dominant predators in the trophic chains during the isolation period occurred in South America in the Cenozoic, a role that they have shared with marsupials and terrestrial crocodiles. Its high, narrow and long beak that ends in a hook is an exclusive feature; however it is not its only peculiar characteristic. Unlike the rest of the Neornithes, phorusrhacids lost their capacity to dorso-ventrally flex their beak (quality known as avian kinesis). This cranial immobility called akinesis is unknown in other predator birds and doubtless constitutes a derived feature of this clade.

The 19 species originally considered as phorusrhacids were studied and all the Phorusrhacidae materials, housed in national and international museums, were analyzed. A quantitative and qualitative description of the skull design (as an expression of how it acquires and manipulates food) and the posterior appendicular complex (as relevant in the locomotion) was made. This was accomplished using modern techniques of classic and geometric morphometry, biomechanics, and muscle reconstruction in a proper phylogenetic context. We analyzed the skull performance from a kinetic analysis and finite element analysis which set the basis for interpreting the hunting strategy of these animals.

Considering all the lines of evidence together, it can be argued that the design of the skull, particularly the singular shape of the beak and the skull rigidity linked to akinesis, are, as a whole, well suited to kill. The skull is well designed to exert powerful bite forces and accurate vertical strikes against potential prey rather than to resist lateral and torsion loadings as they would be potentially harmful. The muscle reconstruction, the akinesis, and the biomechanical analysis of the skull and of the mandibular adductor muscles of the phorusrhacids show that the trophic apparatus is optimized for strength at the expense of speed. It is interpreted that the capture and manipulation of prey would consist in the quick opening of the mouth, submission from vertical strokes of the head, immobilization of the prey with a powerful bite force preventing any lateral or torsional effort that might be caused due to its movement. Finally, dismemberment and tear of the prey using the hook of the beak by pullback movements. 
As for the posterior appendicular complex, the phorusrhacids have morphological attributes that can be unequivocally associated with cursorial locomotion: a high and elongated postacetabularly pelvis, with a highly developed antitrochanter, elongated tarsometatarsus and tibiotarsus, the high development of the cristae cnemialis of the tibiotarsus, three relatively short digits directed forward and the elevated position of a digit that does not make contact with the ground. These features, together with the strong development of the extensor muscles, indicate the terrestrial locomotor habit and also highlight the cursorial ability of these birds. In terms of lifestyle, the posterior locomotor module characters indicate a technique for detecting prey by slow moving (walking) and a capture technique based on the active pursuit of prey (cursorial). The latter evidenced by high maneuverability that empowered to pursue their prey for long periods and even using elusive movements.

The morphological evidence analyzed in this thesis allows to discriminate two morphological patterns for both the skull and the pelvis: the "psilopterine" type and the “terror-bird” type. However, these two morphotypes may have had a very similar performance. While the "terror bird" could be considered as an evolutionary specialization, form and function of both complexes (trophic and appendicular) show that the capacities of both morphotypes is to hit and to run, respectively, so it is inferred that the final biological role is the adaptation to a very particular type of hunting, chasing and killing using their beaks. In other words, all phorusrhacids are similar from the ecomorphological point of view and played the role of active cursorial predators.

In predators, body mass is strongly linked to the prey selection: the larger the predator, the greater will be the size of potential prey. Available prey depends on the mass ratios and the behavior of both the predator and the prey, with bite force playing a secondary role. The morphology of the phorusrhacid beak and the high value of stress calculated for lateral forces suggest that large prey could be harmful. While birds cannot use the forelimbs to manipulate their prey and only depend on the actions of the head, neck and hindlimbs, it can be inferred that the phorusrhacids consumed prey smaller than themselves. It is possible to assume a distribution of niches on the size of prey between phorusrhacids of different sizes. The smaller prey such as rodents could have been eaten by Psilopterinae; mammals with masses up to 10 or $20 \mathrm{~kg}$ would be available to Patagornithinae while those of greater mass and size would be potential prey of Mesembriornithinae and Phorhusracinae, who probably could chase and kill animals 
that weight up to 100-130 kg. Forms of higher body masses were probably inaccessible to phorusrhacids.

The execution of this thesis represents an important attempt to a better unification of the anatomy, functional morphology and ecology fields, and to complete the information about the Phorusrhacidae, trying to integrate functional, biomechanical, ecomorphological and paleontological studies in a phylogenetic framework suitable for testing hypotheses about the predatory role of these birds. 


\section{Capítulo 1. Introducción}

Desde sus primeros descubrimientos a finales del siglo XIX, los taxones incluidos en la familia Phorusrhacidae llamaron la atención por el gran tamaño de algunos de estos animales y la estructura del pico terminado en gancho. A partir de esta imagen se enraizó en la bibliografía la idea que eran aves depredadoras violentas y sanguinarias a tal nivel que Larry G. Marshall en 1978 las nominó "terror birds". De esta manera, la imagen que popularmente se asocia a un fororraco es la de un "terror bird" (Figura 1.1). Lo cierto es que los fororracos incluyen formas de grandes dimensiones, pero también de mucho menor porte. Los representantes más pequeños (algunos con aproximadamente 90 centímetros de altura) no constituyen aquello que en términos populares es un ave del terror.

Los fororracos comprenden uno de los grupos de aves más característicos y diversos del Cenozoico sudamericano. Son considerados como uno de los depredadores dominantes en las cadenas tróficas del Cenozoico sudamericano (Ameghino, 1895; Andrews, 1899; Sinclair y Farr, 1932; Kraglievich, 1940; Tambussi y Noriega, 1996; Alvarenga y Höfling, 2003; Chiappe y Bertelli, 2006; Alvarenga et al., 2011). Durante la mayor parte del tiempo en que se registran los Phorusrhacidae, esto es del Eoceno al Pleistoceno, América del Sur permaneció aislada del resto de los continentes y estaba habitada por una fauna muy particular: entre las aves la función de carniceros era ocupada fundamentalmente por los fororracos y entre los no-avianos la desempeñaban marsupiales y reptiles mientras que los herbívoros (como en el resto del mundo) eran mamíferos placentarios. Los marsupiales tendieron a estar representados por formas grandes como los Borhyaenidae, mientras que los reptiles por los cocodrilos terrestres (Tambussi, 2011). Los últimos posiblemente habitaran ambientes forestados mientras que los grandes fororracos lo hacían en ambientes más abiertos. Las Américas se conectaron hace aproximadamente 3 millones de años con el surgimiento del istmo de Panamá y los fororracos son uno de los ejemplos de fauna que se desplazó del sur al norte participando del Gran Intercambio Biótico Americano (e.g., MacFadden et al., 2007). Los carnívoros placentarios por su lado se desplazaron hacia América del Sur. No es fácil de entender si los fororracos fueron los competidores directos con estos últimos o si la diversidad estaba declinando por otras razones por ejemplo ambientales, pero lo cierto es que los fororracos declinan en diversidad hacia el Plioceno. Sus últimos 
registros en América del Sur datan del Pleistoceno (Tambussi et al., 1999, Alvarenga et al., 2010; Montenegro et al., 2010).

\section{1. ¿Qué es un fororraco?}

Los fororracos (=Phorusrhacidae) son aves Cariamiformes extinguidas con miembros posteriores alargados, pelvis angostas, miembros anteriores reducidos y especialmente cráneos llamativamente grandes, dotados de un pico alto, angosto y largo terminado en un gancho.

Incluyen a los psilopterinos de pequeño porte y a los "terror birds". Se caracterizan por su hábito depredador con gran capacidad cursorial y escasa o nula capacidad de vuelo. Numerosos caracteres son comunes a todos ellos: la presencia de un paladar completamente desmognato, una articulación basipterigoidea con procesos en el rostrum parasphenoidale y sobre el os pterygoideum, ausencia de processi uncinatum en las costillas, reducción del processus acrocoracoideus y procoracoideus del os coracoideum, la presencia de un processus flexorius del húmero muy desarrollado y un hypotarsus de contorno triangular cuando se lo observa en vista caudal. Su pico alto, angosto y largo terminado en gancho es un rasgo exclusivo, que no está presente en ninguna otra ave, sea fósil o actual. Si algo hace referencia inequívoca a los fororracos es la morfología de su pico. Sin embargo, no es la única característica peculiar que tienen. A diferencia del resto de las Neornithes, los fororracos perdieron la capacidad de flexionar el pico dorso-ventralmente (una cualidad conocida como quinesis aviana). Esta inmovilidad craneana denominada aquinesis no es conocida en otras aves depredadoras. La aquinesis sumada a la forma tan singular del pico son en conjunto muy apropiados para matar.

\subsection{Generalidades acerca del marco de estudio}

Hay una fuerte tendencia a correlacionar la morfología y su uso potencial, aunque elucidar adecuadamente la manera en que este acoplamiento actúa, depende en última instancia de las posibilidades de encontrar análogos biológicos vivientes y/o la modelización mecánica. No se reconocen análogos para estas aves y los eventos cladogenéticos de diferenciación parecen haber sido muy distantes, por lo cual la adjudicación de modos de vida en general y más en particular de roles tróficos se ven seriamente restringidas. 
La morfología del cráneo se encuentra relacionada por una parte con la biomecánica y energética de la alimentación y, por otra parte, con otros aspectos ecológicos y etológicos. Estos últimos están íntimamente relacionados con la selección de hábitat y con la conducta que despliega el animal durante la captura y selección de alimento, por lo cual indudablemente tiene relevancia su capacidad de locomoción. La especialización morfológica y de la manipulación de las presas puede proveer a algunos depredadores de los recursos alimentarios que pudieran ser inaccesibles a otras especies de hábitos relacionados. Como consecuencia, puede producirse una partición de nichos, dislocación de caracteres y diversificación evolutiva. De hecho, hay un precedente fuerte para predecir la relación entre la morfología y su uso potencial (Wainwright, 1991; Wainwright y Reilly, 1994). Sin embargo, elucidar las causas de este acoplamiento depende, en última instancia, de las posibilidades de relacionar morfología con ecología a través del funcionamiento (Huey y Stevenson, 1979; Arnold, 1983; Emerson y Arnold, 1989; Wainwright, 1991).

El uso del recurso está ligado funcionalmente a la abundancia y distribución de las especies. Consecuentemente, el conocimiento de la relación entre fenotipo y capacidad de alimentación puede aumentar la posibilidad de predecir patrones de abundancia y distribución de especies (Mittelbach, 1984; Mittelbach y Osenberg, 1994). Asimismo, el conocimiento de los mecanismos morfológicos de un organismo y de sus requerimientos ecológicos básicos permite inferir apropiadamente qué rol desempeñaría ese diseño en el sistema.

Con este contexto, se plantea una estrategia de análisis sustentada en la integración de estudios funcionales, biomecánicos y ecomorfológicos para enunciar hipótesis sobre patrones tróficos y de locomoción en los fororracos e inferir patrones conductuales en los ecosistemas de los que formaban parte. De esta manera, la descripción cuantitativa y cualitativa del diseño del cráneo (como expresión de la manera en que se adquiere y manipula el alimento) y del complejo apendicular posterior CAP (como relevantes en la locomoción) es central a la investigación propuesta.

\subsection{Objetivos de esta tesis}

La ejecución de esta investigación representa una importante tentativa para unificar mejor los campos de la anatomía, la morfología funcional y la ecología y completa la información sobre los Phorusrhacidae, un grupo peculiar de aves fósiles 
típicamente sudamericano que ocuparon los niveles más altos de las cadenas tróficas del Cenozoico.

\subsubsection{Objetivo general}

Este proyecto pretende integrar estudios funcionales, biomecánicos, ecomorfológicos y paleontológicos en un marco filogenético adecuado para evaluar hipótesis sobre el rol de los Phorusrhacidae en los ecosistemas cenozoicos.

\subsubsection{Objetivos específicos}

Reconstruir las principales masas musculares relacionadas con la quinesis craneana y complejo apendicular posterior.

$>$ Caracterizar el aparato trófico de los fororracos e inferir su hábito trófico.

Correlacionar los hábitos tróficos con la capacidad locomotora e identificar ecomorfos.

Establecer el rol de los fororracos en las cadenas tróficas y las posibles relaciones depredador-presa que pudieran haberse establecido en los ecosistemas terrestres cenozoicos sudamericanos principalmente del Mioceno patagónico.

\subsection{Hipótesis de trabajo}

H1. Los Phorusrhacidae exhiben tres patrones morfológicos dados por el desarrollo diferencial muscular y óseo del cráneo y del complejo apendicular posterior.

$\mathrm{H} 2$. Los patrones morfológicos y funcionales encontrados se corresponden con aquellos de aves de reconocidos hábitos carnívoros.

H3. Los Phorusrhacinae, Patagornithinae, Mesembriornithinae y Psilopterinae son capaces de desarrollar desplazamientos veloces típicos de aves cursoriales y depredadoras.

H4. La graviportalidad se restringe a Phorusrhacidae de masas corporales grandes (mayores a $200 \mathrm{~kg}$.) y hábitos necrófagos.

H5. En ningún momento del Cenozoico ni en ningún lugar se verifica la coexistencia de los tres ecomorfos propuestos por Tonni (1977).

H6. Los Phorusrhacidae muestran una tendencia al incremento de tamaño y a la terrestrialidad.

H7. Solo los Phorusrhacinae habrían sido capaces de manipular presas del tamaño del mamífero Paedotherium. 


\subsection{Desarrollo de la tesis}

La presente tesis se desarrolla en 10 capítulos. Los capítulos 6, 7, 8 y 9 incluyen las conclusiones parciales que se analizan en conjunto en el capítulo 10.

En el capítulo 2 se presentan los antecedentes tanto paleobiológicos como sistemáticos. También se desarrolla in extenso el marco teórico específico que comprende el estudio del complejo forma-función y la ecomorfología.

En el capítulo 3 se enumeran los materiales y colecciones estudiadas.

El capítulo 4 se dedica a la osteología del cráneo y de los elementos del complejo apendicular posterior (pelvis, fémur, tibiotarso, fíbula, tarsometatarso y dígitos).

En el capítulo 5 se analizan las relaciones filogenéticas de los Phorusrhacidae en un marco comparativo amplio a fin de enmarcar las reconstrucciones musculares utilizando EPB (Extant Phylogenetic Bracket).

En el capítulo 6 se estiman el tamaño corporal, la altura, la postura y la fuerza de mordida de los fororracos.

En el capítulo 7 se realiza la reconstrucción de los músculos mandibulares y del complejo apendicular posterior de los fororracos bajo la aproximación metodológica del EPB.

En el capítulo 8 se caracteriza el funcionamiento del cráneo de los fororracos, analizando la estructura y los mecanismos actuantes sobre y en el cráneo.

En el capítulo 9 se analiza cuantitativamente el cráneo y complejo apendicular posterior de los fororracos, aplicando morfometría geométrica al cráneo y pelvis. Los miembros posteriores se estudian mediante técnicas multivariadas aplicadas a medidas lineales e índices.

En el capítulo 10 se presenta la discusión y conclusiones finales acerca de la locomoción, hábito trófico y posible división de nichos de los fororracos. 


\section{Capítulo 2. Antecedentes y marco teórico}

\subsection{Antecedentes}

\subsubsection{Propuestas sistemáticas previas: Los “Gruiformes” Phorusrhacidae}

En 1887, Florentino Ameghino da a conocer una mandíbula proveniente de la Formación Santa Cruz que asignó a un edentado y la nominó Phorusrhacos longissimus, estableciendo la familia "Phororhacosidae" (término que luego enmendó como Phororhacidae) en 1889. Luego, en 1891 da a conocer un resto de premaxila proveniente de la misma zona y que nomina Tolmodus inflatus, al que también reconoce como un mamífero edentado con afinidades con Phorusrhacos y que posteriormente el mismo Ameghino reubica en este género (Ameghino 1891b). Más tarde ese mismo año, basándose en hallazgos más completos encontrados por su hermano Carlos, reconoce la naturaleza aviana de ambos taxones, resaltando que son aves muy peculiares. Moreno y Mercerat (1891) de forma simultánea dan a conocer nuevos géneros de fororracos reconociéndolas como carenadas y ubicándolas en el orden Stereornithes. Dividen al orden en las familias Stereornithidae, Darwinornithidae, Dryornithidae y Brontornithidae. Para ellos los Stereornithes presentan relaciones con "los Herodiones, Accipitres y Anseres” (i.e., Ciconiiformes, Falconiformes y Anseriformes). En una publicación de Diciembre de 1891 Ameghino describe a Pelecyornis, reubicando a los fororracos dentro las Ratitae sobre la base de su supuesta incapacidad para el vuelo, idea que reafirma en sucesivas publicaciones (1895 y 1899) y seguida por Lydekker (1893). Sin embargo Andrews (1896, 1899), estudiando un material muy completo de Patagornis marshi (=Tolmodus inflatus), relaciona a los fororracos con los Cariamidae, un grupo de aves sudamericanas fundamentalmente terrestres en el cual se incluyen las chuñas vivientes (Cariama cristata y Chunga burmeisteri). Esta propuesta es aceptada por todos los autores siguientes. Debido a su relación con los Cariamidae y de éstos con los Gruiformes Bonaparte 1854 o Ralliformes Coues 1884, los fororracos fueron incluidos en este orden, una propuesta corroborada por Livezey (1998), Mayr (2002), Agnolín (2009) y Alvarenga et al. (2011) mediante análisis filogenéticos.

Varias de las publicaciones siguientes mostraron una tendencia a seguir los nombres propuestos por Ameghino por sobre los de Moreno y Mercerat, como es el caso de Tolmodus (=Phorusrhacos) inflatus (Andrews, 1896, 1899) y de Pelecyornis (Sinclair y Farr, 1932). Otras por el contrario (e.g. Dolgopol de Saez, 1927) utilizaron 
los nombres originales propuestos por Moreno y Mercerat (1891) para los mismos taxones. La gran diversidad de nominaciones (en particular, por parte de Ameghino) basadas en restos no homólogos y las diferencias acerca de la posición de determinados taxones (véase más abajo) generaron grandes confusiones acerca de la clasificación y sistemática del grupo. Desde los trabajos de Florentino Ameghino ya mencionados, diferentes autores subsiguientes como Dolgopol de Saez (1927), Patterson y Kraglievich (1960), Brodkorb (1967), Mourer-Chauviré (1981), Alvarenga y Höfling (2003) y Agnolín (2009) han propuesto diversos esquemas sistemáticos, aunque en todos ellos, como se señaló previamente, se los considera como Gruiformes emparentados con los Cariamidae.

El orden Gruiformes en su acepción tradicional incluye formas muy heterogéneas como las tiganas (Eurypygidae), el kagú (Rhynochetidae), las gallaretas, las pollas y los burritos (Rallidae), las grullas (Gruidae), los trompeteros (Psophiidae), las avutardas (Otididae) y las chuñas (Cariamidae) entre otros. Todas estas aves no solo son dispares en su morfología, sino también en sus hábitos. Esta altísima diversidad morfológica puso en duda su status de grupo natural y de hecho, en las investigaciones más recientes, no se las considera como un grupo natural (Mayr y Clarke, 2003; Fain y Houde, 2004; Cracraft et al., 2004; Fain et al., 2007 y literatura allí citada) sino por el contrario, se las trata como un grupo polifilético. Este panorama también complica la posición filogenética de los Cariamidae y concomitantemente de los fororracos (véase más abajo y capítulo 5).

\subsubsection{Los Cariamiformes Phorusrhacidae}

En base a una propuesta de Van Remsen al South American Classification Committee (Propuesta 290, aprobada en Octubre de 2007), se acepta que los Cariamidae pertenecen al orden Cariamiformes Verheyen, 1957, excluyéndolos definitivamente del orden “Gruiformes”. En esta tesis se propone aceptar la inclusión de los Phorusrhacidae en este orden Cariamiformes mientras que a nivel intrafamiliar se sigue la propuesta sistemática de Alvarenga y Höfling (2003) (cf. con Agnolín, 2009) con algunas modificaciones y actualizaciones. Por ejemplo, se descarta la relación de Brontornis burmeisteri y Paleopsilopterus itaboraiensis con los Phorusrhacidae (véase ítem 2.1.3 y capítulo 5). El arreglo sistemático adoptado es el que sigue: 
AVES Linnaeus 1758

NEOGNATHAE Pycraft 1900

CARIAMIFORMES Verheyen, 1957

CARIAMAE Fürbringer 1888

PHORUSRHACIDAE Ameghino, 1899

Incertae familiae

Género Lavocatavis

L. africana Mourer-Chauviré et al., 2011

Subfamilia Physornithinae Agnolín, 2007

Género Physornis Ameghino, 1895

$P$. fortis Ameghino, 1895

Género Paraphysornis Alvarenga, 1993

P. brasiliensis (Alvarenga, 1982)

Subfamilia Phorusrhacinae Ameghino, 1889

Género Phorusrhacos Ameghino, 1889

P. longissimus Ameghino, 1899

Género Devincenzia Kraglievich, 1932

D. pozzi (Kraglievich, 1931)

Género Titanis Brodkorb, 1963

T. walleri Brodkorb, 1963

Género Kelenken Bertelli et al., 2007

K. guillermoi Bertelli et al., 2007

Subfamilia Patagornithinae Mercerat, 1897

Género Patagornis Moreno y Mercerat, 1891

P. marshi Moreno y Mercerat, 1891

Género Andrewsornis Patterson, 1941

A. abbotti Paterson, 1941

Género Andalgalornis Patterson y Kraglievich, 1960

A. steulleti (Kraglievich, 1931)

Subfamilia Psilopterinae Dolgopol de Saez, 1927

Género Psilopterus Moreno y Mercerat, 1891

P. bachmanni (Moreno y Mercerat, 1891)

P. lemoinei (Moreno y Mercerat, 1891)

P. affinis (Ameghino, 1899)

P. colzecus Tonni \& Tambussi, 1988

Género Procariama Rovereto, 1914

P. simplex Rovereto, 1914

Subfamilia Mesembriornithinae Kraglievich, 1932

Género Mesembriornis Moreno, 1889

M. milneedwardsi Moreno, 1889

M. incertus (Rovereto, 1914)

Taxón nuevo A MMP 5050

\subsubsection{Los controversiales "Brontornithinae” y Paleopsilopterus}

Brontornis burmeisteri. Las relaciones de Brontornis burmeisteri con los

Phorusrhacidae han sido cuestionadas en varias oportunidades (Moreno y Mercerat, 1891; Agnolín, 2007). Esta especie es conocida en base a restos provenientes del Mioceno de la provincia de Santa Cruz e incluye elementos de los miembros 
posteriores, falanges, vértebras troncales, un cuadrado (os quadratum) muy fragmentario y principalmente fragmentos mandibulares (Figura 2.1). Moreno y Mercerat (1891) señalaron algunas semejanzas de los huesos del miembro posterior con el cisne Cygnus (Anseriformes Anatidae) y Dolgopol de Saez (1927), incluso, crea un orden aparte para los géneros Brontornis y Rostrornis (sinónimo junior del primero), basándose en el grado de divaricación de las trochlea metatarsi y la forma de las falanges ungueales. Agnolín (2007) propuso que esta especie está emparentada con los Galloanserae y en particular con los Anseriformes. Sin embargo, es destacable que se trata de un fragmento de cuadrado hallado de forma aislada y cuya asignación a la especie es muy cuestionable. La ubicación de Brontornis dentro de los Galloanserae se sostiene básicamente por el número de cóndilos presentes en el proceso mandibular (processus mandibularis) del cuadrado. Agnolín (2007) se equivoca cuando se refiere a la cantidad de cóndilos del cuadrado en Paraphysornis, un Phorusrhacidae emparentado con Brontornis según Alvarenga y Höfling (2003) y Alvarenga et al. (2011). Paraphysornis presenta dos cóndilos como señala Alvarenga (1982) y no tres como señala Agnolín (2007). Más aún, la ausencia de sinapomorfías para los Phorusrhacidae en el análisis filogenético de este último autor origina (aunque no la figura) una politomía entre los fororracos, Paraphysornis y el resto de los taxones cuando se codifica el os quadratum de Paraphysornis con tres condyli. Aún así, Brontornis no es un fororraco sino un Anseriformes fundamentalmente por la morfología de los miembros posteriores como resaltan Moreno y Mercerat (1891) y en base al análisis cladístico realizado en el capítulo 5 de esta tesis.

Paleopsilopterus itaboraiensis. Paleopsilopterus itaboraiensis procede del Paleoceno superior (Itaboraiense) de Brasil y fue erigida por Alvarenga (1985) en base a un tarsometatarso derecho muy fragmentario y dos tibiotarsos muy deformados. Este autor establece que su inclusión dentro de los fororracos Psilopteridae está sustentada por la presencia del pons supratendineus del tibiotarso orientado transversalmente al eje longitudinal. Sin embargo, este rasgo no se encuentra en ningún otro fororraco (donde el pons es oblicuo, véase capítulo 4). Más aún, Alvarenga y Höfling (2003) resaltan que se diferencia del resto de los Psilopterinae por presentar la eminentia intercotylaris amplia, redondeada y poco extendida proximalmente. Agnolín (2009) provee una lista de otros caracteres que establecen la exclusión de este taxón de los Phorusrhacidae y su inclusión, con muy poco sustento, en la familia europea Idiornithidae. Aquí se prefiere aceptar la exclusión de Paleopsilopterus de los Phorusrhacidae pero mantenerlo dentro 
del orden Cariamiformes con el estatus de incerti familae. Los argumentos que sostienen esta decisión son el estado fragmentario del material y que gran parte de las características observables en el fósil son compartidas con otros Cariamiformes.

\subsubsection{Distribución estratigráfica y geográfica de los Phorusrhacidae}

Los Phorusrhacidae se distribuyen desde el Eoceno al Pleistoceno y provienen de Argentina, Brasil, Uruguay, Estados Unidos de Norte América y Argelia en África.

Tonni y Tambussi (1986) destacan la presencia de un Psilopterinae del Eoceno inferior (Vaquense) de Cañadón Vaca, Argentina, el cual corresponde al registro más antiguo de la familia. Otros registros del Eoceno corresponden a aquellos reportados por Mourer-Chauviré et al.(2011) quienes dan a conocer el único registro de un fororraco para el continente africano, procedente del Eoceno medio de la zona de Gour Lazib y Acosta Hospitaleche y Tambussi (2005) quienes reportan la presencia de psilopterinos en el Eoceno tardío de la localidad de Gran Hondonada, Argentina. Sin embargo, la asignación de los restos argentinos (un extremo proximal de tarsometatarso derecho y una falange ungueal) a Phorusrhacidae es cuestionable. Recién a partir del Oligoceno los Phorurhacidae están representados por al menos tres subfamilias, dos de ellas en la Patagonia argentina, Patagornithinae (Andrewsornis) y Psilopterinae (Psilopterus affinis) y una en Brasil, la de Physornithinae (Paraphysornis). Los Phorusrhacidae alcanzaron su máxima diversidad en el Mioceno temprano tardío (Santacrucense) donde se registran hasta cuatro especies conviviendo en una localidad (Degrange et al., en prensa). Los registros más recientes de fororracos (Figura 2.2) se encuentran en el Plioceno temprano de Texas y Plioceno tardío de Florida (Brodkorb, 1963; Chandler, 1994; Baskin, 1995; MacFadden et al., 2007) y en el límite entre el Plioceno tardío y Pleistoceno temprano (Tambussi et al., 1999) y Pleistoceno tardío (Alvarenga et al., 2010; Montenegro et al., 2010) de Uruguay.

La mayor frecuencia de restos y diversidad de fororracos han sido hallados en la República Argentina (Figura 2.3) (15 de 18 especies). De Uruguay procede la especie Devincenzia pozzi (Kraglievich, 1932) además de materiales asignados a Phorusrhacinae (Tambussi et al., 1999) y Phorusrhacidae (Alvarenga et al. 2010; Montenegro et al., 2010). De Brasil, excluído Paleopsilopterus de los Phorusrhacidae, solo se conoce la especie Paraphysornis brasiliensis (Alvarenga, 1982). De Florida y Texas en los Estados Unidos de América del Norte, los Phorusrhacidae se encuentran 
representados por Titanis walleri (Brodkorb, 1963). Finalmente de Argelia en África se describió Lavocatavis africana (Mourer-Chauviré et al., 2011).

Los registros de supuestos fororracos antárticos requieren consideraciones aparte. Case et al. (1987, 2006) seguidos por Tambussi y Acosta Hospitaleche (2007) reportan restos de fororracos en la Isla Marambio en Antártida, una asignación que no es seguida en esta tesis: ninguno de estos restos procedentes del Eoceno pertenece a la Familia Phorusrhacidae. Uno de los restos, un fragmento de pico (cast UCR 22175), presenta surcos laterales que no están presentes en ningún fororraco conocido. Más aún, recuerda a los Pelecaniformes Pelagornithidae aunque debido a la naturaleza fragmentaria del resto esta asignación no puede ser corroborada. Otro de los restos, un extremo distal de tarsometatarso (cast UCR 22175), presenta la trochlea metatarsi II bastante retraída proximalmente y torsionada caudalmente, rasgo que no se corresponde con las características del tarsometatarso de los Phorusrhacidae conocidos. También se han reportado icnitas pertenecientes a un ave dotada de tres largos dedos anteriores y que podría pertenecer a una Ratitae o a un Phorusrhacidae (Case et al., 1987). Más recientemente Case et al. (2006) dan a conocer el registro de un ave cursora procedente del Cretácico superior (Maastrichtiano) de la Isla Vega, Península Antártica, y que correspondería según los autores a una forma ancestral a los Cariamidae y Phorusrhacidae o a un Cariamidae basal. Las afinidades de estos restos no pudieron ser corroborados. Sin embargo, al menos uno de los especímenes presentados es un tibiotarso correspondiente a un Sphenisciformes (Tambussi com. pers.).

En base a la evidencia fósil es posible sostener un origen sudamericano de los Phorusrhacidae con una posterior dispersión a África (Mourer-Chauviré et al., 2011) y mucho más tardíamente a América del Norte. La primera puede explicarse mediante dos hipótesis de dispersión (Mourer-Chauviré et al., 2011) y ninguna de ellas incluye la migración a través de Norteamérica y Europa: (1) que las formas más pequeñas de fororracos capaces de realizar vuelos limitados (Tonni, 1977; Tonni y Tambussi, 1988; Tambussi y Noriega, 1996; Degrange y Tambussi inédito; esta tesis) utilizaran el vuelo como medio de dispersión o (2) que fororracos no voladores arribaran a África durante el Paleoceno o Eoceno temprano, cuando la distancia entre Brasil y África no era muy extensa y existían numerosas islas, hoy sumergidas (de Oliveira et al., 2008). El hallazgo de un fororraco en el Eoceno de África tiene connotaciones fundamentales para comprender la evolución de estas aves. Asumiendo como válidas estas rutas de 
dispersión podemos suponer una rápida radiación pre-eocena del grupo acentuándose durante tiempos oligocenos.

La dispersión hacia América del Norte habría sido posible posteriormente al establecimiento del istmo de Panamá durante el Plioceno.

\subsection{Estudios paleobiológicos previos}

La hipótesis de carnivoría de los fororracos ha sido sostenida por muchos investigadores (Ameghino, 1895; Andrews, 1896, 1899; Sinclair y Farr, 1932; Marshall, 1978; Tambussi y Noriega, 1996; Alvarenga y Höfling, 2003; Chiappe y Bertelli, 2006) en base al gran tamaño de algunos (0,9 hasta casi 3 metros de altura) y, fundamentalmente, por la morfología del pico terminada en gancho. Aceptada indiscutiblemente la carnivoría de los fororracos, se propusieron dos técnicas de cacería: (1) que habrían utilizado sus miembros posteriores para desestabilizar a sus presas durante la persecución o la hipótesis más tradicional (2), que habrían utilizado solamente su pico para matar.

Los cuestionamientos acerca de los roles que habrían desempeñado los fororracos no son nuevos (Tonni, 1977; Tambussi, 1997; Tambussi y Hoffmann, 1998). Tradicionalmente se discriminaron tres grupos funcionales (Tonni, 1977): depredadores cursoriales no voladores (Phorusrhacinae, Mesembriornithinae y Patagornithinae), depredadores con escasa capacidad de vuelo (Psilopterinae) y carroñeros graviportales (Brontornithinae -en el sentido de Alvarenga y Höfling, 2003-).

Sin embargo, son pocos los trabajos morfofuncionales realizados en estas aves y en todos ellos se analiza la morfología craneana independientemente de los miembros posteriores y sin mediar en ningún caso reconstrucciones musculares. Se pueden citar los trabajos de Tambussi y Hoffmann (1998) realizados sobre el cráneo de Andalgalornis y Devincenzia, donde se estudió la resistencia del pico de estas dos especies y el trabajo de Degrange et al. (2010) quienes estudiaron la morfología y biomecánica del cráneo de Andalgalornis (dicho estudio constituye parte de esta tesis, véase capítulo 8).

En cuanto a los miembros posteriores, pueden citarse los análisis biomecánicos realizados por Tambussi (1997), Blanco y Jones (2005) y Jones (2010). Tambussi (1997) calcula índices de capacidad atlética (ICA) de algunas especies, concluyendo que los Mesembriornithinae y Phorusrhacinae eran capaces de realizar movimientos tan atléticos como Struthio o Rhea. Blanco y Jones (2005) estudiaron tres especies de 
fororracos para las que sugieren que, si bien algunas eran capaces de alcanzar grandes velocidades (hasta $50 \mathrm{~km} / \mathrm{h}$ ), también podrían utilizar sus miembros para romper huesos y acceder a la médula (Jones, 2010). Por último, Jones (2010) realiza una caracterización anatómica y biomecánica mediante el análisis de vigas de las falanges ungueales de los fororracos, concluyendo que son lo suficientemente resistentes para realizar actividades como la reducción de presas por retención de las mismas contra el sustrato.

\subsection{Marco teórico}

En la presente tesis se trabajó bajo el marco teórico de la morfología funcional y la ecomorfología, asumiendo que puede establecerse una fuerte vinculación entre la forma y la función que alcanza a desempeñar el cráneo y el complejo apendicular posterior (objetos principales del estudio aquí realizado).

El estudio paleobiológico de los fororracos parte de tres atributos necesarios para la caracterización biológica de cualquier animal, actual o extinto: masa corporal, dieta y locomoción. La masa corporal -y su correlato en el tamaño del cuerpo- es una de las variables con mayor influencia sobre la anatomía, estructura y funcionamiento de un organismo (Kardong, 1998; Liem et al., 2001), afectando directamente los requerimientos mecánicos y fisiológicos (Peters, 1983; Schmidt-Nielsen, 1984; Wolff, 1991) y sus interacciones con el medio. La dieta de un organismo puede ser caracterizada a partir del aparato trófico (Vizcaíno et al, 1998; Bargo y Vizcaíno 2008, Desojo y Vizcaíno, 2009), mientras que el análisis del complejo apendicular posterior permite hipotetizar el tipo de locomoción o preferencia en el uso del sustrato por parte de un ave: terrestres (saltadora, caminadora, cursora), arborícolas, nadadoras o vadeadoras (Zeffer et al., 2003).

El hábito trófico y locomotor brindan un amplio campo para realizar análisis morfofuncionales, los componentes son fácilmente separables y pueden estudiarse por medio de numerosas técnicas y, en el caso de los fósiles, forma y función pueden ser inferidos a partir de la comparación con parientes cercanos o análogos funcionales (Wake, 1992).

\subsubsection{Morfología funcional y el complejo forma-función}

Los intentos de inferir la función a partir de la forma involucran disciplinas tan variadas dentro de la biología como la ecología, etología, sistemática, 
paleontología y evolución y representan un intento por entender de forma más completa “qué hacen los organismos y como viven” (Lauder, 1995).

La morfología involucra el estudio de la forma, tamaño y estructura de los organismos (Koehl, 1996). Incluye la descripción de los rasgos anatómicos (estructura y disposición de las partes) y de los patrones estructurales (cómo esas partes se integran para constituir un todo), la comprensión del significado de esta integración para el desempeño del organismo y el análisis de las posibilidades y restricciones que implica una morfología dada para los procesos evolutivos (Kardong, 1998). Dentro de este campo, la morfología funcional estudia la relación entre la forma y la función de un organismo. Desde una perspectiva adaptativa y evolutiva, se centra en aquellos caracteres anatómicos relevantes para comprender el funcionamiento de los organismos, sobre la base de información biomecánica, fisiológica, ecológica y/o etológica (Hildebrand, 1988), analizando de qué manera la forma causa, permite o restringe las funciones que puede desempeñar un organismo, vinculando los aspectos morfológicos con la función que tales estructuras realizaban, realizan o podrían realizar. La morfología funcional desempeña un papel fundamental en los análisis evolutivos de forma y función, ya que proporciona la base experimental, teórica y mecánica para entender la evolución de caracteres correlacionados (Morgan, 2009).

Comúnmente se asume que existe una estrecha relación entre la forma y la función, de manera que la función puede ser predicha a partir de la forma (Radinsky, 1987). Sin embargo, esta relación resulta ser compleja y la predicción de una a partir de la otra no siempre es posible (Lauder, 1995). Pueden cometerse muchos errores si se asume que una estructura particular está adaptada a un propósito particular debido a que parece obvio o a que es la única explicación posible o incluso cuando se extrapola dicha función a grupos más inclusivos (Hildebrand, 1988).

Entonces los análisis morfo-funcionales involucran conceptos como función, forma y rol entre otros. Estos términos han sido muchas veces mal interpretados, debido a que sus definiciones no eran claras y precisas. Incluso función tiene más de una acepción (e.g., Tinbergen, 1963; Dullemeijer, 1974; Zweers, 1979; Lauder, 1986; 1990). Bock y von Wahlert (1965) esclarecen la terminología relacionada a los análisis morfo-funcionales y establecen las siguientes definiciones que se aplican en esta tesis: 
Rasgo (feature): cualquier parte o característica de un organismo, pudiendo ser morfológica, etológica, fisiológica o bioquímica, entre otras. Se refiere a las estructuras de un organismo.

Forma (form): se refiere a la apariencia, configuración y composición de un rasgo.

Función (function): hace referencia a lo que un rasgo hace o cómo lo hace. Incluye las propiedades físicas y químicas que derivan de su forma. Puede ser inferida en condiciones experimentales de laboratorio (Bock y von Wahlert, 1965).

Facultad (faculty): constituye en sí mismo el complejo forma-función. Resulta de la combinación de una forma dada y una función particular. Se define como lo que un rasgo es capaz de hacer en la vida del organismo, evidenciando la relación o compromiso que tiene dicho organismo con el ambiente.

Rol biológico (biological role): se refiere a cómo el organismo utiliza la facultad durante toda su vida en el contexto de su ambiente. La misma facultad puede tener múltiples roles biológicos. De acuerdo con Bock y von Wahlert (1965) y Bock (1980, 1990, 1994) el rol biológico no puede ser inferido bajo condiciones experimentales y debe ser observado directamente en el campo.

En un estudio morfo-funcional, los pasos metodológicos a seguir son la descripción de la forma, para luego inferir la función e hipotetizar la facultad. Por último, se especula sobre el rol biológico (Cassini, 2011).

Existen varias aproximaciones metodológicas aplicables en los análisis funcionales de las formas fósiles: filogenéticas, analogías y biomecánica.

Los métodos filogenéticos se basan fundamentalmente en la comparación de la forma fósil con organismos vivos emparentados a fin de poder estudiar y extrapolar la función a partir de la estructura. Se presume que estructuras que son homólogas entre las formas vivientes y el fósil cumplen funciones homólogas (Stanley, 1970). Esto requiere la utilización de filogenias y la optimización de caracteres entre taxones. Sin embargo en muchos casos, estructuras homólogas en taxones cercanamente emparentados poseen funciones diferentes; por lo tanto, cuanto más alejados estén los taxones bajo estudio, más factible es que la relación entre estructura y función se pierda (Lauder, 1995). 
Cuando no se disponen de homologías adecuadas, se puede intentar demostrar la función de un rasgo a través de análogos biológicos. Sino se encontrasen disponibles análogos biológicos, se puede recurrir a la utilización de análogos mecánicos.

Por último, la biomecánica analiza la interrelación entre forma y función a partir de los principios de la física. La biomecánica no requiere de homólogos vivientes, análogos mecánicos o biológicos (Radinsky, 1987), aunque puede utilizarse alguno como punto de partida. Según Lauder (1995), la biomecánica ayuda a entender la realidad de lo posible.

\subsubsection{Ecomorfología y aproximaciones "Taxon free”}

Durante los años 1950 y 1960, numerosos ecólogos trabajando principalmente en aves, analizaron problemáticas relacionadas con la partición de hábitat, nicho, estructura de las comunidades y diversidad entre otros aspectos, tratando de relacionar estos factores con medidas morfológicas simples. Desde esta perspectiva se acuñó el término ecomorfología (Karr y James, 1975) para englobar estudios donde se examina la relación entre la morfología y el ambiente desde una perspectiva ecológica. En la ecomorfología el concepto de rol biológico desempeña un papel fundamental (Bock, 1994) ya que se estudia y analiza la vinculación existente entre forma y función y su correlación con el ambiente donde habita un organismo (Wainwright, 1991; Plotnick y Baumiller, 2000). En otras palabras, estudia la relación entre la morfología y el ambiente (Van der Klaauw, 1948). Es una disciplina de la morfología que habría surgido con el mismo Charles Darwin quien estudió la diversidad morfológica del pico de los pinzones de las Islas Galápagos y la asoció con distintos usos del pico. Si bien el término se usó originalmente para explicar la variación en la morfología y fisiología, la mayor parte de las aplicaciones hacen referencia a la morfología.

Los estudios ecomorfológicos pretenden realizar inferencias ecológicas a través de la medición de la correlación ecología-morfología, mediante la cuantificación de los patrones de la variación morfológica. Finalmente se elucida la relación funcional entre morfología y ecología a través del comportamiento y performance de un organismo (Ricklefs y Miles, 1994). En particular se busca relacionar y/o explicar la variación que pueda ser atribuida al ambiente, considerada una adaptación, diferenciándola de aquella variación explicada por la historia de un organismo, ya sea ontogenética y/o filogenética (Cassini, 2011). Se asume que la variación de la forma del organismo está correlacionada con la acción de la selección natural y la adaptación para explicar el 
ajuste al ambiente (Wainwrigth, 1991). Cuando el ambiente impone restricciones a la morfología y a la ecología de los organismos, se puede predecir la relación entre forma y función (Karr y James, 1975).

Los estudios ecomorfólogicos más comunes buscan establecer la adaptación de la complejidad morfológica de estructuras o sistemas en especies individuales, para luego comparar estas adaptaciones con otros organismos, sea que estos estén relacionados o no. Para ello se analiza la morfología de un rasgo, estudiando su estructura y forma a través de descripción o cuantificación de las mismas (e.g., medidas lineales, angulares, superficies, etc.) para luego hacer inferencias funcionales (biomecánicas o fisiológicas). Esto permite hipotetizar el nicho fundamental de un organismo (i.e., cómo a través del desempeño de una estructura se puede explotar potencialmente un recurso). Luego se contrasta con el nicho real a través de las observaciones de campo que permiten estudiar los roles biológicos (Bock, 1994). A partir de esta parte del estudio se pueden estimar las presiones selectivas que actúan sobre un organismo, evidenciando la adaptatividad del rasgo en cuestión (Bock, 1980, 1993). El éxito reproductivo (o “fitness”) finalmente permite evaluar definitivamente el significado adaptativo de cualquier rasgo.

El hecho de poder comparar los rasgos entre especies no emparentadas permite realizar un aproximación de tipo "taxon free” (Damuth et al., 1992), que trata de elucidar el vínculo directo entre las comunidades y factores climáticos, bióticos o ambientales específicos (Box, 1981, 1996; Damuth et al., 1992; Steffen et al., 1992; McIntyre et al., 1999; Eronen et al., 2010). Los análisis taxon free o ecometría se basan en la idea que la distribución en una comunidad de un rasgo ecomorfológico como la estructura del diente, las proporciones de las extremidades, la masa corporal, la forma de un garra o cualquier aspecto de la anatomía o fisiología puede ser medido a través de un subconjunto de los organismos de una comunidad. Independientemente del espacio y del tiempo, los rasgos son los medios por los cuales los organismos interactúan con su medio ambiente, biótico y/o abiótico. La ecometría mide estas interacciones al focalizarse en rasgos fácilmente cuantificables y cuya estructura está estrechamente relacionada con su función, la cual interactúa directamente con el medio ambiente local (Eronen et al., 2010). En el tiempo los rasgos evolucionan, así como su relación funcional con el medio ambiente. El enfoque ecométrico proporciona un mecanismo fructífero para vincular los datos a través de la escala temporal y espacial ya que los rasgos puede ser separados de los taxones específicos, permitiendo el mapeo de la 
distribución de los mismos a través del tiempo y espacio, independientemente de la evolución o extinción.

Los métodos estadísticos aplicados en estudios ecomorfológicos son muy variados, aunque se basan fundamentalmente en la aplicación de métodos univariados y multivariados a fin de posicionar una especie en un morfoespacio. En el caso de las aves varios trabajos han tratado de examinar la correlación de la morfología con factores ecológicos, incluyendo formas tropicales frugívoras (Karr y James, 1975), aves de matorral (Ricklefs y Travis, 1980), aves insectívoras de pastizal (Leisler y Winkler, 1985), inambúes (Degrange y Picasso, 2010), pingüinos (Acosta Hospitaleche y Tambussi, 2006) y Passeriformes (Miles et al., 1987; Kulemeyer et al., 2009). La aplicación de estos métodos a formas fósiles también se encuentra extendida: Sphenisciformes (Livezey, 1989; Tambussi y Acosta Hospitaleche, 2008), Anatidae (Livezey, 1993a), Columbiformes (Livezey, 1993b) y aves rapaces (Hertel, 1995).

Obviamente parte de las variaciones de forma que exhiben los organismos están relacionadas al constraint filogenético y es en estos casos donde debe analizarse qué proporción de la variación puede explicarse por ancestralidad común. Numerosos métodos y aproximaciones metodológicas conocidos comúnmente como "métodos comparativos” han sido propuestos para alcanzar dicho objetivo (e.g., Felsenstein, 1985; Garland Jr et al., 1993, 2005; Grafen, 1995; Ackerly, 2000; Giannini, 2003). Sin embargo, todas ellas han recibido severas críticas (Martins, 2000). Más allá de los aspectos teóricos de estas metodologías (e.g., el movimiento browniano, la supuesta evolución gradual y la igual longitud de ramas), la principal dificultad en su aplicación comúnmente radica en la ausencia de una filogenia que incluya a todos los taxones estudiados. Entre otras problemáticas se incluye que los contrastes derivados sobre topologías incorrectas son más propensos a producir conclusiones erróneas cuando existe una verdadera relación significativa entre las variables que se prueban, o que el uso de filogenias elegidas al azar no es beneficiosa y que en ausencia de información sobre las relaciones evolutivas no es posible en absoluto un análisis filogenético comparativo. Symonds (2002) establece que "el uso de una filogenia puede no ser tan importante en un análisis a niveles taxonómicos superiores ya que los grupos involucrados están más distantes de su antepasado común y han experimentado una considerable evolución mucho más independiente” (... using a phylogeny may not be so important in an analysis at higher taxonomic levels because the groups involved are 
more distant from their common ancestor and will have experienced considerably more independent evolution, Symonds 2002: 552).

\subsubsection{Módulos locomotores: bipedalismo, terrestrialidad y cursorialidad}

Gatesy y Dial (1996) desarrollaron el concepto de módulos locomotores para explicar el origen y evolución del vuelo y la diversificación de los estilos locomotores de las aves modernas. De acuerdo con estos autores, un módulo locomotor es una subregión anatómica del sistema músculo-esqueletario altamente integrada que actúa como una unidad durante la locomoción debido a que consta de controles neuromusculares independientes.

Los terópodos son formas bípedas y cuentan de un único módulo locomotor formado por la cola y el miembro posterior (Gatesy y Dial, 1996). Estas dos estructuras funcionan al unísono durante la locomoción ya que gran parte de la musculatura apendicular posterior se originaría en la cola, como ocurre también en cocodrilos actuales (Gatesy, 1990, 1994). Los miembros anteriores no representan un módulo locomotor en sí, ya que son utilizados para la manipulación de las presas.

A diferencia de los terópodos que les dieron origen (Ostrom, 1976; Gauthier, 1986), las aves constan de tres módulos locomotores (Figura 2.4): el módulo pectoral o anterior que incluye los miembros anteriores, el módulo pélvico o posterior que incluye los miembros posteriores y el módulo caudal que incluye la cola. Gatesy y Dial (1996) proponen que en la transición Theropoda-Aves se produjo un desacoplamiento del miembro posterior y la cola y, luego, la última se vinculó al ala durante el perfeccionamiento del vuelo. El desacople y desarrollo de la cola representó un punto clave en la evolución del vuelo de las aves ya que proporciona mayor estabilidad, evitando el balanceo.

El desarrollo de los módulos locomotores se encuentra influenciado por la especialización en el estilo de vida (Figura 2.4). El mayor desarrollo de alguno de estos módulos puede producir la reducción de los demás (Gatesy y Dial, 1996) ya que no son completamente independientes debido a que comparten partes del cuerpo. Por ejemplo, aves voladoras de alta maniobrabilidad presentan los módulos locomotores anterior y caudal muy desarrollados, mientras que el miembro posterior se encuentra pobremente desarrollado. Dial (2003) propuso además que el estilo locomotor (dado por el desarrollo de los módulos locomotores) está fuertemente vinculado a otros factores 
como masa corporal, grado de maduración de los pichones y a factores etológicos como construcción de nidos y cuidados parentales.

Las aves vuelan con los miembros anteriores y se mueven en tierra solo con los miembros posteriores. De hecho, en general, pueden exhibir un excelente desempeño y movilidad en tierra independientemente de su capacidad de vuelo (Paul, 2002). Debido a que los miembros anteriores de las aves se han modificado en alas, las aves son consideradas bípedas obligadas, es decir, cuando se desplazan en tierra lo hacen únicamente sobre sus miembros posteriores. Son además, digitígradas y asumen una postura erecta de los miembros (Hutchinson y Gatesy, 2000). Esta característica se encuentra únicamente en las aves y en los Hominidae.

Las aves utilizan sus miembros posteriores para la locomoción de manera muy diversa, desde un uso muy limitado en aves “hiperaéreas” (i.e., aves cuyo medio locomotor es fundamentalmente el vuelo) a un uso exclusivo en las aves no voladoras o terrestres. En estas últimas generalmente hay un predominio del módulo locomotor posterior desplazándose exclusiva o fundamentalmente en tierra; ejemplos son las Ratitae, los Tinamidae, Galliformes, Cariamidae, Psophiidae y Otididae entre otras. Justamente, en las aves terrestres, la masa de los miembros posteriores se encuentra muy desarrollada y son éstos los que actúan como fuente primaria de la locomoción; mientras que los miembros anteriores, generalmente reducidos, cumplen funciones menores en la locomoción por vuelos cortos, cortejo o equilibrio durante la carrera, prácticamente sin intervenir durante el desplazamiento.

La máxima expresión de la terrestrialidad está representada por la pérdida total de la capacidad de volar, un fenómeno que se ha repetido numerosas veces de forma independiente en la historia evolutiva de las aves (Feduccia, 1999, 2003; Paul, 2002) e incluye grupos tales como Struthioniformes, Apterygiformes, Dinornithiformes, Aepyornithiformes, Dromeornithiformes, Anseriformes, Columbiformes y Cariamiformes, entre otros.

En tierra, las aves pueden desplazarse caminando, corriendo o saltando (Alexander, 2004; Hutchinson y Gatesy, 2001, Picasso 2010a). Caminar es el andar lento mientras que saltar o correr representa una locomoción rápida, diferenciándose por la duración de las fases en las cuales el pie está en el aire (fase aérea o de balanceo) o en contacto con el suelo (fase de apoyo) (Hutchinson y Gatesy, 2001). En el caminar, la fase de apoyo es más prolongada que la fase aérea, mientras que en la carrera la fase de balanceo es más prolongada y en algún momento ambos pies no contactan con el suelo. 
Saltar es similar a correr, aunque ambos miembros están en el aire o contactan con el suelo al mismo tiempo (es decir, se mueven sincrónicamente).

Los miembros anteriores reducidos y los miembros posteriores alargados de los fororracos indican que son aves terrestres (Ameghino, 1895; Andrews, 1899; Sinclair y Farr, 1932; Alvarenga y Höfling, 2003; Chiappe y Bertelli, 2006). Muchos autores sostienen en particular que se trata de aves cursoras (Alvarenga y Höfling, 2003; Blanco y Jones; 2005; Chiappe y Bertelli, 2006) incapaces de volar (Alvarenga y Höfling, 2003) o capaces de realizar vuelos, aunque sean breves y torpes (Tonni, 1977; Tonni y Tambussi, 1988; Tambussi y Noriega, 1996; Mourer-Chauviré et al., 2011) en las formas más pequeñas. Estos aspectos se discuten en el último capítulo de esta tesis.

El hábito corredor se conoce como cursorialidad, un término introducido por Gregory (1912) para referirse a la especialización a la carrera e incluye formas estructuralmente modificadas para resistir y alcanzar grandes velocidades (Hildebrand, 1985). El animal que desarrolla carreras se denomina cursor o cursora en el campo de las aves. Cabe aclarar que este término fue acuñado para los mamíferos cuadrúpedos, aunque su uso se ha extendido a varios grupos, entre los cuales se encuentran las aves. Los animales cursores son aquellos capaces de correr largas distancias (Gregory, 1912; Stein y Casinos, 1997) y están dotados de estructuras y sistemas que le otorgan estabilidad, propulsión, maniobrabilidad y eficiencia durante la carrera (Hildebrand, 1985, 1988).

El estilo de vida cursorial ha sido poco estudiado en las aves. Se pueden citar los trabajos de Engels (1938) en el correcaminos Geococcyx; Berger (1952) quien estudia tres géneros de Cuculidae incluyendo al correcaminos; de Alexander et al. (1979) y Alexander (1985) en los cuales se caracteriza el hábito cursorial de Struthio (Struthionidae); de Abourachid y Renous (2000) y Abourachid (2001) quienes estudian la cursorialidad en las Palaeognathae; de Abourachid et al. (2005) en el cual se describe el andar de Cariama (Cariamidae) comparándola con los Tinamidae y por último, el de Picasso (2010a) quien realiza un pormenorizado estudio de la variación osteo-muscular del complejo apendicular posterior de Rhea americana (Rheidae) y su vinculación con el hábito cursorial durante la ontogenia postnatal.

La especialización en este tipo de locomoción involucra cambios anatómicos y en el modo de andar (Wolff, 1991). Engels (1938), Storer (1971) y Coombs (1978) listan una serie de características típicas de las formas cursoras, las cuales también se encuentran en los fororracos: 
$>$ Miembros anteriores reducidos

$>$ Miembros posteriores alargados en relación al cuerpo

> Mayor alargamiento del tibiotarso y tarsometatarso en relación al fémur

Tarsometatarso más alargado que el tibiotarso

$>$ La musculatura del miembro posterior se concentra en los segmentos más proximales

$>$ Reducción (en tamaño y cantidad) de los dedos

> Masa corporal óptima alrededor de los $50 \mathrm{~kg}$.

Un tibiotarso y tarsometatarso largo tienen como correlato la posibilidad de una zancada amplia (y concomitantemente un aumento de velocidad); además, la concentración de la musculatura del miembro posterior en los segmentos más proximales disminuye la inercia de la porción distal (Hildebrand, 1985) y la reducción de los dedos reduce la superficie de apoyo sobre el suelo, reduciendo la fricción.

Sin embargo, es destacable que gran cantidad de estas características también se encuentran presentes en aves que no presentan un hábito cursorial. Tal es el ejemplo de las aves vadeadoras como las garzas y flamencos que presentan los tibiotarsos y los tarsometatarsos alargados (Gatesy y Middleton, 1997; Zeffer et al., 2003). Este es un aspecto que se discute profundamente en esta tesis.

Finalmente, la cursorialidad ofrece numerosas ventajas (Hildebrand, 1988): los animales cursores pueden forrajear y alimentarse en áreas más grandes, pueden buscar más fácilmente nuevas zonas cuando los recursos escasean o durante los cambios estacionales, los predadores cursores pueden cazar mayor cantidad de presas y las presas cursoras pueden escapar más fácilmente de los depredadores. 
Capítulo 3. Materiales

\subsection{Abreviaturas institucionales}

AMNH, American Museum of Natural History, New York, New York, EEUU;

BAR, Museo Asociación Paleontológica Bariloche, Río Negro, Argentina; BMNH ${ }^{1}$, Natural History Museum, London, UK; CORD-PZ, Museo de Paleontología de la Universidad de Córdoba, Córdoba, Argentina; DGM, Departamento Nacional de Produção Nacional, Taubaté, Brasil; FCP, Museo de Paleontología, Mineralogía y Arqueología, Firmat, Santa Fé, Argentina; FM, Field Museum of Natural History, Chicago, Illinois, EEUU; MACN, Museo Argentino de Ciencias Naturales Bernardino Rivadavia, Ciudad Autónoma de Buenos Aires, Buenos Aires, Argentina; MM, Museo Municipal de Ciencias Naturales Punta Hermengo, Miramar, Buenos Aires, Argentina; MLP, Museo de La Plata, Buenos Aires, Argentina; MMP, Museo Municipal de Ciencias Naturales Lorenzo Scaglia, Mar del Plata, Buenos Aires, Argentina; MNHN, Museo Nacional de Historia Natural de Montevideo, Montevideo, Uruguay; MPEF-PV, Museo Paleontológico "Egidio Feruglio", Trelew, Chubut, Argentina; MPM-PV, Museo Padre Molina, Río Gallegos, Santa Cruz, Argentina; OUVC, Ohio University Vertebrate Collections, Athens, Ohio, EEUU; UCR, University of California Riverside, Riverside, California, EEUU; UF, Florida Museum of Natural History, Gainesville, Florida, EEUU; YPM-PU, Peabody Museum of Natural History, New Haven, Connecticut, EEUU.

\subsection{Material estudiado}

\subsubsection{Especies fósiles}

A) Phorusrhacidae

Andalgalornis steulleti (Kraglievich, 1931)

MACN Pv 14374, fragmento distal de tarsometatarso izquierdo; MLP 88-IX-2016, extremo distal de tibiotarso izquierdo. Phororhacos steulleti Kraglievick, 1931: MACN Pv 4244, falange 1 de dedo IV. Phororhacos deautieri Kraglievich, 1931: MACN Pv 6932, fragmento distal de fémur derecho. Andalgalornis ferox Patterson y

\footnotetext{
${ }^{1}$ Actualmente el acrónimo BMNH ha sido sustituido por NHMUK (Natural History Museum of United Kingdom). Debido a que los materiales han sido originalmente referidos como BMNH, en esta tesis se prefirió conservar la asignación original a fin de evitar confusiones.
} 
Kraglievich, 1960: FM-P14357, cráneo completo, columna vertebral y pelvis.

Andalgalornis aff. ferox: MACN Pv 6737, tarsometatarso izquierdo y falanges 1 y 2 del dedo II.

Andrewsornis abbotti Patterson, 1941

FM-P13417, fragmento de cráneo y mandíbula; FM-P13383, fragmento de sínfisis mandibular; FM-P14678, fémur izquierdo. ?Andrewsornis abbotti: MLP 59-II26-82, extremo proximal de fémur derecho; MLP 59-II-26-83, falange ungueal.

Devincenzia pozzi (Kraglievich, 1931)

FCP-V-R-001, vértebra cervical; MLP 88-IX-20-17, vértebra cervical. Phororhacos pozzi Kraglievich, 1931: MACN Pv 6554, extremo distal de tarsometatarso derecho; MACN Pv 6681, falange ungueal del dedo III. Phororhacos longissimus mendocinus Kraglievich, 1931: MACN Pv 6930, extremo proximal de fémur derecho. Devincenzia gallinali Kraglievich, 1932: MNHN-M-189, tarsometatarso derecho. Onactornis depressus Cabrera, 1939: MLP 37-III-7-8, cráneo incompleto y falanges podales. Onactornis pozzi Brodkorb, 1967: MACN Pv 6681, falange ungueal del dedo III. ?Onactornis pozzi: MACN Pv 13243, extremo distal de tibiotarso izquierdo.

Kelenken guillermoi Bertelli, Chiappe y Tambussi, 2007

BAR 3877-11, cráneo, tarsometatarso izquierdo, una falange podal fragmentaria $\mathrm{y}$ varios restos indeterminados.

Mesembriornithinae indet.

MACN Pv 12745, fragmento de cintura escapular.

Mesembriornithinae Taxón nuevo A.

MMP 5050, esqueleto completo. Psilopterus sp.: MLP 89-III-20-1, neurocráneo y fragmentos vertebrales.

Mesembriornis incertus (Rovereto, 1914)

Prophororhacos incertus Rovereto, 1914: FM-P14422, tibiotarso, fíbula, tarsometatarso y falanges podales derechos; MACN Pv 6934, vértebra dorsal, húmero, 
fragmento de coracoides, ulna y radio, fragmento de pelvis, extremo distal de tarsometatarso derecho y tres falanges podales.

Mesembriornis milneedwardsi Moreno, 1889

MLP 20-140, vértebra cervical; MLP 20-141, fragmento de tibiotarso derecho; MLP 20-142, fíbula derecha; MLP 20-170, extremo distal de fémur derecho.

Paleociconia australis Moreno, 1889: MLP 20-87, fragmento distal de tarsometatarso izquierdo. Hermosiornis milneedwardsi Rovereto, 1914: MACN Pv 5944, esqueleto parcialmente completo, faltando el cráneo. Hermosiornis rapax Kraglievich, 1946: MMP 155-S, cráneo, fémures, tibiotarso y tarsometatarso derecho.

Paraphysornis brasiliensis (Alvarenga, 1982)

Physornis brasiliensis Alvarenga, 1982: MLP DGM-1418R (calcotipo).

Patagornithinae

MLP 61-IV-6-3, extremo proximal de tarsometatarso derecho.

Patagornis marshi Moreno y Mercerat, 1891

CORD-PZ-1341, fragmento de cráneo, escápula derecha, tarsometatarso derecho, falanges podales y restos fragmentarios; MLP 20-143, fragmento mandibular; MLP 20-147, fragmento de sinsacro; MLP 20-148, vértebras; MLP 20-151, extremo proximal de fémur derecho; MLP 20-152, extremo distal de fémur izquierdo; MLP 20153, diáfisis de fémur izquierdo; MLP 20-154, extremo distal de tibiotarso derecho; MLP 20-155, trochlea metatarsi III izquierda; MLP 20-157, falange ungueal del dedo IV; MLP 20-158, fragmento proximal de tibiotarso derecho; MLP 20-164, falange ungueal del dedo II; MLP 20-184, falange ungueal; MLP 20-189, falange ungueal del dedo II derecho; MLP 59-XII-14-14, extremo distal de tibiotarso derecho; MLP 84-III9-21, cráneo, fragmentos mandibulares, pelvis, fémur izquierdo, ambos tibiotarsos, fíbulas y tarsometatarsos y una falange podal. Phororhacos inflatus Ameghino, 1891: AMNH 7005, extremo distal de tarsometatarso derecho y falanges podales; AMNH 7009, falanges podales; BMNH-A516, esqueleto parcialmente completo faltando la columna vertebral; FM-P13213, esqueleto parcialmente completo (faltando el cráneo) de un juvenil; MLP 20-122, neurocráneo. Phororhacos sp.: AMNH 9264, fragmento de pelvis, fémur izquierdo, ambos tibiotarsos y fíbulas, tarsometatarso derecho y autopodio 
posterior derecho incompleto. cf. Patagornis marshi: MPM-PV4242, esternón. Paleociconia cristata Brodkorb, 1967: MLP 20-85, falange ungueal; MLP 20-86, falange ungueal del dedo II izquierdo.

Phorusrhacidae indet.

MACN Pv 191810, extremo distal de tarsometatarso derecho (calco); MACN A 52-193, falanges podales. ?Phorusrhacidae MLP 20-584, falange. Phororhacidae: MACN A 11030, restos fragmentarios varios; MACN Pv 17749, extremo distal de tibiotarso izquierdo; MACN Pv 17748, extremo distal de tibiotarso derecho. Phorusrhacinae MNHN-1563, tibiotarso izquierdo.

Phorusrhacos longissimus Ameghino, 1887

BMNH-A530, mandíbula incompleta; MACN Pv 8592, extremo distal de tibiotarso izquierdo; MLP 118, sínfisis mandibular; MLP 559-II a V, extremo proximal de tarsometatarso (calco); MPM-PV4241, mandíbula, vértebras fragmentarias, fémur y tibiotarso izquierdo, ambas fíbulas y otros restos. Phororhacos longissimus Ameghino, 1889: AMNH 7004, falange ungueal del dedo II; AMNH 7010, extremo distal de tarsometatarso izquierdo; BMNH-A529, mandíbula y fragmento de lacrimal; BMNHA535, fragmentos craneanos; MACN Pv 10602, porción de sínfisis mandibular. Stereornis rollieri Moreno y Mercerat, 1891: MLP 20-119, fragmento proximal de tibiotarso izquierdo; MLP 20-120, extremo proximal de tarsometatarso izquierdo. Stereornis gaudryi Moreno y Mercerat, 1891: MLP 20-121, extremo proximal de tarsometatarso derecho. Mesembriornis studeri Moreno y Mercerat, 1891 MLP 20-125, fragmentos vertebrales; MLP 20-128, extremo proximal de fémur derecho; MLP 20129, extremo proximal de fémur izquierdo; MLP 20-130, tibiotarso derecho; MLP 20131, tarsometatarso derecho; MLP 20-132, extremo distal de tarsometatarso derecho. Mesembriornis quatrefagesi Moreno y Mercerat, 1891: MLP 20-135, extremo distal de húmero izquierdo; MLP 20-136, extremo proximal de ulna izquierda; MLP 20-137, diáfisis de tibiotarso izquierdo; MLP 20-138, extremo distal de tarsometatarso derecho; MLP 20-139, falange ungueal. Darwinornis copei Moreno y Mercerat, 1891: MLP 20171, fragmento distal de tibiotarso izquierdo; MLP 20-172, mesotróclea izquierda. Darwinornis zitteli Moreno y Mercerat, 1891: MLP 20-174, cóndilo lateral de tibiotarso derecho; MLP 20-175, mesotróclea izquierda. Darwinornis socialis Moreno y Mercerat, 1891: MLP 20-176, mesotróclea izquierda. Owenornis affinis Moreno y Mercerat, 1891: 
MLP 20-177 mesotróclea derecha. Owenornis lydekkeri Moreno y Mercerat, 1891:

MLP 20-178, fragmento vertebral; MLP 20-180, cóndilo mesial de tibiotarso derecho; MLP 20-181, mesotróclea derecha; MLP 20-182, ectotróclea izquierda. Phororhacos sehuensis Ameghino, 1891: MLP 20-118, sínfisis mandibular. Phororhacos aff. platygnathus: MACN Pv 6933, sínfisis mandibular fragmentaria. Phororhacos sp.: AMNH 9146, tarsometatarso izquierdo; AMNH 9148, restos fragmentarios; AMNH 9150, restos fragmentarios; AMNH 9153, restos fragmentarios; AMNH 9158, restos fragmentarios; AMNH 9497, miembro posterior izquierdo; MACN Pv 18602, extremo distal de tarsometatarso derecho; YPM-PU15179, extremo distal de maxila; YPMPU15186, axis; YPM-PU15353, margen anterior de fenestra antorbital y arco yugal izquierdo; YPM-PU15557, restos fragmentarios; YPM-PU15856, falange ungueal; YPM-PU15862, fragmento vertebral; YPM-PU15905, fragmentos vertebrales. Phorusrhacos sp.: MLP 20-572, falange ungueal del dedo II; MLP 20-573, falange 1 del dedo II; MLP 67-VIII-28-1, falange ungueal del dedo II; MLP 67-VIII-28-2, falange ungueal del dedo III; MLP 68-I-16-1, extremo distal de tarsometatarso derecho; MLP 76-V-10-11, tarsometatarso derecho. Phorusrhacos?: MACN Pv 6931, vértebra cervical; MLP 52-X-5-93, fragmento distal de tarsometatarso.

Physornis fortis Ameghino, 1895

BMNH-A583, fragmento de sínfisis mandibular. Aucornis euryrhyncus Ameghino, 1898: MACN A 52-185, extremo proximal de tarsometatarso izquierdo; MACN A 52-186, fragmento de sínfisis mandibular; MACN A 52-187, falange podal fragmentaria; MACN A 52-188, falange podal. Aucornis sp.: FM-P13619, restos fragmentarios; FM-P13340, mandíbula, escápula, cuadrado, falanges podales y varios fragmentos.

Psilopterinae indet.

MPEF-PV1721, falange ungueal; MPEF-PV1722, fragmento proximal de tarsometatarso derecho; MLP 60-VI-15-7, fragmento de pelvis. Phororhacos sp.: YPMPU15363, miembros posteriores fragmentarios.

Psilopterus affinis (Ameghino, 1899)

Phororhacos affinis Ameghino, 1899: MACN A 52-184, tarsometatarso derecho. 
Psilopterus bachmanni (Moreno y Mercerat, 1891)

MLP s/n, pelvis fragmentaria; MPM-PV4243, fúrcula fragmentaria, vértebras, miembro anterior y posterior izquierdo, restos fragmentarios. Patagornis bachmanni Moreno y Mercerat, 1891: MLP 20-165, extremo proximal de fémur izquierdo; MLP 20-166, extremo distal de fémur izquierdo; MLP 20-167, extremo distal de tibiotarso izquierdo; MLP 20-168, extremo proximal de tarsometatarso izquierdo. Psilopterus communis Moreno y Mercerat, 1891: MLP 20-187, extremo distal de tarsometatarso izquierdo. Psilopterus intermedius Moreno y Mercerat, 1891: MLP 20-190, extremo distal de tarsometatarso izquierdo. Psilopterus minutus Ameghino, 1891: FM-PA-9, extremo distal de tibiotarso y tarsometatarso izquierdo (calcotipo). ?Psilopterus delicatus MLP 20-567, extremo proximal de tarsometatarso derecho. Pelecyornis pueyrredonensis Sinclair y Farr, 1932: YPM-PU15904, esqueleto parcial. "Bird”: AMNH 9154, tarsometatarso derecho fragmentario.

Psilopterus colzecus Tonni y Tambussi, 1988

MLP 76-VI-12-2, mandíbula incompleta, húmero, radio y ulna fragmentarios, diáfisis de ambos tibiotarsos, fémur derecho incompleto, porción de diáfisis de ambos tarsometatarsos, extremo distal de tarsometatarso izquierdo, autopodio posterior izquierdo completo.

Psilopterus lemoinei (Moreno y Mercerat, 1891)

MPM-PV3649, húmero, escápula, fémur y fíbula derechos, ambos tibiotarsos y tarsometatarsos; MPM-PV3650, esplacnocráneo; MPM-PV4240, tibiotarso izquierdo; CORD-PZ-1340, extremo distal de tarsometatarso derecho. Patagornis lemoinei Moreno y Mercerat, 1891: MLP 20-161, fragmento distal de fémur izquierdo; MLP 20162, fragmento distal de tibiotarso derecho. Psilopterus australis Moreno y Mercerat, 1891: AMNH 7006, extremo distal de tibiotarso derecho y falanges podales; AMNH 7008, extremo distal de tarsometatarso izquierdo; FM-PA-4, extremos proximal y distal de húmero derecho (calcotipo); FM-PA-5, extremo distal de tarsometatarso derecho (calcotipo); FM-P13257, cráneo; FM-P13260, extremo distal de tarsometatarso izquierdo; MLP 20-83, 6ta. vértebra cervical; MLP 20-84, 7ma. vértebra cervical; MLP 20-188, extremo distal de tarsometatarso izquierdo; MLP 20-161, extremo distal de fémur izquierdo; MLP 20-162, extremo distal de tibiotarso derecho; MLP 20-188, extremo distal de tarsometatarso izquierdo. Pelecyornis australis Moreno y Mercerat, 
1891: AMNH 9257, cráneo, columna vertebral, ambos húmeros, pelvis, miembro posterior izquierdo y restos varios; YPM-PU15109, cráneo; YPM-PU15402, esqueleto parcial; YPM-PU15479, tarsometatarso derecho. Pelecyornis tubulatus Ameghino, 1895: FM-PA-6, fragmentos de fémur, tarsometatarso, vértebra troncal y falanges (calcotipo); FM-PA-7, extremo distal de tibiotarso y tarsometatarso izquierdo (calcotipo); FM-PA-8, tarsometatarso izquierdo (calcotipo); FM-PA-10, extremo distal de tibiotarso izquierdo (calcotipo). Pelecyornis tenuirostris Sinclair y Farr, 1932: AMNH 9157, esqueleto parcial. cf. Psilopterus lemoinei: MACN A 11030-68, extremo distal de tarsometatarso derecho. "Bird” YPM-PU15477, fémur y tarsometatarso derechos fragmentarios.

\section{Psilopterus sp.}

FM-P15303, falange ungueal; MLP 20-582, falange 1 del dedo II derecho; MLP 20-586, extremo distal de tarsometatarso izquierdo. Pelecyornis sp.: YPM-PU15448, sinsacro; YPM-PU15802, vértebra dorsal. Psilopterus? MLP 20-583, falange 1 del dedo III izquierdo "Bird”: YPM-PU15270, vértebra dorsal.

Procariama simplex Rovereto, 1914

FM-14353, cráneo fragmentario, molde endocraneano, vértebras y restos varios; FM-P14375, vértebra, húmero derecho y extremo distal de maxila; FM-P14525, esqueleto prácticamente completo; FM-P15231, extremo distal de tibiotarso y tarsometatarso izquierdos; MACN Pv 6939, fémur y tibiotarso derechos, varios tarsometatarsos fragmentarios; MACN Pv 8225, neurocráneo, pelvis, ambos fémures, extremo distal de tibiotarso izquierdo, ambos tarsometatarsos y autopodio posterior derecho; MACN Pv 8275, falanges ungueales de los dedos II y III; MMP 990, tibiotarso $\mathrm{y}$ tarsometatarso izquierdos muy fragmentarios, falanges podales, húmero izquierdo $\mathrm{y}$ porción de sínfisis mandibular. cf. Procariama sp.: YPM-PU23664, restos fragmentarios.

Titanis walleri Brodkorb, 1963

UF 30003, carpometacarpo izquierdo (calco); UF 137839, extremo proximal de húmero izquierdo (calco); s/n, extremo proximal de tibiotarso izquierdo (calco). 
Numerosas aves que han sido consideradas en la literatura como formas afines o pertenecientes a Phorusrhacidae fueron removidas de esta familia. Tal es el caso de Brontornis burmeisteri Moreno y Mercerat, 1891 y Paleopsilopterus itaboraiensis Alvarenga, 1985 (véase capítulos 2 y 5), Aucornis solidus Ameghino, 1899, MACN Pv 11052 (considerado como nomen dubium sensu Tambussi y Degrange inédito) y los restos fragmentarios originalmente asignados a Smiliornis penetrans Ameghino, 1891, MACN A 183, Riacama caliginea Ameghino, 1899, MACN A 52-189 y Pseudolarus guaraniticus Ameghino, 1899, MACN Pv 52-190. Ciconiopsis antarctica Ameghino, 1899, MACN A 11666 es considerado un Phorusrhacidae nomen inquirendum por Tambussi y Degrange (inédito). Por su parte los materiales estudiados Liornis sp., MLP 20-581, Phororhacoidea, MACN A 10890, ?Phorusrhacidae, MACN A 52-196, MLP 20-585 y Phororhacos, YPM-PU15866 son considerados aquí como incerti ordinis. Asimismo fueron excluidos los taxones asignados a la familia extinguida Ameghinornithinae Mourer-Chauviré, 1981 del Eoceno de Francia y Strigogyps sapea (Peters, 1987) cuyas diferencias con los fororracos ya han sido expuestas (e.g., Alvarenga y Höfling, 2003; Mayr, 2005, 2009).

B) Otras aves fósiles

Anseriformes:

Incertae familiae: Brontornis burmeisteri Moreno y Mercerat, 1891, BMNHA578, BMNH-A580, MLP 20-88, MLP 20-90, MLP 20-91, MLP 20-92, MLP 20-568, MLP 20-569, MLP 20-574, MLP 20-575, MLP 20-576, MLP 20-579, MLP 20-580; Brontornis sp., FM-P15309, MLP 20-570, MLP 20-578, MLP 20-593; ?Brontornis, MLP 20-577; Rostrornis floweri Moreno y Mercerat, 1891, FM-P13259, 20-94, 20-95, 20-96, 20-97, 20-108, 20-109, 20-110, 20-111, 20-112, 20-113, 20-114, 20-116.

Cariamiformes:

Incertae familiae: Paleopsilopterus itaboraiensis Alvarenga, 1985, MACN Pv 19163, MACN Pv 19170.

Cariamidae: Chunga incerta (Tonni, 1974), MLP 71-VII-5-1, MLP 71-VII-5-2, MLP 71-VII-5-4; Cariama santacrucensis Noriega et al., 2009, MPM-PV3511.

Dinornithiformes: 
Dinornithidae: Emeus crassus, MLP 86-VI-15-1.

\subsubsection{Especies actuales}

Para comparación se utilizaron esqueletos de las siguientes especies modernas:

Anseriformes

Anas platalea (MLP 84, Anatidae), Chauna torquata (MLP 569, Anhimidae).

Cariamiformes

Cariama cristata (MLP 533, MACN 3717a, MACN 25919, FM 105635, AMNH 8604, Cariamidae), Chunga burmeisteri (MACN 2351a, FM 106731, MLP 52, MLP 535, Cariamidae).

Charadriiformes

Fratercula corniculata (MACN 22325, Alcidae), Burhinus capensis (YPM 111287, Burhinidae), Burhinus grallarius (YPM 102096, Burhinidae), Burhinus oedicnemus (MLP 531, Burhinidae), Vanellus chilensis (MLP 615, Charadriidae), Chionis alba (MLP 412, Chionididae), Larus maculipennis (MLP 814, Laridae), Catharacta maccormicki (MLP 871, Stercoraridae).

Ciconiiformes

Ardea cocoi (MACN 20958, Ardeidae), Cochlearius cochlearius (YPM 102541, Ardeidae), Egretta thula (MLP 410, Ardeidae), Nycticorax nycticorax (MLP 804, Ardeidae), Cathartes aura (MLP 3124, Cathartidae), Coragyps atratus (MLP 344, Cathartidae), Vultur gryphus (MLP 807, Cathartidae), Ciconia maguari (MLP 712, Ciconiidae), Jabiru mycteria (YPM 106519, Ciconiidae), Leptoptilos crummeniferus (YPM 102534, YPM 102550, YPM 106133, Ciconiidae), Leptoptilos dubius (YPM 102102, Ciconiidae), Mycteria americana (YPM 105903, Ciconiidae), Mycteria ibis (YPM 105272, Ciconiidae), Mycteria leucocephala (YPM 102099, Ciconiidae), Theristicus melanopis (MLP 474, Threskiornithidae).

Columbiformes

Columba picazuro (MLP 399, Columbidae), Zenaida auriculata (MLP 261, Columbidae). 
Coraciiformes

Ceryle torquata (MLP 6, Alcedinidae), Buceros bicornis (YPM 103256, Bucerotidae), Buceros rhinoceros (YPM 102223, Bucerotidae), Rhyticeros undulatus (YPM 107215, Bucerotidae).

Cuculiformes

Guira guira (MLP 97, Cuculidae), Opisthocomus hoazin (MLP 536, Ophistocomidae).

Falconiformes

Buteo magnirostris (MLP 362, Accipitridae), Geranoaetus melanoleucus (MLP 696, Accipitridae), Sagittarius serpentarius (YPM 102276, YPM 105490, YPM 111125, Sagittariidae), Pandion haliaetus (MACN 20366, Pandionidae), Falco femoralis (MLP 866, Falconidae), Falco peregrinus (MLP 638, Falconidae), Falco sparverius (MLP 56, Falconidae), Polyborus plancus (MLP 62, Falconidae).

Galbuliformes

Galbula ruficauda (MLP 319, Galbulidae).

Galliformes

Penelope purpurascens (MACN 343438, Cracidae), Lophortyx californica (MLP 364, Phasianidae).

Gaviiformes

Gavia immer (OUVC 10407, OUVC 10563, Gaviidae).

"Gruiformes"

Aramus guarauna (MACN 63320, Aramidae), Grus canadensis (YPM 110401, YPM 102100, YPM 102538, Gruidae), Ardeotis arabs (YPM 102540, Otididae), Ardeotis kori (YPM 105866, Otididae), Otis tarda (YPM 102227, Otididae), Tetrax tetrax (YPM 102062, Otididae), Psophia crepitans (YPM 102505, YPM 103260, YPM 110540, Psophiidae), Psophia viridis (YPM 104524, Psophiidae), Fulica armillata (MLP 49, Rallidae), Porphyrula martinica (MLP 403, Rallidae), Rallus maculatus (MLP 363, Rallidae). 
Passeriformes

Xiphocolaptes major (MLP 178, Dendrocolaptidae), Taraba major (MLP 185, Formicariidae), Pseudoseisura lophotes (MLP 126, Furnariidae), Psarocolius decumanus (MLP 355, Icteridae), Turdus rufiventris (MLP 777, Turdidae), Pitangus sulphuratus (MLP 141, Tyrannidae).

Pelecaniformes

Phalacrocorax albiventer (MLP 476, Phalacrocoracidae), Sula leucogaster (MLP 482, Sulidae).

Phoenicopteriformes

Phoenicopterus chilensis (MLP 564, Phoenicopteridae).

Piciformes

Monasa nigrifrons (MLP 330, Bucconidae), Ramphastos toco (MACN 1390a, Ramphastidae), Ramphastos vitellinus (MLP 314, Ramphastidae).

Podicipediformes

Podiceps major (MLP 522, Podicipedidae).

Procellariiformes

Macronectes giganteus (MLP 812, Procellariidae), Pagodroma nivea (MLP 488, Procellariidae), Puffinus diomedea (MLP 79, Procellariidae).

Psittaciformes

Cyanoliseus patagonus (MLP 65, Psittacidae).

Strigiformes

Asio otus (MLP 541, Strigidae), Bubo virginianus (MLP 401, Strigidae), Tyto alba (MLP 53, Tytonidae).

Sphenisciformes

Pygoscelis adeliae (MLP 469, Spheniscidae). 
Struthioniformes

Dromaius novahollandie (MLP 685, Dromaiidae), Pterocnemia pennata (MLP 411, Rheidae), Rhea americana (MLP 878, Rheidae), Struthio camelus (MLP 678, Struthionidae).

Tinamiformes

Eudromia elegans (MLP 327, Tinamidae), Rhynchotus rufescens (MACN 68089, Tinamidae). 


\section{Capítulo 4: Descripción osteológica}

\subsection{Nomenclatura anatómica}

La terminología osteológica utilizada en este capítulo corresponde a aquella propuesta por Baumel y Witmer (1993) y se resalta en cursiva en el texto. En el caso de las piezas óseas más comunes, se aplican los nombres vernáculos, por ejemplo, cráneo (cranium), mandíbula (mandibula), pelvis (pelvis), fémur (femur), tibiotarso (tibiotarsus), fíbula (fibula) y tarsometatarso (tarsometatarsus). En la descripción del paladar se aplica además la terminología de Zusi y Livezey (2006). La terminología artrológica sigue a Baumel y Raikow (1993).

\subsection{Descripción}

Debido a que uno de los objetivos de esta tesis es estudiar la forma en la cual se adquiere y manipula el alimento, así como la forma de locomoción de los fororracos (véase capítulo 1), en este capítulo se describen exclusivamente el cráneo y los elementos del complejo apendicular posterior (pelvis, fémur, tibiotarso, tarsometatarso y dígitos).

\subsubsection{Generalidades del cráneo}

Se estudiaron los cráneos de Psilopterus lemoinei, Psilopterus bachmanni, Procariama simplex, Mesembriornis milneedwardsii, Taxón nuevo A, Patagornis marshi, Andrewsornis abbotti, Andalgalornis steulleti, Kelenken guillermoi, Devincenzia pozzi y varios fragmentos craneanos de Phorusrhacos longissimus. A su vez, se analizaron las mandíbulas de Psilopterus lemoinei, Procariama simplex, Mesembriornis milneedwardsi, Taxón nuevo A, Patagornis marshi, Andrewsornis abbotti, Andalgalornis steulleti y Phorusrhacos longissimus. En el caso de Procariama y Mesembriornis, las mandíbulas son fragmentarias y se encuentran reconstruidas en gran parte. Lamentablemente, no se conocen cráneos de individuos juveniles que pudieran dar cuenta de los límites de cada hueso antes de la fusión que ocurre durante el crecimiento. Por esta razón, se recurre a la ubicación topográfica (siguiendo a Baumel y Witmer, 1993) para el reconocimiento óseo.

La forma del cráneo de los Phorusrhacidae resulta de una singular combinación de caracteres (Figura 4.1): el os lacrimale presenta una rama descendente robusta y un 
processus supraorbitalis muy expandido caudalmente; la región occipital es muy expandida y vertical, las fossae temporalis son muy grandes, de contorno triangular en vista dorsal, confluyendo hacia la línea media dorsal del cráneo y con la base mayor de dicho triángulo orientada paralela al plano sagital. Estas dos últimas características son muy similares a las presentes en aves acuáticas como Sphenisciformes, Procellariiformes, Charadriiformes Lariidae, Pelecaniformes Sulidae y Phalacrocoracidae y no se han visualizado en ninguna otra especie con la cual hayan sido comparados los Phorusrhacidae.

El pico es muy alto, largo, muy comprimido y totalmente hueco con paredes delgadas. El culmen es convexo proximal y distalmente, y cóncavo en el sector medio. El extremo distal es en gancho o garfio, característica que recuerda al pico de las aves rapaces. Las narinas son proporcionalmente muy pequeñas.

La mandíbula (Figura 4.2) es larga y relativamente angosta (i.e., las rami mandibularis divergen poco), la symphysis mandibularis es robusta (Alvarenga y Höfling, 2003). Presenta un processus medialis mandibulae angosto y bien desarrollado.

\subsubsection{Ossa cranii}

A) Región occipital (Figura 4.1D y 4.3). El occiput es vertical (Ameghino, 1895), plano y muy expandido, limitado dorsocranealmente por la crista nucalis transversa, muy desarrollada y conspicua, perpendicular al plano sagital o levemente dirigida caudalmente y que se continua ventrolateralmente hasta los processi paraoccipitalis (Andrews, 1899). El foramen magnum es proporcionalmente pequeño, de contorno ovalado a subpentagonal (incluso triangular en Kelenken o circular en Taxón nuevo A). Dorsalmente, la prominentia cerebellaris sobre el os supraoccipitalis es conspicua y saliente. El condylus occipitalis es redondeado, levemente arriñonado, pedicelado (sésil en Taxón nuevo A) y presenta una incisura medialis condylaris bien desarrollada sobre la superficie dorsal. A ambos lados, en cada fossae parabasalis, se observa un surco arqueado profundo que se dirige dorsalmente. En el extremo dorsal de dicho surco se ubica el foramen de la vena occipitalis externa. Inmediatamente a los lados del condylus occipitalis, se ubican los forámenes del nervus hypoglossi y ventrolateralmente a éstos, se encuentra el foramen del nervus vagi, de contorno circular y bien conspicuo (Figura 4.3). Lateralmente, cubiertos por un reborde, se encuentran los ostia canalis ophthalmici externi y, cranealmente, el ostium canalis carotici. La fossa subcondylaris es conspicua, bien excavada -a excepción de Kelenken donde se 
encuentra ausente (Bertelli et al., 2007)- y de contorno ovalado. Los fonticuli occipitalis (Ericson, 1997) están ausentes (presentes en Taxón nuevo A). Los ossa exoccipitalis forman los processi paraoccipitalis robustos, subparalelos al occiput, de extensión ventral escasa aunque variable. Los processi parasphenoidalis medialis (tuberosidades mamilares de Andrews, 1899) se ubican sobre el os basisphenoidale mediocranealmente a los processi paraoccipitalis (Figura 4.3). Consisten en un par de protuberancias ovaladas muy bien desarrolladas (más marcadas en Psilopterinae), mediocranealmente dirigidas y proyectadas ventralmente. En Patagornis marshi, medialmente a estos processi, se encuentran un par de tubérculos accesorios muy robustos (Figura 4.4B). Los processi parasphenoidalis lateralis están muy poco desarrollados (proyectados a la altura del recessus columellae, muy extendidos en Cariamidae).

B) Región parietal (ossa parietalis). Como fue mencionado previamente, las fossae temporalis son amplias y profundas, de forma triangular en vista dorsal y convergentes hacia el plano sagital (Figura 4.1 y 4.6).

La crista temporalis es muy conspicua, de margen redondeado que se dirige ventrocranealmente hacia el extremo de los processi postorbitalis. La crista nuchalis sagitalis se encuentra muy marcada y presenta ancho variable. Las cristae nuchalis transversa son muy salientes y lateroventralmente se bifurcan: una rama continúa hasta el processus paraoccipitalis, mientras que la otra alcanza el processus suprameaticus saliente y agudo ubicado entre los processi paraoccipitalis y los processi zygomaticus. El processus suprameaticus parece funcionar como una 'traba' caudal para el os quadratum, en tanto limita caudalmente su movimiento.

El processus zygomaticus es corto, robusto, de margen anterior ancho, dirigido cranealmente de forma paralela al plano sagital. Dorsalmente presenta una cresta dirigida posteriormente hacia la crista nuchalis transversa. Constituye el margen dorsal de la fossa subtemporalis, que es muy amplia, con forma de triángulo invertido (no invertido en Taxón nuevo A) y se encuentra delimitada caudalmente por la crista nuchalis transversa.

C) Región paraesfenoidal. El os basisphenoidale (basitemporalis) está totalmente fusionado con el os parasphenoidale. La lamina parasphenoidalis es estrecha, cóncava y pentagonal (como en Cariama) y no triangular como indica Andrews (1899). Se encuentra limitada caudo-lateralmente por los processi parasphenoidalis medialis y caudalmente por la fossa subcondylaris. Las alae parasphenoidalis se encuentran poco desarroladas cráneo-lateralmente (ausentes en 
Taxón nuevo A), formando un reborde o labio (véase más abajo). Ubicados lateralmente y cranealmente a la tuba auditiva communis, se encuentran los processi basipterygoideus muy conspicuos (Alvarenga y Höfling, 2003; Mayr, 2009, Alvarenga et al., 2011), pedunculados y con una superficie de articulación lisa de sección ovalada (Figura 4.4). Por delante, se continúa el rostrum parasphenoidalis delgado.

D) Región ótica (Cavum tympanicum). La región auditiva (Figura 4.5) es más alargada y más angosta que la de los Cariamidae. El recessus tympanicus dorsalis, limitado lateralmente por el processus zygomaticus, es ovalado y sumamente profundo. Laterocranealmente, se encuentra la cotyla quadratica squamosi ovalada. Medialmente, se encuentra un cuenco donde se aloja el foramen nervus facialis. Mediocaudalmente al recessus tympanicus dorsalis, se encuentra la cotyla quadratica otici que se presenta subdividida en dos cuencos, uno caudolateral y otro craneomedial. Medialmente a esta cotyla, se encuentra el recessus tympanicus rostralis en el que se disponen tres invaginaciones: la caudal corresponde al recessus columellae, que conduce al os prooticum y a la ventana ovalis donde se aloja la columella; la dorsal corresponde a la fenestra vestibularis y la invaginación medial, la fenestra cochelaris, presenta un reborde o labio formado por el ala parasphenoidalis. Este reborde es principalmente anterior y presenta un perfil en " $\mathrm{V}$ " con el vértice dirigido cranealmente, característica muy marcada en Psilopterinae (en Patagornis marshi el reborde presenta un margen redondeado). Esta condición no existe en los Cariamidae, donde el reborde es principalmente dorsal y presenta una escotadura anterior que correspondería parcialmente al canalis orbitalis.

E) Los ossa laterosphenoidalis se disponen oblicua a subverticalmente respecto al plano palatal y son cóncavos. El area muscularis aspera corresponde a una cuenca, ovalada, con su eje mayor vertical, ubicada lateralmente al foramen nervus ophthalmicus (ubicado sobre el septum interobitalis) y cranealmente al foramen maxillomandibularis $\left(\mathrm{V}_{2-3}\right)$ y se encuentra limitada lateralmente por una cresta marcada, extendiéndose dorsalmente hasta el nivel de la base del processus postorbitalis. $\mathrm{Su}$ desarrollo craneodorsal culmina a nivel de la fontanela orbitocraneana.

F) Región frontal (ossa frontalis). La región frontal es plana (Ameghino, 1895; Andrews, 1899; Sinclair y Farr, 1932; Bertelli et al., 2007) a levemente convexa y de forma variable (ver más abajo, morfotipos craneanos). Esta región es más ancha a nivel de los processi postorbitalis y presenta profundos y abundantes surcos de vascularización (Figura 4.6). Una pequeña depressio frontalis se ubica por delante de 
las fossae temporalis. El processus postorbitalis es masivo, muy desarrollado, dirigido craneolateralmente. Es triangular y muy expandido tanto ventral como lateralmente. Cranealmente, los ossa frontalis y los ossa nasalis están completamente fusionados, un carácter que ya habían notado Bertelli et al. (2007) para Kelenken guillermoi.

G) Zona flexoria craniofascialis. Esta zona de flexión entre el neurocráneo y el esqueleto facial, sumamente importante para la quinesis aviana (véase capítulo 8), en la mayoría de las Neornithes delimita una zona estrecha transversal y poco extendida craneocaudalmente (Baumel y Witmer, 1993). Participan en su formación los processi nasalis de los ossa premaxillaris, los processi premaxillaris de los ossa nasalis en su unión con el extremo craneal de los ossa frontalis y la lamina dorsalis del os mesethmoidalis (Bock, 1964; Zusi, 1984; Baumel y Witmer, 1993). En el caso de los Phorusrhacidae, la zona flexoria craniofascialis solo persiste en los Psilopterinae y Mesembriornithinae y se ubica por detrás de las narinas (Figuras 4.6 y 4.7). En los fororracos, al igual que en los Cariamidae, la zona flexoria adopta la forma de una "V" con el vértice dirigido caudalmente. Si bien se encuentran totalmente fusionados a los ossa frontalis, se puede apreciar que la configuración caudal de los ossa nasalis es similar a la de los Cariamidae (Figura 4.6.).

H) Región orbital (Figura 4.8). Las órbitas son grandes. Solo se conoce el septum interorbitale completo en algunos especímenes de Psilopterinae (Psilopterus lemoinei AMNH 9257, AMNH 9157, Psilopterus bachmanni YPM-PU15904) y Taxón nuevo A MMP 5050. El septum es muy delgado con una gran fontanela orbitocraneana caudal, de márgenes delgados y agudos. Caudalmente se ubica el foramen nervus ophthalmicus y, lateralmente, el foramen nervus trochlearis (IV) que presenta un pequeño surco craneal. Dorsalmente a la fontanela y a cada lado del septum se observa un surco dirigido cranealmente, delimitado por rebordes muy conspicuos, correspondiente al sulcus nervus olfactorii y que se origina en el foramen nervus olfactorii ubicado en la superficie dorsocaudal del septum sobre el os laterosphenoidale. Ocupa una posición más ventral que en los Cariamidae. Ventralmente, el septum interorbitale presenta un canal neumático, con pequeñas trabéculas internas que forman un entramado.

Solo se conocen los ossa ectethmoidalis de Taxón nuevo A. Se ubican anteriormente al septum interorbitale, conformando a cada lado unas saliencias pequeñas levemente curvadas cranealmente y que no entran en contacto con los ossa lacrimalis (Figura 4.8). Por delante continúa el os mesethmoidale que forma una 
delgada lámina más desarrollada cranealmente que en Cariamidae. Es destacable que en estos últimos la lamina dorsalis del os mesethmoidale se encuentra totalmente fusionada dorsalmente a los ossa frontalis.

Annulus ossicularis sclerae (Figura 4.9). Solamente se conocen los anillos escleróticos de dos especímenes de fororracos, un Psilopterinae (MM de Miramar referido a un Psilopterinae gen. et sp. indet. según Tambussi, 1989) y de Taxón nuevo A. Del Psilopterinae MM solo se conoce el anillo esclerótico izquierdo y no ha estado disponible para este estudio. De Taxón nuevo A MMP 5050 se conocen los anillos escleróticos muy bien preservados de ambos globos oculares. Se trata de annuli delgados (Figura 4.8 y 4.9), con corta longitud máxima (medida definida por Hall, 2008, 2009). Los annuli son más anchos en los laterales y dorsalmente que ventralmente. Los ossiculae sclerae -cada uno de los elementos que constituye el annulus- son rectangulares, anchos y bajos (angostos y altos en rapaces diurnas). Contactan entre sí a través del borde externo del ossicula, dándole forma triangular a la superficie de imbricación. Esta misma conformación está presente en Psittaciformes, Columbiformes, Coraciiformes, Passeriformes, Charadriiformes y Gruiformes (Lima et al., 2009). Siguiendo a Curtis y Miller (1938), los ossiculae se diferencian en tres tipos fácilmente discernibles en base a las zonas de superposición: overplates, underplates e interlocking plates (para evitar confusiones se retienen los términos en inglés en esta descripción). En muchas especies de aves (Bertelli et al., 2010) hay dos overplates (un osículo lateral que se superpone a los dos oscículos adyacentes) y dos underplates (un osículo medial que está superpuesto por los dos oscículos adyacentes).

Lemmrich (1931) propone enumerar los oscículos a partir del overplate más dorsal del anillo en sentido antihorario; este es el método aquí seguido. El annulus ossicularis sclerae derecho cuenta con 13 osículos que incluyen: 1 overplate, 1 interlocking plate, 1 underplate, 4 interlocking plates, 1 overplate, 3 interlocking plates, 1 underplate y 1 interlocking plate ( 2 overplates, 2 underplates y 9 interlocking plates en total). El annulus ossicularis sclerae izquierdo posee 14 oscículos que incluyen: 1 overplate, 6 interlocking plates, 1 overplate, 4 interlocking plates, 1 underplate y 1 interlocking plate ( 2 overlaps, 1 underlap y 11 interlocking plates en total). La presencia de 14 osículos se interpreta como la condición primitiva para las Neornithes (Warheit et al., 1989; Lima et al., 2009). La diferencia en la cantidad de ossiculae entre ambos ojos en el ejemplar MMP 5050 no es llamativa ya que el número de osículos puede ser variable entre diferentes géneros y especies e incluso variable entre los anillos derecho e 
izquierdo de un mismo individuo (Lemmrich, 1931; Curtis y Miller, 1938; De Queiroz y Good, 1988; Wartheit et al., 1989; Lima et al., 2009) como se aprecia en el ejemplar aquí estudiado.

Ossa lacrimalis y sutura frontolacrimale. El os lacrimale de los Phorusrhacidae presenta dos ramas muy conspicuas: una conformada por el processus supraorbitalis muy desarrollado caudalmente (más de la mitad de la órbita) y una rama descendente conspicua, que puede contactar o no con el arcus jugalis (Figura 4.10).

Os lacrimale communicans (=os uncinatum). Este hueso corresponde a la osificación del ligamentum lacrimojugale y une la rama descendente del os lacrimale con el arcus jugalis. Esta situación también está presente en los Cariamidae. Mantiene su identidad como hueso independiente en Taxón nuevo A y Psilopterinae ( $c f$. con Sinclair y Farr, 1932 quienes no encontraron indicios de su presencia). La porción distal de la rama descendente del os lacrimale de Psilopterus y en Taxón nuevo A se encuentra expandida lateralmente y presenta una carilla de articulación distal para el os lacrimale communicans. Este hueso es comprimido, corto, más expandido en su extremo dorsal (Figura 4.10). Su margen craneal es filoso, mientras que el caudal es ancho y romo. En vista medial presenta un foramen pneumático grande ovalado ubicado en su extremo dorsal y en su extremo ventral presenta una pequeña fosa caudal. $\mathrm{Su}$ contacto dorsal con el os lacrimale se ubica justo por debajo del foramen pneumático ubicado en la expansión distal del os lacrimale, mientras que su contacto con el arcus jugalis se produce donde este último tiene un quiebre (véase Arcus jugalis) y se expande cranealmente, emitiendo dorsalmente una pequeña proyección triangular (como se observa en Taxón nuevo A y Mesembriornis milneedwardsi). En Psilopterus no existe dicha proyección dorsal triangular, pero a la misma altura existe una pequeña depresión oval que indicaría el contacto con el os lacrimale communicans. En los Patagornithinae y los Phorusrhacinae, el os lacrimale communicans se encuentra fusionado a la rama descendente del os lacrimale (Degrange et al., 2010), constituyendo una unión única y rígida entre el os lacrimale y el arcus jugalis.

\subsubsection{Ossa faciei}

A) Fenestra antorbitalis. Es amplia, triangular y de mayor tamaño que las narinas. Su límite craneal está representado por una barra de disposición oblicua excepto en Andalgalornis steulleti que presenta un margen anterior vertical (Patterson y 
Kraglievich, 1960). Las homologías de la barra oblicua se discuten a continuación (veáse además Degrange y Tambussi, 2011).

Dorsocranealmente a la fenestra antorbitalis se ubican las narinas externas que están delimitadas dorsalmente por los ossa nasalis y los ossa premaxillaris, caudalmente por los ossa nasalis y ventralmente por los ossa maxillaris (Witmer, 1995a). Sin embargo, la forma en la cual participan estos huesos en la constitución de las narinas y del margen anterior de la fenestra antorbitalis en los fororracos es poco clara. La situación es muy variable en formas actuales emparentadas a los Phorusrhacidae, como los Cariamidae y los Psophiidae (Chandler, 1997; Livezey, 1998; Mayr, 2002; Agnolín, 2009; Degrange et al., 2010; Alvarenga et al., 2011). En Cariamidae la barra oblicua que separa la narina de la fenestra antorbitalis está formada en su mayor parte por un proceso ascendente, el processus nasalis de los ossa maxillaris que contacta levemente con la parte más anterior del contacto de los ossa lacrimalis con los ossa nasalis. Cranealmente a dicho contacto, los ossa nasalis emiten dos procesos: (1) el processus maxillaris, muy corto, que forma el límite dorso-caudal de las narinas y que contacta con el processus nasalis del os maxillare constituyendo el límite ventrocaudal de las narinas y (2) el processus premaxillaris que se dirige dorsalmente hasta la porción más craneal de las narinas (Figura 4.11B). En Psophia crepitans y en Galliformes como Crax sp. y Penelope sp., el processus nasalis de los ossa maxillaris está ausente y el límite posterior de las narinas y el anterior de la fenestra antorbitalis está dado por el processus maxillaris del os nasale que contacta directamente con los os maxillare (Figura 4.11A). En el caso de los Psilopterinae Psilopterus lemoinei FMP13257 y AMNH 9257 se observa una pequeña cresta oblicua, dirigida craneoventralmente hasta alcanzar la mitad de la altura de las narinas y que representaría el límite entre el processus maxillaris del os nasale y el processus nasalis del os maxillare (Figura 4.11D). En Psilopterus lemoinei YPM-PU15402 (Figura 4.11C) del lado izquierdo, el cráneo presenta una fractura que separa el processus nasalis del os maxillare del processus maxillaris del os nasale, evidenciando que la situación es idéntica a aquella presente en Cariamidae (Sinclair y Farr, 1932) y similar a aquella reconocida en Patagornis marshi por Andrews, (1899). Sin embargo, en la descripción hecha por Sinclair y Farr (1932) no queda esclarecido si reconocen o no la presencia de un proceso descendente (processus maxillaris) de los nasales uniéndose a un proceso ascendente (processus nasalis) de los maxilares. Más aún, establecen que los nasales forman parte del margen ventral de las narinas, situación con la cual no se está de 
acuerdo aquí. En los restantes fororracos hay una completa fusión entre los dos procesos (i.e., el processus nasalis y maxillaris) debido a lo cual no es posible establecer el límite entre ambos.

B) Os maxillare y processus maxillopalatinus. Dentro de la fenestra antorbitalis se observa un hueso con forma de "Y" (Sinclair y Farr, 1932) que corresponde al processus maxillopalatinus del os maxillare (Figura 4.11) que se fusionan medialmente entre sí, formando en su parte posterior un canal vertical y constituyendo el límite caudal de la fossa palatalis. Ventralmente se continúa con los ossa palatina y oblitera cranealmente a la fossa choanalis. Dorsocranealmente toma contacto con el margen craneal de la fenestra antorbitalis, donde desarrolla algunas trabéculas. Su superficie es en general lisa. Esta estructura fue interpretada erróneamente como el os ethmoidale unido en su base con los processi maxillopalatinus por Andrews $(1896,1899)$ y Sinclair y Farr (1932).

La fusión de los processi maxillopallatinus en su línea media certifica la condición de paladar desmognato (sensu Huxley, 1867) para los Phorusrhacidae tal como se había afirmado previamente (Andrews, 1899; Sinclair y Farr, 1932; Patterson y Kraglievich, 1960; Alvarenga y Höfling, 2003; Agnolín, 2009; Alvarenga et al., 2011).

C) El pico de los Phorusrhacidae es comprimido lateralmente, alto y largo, de sección transversal triangular, con todos sus elementos totalmente fusionados (Andrews, 1899; Sinclair y Farr, 1932). Tomografías computadas helicoidales revelan que es completamente hueco (Figura 4.12). En el interior se ubicaría un gran sinus antorbitalis (Witmer com. pers., Witmer, 1995a, 1997; Witmer y Ridgely, 2008). Internamente las paredes del pico muestran algunas diferencias en cuanto al espesor y estructura trabecular (ver más abajo).

Visto lateralmente, el tomium es falcado, cóncavo inmediata y caudalmente al ápice del pico y convexo en su recorrido caudal hasta el nivel del contacto más craneal entre ossa palatina y tomia. A partir de allí describe una concavidad suave hasta alcanzar el arcus jugalis. El margen craneal del tomium es filoso y el margen caudal es romo y redondeado (a excepción de Taxón nuevo A, donde es filoso en todo su recorrido).

Tanto el culmen como los laterales del pico están fuertemente marcados por surcos sumamente ramificados e interconectados indicando una gran vascularización del pico y ranfoteca. 
Ventralmente, los ossa palatina constituyen el límite caudal de la fenestra palatalis, una fosa ovalada (obliterada en Taxón nuevo A) ubicada sobre el paladar a la altura de las narinas. Típicamente en las aves, esta fenestra está delimitada anteriormente por los ossa premaxillaris (Baumel y Witmer, 1993). Queda demostrado entonces que la mayor parte del pico estaría constituido en los fororracos por los ossa premaxillaris, un supuesto sostenido sin evidencias por Sinclair y Farr (1932) y Kraglievich (1920). El límite caudal de la fenestra está constituido por la fusión medial de los processi maxillopalatinus de los ossa maxillaris.

La estructura de las paredes y la condición hueca del pico eran desconocidas hasta muy recientemente (Degrange et al., 2010; Degrange y Tambussi, 2011). Las características de las paredes del pico pueden ser observadas particularmente en un especímen asignado a Psilopterus lemoinei MPM-PV3649 (Figura 4.13). Presentan un espesor de $0,88 \mathrm{~mm}$ estando internamente reforzadas por trabéculas óseas relativamente bajas (de 1,76 mm) que forman un entramado de retículos subcuadrangulares de tamaños variables ubicados sobre las paredes laterales (Figura 4.13C). Las trabéculas se encuentran concentradas en la región anterior y son menos perceptibles hacia la porción posterior; a la altura de la fenestra antorbitalis se restringen únicamente a la zona ventral. También se forman pequeñas barras ubicadas a lo largo de todo el pico, restringidas al ángulo ventrolateral del pico. Por delante de la fenestra antorbitalis y sobre la cara interna de las paredes laterales hay unos pequeños cuencos que alojarían divertículos del sinus antorbitalis. Esta compleja estructura interna no se desarrolla en Patagornis ni Andalgalornis.

D) Apertura nasi ossea. Las narinas son proporcionalmente pequeñas y se ubican en el margen dorsocaudal del pico (Andrews, 1899; Alvarenga y Höfling, 2003; Bertelli et al., 2007). Su forma es variable (ver más abajo) y en algunos taxones se encuentra presente una fossa premaxilar (Agnolín, 2009), ubicada en el margen craneoventral de las mismas. Tradicionalmente ha sido establecido que los Phorusrhacidae carecen de septum nasi osseum, -i.e., condición perviada- (Ameghino, 1895; Andrews, 1899; Sinclair y Farr, 1932; Alvarenga y Höfling, 2003). Sin embargo, en Psilopterus lemoinei MPM-PV3649 existe en la porción más anterior de las narinas, un septum nasi osseum débil e incompleto, mientras que en Psilopterus lemoinei YPMPU15402 existe un septum casi completo. Esta situación permite suponer la misma condición en otros fororracos y en consecuencia pone en duda la condición perviada para todos los Phorusrhacidae. 
Los Phorusrhacidae son holorhinos (Ameghino, 1895; Andrews, 1899; Sinclair y Farr, 1932). Se define esta condición cuando las narinas presentan margen posterior redondeado ubicado cranealmente a la zona flexoria craniofascialis y los processi nasalis de los ossa premaxillaris sobrepasan el margen caudal de las narinas (Garrod, 1873). La porción craneal de estos procesos se encuentra totalmente fusionada a los processi premaxillaris de los ossa nasalis.

E) Ossa palati: ossa palatina y ossa pterygoidei. Solamente se conoce un único paladar completo de fororraco, el de Taxón nuevo A (Figura 4.14). Algunos especímenes de Psilopterus bachmanni, P. lemoinei, Patagornis marshi, Andalgalornis steulleti y Kelenken guillermoi conservan paladares parciales.

Pueden destacarse tres características sobresalientes de los ossa palatina: (1) presentan una gran extensión ventral (Andrews, 1899; Sinclair y Farr, 1932); (2) son comprimidos, fuertemente convexos y (3) el processus maxillaris presenta una fuerte asociación craneocaudal con los ossa maxillaris y con los ossa premaxillaris y los arci jugalis. Esto último resulta en la fusión total de estos huesos y en la ausencia de zona flexoria palatina (Degrange et al., 2010; Figura 4.11). La extensión craneal de los ossa palatina es difícil de establecer en tanto se encuentran totalmente fusionados lateralmente a la porción más craneal del arcus jugalis, ossa maxillaris y ossa premaxillaris. La pars lateralis es angosta y larga, presenta una fossa ventralis muy marcada, delimitada por dos cristae muy conspicuas y filosas: la crista medialis poco extendida ventralmente y la crista lateralis, muy extendida ventralmente (Andrews, 1899). El angulus caudolateralis se encuentra ausente. El processus rostralis (=processus o lamella choanalis de Livezey y Zusi, 2006) se encuentra muy desarrollado. Contacta cranealmente con los processi maxillopalatinus. El processus pterygoideus es corto, robusto y amplio (Andrews, 1899). La fossa choanalis es larga y angosta, delimitada lateralmente por las cristae medialis de los ossa palatina.

Según Andrews (1899) y Sinclair y Farr (1932), los ossa palatina de los Phorusrhacidae recuerdan a los de Diomedea (Procellariiformes). Acordamos parcialmente con esta apreciación en tanto los ossa palatina de los Phorusrhacidae carecen de una crista ventralis (processus caudomedialis y angulus caudomedialis) extendida ventralmente y que sí está presente en Diomedea. Tal como fue mencionado previamente, la crista lateralis en los Phorusrhacidae se encuentra muy extendida ventralmente. 
Ossa pterygoidei. Solo se conocen los ossa pterygoidei de Taxón nuevo A, Andalgalornis steulleti, Patagornis marshi y de Psilopterus bachmanni, además de un posible os pterygoideus de Psilopterus lemoinei. Presenta un corpus pterygoidei robusto, de forma variable, en cuya superficie dorsal se observa la facies articularis basipterygoidea. Esta última conforma un proceso sobresaliente, de extremo oval plano o convexo. Es el lugar donde los ossa pterygoidei articulan con los processi basipterygoideus del os basisphenoidale ("articulación basipterigoidea" de Mayr y Clarke, 2003). En su superficie ventral hay dos crestas longitudinales, siendo la medial la de mayor desarrollo. Estas crestas son paralelas en su extremo más distal, pero convergen proximalmente hacia la facies articularis quadratica. La pars palatina es corta y presenta una facies articularis palatina amplia, con un reborde o proyección ventrolateral y dos cotylae para el contacto con el os palatinum. El processus quadraticus es pedunculado (sésil en Taxón nuevo A, Figura 4.14) y presenta la facies articularis quadratica redondeada y profunda (ovalada en Taxón nuevo A).

Vomer. Solo se conoce el vomer de Taxón nuevo A (Figura 4.14). Corresponde a una lámina vertical muy delgada, con la misma extensión que las lamellae choanalis de los ossa palatina. Se encuentra limitado cranealmente por la fusión medial de los processi maxillopalatinus. La ausencia de vomer en los cráneos de casi todos los fororracos puede ser interpretada como una ausencia real del mismo, tal como ocurre en los paladares desmognatos (Zusi y Livezey, 2006) o a una pérdida por causas tafonómicas, siendo ésta última la más plausible. Andrews (1899) indica que, en Patagornis marshi, unas trazas de hueso ubicadas en el espacio anterior entre los ossa palatina podrían corresponder al vomer.

F) Arcus jugalis. Forma una barra comprimida que presenta un reborde dorsal filoso y angosto en su porción craneal y uno ventral redondeado y ancho. El os jugale y os quadratojugale están completamente fusionados. El arcus jugalis se fusiona en su extremo craneal al os maxillare y craneomedialmente al os palatinum. Esta fusión trae como correlato la ausencia de zona flexoria arcus jugalis (Figuras 4.6 y 4.7). Taxón nuevo A constituye un caso especial en el cual la fusión entre os palatinum y arcus jugalis es craneal y caudalmente contactan mediante una carilla, pero sin fusionarse. En general, el arcus jugalis describe un arco muy abierto (poco perceptible en las formas menores, poco abierto en Taxón nuevo A). Su porción craneal se dirige dorsocaudalmente y desciende en su porción mediocaudal hasta el contacto con el os quadratum. El condylus quadraticus es robusto, redondeado y muy saliente. 
G) Os quadratum (Figura 4.15). Se conocen los ossa quadrati de Patagornis marshi, Andalgalornis steulleti, Devincenzia pozzi, Procariama simplex, Psilopterus lemoinei, Psilopterus bachmanni, Taxón nuevo A, Paraphysornis brasiliensis y restos fragmentarios asignados a Physornis fortis y Phorusrhacos longissimus.

El corpus ossa quadrati es ancho y robusto, incluso en los Psilopterinae (contrario a lo establecido por Sinclair y Farr, 1932). Presenta una depresión laterocaudal marcada (ausente en Andalgalornis steulleti y Taxón nuevo A). El processus oticus es ancho y consta de dos cóndilos (capitulum en este caso). El capitulum squamosum es oblongo (reniforme en Taxón nuevo A) y de superficie redondeada con su eje mayor caudomedialmente dirigido. La incisura intercapitularis es ancha y moderadamente profunda. El capitulum oticum es muy angosto y alargado. Ambos capitula se ubican en un mismo plano, pero el capitulum squamosum se encuentra ubicado más cranealmente que el capitulum oticum. Esta situación es más evidente en los Patagornithinae. La facies tympanica es ancha, cóncava y se proyecta caudalmente formando una cresta filosa en Patagornis marshi. El foramen pneumaticum posterior es grande (pequeño en Taxón nuevo A), ovalado y se ubica dorsalmente. Se continúa a través de un sulcus pneumaticus dirigido ventromedialmente que forma una muesca entre el condylus medialis y el condylus pterygoideus. Lateralmente al margen dorsal del foramen pneumaticum se ubica una pequeña cresta caudal filosa que contiene una pequeña concavidad que se acomoda en el processus suprameaticus (Figura 4.15D).

El processus orbitalis es comprimido y largo, levemente curvado dorsomedialmente. Sobre su cara medial se ubican dos forámenes pneumáticos: uno dorsal y otro ventral de mayor tamaño. En el caso de Taxón nuevo A, ambos forámenes son grandes aunque subiguales, siendo el dorsal reniforme, mientras que el ventral es ovalado. En Psilopterus, el foramen dorsal es pequeño y circular, mientras que el ventral es circular, pero mucho mayor que el dorsal (Figura 4.15A). La presencia de un único foramen circular pequeño se ha registrado en algunos Accipitridae y Sulidae. La presencia y disposición de los dos forámenes podrían constituir una autapomorfía de los Phorusrhacidae (Defeau com. pers.). En el caso de Andalgalornis los forámenes parecen estar obliterados.

El processus mandibularis es más ancho y robusto que el processus oticus. Consta de cuatro condyli: el medialis, el caudalis, el lateralis y el pterygoideus. El condylus medialis es ovalado, con su eje mayor dirigido mediocranealmente (en 
Cariamidae es perpendicular al plano sagital) e inclinado mediocranealmente. Una muesca separa caudolateralmente el condylus medialis del condylus caudalis. Este último es pequeño, reniforme, dispuesto mediocranealmente. El condylus lateralis es robusto, angosto y presenta un reborde caudomedial que contacta ambos cóndilos. El sulcus intercondylaris es profundo. La cotyla quadratojugalis se encuentra bien marcada, es redondeada, profunda y presenta un reborde en toda su circunferencia. El condylus pterygoideus se ubica mediodorsalmente al condylus medialis. Forma un pequeño domo ovalado, ubicado ventromedialmente al processus orbitalis.

Ameghino (1895), Andrews (1899), Sinclair y Farr (1932) y Tambussi (1989) declaran que la condición para los Phorusrhacidae Patagornis, Psilopterus y Devincenzia es la presencia de dos condyli que articulan con la mandíbula (en lugar de tres), una condición idéntica a la de los Galloanserae (Cracraft, 1988; Andors, 1992). Efectivamente, el os quadratum de Paraphysornis brasiliensis (DGM-1418-R) presenta únicamente dos condyli (Alvarenga, 1982), pero esta condición no se cumple para el resto de los taxones.

En el caso de Patagornis, el condylus caudalis es levemente convexo, inclinado cráneo-ventralmente (Figura 4.15D). Se encuentra pobremente separado del condylus lateralis, el cual es fuertemente convexo. Sin embargo, se dispone de forma oblicua con respecto a este último, formando una "V", limitando caudalmente al sulcus intercondylaris que tiene disposición curva. El condylus medialis presenta una superficie convexa. En el caso de Psilopterus (Figura 4.15), el os quadratum presenta los condylus lateralis y medialis claramente definidos. En Psilopterus lemoinei YPMPU15402 la zona donde se ubicaría el condylus caudalis se encuentra pobremente conservada, mientras que en Psilopterus bachmanni YMP-PU15904 la situación es similar a aquella de Chunga burmeisteri (Cariamidae). En este caso el condylus caudalis forma una pequeña saliencia triangular caudal, prácticamente continua al condylus lateralis, formando un único condylus simple. Sin embargo, en P. bachmanni, el condylus caudalis presenta una disposición oblicua (al igual que en Patagornis marshi y Taxón nuevo A), mientras que en Chunga es fundamentalmente horizontal. Además, en P. bachmanni se forma una foseta craneal curva somera (el sulcus intercondylaris) de dirección caudal, que marca el límite entre el condylus lateralis y el caudalis, similar a Patagornis marshi, aunque de forma menos marcada. Esta condición no está presente en Chunga burmeisteri. Esto es sumamente contrastante con la situación de Procariama simplex en la cual los tres condyli están claramente separados. 
En el caso de Devincenzia, el processus mandibularis es sumamente fragmentario y los dos condyli figurados por Tambussi (1989) son reconstrucciones. Los ossa quadrata de Physornis fortis y Phorusrhacos longissimus (Figura 4.15) son muy fragmentarios como para establecer la real cantidad de condyli.

\subsubsection{Ossa mandibulae}

La mandíbula de los fororracos (Figura 4.2) es alta, larga y angosta, en tanto las rami mandibulae son poco divergentes (entre $14^{\circ}$ y $18^{\circ}$ ) y la symphysis mandibularis es robusta (Alvarenga y Höfling, 2003) y en algunos casos se curva dorsalmente.

Principalmente en su parte ventral, la symphysis mandibulae se encuentra surcada por los canaliculi neurovascularis y foramina neurovascularia muy marcados. El tomium es filoso en la zona de la symphysis y caudalmente es más redondeado. Los rami mandibulae son altos y robustos, poco divergentes, de sección en "8", siendo su porción ventral más robusta. La fenestra mandibulae puede ser simple, doble o incluso triple. Cuando es única (e.g., Patagornithinae no Andrewsornis), la fenestra es ovalada, con su eje mayor horizontal. En los Psilopterinae es doble y ambas fenestrae son elongadas, con rebordes filosos, siendo la anterior la de mayor tamaño. En Taxón nuevo A es triple incluyendo una fenestra craneal y dos caudales elongadas, siendo la fenestra caudodorsal mayor que la fenestra caudoventral. En todos los casos, las fenestrae cranealmente presentan un margen dorsal filoso y un margen ventrocraneal constituido por dos rebordes separados por una pequeña fosa craneal. El processus coronoideus presenta desarrollo variable. El angulus mandibulae no se encuentra marcado. Sobre el margen ventral de los rami mandibulae, a nivel de la fenestra mandibulae, se observa la sutura entre el os dentale y el os angulare. Este último forma una espina que indenta entre dos proyecciones caudales del os dentale (Lámina 4.7C). No hay indicio de zona flexoria intramandibularis. El tuberculum pseudotemporalis es conspicuo, ovalado y pequeño. En la fossa articularis quadratica (Figura 4.16), la cotyla medialis es amplia, profunda y ovalada, con su eje mayor oblicuo cráneomedialmente. Lateralmente se encuentra más excavada, formando una fosa circular más profunda (ausente en Andrewsornis). Se encuentra delimitada mediocranealmente por un reborde que forma un arco. En todas las mandíbulas disponibles la cotyla caudalis es prácticamente plana (en Taxón nuevo A es convexa), ovalada y oblicua craneoventralmente. Se ubica a diferente nivel de la cotyla medialis de la cual además está separada por una cresta cóncava lateralmente. La cotyla caudalis está separada de la cotyla lateralis por una 
incisura oblicua dirigida mediocranealmente. La cotyla lateralis es oblonga, somera y cóncava, con un reborde mediocraneal vertical. El processus lateralis mandibulae está bien desarrollado (Figura 4.16). El processus medialis mandibulae se encuentra muy desarrollado y extendido medialmente. Presenta una superficie anterior plana, una dorsal angosta y redondeada (formando un labio), una caudal recta y una ventral plana (separada de la caudal por una cresta pequeña). El foramen pneumaticum articulare se encuentra presente, es pequeño y se ubica en la porción caudomedial de la cotyla medialis (este foramen se encuentra obliterado en Andalgalornis FM-P14357 posiblemente debido a la edad avanzada del individuo). La crista transversa fossae es elevada, pero de bordes romos (filosos en Andrewsornis). Caudalmente se encuentra el processus retroarticularis dirigido caudolateralmente. La fossa caudalis es subtriangular (condición muy marcada en Psilopterinae) de disposición mediocraneal (Figura 4.16).

\subsubsection{Morfotipos craneanos}

De acuerdo a las diferencias craneanas y mandibulares se establecen dos morfotipos craneanos.

A) Morfotipo I o "cráneo tipo Psilopterinae". Se incluyen dentro de esta categoría a los taxones Psilopterus (Láminas 4.1, 4.2, 4.3 y 4.4), Procariama (Lámina 4.5) y Taxón nuevo A (Lámina 4.6).

Neurocráneo de constitución más globosa, grande en relación al tamaño total del cráneo. Crista nuchalis sagittalis delgada (ancha en Taxón nuevo A) y muy marcada. Crista nuchalis transversa filosa. Prominentia cerebelaris aguda. Processi parasphenoidalis medialis muy salientes, sin tubérculos mediales accesorios. Superficie de la región frontal subpentagonal, con concavidades laterales a los lados de una leve cresta media craneal. Bordes orbitales de los ossa frontalis filosos y angostos, sin contacto con el processus supraorbitalis de los ossa lacrimalis. Estos últimos solo contactan con los ossa frontalis en la sutura frontolacrimale, limitada a la parte más craneal de la región orbital, constituyendo en vista dorsal un "escalón” de margen medial paralelo al plano sagital y margen posterior oblicuo. Rama descendente del os lacrimale con dos forámenes pneumáticos, (el ventral más grande que el dorsal). Contacto entre el os lacrimale y arcus jugalis indirecto a través del os lacrimale communicans. Zona flexoria craniofascialis presente. Zona flexoria palatina y zona 
flexoria arcus jugalis ausentes. Pico relativamente bajo y proporcionalmente más largo que en el morfotipo II, de paredes extremadamente delgadas, reforzado internamente por un entramado trabecular (Figura 4.13). Gancho distal del pico de sección triangular, poco desarrollado ventralmente. Tomium con forma falcada poco evidente. Narinas proporcionalmente grandes en relación al tamaño total del pico, de forma triangular. Fossa premaxilar presente. Ossa pterygoidei aplanados dorsoventralmente y curvados medialmente. Arcus jugalis recto y poco robusto. Os quadratum estilizado. Tres forámenes pneumáticos en el corpus quadrati (uno caudal y dos mediales). Processus oticus dispuesto perpendicularmente al plano sagital. Processus orbitalis delgado y largo.

Mandíbula relativamente baja, con el extremo distal recto. Rami mandibulae subrectos vistos lateralmente. Fenestra mandibulae doble o triple. Processus coronoideus bien desarrollado, piramidal, comprimido. Processus lateralis mandibulae muy desarrollado (en relación a la longitud total de la mandíbula). Cotyla lateralis cóncava, abierta craneomedialmente, fosa triangular craneal ausente. Processus lateralis mandibulae grande. Processus medialis mandibulae de base angosta, orientado medialmente. El tuberculum intercotylaris oblongo y robusto (ausente en Taxón nuevo A). Processus retroarticularis alto, caudalmente corto y delgado, con escaso desarrollo lateral. Fossa caudalis profunda.

B) Morfotipo II o “cráneo tipo Terror bird". Se incluyen dentro de este morfotipo los cráneos de Andalgalornis steulleti (Láminas 4.7 y 4.8), Patagornis marshi (Láminas 4.9 y 4.10), Andrewsornis abbotti (Láminas 4.12), Phorusrhacos longissimus (Lámina 4.13) y Kelenken guillermoi (Lámina 4.14).

Neurocráneo pequeño en relación al resto del cráneo, no globoso. Crista nuchalis sagittalis robusta, ancha y muy marcada. Prominentia cerebelaris redondeada. Cristae nuchalis transversa de márgenes romos. Processi paraoccipitalis extendidos ventralmente. Processi parasphenoidalis medialis salientes, con tubérculos mediales accesorios. Región frontal de forma triangular y convexa. Bordes orbitales de los ossa frontalis engrosados con rebordes rugosos para el contacto con el processus supraorbitalis del os lacrimale. Processus supraorbitalis del os lacrimale muy desarrollado y expandido lateromedialmente, adosado en toda su longitud a los ossa frontalis. Sutura frontolacrimale conspicua, recta y convergente anteriormente con su contraparte (en Andalgalornis la fusión entre estos huesos es total en su porción más 
craneal). Rama descendente del os lacrimale robusta fusionada con el os lacrimale communicans. Contacto con el arcus jugalis amplio y reforzado medialmente por una lámina o labio medial. Ausencia de zona flexoria palatina, zona flexoria arcus jugalis y zona flexoria craniofascialis. Pico hueco alto y proporcionalmente corto, de paredes relativamente gruesas (especialmente la porción dorsocraneal), sin entramado trabecular (véase figura 4.12). Gancho distal del pico de sección ovalada, muy desarrollado ventralmente. Tomium marcadamente falcado. Narinas redondeadas o arriñonadas y pequeñas en relación al tamaño total del pico. Fossa premaxilar ausente. Ossa pterygoidei comprimidos, altos, de base ventral angosta y plana. Arcus jugalis muy robusto y arqueado dorsoventralmente (salvo en Andrewsornis donde es prácticamente recto), de margen ventral redondeado y dorsal filoso y porción caudal fuertemente dirigida dorsalmente. Os quadratum robusto, de gran tamaño. Processus oticus dirigido craneolateralmente. Processus orbitalis alto y largo.

Mandíbula alta. Symphysis mandibularis curvada dorsalmente. Las rami mandibulae describen una leve onda sigmoidea. Fenestra mandibularis simple o doble. Processus coronoideus pequeño de forma variable: en Andrewsornis es muy pequeño y cónico, en Andalgalornis es aplanado lateralmente, mientras que en Patagornis y Phorusrhacos es alargado y muy marcado. Cotyla medialis muy excavada con una concavidad caudal más profunda (rasgo ausente en Andrewsornis). Processus lateralis mandibulae pequeño. Cotyla lateralis delimitada craneomedialmente por un reborde que la separa de una fosa triangular anterior. Processus medialis mandibulae de base ancha orientado dorsomedialmente. Tuberculum intercotylaris ausente. Crista intercotylaris robusta y roma. Processus retroarticularis bajo, caudalmente largo y relativamente robusto, fuertemente dirigido lateralmente. Fossa caudalis somera.

Los cráneos de Mesembriornis milneedwardsi MMP 155-S (Lámina 4.15) y Devincenzia pozzi MLP 37-III-7-8 (Lámina 4.16) son muy fragmentarios y fueron inadecuadamente reconstruidos. Por tal motivo, su asignación a alguno de los morfotipos aquí definidos resulta cuestionable. Sin embargo, características en Mesembriornis milneedwardsi tales como la presencia de una fossa premaxillar y la posible existencia de un os lacrimale communicans como hueso independiente, permiten inferir su asignación al primer morfotipo. En el caso de Devincenzia, el cráneo además se encuentra muy deformado (principalmente aplastado). Su asignación al 
morfotipo II de cráneo solo se sustentaría por su pertenencia taxonómica a los Phorusrhacinae (Alvarenga y Höfling, 2003).

\subsubsection{Pelvis: ossa coxae}

Se conocen y estudiaron las pelvis de Psilopterus lemoinei, Psilopterus bachmanni, Procariama simplex, Taxón nuevo A, Patagornis marshi y Andalgalornis steulleti. La única pelvis que se conoce de Mesembriornis milneedwardsi es muy fragmentaria.

Las diferencias que exhiben las pelvis disponibles son muy notables fundamentalmente en la porción postacetabular.

El synsacrum presenta una crista spinosa synsacri muy alta principalmente en el sector preacetabular. Los processi costalis de las vertebrae acetabularis son elongados y muy numerosos, formando pilares robustos que aseguran una unión rígida con los ossa coxae. El sulcus ventralis synsacri se encuentra marcado y es lentiforme. Consta de 13 vértebras en Taxón nuevo A y Psilopterus (y probablemente en Procariama), aunque Sinclair y Farr (1932) declaran que son 15. En Patagornis serían 15 según Andrews (1899), aunque Ameghino (1895) declara que son 12 ó 13. El material BMNH-A516, que no pudo ser estudiado, se encuentra cubierto de sedimento y presenta partes reconstruidas, razón por la cual el número real no puede establecerse.

La pelvis es muy alargada y comprimida (Ameghino, 1895; Andrews, 1896, 1899; Patterson y Kraglievich, 1960; Alvarenga y Höfling, 2003), con una región postacetabular hasta dos veces más larga que la región preacetabular (Figura 4.17). Esta condición también está presente en aves acuáticas como Gaviiformes y Podicipediformes (Ibañez, 2006).

El ilium es el hueso de mayor desarrollo de la pelvis. El ischium se encuentra muy extendido caudalmente, limitando caudoventralmente el foramen ilioischiadicum. El corpus ischii es someramemente cóncavo y ventralmente forma un reborde filoso. Caudalmente se proyecta constituyendo el processus terminalis ischii.

Las alae preacetabularis ilii son fundamentalmente verticales (poco deflectadas lateralmente). Son cortas y altas, presentando una fossa iliaca dorsalis muy somera. Las cristae iliacas dorsalis confluyen y se fusionan en la línea media dorsalmente a la crista spinosa synsacri. El canalis iliosynsacralis es cerrado, quedando delimitado por ambas cristae que se fusionan a su vez con la crista spinosa synsacri. 
En Psilopterus, Procariama, Mesembriornis y Taxón nuevo A, el margen dorsal de la porción preacetabular está representado por una cresta roma y angosta que describe un arco muy acentuado de recorrido dorsocaudal, imperceptible en el nivel de unión de las cristae supratrochanterica (Rovereto, 1914; Sinclair y Farr, 1932; Patterson y Kraglievich, 1960). A partir de dicha unión, caudalmente la pelvis es plana conformando la "plataforma dorsal ilíaca" de Rovereto (1914) y que carece de cresta media. En estos taxa, sobre las cristae iliacas dorsalis se desarrolla una expansión romboidal que Rovereto (1914) denominó “escudo ilíaco” (Láminas 4.19-4.22).

El acetabulum es ovalado a subcircular, limitado anteriormente por un reborde o labio interrumpido ventralmente (continuo en Procariama).

El foramen ilioischiadicum es relativamente pequeño en comparación a la longitud total de la pelvis. El margen craneal es vertical, prácticamente recto. Su margen ventral es amplio, aunque solo abarca entre $1 / 4$ en Procariama y un 1/5 en Andalgalornis de la longitud total de la pelvis. El margen caudal es redondeado.

El foramen obturatum es alargado craneocaudalmente, angosto y cerrado caudalmente por un processus obturatorius robusto. Este último brinda, a su vez, el límite craneal de la fenestra ischiopubica.

El antitrochanter se encuentra muy extendido lateralmente, inclinado caudoventralmente, con un margen lateral redondeado. Dorsalmente se desarrolla una cresta relativamente gruesa y roma que disminuye en altura en su recorrido medial y que forma un alero. Andrews (1899) la denomina crista supratrochanterica. Dicha crista presenta desarrollo muy variable: (1) robusta aunque baja, carente de una proyección lateral que sobrepasa al antitrochanter, como en Psilopterus y probablemente Procariama; (2) gruesa de borde romo, más extendida lateralmente que el antitrochanter en Mesembriornis y Taxón nuevo A y (3) gruesa de borde romo, alta y carente de una proyección lateral que sobrepase al antitrochanter en Andalgalornis y Patagornis. El sulcus antitrochantericus presenta un desarrollo variable, aunque siempre se encuentra delimitado caudalmente por un alero craneal de la crista supratrochanterica.

En la parte caudal, las cristae dorsolateralis ilii se proyectan caudalmente en una spina dorsolateralis ilii. Esta puede ser angosta (Psilopterus) o ancha (Taxón nuevo A). La crista dorsolateralis ilii se manifiesta desde el extremo más caudal de la spina dorsolateralis ilii formando un arco convexo conspicuo con un reborde agudo (erróneamente interpretado como la synchondrosis ilioischiadica por Andrews, $1899 \mathrm{y}$ 
Sinclair y Farr, 1932). Se dirige ventrocranealmente hacia el margen caudal del foramen ilioischiadicum. A su vez, desde la spina dorsolateralis ilii se extiende la synchondrosis ilioischiadica que presenta una disposición subhorizontal en Taxón nuevo A o describe un arco convexo ventralmente muy marcado en Psilopterus y Procariama. Confluye cranealmente con la crista dorsolateralis ilii.

En algunos taxa, ubicado sobre el margen caudal del foramen ilioischiadicum (donde confluyen la crista dorsolateralis ilii y la synchondrosis ilioischiadica) se forma un proceso de desarrollo variable (Figura 4.18): (1) muy desarrollado, formando una espina dirigida cranealmente en Psilopterus y probablemente Procariama; (2) poco desarrollado, como un promontorio pequeño en Taxón nuevo A; (3) reducido formando un pequeño tubérculo alargado en Patagornis y (4) ausente en Andalgalornis.

Entre la crista dorsolateralis illii y la synchondrosis ilioischiadica se desarrolla la lamina infracristalis ilii alargada y lentiforme. Por debajo, el ala ischii forma una concavidad.

El processus terminalis ischii también se encuentra fuertemente proyectado caudalmente, aunque menos que la spina dorsolateralis ilii (subiguales en extensión en Andalgalornis). Es amplio y de contorno triangular.

El sulcus obturatorius es alargado, profundo y amplio dorsoventralmente. Se encuentra limitado ventralmente por un reborde redondeado muy robusto y conspicuo que se continúa desde el límite ventral del foramen ilioischiadicum.

La crista iliaca obliqua está bien marcada.

El borde caudal del ala ischii (entre la spina dorsolateralis ilii y el processus terminalis ischii) presenta forma variable. En Taxón nuevo A conforma un ángulo cuyo margen ventral se dirige muy ventralmente y el dorsal caudodorsalmente. En Psilopterus, Procariama, Andalgalornis y Patagornis forma un arco cóncavo caudalmente.

La fossa renalis se ubica dorsalmente al foramen ilioischiadicum en su mitad caudal. Es relativamente corta, aunque muy amplia, mientras que el recessus caudalis fossae es muy extenso (en Taxón nuevo A se extiende hasta la altura de la última vertebra synsacral).

El pubis tiene desarrollo variable (Figura 4.17), pudiendo estar completo o constituído por dos porciones. En este último caso, la porción media no se desarrolla.

En Taxón nuevo A, el pubis se encuentra completo. El corpus pubis es delgado con el sector anterior fusionado ampliamente a la pelvis (Sinclair y Farr, 1932). Sigue el 
recorrido del borde lateral del ischium, delimitando una fenestra ischiopubica muy alargada, angosta y cerrada. Contacta caudalmente con el processus terminalis ischii. El apex pubis es muy robusto, con un quiebre medioventral por detrás del contacto entre ischium y pubis. Esto se contrapone con la hipótesis de Sinclair y Farr (1932) para Psilopterus, quienes declararon que no existía proyección púbica posterior más allá del foramen obturatum y marcadamente contrastante con la declaración de Patterson y Kraglievich (1960) y Alvarenga y Höfling (2003) de que el pubis de todos los Phorusrhacidae se encuentra atrofiado. En Andalgalornis FM-P14357, el processus terminalis ischii derecho se encuentra acompañado por una porción conservada del apex pubis que consiste en una barra de sección oval. Cranealmente, el pubis se fusiona al ischium, cerrando ventralmente el foramen obturatum (caudalmente delimitado por el robusto processus obturatorius). La porción de pubis faltante es la porción media y no la craneal como había sido establecido por Alvarenga y Höfling (2003); en consecuencia la fenestra ischiopubica se encuentra abierta ventralmente.

\subsubsection{Morfotipos pélvicos}

Pueden distinguirse dos morfotipos pélvicos en los Phorusrhacidae.

A) Morfotipo I o "pelvis tipo Psilopterinae". Se incluyen las pelvis de Psilopterus bachmanni (Lámina 4.17), Psilopterus lemoinei (Láminas 4.18 y 4.19), Procariama simplex (Lámina 4.20), Mesembriornis milneedwardsi (Lámina 4.21) y Taxón nuevo A (Lámina 4.22).

Pelvis ensanchada postacetabularmente. Lamina infracristalis ilii marcadamente lentiforme, describiendo un arco muy conspicuo. Tuberculum preacetabulare muy desarrollado. Foramina intertransversaria visibles. Sulcus ventralis synsacri somero. Fenestra ischiopubica cerrada ventralmente.

Alae preacetabularis ilii verticales, con inflexión latero-ventral.

Margen dorsal de la porción preacetabular en arco muy acentuado, de recorrido dorsocaudal. Escudo ilíaco presente, muy bien desarrollado en Procariama, Mesembriornis y Taxón nuevo A, pero poco en Psilopterus. Plataforma dorsal ilíaca presente.

Sulcus antitrochantericus somero.

Cristae iliaca dorsalis sin fusión postacetabular medial que divergen caudalmente por detrás del acetabulum, luego convergen a nivel de la unión con las 
cristae supratrochanterica. Pocos foramina intertransversaria, algunos obliterados. Entre ellos se ubica una fosa lentiforme, donde se observa la crista spinosa synsacri robusta y baja que limita pares de forámenes confluyentes caudalmente. Dicha fosa se cierra caudalmente donde se forma una cresta media.

Proceso ubicado sobre el margen caudal del foramen ilioischiadicum presente.

Spina dorsolateralis ilii muy proyectada caudalmente, levemente más extendida caudalmente que el processus terminalis ischii y curvada dorsalmente.

Los Cariamidae presentan una pelvis similar a la de este morfotipo (Figura 4.19).

B) Morfotipo II o "pelvis tipo Terror bird". Se incluyen las pelvis de Andalgalornis steulleti (Lámina 4.23) y Patagornis marshi (Lámina 4.24).

Pelvis muy comprimida, de ancho homogéneo en toda su longitud. Lamina infracristalis ilii lentiforme en Patagornis, pero no en Andalgalornis. Tuberculum preacetabulare poco desarrollado. Foramina intertransversaria no visibles por estar cubiertas por la fusión medial de las cristae iliaca dorsalis a nivel postacetabular. Escudo ilíaco ausente. Sulcus ventralis synsacri profundo y muy marcado. Fenestra ischiopubica abierta ventralmente.

Cristae iliacas dorsalis fusionadas medialmente a lo largo de toda la longitud de la pelvis, incluyendo la porción postacetabular. Postacetabularmente, la crista iliaca se inclina caudoventralmente, aunque es esencialmente recta; preacetabularmente, la crista describe una curva convexa suave dorsalmente. Como consecuencia, la pelvis en vista lateral adopta una forma "quebrada ventralmente".

Alae preacetabularis ilii fuertemente verticalizadas, no se deflectan lateralmente.

Sulcus antitrochantericus profundo y bien marcado.

Alae postacetabularis ilii verticales. Lamina infracristalis ilii lentiforme en Patagornis. En Andalgalornis las cristae dorsolateralis ilii se encuentran poco marcadas. Spina dorsolateralis ilii ancha y proyectada caudalmente (más en Patagornis). Processus terminalis ischii de extensión caudal similar a la de la spina dorsolateralis.

\subsubsection{Ossa membri pelvici}


Los miembros posteriores de los Phorusrhacidae presentan huesos largos y delgados.

A) Fémur (Láminas 4.25-4.28)

El corpus femoris en vista lateral es: (1) muy curvo en Psilopterus, (2) poco curvo en M. milneedwardsi (Kraglievich, 1946; Tambussi, 1989) y Taxón nuevo A o (3) recto en Phorusrhacos y Patagornis. La linea intermuscularis cranialis es oblicua y muy marcada -poco marcada en M. milneedwardsi (Rovereto, 1914; Kraglievich, 1940), Phorusrhacos y Taxón nuevo A-. Distalmente se bifurca y se dirige hacia los condyli. La linea intermuscularis caudalis también se encuentra muy bien marcada y forma un reborde filoso (robusto en Phorusrhacos) que se une a la crista supracondylaris medialis.

La facies articularis antitrochanterica se encuentra bien marcada. El límite craneal está dado por un reborde de desarrollo variable (ausente en Taxón nuevo A) y el caudal por un reborde dirigido caudalmente (ausente en Mesembriornithinae). La facies articularis acetabularis presenta una proyección ventral similar a Cariamidae (ausente en Procariama), pero más ancha y redondeada.

El caput femoris en vista medial tiene forma de corazón invertido (al igual que en los Cariamidae) y limita medialmente una fosa muy conspicua ubicada sobre la incisura del collum femoris. El caput se ubica proximalmente a la misma altura que la crista trochanteris en Psilopterus (Sinclair y Farr, 1932), mientras que es más proximal en Patagornis (Andrews, 1896, 1899), Phorusrhacos y Taxón nuevo A y más distal en Procariama y M. milneedwardsi. La fovea ligamentum capitis es única (doble en Procariama, no marcada en Taxón nuevo A), subcircular y somera, limitada cranealmente por una saliente.

El trochanter femoris forma un promontorio alargado muy saliente. La crista trochanteris está bien desarrollada, es ancha y robusta y se encuentra expandida cranealmente, aunque menos que en Cariamidae. Las impressiones obturatorie se encuentran muy marcadas, son subovales y se ubican sobre la cara lateral del fémur. Las impressiones iliotrochanterica se encuentran poco marcadas, ubicadas cráneodorsalmente al trochanter femoris y caudalmente a la crista trochanteris.

El sulcus patellaris es somero y amplio. En vista distal, es más simétrico que en los Cariamidae (donde alcanza mayor profundidad medialmente). La crista lateralis sulci patellaris es generalmente suave (como en Phorusrhacos, M. milneedwardsi, 
Psilopterus bachmanni y Procariama) o proximalmente abrupta (Psilopterus lemoinei y Taxón nuevo A). La crista medialis sulci patellaris es suave (roma y robusta como en M. milneedwarsi; abrupta en Cariamidae).

El sulcus intercondylaris se encuentra bien marcado y si bien es profundo, lo es menos que en los Cariamidae. El condylus medialis se encuentra menos extendido distalmente que el lateralis y en vista medial presenta una saliencia baja, menos marcada que en Cariamidae (poco marcada en Patagornis, ausente en Phorusrhacos, Procariama y M. milneedwardsi). La crista supracondylaris medialis forma un reborde saliente y filoso (pequeño en M. milneedwardsi; romo y robusto en Phorusrhacos) que delimita medialmente un área triangular. El condylus lateralis se encuentra fuertemente proyectado caudalmente.

La fossa poplitea es ovalada y muy profunda (a diferencia de los Cariamidae) y limitada distalmente por una barra ósea muy desarrollada que une los condyli medialis y lateralis caudalmente. Este rasgo es diagnóstico de los fororracos y permite asignar al ave africana Lavocatavis a la familia Phorusrhacidae (Mourer-Chauviré et al., 2011). La impressio ligamentum cruciati cranialis es bien profunda (salvo en P. bachmanni y Andrewsornis abbotti), mientras que la impressio ligamentum cruciati caudalis está poco marcada y se ubica en la superficie proximal posterior del condylus lateralis, bordeada por un reborde proximal. La impressio ansae m. iliofibularis presenta dos marcas, la primera es arriñonada (e.g., Patagornis), ovalada (e.g., P. bachmanni, Taxón nuevo A y Procariama) o subcircular (e.g., M. milneedwardsi), de gran tamaño, ubicada dorsalmente a la crista tibiofibularis; mientras que la segunda consiste en una pequeña marca alargada y oblicua, ubicada cranealmente al primero de los orígenes. La fovea tendineus $m$. tibialis cranialis se encuentra bien marcada. Medialmente, a su lado, se encuentra una pequeña fosa la cual "orada" sobre el condylus lateralis (en los Phorusrhacidae de mayor tamaño la excavación sobre el condylus es aún mayor). La crista tibiofibularis es angosta.

B) Tibiotarso (Láminas 4.29-4.33)

El corpus tibiotarsi es más ancho lateralmente que en Cariamidae. Es levemente curvo (no recto como establecieron Sinclair y Farr, 1932 para Psilopterus) y, distalmente, describe una onda sigmoidea muy suave (apenas marcada en $M$. milneedwardsi y Phorusrhacos, recto en M. incertus). Tanto la facies cranialis como la 
caudalis presentan una superficie suave. La linea extensoria (= linea aspera de Sinclair y Farr, 1932) es conspicua.

Las cristae cnemialis se encuentran muy desarrolladas y son muy salientes. La crista cnemialis cranialis presenta un reborde ventral oblicuo. La crista cnemialis lateralis es más alta y menos expandida lateralmente que en Cariamidae y carece de la proyección distal que forma un gancho en los Cariamidae, aunque presenta una expansión (craneocaudal en Psilopterus y Patagornis y caudal en M. milneedwardsi). El sulcus intercnemialis es profundo. La facies gastrocnemialis se encuentra bien expandida medialmente sobre la crista cnemialis cranialis y el caput tibiae.

El caput tibiae es proporcionalmente más ancho que en los Cariamidae. La facies articularis medialis es plana, más expandida caudalmente y se encuentra más inclinada que en los Cariamidae. La facies articularis lateralis es sobresaliente y levemente elipsoidal. El area interarticularis se encuentra poco marcada. La fossa retropatellaris se encuentra bien marcada. La incisura tibialis es ancha. La crista patellaris está presente aunque poco desarrollada. La fossa flexoria es conspicua y bien excavada. Las tuberositas popliteus son muy variables en forma y desarrollo: forman una única prominencia dirigida craneolateralmente en Psilopterus lemoinei; en $P$. bachmanni hay dos crestas conspicuas; en M. milneedwardsi hay tres crestas acompañadas de tubérculos; en Phorusrhacos puede haber dos o tres crestas; en Patagornis puede haber un tubérculo único o incluso dos crestas poco marcadas y en Taxón nuevo A hay dos tubérculos.

La crista fibularis es robusta, ancha y bien marcada, con escaso desarrollo lateral (excepto en P. lemoinei). Se extiende aproximadamente hasta un cuarto de la extensión total de la diáfisis.

El sulcus extensorius es profundo (Figura 4.20), se ubica más medialmente que en los Cariamidae y su extensión proximal es solo $1 \frac{1}{4}$ de la longitud del tibiotarso (restringido a la zona del pons en Phorusrhacos). El pons supratendineus es oblicuo, ancho y robusto, presenta una muesca proximal medial (ausente en P. bachmanni) bien excavada (en Psilopterus lemoinei presenta además un reborde o labio distal). Esta observación es contraria a la expuesta por Patterson y Kraglievich (1960) y Alvarenga (1985) quienes indican que los Psilopterinae y Mesembriornithinae se caracterizan por presentar el pons supratendineus orientado casi transversalmente al eje longitudinal del tibiotarso. Más aún, Alvarenga (1985) utiliza este carácter para justificar la inclusión de Paleopsilopterus itaboraiensis dentro de los Psilopteridae. 
Laterodistalmente al pons existe un tubérculo de desarrollo variable: muy desarrollado en P. lemoinei, M. milneedwardsi (Rovereto, 1914) y Taxón nuevo A, poco marcado en Phorusrhacos y Patagornis (Figura 4.20). El canalis extensorius es profundo. La incisura intercondylaris es profunda y presenta dos marcas de inserción (ausentes en Cariamidae).

El condylus lateralis presenta contorno redondeado. El condylus medialis es alargado craneocaudalmente: es alto y delgado en Psilopterus, alto y robusto con una proyección medial poco marcada en Patagornis y Mesembriornis. La depressio epicondylaris lateralis se encuentra poco excavada. El epicondylus medialis está pobremente desarrollado, mientras que el epicondylus lateralis se encuentra ausente, al igual que en Cariamidae. El tuberculum retinaculi $m$. fibularis es alargado y vertical, delimitando posteriormente un canal suave (poco desarrollado en Patagornis). La trochlea cartilaginalis tibialis está expandida proximalmente (poco expandida en Devincenzia y Mesembriornis). La cristae lateral es redondeada y menos saliente que en Cariamidae, mientras que la cristae medial es filosa.

\section{C) Fíbula}

Presenta forma de daga (Figura 4.21) y es muy similar a la de los Cariamidae, abarcando entre un 50 y $60 \%$ de la longitud total del tibiotarso. El caput fibulae es ancho transversalmente, elongado craneocaudalmente y con una inclinación caudocraneal mayor que en Cariamidae. La facies articularis tibialis es larga, elongada y elevada. El tuberculum m. iliofibularis es ovalado y muy marcado. La spina fibulae presenta sección triangular. El foramen interosseum proximale es elongado, más angosto transversalmente que en Cariamidae. El foramen interosseum distale es largo y angosto.

D) Tarsometatarso (Láminas 4.34-4.38)

El ancho de la diáfisis es constante en toda su longitud, excepto en Taxón nuevo A en el cual decrece distalmente. Proporcionalmente, el tarsometatarso es más robusto que en Cariamidae (Andrews, 1899; Sinclair y Farr, 1932; Mayr, 2002), aunque es alargado y relativamente grácil, especialmente en Mesembriornithinae donde alcanza el $80-85 \%$ de la longitud del tibiotarsus (Alvarenga y Höfling, 2003) y en Procariama donde alcanza el $75-80 \%$. 
Ambas cotylae son de superficie amplia y cóncava, estando la cotyla lateralis dispuesta en un plano más distal que la medialis -particularmente en Patagornis-, excepto en Psilopterus lemoinei y Phorusrhacos en los cuales se disponen aproximadamente en el mismo plano. La cotyla medialis presenta un reborde ovalado. El margen ventral de la cotyla lateralis es recto (salvo en Mesembriornithinae que es cóncavo). La eminentia intercotylaris es muy sobresaliente (Ameghino, 1895) y se encuentra excavada en su base por un surco orientado proximolateralmentedistomedialmente (Andrews, 1899; Sinclair y Farr, 1932), poco marcado en Patagornis y ausente en Mesembriornis milneedwardsi.

Una característica diagnóstica de los Phorusrhacidae es la presencia de un hypotarsus con forma triangular (Alvarenga y Höfling, 2003), simétrico en Psilopterus y Patagornis; asimétrico en Procariama, Mesembriornis y Taxón nuevo A (Figura 4.22). En el hypotarsus, se pueden distinguir dos plataformas ubicadas a diferentes niveles: la medial se encuentra levemente más dorsal y es surcada (Andrews, 1899; Sinclair y Farr, 1932; Acosta Hospitaleche y Tambussi, 2005), formando un canal; la lateral es completamente lisa y levemente convexa. En cambio Procariama presenta dos crestas, una medial angosta y otra lateral muy robusta (Rovereto, 1914; Alvarenga y Höfling, 2003) que delimitan un surco medio (Rovereto, 1914). El hypotarsus se continúa distalmente a través de una crista medianoplantaris muy corta y robusta (Sinclair y Farr, 1932). Los márgenes del hypotarsus no sobresalen proximalmente (muy sobresalientes en Procariama).

En vista caudal, los foramina vascularia proximalia son visibles (ocultos por expansiones laterales del hypotarsus en Paleopsilopterus). Dichos foramina se encuentran al mismo nivel en Psilopterus lemoinei y Taxón nuevo A, mientras que en Cariamidae, P. bachmanni, Procariama y Patagornis (Andrews, 1899) lo están a diferentes.

La fossa infracotylaris dorsalis es ovalada, profunda y restringida a la porción más proximal del tarsometatarso. En la porción más distal de la fossa se encuentran las tuberositas $m$. tibialis cranialis que forman dos estructuras ovaladas muy marcadas. La impressio retinaculi extensorii es única, medial y forma un tubérculo que se ubica sobre el margen del corpus tarsometatarsi. Medialmente a la impressio, el margen medial del corpus forma un pequeño alero en Psilopterinae y Mesembriornis milneedwardsi.

Tanto el sulcus extensorius como el flexorius son profundos, aunque este último se encuentra muy poco desarrollado en Patagornis y Phorusrhacos. El primero se 
encuentra delimitado por márgenes romos y robustos. Las cristae plantaris lateralis et medialis son robustas y de rebordes redondeados (más salientes y filosos en Cariamidae). Tanto el sulcus extensorius como el flexorius ocupan los 2/3 de la longitud total del tarsometatarso (1/2 de la longitud del tarsometatarso en P. bachmanni).

La fossa supratrochlearis plantaris está muy poco marcada (ausente en Cariamidae y en P. affinis), aunque se evidencia su forma subtriangular. La fossa metatarsi I es ovalada y denota la presencia de un dedo I ubicado en una posición más distal que en Cariamidae, que no contacta con el suelo (Jones, 2010). El foramen vasculare distale es levemente ovalado y bien conspicuo, atravesando el hueso desde la facies dorsalis hasta la plantaris y presentando la apertura entre la trochlea metatarsi III y la trochlea metatarsi IV (Andrews, 1899; Dolgopol de Saez, 1927; Sinclair y Farr, 1932).

La trochlea metatarsi III es la más extendida distalmente (Figura 4.23). Se expande distalmente en Titanis walleri y Mesembriornithinae (Alvarenga y Höfling, 2003; Acosta Hospitaleche, 2002). Presenta rebordes dirigidos proximalmente en $P$. lemoinei, P. bachmanni, P. colzecus (Tonni y Tambussi, 1988), Procariama y Taxón nuevo A, que son paralelos en los Cariamidae y P. affinis (Agnolín, 2006). En Phorusrhacos, Mesembriornis y Patagornis la situación es intermedia, ya que distalmente los bordes son paralelos pero proximalmente son convergentes. La trochlea metatarsi II es ancha y convexa en todas las direcciones, carente de un surco y se encuentra menos extendida distalmente que las otras dos trochleae metatarsi. En Psilopterus dicha trochlea sobresale medialmente (Alvarenga et al., 2010), mientras que es menos sobresaliente en Procariama y Taxón nuevo A. Los Psilopterinae y Mesembriornithinae presentan una cresta caudomedial, dirigida caudalmente sobre la trochlea metatarsi II. Esta cresta es larga y de extremo angosto en Psilopterus lemoinei mientras que en P. bachmanni es corta y ancha y, en Procariama y Taxón nuevo A, está levemente menos desarrollada, formando un reborde triangular. En Phorusrhacos y Patagornis está muy poco desarrollada, incluso menos que la de la trochlea metatarsi $I V$. La trochlea metatarsi $I V$ es relativamente angosta, levemente surcada y presenta una cresta ventral angosta redondeada (muy saliente en Psilopterinae) -con forma de aleta en Taxón nuevo A-. La fovea ligamentum collateralis es redondeada y profunda.

\section{E) Ossa digitorum pedis}


No es objetivo de esta tesis describir e interpretar las falanges de las patas de los fororracos. Por lo tanto, solo se mencionan aquí algunos caracteres muy generales y distintivos. Se conocen pies parcialmente completos (Figura 4.24) de Psilopterus colzecus, Procariama simplex, Paraphysornis brasiliensis y Taxón nuevo A. Las especies Patagornis marshi, Mesembriornis milneedwardsi y Psilopterus lemoinei están representadas por patas aún más incompletas, mientras que Phorusrhacos, Devincenzia, Physornis, Psilopterus bachmanni y Mesembriornis milneedwardsi están representados por dedos incompletos y falanges sueltas. En muchos de estos casos, el hallazgo de falanges sueltas durante finales del siglo XIX y principios del XX produjeron la creación de gran cantidad de nombres por parte de F. Ameghino, M. Moreno y A. Mercerat. De éstos, todos resultaron ser sinónimos junior de Phorusrhacos longissimus, Psilopterus bachmanni o P. lemoinei.

El autopodio posterior de los Phorusrhacidae es similar al de los Cariamidae, especialmente en las proporciones relativas y la morfología de las falanges ungueales (Tonni y Tambussi, 1988; Jones, 2010).

El patrón de dígitos es anisodáctilo, siendo el dedo III el más largo y el dedo I elevado.

El dedo III es mucho más largo y robusto (Figura 4.24), mientras que los dedos II y IV son mas gráciles y subiguales en longitud (Ameghino, 1895). El dedo I es pequeño, corto y elevado (Jones, 2010). Como se mencionó previamente, se ubica más distalmente que en los Cariamidae. El dedo II evidencia una gran posibilidad de extensión, al igual que los Cariamidae, posibilitando un mayor aferre de sus presas (Jones, 2010).

Las falanges, especialmente las ungueales, han sido profundamente estudiadas por Jones (2010). Aquí se destacan solo algunos caracteres. Las ungueales son agudas, arqueadas, comprimidas (Ameghino, 1895, Alvarenga y Höfling, 2003; Jones, 2010), similares a las de los Cariamidae (Tonni y Tambussi, 1988) y carentes de tuberculum extensorium (Jones, 2010). En relación al dedo II, la primera falange se caracteriza por presentar un tuberculum flexorium muy desarrollado y una facies articularis que forma una polea muy profunda. La falange ungueal de este dígito es muy curva (notoriamente más curva que las ungueales de los otros dígitos), presenta el tuberculum flexorium muy desarrollado (Jones, 2010) y surcos o canales laterales. Las falanges del dedo III son alargadas y la falange ungueal es menos curva que la del dígito II, de sección subtriangular (Jones, 2010) y presenta surcos laterales. En el dedo IV, la falange 1 es la 
más larga. Las restantes disminuyen sustancialmente su longitud. La falange ungueal de este dedo presenta base ancha (Jones, 2010) al igual que la del dedo III y presenta surcos laterales poco desarrollados. 


\section{Capítulo 5: Posición Filogenética de los Phorusrhacidae}

\subsection{Contexto filogenético}

Cualquier inferencia paleobiólogica se encuentra mejor fundamentada si se realiza en un marco filogenético adecuado que permita discriminar "constraints" de rasgos adaptativos. En especial, la inferencia de la función (Lauder, 1995), así como la reconstrucción de tejidos blandos (Witmer, 1995b, 1997; véase capítulo 7) están fuertemente afectadas a las hipótesis filogenéticas sobre las cuales se trabaja. En particular, para poder realizar inferencias acerca de la presencia o ausencia de un tejido blando mediante la aproximación del Soporte Filogenético Viviente (Extant Phylogenetic Bracket, EPB) es necesario contar con una filogenia (Witmer 1995b, 1997), ya que se busca ubicar en un diagrama de parentesco o cladograma al taxón fósil bajo estudio entre los dos outgroups vivientes más cercanamente emparentados a fin de establecer la presencia de un tejido con un cierto nivel de inferencia (véase capítulo 7).

En el caso particular de las Aves, son pocas las propuestas filogenéticas realizadas con metodología cladista que incluyan un número representativo de Neornithes y, en la mayor parte de los casos, las relaciones dentro de este clado no se encuentran resueltas satisfactoriamente (e.g., Cracraft y Clarke, 2001; Ericson et al., 2001; Livezey y Zusi, 2001). Propuestas más recientes pueden encontrarse en Ericson et al. (2006), Hackett et al. (2008), Livezey y Zusi (2006, 2007) y Mayr y Clarke (2003). A la dificultad de contar con propuestas filogenéticas representativas para este grupo, se suma la escasa proporción de caracteres osteológicos en comparación con la de caracteres tomados de tejidos blandos e información molecular, que resultan prácticamente inaplicables al registro fósil.

Inicialmente los Phorusrhacidae fueron clasificados como Ratitae por Ameghino (1891b, 1895, 1899) -quien los había considerado originalmente como mamíferos edentados en 1887, 1889 y 1891a- y Lydekker (1893). Sin embargo, se los ha incluido dentro de los Gruiformes Bonaparte 1854 y, en particular, se los ha relacionado con los Cariamidae Bonaparte 1853 (aves comúnmente conocidas como "chuñas" o "seriemas") desde la propuesta de Andrews (1896, 1899), esquema corroborado por Livezey (1998), Mayr (2002), Agnolín (2009) y Alvarenga et al. (2011) (Figura 5.1). Sin embargo, las relaciones de los Phorusrhacidae (y los Cariamidae) con el resto de las aves no cuentan con un marco filogenético adecuado ya que ninguno de los autores previamente 
mencionados testeó la posibilidad de que los Phorusrhacidae no estuviesen relacionados con los Gruiformes.

Numerosos trabajos actuales demuestran que la monofilia de los Gruiformes no se encuentra sustentada (Mayr y Clarke, 2003; Fain y Houde, 2004; Cracraft et al., 2004; Fain et al., 2007 y literatura allí citada). La posición filogenética de los Cariamidae es también problemática: 1) Olson (1985), Chandler (1997) y Mayr y Clarke (2003), basados en datos morfológicos, sostienen que los Cariamidae están relacionadas con los Opisthocomidae (hoatzines) y con los Cuculidae (cucos, correcaminos, pirinchos y anis) + Musophagidae (turacos); 2) Livezey y Zusi (2006, 2007) recuperan el clado Gruiformes incluyendo a los Cariamidae, los que están más relacionados con los Psophiidae (trompeteros); 3) Sibley y Ahlquist (1990) reconocen la monofilia de Gruiformes (incluyendo Cariamidae) en base a datos moleculares y 4) Ericson et al. (2006) y Hackett et al. (2008), basados en el mismo tipo de datos, reconocen que los Cariamidae son el grupo hermano de un clado que incluye Falconidae (halcones) + Psittaciformes (loros y cacatúas) + Passeriformes (aves canoras).

En el presente capítulo de tesis se analizan, por primera vez, las relaciones filogenéticas de los Phorusrhacidae con las demás Neornithes en un marco comparativo amplio utilizando metodología cladística a fin de poder aplicar EPB (capítulo 7). Queda fuera del objetivo del presente capítulo el reanalizar y discutir cada una de las sinapomorfías de los clados recuperados.

\subsection{Análisis cladístico}

A fin de establecer las relaciones filogenéticas de los Phorusrhacidae se eligió la propuesta de Mayr y Clarke (2003). Esta aplica un número razonable de caracteres, en su mayoría osteológicos y fácilmente codificables. La propuesta de Livezey y Zusi (2006, 2007) fue ampliamente denostada por Mayr (2008) ya que incluye más de 2950 caracteres, muy complejos, difícilmente entendibles (y por lo tanto incodificables), repetitivos en algunos casos y de los cuales más de 500 son caracteres de tejido blando.

Para realizar el análisis se eligieron los ejemplares más completos de fororracos, pertenecientes a cuatro especies: Mesembriornis milneedwardsi; taxón nuevo A, Patagornis marshi y Psilopterus lemoinei. Además, fue incluido en el análisis el Anseriformes Brontornis burmeisteri, considerado previamente un Phorusrhacidae por Alvarenga y Höfling (2003) y Alvarenga et al. (2011) (véase el capítulo 2 de esta tesis). Apsaravis se eligió como outgroup de acuerdo a Mayr y Clarke (2003). 
Los caracteres fueron codificados e incluidos en la matriz de taxones por caracteres de Mayr y Clarke (2003). De esta forma, la matriz quedó constituida por 148 caracteres y 51 taxones, mayoritariamente representados por familias, cuatro especies de fororracos y Brontornis burmeisteri. De los 148 caracteres, 138 son binarios, 10 son multiestado y 43 son polimórficos para determinados taxa. Dentro de la matriz los caracteres faltantes se codificaron con “?”. Los caracteres polimórficos se señalan entre corchetes, (i.e., [01].) (Apéndice 5.1).

Para la construcción de los cladogramas se siguió el principio de parsimonia (Hennig, 1968), en el cual el árbol más corto constituye la reconstrucción más probable de la filogenia del grupo. El principio de parsimonia sostiene que la explicación más simple (aquella con menor número de homoplasias) es preferible a la más compleja (Camin y Sokal, 1965; Kluge y Farris, 1969).

La matriz de datos fue analizada con el programa TNT (Tree analysis using New Technology), versión 1.1 (Goloboff et al., 2000). Para el análisis se consideraron todos los caracteres igualmente pesados, debido a que el uso de pesos diferenciales en cualquiera de sus esquemas propuestos (e.g. pesado a posteriori, pesado sucesivo, pesos implicados) no se encuentra libre de críticas (Farris, 1969, 1989; Goloboff, 1993; Kluge, 1997). Los caracteres 55, 71 y 91 fueron tratados como ordenados y de acuerdo con Mayr y Clarke (2003) se excluyó al taxón conflictivo Gaviidae (somormujos) para el análisis, debido a produce politomías en el árbol consenso de Mayr y Clarke (2003).

El análisis fue llevado a cabo a partir de la generación al azar de diez árboles de Wagner con 100 secuencias de adición, utilizando el algoritmo TBR y salvando 100 árboles por réplica, colapsando los árboles después de la búsqueda.

\subsection{Resultados: Posición filogenética}

Del análisis se obtuvieron 14 árboles de 746 pasos. En todos ellos, los Phorusrhacidae constituyen un grupo monofilético y hermano de los Cariamidae, sin relación alguna con los demás "Gruiformes". El grupo hermano de Phorusrhacidae + Cariamidae es Opisthocomidae y el grupo hermano de este clado es Cuculidae + Musophagidae. Además, en todos estos árboles, Brontornis queda excluido de los Phorusrhacidae e incluido en los Anseriformes y constituye el grupo hermano de los Anhimidae (chajáes).

El árbol consenso consta de 806 pasos con un índice de consistencia (CI) de 0,20596 y un índice de retención (RI) de 0,45399 (Figura 5.2). En este árbol consenso, 
contrario a lo figurado por Mayr y Clarke (2003, Fig. 3), la gran mayoría de las relaciones entre los principales grupos de aves dentro de las Neoaves no quedan resueltas. Solo dos de los 14 árboles son muy similares en lo que respecta a las relaciones de las Neoaves al árbol consenso figurado por Mayr y Clarke (2003, Fig. 3).

Se enuncian a continuación las sinapomorfías de Cariamidae y Phorusrhacidae, así como las de los Anseriformes (incluyendo Brontornis).

De acuerdo al análisis, Cariamidae + Phorusrhacidae (Figura 5.2, nodo 68) definido aquí como Cariamiformes (véase más adelante)- se caracterizan por las siguientes sinapomorfías no ambiguas: (11) processus maxillopalatini fusionados a lo largo de su línea media (i.e., paladar directamente desmognato) -este carácter es discutido más adelante-, (12) el proceso descendente del os lacrimale no contacta con el arcus jugalis, (13) processus supraorbitalis del os lacrimale caudalmente proyectado, (21) el vomer forma una lámina media angosta y alta, (83) extremo proximal de la ulna dorso-ventralmente comprimido y cráneo-ventralmente flexionado, (103) hypotarsus del tarsometatarso sin cristae/sulci bien desarrolladas y (110) hallux fuertemente reducido.

Los Phorusrhacidae (Figura 5.2, nodo 85) se caracterizan por las sinapomorfías: (2) premaxila terminada en gancho, (23) articulación basipterigoidea presente, (24) processus basipterygoideus con faceta de articulación para los ossa pterygoidei larga y ovoide, (31) pila otica carente de pequeños forámenes pneumáticos, (53) puente óseo que conecta los processi costalis con la parte media del corpus vertebrae en al menos la séptima y octava vértebra cervical, (73) margen caudal del esternón carente de escotaduras o fenestras, (74) processus uncinati de las costillas ausentes, (81) sulcus scapulotricipitalis del húmero poco desarrollado, (84) depressio radialis de la ulna bien marcada, (90) pelvis muy elongada y fuertemente comprimida mediolateralmente, (93) tuberculum preacetabulare desarrollado, (101) presencia de un tubérculo latero-distal al pons supratendineus del tibiotarso y (102) margen distal del condylus medialis del tibiotarso marcadamente excavado. Los caracteres 23 y 24 serán discutidos en el capítulo 8 de esta tesis.

Desafortunadamente, en el árbol consenso las relaciones intrafamiliares de los Phorusrhacidae no han sido resueltas. Los taxones incluidos se caracterizan por: (A) Patagornis: (12) el proceso descendente del os lacrimale contacta con el arcus jugalis (véase capítulo 4), (45) processus medialis de la mandíbula largo, angosto y orientado dorsalmente, (84) ulna carente de depressio radialis marcada, (96) fémur corto y robusto, con un índice longitud/ancho menor de 9,0 y (101) ausencia de un tubérculo 
latero-distal al pons supratendineus del tibiotaroso; (B) Mesembriornis presenta una única autapomorfía: (96) fémur corto y robusto, con un índice longitud/ancho menor de 9,0; (C) Taxón nuevo A: (10) os mesethmoidale más extendido cranealmente que la zona flexoria craneofascialis, (27) fonticuli occipitalis presentes y (102) margen distal del condylus medialis del tibiotarso sin excavación y (D) Psilopterus: carece de autapomorfías, lo que estaría indicando el carácter plesiomórfico del taxon.

Los Anseriformes (Figura 5.2, nodo 60) se caracterizan por: (11) processi maxillopalatini fusionados a lo largo de su línea media (i.e., paladar directamente desmognato), (17) ossa palatina completamente fusionados a lo largo de su línea media y (33) processus zygomaticus ausente o vestigial. Agnolín (2007) establece que Brontornis es el grupo hermano de los Dromornithidae (aves gigantes del Neógeno y Pleistoceno de Australia) + Anseres (un grupo que incluye a los Anatoidea, Anseranatidae y a los Anhimidae). Sin embargo, en su análisis el autor se equivoca en la codificación de algunos caracteres. En el presente análisis, Brontornis es el grupo hermano de los Anhimidae (chajáes) (Figura 5.2, nodo 59). El clado constituido por estos dos taxa presenta las siguientes sinapomorfías: (100) pons supratendineus del tibiotarso no osificado, (102) margen distal del condylus medialis del tibiotarso marcadamente excavado y (103) hypotarsus del tarsometatarso sin cristae/sulci bien desarrolladas. Brontornis presenta una única autapomorfía: (96) fémur corto y robusto, con un índice longitud/ancho menor de 9,0.

\subsection{Filogenia intrafamiliar}

Como fuera mencionado previamente, en el árbol consenso del análisis aquí realizado no existe una buena resolución de las relaciones intrafamiliares. Diferentes propuestas alternativas acerca de las relaciones intrafamiliares pueden ser consultadas en Agnolín (2009) y Alvarenga et al. (2011) (Figura 5.1). En los 14 árboles más parsimoniosos, las relaciones intrafamiliares se resuelven con dos patrones de cladogénesis distintos (Figura 5.3):

(1) Los Mesembriornithinae (Mesembriornis + MMP 5050) + Psilopterus constituyen un grupo monofilético (Figura 5.3, nodo 96), correspondiéndose con los "Psilopteridae" de Agnolín (2009) (Figura 5.1). Se caracterizan por las sinapomorfías: (84) extremo distal de la ulna con una marcada depressio radialis y (101) presencia de un tubérculo latero-distal al pons supratendineus del tibiotarso. Los Mesembriornithinae (Figura 5.3A, nodo 98) se caracterizan por 
(50) presencia de processus costalis en el axis. Patagornis marshi constituye la forma más basal y es el grupo hermano de los "Psilopteridae".

(2) Psilopterus + Mesembriornithinae constituyen un grupo parafilético, basal (dentro de los Phorusrhacidae) y hermano de Patagornis marshi que representaría una forma derivada. El nodo 97 (Mesembriornis + Patagornis, Figura 5.3B) presenta una única sinapomorfía: (96) fémur corto y robusto, con un índice longitud/ancho menor de 9,0. El nodo 98 se caracteriza por: (30) processus parasphenoidalis medialis desarrollado y (50) presencia de processus costalis en el axis. Esta propuesta es similar a la de Alvarenga et al. (2011), aunque dichos autores postulan que los Mesembriornithinae son más basales que los Psilopterinae (Figura 5.1).

\subsection{Discusión y conclusiones: Cariamiformes}

El análisis cladístico aquí realizado indica que los Phorusrhacidae constituyen un grupo monofilético, hermano de los Cariamidae, situación ya establecida por autores previos sin mediar incluso análisis filogenéticos (Brodkorb, 1967; Cracraft, 1968, 1971; Mourer-Chauviré, 1983; Alvarenga y Höfling, 2003; Agnolín, 2009; Alvarenga et al., 2011). A su vez, corrobora la relación de Brontornis con los Anseriformes como fuese propuesto por Agnolín (2007), pero contrario a Alvarenga et al. (2011), aunque se encontraría más relacionado con los Anhimidae al igual que los Dromornithidae (Murray y Vickers-Rich, 2004). Brontornis constituye entonces una forma más derivada dentro del clado Anseriformes.

Existe un cierto consenso entre los distintos autores (Patterson y Kraglievich, 1960; Mayr, 2002; Alvarenga y Höfling, 2003; Agnolín, 2009; Alvarenga et al., 2011) acerca de algunas de las posibles sinapomorfías de los Phorusrhacidae consistentes en: (1) maxilla dorsoventralmente muy profunda y fuertemente comprimida mediolateralmente, dotada de un extremo distal terminado en gancho; (2) processi basipterygoideus bien desarrollados; (3) presencia en los ossa pterygoidei de una carilla de articulación bien desarrollada en su porción media que contacta con los processi basipterygoideus; (4) procesus acrocoracoideus del os coracoidei extremadamente reducido; (5) processus flexorius muy desarrollado; (6) processi uncinati ausentes y (6) pelvis fuertemente comprimida mediolateralmente, entre otras. En particular, varios autores sostienen como sinapomorfía de los Phorusrhacidae la presencia de paladar desmognato (Patterson y Kraglievich, 1960; Agnolín, 2009; Alvarenga y Höfling, 2003, 
Alvarenga et al., 2011), estableciendo que su grupo hermano, los Cariamidae, presentan un paladar de tipo esquizognato (Agnolín, 2009; Zusi y Livezey, 2006). Mayr y Clarke (2003) declaran que los Cariamidae tienen un paladar de tipo desmognato, debido a que los processi maxillopalatinus se encuentran unidos y fusionados a lo largo de su línea media (carácter 11). La revisión aquí realizada de material craneano de Cariamidae permite establecer que los processi maxillopalatinus no se encuentran fusionados, aunque si unidos en el plano medio, contactando el uno con el otro. Siguiendo la definición de Huxley (1867), los Cariamidae efectivamente tienen paladar de tipo desmognato ya que los processi maxillopalatinus se encuentran muy desarrollados y se unen (no necesariamente a través de fusión) en su línea media. Este tipo de paladar es claramente contrastante con el tipo de paladar esquizognato definido por el mismo autor, típico de los Charadriiformes, Columbiformes y de algunos "Gruiformes" como Psophia, Grus, Otididae y Eurypyga. Agnolín (2009) malinterpreta la condición de estar el vomer presente en Cariama como típica de un paladar esquizognato. Además, el vomer está presente en el Taxón nuevo A (véase el capitulo 4) y podría también estarlo en Patagornis marshi BMNH A516.

Por último, debido a la ya mencionada polifilia de los "Gruiformes" y en base a una propuesta hecha por Van Remsen al South American Classification Committee (Propuesta 290, aprobada en Octubre de 2007), se propone la utilización del taxón Cariamiformes Verheyen, 1957 para incluir a los taxones Cariamidae + Phorusrhacidae, removiéndolos del orden "Gruiformes”. Dicho taxón podría incluir, además, (aunque queda pendiente un análisis filogenético más exhaustivo) a los taxones fósiles Paleopsilopterus, Elaphrocnemus, Salmilidae Mayr, 2002, Bathornithidae Wetmore, 1933, Ameghinornithidae Mourer-Chauviré, 1981 e Idiornithidae Brodkorb, 1965, formas todas emparentadas con los Cariamidae (Mayr, 2002; Mourer-Chauviré, 1981, 1983; Agnolín, 2009; Alvarenga et al., 2011). De este modo, una de las sinapomorfías de los Cariamiformes es la presencia de un paladar desmognato. Otro carácter derivado de los Cariamiformes corresponde a la presencia de la osificación del lig. lacrimojugale, denominada os lacrimale communicans por Burmeister (1854) quien resaltó que se trataba de un rasgo único y exclusivo de los Cariamidae. Como ha sido resaltado en esta tesis, el os lacrimale communicans también se encuentra presente en los Phorusrhacidae como un hueso individual en los cráneos morfotipo I y fusionado a la rama descendente del os lacrimale en los cráneos morfotipo II (véase capítulo 4). 
Se enmienda aquí la definición de la sinapomorfía de los Phorusrhacidae en relación al paladar: los fororracos presentan como sinapomorfía la fusión medial extendida craneocaudalmente de los processi maxillopalatinus (i.e., paladar directamente desmognato). 
Capítulo 6. Estimaciones de tamaño y fuerza de mordida

El tamaño del cuerpo es una de las variables con mayor influencia sobre la anatomía, estructura y funcionamiento de un organismo (Kardong, 1998; Liem et al., 2001), afectando directamente los requerimientos mecánicos y fisiológicos (Peters, 1983; Schmidt-Nielsen, 1984; Wolff, 1991) y sus interacciones con el medio. Por lo tanto, estimar el tamaño es una de las primeras caracterizaciones necesarias en cualquier estudio paleobiológico (Cassini, 2011).

El presente capítulo tiene por objetivo estimar el tamaño corporal de los fororracos. Como veremos más adelante, aunque el principal estimativo del tamaño corporal es la masa (Rising y Somers, 1989), la altura y la postura también representan variables de relevancia en la estimación del tamaño.

Otro aspecto correlacionado con la masa es la fuerza de mordida que el animal es capaz de ejercer (van der Meij and Bout, 2004, 2008). La fuerza de mordida es otra de las variables estimada a partir de las masas corporales calculadas y de los cráneos disponibles.

\subsection{Altura y postura}

La altura (distancia vertical desde el suelo) es una indicación intuitiva del tamaño de un animal y da una idea del alcance potencial sobre el alimento cuando el ave se encuentra en tierra en posición estática. Además, tiene influencia sobre el movimiento, la agilidad y el campo visual.

Por otro lado, la altura está estrechamente relacionada con la postura (la posición del organismo en el espacio) que en las aves, particularmente las de cuello largo, es muy variable dificultando así las estimaciones (Murray y Vickers-Rich, 2004). La postura y longitud del cuello son atributos fundamentales para mantener la cabeza en una posición adecuada durante toda clase de comportamientos (Zweers et al., 1994; Bout, 1997). Todas las aves tienen un cuello flexible que adopta la forma de "S", pero la capacidad de flexionarlo varía entre los distintos grupos (Tambussi et al., inédito) y de acuerdo a las actividades que requieran movimientos más complejos, como aparearse o defenderse (Grzimek, 1968; Dzemski y Christian, 2007). La postura de los miembros es un atributo muy importante ya que influencia el patrón de movimiento y la actividad muscular que produce la propulsión (Blob, 2001; Biewener, 2005). 
Insospechadamente, existen pocas mediciones de altura en la literatura y están restringidas a algunas Palaeognathae y Galloanserae (Gatesy y Biewener, 1991; Hutchinson y García, 2002; Hutchinson, 2004; Abourachid et al., 2005; Rubenson et al., 2007).

La altura de las aves es la resultante de la posición de los miembros posteriores, la inclinación de la cintura pélvica y la posición del cuello y la cabeza. Para calcular la altura tanto a nivel del dorso como de la cabeza (caput) en los fororracos en estado estacionario se midió la distancia desde el suelo al acetabulum (alto del miembro posterior), desde el acetabulum hasta la crista iliaca dorsalis (alto de la pelvis) y desde la crista iliaca dorsalis hasta el caput (alto del cuello y cabeza). Para ello los elementos óseos fueron ubicados mediante manipulación en posición natural estática (Figura 6.1).

\subsubsection{Resultados}

En las aves en general, el fémur se mantiene en posición horizontal o subhorizontal (pudiendo alcanzar los $30^{\circ}$ con respecto de la horizontal) y es capaz de efectuar movimientos limitados con respecto a la cintura pélvica (Gatesy, 1990, 1991, 1999a, b; Gatesy y Biewener, 1991; Campbell y Marcus, 1992; Carrano y Biewener, 1999). El ángulo más frecuente rara vez es mayor a $45^{\circ}$ con el eje longitudinal de la pelvis y de hecho suele ser más cercano a cero (Alexander, 1975; Campbell y Marcus, 1992).

En aves terrestres, la reducción osteológica y de la masa muscular vinculada a la reducción del miembro anterior y el mayor desarrollo del complejo apendicular posterior ubica el centro de masa del animal por detrás de los pies (Murray y VickersRich, 2004). En las ratites actuales la pelvis es angosta y la masa muscular ubicada por detrás de la articulación pelvis-fémur es reducida, motivo por el cual la ubicación del centro de gravedad queda compensada. Este sería a priori un buen modelo para aplicar a los fororracos en los cuales a juzgar por los morfotipos pélvicos (véase capítulo 4), la situación sería similar. Sin embargo, el tronco o porción corporal preacetabular es relativamente corta y la pelvis es alta además de comprimida, masiva y con la región postacetabular sumamente larga, proporcionalmente más larga que la de una Ratitae. Esta situación produce que el centro de masa se ubique relativamente más atrás. Estudiando manualmente las articulaciones de los miembros y la posición de la pelvis de los fororracos, se arribó a dos escenarios posibles: 
(1) En las aves, el movimiento mayor del miembro posterior es el resultado del desplazamiento del tibiotarso y tarsometatarso, manteniendo el fémur subhorizontal. En los fororracos, mantener el fémur subhorizontal, resultaría en un ángulo fémur-tibiotarso relativamente bajo, acomodando la articulación tibiotarso-tarsometatarso debajo del centro de gravedad.

(2) En aves de patas largas (como los fororracos) para caminar o simplemente estar de pie, parece mejor tener una disposición casi vertical del miembro distal (tibiotarso-tarsometatarso) (Campbell y Marcus, 1992). El aumento del ángulo pelvis-fémur produciría un aumento de los ángulos fémur-tibiotarso y tibiotarsotarsometatarso, manteniendo el cuerpo elevado, con los miembros posteriores lo más extendidos posible a modo de alejar el centro de masa del suelo, dándole mayor altura al animal.

Por otro lado, en aves extintas gigantes como Moas, Aves Elefantes, Mihirungs y Gastornithidae con pelvis anchas, la presencia de tarsometarsos cortos y anchos producen que el pie se ubique por debajo del centro de masa (Alexander, 1983; Murray y Vickers-Rich, 2004). Si bien no se conocen las pelvis de Physornis y Paraphysornis, los tarsometatarsos cortos y robustos conocidos para estas especies indicarían que esta podría ser la disposición de los Physornithinae para estar balanceados.

De esta manera, el fémur fue ubicado a $30^{\circ}$ con respecto de la horizontal y se midieron los ángulos entre los distintos elementos del miembro posterior en Psilopterus bachmanni, Psilopterus lemoinei, Procariama simplex, Patagornis marshi, Mesembroirnis milneedwardsi y Taxón nuevo A. Las mediciones resultaron en que el ángulo entre el fémur y el tibiotarso en estado de reposo es de $85^{\circ}$, entre el tibiotarso y el tarsometatarso de $135^{\circ}$ y entre el tarsometatarso y el pie de $106^{\circ}$. La altura del miembro posterior (hasta el acetabulum) (Tabla 6.1) se calculó aplicando razones trigonométricas a los ángulos obtenidos y las longitudes de fémur, tibiotarso y tarsometatarso. Los ángulos aquí estimados son notablemente diferentes a los de Blanco y Jones (2005) quienes ubican el fémur a $80^{\circ}$ con respecto a la horizontal.

Tomados en conjunto la altura de la pelvis y del miembro, nos da como resultado que Psilopterus lemoinei habría tenido una altura de aproximadamente $46 \mathrm{~cm}$ hasta el dorso, Psilopterus bachmanni de $38 \mathrm{~cm}$, Procariama simplex de $55 \mathrm{~cm}$, Mesembriornis milneedwardsi de $93 \mathrm{~cm}$, el Taxón nuevo A de $70 \mathrm{~cm}$ y Patagornis marshi habría alcanzado los $72 \mathrm{~cm}$. 
Para estimar la altura al caput se manipularon los cuellos de Andalgalornis, Procariama y Mesembriornis continuando con los análisis de Tambussi et al. (inédito) (Tabla 6.1). La altura total de Mesembriornis y Procariama habría sido de $153 \mathrm{~cm}$ y 84 cm respectivamente. Para Andalgalornis se aplicó la altura del miembro posterior de Patagornis en la sumatoria, asumiendo que habrían sido de porte similar (Alvarenga y Höfling, 2003). Los resultados indican una altura total de $116 \mathrm{~cm}$.

Adicionalmente, el eje longitudinal de la pelvis se dispone formando un ángulo con la horizontal que varía entre $\operatorname{los} 45^{\circ}$ y $\operatorname{los} 15^{\circ}$ (Campbell y Marcus, 1992) de manera tal que la porción craneal de la pelvis está a mayor distancia del suelo que la porción posterior. Como consecuencia, el tronco y el cuello están elevados. De esta manera se estimaron alturas totales suponiendo ángulos de $45^{\circ}$ a $15^{\circ}$ (Tabla 6.1). Por ejemplo, Mesembriornis tendría una altura total de $162 \mathrm{~cm}$, Procariama de $88 \mathrm{~cm}$ y Andalgalornis de $125 \mathrm{~cm}$ cuando la pelvis se ubica a $15^{\circ}$ respecto al plano. Estos valores son contrastantes con las estimaciones de Alvarenga y Höfling (2003) quienes se basaron únicamente en comparaciones de masa corporal y longitudes -no posturas- de los elementos de los miembros con otras aves.

\subsection{Estimación de masa}

Numerosos autores han tratado de encontrar estimaciones confiables de la masa corporal (Prange et al. 1979; Freeman y Jackson 1990; Bennet, 1996; Olmos et al., 1996; Cubo y Casinos, 1998; Hurlburt, 1999; Casinos y Cubo 2001; Murray y VickersRich, 2004) en tanto es la medida más común para cuantificar el tamaño corporal (Rising y Somers, 1989) y base de cualquier estudio biomecánico y morfo-funcional (Biewener, 2005). En los depredadores en particular, la masa corporal está ligada fuertemente a la selección de la presa de manera tal que cuanto mayor sea el tamaño del depredador, mayor podrá ser la diversidad y tamaño de sus presas potenciales (Wheelwright, 1985).

Para estimar las masas de los fororracos se aplicaron modelos predictivos regresionando la masa corporal con un predictor (i.e., "scaling") que fue considerado como la variable independiente.

Para aves extinguidas como los fororracos resulta dificultoso encontrar buenos modelos alométricos que nos permitan realizar inferencias. La profunda especialización morfológica que exhiben excluye la utilización de los Cariamidae (los representantes vivientes más cercanos, véase capítulo 5) y los Otididae (cuyas proporciones de los 
miembros posteriores son semejantes sensu Jones, 2010 y capítulo 9 de esta tesis) como buenos modelos.

Cabe mencionar que la proporción de la masa de las plumas respecto a la masa total del animal varía según las diferentes especies. Como ejemplo, en Rhea americana ocupa el 2,89\% de la masa total (Giardina, 2006) mientras que en Larus spp.

(Charadriiformes Laridae) y Cathartes aura (Ciconiiformes Cathartidae) es de 9-10\% (Hamershock et al., 1993). La proporción de plumas respecto a la masa total es inestimable en el caso de los fororracos.

Anderson et al. (1985) establecieron que la circunferencia y la sección de los huesos de los miembros de aves y mamíferos caminadores y cursoriales están fuertemente correlacionadas con la masa corporal. Bajo este precepto, Campbell y Marcus (1992) han elaborado un modelo más complejo que asume que los diámetros de la diáfisis del fémur y tibiotarso están fuertemente correlacionados con la masa corporal en tanto ambos son los encargados de soportar el cuerpo. Campbell y Marcus (1992: 395) señalan: "within a series of similarly shaped animals of many different sizes one might expect to find a clear functional relationship between body mass and the size of the supporting skeletal structure". Basados en relaciones alométricas, utilizan modelos de regresión de tipo I y tipo II para expresar estas relaciones y realizar estimaciones de masa en taxones fósiles.

Campbell y Marcus (1992) discriminan grupos morfológicos según hábitos y sistemática; entre ellos el grupo LL de patas elongadas ("Long-Legged birds”) que incluye a los Struthionidae, Rheidae, Phoenicopteridae, Plataleidae, Ardeidae, Ciconiidae, Otididae, Scopidae, Cochleariidae, Rallidae, Gruidae, Aramidae y Burhinidae. La masa corporal de los Phorusrhacidae fue calculada considerándolos como pertenecientes a este grupo así como al grupo AL (“all birds"), que incluye a todas las aves estudiadas por los autores.

De acuerdo con dichos autores, los modelos de regresión utilizados fueron gsr (general structural relation), OLS (ordinary least square, modelo I) y RMA (reduced major axis regression, modelo II). Además, en la bibliografía suele utilizarse una fórmula derivada del estudio de Cambpell y Marcus que también ha sido empleada aquí. Dicha ecuación es la siguiente:

$\frac{\log 10 \text { Masa grupo Campbell y Marcus }}{\log 10 \text { circunf. hueso grupo Campbell y Marcus }}=\frac{\log 10 \text { Masa fósil }}{\log 10 \text { circunf. hueso fósil }}$


donde la masa del fósil es la incógnita.

Si bien Campbell y Marcus (1992) y años antes Rayner (1985) establecen que los resultados del modelo gsr son más confiables, la escasez de materiales (fémur y tibiotarso), así como las marcadas diferencias entre unas y otras formas de fororracos, hace que cualquier inferencia acerca de la naturaleza de la variabilidad y covariabilidad en las especies no pueda ser determinada. Por esta razón y de acuerdo con Warton et al. (2006) quienes claramente enfatizan que el modelo I (regresión lineal: OLS) es el modelo regresional más adecuado para realizar predicciones acerca de la variable "Y", se prefieren los resultados obtenidos por el método OLS (modelo I) para el grupo AL y LL (Tabla 6.2).

Como fuese señalado previamente, Campbell y Marcus resaltan que el fémur es una estructura conservadora y su principal función es el soporte corporal, mientras que el tibiotarso, si bien también encargado del soporte, presenta cambios de forma de acuerdo a la función. Por lo tanto cualquier estimación basada en el diámetro del fémur será más precisa que aquellas basadas en tibiotarso (Campbell y Marcus, 1992). De esta forma, y dado que las masas estimadas en base al tibiotarso tienden a estar sobredimensionadas, se utilizarán aquellos resultados basados en el fémur y solo se hará referencia a masas corporales estimadas en base a tibiotarso cuando sea estrictamente necesario.

Utilizando el principio de similitud geométrica, la masa corporal puede ser también estimada mediante modelos a escala (Alexander, 1985, 1989) sumergidos en agua (Bargo et al., 2000; Murray y Vickers-Rich, 2004). A continuación se mide el volumen de agua desplazado por el modelo plástico para finalmente escalarlo al tamaño del fósil. Sin embargo, una de las restricciones básicas en este método es el de la reconstrucción apropiada que implica un meticuloso conocimiento de la anatomía del organismo (Murray y Vickers-Rich, 2004; Jones, 2010) y una estimación de la proporción de plumas respecto a la masa total. En el caso de los fororracos y con las restricciones mencionadas, ha sido aplicado solamente para estimar la masa de Andalgalornis steulleti (Tambussi inédito).

Finalmente, es importante destacar que la masa corporal es una magnitud escalar y hace referencia a la cantidad de materia que ocupa un cuerpo en el espacio y se expresa en kg. Por su parte, el peso es una magnitud vectorial que representa la fuerza 
con la que dicho cuerpo es atraído por la gravedad y se expresa en N/m2 o su equivalente en kilogramo fuerza. Si bien difieren conceptualmente, suelen utilizarse indistintamente como sinónimos y en la práctica, dado que en la Tierra el valor 9,8 $\mathrm{N} / \mathrm{m}^{2}$ es muy cercano a 10 , resulta que peso y masa poseen magnitudes similares. A lo largo de esta tesis se hará referencia a la magnitud escalar, es decir, a la masa.

\subsubsection{Resultados}

Las masas corporales estimadas se incluyen en la tabla 6.2.

Dentro de los Psilopterinae se incluye a las formas más pequeñas (Tambussi y Noriega, 1996; Alvarenga y Höfling, 2003). Psilopterus bachmanni es sin duda el menor de los fororracos (Alvarenga y Höfling, 2003), con una masa corporal de $5 \mathrm{~kg}$. Psilopterus lemoinei presenta una masa de $9 \mathrm{~kg}, 2 \mathrm{~kg}$ más que la estimación de Alvarenga y Höfling, (2003). Procariama simplex presenta una masa de $11 \mathrm{~kg}$. Tradicionalmente se ha considerado que este último es el más grande de los Psilopterinae. Sin embargo, mediciones hechas en base al tibiotarso demuestran que este fororraco podría haber pesado hasta $12 \mathrm{~kg}$, mientras $P$. lemoinei podría haber alcanzado los $15 \mathrm{~kg}$ (Tabla 6.2). En base al tibiotarso, Psilopterus colzecus habría alcanzado una masa de casi $10 \mathrm{~kg}$.

La variación de masa corporal de los Mesembriornithinae es muy amplia: el Taxón nuevo A habría alcanzado los $18 \mathrm{~kg}$, mientras que Mesembriornis milneedwardsi habría alcanzado los $66 \mathrm{~kg}$. Esta última estimación se acerca a la obtenida por Alvarenga y Höfling, (2003) de $70 \mathrm{~kg}$. Mesembriornis incertus, cuya masa está basada en tibiotarso, habría alcanzado los $30 \mathrm{~kg}$. De acuerdo al tibiotarso, M. milneedwardsi tendría una masa de casi $100 \mathrm{~kg}$, mientras que Taxón nuevo A habría alcanzado los 24 $\mathrm{kg}$. Por estas razones, probablemente la masa de $M$. incertus sea en realidad menor (de 20-25 kg.).

Las estimaciones del Patagornithinae Patagornis marshi indican que habría alcanzado los $31 \mathrm{~kg}$. Alvarenga y Höfling (2003) establecen que Andalgalornis y Patagornis son formas de tamaño muy similar, de entre 45 y $50 \mathrm{~kg}$. Los resultados de estos autores son levemente contrastantes con la estimación aquí realizada para Patagornis, como también lo es con la estimación de $40 \mathrm{~kg}$ para Andalgalornis realizada por C.P. Tambussi en base a modelos a escala (inédito) y la estimación aquí realizada en base al tibiotarso del mismo taxón (30 kg; Tabla 6.2). 
Los fororracos más grandes sin dudas fueron los Phorusrhacinae y Physornithinae. No se cuentan con estimaciones realizadas para estos últimos. Sin embargo, Alvarenga y Höfling (2003) establecen que Paraphysornis habría tenido una masa de $180 \mathrm{~kg}$. Las estimaciones realizadas aquí para Phorusrhacos longissimus (117 $\mathrm{kg}$ ) son levemente menores que aquellas de Alvarenga y Höfling $(2003,130 \mathrm{~kg}$ ) y marcadamente diferentes a las de Jones (2010), de $160 \mathrm{~kg}$. Las estimaciones hechas en base al tibiotarso muestran que Devincenzia habría tenido una masa de $162 \mathrm{~kg}$, mientras que Phorusrhacos habría alcanzado los $180 \mathrm{~kg}$. Sin embargo, gran cantidad de material (especialmente tarsometatarsos) asignado a Devincenzia muestra que esta forma sería, en realidad, mayor que Phorusrhacos.

Las ratites incluyen las formas vivientes de mayor masa; en particular el avestruz Struthio camelus tiene una masa de 41,5 kg según Alexander (1984), 80,9 kg según Anderson et al. (1985) o 100 kg según Amadon (1947). Los datos de Campbell y Marcus (1992) incluyen individuos con una masa que varía entre 138 y $161 \mathrm{~kg}$, aunque Hutchinson (2004) publica una masa corporal de $65 \mathrm{~kg}$. Comparados con las aves vivientes de mayor tamaño, los fororracos deben ser considerados como aves de porte mediano a gigante.

\subsection{Tamaño}

En base al tamaño, entendido aquí como la propiedad influenciada por masa, postura y altura, pueden discriminarse al menos tres grupos de fororracos:

(1) Fororracos pequeños que presentaban una altura hasta el dorso de entre $38 \mathrm{y}$ $60 \mathrm{~cm}$, con una masa que no superaba los $15 \mathrm{~kg}$. Se incluyen aquí a los Psilopterinae.

(2) Fororracos medianos que alcanzaron una altura de 70-75 $\mathrm{cm}$ hasta el dorso y una masa corporal de entre 15 y $40 \mathrm{~kg}$. Se incluyen aquí a los Patagornithinae y a los Mesembriornithinae Mesembriornis incertus y Taxón nuevo A.

(3) Fororracos grandes-gigantes que superaban la altura de $75 \mathrm{~cm}$ hasta el dorso y superaban la masa corporal de $40 \mathrm{~kg}$. Se incluye a Mesembriornis milneedwardsi, de casi un metro de altura hasta el dorso y $66 \mathrm{~kg}$, y a los Phorusrhacinae y Physornithinae que superaban los $100 \mathrm{~kg}$ de masa.

Probablemente este último grupo pueda ser separado en grandes y gigantes con el descubrimiento de mayor número de ejemplares que permitan realizar nuevas estimaciones de masa y la altura al dorso. Se incluyen aquí Kelenken, Devincenzia y 
Physornis cuyas estimaciones de masa no son posibles, pero que sin dudas son los mayores de los fororracos.

\subsection{Fuerza de mordida de los Phorusrhacidae}

Se entiende como fuerza de mordida (FM) a la cantidad de fuerza que puede ser ejercida por los músculos aductores de la mandíbula en función de la geometría de la misma (Meers, 2002). Es el resultado de una estructura generadora de dicha fuerzas (i.e, músculos mandibulares) y de una estructura trasmisora de dichas fuerzas (i.e., el pico) (Herrel et al., 2005a).

La FM resulta esencial para entender la ecología trófica de cualquier vertebrado (Christiansen y Wroe, 2007; Anderson et al., 2008) y es un factor importante que determina la capacidad de tomar, procesar y manipular el alimento o distintos objetos (Carril, 2010). Por lo tanto, la elaboración de un modelo predictivo para los organismos fósiles se vuelve imperiosa. La fuerza de mordida ha sido motivo de estudio en una gran variedad de vertebrados (Sinclair y Alexander, 1987; Thomason, 1991; Cleuren et al., 1995; Erickson et al., 1996; Binder y van Valkenburgh, 2000; Christiansen y Adolfssen, 2005; Christiansen y Wroe, 2007; Carril, 2010; Goswami et al., 2011), recibiendo poca atención en el caso de las aves.

Al igual que la masa corporal, la FM limita la masa corporal de la presa en el caso de los depredadores (Wheelwright, 1985): mayor masa corporal y mayor fuerza de mordida permiten acceder a una gama mayor de tamaños de presa (Meers, 2002; Vizcaíno y de Iuliis, 2003; Rayfield, 2004; Wroe et al., 2005). Además, la fuerza de mordida tiene fuerte influencia sobre las estrategias depredadoras: un depredador debe poder discernir qué presa es capaz de matar mediante la mordida (Meers, 2002).

Varios estudios muestran que existe una correlación entre la fuerza de mordida y la masa corporal (van der Meij and Bout, 2004, 2008; Wroe et al., 2005; Christiansen y Wroe, 2007). Particularmente los datos publicados de fuerza de mordida de aves tomados in vivo son escasos y se encuentran principalmente restringidos a Passeriformes (van der Meij and Bout, 2004, 2006), un grupo derivado de aves, caracterizadas por su pequeño tamaño. Estos estudios han revelado que la fuerza de mordida está principalmente relacionada con la morfología del cráneo y su geometría, así como a la capacidad de contracción de los músculos mandibulares (van der Meij and Bout, 2004; Herrel et al., 2005a, b). En los pinzones de las Galápagos, el tamaño del pico y en especial el ancho de la cabeza están fuertemente correlacionados con la fuerza 
de mordida, mientras que el tamaño de la cabeza se correlaciona con el tamaño de los músculos mandibulares (Herrel et al., 2001, 2002). Los Passeriformes obviamente constituyen un pobre modelo para la estimación de la fuerza de mordida de los fororracos, no solo debido a las diferencias filogenéticas, sino también a la morfología y tamaño del cráneo.

Degrange et al. (2010) construyen una recta de regresión a fin de poder estimar la fuerza de mordida de Andalgalornis steulleti, para lo cual utilizan datos éditos de fuerza de mordida (van der Meij and Bout, 2004) y de masa corporal (van der Meij and Bout, 2004; Jimenez y Jaksic, 1990; Abourachid et al., 2005) y datos propios obtenidos mediante un transductor particularmente diseñado para medir la fuerza de mordida in vivo en aves en cautiverio. Sin embargo, argumentan que el valor de fuerza de mordida estimada (133 Newtons) para Andalgalornis representa una mordida débil y que probablemente este ave fuese capaz de ejercer una mayor fuerza de mordida. Además, los valores medios de stress (Tabla 8.1 del capítulo 8) registrados para el modelo de Andalgalornis son mucho menores que aquel estimado para Cariama y Haliaeetus. Esto se debe a que existen factores de seguridad muy altos en el cráneo de Andalgalornis o que, como se dijo previamente, la fuerza de mordida de $133 \mathrm{~N}$ se encuentra subestimada (véase ítem 8.2 para una mayor discusión).

En la presente tesis, se realizó un análisis regresional, actualizando el modelo de Degrange et al. (2010) utilizando la masa corporal y la fuerza de mordida (Apéndice 6.1). Para ello fueron incorporados los datos éditos de Carril (2010) y Sustaita y Hertel (2010). Se realizaron los modelos regresionales OLS y RMA, aunque se prefirieron aquellos obtenidos mediante OLS, debido a su mejor poder predictivo (Warton et al., 2006), como fue explicado previamente. Los datos de masa corporal fueron tratados en kilogramos $(\mathrm{kg})$ y los de fuerza de mordida en Newtons $(\mathrm{N})$ y para realizar la regresión dichos datos fueron transformados mediante la función logarítmica con base 10 .

Las fuerzas de mordida obtenidas mediante la regresión masa-fuerza de mordida se resumen en la tabla 6.3. Dichas fuerzas fueron estimadas únicamente en base a las estimaciones de masa realizadas sobre el fémur. Los resultados aquí presentados muestran que, en el caso de las aves, la fuerza de mordida está correlacionada con la masa corporal $\left(R=0,77912 ; R^{2}=0,607 ; p=0,0000\right)$. Sin embargo, las extrapolaciones hechas en base a la masa corporal de los fororracos arrojaron valores relativamente bajos. Los menores valores se encuentran entre los Psilopterinae (42 N) y los mayores entre los Phorusrhacinae (158 N). Los Psilopterinae presentan valores entre 42 
(Psilopterus bachmanni) y $57 \mathrm{~N}$ (Procariama simplex). Mesembriornis milneedwardsi presenta una fuerza de mordida de $124 \mathrm{~N}$, el Taxón nuevo A de 71 N, Patagornis marshi de $90 \mathrm{~N}$ y Phorusrhacos longissimus de hasta $158 \mathrm{~N}$ (Tabla 6.3).

Wroe et al. (2005) recomiendan que las fuerzas de mordida de formas fósiles sean estimadas utilizando formas de morfología craneana similar o de hábitos similares. Siguiendo estos autores, en un segundo análisis regresional se restringió la estimación de fuerza de mordida utilizando los datos de masa corporal y fuerza de mordida de las aves carnívoras. Los valores obtenidos mediante esta nueva regresión utilizando OLS $\left(\mathrm{R}=0.91653 ; \mathrm{R}^{2}=0.84002 ; \mathrm{p}=0.0000\right)$ se listan en la Tabla 6.3 y son significativamente mayores que aquellos obtenidos mediante el primer análisis.

Un tercer análisis incluyó correlaciones con la fuerza de mordida entre las medidas craneanas ancho del cráneo, largo, ancho y alto del pico de aves no Passeriformes. Si bien los datos utilizables fueron muy escasos, el ancho de la cabeza resultó estar fuertemente correlacionado con la fuerza de mordida $(\mathrm{R}=0.96518$; $\left.\mathrm{R}^{2}=0.93157 ; \mathrm{p}=0.0004\right)$ en acuerdo con lo establecido por Herrel et al. $(2001,2002)$ para los Passeriformes Fringillidae. Si bien estos valores también son significativamente más altos (Tabla 6.4) que aquellos obtenidos mediante el primer análisis, son menores que los del segundo análisis regresional (solo carnívoros).

El diseño rígido del cráneo (Degrange et al., 2010; capítulos 4 y 8 de esta tesis), así como la disposición de los músculos mandibulares (Degrange, 2007, 2008; capítulos 7 y 8 de esta tesis) indican que los fororracos presentaban fuerzas de mordida altas. En particular, el fuerte desarrollo de las fossae temporalis, el sitio de inserción de uno de los principales músculos adductores (el m. adductor mandibulae externus), muy extendidas medialmente, indica la presencia de un músculo muy voluminoso que favorece la fuerza en detrimento de la velocidad (Degrange, 2008), contribuyendo a la alta fuerza de mordida total de estos animales. Esta suposición tiene sustento además en el hecho que aves de mucho menor masa que los fororracos más pequeños, como es el caso del Cathartidae Sarcoramphus papa (3,4 kg.) serían capaces de morder a más de $110 \mathrm{~N}$ (Carril, 2010), indicando que al menos los valores obtenidos mediante el primer análisis regresional son muy bajos. De esta forma, los valores obtenidos utilizando el ancho craneano resultan ser más adecuados que aquellos obtenidos mediante la utilización de la masa (primero y segundo análisis).

Sin embargo, es destacable que los dos últimos análisis arrojan valores de mordida llamativamente altos para los fororracos más grandes: $1369 \mathrm{~N}$ para 
Phorusrhacos usando la masa; 1945 N para Kelenken y 2979 N para Devincenzia utilizando el ancho craneano. Fuerzas de mordida tan altas podrían indicar que estos animales estaban capacitados para romper huesos, como fuese establecido por Tambussi y Hoffman (1998), lo cual no indica necesariamente que se trataba de formas carroñeras, sino a la capacidad de manipulación de presas grandes.

Debido a que la fuerza de mordida depende de varios factores, entre ellos la masa corporal, la geometría del cráneo, el largo del pico, y la fuerza y configuración de los músculos mandibulares (van der Meij y Bout, 2004, 2008), la estimación de la fuerza de mordida en aves fósiles se dificulta en ausencia de modelos más complejos. Es necesario aclarar que la falta de buenos estimadores se debe en parte a que se desconoce el poder predictivo real de los análisis regresionales cuando se tiene un valor del predictor muy superior a aquellos utilizados en el análisis (como la masa o el ancho craneano de los fororracos más grandes). Sin embargo, los valores aquí presentados representan un intento por obtener estimaciones, utilizando una gama amplia de aves de distintos hábitos, aplicables a diversos análisis paleobiológicos. Si bien el tamaño muestral de estos análisis puede resultar bajo, dado el fuerte correlato evolutivo que existe entre morfología, fuerza de mordida y ecología trófica (Herrel et al., 2002), estos estudios parecen prometedores para futuros estudios ecomorfológicos y patrones del sistema trófico de las aves fósiles y en particular de los fororracos. 


\section{Capítulo 7. Miología mandibular y apendicular posterior de los fororracos}

\subsection{La factibilidad y la importancia de reconstruir partes blandas}

Raros son los casos en los cuales se preservan o detectan los tejidos blandos en los fósiles. Por esta razón, es importante contar con herramientas que permitan inferir la presencia o ausencia de una estructura blanda de interés. La reconstrucción de tejidos blandos en formas extintas requiere de la integración de datos tanto paleontológicos como neontológicos, así como de una metodología explícita (Bryant y Seymour, 1990; Bryant y Russell, 1992; Witmer, 1995b) que permita obtener datos de relevancia filogenética, anatómica y funcional. Reconstrucciones blandas precisas son a menudo la base de inferencias acerca del comportamiento, ecología y estructura de una comunidad (Witmer, 1995b: Figura 2.1).

Witmer (1995b, 1997) establece tres razones fundamentales que justifican la reconstrucción y el estudio de la anatomía blanda en formas fósiles: (1) los tejidos blandos son, en gran medida, los responsables de la existencia, posición, mantenimiento y forma de los huesos. En efecto, la presencia o ausencia de un hueso en particular depende de aquellos tejidos blandos que se forman antes en la morfogénesis (Wolpert, 1983; Hall, 1988; Wedden et al., 1988); (2) la forma y acción de los tejidos blandos son la base para realizar inferencias paleobiológicas y (3) los tejidos blandos pueden proveer hipótesis contrastables acerca de la independencia o no de caracteres filogenéticos.

La información acerca de la anatomía blanda debe provenir de taxones actuales en tanto son la única fuente confiable de detalle acerca de los tejidos blandos y de su relación causal con el esqueleto. Se busca, entonces, encontrar la expresión de esta asociación causal entre tejido blando-tejido duro, es decir los "correlatos osteológicos" para dicho tejido blando. Idealmente, se busca identificar el tejido blando que es necesario y suficiente para explicar una cicatriz ósea en particular (Witmer, 1995a). Los correlatos osteológicos han demostrado ser sumamente útiles en la reconstrucción de estructuras blandas, tanto craneanas (Witmer 1995a, b, 1997; Degrange, 2007; Snively y Russell, 2007; Desojo y Vizcaíno, 2009) como postcraneanas (e.g., Hutchinson, 2001a, b; Carrano y Hutchinson, 2002; O’Connor, 2006) en Archosauria fósiles.

Particularmente, la reconstrucción de los músculos permite obtener datos fundamentales acerca de las facultades motrices de un organismo. A partir del correlato 
óseo es posible predecir la función y el rol biológico de los caracteres implicados por ejemplo, en el hábito trófico y la locomoción.

Todo músculo tiene un origen y una inserción. El origen es una superficie llana o deprimida que se mantiene fija durante el accionar muscular. En cambio, los sitios de inserción suelen ser áreas positivas (e.g., apófisis, crestas, tubérculos, asperezas), ubicadas en el hueso que se mueve durante dicho accionar. El correlato osteológico de un músculo puede indicar no solo la presencia y sitio de fijación de un músculo en particular, sino también el tamaño de la fijación. Las fijaciones al hueso a través de tendones o aponeurosis dejan marcas o cicatrices más robustas que las fijaciones carnosas (i.e., cuando el vientre del músculo se inserta directamente sobre el hueso, sin tendones o aponeurosis de por medio) (Hildebrand, 1988; Bryant y Seymour, 1990; Bryant y Russell, 1992, Carrano y Hutchinson, 2002).

Sin embargo, se debe ser muy cuidadoso al momento de realizar reconstrucciones musculares en formas extintas, particularmente cuando el hábito trófico o locomotor de dicho taxón es muy diferente de aquel de las formas actuales emparentadas (Haas, 1969; Bryant y Seymour, 1990; Witmer, 1995a, b; Carrano y Hutchinson, 2002; Holliday y Witmer, 2008; Toledo, 2009). Bryant y Seymour (1990) señalan que cualquier tipo de inferencias acerca del tamaño y forma del músculo basadas en las reconstrucciones son, en gran medida, especulativas. Además, ya que más de un tejido blando puede producir una misma marca osteológica se dificulta la determinación de homologías (Holliday, 2009).

\subsection{Extant Phylogenetic Bracket (EPB)}

El EPB representa una aproximación metodológica desarrollada por Witmer (1992, 1995b) que, basada en los principios básicos de la cladística, comparaciones anatómicas (Bryant y Russell, 1992; Witmer, 1995a, b, 1997) y determinación de homologías secundarias (Patterson, 1982; Rieppel, 1988; de Pinna, 1991), permite reconstruir tejidos blandos en organismos extintos con distintos grados de inferencia. Para ello se comparan taxones actuales que representen a los grupos externos del taxón extinto bajo estudio. Su utilización está muy difundida en trabajos recientes (e.g., Witmer, 1997; Carrano y Hutchinson, 2002; Rieppel, 2002; Perry y Sander, 2004; Holliday y Witmer, 2007; Holliday, 2009).

Esta aproximación busca ubicar en un diagrama de parentesco o cladograma previamente establecido al taxón fósil bajo estudio entre los dos outgroups vivientes 
más cercanamente emparentados. Una vez efectuado este procedimiento, se mapean las relaciones causales tejido blando-tejido duro en los taxones actuales. A continuación se hipotetiza la relación causal del ancestro que incluye a los tres taxones, fósil y actuales (i.e., "bracket ancestor") y por último, se testea esta hipótesis buscando el correlato óseo en la forma fósil (Figura 7.1). De esta forma, el tejido blando puede ser inferido en el taxón extinto con diversos grados de certeza (Witmer, 1995b, 1997). En otras palabras, el EPB asume que si los taxones actuales comparten la presencia de un tejido blando en particular y presentan el correlato óseo para dicho tejido, se puede asumir que dicho tejido blando también se encontraría presente en la forma extinguida por ancestralidad común.

Además, como requerimiento ineludible para la aplicación del EPB se necesita que se estén comparando estructuras homólogas y que la relación tejido blando-tejido duro también lo sea (i.e., tejidos blandos homólogos producen correlatos óseos homólogos). Estos correlatos pueden manifestarse como tuberosidades, crestas, fosas, forámenes, fenestras, septos, trocánteres o cualquier otra estructura que indique inequívocamente la presencia de determinado tejido blando.

Witmer (1995b) además incorporó el uso de niveles de inferencia, los cuales proveen una medida del nivel de especulación inherente de las reconstrucciones de tejido blando en un análisis paleobiológico. Son tres los niveles de especulación propuestos en dependencia de la ubicación del nodo del outgroup (i.e, el nodo que contiene a la forma fósil y a su grupo hermano) (Figura 7.2):

Nivel I: asignación decisiva y positiva, cuando ambos grupos actuales poseen el carácter blando (y su correspondiente correlato óseo) inferido en el taxón fósil. Nivel II: asignación equívoca, cuando solo uno de los grupos actuales posee el atributo blando.

Nivel III: asignación decisiva y negativa, cuando ninguna de las formas actuales posee el tejido blando.

Los niveles inferenciales II o III pueden ser robustecidos mediante evidencia morfológica en otros outgroups. Para los casos en los cuales los atributos observados en los taxones actuales no posean correlatos osteológicos, el EPB propone que se les atribuyan niveles de inferencia paralelos, denominados I', II' y III'.

Si bien el EPB es una aproximación metodológica muy extendida en las investigaciones recientes, no está exento de problemáticas: está fuertemente sujeto a la hipótesis filogenética elegida para hacer la reconstrucción. Witmer (1997) declara que el 
método solo es válido si los nodos están fuertemente soportados y no han de colapsar con la incorporación de nuevos datos. Toledo (2009) resalta que existen situaciones problemáticas que trascienden la capacidad explicativa del EPB. Éstas se deben a casos en los cuales la disparidad morfológica entre los taxones vivientes y el fósil en estudio es tan grande que las hipótesis a testear pueden verse entorpecidas con problemas graves de validación. Un soporte adicional a esta problemática podría obtenerse mediante la mayor incorporación de evidencia morfológica o la utilización de otras aproximaciones metodológicas, como las relaciones de forma y función, o la parsimonia (Toledo, 2009). Existen además situaciones donde puede no ser necesario aplicar EPB. En grupos actuales donde las estructuras blandas son muy conservativas en cuanto a su presencia-ausencia (e.g., la musculatura mandibular de las Neornithes) y los correlatos óseos de la forma fósil se encuentran presentes, cualquiera sean los grupos elegidos para inferir dicha estructura en el taxón fósil, producirán siempre niveles de inferencia I (o I' si los correlatos están poco marcados en el fósil; véase tablas 7.1 y 7.2). La misma conclusión puede obtenerse utilizando solo el criterio topológico. En estos casos, no existen razones para dudar de la existencia de la estructura blanda y no es necesario utilizar el EPB (Holliday com. pers.).

\subsection{Nomenclatura anatómica}

La terminología artrológica utilizada en este capítulo se basa en la de Baumel y Raikow (1993); la muscular craneana en la de Holliday y Witmer (2007), mientras que la musculatura apendicular posterior sigue a Vanden Berge y Zweers (1993). El marco anatómico fue provisto a través de disecciones en material fresco disponible de Tinamidae, Phoenicopteridae, Cuculidae, Accipitridae, Falconidae, Tytonidae y Rheidae, así como de otros grupos de Neornithes Neoaves de referencias bibliográficas (Hudson, 1937; Berger, 1952; Zusi y Storer, 1969; Rosser et al., 1982; Vanden Berge y Zweers, 1993; Verstappen et al., 1998; Holliday y Witmer, 2007) y de la observación directa de datos osteológicos de aves actuales.

\subsection{Reconstrucción muscular}

El presente capítulo tiene por objetivo realizar la reconstrucción de los músculos mandibulares y del complejo apendicular posterior de los fororracos bajo la aproximación metodológica del EPB. Para el presente análisis, se tomaron como grupos externos a los Cuculidae (el taxón externo más cercanamente emparentado a los 
Phorusrhacidae, véase capítulo 5), Accipitridae y Falconidae, así como también Neornithes basales (Anhimidae, Tinamidae y Rheidae) para contar con un panorama más amplio de los cambios de cada músculo analizado.

\subsubsection{Músculos mandibulares}

Los músculos mandibulares son estructuras blandas esenciales y críticas al momento de realizar homologías, análisis de la función y evolución craneana (Zweers et al., 1994; Gussekloo y Bout, 2005; Holliday, 2009). Comprenden músculos tanto pinnados como paralelos adaptados para generar fuerza o velocidad (Leiber, 1992a,b), fijándose a diferentes porciones del neurocráneo, paladar y mandíbula.

La mayor parte de los músculos mandibulares se encargan de cerrar (aducción) la mandíbula, mientras que la abertura (abducción) se logra mediante la depresión de la misma (a través del $m$. depressor mandibulae) y/o la protracción del paladar y pico (a través del $m$. protractor pterygoideus et quadrati, véase capítulo 8) (Bock, 1964). Los músculos mandibulares están principalmente inervados por el nervio V (trigémino) (Figura 7.3), aunque el $m$. depressor mandibulae se encuentra inervado por el nervio VII (facial) (Vanden Berge y Zweers, 1993; Holliday, 2006; Holliday y Witmer, 2007).

La miología mandibular de las aves ha sido descripta y detallada en numerosos trabajos comparativos (Hofer, 1950; Starck y Barnikol, 1954; Vanden Berge y Zweers, 1993; Holliday, 2006; Holliday y Witmer, 2007) y en otros focalizados en algunos taxones en particular: Tinamiformes (Elzanowski, 1987), Anseriformes (Goodman y Fisher, 1962); Galloanseres (Zusi y Livezey, 2000), Columbiformes (Bhattacharyya, 1980, 1989, 1994); Struthionidae (Webb, 1957), Podicipediformes (Zusi y Storer, 1969); Gruidae (Fisher y Goodman, 1955); Phalacrocoracidae (Dullemeijer, 1951, 1952), Psittaciformes (Hofer, 1950, 1953), Trochilidae (Zusi y Bentz, 1984) y Passeriformes (Bowman, 1961; Beecher, 1962; Zusi, 1967). Sin embargo, las reconstrucciones de la musculatura mandibular en aves fósiles en la literatura científica son escasas (e.g., Murray y Vickers-Rich, 2004; Degrange, 2007, 2008).

En esta sección se presentan los correlatos óseos y los músculos inferidos del aparato mandibular de los fororracos. Las reconstrucciones se basan fundamentalmente en Andalgalornis steulleti, Patagornis marshi, Psilopterus lemoinei y Taxón nuevo A. Debido a la carencia de análogos actuales, la reconstrucción muscular del cráneo de estas aves resulta de vital relevancia en la comprensión de su biología trófica. Debido a que los músculos mandibulares de las Neornithes son muy conservativos en cuanto a su 
presencia o ausencia, todos los músculos inferidos según EPB tienen nivel I o I' (Tabla 7.1).

\section{A) M. Adductor mandibulae internus}

En los Sauropsida, este grupo muscular se encuentra delimitado medialmente por el neurocráneo y lateralmente por la ramus maxillaris $\left(\mathrm{V}_{2}\right)$ (Holliday y Witmer, 2007). Se reconocen fundamentalmente dos subgrupos musculares: pterygoideus y pseudotemporalis.

En todos los Archosauria, el m. pterygoideus se origina en los ossa palatinum y en los ossa pterygoidei y se inserta fundamentalmente en la porción caudomedial de la mandíbula (Figura 7.4). Se subdivide en dos porciones: $m$. pterygoideus dorsalis y $m$. pterygoideus ventralis, ambas encargadas de elevar la mandíbula y deprimir las maxilas al mismo tiempo (Beecher, 1962; Bock, 1964). Sin embargo, en las Neornithes cada una de estas porciones puede subdividirse en varias partes (pars, e.g., pterigoidea y palatina, Vanden Berge y Zweers, 1993; Holliday, 2009).

En las Neornithes, el m.pterygoideus dorsalis se origina en la superficie dorsal y lateral de los ossa palatinum y ossa pterygoidei y se inserta en la superficie craneodorsal del processus mandibularis medialis, ventralmente a la articulación mandibular, bordeado ventrolateralmente por el $m$. pterygoideus ventralis, dorsalmente por el seno suborbital (Witmer, 1995a; Witmer y Ridgely, 2008) y lateralmente por el m. pseudotemporalis profundus.

En todos los fororracos se encuentra el correlato osteológico de este músculo (Figura 7.5). Con respecto al origen, en el Taxón nuevo A MMP 5050, sobre la cara dorsal de los ossa palatinum, se observa una depresión muy somera que se continúa sobre el processus rostralis delimitada caudoventralmente por un reborde de la crista lateralis. Dicho reborde se continúa cranealmente hasta perderse en el contacto con los ossa maxillaris y arcus jugalis. El límite lateral de este músculo sobre los ossa pterygoidei está delimitado por una cresta lateroventral ubicada sobre el corpus pterygoidei. En Andalgalornis steulleti FM-P14357, los ossa pterygoidei presentan una superficie ventral recta, delimitando ventralmente la superficie de origen. La superficie de los ossa pterygoidei en Psilopterus bachmanni YPM-PU15904 es suave, carente de cresta marcadas. Este músculo se inserta en una fosa caudomedial (muy marcada en Andalgalornis FM-P14357 y Andrewsornis FM-P13417, más somera y extendida en Taxón nuevo A MMP 5050) de la mandíbula, de contorno triangular (similar a 
Cathartidae y Accipitridae), delimitada dorsalmente por la articulación mandibular y caudalmente por el processus mandibularis mesialis y por un reborde caudoventral de la mandíbula.

El m. pterygoideus ventralis se origina en la superficie ventral de los ossa palatinum y ossa pterygoidei. Se inserta en la superficie craneoventral del processus mandibularis medialis y en algunos casos, sobre la superficie ventrocaudolateral de la mandíbula (e.g., Procellariiformes, entre otros), cubriendo ventralmente al $m$. pterygoideus dorsalis y al processus retroarticularis (Figura 7.4) cuando éste está presente, quedando bordeado ventrolateralmente por un músculo hyolingual (el $m$. serpihyoideus) (Holliday, 2006; Holliday, 2009).

En los fororracos, en los ossa palatinum, el $m$. pterygoideus ventralis se origina en la fossa ventralis, muy profunda y extendida cranealmente (Degrange y Tambussi, 2011), delimitada medialmente por la crista mesialis y lateralmente por la crista lateralis muy saliente ventralmente (véase capítulo 4), en una situación similar a la de los Cathartidae. Sobre los ossa pterygoidei, en el Taxón nuevo A MMP 5050 se observan dos crestas paralelas, siendo la medial más pronunciada. Estas crestas delimitan el área de origen del músculo. En Andalgalornis FM-P14357 la superficie plana ventral, carente de crestas, corresponde a la misma área de inserción (compárese con el origen del m. pterygoideus dorsalis) (Figura 7.5). El músculo se inserta sobre el reborde caudoventral de la mandíbula (caudalmente a la inserción del $m$. pterygoideus dorsalis), sobre la cara caudolateral de la mandíbula y sobre el processus retroarticularis (Figura 7.5 y 7.6). En Phorusrhacos longissimus BMNH-A529, sobre la superficie caudoventral de los rami mandibulae se observa una pequeña quilla (en continuación con el reborde caudal) que marca el margen lateral del $m$. pterygoideus dorsalis y el medial del m. pterygoideus ventralis. En Andrewsornis abbotti FM-P13417 sobre la superficie laterocaudal de la mandíbula se observa una suave cresta que se origina en el margen dorsal del processus retroarticularis y se dirige hacia el margen ventral de la mandíbula, delimitando dorsalmente la inserción del $m$. pterygoideus ventralis (y caudalmente al $m$. adductor mandibulae externus superficialis, véase más abajo), una condición menos marcada en otros Patagornithinae (e.g., Andalgalornis), de forma que este músculo está ampliamente extendido sobre la cara lateral de la mandíbula. En función al desarrollo del processus retroarticularis (véase capítulo 4) en los cráneos morfotipo I, este músculo tiene una extensa área de inserción caudal, 
mientras que en los cráneos morfotipo II este músculo tiene una mayor área de inserción lateral.

Los músculos pseudotemporalis en los Archosauria son dos: $m$. pseudotemporalis profundus y $m$. pseudotemporalis superficialis. El m.

pseudotemporalis profundus, en las Neornithes, se origina en la superficie lateral del processus orbitalis del os quadratum, cranealmente al $\mathrm{m}$. adductor mandibulae posterior. Se inserta en la superficie ventromedial del processus coronoideus y en la fossa mandibularis medialis, medialmente al foramen de entrada de la ramus mandibularis $\left(\mathrm{V}_{3}\right)$ hacia el canal meckeliano (Holliday y Witmer, 2007; Holliday, 2009), craneoventralmente al m. pseudotemporalis superficialis, ventralmente al $m$. adductor mandibulae externus profundus y laterocranealmente al m. pterygoideus dorsalis (Figura 7.4).

En los fororracos, tanto el origen como la inserción del m. pseudotemporalis profundus se encuentran poco marcados, por lo cual la reconstrucción resulta dificultosa. Solamente en Psilopterus lemoinei YPM-PU15402 y Taxón nuevo A MMP 5050 se observa sobre el processus orbitalis una cresta tenue dirigida ventrocranealmente, que limita una depresión dorsal donde se origina el músculo (el área por debajo de esta cresta corresponde al origen del $m$. adductor mandibulae posterior). En Procariama simplex FM-P14353 y Psilopterus bachmanni YPMPU15904 dicho reborde es aún más leve. Sobre el extremo más craneal del processus orbitalis del Taxón nuevo A MMP 5050 se evidencia una cresta vertical que constituiría el límite craneal del origen. En Andalgalornis FM-P14357 estas características son imperceptibles. Con respecto a la inserción, solamente en Procariama simplex FMP14525 se observa medialmente sobre el processus coronoideus una pequeña cresta que delimita ventralmente al $m$. pseudotemporalis profundus. Por detrás de dicho processus, esta cresta se encuentra poco marcada, aunque se aprecia que se dirige ventralmente. En Andalgalornis FM-P14357 se observa sobre la cara medial de la mandíbula, caudalmente y a continuación del reborde medioventral de la fenestra mandibulae (véase capítulo 4, ossa mandibulae), un reborde que delimita ventralmente a este músculo. La cresta medioventral de la fenestra mandibularis previamente mencionada presenta un margen recto, excavado por un surco medio que serviría de punto de inserción. En los morfotipos craneanos tipo II, la fenestra mandibularis tiene un doble reborde (medial y lateral). Es probable que este músculo se inserte entre medio de las mismas, obliterando la fossa mandibularis, como ocurre en otras aves (e.g., 
Procellariiformes, Ciconiiformes Cathartidae), que dotaría a estas aves de un gran músculo de gran extensión craneal (Figura 7.5 y 7.6).

El m. pseudotemporalis superficialis es uno de los músculos mandibulares de menor volumen (Holliday, 2009). Generalmente, en las Neognathae se origina en la superficie craneodorsolateral del os laterosphenoidale (i.e., area muscularis aspera), ventralmente al $m$. tensor periorbitae, lateralmente al $m$. rectus lateralis y cranealmente al m. adductor mandibulae externus profundus. En otras casos (e.g., Tinamidae, Ratitae, Ciconiiformes, Phalacrocorax y Anhinga) también se origina sobre la fossa temporalis, junto al $m$. adductor mandibulae externus. Se inserta en la superficie dorsomedial de la mandíbula sobre el processus coronoideus, dorsalmente al m. pseudotemporalis profundus, medioventralmente a la inserción del $m$. adductor mandibulae externus profundus y cranealmente a la inserción del $m$. adductor mandibulae posterior (Figura 7.4).

Al igual que en la mayoría de las Neornithes, el m. pseudotemporalis superficialis de los Phorusrhacidae no presenta un origen muy bien marcado (especialmente en Patagornithinae). El area muscularis aspera corresponde a una cuenca somera, alargada, dispuesta de forma oblicua laterodorsalmente (véase capítulo 4). Se encuentra limitada ventralmente por una cresta angosta que se dirige hasta la base del processus postorbitalis de los ossa frontalis. En Psilopterus lemoinei AMNH 9257 y YPM-PU15402 se aprecia que el area se encuentra también delimitada cranealmente por un reborde romo que abarca gran parte de la superficie craneal del processus postorbitalis, indicando que este músculo se originaría también sobre estos processi (situación similar a Cariamidae). El area en general presenta una disposición verticalizada en Psilopterinae, pero en Patagornis marshi MLP 20-122 se encuentra más inclinada craneodorsalmente. En general y al igual que la inserción del $m$. pseudotemporalis profundus, la inserción del $m$. pseudotemporalis superficialis no se encuentra bien marcada. En Procariama simplex FM-P14525 sobre la superficie mediocraneal del processus coronoideus se observa un reborde que delimita craneodorsalmente la inserción del músculo. Por detrás del processus, se observa un fino reborde que delimita dorsalmente la inserción. Su límite ventral está muy poco marcado, evidenciado solo por unas pequeñas crestas que separan a ambos $\mathrm{m}$. pseudotemporalis. En Patagornis marshi BMNH-A516 se observa sobre la cara medial del processus coronoideus una pequeña fosa muy somera que correspondería a la 
inserción de este músculo; en el resto de los Patagornithinae y en los Phorusrhacinae esta condición no se observa.

\section{B) M. Adductor mandibulae externus}

Este grupo de músculos se dispone lateralmente al nervio $\mathrm{V}_{2}$, constituyendo el grupo más externo de los músculos mandibulares. Se origina en la fossa temporalis (= dorsotemporal fossa de Holliday y Witmer, 2007; superficie lateral de los ossa parietalis y ossa squamosi), sobre una porción de los ossa laterosphenoidalis, sobre los processus orbitalis (ossa frontalis) y zygomaticus (ossa squamosi) y en parte del processus oticus del os quadrati. Se inserta en la superficie dorsolateral del processus coronoideus, en la superficie dorsolateral y lateral de la mandíbula y en algunos casos (e.g., Anseriformes) sobre el processus mandibularis lateralis (Figura 7.4).

Este grupo se subdivide en tres músculos principales: $m$. adductor mandibulae externus profundus, medialis y superficialis de acuerdo a la posición que ocupan en la compartimiento aductor ("adductor chamber" de Holliday y Witmer, 2007) de los Archosauria. En las Neornithes, el m. adductor mandibulae externus profundus corresponde a la porción más profunda del grupo y con el mayor origen, ocupando gran parte de la fossa temporalis; se inserta sobre la superficie dorsolateral del processus coronoideus de la mandíbula. El m. adductor mandibulae externus medialis es indistinguible anatómica y topológicamente del $m$. adductor mandibulae externus profundus y superficialis en las Neornithes (Holliday y Witmer, 2007; Holliday, 2009). El $\boldsymbol{m}$. adductor mandibulae externus superficialis en la mayoría de las Neognathae se origina en la fossa subtemporalis (ossa squamosi), aunque puede originarse también en una pequeña porción del processus oticus del os quadratum. Este último músculo presenta la mayor área de inserción, fundamentalmente sobre el aspecto laterocaudal de la mandíbula, cranealmente a la articulación mandibular, caudalmente al $\mathrm{m}$. adductor mandibulae externus profundus y dorsalmente al $m$. pterygoideus ventralis.

En los fororracos, el m. adductor mandibulae externus profundus se origina sobre toda la fossa temporalis (Figura 7.5 y 7.6), la cual es triangular (como ocurre en Procellariiformes, Charadriiformes Lariidae y Sphenisciformes, entre otros), limitada cranealmente por el processus postorbitalis; craneomedialmente por la crista temporalis y caudalmente por la crista nuchalis transversa (véase capítulo 4). Una cresta débil dirigida craneoventralmente hacia el processus zygomaticus (más marcada en Procariama simplex MACN Pv 8225) delimita ventralmente el origen de este músculo. 
Este processus forma un reborde en Psilopterus lemoinei, Andalgalornis steulleti y Patagornis marshi (en que se encuentra muy desarrollado), pero está ausente en Psilopterus bachmanni y Taxón nuevo A MMP 5050. Este músculo también se origina en una fosa medial continua a la fossa temporalis, ubicada cranealmente a la región ótica y caudalmente al area muscularis aspera. La inserción sobre el processus coronoideus se encuentra poco marcada. Tanto en Phorusrhacos MPM-PV4241 como en Andrewsornis FM-P13417, se encuentra fundamentalmente localizada sobre el processus coronoideus cónico, donde se observa una superficie rugosa (limitada caudalmente por una cresta subvertical en Phorusrhacos MPM-PV4241). En los cráneos morfotipo I, la inserción se encuentra levemente más extendida caudalmente debido a la forma alargada del processus coronoideus.

La situación con respecto al $m$. adductor mandibulae externus medialis parece ser en los fororracos similar a las restantes Neornithes.

El $m$. adductor mandibulae externus superficialis se origina en la totalidad de la amplia fossa subtemporalis, cranealmente al processus suprameaticus y la crista nuchalis transversalis y ventralmente al processus zygomaticus (Figura 7.5), condición apreciable en cualquiera de los cráneos de fororracos disponibles. En general, esta fossa puede ser plana (e.g., Psilopterus lemoinei AMNH 9257) o levemente cóncava (e.g., Procariama simplex MACN Pv 8225 y Taxón nuevo A MMP 5050). Solamente en Andalgalornis FM-P14357 se puede confirmar que este músculo se habría originado también sobre el os quadratum: lateralmente sobre la cotyla squamosi, se observa un pequeño reborde curvo que se dirige caudoventralmente hacia el punto donde contactan lateralmente el corpus ossa quadrati con el processus suprameaticus. El área dorsal a este reborde presenta numerosas rugosidades correspondientes a la zona de origen de este músculo. El m. adductor mandibulae externus superficialis se inserta sobre la superficie caudolateral de la mandíbula, craneodorsalmente al $m$. pterygoideus ventralis y ventralmente al $m$. adductor mandibulae externus profundus (Figura 7.5). El área de inserción está representada por una fosa muy somera (en Andalgalornis FM-P14357 no hay fosa, sino una superficie convexa) y poco marcada (marcada en Taxón nuevo A MMP 5050) de contorno irregular que se extiende dorsalmente a la fenestra mandibularis, casi hasta el extremo distal de la misma en Patagornis BMNH-A516 y solamente hasta la mitad en Andalgalornis FM-P14357. En Patagornis BMNH-A516 y Taxón nuevo A MMP 5050 este músculo pareciera extenderse también por debajo de la fenestra mandibularis. 
De esta forma, la reconstrucción de este grupo muscular en los fororracos indica que es de gran desarrollo y volumen, ampliamente extendido cranealmente. Esta situación es compartida con aves carnívoras como Procellariiformes, Accipitriformes y Cariamiformes.

\section{C) M. Adductor mandibulae posterior}

El m. adductor mandibulae posterior en las Neornithes se origina en la superficie caudolateral del processus orbitalis y sobre una porción del corpus del os quadratum, caudalmente al origen del $m$. pseudotemporalis profundus y se inserta en la superficie caudodorsomedial y caudodorsal de la mandíbula, por delante de la zona de articulación mandibular (Figura 7.4).

Solamente en unos pocos materiales de fororracos se observa una cresta de dirección ventrocraneal que separa el origen de este músculo del m. pseudotemporalis profundus (con el que limita cranealmente): dorsocranealmente a esta cresta se encuentra el $m$. pseudotemporalis profundus y ventrocaudalmente el $m$. adductor mandibulae posterior (Figura 7.5). Caudolateralmente al processus orbitalis, sobre el corpus ossa quadrati, existe una pequeña fosa (ausente en Procariama simplex) donde también se origina este músculo. El límite caudal del $m$. adductor mandibulae posterior lo constituye el margen lateral del corpus ossa quadrati, mientras que el límite ventral no se encuentra marcado. Con respecto a la inserción, por delante de la fossa articularis quadratica se observa una pequeña fosa medial triangular y, lateralmente por delante del processus lateralis mandibulae, hay una pequeña cresta inclinada craneodorsalmente, de superficie muy rugosa, ubicada sobre la superficie lateral de la mandíbula (condición muy similar a Procellariiformes). De esta forma queda delimitada la inserción de este músculo, ubicado dorsalmente al $\mathrm{m}$. adductor mandibulae externus superficialis y caudalmente al $m$. adductor mandibulae externus profundus (Figura $7.5 \mathrm{y}$ 7.6)

\section{D) M. Constrictor internus dorsalis}

Este grupo muscular en las Neornithes consiste en solo dos músculos: el $m$. tensor periorbitae y el $m$. protractor pterygoideus et quadrati. Mientras que el primero se encuentra fundamentalmente relacionado con el aislamiento del ojo de los movimientos de la musculatura mandibular (Elzanoswki, 1987; Holliday, 2006), el segundo conecta el neurocráneo con el paladar y su contracción contribuye a la quinesis 
craneana. Debido a que el $m$. tensor periorbitae no interviene en la adducción mandibular, no es reconstruido en esta tesis. El m. protractor pterygoideus et quadrati (Figura 7.4) se origina en el septum interorbitale y en la superficie ventrolateral de los ossa laterosphenoidale ventralmente o ventromedialmente al foramen maxillomandibularis, en una fosa somera ubicada dorsalmente a las alae parasphenoidalis. Típicamente presenta dos vientres, insertos en dos huesos: se inserta en la superficie dorsomedial de los ossa pterygoidei (generalmente en una fosa ubicada en la superficie caudodorsal del hueso, por delante de la articulación con el os quadratum) y en una fosa ubicada en la superficie medial del processus orbitalis del os quadratum. La contracción de este músculo produce la rotación craneal del os quadratum, empujando los ossa pterygoidei, ossa palatinum y los arci jugalis hacia adelante, que mediante zonas de flexión craneales (zona flexoria palatina, zona flexoria arcus jugalis y zona flexoria craneofascialis), permiten los movimientos proquinéticos (Beecher, 1962; Bock, 1964; Zusi, 1993) (véase capítulo 8).

Solamente en los materiales Psilopterus lemoinei AMNH 9257, Patagornis marshi MLP 20-122 y Taxón nuevo A MMP 5050 puede observarse el origen de este músculo: en un área ovalada, muy bien delimitada por rebordes sobre el septum interorbitale, ventrocranealmente al foramen maxillomandibularis, ventralmente al foramen nervus optici y dorsalmente al processus basipterygoideus, y en una pequeña muesca que se continúa con aquella ubicada sobre el septum, craneodorsomedialmente al reborde o labio que cubre la fenestra cochelaris (formado por el ala parasphenoidalis, véase capítulo 4). La inserción resulta más compleja de reconstruir. Los ossa pterygoidei de Andalgalornis FM-P14357 son muy fragmentarios y en Psilopterus lemoinei AMNH 9257 no hay una fosa o marca alguna que delimite claramente la inserción sobre este hueso. Sin embargo, en el Taxón nuevo A MMP 5050 se observa por detrás del proceso de la facies articularis basipterygoidea, una pequeña fosa que indica que el músculo sobre este hueso se inserta por detrás de este proceso. Es también evidente que este músculo se origina dorsalmente a la cresta medial que delimita el $m$. pterygoideus ventralis, donde se encuentra una fosa (continua con la descripta previamente) que alcanza el nivel de los procesos de la facies articularis basipterygoidea ventralmente. Cranealmente, por encima de esta cresta ventromedial se observa una pequeña fosa alargada. Se descarta la posibilidad que esta fosa corresponda a la inserción en tanto en las Neornithes este músculo se inserta en una fosa ubicada en la porción caudal del os pterygoidei (Holliday, 2006). La inserción de este músculo 
sobre el os quadratum no ofrece tanta controversia: se inserta en una fosa ubicada en la cara medial del processus orbitalis, cranealmente a los forámenes pneumáticos mediales ubicados sobre el corpus ossa quadrati (véase capítulo 4). Esta fosa en Andalgalornis FM-P14357 y Psilopterus lemoinei YPM-PU15402 está pobremente limitada. En el Taxón nuevo A MMP 5050 se observa, además, una cresta medial subhorizontal que delimita ventralmente la inserción de este músculo.

\section{E) M. Abductores}

Incluye al m. depressor mandibulae encargado de la abertura de las quijadas. Este músculo actúa de forma conjunta con el $m$. protractor pterygoidei et quadrati en la abertura bucal: mientras el $m$ depressor mandibulae deprime la mandíbula, el $m$. protractor pteryigoidei et quadrati eleva las maxilas (Bock, 1964; Zusi, 1959; 1967). De hecho, el movimiento de acomodación mandibular ocurrido durante la contracción del $m$. depressor mandibulae puede producir una mayor elevación de las maxilas durante la contracción del músculo protractor (Bock, 1964). Se origina en la superficie caudodorsal del neurocráneo, en la fossa subtemporalis caudalmente al processus suprameaticus, sobre el processus paraoccipitalis, la membrana postmeatica y el ligamentum occipitomandibulare. Se inserta en la fossa caudalis y sobre el processus retroarticularis (cuando está presente) medialmente (Bock, 1964; Vanden Berge y Zweers, 1993) (Figura 7.4).

En los fororracos, el área de origen es relativamente angosta (Figura 7.5). Caudalmente al processus suprameaticus y en continuación con la crista nuchalis transversa, se observa una superficie rugosa, elevada, que se continúa ventralmente con el processus paraoccipitalis. Dicha superficie es angosta y de contorno subtriangular, de gran extensión dorsal sobre la crista nuchalis transversa. Craneoventralmente se extiende hasta el processus suprameaticus a través de una cresta (ausente el Procariama MACN Pv 8225). La superficie de los processi paraoccipitalis es ancha y presenta una superficie delimitada craneocaudalmente por unos rebordes, constituyendo la superficie de origen del músculo sobre los processi. El origen de este músculo se continúa ventralmente hasta el nivel donde los processi paraoccipitalis se conectan con las fossae parabasali. Este músculo se inserta sobre la fossa caudalis, que en general es profunda y de contorno triangular. También se inserta sobre la cara caudal del processus medialis mandibulae y sobre la superficie medial del processus retroarticularis, ambos en continuación a la fossa caudalis. El límite dorsal del origen lo marca un reborde 
caudal romo formado por la crista transversa fossae. Dorsolateralmente sobre la cara medial del processus retroarticularis, un reborde delimita lateralmente la inserción del músculo.

\subsubsection{Músculos del complejo apendicular posterior}

La locomoción animal es un fenómeno complejo y su estudio involucra la integración de información morfológica (osteológica y miológica) y de las consecuencias ecológicas y evolutivas de esa morfología apendicular (Bennet, 1989). La mayoría de los estudios acerca de la locomoción en aves se han concentrado fundamentalmente en el vuelo, aunque para algunas aves (e.g., Struthioniformes, Tinamiformes, Galliformes, Cariamiformes), la locomoción terrestre representa la principal forma de desplazarse (Picasso, 2010a), sino la única (véase capítulo 2). El conocimiento de la musculatura apendicular posterior brinda una fuente fundamental de información acerca de cómo se mueve el miembro y de cómo un ave lo utiliza durante la locomoción. El análisis de su miología representa un paso fundamental a fin de entender la relación de un ave con el sustrato, así como la contribución de cada músculo al movimiento total, la contribución diferencial de extensión vs. flexión de las diferentes partes que lo constituyen (Picasso, 2010a) y la diferenciación de aves caminadoras, saltadoras y cursoras. Es por esto que su reconstrucción constituye un paso fundamental en la formulación de hipótesis acerca de la locomoción en aves extintas como los fororracos.

La miología apendicular de las aves en general ha sido descripta y detallada en los trabajos comparativos de Hudson (1937), George y Berger (1966), Raikow (1985) y Vanden Berge y Zweers (1993), entre otros. En referencia a la musculatura apendicular de algunas especies, familias u órdenes de aves en particular, se pueden citar aquellos realizados en Falconiformes (Hudson, 1948), Cuculidae (Berger, 1952), Apterygidae (McGowan, 1979), Passeriformes (Gaunt, 1969; Raikow, 1978, 1987; McKitrick, 1985; Verstappen et al., 1998), Charadriiformes (Barbosa y Moreno, 1999), Fulica americana (Rosser et al., 1982) y Rhea americana (Picasso, 2010a, b).

Cabe mencionar que la información disponible acerca de la miología apendicular posterior de las aves ha sido utilizada para reconstruir la de dinosaurios terópodos (e.g., Carrano y Hutchinson, 2002; Hutchinson et al., 2005) y saurópodos (e.g., Otero y Vizcaíno, 2008; Otero, 2011; Gallina, 2011). Sin embargo, las reconstrucciones de la musculatura apendicular posterior en Neornithes fósiles son escasas (e.g., Noriega, 
2001; Murray y Vickers-Rich, 2004). Una explicación posible a este hiato en el conocimiento es debida a que la gran mayoría de los músculos no presentan un correlato óseo distintivo. Asimismo, un gran número de músculos se inserta en otras estructuras blandas (músculos, aponeurosis, tendones), dificultando aún más cualquier inferencia acerca de la presencia/ausencia, trayectoria y participación de un músculo determinado. La observación directa del material osteológico actual y fósil aquí estudiado (capítulo 3), así como las disecciones realizadas, corroboran esta conclusión.

Un impedimento importante en la reconstrucción muscular apendicular llevada a cabo en esta tesis ha sido la imposibilidad de contar con especímenes de chuñas (Cariamidae). Por esta razón se debieron seleccionar otros taxones que, sin ser los ideales, resultasen igualmente apropiados. Muy recientemente, Picasso (2010a, b) realizó un trabajo muy detallado, basado en gran cantidad de material, analizando la miología de Rhea americana. De esta manera, sus resultados conforman una base sólida sobre la cual realizar reconstrucciones, utilizando un criterio topológico en ausencia de cicatrices óseas bien marcadas, por dos razones: (1) como ya fue mencionado reiteradamente se trata de un ave cursora y (2) tal como señala McGowan (1979), no existen diferencias sustanciales entre la anatomía muscular de Palaeognathae y Neognathae. Asimismo, se complementó esta información con datos miológicos obtenidos en otras aves.

Sin embargo, la morfología pélvica tan peculiar de los fororracos (capítulo 4) induce la consulta de un mayor número de fuentes de información. De esta manera, se utilizó la información brindada por Berger (1952) referida a la miología de tres especies de Cuculiformes. Como fuese expresado en el capítulo 5 de esta tesis, los representantes de este orden están cercanamente emparentados con los fororracos. Asimismo, se realizaron disecciones en otras aves en búsqueda de información complementaria (e.g., Tinamidae, Tytonidae).

Ante este panorama (ausencia de cicatrices bien definidas así como la morfología tan peculiar de la pelvis), se escogió prestar especial énfasis a la reconstrucción de los principales músculos encargados de la flexión y extensión de las distintas porciones del miembro. Para ello se siguió el criterio de Raikow (1985), Barbosa y Moreno (1999) y Picasso (2010a, b). La profundización en la reconstrucción de la musculatura apendicular utilizando especies más apropiadas para lograr tal fin (como serían los Cariamidae) queda pendiente para estudios futuros (véase Perspectivas). 
Se presentan aquí los correlatos óseos y los músculos inferidos del miembro posterior de los fororracos Patagornis marshi, Psilopterus lemoinei, Mesembriornis milneedwardsi y Taxón nuevo A de los cuales se dispone de complejos apendiculares posteriores completos. El miembro posterior consta de aproximadamente 36 músculos (George y Berger, 1966), de los cuales solo 19 han podido ser reconstruidos. Para su descripción se los ha agrupado de acuerdo a su función y localización superficialprofundo (Figuras 7.7, 7.8 y 7.9) en los distintos segmentos del complejo apendicular posterior. Los niveles de inferencias asignados para los músculos apendiculares se reúnen en la tabla 7.2 .

\section{A) Músculos extensores de la cadera (articulación pelvis-fémur)}

El m. iliotibialis lateralis es el músculo más superficial del muslo. Presenta un gran desarrollo, es delgado y amplio. Su forma general es triangular y cubre gran parte del resto de la musculatura apendicular. Se origina a lo largo de la crista iliaca del ala preacetabularis et postacetabularis, pudiendo en algunos casos reconocerse hasta tres pars (i.e., preacetabularis, acetabularis y postacetabularis). Este músculo se inserta a través de una aponeurosis a nivel de la articulación fémur-tibiotarso y en el ligamentum patellae (= tendón rotuliano). Este último se inserta en la crista patellaris del tibiotarso.

En los fororracos, este músculo se origina en la porción postacetabular del ilium, fundamentalmente en la porción dorsal de la concavitas infracristalis de la lamina infracristalis ilii y sobre el margen de la crista dorsolateralis ilii que la delimita dorsalmente. El origen se extiende caudalmente sobre la spina dorsolateralis ilii y se continúa ventro-cranealmente hacia el extremo caudal del foramen ilioischiadicum (Figura 7.7). Este origen se encuentra más extendido dorso-ventralmente en Patagornis. No se evidencian cicatrices que indiquen la presencia de un origen acetabular y preacetabular. Este músculo quedaría recubierto dorso-lateralmente por el proceso óseo ubicado en el margen caudal del foramen ilioischiadicum (Figura 4.18), muy desarrollado en Psilopterus. El límite ventral del origen de este músculo con el $m$. flexor cruris lateralis se encuentra muy poco marcado. La inserción ligamentosa se produce en la crista patellaris (Figuras 7.9) poco desarrollada (véase capítulo 4). Su inserción aponeurótica no ha podido ser reconstruida.

El m. flexor cruris lateralis es el músculo flexor del fémur más poderoso (Berger, 1952). Se origina fundamentalmente en la región caudodorsal de la pelvis, sobre la crista dorsolateralis ilii y, en algunos casos, en las primeras vértebras caudales. 
Comúnmente consta de dos pars (pelvica y accesoria) unidas entre sí a través de un rafe, variablemente visible de acuerdo a las especies. La inserción en la porción distal del fémur se localiza a través de la pars accesoria. Sin embargo, esta última puede estar ausente y entonces la inserción del músculo es directamente a través de la pars pelvica dando lugar a un tendón o una aponeurosis (George y Berger, 1966).

En los fororracos, este músculo tiene su origen en la concavitas infracristalis de la lamina infracristalis ilii de forma lentiforme (Figura 7.7), extendiéndose caudalmente sobre la spina dorsolateralis ilii, ventralmente al origen del $m$. iliotibialis lateralis. Se inserta lateralmente al $m$. puboischiofemoralis y medialmente al $m$. femorotibialis lateralis, aunque la cicatriz de inserción no se encuentra marcada. Se infiere que su ubicación es en el tercio más distal del fémur sobre el condylus lateralis (Figura 7.8), de manera similar a numerosas aves incluidos los Cuculiformes. Siguiendo los lineamientos del método de EPB, este músculo presentaría las dos pars (Tabla 7.2).

El m. flexor cruris medialis ocupa la porción caudomedial del muslo, ubicándose medialmente al $m$. flexor cruris lateralis y cubierto por el mismo. El $m$. flexor cruris medialis se origina principalmente en la superficie lateral o ventrolateral del ischium y en el pubis. Se inserta a través de un tendón en la porción proximal del tibiotarso, de forma independiente o junto al $m$. flexor cruris lateralis, pasando entremedio de la pars intermedia y medial del $m$. gastrocnemius.

En los fororracos, este es el músculo que presenta el origen menos preciso en comparación con todos los músculos pélvicos. Aparentemente, presenta forma alargada, ubicado ventro-caudalmente al foramen ilioischiadicum, extendiéndose ventralmente al origen del $m$. ischiofemoralis, separado de éste por un pequeño reborde y ubicado dorsalmente al origen del m. puboischiofemoralis (Figura 7.7). Su inserción es muy conspicua. Se inserta en la superficie medial del tibiotarso en una cicatriz alargada, proximal al caput tibiae (Figura 7.9).

El m. ischiofemoralis es el más profundo de los músculos de la cadera. De forma triangular, se origina profundamente en la superficie lateral del ischium postacetabular y se inserta en la porción caudal de la crista trochanterica del fémur.

En los fororracos, este músculo tendría gran desarrollo. Se origina ventralmente a la synchondrosis ilioischiadica, en una superficie muy amplia ubicada caudalmente al foramen ilioischiadicum y extendida caudalmente hasta el margen caudal de la pelvis (una situación muy común entre las aves, George y Berger, 1966) y delimitada ventralmente por un pequeño reborde que lo separa del origen del $m$. flexor cruris 
medialis (Figura 7.7). Este músculo también estaría confinado dorsalmente por el proceso que delimita al $m$. iliotibialis lateralis. El $m$. ischiofemoralis se inserta en una pequeña cicatriz ovalada, ubicada caudalmente al trochanter femoris y proximalmente a las impressiones obturatoriae (Figura 7.8).

El m. puboischiofemoralis es el músculo más profundo del muslo. Se encuentra formado por dos porciones íntimamente relacionadas, la externa y la interna. Se origina en la superficie ubicada dorsalmente a la fenestra ischiopubica, sobre la membrana ischiopubica (que cubre a la fenestra ischiopubica) y en el pubis. Se inserta en la superficie caudal del fémur, proximalmente a la fossa poplitea, medialmente al $m$. femorotibials intermedius y lateralmente al $\mathrm{m}$. flexor cruris lateralis (pars accesoria).

En los fororracos este músculo se origina sobre una superficie pobremente marcada, ubicada ventralmente al origen del $m$. flexor cruris medialis, cubriendo la fenestra ischiopubica y sobre el margen dorsal del pubis (Figura 7.7). Se inserta en la superficie caudal del fémur en un área triangular ubicada proximalmente a la fossa poplitea y lateralmente a la linea intermuscularis caudalis (Figura 7.8). Sin embargo, la extensión proximal de la cicatriz no se encuentra marcada.

\section{B) Músculos flexores de la cadera (articulación pelvis-fémur)}

El m. iliotibialis cranialis es el principal músculo flexor de la cadera (Raikow, 1985) y es, en general, un músculo con forma de faja que une el extremo más anterior de la pelvis con la articulación fémur-tibiotarso. Si bien su origen es variable (George y Berger, 1966), típicamente se origina preacetabularmente en la crista iliaca dorsalis y se inserta en el extremo proximal del tibiotarso sobre la crista cnemialis cranialis y sobre el ligamentum patellae.

En los fororracos este músculo se origina en la porción más craneal del ala preacetabularis ilii, cranealmente al origen del $m$. iliotrochantericus cranialis. $\mathrm{Su}$ origen se continua dorsalmente sobre la crista iliaca dorsalis (Figura 7.7), por encima del origen del m. iliotrochantericus cranialis y del m. iliotrochantericus medialis como sucede en el Taxón nuevo A y Patagornis, mientras que en Psilopterus solo se extiende sobre el origen del $m$. iliotrochantericus cranialis. Caudalmente se extiende aproximadamente hasta la mitad de la crista iliaca dorsalis. Se inserta en la superficie proximal del tibiotarso (Figura 7.9) en una muesca ovalada muy profunda ubicada sobre la crista cnemialis cranialis. 
El m. iliotrochantericus caudalis se origina en la superficie lateral de la porción más caudal del ilium preacetabular y se inserta caudo-dorsalmente al trochanter femoris.

En los fororracos, este músculo se origina en un área preacetabular subtriangular, ubicada cranealmente a la crista supratrochanterica y cráneodorsalmente al acetabulum (Figura 7.7), limitando cranealmente con el origen del $m$. iliotibialis cranialis. Sin embargo, en Patagornis y el Taxón nuevo A, este músculo se encuentra menos extendido cranealmente que en Psilopterus lemoinei y limita cranealmente con el origen del $m$. iliotrochantericus medialis (cuyo origen es subrectangular). En P. lemoinei, el origen del m. iliotrochantericus caudalis se extiende cranealmente por encima del origen del $m$. iliotrochantericus medialis (cuyo origen es circular). El $m$. iliotrochantericus caudalis se inserta en una cicatriz ovalada (que forma parte de las impressiones iliotrochantericae), ubicada caudalmente al trochanter femoris y a la cicatriz de origen del $m$. iliotrochantericus medialis (ubicada cranealmente al trochanter femoris) y dorsalmente a la cicatriz de inserción del $m$. ischiofemoralis (Figura 7.8).

El m. iliotrochantericus cranialis se origina sobre el margen cráneolateral del ischium preacetabular, ventro-caudalmente al $m$. iliotibialis cranialis. Se inserta sobre la superficie cráneolateral del fémur, en la superficie más distal de la crista trochanterica.

En los fororracos este músculo se origina en la porción craneal del ala preacetabularis ilii (Figura 7.7), incluyendo la fossa iliaca dorsalis, caudo-ventralmente al origen del $m$. iliotibialis cranialis y cranealmente al origen del m. iliotrochantericus medialis. En Psilopterus lemoinei este músculo presenta un origen más extendido cráneo-caudalmente que en Taxón nuevo A y Patagornis. Su inserción ocupa parcialmente las impressiones iliotrochanterica, por delante de la inserción del $\mathrm{m}$. iliotrochantericus medialis sobre la superficie lateral de la crista trochanterica (Figura 7.8), aunque la cicatriz se encuentra poco marcada (véase capítulo 4).

\section{C) Músculos extensores de la articulación fémur-tibiotarso}

El $\boldsymbol{m}$. femorotibialis lateralis es el principal extensor de la articulación fémurtibiotarso (Raikow, 1985). Es un músculo de gran desarrollo y poco variable entre las aves (George y Berger, 1966), que se origina en la superficie craneal y lateral del fémur, cubierto lateralmente por los $m$. iliotibialis cranialis y $m$. iliotibialis lateralis. Está formado por tres porciones: pars lateralis, intermedia y medialis. La inserción es en el ligamentum patellae contribuyendo a su formación (George y Berger, 1966). 
El m. femorotibialis intermedius está fuertemente relacionado con el $m$. femorotibialis lateralis. Se origina sobre la superficie craneal del fémur, medialmente al m. femorotibialis lateralis, distalmente a la crista trochanterica, y se inserta sobre la superficie proximal del lig. patellae.

El m. femorotibialis medialis se origina en la superficie medial de la mayor parte de la diáfisis del fémur y se inserta en la superficie medial de la crista cnemialis cranialis del tibiotarso.

Debido a la ausencia de cicatrices fuertes, no se ha podido identificar en los fororracos el origen de cada uno de los músculos femorotibialis (Figura 7.8). Sin embargo, la línea intermuscularis cranialis representa el límite entre el origen del $m$. femorotibialis lateralis y el del $m$. femorotibialis intermedius + medialis. El límite caudolateral del origen del $m$. femorotibialis lateralis está representado por una cicatriz curva muy poco pronunciada que se extiende a lo largo de toda la diáfisis en la superficie lateral y que lo separaría, al menos distalmente, de la inserción del $m$. flexor cruris lateralis. Caudo-medialmente, los m. femorotibialis intermedius + medialis están limitados por la linea intermuscularis caudalis. El m. femorotibialis lateralis + intermedius se insertan en el ligamentum patellae (conformado también por el $\mathrm{m}$. iliotibialis lateralis). Este ligamento se inserta en la crista patellaris del tibiotarso (Figura 7.9). El $m$. femorotibialis medialis se inserta medialmente a la inserción del $m$. iliotibialis cranialis, sobre la cara medial del caput tibiae en una superficie ovalada pequeña, cranealmente a la inserción del $m$. fibularis longus (Figura 7.9).

\section{D) Músculos flexores de la articulación fémur-tibiotarso}

El $\boldsymbol{m}$. iliofibularis es un músculo triangular, cubierto por el $m$. iliotibialis lateralis. En la mayoría de las aves, se origina en la superficie postacetabular del ilium. Se inserta mediante un tendón en el tuberculum $m$. iliofibularis de la fíbula, luego de atravesar el puente tendinoso que conforma el ansa m. iliofibularis.

En los fororracos, el origen del $m$. iliofibularis se ubica cranealmente al origen del $m$. iliotibialis lateralis y dorso-caudalmente al foramen ilioischiadicum y sobre el proceso ubicado caudalmente a dicho foramen (Figura 7.7). Cranealmente, se origina por detrás del antitrochanter en una fosa somera. Dorsalmente se expande ampliamente sobre la plataforma dorsal ilíaca. Se inserta en el tuberculum m. iliofibularis de la fíbula (Figura 7.9). Dicho tuberculum es ovalado, muy marcado y saliente (véase capítulo 4). 


\section{E) Músculos extensores de la articulación tibiotarso-tarsometatarso}

El m. fibularis longus se origina en el extremo proximal del tibiotarso sobre el lig. patellae y su correspondiente fascia, extendiéndose sobre toda la superficie cráneomedial de la diáfisis del tibiotarso. Luego se continúa a través de un largo tendón que recorre la mitad distal del tibiotarso. El tendón de este músculo se bifurca tras cruzar la articulación tibiotarso-tarsometatarso, dando lugar a una doble inserción. Por un lado, se inserta inmediatamente proximal al condylus lateralis del tibiotarso sobre el cartilago tibialis (una estructura fibrocartilaginosa ubicada en la porción caudal de la trochlea cartilaginis tibialis del tibiotarso). El otro punto de inserción es sobre la superficie lateral del tarsometatarso, uniéndose al $m$. flexor perforatus digiti III distalmente al hypotarsus (George y Berger, 1966), el cual se inserta en las primeras dos falanges del dedo III.

En los fororracos, este músculo se origina sobre la superficie craneal de la crista cnemialis cranialis (Figura 7.9) y se extiende distalmente sobre la facies cranialis, lateralmente a la linea extensoria. El origen sobre la facies cranialis no se encuentra bien marcado, aunque se extendería aproximadamente hasta la mitad de la longitud del tibiotarso. Debido a que este músculo se inserta sobre otras estructuras blandas, las inserciones no han podido ser delimitadas con precisión en los fororracos.

El m. gastrocnemius es un músculo muy desarrollado en las Neornithes. Es el musculo más superficial de la parte caudal de la pata, formado típicamente por tres cabezas de origen (aunque puede tener dos o cuatro): pars lateralis, pars intermedia y pars medialis. El m. gastrocnemius se originan en el tibiotarso y en el fémur. En general estas porciones suelen forman un tendón común (=tendo achillis) que se inserta en la zona de articulación intertarsiana y fundamentalmente en el hypotarsus, aunque esta inserción se continúa sobre las cristae plantaris lateralis et medialis del tarsometatarso a través de aponeurosis. También influye en la flexión plantar de los dedos mediante inserciones aponeuróticas. En general, la pars lateralis se origina sobre el condylus lateralis del fémur a través de un corto tendón, aunque también se origina en una aponeurosis a la superficie lateral de la zona de dicho condylus. La pars intermedia se origina caudalmente en la superficie lateral del condylus medialis, en la superficie medial de la fossa poplitea. Esta pars se inserta a la pars medialis y se continúa en un tendón común de inserción. La pars medialis se origina sobre la superficie medial del tibiotarso en la facies gastrocnemialis y sobre la mayor parte de la superficie 
caudomedial del tibiotarso, para luego unirse a la pars lateralis o insertarse en la zona de articulación intratarsal a través de un tendón independiente.

En los fororracos la pars lateralis tiene un doble origen: la inserción más pequeña se ubica en la superficie caudal del fémur, dorso-lateralmente a la fossa poplitea, cranealmente a la impressio ligamentum cruciati caudalis; la inserción de mayor tamaño es bastante amplia y se ubica proximalmente al condylus lateralis y cráneo-proximalmente a la mayor de las impressio ansae m. iliofibularis y se encuentra delimitada proximalmente por una pequeña cicatriz que la separa del origen del $m$. femorotibialis lateralis (Figura 7.8). La pars intermedia se origina en una cicatriz ovalada ubicada próximo-medialmente sobre la fossa poplitea, lateralmente a la crista supracondylaris medialis y distalmente a la inserción del $m$. puboischiofemoralis (Figura 7.8). La pars medialis se origina en la facies gastrocnemialis del tibiotarso (Figura 7.9), la cual es muy amplia y profunda y se ubica en la superficie medial de la crista cnemialis cranialis. Con respecto a la inserción de este músculo, solo se observa la de la superficie caudal del hypotarsus (Figura 7.9). En las cristae plantaris se encuentran cicatrices que corren todo a lo largo de estas cristae aunque no puede establecerse que estas marcas pertenezcan a las inserciones aponeuróticas de este músculo.

\section{F) Músculos flexores de la articulación tibiotarso-tarsometatarso}

El m. tibialis cranialis es el músculo más desarrollado de la superficie craneal del tibiotarso en Neornithes. Este músculo presenta dos cabezas de origen. Se origina en la superficie cráneodistal del condylus lateralis (en la fovea tendineus m. tibialis cranialis) del fémur y en el extremo proximal del sulcus intercnemialis del tibiotarso y se inserta en las tuberositas $m$. tibialis cranialis del tarsometatarso.

En los fororracos este músculo se origina en la fovea tendineus m. tibialis cranialis del fémur (Figura 7.8), la cual se encuentra bien marcada, así como en la superficie proximal y lateral del tibiotarso (Figura 7.9) y en la expansión lateral de la crista cnemialis lateralis (véase capítulo 4). El músculo se inserta en la porción distal de la fossa infracotylaris dorsalis, en las tuberositas $m$. tibialis cranialis que forman dos estructuras ovaladas muy marcadas (Figura 7.9).

\section{G) Músculos de los dedos}


Fue posible reconocer las cualidades de solo cuatro de los músculos individuales de los dedos. Debido a su complejidad y a la ausencia de cicatrices evidentes de origen e inserción muscular, no fue posible reconstruir en detalle los restantes músculos.

\section{G.1) Músculos extensores de los dedos}

El m. extensor digitorum longus es el músculo más profundo de la superficie craneal de la pata. Este músculo se encuentra cubierto por el $m$. tibialis cranialis cuyo recorrido es conjunto y se origina en el sulcus intercnemialis del tibiotarso. Se inserta a través de un tendón que distalmente entra en el sulcus extensorius y pasa por debajo del pons supratendineus; luego se extiende por el sulcus extensorius del tarsometatarso. Al cruzar la articulación tarsometatarso-falanges, este tendón se divide en tres ramas insertándose primariamente en el tuberculum extensorium de las falanges ungueales de los dedos II, III y IV (raramente también al I), aunque presenta inserciones accesorias a cada una de las cápsulas articulares interfalangeales de dichos dedos.

En los fororracos, este músculo se origina en el sulcus intercnemialis (Figura 7.9). Si bien la cicatriz de origen no se encuentra bien marcada, se extendería solo apenas más distalmente que la crista cnemialis cranialis, donde quedaría limitada medialmente por el origen del $m$. fibularis longus. Su inserción es sobre el tuberculum extensorium de las falanges ungueales al menos en los dedos II, III y IV.

El m. extensor hallucis longus es un músculo que se origina en el extremo proximal del tarsometatarso sobre su superficie cráneomedial. Se inserta en el tuberculum extensorium de la falange ungueal del dedo I.

En los fororracos, este músculo se origina en un surco ubicado en la superficie medial del tarsometatarso (Figura 7.9), distalmente a la cotyla medialis, medialmente al alero medial a la fossa infracotylaris dorsalis presente en Psilopterus y Mesembriornis (véase capítulo 4). Se inserta en el tuberculum extensorium de la falange ungueal del dedo I.

\section{G.2) Músculos flexores de los dedos}

Se trata de varios músculos subyacentes al $m$. gastrocnemius. Sus puntos de origen están ubicados sobre la fíbula, la porción proximal del tibiotarso y en la fossa poplitea sobre los cuales no dejan marcas, e incluso sobre vientres y tendones de otros músculos. Estos rasgos sumados a su íntima asociación dificultan su identificación y, por ende, su reconstrucción a partir del material óseo únicamente. En las aves estos músculos son el $\boldsymbol{m}$. flexor perforans et perforatus digiti II, m. flexor perforans et perforatus digiti III, m. flexor perforatus digiti II, m. flexor perforatus digiti III, $m$. 


\section{flexor perforatus digiti IV, $\boldsymbol{m}$. flexor digitorum longus y el $m$. flexor hallucis longus.}

En los fororracos solo el $m$. flexor hallucis longus y el $m$. flexor digitorum longus pudieron ser reconstruidos.

El m. flexor digitorum longus es el músculo más profundo de la superficie caudal del tibiotarso. Se origina en la fossa flexoria y en gran parte de la facies caudalis del tibiotarso, así como en la superficie caudomedial de la fíbula. Atraviesa el cartilago tibialis, corre por el sulcus flexorius (cuando existe) y se inserta en las falanges ungueales en el tuberculum flexorium y en su cápsula articular interfalangeal. Sin embargo, el patrón de inserción es muy variable dentro de las Neornithes (George y Berger 1966, Raikow, 1985) y puede hacerlo también en las cápsulas articulares interfalangeales de las restantes falanges.

En los fororracos este músculo se origina en la fossa flexoria muy marcada y profunda (Figura 7.9), aunque su extensión distal no puede establecerse con precisión en tanto no hay una cicatriz marcada. Se origina también en la porción distocaudomedial de la fíbula. Se inserta en el tuberculum flexorium de los dedos II, III y IV, aunque no pudo establecerse el patrón de ramificación e inserción en cada una de las cápsulas articulares interfalangeales (donde también se insertarían los demás músculos flexores de los dedos que no pudieron ser reconstruidos).

El m. flexor hallucis longus se ubica entre el $m$. flexor digitorum longus más profundo y los demás músculos flexores de los dígitos más superficiales. Se origina en la fossa poplitea y típicamente se inserta solo en la falange ungueal del dedo I, aunque puede insertarse también en todas las cápsulas articulares interfalangeales de dicho dedo (George y Berger, 1966).

En los fororracos no se ha podido establecer su origen. Sin embargo, se reconoce la presencia de este músculo ya que su inserción en el tuberculum flexorium de la falange ungueal del dedo I es evidente.

\subsection{Discusión y conclusiones}

En la presente sección se discuten los resultados de la reconstrucción de la musculatura del complejo apendicular posterior. En cambio, los aspectos relacionados con la musculatura mandibular serán discutidos en el capítulo 8 conjuntamente con el análisis de la biomecánica craneana.

La gran variabilidad de orígenes e inserciones de la musculatura apendicular posterior que se observa en las aves (George y Berger, 1966) dificulta la reconstrucción 
muscular de cualquier forma fósil. La información referida a la musculatura de los Cariamidae podría complementar y completar el esquema muscular al que se arribó en base a las diversas disecciones realizadas así como a la amplia consulta bibliográfica. En este sentido, los resultados son preliminares.

Los sitios de inserción (o “entesis” sensu Benjamin et al., 2006) son sitios de concentración del estrés, donde se fijan los tendones y ligamentos al hueso. Una mayor actividad muscular (y por lo tanto, mayor stress sobre el hueso) produce sitios de inserción más marcados (Benjamin et al., 2006). Con los recaudos que implica suponer el grado de desarrollo de un músculo en base a sus cicatrices, se puede establecer que la musculatura extensora del miembro posterior de los fororracos se encontraría muy bien desarrollada, en particular la extensora de la pelvis. No parece haber diferencias significativas en cuanto a los orígenes e inserciones entre los fororracos aquí estudiados, por lo cual se infiere que todos los fororracos comparten un patrón muscular apendicular similar.

El m. iliotibialis lateralis es un músculo extensor muy desarrollado en las Neornithes terrestres y en particular cursoras (Carr, 2008), tanto Palaeognathae (e.g., Rhea, Struthio, Dromaius) como Neognathae (e.g., Galliformes, "Gruiformes"), o en aves nadadoras (Gaviidae, Podicipedidae). Por el contrario, comúnmente está reducido en aves donde no predomina la locomoción terrestre (Ellerby et al., 2005). Cumple la función de extender la cadera (Gatesy, 1999b) y estabilizar la articulación fémurtibiotarso (Jacobson y Holliday, 1982). En los fororracos, si bien se encontraría restringido a la porción postacetabular del ilium, su origen se encuentra muy extendido, indicando un fuerte desarrollo relacionado con la estabilización de la articulación fémur-tibiotarso durante la locomoción terrestre.

El $m$. flexor cruris lateralis, el $m$. flexoris cruris medialis y el $m$. puboischiofemoralis son los músculos extensores de la cadera más importantes tanto en términos de masa como de sección (Verstappen et al., 1998). En el caso particular del m. flexor cruris lateralis y estudiando el Cuculidae Geococcyx, Berger (1952) resalta que el gran desarrollo de este músculo está relacionado con la adaptación al hábito cursorial. La pars accesoria de este músculo es muy importante en formas terrestres, cumpliendo una importante función en el soporte corporal (Raikow, 1985). Esta pars estaría presente en los fororracos, aunque su inferencia solo puede hacerse a través del EPB. Si bien no es posible determinar el desarrollo relativo de ambas pars (i.e., pelvica 
y accesoria), es evidente que este músculo estaba muy desarrollado y relacionado con el soporte de la masa del animal (véase capítulo 6).

En los fororracos, la extensión cráneolateral del m. flexor cruris lateralis, así como la retracción del $m$. iliotrochantericus caudalis (especialmente en los fororracos de mayor tamaño), son dos condiciones que comparten con Geococcyx y estarían asociadas a la capacidad cursora del ave. La contracción de ambos músculos evita el balanceo del cuerpo del animal durante la carrera (Berger, 1952).

Debido a que los movimientos del fémur son muy restringidos (Campbell y Marcus, 1992), la extensión fémur-tibiotarso y tibiotarso-tarsometatarso debe ser máxima en aves cursoras a fin de garantizar una amplia zancada. Los extensores distales de los miembros producen la rápida extensión fémur-tibiotarso y tibiotarsotarsometatarso, que resulta en un aumento de la zancada y la velocidad (Smith et al., 2006). El m. fibularis longus y el $m$. gastrocnemius (ambos extensores de la articulación tibiotarso-tarsometatarso) se encuentran muy desarrollados, carácter compartido con los Cuculidae de hábitos terrestres (Berger, 1952), pero no con los arborícolas. El desarrollo de las cristae cnemialis en los fororracos indicaría un amplio desarrollo de los extensores originados allí (e.g., m. gastrocnemius, m. extensor digitorum longus) y la longitud de los segmentos distales del miembro (véase capitulo 9) permite inferir la presencia de largos tendones de inserción de los músculos $m$. gastrocnemius y $m$. fibularis longus, optimizando el gasto energético durante la carrera (Alexander, 1991; Alexander, 1979; Biewener et al., 2004).

La musculatura flexora actúa principalmente durante la fase de balanceo y los músculos no están comprometidos en el soporte corporal. Por lo tanto presentan menor masa. El m. iliofibularis de Rhea es una excepción (Picasso, 2010a). Es un músculo que produce la flexión del fémur-tibiotarso, levantando el miembro y llevándolo hacia adelante (Gatesy y Biewener, 1991) y secundariamente funciona como extensor de la cadera (Gatesy, 1999a). En los fororracos, este músculo parece originarse sobre el proceso ubicado caudalmente al foramen ilioischiadicum. Este proceso produciría que la principal línea de acción pase por dicho proceso, aumentando el brazo de momento de entrada del músculo (distancia perpendicular entre el fulcro y la dirección de la fuerza muscular, véase capítulo 8). Esta situación produce un aumento de la fuerza en detrimento de la velocidad. El amplio desarrollo de este músculo implica una gran participación en la extensión de la cadera y produciría además rápidos movimientos de flexión a fin de mantener la carrera. 
Con respecto a la flexión del tibiotarso-tarsometatarso, la inserción proximal del m. tibialis cranialis está relacionada con la mayor producción de velocidad a expensas de la fuerza durante la flexión de la articulación, una característica que ha sido atribuida a algunos Passeriformes de hábitos terrestres (Zeffer y Lindhe Norberg, 2003). En el caso de los fororracos, la inserción de este músculo es proximal (en la fossa infracotylaris dorsalis) y asumiendo que las proporciones de los miembros de Psilopterus y los Passeriformes terrestres son similares (véase capítulo 9), la relación fuerza/velocidad de este músculo es comparable entre estas formas.

El m. flexor digitorum longus es uno de los principales músculos encargados de la flexión de los dedos. Este músculo se origina en la fossa flexoria, muy desarrollada en los fororracos (incluso más que en las chuñas). Esta situación permite inferir una amplia sección del $m$. flexor digitorum longus que dotaría a los fororracos de una fuerza de prensión suficientemente fuerte como para asir a sus presas. En este sentido, suponemos para los fororracos un hábito de alimentación similar al de las chuñas, las cuales sujetan sus presas con los dedos contra el suelo mientras la trozan con el pico.

El $m$. flexor hallucis longus se encuentra ausente en aves donde el hallux es vestigial o ausente (George y Berger, 1966). Este músculo se encuentra presente en los fororracos, pero debido a la elevación del dedo I, tanto el músculo como el dedo no habrían sido funcionales ni durante la carrera ni durante la sujeción de presas (Jones, 2010).

La proporción masa corporal/masa muscular de los miembros posteriores brinda información acerca de la actividad que realiza la musculatura en la locomoción (Hartman, 1961). En Rhea americana por ejemplo, la alta proporción de musculatura apendicular posterior es indicativa de su amplio grado de desarrollo y la posible actividad del miembro en la locomoción (Picasso, 2010a). Lamentablemente, no se puede calcular con certeza el porcentaje de la masa de musculatura apendicular en los fororracos, así como no se puede establecer la proporción exacta de la masa de músculos extensores vs. flexores. El amplio desarrollo de la musculatura extensora ha sido interpretada como una adaptación a la cursorialidad y se ha registrado en formas cursoras, tanto de mamíferos (Equidae, Payne et al., 2005) como en aves como Struthio (Smith et al, 2006), Dromaius (Hutchinson, 2004) y Rhea (Picasso 2010b).

Los movimientos de extensión son los que ocurren en la fase de apoyo o contacto con el suelo (Gatesy, 1999a) la cual representa una fase crítica en la locomoción terrestre ya que se genera mayor stress muscular y óseo debido al soporte 
de la masa corporal y la aceleración del cuerpo (Gatesy, 1999b). Los grandes músculos extensores proximales son los principales encargados de controlar el trabajo producido por el miembro (Biewener et al., 2004), soportando la masa corporal y evitando el desbalance del cuerpo en la carrera producido por movimientos de rotación o inclinación de la misma (Berger, 1952). Algunos investigadores estiman la masa muscular de distintos animales moldeando músculos con material plástico, pero el método no resulta muy confiable de manera tal que no fue aplicado en esta tesis.

La producción de fuerza y velocidad de los movimientos apendiculares es el resultado no solo de las propiedades de los músculos, sino también de la forma en que se disponen. El alargamiento postacetabular de la pelvis de los fororracos produciría un mayor brazo de momento de entrada y en consecuencia un menor índice de velocidad. Esta situación indica que el sistema muscular extensor de los fororracos está mejor diseñado para producir fuerza en detrimento de la velocidad, de manera concordante con la resistencia que se debe generar frente a los golpes contra el sustrato durante la carrera.

En suma, la miología apendicular de los fororracos se corresponde con el patrón muscular de un ave cursora y permite asumir una gran capacidad cursorial. La propuesta de cursorialidad no es nueva (e.g., Tambussi y Noriega, 1996; Alvarenga y Höfling, 2003; Blanco y Jones, 2005; Chiappe y Bertelli, 2006), pero no había sido sustentada previamente en base al estudio de la musculatura apendicular. Alvarenga y Höfling (2003) afirman, analizando las proporciones de los miembros posteriores, que las especies de Psilopterus eran corredoras más lentas que Cariama. Sin embargo, queda demostrado que la utilización de las proporciones como indicadoras de hábitos locomotores es muy controvertida (véase capítulo 9). La morfología postacetabular de la pelvis y su correspondiente musculatura señala el hábito locomotor terrestre y resalta también la capacidad cursorial de estas aves. Los fororracos en general eran excelente cursoras. 


\title{
Capítulo 8. Caracterización del aparato trófico de los fororracos
}

\author{
mammals." \\ “...The phororhacids...were more likely to kill than to be killed by
}

G.G. Simpson

La capacidad de un organismo para llevar exitosamente a cabo diversas actividades como capturar su alimento implica una mayor posibilidad de supervivencia, reproducción y crecimiento (Waingwright, 1994). Adicionalmente, es necesario un entendimiento del contexto ecológico en el cual un organismo utiliza su capacidad máxima a fin de poder reconocer las razones que condujeron a la evolución de un rasgo en particular (Irschick y Losos, 1998), así como de su uso. Por lo tanto, se establece una relación crítica entre la morfología, rendimiento y el uso de un recurso trófico.

Obviamente, la mayor comprensión de la forma y funcionamiento del cráneo es de vital importancia.

El cráneo es una de las partes más complejas del esqueleto aunque la función y biomecánica del mismo se encuentra pobremente estudiada (Preuschoft y Witzel, 2004). Diversos estudios han resaltado la importancia de la información funcional y ecológica relevante que se encuentra disponible únicamente en la morfología esqueletaria (e.g., Bierregaard, 1978; Burton y Alford, 1994; Hertel, 1994, 1995; Schmidt, 1996). Sin embargo, es necesario analizar el sistema músculo-esqueletario en conjunto ya que la fuerza de un músculo, así como la palanca con la que actúa sobre una articulación, afectan a la velocidad y la fuerza del movimiento (Bock, 1974; Hildebrand y Goslow, 2001). Testear predicciones sobre la importancia funcional y ecológica de la anatomía en un marco biomecánico puede revelar relaciones causales entre la morfología y el comportamiento alimenticio (Wainwright, 1991; Lauder, 1991; Zeffer y Lindhe Norberg, 2003).

El cráneo de los vertebrados muestra una amplia diversidad en lo que respecta a forma y función. Esta diversidad se debe a las numerosas funciones con las que se encuentra relacionado, entre las que se destacan funciones de protección (del encéfalo, los órganos de los sentidos y de la porción más anterior del tracto digestivo y respiratorio), así como otras conductuales (construcción de nidos, acicalamiento, defensa, actividades sociales, etc.). Sin embargo, la alimentación es la función que evidencia mayor relación con la estructura del cráneo (Smith, 1993). El cráneo (y en 
particular el esplacnocráneo) es la principal estructura encargada de obtener, procesar e ingerir el alimento.

En las aves, el aparato trófico está constituido por la maxila (= "upper bill/jaw" sensu Zusi, 1993), el paladar, los arcos yugales y la mandíbula. En la mayoría de las Neornithes, se encuentra conectado con el neurocráneo por diartrosis del cuadrado y paladar y por zonas flexorias de la maxila (Zusi, 1993). Esto dota al cráneo de una manifiesta quinesis craneana que lo convierte en una herramienta de alta versatilidad (Zusi, 1967, 1993). Sin embargo, el cráneo de las aves no se encuentra diseñado para procesar el alimento (como en los mamíferos) sino más bien para atraparlo, manipularlo e ingerirlo in situ (Zweers et al., 1994) y su forma presenta una relación directa con el modo en que se atrapa y manipula la comida (Zusi, 1993; Zweers et al., 1994) así como con la naturaleza del ítem trófico.

En este capítulo se pretende caracterizar el funcionamiento del cráneo de los fororracos. Analizar la estructura y los mecanismos actuantes sobre y en el cráneo representa un avance en la inferencia del ítem trófico así como del comportamiento trófico y manipulación del alimento en estas aves. La estructura del cráneo de los fororracos fue descripta en el capítulo 4. En este capítulo se profundizan los rasgos anatómicos relacionados con la movilidad intracraneana.

\subsection{Análisis de la quinesis en los Phorusrhacidae}

El caso de los fororracos resulta de particular interés en el estudio de la quinesis de las Aves ya que representan una novedad evolutiva en el linaje de las Neornithes. Degrange et al. (2010), basándose fundamentalmente en estructuras anatómicas de Andalagalornis steulleti, postularon que todos los Phorusrhacidae eran aquinéticos, entendiéndose a la aquinesis como la ausencia de capacidad proquinética (i.e., mover la maxila, tanto dorsal como ventralmente). Esta idea es aceptada y desarrollada a lo largo de este capítulo.

\subsubsection{Quinesis aviana}

La quinesis craneana se define como la presencia de movimientos entre porciones craneanas en uniones intracraneanas (Versluys, 1910, 1912; Holliday y Witmer, 2008) y es considerada como un rasgo plesiomórfico de los tetrápodos (Iordansky, 1990). La acción de un complejo mecanismo compuesto por huesos, 
músculos y ligamentos es la responsable del alto grado de quinesis craneana que exhiben la casi la totalidad de las especies de aves Neornithes (Zusi, 1993).

La quinesis craneana de las aves ha sido motivo de profundos estudios (Fisher, 1955; Beecher, 1962; Bock, 1964; Zusi, 1967, 1993; Bühler, 1981; Bout y Zweers, 2001; Gussekloo et al., 2001; Meekangvan et al., 2006) e incluye varios tipos de movimientos intracraneanos (Figura 8.1):

Proquinesis: movimientos entre el neurocráneo y el esqueleto facial a partir de la unión naso-frontal (=zona flexoria craniofascialis). Se halla en la mayoría de las Neornithes (Bock, 1964).

Neuroquinesis: movimientos entre el neurocráneo y el paladar a nivel de la articulación basipterigoidea (Iordansky, 1990).

Estreptostilia: el os quadratum es móvil a nivel de su articulación con el neurocráneo (Stannius, 1856).

Rincoquinesis: movimientos intramaxilares, particularmente a partir de los ossa nasalis. Se halla típicamente en Charadriiformes (Bock, 1964; Zusi, 1993).

Anfiquinesis: se hallan dos zonas de flexión en el pico. Se encuentra en algunos Rallidae (Meekangvan et al., 2006).

Estreptognatismo: movimientos latero-mediales de la mandíbula, por ejemplo en los extintos Pelagornithidae (Zusi y Warheit, 1992) y en los Nyctibiidae (Yudin, 1961).

Tradicionalmente, cuando se habla de quinesis aviana se hace referencia en particular a la proquinesis, que incluye tanto movimientos de protracción como de retracción de la maxila. Sin embargo, es de destacar que la capacidad proquinética está fuertemente relacionada con la estreptostilia, ya que el os quadratum es el que inicia la quinesis (Zusi, 1967).

El complejo morfofuncional que actúa en la proquinesis consta de varios huesos o unidades funcionales unidas por uniones móviles o zonas flexorias (Beecher, 1962; Bock, 1964; Zusi, 1967, 1993; Bühler, 1981; Bout y Zweers, 2001, Gussekloo et al., 2001; Meekangvan et al., 2006). Estas unidades son fundamentalmente cuatro: (1) maxila, (2) barra yugal + barra pterigo-palatina, (3) cuadrado y (4) neurocráneo (= "braincase"). Debido a que las barras yugal y pterigo-palatina comparten una función idéntica (i.e., empujar hacia adelante la zona palatal cuando el cuadrado rota cranealmente), se las suele considerar como una única entidad funcional. Las zonas 
móviles que unen todas estas unidades incluyen la articulación sinovial ótica, la articulación cuadrado-pterigoides, la articulación cuadrado-arco yugal, la articulación sinovial basal (no siempre presente), la zona flexoria arcus jugalis, la zona flexoria palatina y la zona flexoria craniofascialis. Estas zonas flexorias son en general reconocibles como áreas de hueso muy delgado (Figura 8.2). Además, en las Neognathae existe la articulación pterigo-palatina.

Todas estas zonas de movimiento se accionan principalmente gracias a la contracción del $m$. protractor pterygoidei et quadrati (véase capítulo 7), cuyo origen se encuentra en el septum interorbitale y su inserción en la cara medial del os quadratum y dorsal del os pterygoideum (Vanden Berge y Zweers, 1993; Holliday, 2006). Funcionalmente, cuando este músculo se contrae, produce la rotación craneal del os quadratum (que rota a nivel de la articulación sinovial ótica), el cual empuja craneomedialmente la barra pterigo-palatina y cranealmente al arcus jugalis. Gracias a las zonae flexoriae craneales ventrales (palatina y arcus jugalis), la maxila puede flexionarse con respecto a los ossa palatinum y arcus jugale respectivamente. Esta flexión se da en el plano sagital y es típicamente dorsal (aunque puede haber flexión ventral) debido al empuje craneal de estos huesos y a la presencia de la zona flexoria craniofascialis, resultando en una elevación del pico que resulta en una mayor abertura bucal.

Se ha argumentado que en este complejo también pueden intervenir el $m$. depressor mandibulae (Zusi, 1967, 1993) que al deprimir la mandíbula empuja el cuadrado cranealmente para facilitar la acomodación de la articulación mandibular y el ligamentum postorbitale (Bock 1964) que acopla la depresión de la mandíbula y la protracción del pico (véase más adelante).

\subsubsection{Aquinesis en Phorusrhacidae}

\section{(A) Anatomía}

Holliday y Witmer (2008) proponen cuatro criterios necesarios para inferir la presencia/ausencia de la quinesis craneana en cualquier diápsido: (1) articulación sinovial ótica (cuadrado-escamosal), (2) articulación sinovial basal (basipterigoidea), (3) musculatura protractora y (4) uniones cinemáticas permisivas. De acuerdo al cumplimiento de uno o varios de estos criterios, los autores reconocen tres estados:

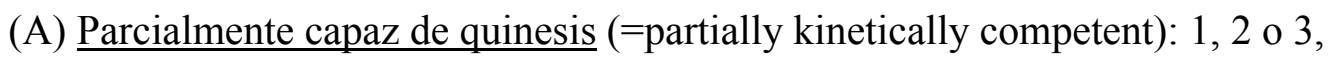
pero no 4 y no hay validación in vivo 
(B) Totalmente capaz de quinesis (=fully kinetically competent): 1-4 sin validación in vivo

(C) Quinético (=kinetic): 1-4 con validación in vivo

Los autores reconocen la existencia de un cuarto estado, "aquinético" (=akinetic), pero aclaran que el término es ambiguo ya que puede incluir a los estados A y B.

En el caso de las Aves, los criterios 1 y 3 siempre se cumplen, pero los criterios 2 y 4 no siempre.

(1) Articulación sinovial ótica: el os quadratum de las Neognathae se caracteriza por presentar dos cóndilos de articulación (con sus respectivas cápsulas sinoviales) con la región ótica.

En el caso de los fororracos hay también dos cóndilos. Estos cóndilos se ubican en un mismo plano horizontal (al igual que las cotylae de la región ótica con las que articulan), aunque el condylus lateralis se ubica cranealmente con respecto al medialis. Esta condición es más evidente en los Patagornithinae (Figura 4.15). La superficie lisa, suave y redondeada de ambos condyli permite inferir la presencia de una cápsula hialina amplia, con una zona fibrosa capsular angosta debido a la constricción de los condyli (Holliday y Witmer, 2008). Esto indica que la articulación con la región ótica en los fororracos es móvil (i.e., los fororracos retienen la estreptostilia).

(2) Articulación sinovial basal: si bien característica de las Palaeognathae, entre las Neognathae se la encuentra en algunos Galliformes, Anseriformes, Ciconiiformes Cathartidae, Procellariiformes, Strigiformes y Trogoniformes donde se desarrollan los processi basipterygoideus.

En el caso de los fororracos este tipo de articulación se encuentra muy desarrollada. Los processi basipterygoideus son ovalados, de superficie plana y pedunculados, craneoventrolateralmente dirigidos (Figura 4.4), contactando con un proceso similar ubicado sobre el cuerpo del os pterygoideus (véase capítulo 4). La unión entre ambos processi no parece ser muy firme, ya que no se trata de una articulación que incluye una superficie convexa del processus basipterygoideus articulando con una superficie cóncava ubicada sobre el os pterygoideus (como ocurre en las 
Palaeognathae), sino más bien de dos superficies planas contactando entre sí, con cápsulas sinoviales uniéndolas.

(3) Musculatura protractora: la musculatura protractora es clave en la quinesis craneal (Holliday, 2009) y, en el caso de las Neornithes, el $m$. protractor pterygoidei et quadrati es el principal encargado de iniciar los movimientos quinéticos (véase capítulo 7). En los fororracos este músculo se encuentra presente y bien desarrollado (Figura $7.5)$.

(4) Uniones cinemáticas permisivas: la naturaleza de las conexiones entre huesos del cráneo es sumamente importante al momento de estudiar el comportamiento mecánico del cráneo ya que permiten o evitan los movimientos intracraneanos (Holliday y Witmer, 2008) e influyen sobre la distribución del stress y deformación (Rayfield, 2005a; Moazen et al., 2009a).

Las zonae flexoriae representan áreas aplanadas y delgadas de hueso que sirven como puntos de rotación. La zona flexoria craneofascialis es dorsal y está representada por una zona delgada ubicada sobre los processi nasalis de los ossa premaxillaris y en los adyacentes processus premaxillaris de los ossa nasalis en continuidad con los ossa frontalis. Las zonas flexorias palatales o ventrales son la zona flexoria palatina y la zona flexoria arcus jugalis y representan zonas delgadas de unión palato-maxillar y yugo-maxillar (Zweers et al., 1997) (Figura 8.2).

En los fororracos pueden estar ausentes tres o solo dos de estas zonas (véase capítulo 4). La ausencia de zona flexoria palatina es el resultado de la fusión de ossa palatinum + ossa maxillaris + arcus jugalis + ?ossa premaxillaris y la de la zona flexoria arcus jugalis se produce por fusión de arcus jugalis + ossa palatinum + ossa maxillaris y produce la inmovilidad del paladar en los fororracos con cráneo morfotipo I (Figura 4.11). En el caso de los fororracos con cráneo morfotipo II se suma el engrosamiento de la pared ósea a la altura de la zona flexoria craniofacialis, produciendo la ausencia de la misma (Figura 4.12), indicando que estas aves carecen de la movilidad proquinética.

En el análisis quinético de las Neornithes, se adiciona a estos cuatro criterios la presencia/ausencia del ligamentum postorbitale. Si bien ausente en las Palaeognathae (Gussekloo y Bout, 2005a), este ligamento se halla en gran cantidad de taxones de 
Neognathae (Bock, 1964; Meekangvan et al., 2006) y ha sido ampliamente estudiado por Bock (1964) ya que tiene la función de acoplar el movimiento mandibular y maxilar durante la quinesis. Su ausencia permite los movimientos independientes de la mandíbula y de la maxila.

Este ligamento se origina en el processus postorbitalis de los ossa laterosphenoidalis y se inserta en el processus mandibularis lateralis de la mandíbula (Baumel y Raikow, 1993), donde actúa como un fulcro durante los movimientos mandibulares (Bock, 1964; Zusi, 1967; Meekangvan et al., 2006). Es un ligamento tenso y poco extensible que se ubica cerca de la zona de articulación mandibular (Bock, 1964; Meekangvan et al., 2006) a fin de cumplir su función acopladora (Figura 7.4). El mecanismo de acople es bastante sencillo: cuando la mandíbula se deprime por acción de $m$. depressor mandibulae, la tensión adquirida por el lig. postorbitale impone el límite máximo en la depresión. Sin embargo, a medida que el os quadratum rota cranealmente por accionar del $m$. protractor pterygoidei et quadrati, la articulación mandibular también se traslada en el mismo sentido y la distancia entre el processus postorbitalis y el processus mandibularis lateralis se reduce y por lo tanto el ligamento se distiende, permitiendo una mayor depresión mandibular. De esta forma, la mayor depresión mandibular solo es posible con la elevación de la maxila (producida por la rotación craneal del os quadratum) durante la quinesis (Bock, 1964; Zusi, 1967).

En los fororracos este ligamento estaba presente. Su origen se encuentra muy extendido laterocranealmente sobre una superficie rugosa ubicada sobre el processus postorbitalis, mientras que la inserción se produce en una pequeña muesca circular ubicada en la cara craneal del processus mandibularis lateralis (véase Figura 4.16).

\section{(B) Modelo mecánico del cráneo de los fororracos}

Alexander (1983) propuso un modelo biomecánico muy sencillo aplicable a cualquier estructura biológica a fin de poder expresar su grado de movimiento. Denominó a estos modelos mecanismos. Un mecanismo es un ensamblaje de partes conectadas en tal forma que el movimiento de una de las partes causa el movimiento definido y predecible de las demás. El grado de movilidad de un mecanismo se puede determinar a partir de la cantidad de partes y eslabones que lo conforman (Hunt, 1978). Si se considera un mecanismo de $n$ partes conectadas por $j_{l}$ articulaciones que permitan un grado de libertad, $\mathrm{y}_{2}$ articulaciones que permitan dos grados de libertad, su movilidad es $M$ y está dada por: 


$$
M=3(n-1)-2 j_{1}-j_{2}
$$

Debido a que el movimiento quinético de las Neornithes se realiza fundamentalmente en el plano sagital (Bock, 1964; 1999; Zusi, 1967; Bühler, 1981; Meekangvan et al., 2006), se asume que el cráneo de un ave puede modelarse en dos dimensiones asumiendo la simetría bilateral del cráneo sin identificar articulaciones con dos grados de libertad (i.e., $j_{2}=0$ ).

En la quinesis del cráneo aviano actúan dos mecanismos: la maxila, el neurocráneo, el cuadrado y la barra yugal + barra pterigo-palatina por un lado y, por el otro, el lig. postorbital, el neurocráneo, el cuadrado y la mandíbula. Estos dos mecanismos se vinculan a través del cuadrado y por lo tanto se los puede fusionar en un único mecanismo de seis barras y siete articulaciones. Estos mecanismos tienen movilidad 1 de acuerdo con Alexander (1983), situación que se aprecia en la mayoría de los cráneos proquinéticos de Neognathae actuales.

Este modelo arroja un valor de 1 para Cariama cristata (Cariamidae) y Psophia crepitans (Psophiidae) que se corresponden con un sistema quinético, pero en el caso de los fororracos, arroja valores de cero para los morfotipos craneanos tipo I y -1 para los morfotipos craneanos tipo II. Valores de cero indican que la estructura es rígida y valores negativos indican que se trata de una estructura "redundante" (Alexander, 1983). Ambos valores obtenidos para los fororracos son correspondientes a un sistema inmóvil, pero no permiten discriminar el tipo de inmovilidad en cada caso.

\subsection{Análisis biomecánicos}

\subsubsection{Análisis de Elementos Finitos (FEA)}

\subsection{1.a. Introducción al FEA}

El Análisis de Elementos Finitos es una herramienta ingenieril inicialmente desarrollada para predecir la distribución del stress (fuerza por unidad de área) y de la deformación (= strain) en estructuras artificiales con geometría relativamente sencilla. Consiste en dividir la geometría de una estructura en pequeños elementos (que forman el enmallado) teniendo en cuenta las relaciones y propiedades de los elementos vecinos sobre los cuales se calculan ecuaciones diferenciales. Sin embargo, con los avances de la tecnología informática, FEA se ha convertido en una poderosa herramienta en la investigación del comportamiento mecánico de estructuras biológicas complejas (e.g., 
Wroe et al., 2008; Rayfield, 2004; Rayfield et al., 2001; Richmond et al., 2005; Tizzard et al., 2005; McHenry et al., 2006; Wroe, 2008; Moreno et al., 2008) debido a que (1) es una herramienta no invasiva; (2) reconstruye el stress en múltiples sitios del esqueleto; (3) es aplicable tanto en paleobiología como neobiología y (4) es capaz de resolver problemas en geometrías bajo condiciones de carga complejas (Rayfield, 2007). En particular, su carácter no destructivo la convierte en una herramienta de un valor único en los estudios paleontológicos (Wroe et al, 2007a; McHenry et al., 2007).

Rayfield (2007) detalla cada uno de los pasos involucrados en un análisis de elementos finitos y los mismos se resumen en la figura 8.3. El primer paso es la creación de una representación digital de la estructura de interés, la cual se logra a través de la utilización de software de alta complejidad que maneje datos obtenidos fundamentalmente a partir de tomografías computadas (ya que reflejan la estructura interna), aunque otras fuentes de datos son factibles (e.g., fotografías digitales y datos de brazo digitalizador tridimensional Microscribe). Esto permite la generación de un modelo continuo conocido como modelo sólido ("solid model”). Este modelo es luego subdividido en varias subregiones o elementos discretos conectados entre sí por nodos mediante software constituyendo el enmallado (“mesh model”). Este proceso se conoce como discretización. La creación de ambos modelos es un proceso complejo que demanda mucho tiempo, pero el producto generado tiene alto uso potencial tanto en biomecánica como anatomía. Luego se fija el enmallado en el espacio (i.e., se definen los grados de libertad del modelo), se le asignan las propiedades del material deseado a los elementos y se le aplican diversas fuerzas a los nodos que conectan dichos elementos. Estas cargas y restricciones se conocen como condiciones limitantes ("boundary conditions"). Cuando se ejecuta el análisis se calcula el desplazamiento de los nodos (que se produce de acuerdo a las propiedades del material), el cual es utilizado para calcular deformación y finalmente stress, que se utiliza para reconstruir el comportamiento mecánico de la estructura de interés. El paso final consiste en la representación e interpretación del stress y la deformación, comúnmente mediante gradientes de color que ilustran el comportamiento mecánico de la estructura en cuestión (Figura 8.3). En cada uno de estos pasos, el análisis puede ser redefinido (e.g., obtener un enmallado más preciso, cambiar las condiciones limitantes, etc.) a fin de lograr una mayor precisión en la representación final (Rayfield, 2004).

Las investigaciones utilizando FEA en biología pueden dividirse en dos amplios campos: los programas deductivos e inductivos. 
El programa deductivo se basa principalmente en los trabajos de Preuschoft y Witzel (e.g., Witzel, 1985; Witzel y Preuschoft, 1999, 2002, 2005; Preuschoft y Witzel, 2002, 2004, 2005). Como hipótesis de trabajo, la forma de la estructura está determinada por la mecánica y más precisamente por el stress (Preuschoft y Witzel, 2005) De acuerdo a estos autores, el análisis se inicia con una masa homogénea que ofrece un amplio volumen para la dispersión del stress entre los puntos de aplicación de la fuerza y los puntos de restricción. Una vez aplicadas las fuerzas externas, aquellas áreas con bajos valores de stress son iterativamente removidas y la forma resultante es comparada con aquella existente en la naturaleza. De acuerdo a los autores, la estructura en cuestión se deduce a partir de unas pocas condiciones limitantes iniciales (Witzel y Preuschoft, 2005). La forma de dicha estructura refleja de forma precisa la función (Rayfield, 2007).

Por su parte, las aproximaciones inductivas son aquellas capaces de testear la premisa de que forma y función están fuertemente relacionadas, teniendo en cuenta que la forma y estructura a investigar son condiciones a priori del análisis, reflejando con mayor fidelidad la realidad (Rayfield, 2007). Este tipo de aproximación es la más difundida entre las investigaciones actuales. Incluye tres tipos fundamentales de análisis: (1) análisis de taxones individuales (e.g., Rayfield, 2001, 2004, 2005a; Mazzetta et al., 2004; Wroe et al., 2007a; Bourke et al., 2008; Degrange et al., 2008; Moreno et al., 2008; Moazen et al, 2009b); (2) comportamiento comparativo (e.g., Rayfield, 2005b; Rayfield et al., 2007; Wroe, 2008; Wroe et al., 2007b; Degrange et al., 2010) y (3) análisis de sensibilidad y validación (e.g., Ross et al., 2005; Strait et al., 2005, Goussard et al., 2010).

Si bien muy poderosa, la aplicación de FEA no carece de problemáticas. Degrange y Tambussi (2009) detallan las problemáticas encontradas al intentar aplicar esta metodología al cráneo de las Aves: las habilidades quinéticas de la mayoría de las Neognathae, así como el cráneo sumamente neumático, dificultan la construcción del modelo; la información referida a los huesos de las aves (módulo de Young, radio de Poisson, densidad) es escasa o inexistente; se carece de datos acerca de la magnitud de las fuerzas extrínsecas (e.g., fuerza de mordida) e intrínsecas (e.g., fuerza muscular) actuantes y cruciales en FEA. De esta forma, resulta imperante generar información de base que brinde mayor fortaleza a los resultados emergentes. Aún así, FEA ha demostrado ser una poderosa herramienta que permite no solo conocer el 
comportamiento biomecánico sino también, en un marco comparativo adecuado, inferir posibles hábitos tróficos en aves extinguidas.

Durante el desarrollo de esta tesis, se tuvo la oportunidad de incorporar esta novedosa herramienta en el análisis de la mecánica craneana de los fororracos, en particular en el Patagornithinae Andalgalornis steulletti y compararla con dos aves actuales: Cariama cristata (Cariamidae) y Haliaeetus albicilla (Accipitridae). Cariama fue elegida para la comparación debido a su cercanía filogenética con los Phorusrhacidae (véase capítulo 5), mientras que Haliaeetus fue elegida por su estilo de vida depredador. Dicho trabajo fue publicado en conjunto con los doctores Claudia Tambussi, Karen Moreno, Lawrence Witmer y Stephen Wroe. Se detalla a continuación el análisis realizado (Degrange et al., 2010).

\subsection{1.b. FEA aplicada a fororracos}

Modelado. El modelo sólido (Figura 8.4A) fue creado a partir de imágenes tomográficas. El cráneo del Patagornithinae Andalgalornis steulleti (FMNH-P14357) fue tomografiado en O'Bleness Memorial Hospital en Athens, Ohio, EEUU, utilizando un tomógrafo computarizado General Electric (GE) LightSpeed Ultra Multislice equipado con la opción de Extended Hounsfield. El cráneo fue escaneado helicoidalmente con cortes de $625 \mu \mathrm{m}$ de grosor, $120 \mathrm{kV}$ y 200-300 mA. El cráneo de la chuña de patas rojas (Cariama cristata, FMNH 105635) fue escaneado en la Ohio University MicroCT Scanning Facility $(\mathrm{OU} \mu \mathrm{CT})$ utilizando un GE eXplore Locus MicroCT Scanner. Para este escaneo se utilizó un grosor de corte de $92 \mu \mathrm{m}$ y $45 \mu \mathrm{m}, 80$ $\mathrm{kV}$ y $500 \mu \mathrm{A}$. También se obtuvieron los cortes tomográficos del águila de cola blanca (Haliaeetus albicilla) de la University of Austin Digital Morphology Web site (http://www.digimorph.org). Las imágenes obtenidas fueron almacenadas en formato DICOM y fueron visualizados y modelados mediante el software Materialise Mimics versión 11.01. Los datos fueron analizados para evaluar la arquitectura interna de las regiones óseas (incluyendo aquellas correspondientes a la quinesis craneal).

Los protocolos implementados para el FEA realizado en Andalgalornis siguen los lineamientos desarrollados por Wroe et al. (2007a), Moreno et al. (2008), Wroe, (2008) y Wroe et al. (2008).

Debido a que el cráneo FMNH-P14357 se encuentra deteriorado en gran parte del neurocráneo, se modeló como un modelo homogéneo (i.e., se asumen propiedades 
constantes a lo largo de toda la estructura). El mismo procedimiento fue aplicado a los cráneos de Cariama y Haliaeetus.

El enmallado (Figura 8.4B) fue realizado con el software Strand7 Finite Element (v. 2.3). Los modelos fueron ensamblados utilizando tetraedros (elementos 3D de cuatro nodos, tet4). En la superficie original del enmallado, las longitudes máximas y mínimas de los bordes del triángulo se mantienen en una proporción de 1:3 $(0,1$ error geométrico) para minimizar las diferencias entre las dimensiones del triángulo, que pueden conducir a importantes discrepancias en el tamaño del elemento e introducir artefactos. A los elementos se les asignó un único conjunto de propiedades aplicados en estudios previos (Wroe et al, 2007a; McHenry et al., 2007; Moreno et al., 2008) (módulo de elasticidad de Young $[\mathrm{Y}]=27,0 \mathrm{GPa}$; índice de Poisson $=0,4$; densidad $=$ $\left.2,19085 \mathrm{~T} / \mathrm{mm}^{3}\right)$.

Para evitar movimientos libres del modelo, éste fue fijado en el espacio. Fijaciones a partir de un nodo individual pueden producir artefactos y resultados imprecisos (Richmond et al., 2005). Para cada carga se utilizaron restricciones más realistas dentro de una red de vínculos rígidos ubicada en el condylus occipitalis. También fue creada una red similar en la punta del pico a fin de obtener una distribución más amplia de las fuerzas (McHenry et al., 2007). Los análisis estadísticos fueron realizados con un código escrito por la Dra. K. Moreno, utilizando el software R.

Análisis. Se simuló la actividad depredadora de Andalgalornis y cómo se habría comportado su cráneo durante la matanza de una presa, comparándosela con la de Haliaeetus y Cariama. Debido a que la mayoría de las aves carnívoras (e.g. Accipitridae y Falconidae) usan el gancho en la punta de su pico para sostener y matar a la presa (Sustaita, 2008), se aplicó la fuerza de mordida en distintos sentidos en la punta del pico en los modelos FE. No se modeló la quinesis aviana debido a que los fororracos son aquinéticos (véase sección 8.1.2).

En cualquier análisis biomecánico, las fuerzas aplicadas sobre un sistema pueden clasificarse en intrínsecas si actúan dentro del sistema o extrínsecas si es el medio el que ejerce fuerzas sobre él. En el caso de Andalgalornis fueron simuladas y resueltas por el modelo dos situaciones de fuerzas: la simulación de las fuerzas musculares generadas por la musculatura adductora (intrínseca) y la simulación del movimiento de las presas en relación con el depredador, o el movimiento del depredador en relación con la presa (extrínseca). 
Se aplicó la fuerza de mordida (intrínseca) para cada taxón como una carga en el extremo distal del hueso premaxilar (es decir, el gancho) en tres sentidos: cráneocaudal ("pullback"), dorsoventral ("normal bite") y lateral ("lateral shake"). En otras palabras, se simularon los movimientos de la presa en relación con la cabeza (Preuschoft y Witzel, 2002). El accionar de cada uno de los músculos mandibulares no fue reconstruido. El comportamiento mecánico relativo se evaluó en base de la media de la medida de tensión en Von Mises (VM), así como mediante los resultados visuales obtenidos con el software de post-procesamiento.

Es importante señalar que en ausencia de validación, los resultados solo pueden ser considerados en un contexto comparativo y debido a que los modelos son homogéneos, el enfoque apunta fundamentalmente a la influencia de la geometría, pero no a las diferencias en la distribución de las propiedades del material. Es decir, que si bien los resultados obtenidos evidencian la influencia de las diferentes geometrías en la distribución del stress en un sentido relativo, no pueden ser considerados como valores de rendimiento absoluto (Wroe et al, 2007a; McHenry et al., 2007).

Los tres taxones considerados en este estudio muestran diferencias notables en cuanto al tamaño y esto plantea una problemática al momento del escalado. Las fuerzas de mordida de los tres taxones han sido efectivamente escaladas sobre la base de regresión y estas mismas fuerzas han sido aplicadas como fuerzas extrínsecas. En un análisis de comparación lineal estática como el aquí realizado, el escalado tiene una fuerte influencia sobre la magnitud absoluta de stress registrado, pero no en cómo se distribuye. Esto quiere decir que el escalado no afectará a la interpretación de si el cráneo de Andalgalornis se encuentra mejor adaptado para resistir fuerzas laterales o dorsoventrales, ya que las relaciones seguirán siendo las mismas. Por lo tanto, las interpretaciones se basan en diferencias proporcionales en lugar de absolutas respecto a valores de stress (véase más adelante).

Para predecir la fuerza de mordida en Andalgalornis, se construyó una línea de regresión $(\mathrm{R}=0,8123 ; \mathrm{R} 2=0,6598, \mathrm{p}=0,0000$; Figura 8.5) utilizando tres diferentes fuentes de datos: datos publicados de fuerza de mordida en aves (van der Meij y Bout, 2004), datos propios de fuerza de mordida obtenidos mediante un transductor diseñado para medir las fuerzas in vivo, y los datos de masa corporal (van der Meij y Bout, 2004; Jimenez y Jaksic, 1990; Abourachid et al., 2005). En base al análisis de regresión, incluyendo Cariama (20 Newtons) y Haliaeetus (50 Newtons), se estimó la fuerza de la 
mordida de Andalgalornis en 133 Newtons en la punta del pico (véase capítulo 6 para nuevos resultados).

Resultados. El modelo del cráneo de Andalgalornis registró menores valores medios de stress que Cariama o Haliaeetus bajo los tres casos de fuerza impuestos (Tabla 8.1; Figura 8.6). El comportamiento mecánico de Andalgalornis es marcadamente diferente en el valor medio de stress de los elementos (Von Mises, VM) para la simulación de movimiento lateral, el cual fue de hasta cuatro veces mayor que aquel registrado cuando se aplica la fuerza en sentido craneocaudal. Los valores de stress obtenidos en condiciones de fuerza craneocaudal fueron los más bajos en los tres taxones. En Cariama y Haliaeetus, el stress medio obtenido para lateral shake y normal bite fueron similares. En Andalgalornis, sin embargo, el stress generado por fuerzas lateralmente direccionadas es del doble de aquel obtenido en condiciones de normal bite (Tabla 8.1). Aún así, parece probable que el cráneo de Andalgalornis podría haber soportado mayor stress que aquellos resultantes de una fuerza de mordida de $133 \mathrm{~N}$. Esto es acorde con los valores superiores de fuerza de mordida obtenidos en el capítulo 6 de esta tesis.

En los tres casos de fuerza aplicada a Andalgalornis, las áreas que concentran el mayor stress son tres: la punta del pico (es decir, el gancho), el condylus occipitalis, y el contacto entre los ossa palatinum y ossa pterygoidei con el septum interorbitalis (Figura 8.6). El stress fue claramente más alto bajo la simulación de lateral shake (Figura 8.6). Lo mismo es cierto para Cariama, pero en el caso de Haliaeetus el stress fue mayor en la simulación de normal bite. Además, en Andalgalornis el stress fue mayor en los bordes ventrolaterales del pico (los tomia), la superficie dorsal de los ossa nasalis, el borde rostral de la fenestra antorbitalis (por debajo de las narinas), el corpus del os quadratum, en la fossa temporalis y el margen ventral del arcus jugalis.

Se considera que los altos valores de stress registrados en el septum interorbitalis en nuestro modelo de FE de Andalgalornis son un artefacto ya que el modelo no incorporó suturas entre ossa palatinum, ossa pterygoidei y el septum (que si están presentes en la realidad). Esta región puede actuar como liberadora de stress, compensando al menos parte por la pérdida de la quinésis.

\subsubsection{Mecánica mandibular: brazos de momento}


Cualquier sistema músculo-esqueletario pueden ser tratado como un mecanismo que transmite fuerzas de un lugar a otro del sistema, generalmente acompañado por un cambio de magnitud (Hildebrand, 1988). Por lo tanto, existe una fuerza de entrada que se aplica al sistema y una fuerza de salida derivada de la misma. En el cráneo de un ave, la mandíbula puede ser considerada como una palanca de tercer orden (i.e., la fuerza de entrada se encuentra entre el fulcro y la fuerza de salida) que transmite las fuerzas de los músculos mandibulares aplicadas sobre ella, rotando en la articulación cuadradoarticular. La fuerza de entrada está dada entonces por la musculatura mandibular y la fuerza de salida es la que aplica la mandíbula sobre un ítem trófico. Las respectivas distancias perpendiculares entre el punto de aplicación de las fuerzas y el fulcro se denominan brazo de momento de entrada y brazo de momento de salida.

En un sistema en equilibrio, el producto de la fuerza de entrada por su respectivo brazo de momento es igual al producto de la fuerza de salida por su brazo de momento. Se puede obtener así cualquiera de las variables deseadas, si se conocen las demás. El análisis de la relación de los brazos de momentos (en un equilibrio estático), permite detectar si el sistema favorece la fuerza o la velocidad.

Los músculos pueden insertarse en diferentes ubicaciones, dependiendo de la función que cumplan. Si la inserción se ubica en una zona cercana a la articulación proximal del hueso, al contraerse producirá un movimiento rápido. Por el contrario, si la inserción se ubica en la zona cercana a la articulación distal del hueso, el brazo de momento será mayor y la contracción producirá un movimiento que prioriza la fuerza a expensas de la velocidad.

La reconstrucción de la musculatura mandibular de los fororracos realizada en el capítulo 7 permite estudiar la biomecánica del aparato trófico como un todo. Ocho músculos proveen la fuerza necesaria para cerrar las quijadas y solo uno permite su abertura.

Metodología. La fuerza y dirección de cada músculo mandibular depende de varios factores, entre los que se pueden mencionar el sitio de origen e inserción, su masa, estructura interna, ángulos entre los músculos y el hueso, vectores relativos de fuerza muscular, trabajo y brazos de momento de las palancas óseas, la relación de los elementos óseos afectados por esos músculos con otros elementos y la relación con otras estructuras blandas (Bock, 1964). 
Debido a que la línea real de acción de un músculo en un fósil muchas veces resulta inestimable ya que no puede saberse su estructura interna o debido a que presentan una superficie de origen y/o de inserción muy amplias, Vizcaíno et al. (1998) propusieron un método geométrico que permite obtener valores de brazos de momento independientemente de dicha línea de acción. Si bien este método fue creado para analizar la mecánica mandibular de mamíferos, el método resulta aplicable a los Archosauria (e.g., Degrange, 2008; Desojo y Vizcaíno, 2009).

Se describe la metodología aquí aplicada (véase Vizcaíno et al., 1998 para más detalle). Se traza una línea de acción desde el extremo más anterior de la inserción del músculo de interés hacia el punto medio del origen. Luego se traza otra línea de acción que une dicho punto del origen con la parte más posterior de la inserción. El ángulo comprendido entre ambas líneas anterior y posterior es subdividido en porciones iguales por la cantidad de líneas de acción que uno desee, aunque Vizcaíno et al. (1998) establecen que no es necesario más de cinco líneas en total. Se miden los brazos de momento para cada línea de acción y se promedian, obteniendo un único valor de brazo de momento para ese punto de origen. Luego se repite el procedimiento utilizando como puntos de origen la parte más anterior y más posterior del músculo y se obtienen los valores promedio para cada uno. Una vez obtenidos los tres valores promedio (anterior, medio y posterior) se obtiene un valor promedio de estos tres. Este valor representa el brazo de momento de la línea de acción del músculo (i.e., el brazo de momento de entrada). Se repite todo el procedimiento para cualquier otro músculo deseado (mandibulares en este caso).

El brazo de momento de cada músculo puede ser utilizado para obtener el índice de velocidad (IV), calculando el brazo de momento de salida, ubicando la fuerza de salida en distintas posiciones en la mandíbula. El brazo de momento de salida puede acortarse si el animal muerde en posiciones más caudales de la mandíbula (que incrementaría la fuerza de mordida) aunque esto depende del comportamiento trófico. Por lo tanto, la ubicación de dicha fuerza sobre la mandíbula puede variar dependiendo del taxón bajo estudio.

El análisis aquí realizado pretende caracterizar cuantitativamente la mecánica mandibular de los fororracos, estimando la contribución que hace cada músculo mandibular a la velocidad o a la fuerza del sistema mediante la aplicación de este método. 
La mandíbula fue representada como una palanca de $3 \mathrm{er}$ orden, con el fulcro o pivote ubicado en la articulación cuadrado-articular. La musculatura adductora provee la fuerza necesaria para cerrar la mandíbula $(\mathrm{Fe})$ sobre el ítem trófico y es en este punto donde se aplica la fuerza de salida $(F s)$. Se calcularon los brazos de momento de entrada $(M e)$ y de salida $(M s)$ y se obtuvo el índice de velocidad $(M s / M e)$. Ms fue calculado únicamente desde el fulcro hasta el extremo de la mandíbula, ya que es fundamentalmente esta parte la que entra en contacto con el ítem trófico (Figura 8.7).

Debido a que la mayoría de las aves son isognatas (i.e., muerden al mismo tiempo en ambos lados) (Witmer y Rose, 1991), el análisis puede ser aplicado a cualquiera de los lados.

Se estandarizó en base a la longitud del cráneo a fin de poder comparar los brazos de momento de animales de diferentes tamaños.

Debido a que el $m$. adductor mandibulae externus medialis es indiferenciable (véase capítulo 7), el m. adductor mandibulae externus fue considerado como una única unidad funcional. No se consideró el $m$. protractor pterygoidei et quadrati por no tener función en la adducción mandibular.

Se comparó la mecánica mandibular de los dos morfotipos craneanos de fororracos (véase capítulo 4). Como representante del morfotipo I se utiliza al Mesembriornithinae MMP 5050 y como representante del morfotipo II se utiliza a Andalgalornis steulleti. A su vez, la mecánica de ambos morfotipos fue comparada con la del águila Geranoaetus melanoleucus.

Resultados. Los resultados se listan en la tabla 8.2 y se muestran en la figura 8.8 . La suma de los brazos de momento de entrada de la musculatura adductora (MA) muestra que no hay diferencias entre el Mesembriornithinae y Geranoaetus. Sin embargo, cuando se comparan los fororracos se observan valores claramente disímiles entre los dos morfotipos, siendo el valor de Andalgalornis un 27\% mayor que el del Mesembriornithinae.

La forma en que cada músculo contribuye al MA total entre los fororracos presenta pequeñas diferencias y éstas son diferentes con respecto a Geranoaetus (Tabla 8.2). En los fororracos, son el m. pseudotemporalis profundus y superficialis los que presentan mayor contribución, mientras que en Geranoaetus los que más contribuyen son el $m$. pseudotemporalis superficialis y el $m$. adductor mandibulae externus. En el Mesembriornithinae, la contribución del $m$. adductor mandibulae externus y del $m$. 
adductor mandibulae posterior es mayor que en Andalgalornis, pero en ambos casos es menor que en Geranoaetus. Las contribuciones de los m. pterygoideus (i.e., ventralis y dorsalis) son similares en Andalgalornis (ambos aportan un 11\%), mientras que en Geranoaetus y en el Mesembriornithinae hay una diferencia de 2,5\% entre las contribuciones de ambos $m$. pterygoideus. Sin embargo, el que más aporta en el Mesembriornithinae es el m. pterygoideus ventralis, mientras que en Geranoaetus es el m. pterygoideus dorsalis.

Otra forma de analizar la contribución de cada músculo a la mecánica mandibular es a través de los índices de velocidad (Tabla 8.2). Se puede observar que la forma en que cada uno de los músculos aporta fuerza o velocidad es diferente entre los morfotipos. Los músculos encargados de aportar velocidad al sistema son fundamentalmente los m. pterygoideus, mientas que los encargados de aportar la fuerza son el $m$. adductor mandibulae externus, el m. pseudotemporalis profundus y fundamentalmente el m. pseudotemporalis superficialis. Sin embrago, en el Mesembriornithinae el índice de velocidad de ambos $m$. pterygoideus es bastante superior a aquel de Andalgalornis. En este último, estos músculos tendrían un mayor aporte a la fuerza de mordida que en el morfotipo I. De hecho, el m. pterygoideus dorsalis es el que presenta un mayor aporte a la velocidad en el Mesembriornithinae (de casi un 21\% más que el $m$. pterygoideus ventralis), mientras que en Andalgalornis el aporte de ambos $m$. pterygoideus es idéntico (Tabla 8.2). El m. adductor mandibulae posterior presenta en ambos fororracos un índice idéntico, pero comparándolo con los índices de los demás músculos mandibulares es claro que en el Mesembriornithinae este músculo presenta una situación intermedia, favoreciendo la velocidad y la fuerza del sistema, pero en Andalgalornis es el músculo con índice más alto y es, por lo tanto, el principal contribuyente a la velocidad del sistema. El índice de velocidad del $m$. depressor mandibulae de ambos fororracos es muy similar en ambas formas y mayor que el de Geranoaetus, lo que indicaría una abertura bucal más veloz.

\subsection{Discusión y conclusiones}

\subsubsection{Aquinesis}

Algunos rasgos anatómicos de los Phorusrhacidae parecen indicar capacidad quinética (e.g., estreptostilia y presencia de musculatura protractora). Sin embargo, otros rasgos, tales como la ausencia de zonae flexoria, claramente certifican que los fororracos eran aquinéticos, es decir, incapaces de movilizar la maxila. 
La función de los processi basipterygoideus es difícil de establecer (Bock, 1964). Sin embargo, se ha hipotetizado que dichos processi sirven como guías (Beecher, 1962) o incluso frenos (Fisher, 1955; Beecher, 1962; Bock, 1964) durante los movimientos quinéticos. Recientemente, Gussekloo y Bout (2005b) propusieron que los processi basipterygoideus de las Palaeognathae bloquean movimientos caudales de los ossa pterygoidei. Estos processi impiden entonces la depresión de la maxila por debajo de su posición de reposo, la que se produce durante la contracción de los $m$. pterygoideus y m. pseudotemporalis profundus (Beecher, 1962; Bock, 1964; Bühler, 1981). De esta forma, parece que en los fororracos la asociación tan peculiar e íntima que existe entre los ossa pterygoidei y los processi basipterygoideus se debe a la inmovilización del paladar, fenómeno que se encontraría relacionado con la evolución de la aquinesis en este grupo (véase más abajo).

La función de la musculatura protractora en los fororracos también resulta compleja de elucidar. Si bien relicto de un ancestro quinético, podría ser una estructura encargada de absorber shocks o impactos o incluso compensar la fuerza ejercida por la musculatura aductora externa y la gran fuerza de mordida estimada (véase capítulo 6), como ha sido sugerido para dinosaurios carnívoros de la talla de Allosaurus y Tyrannosaurus (Erickson et al., 1996; Hurum y Currie, 2000; Rayfield et al., 2001; Meers, 2002), carentes de uniones cinemáticas permisivas y funcionalmente aquinéticos (Holliday y Witmer, 2008). Moreno et al. (2008) sugieren que el $m$. protractor pterygoideus et quadrati controla parte de la deformación que sufre el os pterygoideus durante la contracción de la musculatura pterigoidea, reduciendo el stress sobre dicho hueso en los Lepidosauria Varanidae. Debido a que los músculos pterigoideos de los fororracos están muy desarrollados (véase capítulo 7), parece plausible hipotetizar que el $m$. protractor pterygoideus et quadrati funcionara como un disipador de shocks, compensando cualquier deformación o stress que se pudiese producir por la contracción de la musculatura pterigoidea o incluso de la fuerza de mordida total.

La ausencia de zonae flexoria en los fororracos significa que no es posible ningún tipo de movimiento quinético. En el caso de los cráneos morfotipo II, además de la ausencia de zonae flexoria, aparecen otras uniones rígidas: la rama descendente del os lacrimale se fusiona al os lacrimale communicans (véase capítulo 4), constituyendo una columna que une el os lacrimale con el arcus jugalis (Figuras 4.7 y 4.10 ) y en Andalgalornis, en la zona de contacto con el arcus, se forma un reborde o labio medial 
que garantiza una unión rígida. En este taxón, además, el os lacrimale se fusiona cranealmente con los ossa nasalis y ossa frontalis.

Con respecto al lig. postorbitale, según Bock (1964) tal es el acoplamiento que produce que, en aquellas aves que lo poseen, es imposible deprimir la mandíbula más allá de la posición que ocupa cuando la boca está cerrada si no se eleva la maxila. De hecho, el mecanismo de acople a través de este ligamento ha sido discutido y rechazado por Bout y Zweers (2001). Varias especies que lo poseen son capaces de mover la mandíbula y la maxila de forma independiente (e.g., Van Gennip y Berkhoudt, 1992; Hoese y Westneat, 1996) y datos experimentales muestran que este ligamento produce muy poca resistencia a la depresión mandibular cuando se mantiene fija la maxila (Nuijens y Bout, 1998). Zusi (1967) argumenta que, si se mantiene fija la maxila, el pequeño desplazamiento caudal que se produce en la mandíbula por contracción del $m$. depressor mandibulae es suficiente para reducir la coordinación del sistema, permitiendo una mayor depresión mandibular. Esta autor argumenta, además, que este ligamento podría cumplir otras funciones aparte del acople. El lig. postorbitale serviría para estabilizar y proteger la articulación cuadrado-mandibular manteniendo, ambas superficies en íntima aposición (Zusi, 1967; Bout y Zweers, 2001). La actividad depredadora de los fororracos parece justificar esta función del ligamento coparticipando con las poderosas fuerzas de mordida contra presas activas.

Como señalaran Holliday y Witmer (2008), el término "aquinético" puede resultar ambiguo ya que puede involucrar más de uno de los posibles estados quinéticos creados por ellos. Resulta necesario entonces hacer una distinción entre "morfológicamente/anatómicamente aquinético" y "funcionalmente aquinético". Esta idea había sido esbozada, aunque poco desarrollada por Bock (1964). El caso de los fororracos resulta un excelente ejemplo para esta distinción, ya que si bien hay zonas donde el movimiento intracraneano es posible (e.g., articulación cuadrado-escamosal, articulación pterigo-palatina), la gran mayoría de las zonas craneanas móviles en la mayoría de las Neognathae son inmóviles en los fororracos (por fusión en su mayor parte). Tal es el caso de la zona flexoria arcus jugalis, la zona flexoria palatina y la zona flexoria craneofascialis. Estas zonas son anatómicamente aquinéticas, incapaces de realizar cualquier tipo de movimiento. Por el contrario, el os quadratum estreptostílico, capaz de rotar, es anatómicamente quinético.

De acuerdo a la clasificación de estados quinéticos propuestos por Holliday y Witmer (2008), los fororracos pertenecen a la categoría de "parcialmente capaz de 
quinesis" ya que cumplen con los criterios 1 (articulación sinovial ótica, cuadradoescamosal), 2 (articulación sinovial basal, basipterigoidea) y 3 (presencia de musculatura protractora), pero no cumplen con el criterio 4 (presencia de uniones cinemáticas permisivas). El último criterio es excluyente: no se produce el movimiento dorso-ventral de la maxila característico de la proquinesis. En el caso de los fororracos más pequeños el paladar es el elemento incapaz de flexionarse cranealmente para permitir el movimiento de la maxila, pero en los fororracos de mayor porte no solo el paladar es incapaz de realizar dicha acción sino que es la propia maxila la que también es incapaz de elevarse por ausencia de la zona flexoria craniofascialis. Esto es "funcionalmente aquinético", ya que si bien consta de partes anatómicamente capaces de realizar quinesis, el sistema en su totalidad es incapaz de hacerlo. Esta situación caracteriza a todos los fororracos (Degrange et al., 2010) y en este sentido los fororracos son aquinéticos.

Utilizar el término de "parcialmente capaz de quinesis" puede llevar a confusión ya que no queda explícito qué partes son o no capaces de realizar quinesis, así como tampoco queda esclarecido si el sistema en su totalidad es capaz de realizar proquinesis (en el caso de las Neornithes). El término "aquinético" como se utiliza aquí puede implicar inmovilidad funcional o anatómica, dependiendo además de la escala de estudio (i.e., si se observa un solo hueso o todo el cráneo). Si un cráneo es anatómicamente aquinético esto implica que ninguna de sus partes es móvil y por lo tanto es también funcionalmente aquinético. Si es funcionalmente aquinético también puede implicar que algunas de sus partes son capaces de moverse (aunque el sistema en su totalidad no lo hace). Sea cual fuese el caso, el término "aquinético" en las Neornithes implica que el cráneo es incapaz de realizar movimientos proquinéticos y es en este sentido que su uso es correcto.

La pérdida de quinesis craneal en los fororracos es un carácter derivado remarcable, pero la interpretación de esta pérdida es complicada por persistentes incertidumbres sobre el rol funcional de la quinesis craneal. Es posible que no haya una explicación única para su evolución y función en todas las Neognathae (Gussekloo y Bout, 2005a).

Bock (1964) sugirió seis roles potenciales para la quinesis craneana aviana: (1) mantenimiento pasivo de la mandíbula en posición cerrada; (2) incremento de la fuerza de abertura en "gapers"; (3) mantenimiento del eje de orientación visual primario; (4) cierre más veloz del pico; (5) mecanismo de absorción de shocks y (6) incremento del 
área de inserción de la musculatura mandibular. Sin embargo, otras explicaciones fueron postuladas en los últimos años. Zusi $(1967,1993)$ propuso que la ventaja fundamental de la quinesis craneana es la potencial diversidad y versatilidad que le da al pico (maxila y mandíbula) como herramienta manipuladora. Hoese y Westneat (1996) propusieron que la quinesis podría vincularse con la capacidad de canto. Zweers et al. (1997) relacionan la quinesis con el desarrollo de una mayor fuerza de cierre mandibular debido a un mejor aprovechamiento del componente horizontal de la musculatura pterigoidea, la cual se encuentra muy desarrollada en Neornithes. Sin embargo, también postulan que el mecanismo quinético de las aves podría deberse a las presiones selectivas al desarrollar el vuelo: un mayor desarrollo ocular, cerebral y un aligeramiento del cráneo por desarrollo de fenestración dermatocraneal, así como grandes narinas, resultarían ser preadaptaciones a la quinesis craneana. De hecho, siguiendo esta hipótesis, Bout y Zweers (2001) establecen que el significado adaptativo de la quinesis aviana permanece incierto y que podría ser el resultado del diseño craneano, especialmente asociado al agrandamiento del ojo. Estos mismos autores reconocen además que la fuerza de mordida en un sistema quinético es menor que la que se podría producir en un sistema aquinético. Esto también se ha demostrado en otros diápsidos capaces de realizar movimientos quinéticos (e.g., Moazen et al., 2009a)

De hecho, Gussekloo y Bout (2005b) encuentran que la presencia de quinesis en aves Palaeognathae contradice los datos de Zweers et al. (1997): un paladar quinético no resulta en mayor fuerza de mordida, criterio con el que acordamos. La quinesis craneana limita la fuerza de los músculos mandibulares y por lo tanto representa una limitación para la fuerza máxima de mordida. Cualquier adaptación que resulta en un aumento de rigidez del aparato mandibular, como la transformación de zonas de flexión en zonas rígidas resultará en un aumento de la fuerza de mordida teórica máxima (Wroe et al, 2007a; Wroe et al., 2008). Cráneos aquinéticos producen una fuerza de mordida de hasta 1,3 veces mayor que los cráneos avianos quinéticos (Bout y Zweers, 2001). Esto es concordante con las reconstrucciones musculares realizadas en los fororracos (Degrange 2007, 2008; capítulo 7) que indican que el mecanismo de cierre mandibular está adaptado para favorecer la fuerza en detrimento de la velocidad.

Las implicancias de un cráneo aquinético son profundas, incluyendo simplicidad en la manipulación del alimento y en una mordida más fuerte. Por lo tanto, independientemente de la masa corporal, el análisis del cráneo indica que un fororraco 
con un cráneo morfotipo II podría haber mordido más fuerte que aquel con un cráneo morfotipo I.

\subsubsection{Evolución de la aquinesis en los fororracos}

La aquinesis entre las Neognathae es muy rara y solo se ha reportado en Spheniscidae (Reid, 1835), Coliidae (Schoones, 1963), Ramphastidae (Höfling y Gasc, 1984) y algunos Fringillidae (Sims, 1955). También había sido descripta para las Ratitae por McDowell (1948), pero esta hipótesis fue desestimada por Gussekloo et al. (2001) y Gussekloo y Bout (2005a, b).

Witmer y Rose (1991) establecen que la transformación de zonas flexorias en sindesmosis o diartrosis parece ser un fenómeno vinculado al aumento de tamaño, como ocurre en Diatryma gigantea (Gastornithiformes). Ciertamente, éste no es el caso de los Phorusrhacidae que tienen un cráneo aquinético resultado de la transformación de un cráneo quinético. Utilizando como contexto filogenético el cladograma obtenido en el capítulo 5, se puede hipotetizar la evolución de la aquinesis en los Phorusrhacidae (Figura 8.9).

La condición primitiva para el clado Cuculiformes-Phorusrhacidae es la presencia de quinesis craneana, es decir, que el ancestro común de todos estos taxa era capaz de realizar movimientos proquinéticos.

Los Cariamidae son capaces de realizar proquinesis, aunque se aprecia una unión ligamentosa muy extendida caudocranealmente entre los ossa palatinum y los ossa maxillaris (Figura 4.11), limitando la movilidad de la zona flexoria palatina. Si bien los Cariamidae carecen de processi basipterygoideus que limiten los movimientos palatales, es evidente que en los Cariamiformes aparecen las primeras limitaciones a los movimientos proquinéticos.

Parece probable que los processi basipterygoideus (una de las sinapomorfías de los Phorusrhacidae, véase capítulo 5) se hayan desarrollado antes de la fusión total de los elementos que constituían las zonae flexoria palatales, ya que dichos processi habrían evitado retracciones del paladar durante el accionar de la musculatura pterigoidea (muy desarrollada en los fororracos), cuando las zonae flexoriae permitían movimientos limitados.

En el caso de los Phorusrhacidae, los huesos que constituyen la zona flexoria palatina y la zona flexoria arcus jugalis están totalmente fusionados, resultando en una unión inmóvil que evita cualquier tipo de movimiento palatal. Esto representaría una 
sinapomorfía del clado Phorusrhacidae (véase capítulo 5). Comparando con lo que ocurre en Cariamidae, es probable que primero haya desaparecido la zona flexoria palatina y posteriormente con el desarrollo del arcus jugalis, éste tomara mayor contacto con los ossa palatinum y ossa maxillaris produciendo la desaparición de zona flexoria arcus jugalis.

El caso de los Phorusrhacidae más grandes (Patagornithinae y Phorusrhacinae) es aún más llamativo, ya que no solo carecen de las dos zonas flexorias palatales, sino que además se pierde la zona flexoria craniofascialis, impidiendo por completo la movilidad proquinética, un rasgo que parece ser derivado dentro de los Phorusrhacidae. Como fuese mencionado previamente, estas formas presentan además una rama descendente del os lacrimale que presenta un íntimo contacto con el arcus jugalis (Degrange et al. 2010) -por fusión con el os lacrimale communicans (véase capítulo 4)-, e incluso en Andalgalornis los ossa lacrimalis se encuentran fusionados cranealmente a los ossa nasalis y ossa frontalis, convirtiendo al cráneo en una estructura inmóvil y rígida.

La aquinesis es en definitiva un rasgo derivado de los Phorusrhacidae.

\subsubsection{FEA}

Los valores de stress (VM) obtenidos para Andalgalornis (Tabla 8.1) son consistentes con un muy alto índice altura/ancho de la maxila. El análisis de elementos finitos muestra que el cráneo de Andalgalornis es óptimo para resistir fuerzas dirigidas craneocaudal y dorsoventralmente, pero menos adaptado a resistir fuerzas dirigidas lateralmente. La transformación de zonae flexoriae en gruesas conexiones óseas reorientadas en barras comprimidas transversalmente implicaría una mayor resistencia a fuerzas verticalmente dirigidas, pero menor con respecto a fuerzas laterales. En aves con índices alto/ancho de aproximadamente 1 (i.e., picos tan anchos como altos), como el de Cariama o Haliaeetus, es esperable que el cráneo sea igualmente resistente a fuerzas dirigidas lateral y/o verticalmente, de manera consistente con los resultados obtenidos mediante el FEA. Así mismo, tanto la chuña como el águila retienen las zonae flexoriae aplanadas dorsoventralmente, condición requerida para la quinesis.

Obviamente existen ventajas y desventajas complejas entre factores de seguridad, la presencia o ausencia de quinesis y la masa ósea y muscular requeridas para lograr cualquier límite de performance dado. Por ejemplo, una estructura más rígida y más frágil (como un cráneo aquinético) puede resultar en puntos de rendimiento 
mayores y en la reducción en la masa muscular requerida para conseguir una fuerza de mordida dada, pero puede también limitar el tiempo de respuesta disponible para modificar el comportamiento y evitar fallas catastróficas cuando un organismo muerde materiales inesperadamente resistentes (Wroe et al, 2007). Recientes estudios de elementos finitos han revelado que los tejidos blandos dentro de suturas pueden funcionar como absorbentes de shock, actuando para reducir la tensión potencialmente perjudicial. En ausencia de quinesis, sería el $m$. protractor pteryigoidei et quadrati el principal encargado de absorber y disipar el stress. La pérdida de la quinesis aumenta la rigidez y la robustez del cráneo, pero potencia incrementos locales de deformación (Rayfield, 2005a; Moazen et al., 2009a, b). En lo que concierne a la pérdida de quinesis, una consecuencia neta es que puede necesitarse más hueso o mayor densidad de hueso (i.e. mayor masa ósea) para mantener los márgenes de seguridad efectivos. En los fororracos el requisito de un incremento de la masa ósea parece presumiblemente tolerado debido a que su gran masa corporal impedía el vuelo, restando importancia a la generación de estructuras ultralivianas (e.g., un cráneo quinético).

\subsubsection{Brazos de momento}

El análisis aquí realizado en el cráneo de los fororracos indica que en estos cráneos se favorece la fuerza en detrimento de la velocidad, en concordancia con Degrange (2008) quien estableció esta misma situación para la contracción del $m$. adductor mandibulae externus de Andalgalornis. Es también el caso del águila Geranoaetus y contraria a la obtenida en Coragyps y Cariama, donde se favorece la velocidad. Sin embargo, es destacable que al comparar ambos morfotipos, Andalgalornis (morfotipo II) presenta un cráneo que favorece la fuerza, mientras que el Mesembriornithinae (morfotipo I) sería capaz de morder más rápido. Geranoaetus presenta una situación intermedia entre ambos fororracos.

Según Bock (1964), el m. adductor mandibulae superficialis, el m. adductor mandibulae posterior y el $m$. pseudotemporalis superficialis son músculos mandibulares de velocidad debido a que su inserción se encuentra más cerca de la articulación cuadrado-mandibular; el $m$. adductor mandibulae externus medialis y el $m$. pseudotemporalis profundus tienen una inserción más craneal e integran el accionar de todos los músculos mandibulares mientras la mandíbula se cierra y el m. adductor mandibulae externus profundus es el más efectivo en fuerza por insertarse más alejado del fulcro. Debido a que el $m$. adductor mandibulae externus ha sido tratado como una 
unidad no puede certificarse la contribución de cada parte a la velocidad o a la fuerza por el análisis mecánico aquí realizado, aunque basados en la reconstrucción de la musculatura mandibular, parece claro que el $m$. adductor mandibulae externus superficialis aporta velocidad, mientras que el $m$. adductor mandibulae externus profundus aporta fuerza. Sin embargo, la función del $m$. adductor mandibulae externus medialis no puede ser establecida por ser indiferenciable. El m. pseudotemporalis superficialis es claramente el principal músculo de fuerza en los fororracos, al igual que el m. pseudotemporalis profundus.

Los principales músculos encargados de la depresión de la maxila son los $m$. pterygoideus y el m. pseudotemporalis profundus (Beecher, 1962; Bock, 1964). Debido a que los fororracos son aquinéticos, se infiere que los $m$. pterygoideus se encargan de aportar velocidad al cierre mandibular (especialmente en el morfotipo craneano tipo I), mientras que el $m$. pseudotemporalis profundus se encarga de aportar fuerza al cierre, en conjunto con el $m$. pseudotemporalis superficialis y el $m$. adductor mandibulae externus.

\subsubsection{Comportamiento depredador}

Ha sido ampliamente aceptado un estilo de vida carnívoro para los fororracos (Tambussi y Noriega, 1996; Andrews, 1899; Alvarenga y Höfling, 2003; Sinclair y Farr, 1932). Nuevos enfoques y estudios permiten sostener esta hipótesis.

El análisis biomecánico realizado mediante la aplicación de análisis de elementos finitos revela que si Andalgalornis utilizaba su pico para cazar y matar a presas relativamente grandes, debía aplicar golpes con bastante precisión a fin de evitar altos esfuerzos laterales. Es probable que Andalgalornis consumiera presas de menor tamaño a fin de evitar cualquier tipo de stress alto que pudiese dañar su pico. En el caso de que Andalgalornis atacara presas grandes, entonces lo más probable es que utilizara varios picotazos verticales bien dirigidos, mediante un comportamiento repetitivo de ataque y retirada (Degrange et al., 2010). Teniendo en cuenta que la morfología del pico es muy similar en la mayoría de los fororracos, es probable que esta situación sea extensible a las restantes especies, sobre todo los Psilopterinae, cuyas paredes del pico son muy delgadas (Figura 8.13; Degrange y Tambussi, 2008, Degrange y Tambussi, 2011) y el mismo tipo de comportamiento depredador fuese utilizado por cualquiera de los Phorusrhacidae sobre presas de diversos tamaños dependiendo del tamaño del depredador (véase capítulo 6). 
Considerando todas las líneas de evidencias en conjunto, el cráneo de un fororraco presenta una forma (capítulo 4) y función (aquinesis, FEA) relacionadas con el ejercicio de fuertes fuerzas de mordida (capítulo 6, brazos de momento) y ataques a sus presas utilizando golpes verticales y precisos, tratando de evadir fuerzas laterales y de torsión potencialmente perjudiciales (FEA). La reconstrucción muscular (capítulo 7), la aquinesis y los análisis biomecánicos del cráneo y de la musculatura adductora mandibular de los fororracos muestran que el aparato trófico está optimizado para la fuerza a expensas de la velocidad. La abertura bucal era rápida, permitiéndole atrapar a sus presas que mataba con golpes verticales del cráneo. Al cerrar la boca, la mandíbula debía ejercer una fuerza de mordida lo suficientemente poderosa como para matar o aturdir a la presa, con el fin de evitar cualquier esfuerzo lateral o de torsión que pudiese ser ocasionado por los movimientos de la misma. La presa luego podría haber sido desgarrada utilizando el gancho del pico mediante movimientos de pullback. 


\section{Capítulo 9. Morfometría}

... Wickham, the Captain and myself walked to the famous Baobob tree and measured it more accurately. Cap Fitz Roy first took an angle by a pocket sextant and afterward climbed the tree and let down a string, both ways gave the same result, viz 45 feet in height. Its circumference measured 2 feet from the grounds (there being no projecting roots) gave 35. Its form is oval, and its greatest visible diameter was 13 feet. So that in an accurate drawing its height would be 3.4 of its breadth. Cap Fitz Roy made a sketch which gave a good idea of its proportion, yet in this the height was only about 2.4 of [its] breadth. Proving, what one so often observes, that a faithful delineation of Nature does not give an accurate idea of it.

\section{Darwin. Charles Darwin's Beagle Diary}

\subsection{Introducción al enfoque cuantitativo}

La morfología involucra el estudio de la forma, tamaño y estructura de los organismos cualquiera sea el nivel de organización, desde molecular a organísmico. Debido a ello, se ocupa tanto de describir rasgos anatómicos (cuál es la estructura y disposición de las partes), como de estudiar los patrones estructurales (cómo esas partes se integran para constituir un todo), comprender el significado de esta integración para el desempeño del organismo y analizar las posibilidades y restricciones de una forma dada para los procesos evolutivos (Kardong, 1998). Estudiar la morfología de los organismos, así como su variación permite entender la evolución y la interacción entre genotipo, fenotipo y el ambiente (Amaral et al., 2009).

La forma puede ser analizada de manera complementaria a la anatomía a través de la morfometría o estudio cuantitativo de la forma. Más precisamente, la morfometría es el estudio de la variación de la forma y su covariación con otras variables (Bookstein, 1991; Dryden y Mardia, 1998). Los estudios morfométricos incluyen el análisis de datos cuantitativos de uno o más rasgos medibles mediante métodos estadísticos como el coeficiente de correlación, análisis de varianza y el análisis de regresión. El crecimiento histórico en la complejidad de los análisis estadísticos también alcanzó el campo de la morfología, incorporando además la morfometría multivariada permitiendo profundizar las investigaciones a través de análisis canónicos, análisis de componentes principales y funciones discriminantes.

La morfometría incluye dos grandes campos de estudio: (1) el estudio de la forma a través de medidas lineales y (2) el uso de coordenadas, a través de contornos o de puntos homólogos (=landmarks). Mientras el primero se enmarca en el campo de la morfometría clásica, el segundo lo hace en el de la morfometría geométrica. 
En el presente capítulo se analiza de forma cuantitativa el cráneo y complejo apendicular posterior de los fororracos, aplicando por primera vez morfometría geométrica al cráneo y la pelvis. Los elementos de los miembros posteriores fueron estudiados mediante técnicas multivariadas aplicadas a medidas lineales e índices.

\subsection{Morfometría clásica: medidas}

La aplicación de técnicas estadísticas multivariadas a un set de medidas se conoce como morfometría tradicional o morfometría multivariada. Tradicionalmente, se ha basado en la utilización de medidas lineales y la elaboración de índices en base a las mismas para describir y comparar la forma. Existe una gran variedad de análisis estadísticos que permiten analizar conjuntos de medidas de manera simultánea: análisis de componentes principales (PCA), análisis factoriales, análisis canónicos (CVA) y análisis discriminantes entre otros.

Sin embargo, debe tenerse en cuenta que la morfometría clásica presenta varias problemáticas: las medidas lineales se encuentran fuertemente correlacionadas con el tamaño (Bookstein et al., 1985); la homología de las medidas lineales es difícil de establecer; mismas medidas pueden ser resultado de formas muy distintas y no es posible generar gráficos que representen la forma estudiada en base a las medidas lineales tomadas (Adams et al., 2004).

En esta sección se analizó el fémur, tibiotarso y tarsometatarso de los fororracos, utilizando análisis multivariados clásicos en los estudios morfo-funcionales y ecomorfológicos: PCA y análisis discriminante. Este enfoque se debe a que los huesos apendiculares posteriores ofrecen pocos puntos homólogos que permitan describirlos adecuadamente mediante la utilización de landmarks. Además, la forma en que cada uno de estos huesos contribuye al miembro posterior fue analizada mediante gráficos ternarios.

\subsubsection{Métodos}

El conjunto de datos analizado está constituido por aves actuales y fósiles. Las medidas se efectuaron con un calibre digital de $300 \mathrm{~mm}$ y 0,01 de precisión. No se utilizaron métodos de reconstrucción osteológica. Debido a que gran cantidad de material es muy fragmentario, se crearon individuos promedio para cada especie de fororraco a fin de poder utilizarlos en el análisis. El individuo promedio está constituido por el promedio de cada una de las variables analizadas (=valor de la medida $/ \mathrm{n}^{\mathrm{o}} \mathrm{de}$ 
mediciones efectuadas). Todas las mediciones efectuadas en todos los individuos de fororracos se muestran en las tablas 9.2, 9.3, 9.5, 9.6, 9.8 y 9.9.

Se tomaron las siguientes medidas para los elementos del miembro posterior ( $\mathrm{E}=$ estilopodio, $\mathrm{Z}=$ =zeugopodio, $\mathrm{A}=$ autopodio):

\section{Medidas del fémur (Figura 9.1, Tablas 9.1, 9.2 y 9.3)}

EA - Longitud menor: tomada entre el caput femoris y el condylus medialis

EB - Longitud mayor: tomada entre la crista trochanterica y el condylus lateralis

EC - Ancho latero-medial proximal: tomado entre el caput femoris y el trochanter femoris

ED - Extensión craneal de la crista trochanterica: tomado entre el extremo más craneal de la crista trochanterica y su punto opuesto

EE - Ancho latero-medial distal: tomado entre los condyli

EF - Diámetro latero-medial del corpus femoris: tomado a mitad de B

EG - Diámetro cráneo-caudal del corpus femoris: tomado a mitad de B

EH - Ancho cráneo-caudal del condylus medialis

EI - Ancho cráneo-caudal del condylus lateralis

\section{Medidas del tibiotarso (Figura 9.2, Tablas 9.4, 9.5 y 9.6)}

ZA - Longitud mayor: tomada entre la crista cnemialis cranealis y el condylus medialis

ZB - Longitud menor: tomada entre el area interarticularis y el espacio entre los condyli

ZC - Ancho latero-medial proximal: tomado entre las facies articularis

ZD - Ancho latero-medial de la crista cnemialis lateralis: tomado entre la facies articularis medialis y crista cnemialis lateralis

ZE - Ancho latero-medial distal: tomado entre los epicondyli

ZF - Diámetro latero-medial del corpus tibiotarsi: tomado a mitad de B

ZG - Diámetro cráneo-caudal del corpus tibiotarsi: tomado a mitad de B

ZH - Ancho cráneo-caudal del condylus lateralis

ZI - Ancho cráneo-caudal del condylus medialis

ZJ - Extensión craneal de la crista cnemialis cranialis: tomado entre la crista cnemialis cranialis y el punto más caudal del caput tibiae 
Medidas del tarsometatarso (Figura 9.3, Tablas 9.7, 9.8 y 9.9)

AA - Longitud mayor: tomada entre la eminentia intercotylaris y la trochlea metatarsi III

$\mathrm{AB}$ - Longitud tróclea 2: tomada entre la eminentia intercotylaris y la trochlea metatarsi II

AC - Longitud tróclea 4: tomada entre la eminentia intercotylaris y la trochlea metatarsi IV

AD - Ancho latero-medial proximal: tomado entre las cotylae

AE - Ancho latero-medial distal: tomado entre las trochlea metatarsi II y IV

AF - Diámetro latero-medial del corpus tarsometatarsi: tomado a mitad de A

AG - Diámetro cráneo-caudal del corpus tarsometatarsi: tomado a mitad de A

AH - Diámetro latero-medial de máxima constricción: tomado en el punto más

delgado del corpus tarsometatarsi

AI - Diámetro cráneo-caudal de máxima constricción: tomado

perpendicularmente a $\mathrm{H}$

AJ - Ancho latero-medial del hypotarsus

AK - Longitud del hypotarsus

AL - Ángulo de divaricación 1: medido entre las trochlea metatarsi II y III

AM - Ángulo de divaricación 2: medido entre las trochlea metatarsi III y VI

AN - Ancho cráneo-caudal proximal: tomado entre el hypotarsus y el borde craneal del tarsometatarso

Adicionalmente, se construyeron índices a fin de obtener variables que describan la forma, así como rasgos con posible significado funcional, eliminando el efecto introducido por el tamaño:

-Fémur: EA/EB, EC/ED, EC/EE, EF/EG, EI/EH

-Tibiotarso: ZB/ZA, ZD/ZC, ZJ/ZD, ZC/ZE, ZF/ZG, ZH/ZI

-Tarsometatarso: AA/AB, AA/AC, AD/AP, AD/AE, AJ/AK, AF/AG, AH/AI, $\mathrm{AL} / \mathrm{AM}$

-Miembro posterior: EB/ZB, ZB/AA, EB/AA

Las medidas AL y AM fueron convertidas a radianes. Todas las medidas fueron luego transformadas mediante la aplicación de logaritmo en base 10. Con todas ellas se 
realizaron análisis de componentes principales (PCA) para el fémur, tibiotarso, tarsometatarso y miembro posterior completo, utilizando una matriz de varianzacovarianza. Para el miembro posterior completo, también se realizó un PCA utilizando los índices. Además, se realizó un análisis discriminante sobre las medidas del tarsometatarso (Campbell y Marcus, 1992) y del miembro posterior completo. En todos los casos se utilizó una matriz de correlación.

Todos los análisis fueron realizados con los programas Statistica v.6.0 y R v.2.13.1.

El morfoespacio (el espacio teórico que incluye todas las posibilidades morfológicas) del miembro posterior de los fororracos junto a otras aves fue visualizado también mediante un gráfico ternario, en el cual el porcentaje de la contribución de cada segmento a la longitud total es ploteada en uno de tres ejes que delimitan un triángulo. Se utilizaron las medidas EB, ZB y AA, las que fueron sumadas sin logaritmizar a fin de obtener la longitud total del miembro posterior. Se obtuvieron los porcentajes de cada segmento dividiendo la longitud de cada uno de ellos por la longitud total y multiplicándola por 100. Teóricamente cualquier diseño apendicular puede ser ploteado en este tipo de gráficos siempre y cuando ninguno de sus segmentos sea 0 , evitando caer en el perímetro del triángulo (Gatesy y Middleton, 1997; Middleton y Gatesy, 2000).

En ninguno de los análisis aquí realizados se buscó recuperar asociaciones sistemáticas, sino explorar posibles asociaciones de acuerdo a su hábito locomotor (véase ítem 2.2.2 del capítulo 2).

\subsubsection{Análisis y resultados}

\section{A) Diversidad locomotora: Gráfico ternario}

El grupo de aves estudiadas incluye 75 individuos de distintas especies que ocupan solo el 9\% del área total de triángulo, distribuido en un área coincidente con aquella de Gatesy y Middleton (1997) (Figura 9.4). No se conocen especies con fémures menores al $27 \%$ o mayores de $56 \%$. La longitud del tibiotarso varía entre el $37 \%$ y el $55 \%$, mientras que la del tarsometatarso entre el $14 \%$ y el $45 \%$. Coincidentemente con lo propuesto por Gatesy y Middleton (1997), el tarsometatarso es el que más contribuye a la variación (31\%), seguido por el fémur (29\%) y por último el tibiotarso (18\%) que resulta conservativo en su longitud. En el gráfico (Figura 9.4A), los fororracos se ubican junto a los Otididae, los Passeriformes, Polyborus plancus (Falconiformes), Tyto alba 
(Strigiformes) y a los Rheidae y alejados de los Cariamidae y de Sagittarius, con los cuales tradicionalmente se los ha comparado (e.g., Andrews, 1899).

La contribución del fémur, tibiotarso y tarsometatarso al largo total del miembro posterior es idéntica en Psilopterinae y Patagornithinae, pero en los Mesembriornithinae el tarsometatarso es más largo y el tibiotarso es más corto. El fémur de los Mesembriornithinae puede ser tan largo como en Psilopterinae-Patagornithinae, como es el caso de Mesembriornis, o corto como en Taxón nuevo A. En este último el tarsometatarso es aún más largo, con una proporción similar a la de los Rheidae (Figura 9.4B).

\section{B) Análisis de componentes principales (PCA)}

Fémur. Se incluyeron 74 individuos de distintas especies. Los dos primeros componentes explican el 99\% de la variación total. El PC1 explica el 98,5 \% (Tabla 9.10). Si bien todas las variables presentan una fuerte contribución a este componente, las medidas de la extensión craneal de la crista trochanterica (ED) y el ancho cráneocaudal del condylus medialis (EH) presentan una contribución levemente superior. El CP2 explica el 0,5\% de la variación total en relación con las medidas largo del fémur (EA y EB) y el diámetro cráneo-caudal del corpus femoris (EG). De acuerdo con el supuesto de Campbell y Marcus (1992), las aves no se disgregaron según sus hábitos locomotores, sino más bien por tamaño corporal.

Los fororracos presentan valores negativos por el CP1 y positivos para el CP2. Cuando se grafica el CP1 contra el CP2, los fororracos se separan en dos grupos (Figura 9.5): Patagornis, Taxón nuevo A y Mesembriornis se asocian con formas terrestres con capacidad cursora, tales como Pterocnemia y Rhea, mientras que los Psilopterinae $(P$. lemoinei, P. bachmanni y Procariama simplex) se agrupan con formas voladoras, pero con cierta vinculación al ambiente terrestre, ya sean vadeadoras o caminadoras: Grus, Ciconia, Aramus, Ardea y Penelope. Llama la atención la pertenencia de la rapaz Geranoaetus a este grupo.

El CP1 permite discriminar los fororracos medianos (Patagornis, Taxón nuevo A y Mesembriornis) de los más pequeños (Psilopterinae). Sin embargo, el CP1 está fuertemente influenciado por la masa corporal $\left(\mathrm{R}=0,96 ; \mathrm{R}^{2}=0,93, \mathrm{p}=0,0000\right)$. Esto implica que del 98,5\% explicado por este componente, el 93\% lo está por la masa de los animales analizados. Se observa en la Figura 9.5 que las formas más pequeñas de aves aparecen a la derecha del gráfico, mientras que las más grandes aparecen a la izquierda. 
El CP2 permite discriminar fémures más robustos y cortos (con valores negativos) de aquellas con fémures más gráciles y alargados (indicados por los valores positivos). Los Psilopterinae pertenecen a este segundo grupo, mientas que los fororracos medianos tienen valores de $\mathrm{CP} 2$ más cercanos a 0 , indicando fémures más robustos. Emeus (Struthioniformes), una forma tradicionalmente considerada graviportal, presenta valores negativos para ambos componentes.

Tibiotarso. Se incluyeron 72 individuos de distintas especies. Los dos primeros componentes explican el 98,3\% de la variación total. El CP1 explica el 97 \% (Tabla 9.11) de la variación principalmente en relación con las medidas del diámetro láteromedial del corpus tibiotarsi (ZF), el ancho cráneo-caudal de ambos condyli (ZH y ZI) y la extensión craneal de la crista cnemialis cranialis (ZJ), mientras que el CP2 explica el 1,3\% en relación con las medidas del largo del tibiotarso (ZA y ZB).

En el gráfico del CP1 contra el CP2 (Figura 9.6) del tibiotarso, se observa una agrupación constituida por Patagornis, Taxón nuevo A conjuntamente con formas terrestres con capacidad cursora (Pterocnemia, Rhea y Dromaius), mientras que los Psilopterinae ( $P$. lemoinei y $P$. simplex) se agrupan con otras formas terrestres como los Otididae Ardeotis kori, Ardeotis arabs y Otis tarda, así como con el Anseriformes Chauna torquata, todas capaces de volar (algunas incluso son especies migradoras de grandes distancias), pero que preferentemente caminan.

$\mathrm{Al}$ igual que con el análisis del fémur, el CP1 está fuertemente influenciado por la masa corporal $\left(\mathrm{R}=0,96 ; \mathrm{R}^{2}=0,92, \mathrm{p}=0,0000\right)$ : del $97 \%$ explicado por el $\mathrm{CP} 1$, el $92 \%$ lo está por la masa de los animales analizados. Las formas más grandes se ubican a la izquierda del gráfico, mientras que las más pequeñas se ubican a la derecha. Además, las aves pueden también discriminarse de acuerdo al CP1, en cuanto a su diáfisis y crista cnemialis cranialis: valores negativos corresponden a formas de diáfisis robusta y crista cnemialis cranialis extendida.

El CP2 permite discriminar las aves de acuerdo al largo del tibiotarso. Formas vadeadoras como Phoenicopterus, Ciconia, Leptoptilos, Mycteria, Ardea y Aramus y caminadoras como Grus y Sagittarius presentan tibiotarsos muy largos (valores positivos altos). Los corredores Cariamidae presentan valores positivos cercanos a 0 , indicando la presencia de tibiotarsos más largos que los Phorusrhacidae. Los fororracos más pequeños presentan valores cercanos a 0 , indicando la presencia de tibiotarsos más largos que aquellos de las formas medianas. 
Tarsometatarso. Se incluyeron 76 individuos de distintas especies en el análisis. Los dos primeros componentes explican el 95,8\% de la variación total (Tabla 9.12). El CP1 explica el $88 \%$ de la variación en relación con las medidas largo del tarsometatarso (AA, AB y AC), mientras que el CP2 explica el 7,8\% en relación con las medidas del largo (AA, AB, AC), los diámetros latero-mediales (AF y AH) y los ángulos de divaricación (AL, AM).

Al igual que en el caso del tibiotarso, en el gráfico del CP1 y el CP2 (Figura 9.7) se observa una asociación de Patagornis y Taxón nuevo A con aves terrestres con capacidad cursora, tales como Pterocnemia, Rhea y Dromaius, mientras que los $P$. lemoinei, $P$. bachmanni y $P$. simplex se agrupan con aves terrestres que prefieren caminar, pero que presentan la capacidad de correr, tales como los Otididae Ardeotis kori, Ardeotis arabs y Otis tarda, aunque también aparecen asociadas otras aves terrestres vadeadoras como Chauna, Grus, y Leptoptilos crummeniferus y L. dubius, y terrestre caminadora como Sagittarius. El fororraco Paraphysornis se asocia con el Anseriformes Brontornis y el Struthioniformes Emeus. Phorusrhacos longissimus no aparece asociado a ningún grupo, sino más bien entre medio de las formas corredoras y las "graviportales".

En el caso del tarsometatarso, el CP1 si bien fuertemente influenciado por la masa corporal $\left(\mathrm{R}=0,95 ; \mathrm{R}^{2}=0,90, \mathrm{p}=0,0000\right)$ lo está menos que el fémur y el tibiotarso. Del 95,8\% explicado por el CP1, el 90\% lo está por la masa. Estos resultados son concordantes con el supuesto de Campbell y Marcus (1992) quienes establecen que este hueso es el que refleja mejor el hábito del animal en tanto no se encuentra tan influenciado por la masa. Las formas más voluminosas se ubican a la derecha, mientras que las más pequeñas lo hacen a la izquierda.

Con respecto al CP2, valores positivos indican tarsometatarsos largos, gráciles y con un ángulo de divaricación de las trochleae metatarsi bajo; valores negativos indican formas con tarsometatarsos cortos, robustos y con un ángulo de divaricación alto. En el caso de los fororracos, los Psilopterinae, Patagornis y Taxón nuevo A se corresponden con formas de tarsometatarsos largos y ángulos de divaricación menores a Paraphysornis que presenta ángulos altos y tarsos cortos. Phorusrhacos presenta una longitud intermedia entre los Psilopterinae y Paraphysornis, pero exhibe un alto ángulo de divaricación. 
Miembro posterior. Se incluyeron 72 individuos de distintas especies, analizados mediante el total de las 33 medidas tomadas en el fémur, tibiotarso y tarsometatarso. Los dos primeros componentes explican el 96,5\% de la variación total (Tabla 9.13). El CP1 explica el 92,5 \% de la variación en relación con la extensión craneal de la crista trochanterica (ED), ancho cráneo-caudal de los condyli (EH y EI), diámetro latero-medial del corpus tibiotarsi (ZF), la extensión craneal de la crista cnemialis cranialis (ZJ) y el largo del tarsometatarso (AA, AB y AC), mientras que el CP2 explica el 4\% de la variación en relación con el largo del tarsometatarso (AA, AB y AC) y los ángulos de divaricación (AL y AM).

En el gráfico del CP1 y el CP2 (Figura 9.8), se observa que Patagornis marshi y Taxón nuevo A están claramente agrupados con aves terrestres de capacidad cursora como Dromaius, Rhea y Pterocnemia. Por otro lado, P. simplex y P. lemoinei están asociados con aves más caminadoras como los Otididae Ardeotis kori, Ardeotis arabs, Otis tarda, el Falconiformes Sagittarius, el Gruidae Grus y los Ciconiidae Leptoptilos crummeniferus y L. dubius.

El CP1 está fuertemente influenciado por la masa corporal $\left(\mathrm{R}=0,96 ; \mathrm{R}^{2}=0,92\right.$, $\mathrm{p}=0,0000)$ : del 92,5\% explicado por el CP1, el 92\% lo está por la masa de los animales analizados (y solo el 0,5\% por la forma). Sin embargo, se observa que valores positivos del CP1 indican aves con condyli del fémur proyectados, crista trochanterica extendida cranealmente, tibiotarsos de diáfisis robusta y crista cnemialis cranealis desarrollada, y tarsometatarsos largos.

Al igual que en el análisis del tarsometatarso, valores positivos del CP2 indican tarsometatarsos largos, gráciles y con un ángulo de divaricación de las trochleae metatarsi bajo. Los fororracos muestran valores cercanos a 0 .

Índices del miembro posterior. Los índices resultaron muy poco explicativos. Solamente utilizando los primeros siete componentes se alcanza una explicación del 90\% (Tabla 9.14). Los dos primeros componentes explican solamente el 63,6\% de la variación total. El CP1 explica el 51,2 \% de la variación en relación con los índices relacionados a las proporciones del miembro (EB/AA y ZB/AA) y a la robustez del tarsometatarso (AF/AG y AH/AI), el CP2 explica el 12,4\% en relación con el desarrollo del hypotarsus (AJ/AK) y el CP3 el 9,6\% en relación con el desarrollo de la crista trochanterica (EC/ED), desarrollo relativo de las cristae cnemialis (ZJ/ZD) y robustez del tarsometatarso (AJ/AK). 
Los fororracos muestran valores cercanos a 0,4 para los componentes 1 y 2 (Figura 9.9), y se asocian a un grupo muy heterogéneo de aves formado por Cariamidae, Grus, Sagittarius, Pitangus, Phoenicopterus, Podiceps y Ardeotis arabs entre otros.

El CP1 separa formas de fémures más cortos y tarsometatarsos más largos y gráciles. En el caso del CP2, valores positivos indican hypotarsus más amplios láteromedialmente (índices $\mathrm{AJ} / \mathrm{AK}$ más altos), mientras que valores negativos indican hypotarsus angostos (índices AJ/AK más bajos).

\section{C) Análisis discriminantes}

Se realizaron dos análisis discriminantes no paramétricos del miembro posterior utilizando un código para el software R escrito por A. Scarano, dónde se usa la función fda del paquete mda (utilizando el algoritmo MARS). La elección del método no paramétrico se fundamenta en que la colección de aves actuales aquí estudiada no es lo suficientemente grande. En ambos análisis se utilizaron un total de 67 individuos de distintas especies a fin de elaborar el modelo predictivo. Para realizar este análisis se discriminaron tres grupos: "waders" (W) o aves vadeadoras, "ground birds" (G) o aves terrestres (que incluye aves capaces de caminar, correr y/o saltar) y las demás (X), un grupo que incluye fundamentalmente aves voladoras, arborícolas, rapaces y nadadores. La asignación de cada especie a cada grupo se realizó de acuerdo a Zeffer et al. (2003). Con la aplicación de este enfoque se pretendió explorar la posibilidad que algunos fororracos pudieran haber tenido hábitos vadeadores.

Tarsometatarso. El modelo utilizando solo el tarsometatarso presenta una probabilidad promedio de clasificación correcta de 67,3\% (Error del modelo: 0,20896; $\mathrm{N}=67)$. La probabilidad de clasificación correcta $(C C)$ de cada grupo es de:

\begin{tabular}{l|cccc}
\hline \hline & $\mathbf{G}$ & $\mathbf{W}$ & $\mathbf{X}$ & $\mathbf{C C}$ \\
\hline $\mathbf{G}$ & 11 & 4 & 7 & $50 \%$ \\
$\mathbf{W}$ & 2 & 10 & 7 & $71,4 \%$ \\
$\mathbf{X}$ & 5 & 1 & 25 & $80,6 \%$ \\
\hline
\end{tabular}

De acuerdo a este modelo predictivo, las probabilidades de pertenencia de los fororracos a los grupos aquí utilizados son las siguientes: 


\begin{tabular}{l|ccc}
\hline \hline & G & W & X \\
\hline Psilopterus lemoinei & 0,7379538 & $5,09 \mathrm{E}-04$ & 0,21109676 \\
Psilopterus bachmanni & 0,5336813 & $1,71 \mathrm{E}-05$ & 0,29489904 \\
Procariama simplex & 0,846708 & $5,90 \mathrm{E}-04$ & 0,09427001 \\
Paraphysornis brasiliensis & 0,9775841 & $6,63 \mathrm{E}-02$ & 0,02241585 \\
Patagornis marshi & 0,8731354 & $9,45 \mathrm{E}-03$ & 0,1174179 \\
Phorusrhacos longissimus & 0,9937827 & $1,90 \mathrm{E}-00$ & 0,00621535 \\
Taxón nuevo A & 0,9288799 & $3,71 \mathrm{E}-04$ & 0,03403694 \\
Brontornis burmeisteri & 0,8728768 & $4,93 \mathrm{E}-04$ & 0,12712325 \\
\hline \hline
\end{tabular}

De acuerdo a las medidas del tarsometatarso, los fororracos tienen mayor probabilidad de pertenecer al grupo G (“ground birds", Figura 9.10) que a cualquiera de los otros dos grupos, con una probabilidad de 99\% (Phorusrhacos longissimus) al 53\% (P. bachmanni). Los fororracos Procariama, Patagornis, Taxón nuevo A, Phorusrhacos y Paraphysornis presentan las mayores probabilidades de pertenencia a este grupo. El caso de las especies de Psilopterus no es tan categórico. Si bien, las probabilidades de que fueran vadeadoras son muy bajas, la probabilidad de que $P$. lemoinei pertenezca al grupo constituido por todas las demás aves no es baja (21\%) y en el caso de $P$. bachmanni es de casi 30\% (véase más arriba). Además, se estimó las probabilidades de pertenencia de Brontornis a los tres grupos. Se observa que tiene un $87 \%$ de probabilidad de ser "ground bird" y un $12 \%$ de pertenecer al grupo X.

Miembro posterior. El modelo del miembro posterior completo presenta una probabilidad promedio de clasificación correcta de 60,26\% (Error del modelo: 0,1791; $\mathrm{N}=67)$. La probabilidad de clasificación correcta $(\mathrm{CC})$ de cada grupo es de:

\begin{tabular}{l|cccc}
\hline \hline & $\mathbf{G}$ & $\mathbf{W}$ & $\mathbf{X}$ & $\mathbf{C C}$ \\
\hline $\mathbf{G}$ & 10 & 1 & 11 & $45,50 \%$ \\
$\mathbf{W}$ & 3 & 9 & 2 & $64,30 \%$ \\
$\mathbf{X}$ & 8 & 1 & 22 & $71,00 \%$ \\
\hline
\end{tabular}

De acuerdo a este modelo predictivo, las probabilidades de pertenencia de los fororracos a los grupos aquí utilizados son las siguientes:

\begin{tabular}{l|ccc}
\hline \hline & G & W & X \\
\hline Psilopterus lemoinei & 0,9382756 & $3,87 \mathrm{E}-02$ & 0,0613377 \\
Procariama simplex & 0,985703 & $6,95 \mathrm{E}-01$ & 0,01422747
\end{tabular}




\begin{tabular}{l|ccc} 
Patagornis marshi & 0,9980234 & $1,17 \mathrm{E}-02$ & 0,0018599 \\
Taxón nuevo A & 0,9958515 & $5,34 \mathrm{E}-01$ & 0,00409508 \\
\hline
\end{tabular}

De esta forma los fororracos pertenecen al grupo G (Figura 9.11) de Zeffer et al. (2003) con una probabilidad del 93\% para Psilopterus lemoinei al 99\% para Patagornis y Taxón nuevo A.

\subsection{Morfometría geométrica}

Frente a las problemáticas que ofrece la morfometría tradicional, se han desarrollado nuevas técnicas de análisis que permiten eliminar toda aquella información que no está relacionada con los cambios en la forma, como por ejemplo el tamaño, que tiene una fuerte influencia sobre las medidas lineales. En respuesta a estas problemáticas surgió la morfometría geométrica en la década de los noventas (Rohlf y Marcus, 1993; Adams et al., 2004).

En particular, las técnicas de morfometría geométrica basadas en landmarks o puntos homólogos resultan ser muy efectivas al momento de capturar la información acerca de la forma de un organismo. Esto se debe a que las coordenadas espaciales de los landmarks muestran tanto información acerca de las distancias entre los puntos (i.e., dimensiones lineales) como de la ubicación relativa de cada punto y no ofrecen restricciones a la dirección de cambios de forma. Estos cambios son luego analizados mediante técnicas multivariadas. Una de las ventajas principales de estudiar la forma utilizando landmarks es que el tamaño es descartado por los métodos de superposición, por lo cual las diferencias de forma son las que permanecen invariantes al tamaño (Rohlf y Slice, 1990). Más específicamente, los métodos de superposición eliminan la variación no relacionada con la forma mediante la superposición de acuerdo a algún criterio de optimización (e.g., Generalized Procrustes Analysis o GPA). En primer lugar, el centroide de cada configuración es calculado y trasladado al origen. Las configuraciones son escaladas a una unidad común dividiendo por el tamaño del centroide. Por último, las configuraciones son rotadas a fin de minimizar las diferencias entre los landmarks de distintos individuos (Rohlf y Slice, 1990). El proceso se repite para calcular la forma media que es inestimable antes de la superposición.

Después de la superposición, las diferencias de forma pueden ser descritas por las diferencias en las coordenadas de los landmarks entre los individuos. Las variaciones en forma, así como la dirección del cambio, pueden ser graficadas mediante 
grillas de deformación (thin-plate spline). Los parámetros que describen estas

deformaciones (partial warp scores) se pueden utilizar como variables para realizar análisis estadísticos de la variación de la forma dentro y entre poblaciones. Un análisis clásico es el relative warp analysis, que no es otra cosa que un análisis de componentes principales de los partial warps.

\subsubsection{Método}

Debido a que se trata de estructuras de gran complejidad, la pelvis y el cráneo de los fororracos fueron analizados mediante landmarks en 2D, fotografiados en vista dorsal y lateral (Figuras 9.12, 9.15 y 9.23).

\section{Landmarks seleccionados para el análisis del neurocráneo de los Phorusrhacidae}

(Figura 9.12)

\begin{tabular}{lcl}
\hline \hline Vista & Número & \multicolumn{1}{c}{ Definición del landmark } \\
\hline Dorsal & 1 & Punto más craneal de la sutura frontolacrimale. \\
& 2 & Punto más caudal de la sutura frontolacrimale. \\
3 & Punto de máxima inflexión sobre el margen de la órbita. \\
4 & Punto ubicado en la mitad de la distancia entre órbitas, \\
& 5 & perpendicularmente al landmark 3. \\
6 & Punto más lateral del processus postorbitalis. \\
7 & Punto más medial de la fossa temporalis. \\
& 8 & Punto ubicado en la mitad de la distancia entre las fossae \\
& 9 & Punto más caudal de la crista nucalis transversa. \\
& 10 & Punto de contacto entre la crista nucalis transversa y la \\
& 11 & prominentia cerebellaris. \\
& 1 & Punto más caudal de la prominentia cerebellaris. \\
2 & Punto más craneal de la sutura frontolacrimale. \\
3 & Punto más caudal de la órbita. \\
4 & Punto más ventral del processus postorbitalis. \\
5 & Origen del m. adductor mandibulae externus superficialis: punto \\
6 & más ventrodorsal en la fossa temporalis. \\
7 & Punto más dorsal del occiput. \\
8 & Punto más craneal del processus zygomaticus. \\
9 & Punto más caudal del processus paraoccipitalis. \\
10 & Extensión ventral del processus paraoccipitalis. \\
\hline \hline
\end{tabular}


Landmarks craneanos utilizados en esta tesis (Figura 9.15)

\begin{tabular}{|c|c|c|}
\hline Vista & Número & Definición del landmark \\
\hline \multirow[t]{13}{*}{ Dorsal } & 1 & Punto más craneal del pico. \\
\hline & $2-10$ & Semilandmarks sobre el margen lateral del pico. \\
\hline & 11 & Punto más craneal de la sutura frontolacrimale. \\
\hline & 12 & $\begin{array}{l}\text { Zona flexoria craniofascialis (o zona topográficamente } \\
\text { equivalente). }\end{array}$ \\
\hline & 13 & Punto más caudal de la sutura frontolacrimale. \\
\hline & 14 & Punto más caudal del processus supraorbitalis del os lacrimale. \\
\hline & 15 & Punto de máxima inflexión sobre el margen de la órbita. \\
\hline & 16 & $\begin{array}{l}\text { Punto ubicado en la mitad de la distancia entre órbitas, } \\
\text { perpendicularmente al landmark } 15 .\end{array}$ \\
\hline & 17 & Punto más lateral del processus postorbitalis. \\
\hline & 18 & Punto más medial de la fossa temporalis. \\
\hline & 19 & $\begin{array}{l}\text { Punto de contacto entre la crista nucalis transversa y la } \\
\text { prominentia cerebellaris. }\end{array}$ \\
\hline & 20 & Punto más caudal de la prominentia cerebellaris. \\
\hline & 21 & Punto medio de la Sutura frontoparietalis. \\
\hline \multirow[t]{19}{*}{ Lateral } & 1 & Extremo del pico. \\
\hline & $2-10$ & Semilandmarks sobre el culmen. \\
\hline & 11 & $\begin{array}{l}\text { Zona flexoria craniofascialis (o zona topográficamente } \\
\text { equivalente). }\end{array}$ \\
\hline & 12 & $\begin{array}{l}\text { Origen del } m \text {. adductor mandibulae externus superficialis: punto } \\
\text { más ventrodorsal en la fossa temporalis. }\end{array}$ \\
\hline & 13 & Punto más dorsal del occiput. \\
\hline & 14 & Punto más ventral del processus postorbitalis. \\
\hline & 15 & Punto más craneal del processus zygomaticus. \\
\hline & 16 & Extremo del processus suprameaticus. \\
\hline & 17 & Punto más caudal del processus paraoccipitalis. \\
\hline & 18 & Máxima extensión ventral del processus paraoccipitalis. \\
\hline & 19 & Punto más craneoventral del contacto os quadratum-arcus jugalis. \\
\hline & $20-23$ & Semilandmarks sobre el margen ventral del arcus jugalis. \\
\hline & 24 & Zona flexoria arcus jugalis (o zona topográficamente equivalente). \\
\hline & $25-32$ & Semilandmarks sobre el margen del tomium maxillare. \\
\hline & 33 & Punto más craneal de la narina. \\
\hline & 34 & Punto más caudal de la narina. \\
\hline & 35 & Punto más craneal de la fenestra antorbitalis. \\
\hline & 36 & Punto más craneal de la sutura frontolacrimale. \\
\hline & 37 & Punto más caudal del processus supraorbitalis del os lacrimale. \\
\hline
\end{tabular}

Landmarks pélvicos utilizados en esta tesis (Figura 9.23)

\begin{tabular}{lcl}
\hline \hline Vista & Número & \multicolumn{1}{c}{ Definición del landmark } \\
\hline Dorsal & 1 & Punto más craneal de la crista iliaca dorsalis. \\
& 2 & Punto más lateral del margen del ala preacetabularis ilii. \\
& 3 & Punto más medial y de máxima inflexión del ala preacetabularis ilii.
\end{tabular}




\begin{tabular}{|c|c|c|}
\hline & 4 & Punto más craneal del foramen acetabuli. \\
\hline & 5 & Punto más lateral de la crista supratrochanterica (o estructura \\
\hline & 6 & Punto ubicado sobre la mitad del ancho de la pelvis, ubicado \\
\hline & 7 & Punto de máxima inflexión por detrás del antitrochanter. \\
\hline & 8 & Punto más caudal de la spina dorsolateralis ilii. \\
\hline & 9 & Punto más caudal del synsacrum. \\
\hline \multirow[t]{18}{*}{ Lateral } & 1 & Punto más craneal de la crista iliaca dorsalis. \\
\hline & 2 & Punto más ventral del ala preacetabularis ilii. \\
\hline & $3-6$ & Semilandmarks sobre el margen ventral del ala preacetabularis ilii. \\
\hline & 7 & Punto más craneal del tuberculum preacetabulare. \\
\hline & 8 & Punto más craneal del foramen obturatum. \\
\hline & 9 & Punto más caudal del foramen obturatum. \\
\hline & 10 & Punto más caudal del processus terminalis ischii. \\
\hline & $11-14$ & $\begin{array}{l}\text { Semilandmarks sobre el margen caudal de la pelvis, entre los } \\
\text { landmarks } 10 \text { y } 15 .\end{array}$ \\
\hline & 15 & $\begin{array}{l}\text { Punto de máxima inflexión entre el processus terminalis ischii y la } \\
\text { spina dorsolateralis ilii. }\end{array}$ \\
\hline & $16-17$ & $\begin{array}{l}\text { Semilandmarks sobre el margen caudal de la pelvis, entre los } \\
\text { landmarks } 15 \text { y } 18 .\end{array}$ \\
\hline & 18 & Punto más caudal de la spina dorsolateralis ilii. \\
\hline & 19 & Punto más caudal del foramen acetabuli. \\
\hline & 20 & $\begin{array}{l}\text { Punto sobre el margen dorsal de la pelvis, ubicado verticalmente al } \\
\text { landmark } 19 .\end{array}$ \\
\hline & $21-24$ & $\begin{array}{l}\text { Semilandmarks sobre el margen dorsal del ala postacetabularis ilii, } \\
\text { ubicados entre los landmarks } 20 \text { y } 18 \text {. }\end{array}$ \\
\hline & $25-28$ & $\begin{array}{l}\text { Semilandmarks sobre el margen dorsal del ala preacetabularis ilii, } \\
\text { ubicados entre los landmarks } 20 \text { y } 1 \text {. }\end{array}$ \\
\hline & 29 & Punto más craneal del foramen ilioischiadicum. \\
\hline & 30 & Punto más caudal del foramen ilioischiadicum. \\
\hline & 31 & Punto más caudal del antitrochanter. \\
\hline
\end{tabular}

Las coordenadas $x$ e $y$ de cada landmark fueron digitalizadas utilizando el software TpsDig 1.41 (Rohlf, 2005). Las coordenadas resultantes fueron sometidas a un Generalized Procrustes Analysis para eliminar toda la información no relacionada con la forma (Rohlf y Slice, 1990; Zelditch et al., 2004). Los cambios localizados de forma fueron estimados por los partial warp scores (Bookstein, 1991). Una vez obtenidos estos valores, se realizó un relative warps analysis (RWA) (Rohlf, 1993) para examinar los cambios de forma del cráneo y pelvis utilizando los programas TpsRelw 1.35 (Rohlf, 2003) y MorphoJ v. 1.03c (Klingenberg. 2011).

Los relative warps obtenidos fueron utilizados para analizar si los grupos morfológicos son consistentes con la dieta y el hábito locomotor de los ejemplares. 


\subsubsection{Análisis y resultados}

\section{A) Cráneo}

Neurocráneo dorsal de fororracos. Se analizaron 14 individuos (cinco ejemplares pertenecientes a la familia Cariamidae y nueve a Phorusrhacidae) mediante 11 landmarks (Figura 9.12A). Los tres primeros componentes explican el 89, 7\%: el CP1 explica el 49,7\%, el CP2 el 28,8\% y el CP3 el 8,2\% (Tabla 9.15). Se observan tres grupos constituidos por los Cariamidae, especies asignadas al cráneo morfotipo 1 y al morfotipo 2 (Figura 9.13A y 9.14A).

El CP1 está fuertemente influenciado por el tamaño de la fossa temporalis, el contacto craneal con el os lacrimale, el desarrollo de la prominentia cerebellaris y el tamaño de los ossa frontalis: valores positivos de CP1 corresponden a formas de amplia región frontal, de reducido contacto craneal con el os lacrimale, reducida prominentia cerebellaris y pequeñas fossae temporalis, mientras que valores negativos corresponden a formas de menor área frontal con amplio contacto craneal con el os lacrimale, prominentia cerebellaris muy desarrollada y fossae temporalis muy expandidas. El CP1 permite discriminar el morfotipo craneano I del II, pero no separa el morfotipo I de los Cariamidae.

El CP2 está fuertemente influenciado por el desarrollo y disposición de la fossa temporalis y el contacto del os lacrimale con los ossa frontalis. CP2 negativos corresponden a formas de escaso contacto del os lacrimale con el os frontale, con fossae temporalis reducidas caudalmente dirigidas, mientras que valores positivos muestran formas de amplio contacto del os lacrimale con los ossa frontalis y fossae temporalis medialmente dirigidas.

Neurocráneo lateral de fororracos. Se incluyeron 12 individuos (cinco de la familia Cariamidae y siete de la familia Phorusrhacidae), analizados mediante 10 landmarks (Figura 9.12B). Los tres primeros componentes explican el 87, 9\% de la variación. El CP1 explica el 72,1\%, el CP2 el 11,1\% y el CP3 explica el 4,5\% (Tabla 9.16). Se observan dos grupos: Cariamidae y Phorusrhacidae (Figura 9.13B y 9.14B), claramente separados por el CP1. No se discriminan los morfotipos craneanos en vista lateral.

El CP1 está fuertemente influenciado por el desarrollo de la fossa temporalis y del neurocráneo y por la extensión y disposición de la región frontal: valores negativos incluyen formas con fossae pequeñas y neurocráneos reducidos, región orbitaria amplia 
y cranealmente inclinada; valores positivos incluyen formas de amplias fossae temporalis, con grandes neurocráneos y región frontal reducida subhorizontalmente dispuesta.

El CP2 está fundamentalmente influenciado por la altura del neurocráneo: valores positivos indican neurocráneos bajos mientras que valores negativos indican neurocráneos muy altos.

Cráneo dorsal. Se incluyeron en el análisis 77 individuos (cinco fororracos) aplicando 12 landmarks y 9 semilandmarks (Figura 9.15). Los tres primeros componentes explican el 87, 9\%. El CP1 explica el 72,4\%, el CP2 el 10,84\% y el CP3 el 4\% (Tabla 9.17). Los fororracos forman un grupo con Anas, Grus, Egretta, Podiceps, Rallus, Sula y Macronectes (Figura 9.16), un grupo heterogéneo de aves pertenecientes a distintos órdenes y hábitos tróficos.

El CP1 está relacionado con la longitud y ancho del pico y neurocráneo: valores negativos indican picos muy largos y angostos y neurocráneos muy cortos y angostos, mientras que valores positivos indican picos muy cortos y anchos, con neurocráneos muy amplios (largos y anchos). En este contexto, los fororracos presentan picos largos y angostos, levemente más largos que el neurocráneo (Figura 9.17). Andalgalornis se distingue de los demás fororracos por presentar un pico más corto.

El CP2 está relacionado con el tamaño de la región temporal y la región orbital y en menor contribución la longitud del pico. Valores positivos para el CP2 indican formas de neurocráneo alargados con una región orbitaria pequeña y ossa lacrimalis reducidos y picos relativamente más largos, mientras que valores negativos indican neurocráneos más cortos, aunque más anchos y región orbitaria amplia con ossa lacrimalis muy desarrollados. En general, los fororracos muestran valores negativos excepto Andalgalornis que se segrega por presentar los ossa lacrimalis muy desarrollados.

Cráneo lateral. Se analizaron 74 individuos (dos fororracos) mediante 16 landmarks y 21 semilandmarks (Figura 9.15B). Los tres primeros componentes explican el 84,1\%. El CP1 explica el 64,9\%, el CP2 el 13,2\% y el CP3 el 5,9\% (Tabla 9.18).

Los fororracos se agrupan con Phoenicopterus, Sula, Taraba, Psarocolius, Cochlearius y Monasa (Figura 9.18), un grupo heterogéneo constituido por aves de distintos órdenes y hábitos tróficos. 
El CP1 está fundamentalmente relacionado con la relación pico/neurocráneo, dada fundamentalmente a través del alargamiento del pico y en menor cantidad la reducción del neurocráneo: valores negativos incluyen formas de picos muy largos y neurocráneos pequeños, mientras que valores positivos incluyen aves de neurocráneos grandes y picos más cortos. Es destacable que la zona del pico que cambia de longitud en las aves aquí estudiadas corresponde a la región prenarial (craneal a las narinas), mientras que la región narial cambia muy poco. Formas de picos cortos tienen narinas grandes, mientras que formas de pico muy largos tienen narinas pequeñas. Los fororracos presentan pico levemente más largos que el neurocráneo, y narinas pequeñas (Figura 9.19).

El CP2 tiene relación con la altura total del pico, especialmente a nivel de las narinas y en la punta del pico. Valores positivos indican picos bajos, mientras que valores negativos indican picos altos. Ambos fororracos tienen valores negativos para éste componente. Sin embargo, Taxón nuevo A presenta valores cercanos a 0 , mientras que Andalgalornis tiene valores negativos alejado del 0 (Figura 9.18), indicando que su pico es más alto que el de Taxón nuevo A.

Cráneo lateral de aves carnívoras. A fin de evaluar la asociación de los fororracos con aves actuales depredadoras o carroñeras, se restringió el análisis a 26 individuos (dos fororracos) utilizando los mismos landmarks que en el análisis del cráneo lateral de todas las aves (Figura 9.15). Los tres primeros componentes explican el 84,4\%. El CP1 explica el 61,3\%, el CP2 el 16,1\% y el CP3 el 6,9\% (Tabla 9.19). Curiosamente, los fororracos aparecen como grupo separado de las formas carroñeras y de las depredadoras (Figura 9.20). Se diferencian de las aves rapaces (Falconiformes) fundamentalmente por tener picos más largos, de las carroñeras Cathartidae por presentar picos más altos y más largos y de los Ciconiidae carroñeros (Leptoptilos sp.) por presentar picos más altos, pero más cortos.

Los resultados son muy similares a aquellos obtenidos mediante el análisis de todos los cráneos. El CP1 está fundamentalmente relacionado con la relación pico/neurocráneo, fundamentalmente a través del alargamiento del pico y en menor cantidad la reducción del neurocráneo: valores positivos incluyen aves de picos muy largos, narinas pequeñas y neurocráneos pequeños, mientras que valores negativos incluyen aves de neurocráneos grandes y picos más cortos con narinas grandes. Los 
fororracos presentan picos con narinas relativamente pequeñas, levemente más largos que el neurocráneo.

El CP2 tiene relación con la altura total del pico, especialmente a nivel de las narinas y en la punta del pico. Valores negativos indican picos bajos, mientras que valores positivos indican picos altos. Taxón nuevo A presenta una altura del pico similar a la de las aves rapaces, mientras que Andalgalornis presenta un pico más alto.

Esplacnocráneo. Se realizó un análisis de la forma del pico, margen craneal de la fenestra antorbitalis, os lacrimale y arcus jugalis mediante la utilización de 9 landmarks y 21 semilandmarks. Se incluyeron 74 individuos (dos fororracos). Los tres primeros componentes explican el 84,2\%. El CP1 explica el 56,5\%, el CP2 el 21,5\% y el CP3 el 6,1\% (Tabla 9.20).

Las agrupaciones obtenidas en este análisis son muy similares a aquellas derivadas del análisis de todos los cráneos en vista lateral. Sin embargo, en este último análisis los grupos aparecen más cohesivos. Los fororracos se agrupan con Taraba, Psarocolius, Cochlearius, Monasa, Sula y Phoenicopterus (Figura 9.21).

El CP1 está relacionado con la longitud del pico y del arcus jugalis: valores negativos indican picos muy largos y arci cortos, mientras que valores positivos indican picos muy cortos y arci largos. Los fororracos presentan picos largos y arci de longitud media.

El CP2 está relacionado con la altura del pico: valores positivos indican picos bajos, valores negativos indican picos altos. Los fororracos presentan picos altos (más alto en Andalgalornis que en Taxón nuevo A).

Pico. Este análisis es similar al realizado sobre el esplacnocráneo, aunque se excluyó el arcus jugalis. Se incluyeron 74 individuos (dos fororracos), analizados mediante 8 landmarks y 18 semilandmarks. Los tres primeros componentes explican el 83,4\%. El CP1 explica el 51,3\%, el CP2 el 25\% y el CP3 el 6,9\% (Tabla 9.21). Los fororracos se agrupan con las aves rapaces (Accipitridae, Pandionidae, Falconidae, Sagittaridae, Strigidae) y con el Psittacidae Cyanoliseus (Figura 9.22).

El CP1 está relacionado con la longitud del pico y del processus supraorbitalis del os lacrimale: valores altos indican picos muy largos con processi reducidos, mientras que valores negativos indican picos cortos con processi desarrollados. Este componente separa a los fororracos de las rapaces actuales fundamentalmente porque 
tienen picos más largos y processi supraorbitalis mas cortos (en relación al pico) que las rapaces vivientes.

El CP2 está influenciado por la altura del pico: valores positivos corresponden a picos altos y valores negativos a picos bajos. Taxón nuevo A tiene el pico más bajo que las rapaces actuales. Este componente permite separar a las formas rapaces de las carroñeras: las aves depredadoras presentan picos proporcionalmente más altos, mientras que las carroñeras presentan picos más bajos (Cathartidae) o más bajos y largos (Ciconiidae).

\section{B) Pelvis}

Pelvis Dorsal. Se analizaron 69 individuos (cinco ejemplares de fororracos) mediante 9 landmarks (Figura 9.23A). Los tres primeros componentes explican el 86,7\%. El CP1 explica el 65,9\%, el CP2 el 14,2\% y el CP3 el 6,5\% (Tabla 9.22). Los fororracos se agrupan con las formas de pelvis angostas y alargadas, especialmente con formas terrestres con capacidad cursora como Dromaius y Rhea, separados de otras formas corredoras (Cariamidae) y de formas más caminadoras (Otididae y Psophiidae) por presentar pelvis más largas; y separados de las formas acuáticas Gavia y Podiceps con pelvis aún más largas (Figura 9.24). La excepción es Andalgalornis, cuya longitud es similar a las formas acuáticas, aunque se separa de éstas por presentar la pelvis más ancha (Figura 9.25). No se separan los dos morfotipos pélvicos.

El CP1 está relacionado con la longitud postacetabular y el ancho de la pelvis: valores negativos corresponden a pelvis angostas de región postacetabular larga, mientras que valores positivos indican pelvis anchas de región postacetabular corta. Con algunas excepciones, este componente discrimina a las formas cursoras (y nadadoras) de las terrestres y a éstas de las vadeadoras. Las formas cursoras tienen la región postacetabular muy larga, mientras que las formas más caminadoras (Otididae y Psophiidae) presentan pelvis más cortas, de región postacetabular corta, aunque menos corta que la de las aves vadeadoras.

El CP2 está relacionado con el ancho de la pelvis y la longitud preacetabular: valores positivos indican pelvis anchas de región preacetabular corta, mientras que valores negativos indican pelvis angostas con regiones preacetabulares largas. Los fororracos presentan pelvis angostas con región preacetabular relativamente corta. 
Pelvis Lateral. Se incluyeron 69 individuos (cinco fororracos) y se analizaron mediante 13 landmarks y 18 semilandmarks (Figura 9.23B). Los tres primeros componentes explican el 71,94\%. El CP1 explica el 41,8\%, el 2 el 19,9\% y el 3 el 10,2\% (Tabla 9.23). Los fororracos se asocian con formas como Dromaius, Chunga, Cariama, Gavia, Podiceps, Phalacrocorax y Ramphastos, todas aves con distintos hábitos locomotores, pero con la particularidad de tener regiones postacetabulares muy largas (Figura 9.26 y 9.27). No se discriminan los morfotipos pélvicos.

El CP1 está relacionado con la extensión de las regiones preacetabular y postacetabular: valores negativos indican pelvis de región preacetabular larga y región postacetabular corta, mientras que valores positivos indican pelvis de región preacetabular corta y postacetabular larga. Los fororracos presentan una pelvis de región postacetabular muy larga y región preacetabular muy corta. Este componente separa a los fororracos de las formas terrestres Cariamidae (corredoras) y Otididae (caminadoras) y de las vadeadoras, con pelvis aún más cortas que las anteriores.

El CP2 está relacionado fundamentalmente con la altura de la región postacetabular, esencialmente a través de la extensión del processus terminalis ischii: valores positivos indican pelvis poco extendidas ventralmente y valores negativos indican pelvis fuertemente extendidas ventralmente. Los fororracos presentan pelvis altas, pero con un processus terminalis ischii pobremente extendido ventralmente.

\subsection{Discusión y conclusiones}

\subsubsection{Cráneo y diversidad trófica}

La aplicación de métodos de morfometría geométrica al cráneo de las aves es restringida posiblemente debido a las dificultades en delimitar landmarks de tipo I (Kulemeyer et al., 2009), por ejemplo, ante la imposibilidad de establecer claramente los límites entre huesos producto de la fusión de los mismos en individuos adultos.

Las primeras aproximaciones al estudio de la forma craneana de las aves atribuyen las principales diferencias en el diseño del cráneo a los cambios ocurridos en tres partes: el pico, la órbita y la caja craneana (Marinelli, 1928; Van der Klaauw, 1948). Sin embargo, más recientemente se ha establecido que la vasta diversidad morfológica y trófica es fundamentalmente el resultado de la variación en el pico (Zusi, 1993; Marugán-Lobón y Buscalioni, 2003) que abarca desde aves brevirostras a longirostras (Marugán-Lobón y Buscalioni, 2006). El estudio geomorfométrico aquí realizado soporta esta conclusión. Más aún, resalta que la zona del pico que experimenta 
cambios de longitud corresponde principalmente a la región prenarial, mientras que la región narial es más conservativa.

La amplia diversidad y el diseño del sistema trófico de las aves es difícil de interpretar (Zweers y Vanden Berge, 1997). Las presiones selectivas que producen esta amplia diversidad morfológica pueden deberse a los diferentes ítems tróficos, así como a las diferentes estrategias de captura de ese ítem. En el caso de los taxones estudiados aquí, tanto el pico (con el cual se recoge el alimento) como el neurocráneo (donde se insertan los músculos mandibulares que accionan el aparato trófico) son de forma muy variable. La variación de estas regiones del cráneo podría estar relacionada con el mecanismo de alimentación y a su vez, relacionado con el grado de desarrollo de los músculos mandibulares. Sin embargo, el análisis morfométrico realizado aquí muestra que no existe una correlación morfo-funcional entre los hábitos tróficos y la forma del cráneo. Esto es concordante con los resultados de Marugán-Lobón y Buscalioni (2003, 2006).

No obstante, se discriminan algunos grupos cuando se analiza el cráneo en vista lateral. Por ejemplo, los Ramphastidae (Piciformes) se agrupan con los Bucerotidae (Coraciiformes) que son animales fundamentalmente frugívoros (aunque algunos Bucerotidae -no estudiados aquí- son carnívoros), caracterizados por presentar picos altos, muy largos y anchos (Figuras 9.16, 9.18 y 9.22); los Ciconiidae forman un grupo caracterizado por presentar picos largos, pero presentan diferentes hábitos tróficos: se alimentan de invertebrados, peces e inclusive carroña; las aves rapaces (Strigiformes y Falconiformes) forman un grupo caracterizado por picos altos, cortos y anchos. Sin embargo, en este grupo también aparecen aves folívoras y frugívoras como Opisthocomus e incluso herbívoras como Lophortyx. El resto de las aves (incluidos los fororracos) constituye una nube entre los tres grupos mencionados (Figura 9.18). En este caso la forma del cráneo es marcadamente heterogénea y los hábitos tróficos muy diversos (desde filtradores hasta carroñeros).

Tratar de predecir el hábito trófico de un ave solamente estudiando la morfología de su aparato trófico es aventurado. La carnivoría o incluso la herbivoría exclusiva son casos más bien raros entre las Neornithes. La mayoría de las aves son omnívoras ocasionalmente carnívoras o herbívoras, a veces de forma frecuente y otras de forma estacional u oportunista. Esta condición generalista en el hábito trófico queda reflejada en la amplia diversidad de cráneos de aves oportunistas. En particular, la forma del pico por sí sola, no es un indicador confiable del comportamiento alimenticio de un ave; más 
aún en aves fósiles para las cuales no se conocen análogos vivientes. Este aspecto ha sido señalado reiteradamente (e.g. Murray y Vickers-Rich, 2004). Los estudios del cráneo deben complementarse con los de otras partes del organismo como, por ejemplo, la columna cervical y el miembro posterior que también participan en la captura y manipulación del alimento (Zweers et al., 1994).

La evolución de la forma del cráneo de los fororracos, que implicó modificaciones en la geometría, longitud y altura del pico, podría haber estado influenciada por varios cambios evolutivos relacionados con la adaptación a un nicho específico. Una especialización en la manera de alimentación parece haber ocurrido (véase capítulos 5 y 8) que podría explicar las modificaciones en la forma, longitud y altura del pico. En vista dorsal, el neurocráneo permite discriminar los dos morfotipos craneanos. Esta separación está dada fundamentalmente por la extensión de la fossa temporalis que en el morfotipo II es más amplia y más extendida medialmente. Esto estaría correlacionado con la presencia de un mayor $m$. adductor mandibulae externus en estos fororracos (véase capítulo 7), que se relaciona con una mayor fuerza de mordida (véase capítulo 6) y probablemente con un mayor tamaño de ítem trófico.

La combinación de un pico alto, largo y angosto es un rasgo que se observa solo en aves fósiles: Gastornithiformes (Witmer y Rose, 1991), Dromeornithiformes (Murray y Vickers-Rich, 2004) y en Cariamiformes Phorusrhacidae (Degrange et al., 2010). Sin embargo, la combinación de estas tres características y un gancho distal es exclusiva de los fororracos. El pico de los fororracos presenta una morfología similar a la de las aves rapaces (Degrange, 2008; Degrange y Tambussi, 2008), adecuada para desgarrar carne de sus presas (Hertel, 1995), aunque se diferencia de éstas por ser más largo (Figura 9.22). Otra diferencia importante mencionada previamente es que el gancho distal es de sección ovalada (véase capítulo 4), mientras que en aves rapaces es de sección triangular.

Por su parte, la carroñería es un fenómeno muy difundido en las aves. Algunas se alimentan exclusivamente de carne muerta (Leptoptilos crummeniferus, Cathartidae y algunos Accipitridae), mientras que la mayoría solo lo hacen ocasionalmente (Polyborus sp., Lariidae, Procellariidae entre otros) (Storer, 1971). Incluso el cuervo común (Corvus corax) se alimenta principalmente de carroña gracias a su pico alargado que puede introducir a través de agujeros formados en la misma. Comparado con las aves rapaces, las aves carroñeras presentan un pico largo, angosto y bajo (Hertel, 1995). Un pico largo podría ser beneficioso para revolver la carroña a través de los orificios 
formados en los cadáveres, como hacen los Cathartidae, Leptoptilos y Corvus. Además, un pico curvo aumenta la capacidad de rasgar carne (Kulemeyer et al., 2009) como hacen Corvus y los Cathartidae. El pico de los fororracos se diferencia del de las aves carroñeras Cathartidae por ser más altos y más largos y del de los Ciconiidae carroñeros (Leptoptilos crummeniferus) por ser más altos, pero más cortos. En este contexto, se infiere que la compresión y la altura del pico de los fororracos están relacionadas con la actividad depredadora (véase capítulo 8) y no con la posibilidad de manejar carroña. Sin embargo, esta aseveración no es excluyente habiendo -como en todas las interpretaciones paleobiológicas- un margen de variación posible admitiendo que ocasionalmente pudieran alimentarse de carroña.

\subsubsection{Miembro posterior y locomoción}

Hábito locomotor y uso del sustrato. El desarrollo del módulo locomotor anterior habría distendido las presiones sobre la evolución del complejo apendicular posterior de las aves, permitiendo una diversificación de los hábitos y estilos de vida (Gatesy y Middleton, 1997), distinguiéndose desde aves hiper aéreas (e.g., Apodidae) hasta exclusivamente terrestres (e.g., Rheidae). Entre estos extremos se sitúan todas las aves representativas de una amplia gama de hábitos locomotores y una vasta diversidad de ambientes ocupados. Algunas aves son muy ubicuas mientras que otras son selectivas en la elección del ambiente que frecuentan. Sin embargo, la complejidad del comportamiento animal es tan amplia que se vuelve prácticamente imposible describir hábitos locomotores únicos. Más aún, a medida que se conoce más acerca de la etología de los animales, se disuelven los límites entre los comportamientos definiéndose un espectro continuo de posibles hábitos locomotores, imposibilitando la clasificación de los mismos. Este escenario complica las presunciones que puedan hacerse a partir de la morfología apendicular en tanto ésta no necesariamente tiene una relación inequívoca con la diversidad locomotora o con un hábito en particular.

Existe además gran confusión en la bibliografía acerca de qué es el hábito locomotor y el tipo y uso del sustrato: muchas veces se utiliza el término "arborícolas" (i.e., viven en los árboles) como modo o hábito locomotor en determinadas especies de Passeriformes capaces de volar, cuando en realidad se debería utilizar el término "trepadoras" (por ejemplo), mientras que arborícolas hace referencia al sustrato. Incluso se utiliza el término "rapaz" o "aves de presa" como modo de locomoción (e.g., Zeffer 
et al., 2003) para aves como los Falconidae y Accipitridae, cuando en realidad la forma de desplazarse de estas aves es a través del vuelo.

De cualquier manera, hay ciertas generalizaciones que sí son posibles: un módulo locomotor posterior muy desarrollado está relacionado con una fuerte vinculación al ambiente terrestre (Dial, 2003). Es el caso de los fororracos, en los cuales el módulo locomotor posterior está muy desarrollado (véase capítulo 4 y 7) y este carácter está acompañado de la reducción de los miembros anteriores, indicando que la mayoría de los fororracos eran aves terrestres obligadas, incapaces de volar (véase capítulo 10).

Las aves exhiben una amplia variación en la manera en que usan sus miembros posteriores, desde muy limitado en formas hiper aéreas hasta un uso exclusivo en formas terrestres (Habib y Ruff, 2008). Entre estos dos extremos, las aves voladoras son capaces también de caminar, correr, saltar, chapotear o bucear. En las aves actuales, una simple observación directa permite discriminar si un ave es capaz o no de volar, pero aunque porque sea capaz de hacerlo, no necesariamente se las clasifica como voladoras. Ejemplos de ello son los Tinamidae, los Otididae, los Psophiidae o los Cariamidae, que si bien son capaces de volar, son considerados aves terrestres por transcurrir la mayor parte del tiempo en tierra. De la misma manera, los Anatidae y los Podicipedidae también son capaces de volar, aunque son considerados como nadadoras pues pasan la mayor parte del tiempo en ese medio.

Las aves terrestres o "ground birds" en el sentido de Zeffer et al (2003) son aquellas que utilizan predominantemente sus miembros posteriores en la locomoción sobre el suelo, ya sea para saltar, caminar o correr. Las aves vadeadoras, definidas como aquellas que se alimentan caminando en suelos anegados (i.e., vadean), técnicamente son aves terrestres ya que su modo de locomoción es el caminar (Storer, 1971; Raikow, 1985). Sin embargo, comúnmente se las separa de las primeras (e.g., Zeffer et al., 2003).

Por todo lo expuesto se evidencia que existe un desajuste entre la asignación de un hábitat a través del módulo locomotor anterior y del posterior. Debido a que el hábito locomotor y el sustrato en el que vive un ave no son fáciles de discriminar, muchos estudios ecomorfológicos utilizan el hábito y modo locomotor "preferido" de un ave.

Como ya se expresó previamente, la reducción del miembro anterior asociada a una gran masa corporal de algunas formas (véase capítulo 6) indica que la mayoría de los fororracos eran incapaces de volar (véase capítulo 10), de manera tal que eran aves terrestres obligadas. La terrestrialidad de los fororracos podría incluir diferentes estilos 
no excluyentes como saltador, caminador, cursor o incluso vadeador. Se ha establecido que la longitud de sus miembros delata su capacidad cursorial (e.g., Tambussi y Noriega, 1996; Alvarenga y Höfling, 2003; Blanco y Jones, 2005). Sin embargo, debido a que rasgos como la amplia longitud del tarsometatarso son compartidos por aves cursoras, caminadoras y vadeadoras, se pone en duda que la simple utilización de la métrica del miembro posterior refleje de forma inequívoca la cursorialidad de los fororracos. Ahondar en este aspecto es el motivo principal de lo que resta de este capítulo y de esta discusión.

Proporciones del miembro. Las proporciones de los miembros representan un punto clave en el diseño de cualquier miembro (Gatesy y Middleton, 1997; Middleton y Gatesy, 2000; Gatesy et al., 2009) y han sido aplicadas para categorizar mamíferos especializados en la carrera, excavación o incluso soporte del peso (Gregory, 1912; Osborn, 1929; Smith y Savage, 1956, Garland y Janis, 1993; Gebo y Rose, 1993; Carrano, 1997), así como un indicador de la cursorialidad en dinosaurios (e.g., Osborn, 1916; Holtz, 1994, Ostrom, 1976, Coombs, 1978, Sereno et al., 1996) e incluso en aves (Gatesy y Middleton, 1997; Zeffer et al., 2003). Sin embargo, la real información acerca del hábito locomotor que pueden proveer ha sido fuertemente cuestionada, particularmente en el caso de las Neornithes. Varios estudios indican que las proporciones entre los elementos de la pierna o la longitud total de la misma no son de por sí indicativas del tipo de locomoción (Gatesy y Middleton, 1997; Zeffer et al., 2003; Habib y Ruff, 2008). No es nuevo que las aves con largas patas pueden vivir en hábitats muy distintos. Por ejemplo, el grupo LL (Long-Legged) de Campbell y Marcus (1992) incluye un grupo muy heterogéneo de aves que comparten "sólo" la gran longitud de las piernas como Ciconiidae, Gruiidae o Rheidae.

Un ave sin duda corredora como el ñandú Rhea americana tiene el tarsometatarso y tibiotarso igualmente largos, al igual que Sagittarius que, sin ser cursorial, frecuenta pastizales o que el flamenco Phoenicopterus, un ave claramente vadeadora.

Las proporciones de los miembros posteriores de los Psilopterinae y Patagornithinae se asemejan a las de formas terrestres caminadoras como Otis (Otididae) y, en el otro extremo de la gama de tamaño, al Passeriformes Turdus (Turdidae). En cambio, las proporciones de los miembros de los Mesembriornithinae son similares a formas terrestres con capacidad cursora, como los Rheidae. 
Llamativamente, las chuñas Chunga y Cariama tienen proporciones diferentes a los fororracos (Figura 9.4).

En una serie Psilopterus-Cariama-Rhea hay un aumento progresivo de la longitud relativa de los segmentos distales de la pierna (tibiotarso y tarsometatarso) que implica una reducción progresiva de la longitud relativa del segmento proximal (fémur).

Las chuñas, que pueden alcanzar altas velocidades $(40 \mathrm{~km} / \mathrm{h})$ y se consideran ágiles corredoras (Gonzaga, 1996), tienen el tibiotarso más largo que el tarsometatarso, los dedos II y IV cortos, mientras que el tercer dedo es relativamente largo. Ambos Psophia y especialmente Otis, que mostraron una proporción similar a la pierna de Psilopterus, pueden correr y volar, pero más a menudo caminan (Sherman, 1996; Collar, 1996).

En suma, exclusivamente en base a las proporciones de los elementos del miembro posterior no es posible establecer de manera inequívoca que todos los fororracos hayan sido aves con capacidad cursora.

PCA y análisis discriminantes. El CP1 de todos los análisis de componentes principales de medidas lineales aquí realizados (fémur, tibiotarso, tarsometatarso y miembro posterior completo) está fuertemente influenciado por la masa corporal. Las aves más grandes aparecen en uno de los extremos de los gráficos (Figuras 9.5, 9.6, 9.7 y 9.8). Sin embargo, es evidente que existe una correlación entre la masa corporal y la terrestrialidad: aves más grandes y de mayor masa suelen pasar más tiempo en tierra que en el aire y existe un valor de masa umbral por encima del cual un ave no puede levantar vuelo. Esta masa es del orden de los 12-14 kg (Pennycuick, 1989) o $16 \mathrm{~kg}$ (Pennycuick, 2007). Así queda reflejado en los gráficos en los cuales coincide la distribución de las aves de mayores tamaños con aquellas que están más asociadas al ambiente terrestre (sean caminadoras, cursoras o vadeadoras).

En todos los análisis realizados en esta tesis, los Psilopterinae se asociaron con aves terrestres más caminadoras como los Otididae (Otis y Ardeotis), aunque también aparecen asociados a Leptoptilos crummeniferus (un ave vadeadora según Zeffer et al., 2003), mientras que los Patagornithinae y Mesembriornithinae se asocian a los Rheidae y Casuariidae, aves terrestres con capacidad cursora.

En el caso del fémur es claro que la masa corporal tiene alta influencia sobre la forma (Campbell y Marcus, 1992; Zeffer et al., 2003). Sin embargo, el CP2 discrimina a las aves de acuerdo a la forma del fémur: largos y gráciles de cortos y robustos. Los 
Mesembriornithinae y Patagornithinae presentan una morfología similar a los Rheidae, mientras que los Psilopterinae -que presentan tamaños similares a los Otididade (CP1)-, presentan fémures más largos y gráciles. Las aves vadeadoras presentan fémures más cortos y robustos (e.g., Phoenicopterus) o por el contrario más gráciles y delgados (e.g., Ardea y Ciconia) que los fororracos.

En el caso del tibiotarso, la métrica de los Psilopterinae es idéntica a aquella de los caminadores Otididae y diferente de los corredores Cariamidae; mientras que Patagornithinae y Mesembriornithinae presentan tibiotarso de métrica similar a la de los Rheidae y Casuariidae. Los Psilopterinae presentan una extensión craneal de las cristae cnemialis y una robustez de la diáfisis similar al de aves típicamente vadeadoras, pero se caracterizan por presentar tibiotarsos más cortos que las aves vadeadoras. Los Patagornithinae y Mesembriornithinae presentan cristae cnemialis cranialis más extendidas cranealmente, tibiotarsos más robustos y más cortos que las aves vadeadoras.

La morfología del tarsometatarso está fuertemente influenciado por el hábito de un animal (Campbell y Marcus, 1992). Sin embargo, se evidencia en la Figura 9.7 que aves vadeadoras, caminadoras y algunas corredoras (e.g., Cariamidae) presentan una morfología muy similar. Los Psilopterinae se incluyen en esta asociación. Algunas aves vadeadoras como el flamenco tienen tarsometatarsos marcadamente más largos que los fororracos, con trochleae metatarsi menos divergentes, pero otras como Leptoptilos o Grus presentan una longitud y divaricación troclear muy similar. Los Mesembriornithinae y Patagornithinae presentan tarsometatarsos de morfometría similar a formas cursoras como Rheidae y Casuariidae. Paraphysornis y el Anseriformes Brontornis aparecen asociados a la moa Emeus, una Palaeognathae fósil considerada "graviportal" de acuerdo a su tarsometatarso corto, robusto y de trócleas divergentes. Phorusrhacos presenta tarsometatarsos más cortos que los Patagornithinae (Alvarenga y Höfling, 2003) y más robustos.

Cuando se analiza el miembro posterior en conjunto se observa que los Patagornithinae y Mesembriornithinae se asocian con formas cursoras, pero los Psilopterinae aparecen nuevamente asociados a formas vadeadoras y caminadoras. Incluso los Cariamidae aparecen asociados a Mycteria y Ciconia, aves consideradas vadeadoras. Este análisis de componentes principales en particular refleja que la distinción entre las aves vadeadoras y las aves terrestres utilizando estas variables del miembro posterior resulta sumamente difícil. En otras palabras, en un plano morfométrico un ave vadeadora puede ser terrestre y un ave terrestre puede ser 
vadeadora (Figura 9.11). Las aves vadeadoras y terrestres se diferencian en el ambiente o sustrato que frecuentan, pero no el hábito locomotor, ya que ambas caminan.

Esta afirmación queda reforzada por las reclasificaciones hechas en los análisis discriminantes realizados aquí (véase más arriba). Por ejemplo, en las Figuras 9.10 y 9.11 se observa que no existe una separación clara entre las aves vadeadoras y las aves terrestres. Sin embargo, ambos análisis predijeron que los fororracos son formas terrestres. Las probabilidades de predicción son generalmente altas para la pertenencia al grupo G ("ground birds") y bajas para la pertenencia al grupo W (vadeadoras). Sin embargo, el análisis discriminante realizado sobre tarsometatarso predijo que Psilopterus bachmanni era un ave terrestre con una probabilidad del 53\%, pero también tiene una probabilidad de casi el 30\% de pertenecer al grupo heterogéneo X (constituido por aves trepadoras, chapoteadoras, buceadoras y rapaces), lo cual indicaría que el miembro posterior de P. bachmanni es morfométricamente generalista.

Morfometría de la pelvis. Los análisis de morfometría geométrica realizados sobre la pelvis demostraron que la misma y en particular la longitud postacetabular resulta ser un mejor indicador que los miembros posteriores al momento de discriminar algunos hábitos. Si bien con excepciones (e.g., Ramphastidae) se puede decir que la pelvis con región postacetabular larga corresponde a aves caminadoras, corredoras o buceadoras. Los Cariamidae (que son considerados corredores) presentan regiones postacetabulares más largas y pelvis más altas que los Otididae y Psophiidae. A su vez estos últimos (que son aves caminadoras) presentan pelvis mucho más largas que las aves vadeadoras (que presentan las regiones postacetabulares muy cortas). Los fororracos presentan pelvis altas y largas con regiones postacetabulares muy largas. Esta combinación resulta exclusiva de estas aves y los separa claramente de las aves acuáticas. La extensión postacetabular de la pelvis de los fororracos está relacionada con el mayor desarrollo de la musculatura extensora de la cadera (véase capítulo 7), una característica de las aves con capacidad cursorial.

Habiendo discutido los análisis, se evidencia que la morfometría apendicular no resulta ser $100 \%$ confiable al momento de discriminar los distintos hábitos locomotores de las aves. Si la morfología del miembro posterior de un ave terrestre es en muchos casos indiferenciable de la de un ave vadeadora (y viceversa) ¿por qué al menos algunos de los fororracos no podrían haber sido vadeadores? 
Indudablemente la morfología cualitativa sigue siendo la clave cuando la morfometría conduce a un camino sin respuestas. Si uno analiza aisladamente el módulo locomotor de los Otididae puede suponer que se trata de un ave terrestre incapaz de volar y, por el contrario, son aves que vuelan e incluso algunas especies migran (Collar, 1996). Las Ratitae con capacidad cursorial tienen pelvis elongadas y estrechas, una característica compartida con aves buceadoras. Pero también tienen tibiotarsos y tarsometatarsos elongados, característica que comparten con las aves vadeadoras (que no tienen pelvis elongadas), pero no con las buceadoras. La región preacetabular es corta comparada con la postacetabular y la altura de la pelvis (véase capitulo 6) es mayor en las Ratitae cursoras. En suma, la forma de la pelvis y de los miembros posteriores sumado al desarrollo de las cristae cnemialis $y$ la forma y proporciones de los dedos nos dan una idea aunque sea orientativa, del modo de locomoción.

Obviamente, es el estudio conjunto de todo el módulo locomotor posterior (pelvis + miembro posterior) y del módulo locomotor anterior el que revelaría apropiadamente el modo de locomoción preferencial utilizado por un ave.

Los miembros posteriores actúan en conjunto con la pelvis y es justamente esta estructura (módulo locomotor posterior) la que refleja mejor el hábito locomotor de los fororracos. La pelvis alta y larga, con una región postacetabular muy extendida caudalmente, así como un antitrochanter muy desarrollado y extendido lateralmente son indicadores de un hábito terrestre con capacidad cursora. En las aves caminadoras, el antitrochanter también está muy bien desarrollado, pero la pelvis es más baja y menos alargada. Las aves vadeadoras presentan una pelvis baja, con una región postacetabular muy corta y el antitrochanter poco desarrollado. Recordemos aquí que el antitrochanter es una estructura única de las aves que se relaciona con el sostén corporal y el mantenimiento del balance durante la locomoción bípeda (Hertel y Campbell, 2007). En particular en los fororracos, el amplio desarrollo lateral de esta estructura revela su relación con las grandes masas corporales de estos animales, mientras que el grado de verticalización del antitrochanter limita el movimiento lateral del fémur, evitando la abducción del mismo, maximizando los movimientos cráneo-caudales del fémur durante la locomoción.

El pie de un ave también es orientativo acerca del hábito locomotor. Se generaliza que las grandes aves asociadas con el medio terrestre a menudo tienen dígitos más cortos y reducción en la cantidad de dedos (al menos en las formas más especializadas), minimizando el contacto con el suelo (Raikow, 1985). Las aves 
vadeadoras por su parte, se caracterizan por presentar dedos largos, situación que aumenta la superficie de contacto con el suelo pantanoso (Storer, 1971; Raikow, 1985). Algunas de ellas presentan entre los dedos II, III y IV membranas interdigitales (e.g., flamencos y patos), mientras que otras presentan el dedo I muy alargado, no elevado y en contacto con el sustrato (e.g., garzas) produciendo una mayor superficie de contacto con el sustrato. Los fororracos presentan tres dedos relativamente cortos (véase capítulo 4) y un dedo I elevado y reducido, un carácter compartido con la mayoría de los "Gruiformes" y relacionado con los hábitos terrestres (Raikow, 1985; del Hoyo et al., 1996). De esta manera, se las considera tridáctilas en el sentido de Raikow (1985). Este tipo de pie minimiza la fricción con el suelo durante la carrera y no es adecuado para movilizarse en suelos anegados.

En conclusión, los fororracos poseen atributos morfológicos que pueden ser asociados a una locomoción cursorial: la pelvis alta y elongada postacetabularmente, con un antitrochanter muy desarrollado, el tibiotarso y tarsometatarso alargados, el alto desarrollo de las cristae cnemialis del tibiotarso, tres dígitos relativamente cortos dirigidos hacia adelante y la posición elevada de un dígito que no toma contacto con el suelo. Esto es concordante con los hallazgos de Tambussi (1997) quien demostró mediante análisis de índices de capacidad atlética (ICA) que algunos fororracos tenían la misma capacidad cursorial que un avestruz. La cursorialidad en las aves de gran porte se alcanza a través de zancadas largas, mediante miembros posteriores más alargados; mientras que las aves cursoras de menor porte tienen miembros posteriores más cortos, pero presentan una mayor frecuencia de zancada (Storer, 1971; Abourachid y Renous, 2000; Gatesy y Biewener, 1991; Picasso, 2010a). Esto muestra que hay una limitante en el tamaño y secundariamente en la longitud de los miembros. Los grandes tamaños alcanzados por algunos fororracos y los miembros alargados de los fororracos permitirían el desarrollo de largas zancadas y, por ende, ser exitosos en la carrera. 
"Todo tiene que ver con todo"

Pancho Ibañez

Esta tesis tuvo como eje rector definir el estilo de vida con énfasis en la capacidad de desplazamiento en tierra y el hábito alimentario de los fororracos. Las descripciones osteológicas y las reconstrucciones musculares fueron la base para las inferencias realizadas. Estos enfoques se complementaron con los análisis de morfometría clásica y geométrica y análisis biomecánicos, tanto clásicos como modernos (e.g., análisis de elementos finitos). Las conclusiones de estos aspectos específicos se incluyeron en cada uno de los capítulos respectivos.

En el análisis filogenético efectuado en esta tesis (capítulo 5) no quedan resueltas las relaciones entre las Neoaves al igual que las relaciones intrafamiliares de los Phorusrhacidae (véase capítulo 5), dificultando la aplicación de métodos comparativos. Entonces, debido a que no se detallan las relaciones ancestrodescendiente en el contexto de la filogenia aquí presentada y en ausencia de una caracterización confiable de los ancestros, no se evaluó la señal filogenética mediante métodos filogenéticos comparativos.

Si bien no fue foco de este trabajo analizar el módulo locomotor anterior, la capacidad de vuelo también es parte del estilo de vida del animal y, por lo tanto, se incluyen en este capítulo final algunas consideraciones relacionadas con la misma. Asimismo, en este último capítulo se reúne toda la información obtenida para interpretar de manera holística el rol de los fororracos en los ecosistemas cenozoicos que integraban. Finalmente, se testean las siete hipótesis que rigieron las investigaciones realizadas durante los últimos cinco años.

\subsection{Vuelo}

Las teorías más clásicas respecto al modo de vida de los fororracos proponen que eran incapaces de volar (Ameghino, 1895; Sinclair y Farr, 1932; Alvarenga y Höfling, 2003; Alvarenga et al., 2011) en base a las proporciones de sus miembros anteriores y fundamentalmente por las grandes masas estimadas para la mayoría; otros, como los fororracos psilopterinos, podrían volar inhábilmente como lo hacen las chuñas vivientes (Tonni y Tambussi, 1988; Tambussi, 2011; Mourer-Chauviré et al., 2011). 
Para los fororracos de mayores tamaños (Mesembriornithinae, Patagornithinae, Phorusrhacinae, Physornithinae) su capacidad nula de vuelo es indudable. Sus enormes masas y la reducción marcada del miembro anterior lo indican incuestionablemente. En cambio, la capacidad de vuelo de los Psilopterinae puede ser discutida.

El límite máximo de peso por arriba del cual un ave no puede volar está calculado en 12-14 kg o 16 kg según Pennycuick (1989) y Pennycuick (2007) respectivamente. De cualquier manera, hay ejemplos que están fuera de este rango como Ardeotis kori que alcanza hasta $19 \mathrm{~kg}$ (Collar, 1996) y que es capaz de volar. Las especies de Psilopterus muestran una gama de masa corporal estimada de entre 5 a $9 \mathrm{~kg}$, un valor ciertamente menor que la masa crítica impuesta por el diseño y el peso para las aves en general. En este sentido, la masa no estaría condicionando la capacidad de vuelo de estas formas extinguidas. Analizadas las proporciones de los elementos del miembro anterior se observa que en psilopterinos como P. lemoinei, la longitud total del húmero es mayor que la de la ulna, la cual es aproximadamente el doble de la longitud del carpometacarpo (Tabla 10.1). Tonni y Tambussi (1988) en su trabajo sobre Psilopterus colzecus resaltan que las proporciones de los elementos de sus alas no son similares a los de Cariama y Chunga. Tampoco son las mismas que se observan en Psophia (trompeteros) en la cual húmero y cúbito son de longitud similar, mientras que el carpometacarpo es menor a la mitad de la longitud de la ulna. En base al estudio de proporciones del miembro anterior de $P$. lemoinei se llega a la misma conclusión. Por lo tanto, las alas de los psilopterinos presentan una reducción más acentuada que en los trompeteros y las chuñas vivientes (Tabla 10.1). Esta situación no brinda argumentos inequívocos a favor de la presencia o ausencia de vuelo en los psilopterinos.

El carpometacarpo de Psilopterus es proporcionalmente muy corto, una característica que comparte con Otis, Chunga, Cariama y Psophia (en esta última este carácter es muy evidente). La ulna en cambio, presenta proporciones similares al Frailecillo cornudo Fratercula (Alcidae), aunque el carpometacarpo es más corto. En los Frailecillos, las alas son muy cortas y el vuelo es hiperbatido.

En las aves, la longitud del húmero y la ulna se correlacionan fuertemente con la masa corporal y la longitud del ala (Olmos et al., 1996; Pennicuick, 2007). Nudds et al. (2007) avanzan sobre este aspecto indicando que en aves con húmero o ulna de longitud similar, las formas alares pueden ser muy diferentes y por lo tanto, también lo serán sus capacidades de vuelo. El índice braquial (BI) es la razón entre la longitud del húmero y de la ulna y determina la posición de la mano cuando el ala está plegada (Nudds et al., 
2007). Por esa razón ha sido ampliamente utilizado a fin de evaluar la capacidad de vuelo en aves extintas (e.g., Chiappe y Walker, 2002). Reiterando, aves con igual BI pueden tener una morfología alar externa diferente y en consecuencia, una capacidad de vuelo distinta (Nudds et al., 2004). El valor de BI calculado para Psilopterus lemoinei $(1,33)$ es mayor que el de las chuñas y Psophia (circa 1$)$ y menor al de Uria $(1,38)$; todas estas aves vivientes son capaces de volar (Tabla 10.1).

Con los datos expuestos hasta ahora podemos argumentar a favor de una capacidad voladora existente para los psilopterinos o, dicho de otra manera, no hay ninguna evidencia taxativamente excluyente. El vuelo obviamente está limitado por múltiples factores además de contar con el diseño óptimo para sostener el mismo. El despegue, por ejemplo, es condicionante y depende del peso, del tamaño y la potencia que es capaz de generar el animal. En aves de gran tamaño con alas reducidas, la potencia mínima para el despegue es alta (Pennycuick, 2007). Este sería el caso de los psilopterinos. Particularmente, P. lemoinei parece haber tenido ambas capacidades locomotoras: cursorial y voladora, aunque las proporciones entre el ala y el miembro posterior parecen indicar un uso mucho más acentuado de las patas. Este estilo locomotor es el que tienen en la actualidad los Otididae o los Cariamidae.

Sin embargo, la ausencia de processi acrocoracoideus y procoracoideus del os coracoideum, sumada a la reducción del miembro anterior, indican que el vuelo de los psilopterinos habría sido ineficaz.

\subsection{Locomoción terrestre}

Gran cantidad de rasgos anatómicos y funcionales indican que los fororracos fueron aves terrestres y corredoras, entre ellos la pelvis alta y elongada postacetabularmente, acompañada de un fuerte desarrollo de la musculatura extensora, un antitrochanter muy desarrollado, el tibiotarso y tarsometatarso alargados, el alto desarrollo de las cristae cnemialis del tibiotarso, tres dígitos relativamente cortos dirigidos hacia adelante y la posición elevada del dígito I (véase capítulos 4, 7 y 9). Las masas estimadas para los fororracos (capítulo 6) y los índices de capacidad atlética calculados por Tambussi (1997) son similares a los valores conocidos para aves vivientes con capacidad cursora como el ñandú y el avestruz. Incluso en Devincenzia y Kelenken, fororracos de grandes masas, la morfología alargada de sus tarsometatarsos parece indicar que estos animales eran capaces de correr. Particularmente Devincenzia, cuya masa se estima en $\sim 160 \mathrm{~kg}$, presenta un tarsometatarso de aproximadamente la 
misma longitud que el de Phorusrhacos $(40 \mathrm{~cm})$ aunque más robusto, indicando menor agilidad que Phorusrhacos.

Murray y Vickers-Rich (2004) estudiando los Mihirungs (Dromeornithiformes) australianos concluyen que las grandes masas no imponen límites a la capacidad cursorial de estas aves. Justamente, en base a los rasgos osteológicos y a las reconstrucciones musculares, sostienen que aún aquellos para los cuales se estimaron masas de $500 \mathrm{~kg}$ eran capaces de correr. En términos osteológicos, la robustez del tarsometatarso del fororraco brasileño Paraphysornis no difiere en gran medida de la de Dromornis stirtoni, un mihirung que en propias palabras de Murray y Vickers-Rich (2004), se habría desplazado de forma tan grácil como una bailarina.

Las grandes masas y el enorme tamaño de ciertos fororracos han sido asociados clásicamente al concepto de graviportalidad que analizaremos aquí brevemente. El término graviportal fue introducido por el paleontólogo H. Osborn para hacer referencia a animales pesados con miembros de segmentos proximales cortos y distales elongados y de disposición columnar. Este término fue aplicado luego a varios vertebrados (entre ellos, las Aves Elefante, las Moas, Diatryma y Brontornis) indistintamente como una caracterización postural o como un modo de locomoción (Tambussi et al., 2010), seguramente en asociación a que animales pesados son de andar lento. Sin embargo, es conveniente restringir el uso de este término como descriptor del modo de andar o postura de las aves (Tambussi et al., 2010) en tanto ninguno de los caracteres usados originalmente para definir graviportalidad están presentes o son de muy amplia distribución en las aves. Por ejemplo, la disposición columnar de los miembros con el fémur ubicado verticalmente (ausente en todas las aves), la marcada robustez de los huesos (un carácter compartido por diversas aves, Habib y Ruff, 2008) y la amplia divaricación de los dedos que está presente tanto en aves terrestres como arborícolas e incluso rapaces. En suma, no hay ni ha habido aves graviportales en ninguna de sus acepciones.

Entre los fororracos, Paraphysornis brasiliensis -con un tarsometatarso corto, robusto y con alto grado de divaricación de las trócleas sumado a una masa total de hasta 180 kg (Alvarenga y Höfling, 2003)- es uno de los ejemplos más habituales de graviportalidad en el sentido tradicional. Ciertamente es un ave terrestre, pero debido a que no se conoce su pelvis no puede establecerse con confiabilidad su estilo locomotor ni postural. 


\subsection{Relación depredador-presa y el comportamiento depredador de los} fororracos

De acuerdo al estudio realizado en esta tesis, parece indiscutible que los fororracos eran carnívoros depredadores. En líneas generales, la adquisición de energía a través del alimento es vital para un organismo, un aspecto relacionado con la capacidad de elegir y poder capturar una presa determinada. Las interacciones entre los integrantes del ecosistema influyen obviamente en la disponibilidad de presas que puedan ser capturadas con éxito por el depredador. Incluso las condiciones ambientales limitan las presas disponibles para los depredadores y sus competidores (Ferry-Graham et al., 2002). Tanto es así que en esta interacción la relación depredador-presa y la tasa de crecimiento de una población -la del depredador o la de la presa- influye sobre la otra.

Existen una serie de filtros que eliminan las posibles presas y determinan qué organismo puede y va a comer el depredador. Un depredador debe ser capaz de encontrar una presa potencial mediante un mecanismo de búsqueda adecuado. Debe ser capaz de detectar la presa mediante su visión, oído u otras habilidades sensoriales. Debe reconocer la presa como un ítem adecuado para comer en dependencia de su experiencia (Orians, 1971; Ferry-Graham et al., 2002) y debe decidir atacar a la presa, basado en una evaluación del valor de la energía de la presa y los costes de manipulación.

Finalmente, el depredador debe poseer la capacidad de subyugar con éxito a la presa. En suma, detección, selección y captura son tres factores condicionantes que se ponen en juego durante la alimentación del depredador.

En los depredadores, la masa corporal está fuertemente ligada a la selección de la presa: cuanto mayor sea el depredador, mayor podrá ser el tamaño de sus presas potenciales. Los depredadores solitarios tienden a cazar y matar presas de su propio tamaño o menores, pero los depredadores grupales pueden acceder a presas de mucho mayor tamaño (e.g., lobos, leones y hienas). Esto está relacionado con la vulnerabilidad del depredador a cualquier estrategia defensiva adoptada por la presa (que puede ser más perjudicial cuanto mayor sea su tamaño) (Meers, 2002).

La fuerza de mordida también limita el tamaño o la masa de la posible presa: mayores fuerzas de mordida permiten acceder a mayores tamaños de presa. Además, la fuerza de mordida tiene fuerte influencia sobre las estrategias depredadoras: un depredador debe poder discernir qué presa es capaz de matar mediante la mordida (Meers, 2002) o si requerirá de alguna otra estrategia (e.g., utilizar sus miembros). Sin 
embargo, la fuerza de mordida por sí sola no permite inferir inequívocamente si un animal es depredador o carroñero (Meers, 2002). Aún altos valores de fuerza de mordida como los obtenidos en esta tesis no son indicadores indiscutibles de depredación. Las presas disponibles dependen de las relaciones de masa y del comportamiento tanto del depredador como de la presa, con la fuerza de mordida jugando un papel secundario (Meers, 2002).

Las aves tienen altas tasas metabólicas, que implica como correlato que la ingestión de alimento debe ser alta (Orians, 1971) y que el tiempo dedicado al forrajeo (i.e., búsqueda del alimento sensu Zweers et al, 1994) debe ser el mínimo posible. En el caso de las aves depredadoras actuales (e.g. águilas, halcones y lechuzas), el vuelo activo las habilita a recorrer amplias zonas en busca de alimento. Las aves carroñeras son capaces de volar invirtiendo mucho tiempo en la búsqueda de cadáveres, pero empleando la menor cantidad de energía posible a través de vuelos planeados aprovechando las corrientes térmicas. Un ave carnívora terrestre como un fororraco no cuenta con ninguna de estas estrategias.

Los fororracos presentan un complejo apendicular posterior indudablemente adaptado para la carrera. En términos de hábito de vida, esto indica una técnica de detección del alimento caminando y una técnica de captura basaba en la persecución activa de las presas. Esta última evidenciada por una alta capacidad de maniobrabilidad que los faculta para poder perseguir de forma prolongada a sus presas e incluso seguirlas mediante movimientos esquivos.

La obtención del alimento en los fororracos implica que la presa debe ser inmovilizada para luego ser destrozada, deglutida y digerida. Según los análisis biomecánicos del cráneo, las presas eran principalmente abatidas mediante picotazos verticales bien dirigidos a modo de hachazos. Dependiendo del tamaño de la presa o la efectividad durante la captura, se requiere la repetición de más o menos golpes. La inmovilización total de la presa podría ocurrir en la boca del animal. Los valores altos de fuerza de mordidas calculadas para los fororracos mayores, así como el sistema muscular de cierre mandibular diseñado para favorecer la fuerza, compensarían el accionar de la presa evitando que se produjesen altas concentraciones de stress en el pico. Ante la presa dominada o muerta, puede suponerse la participación de las patas para presionar la presa contra el suelo y comenzar el desmembramiento, tal como es el accionar que utilizan actualmente las aves rapaces y las chuñas. Muchas aves actuales carnívoras tragan animales enteros y regurgitan las porciones no digeribles (huesos, 
pelos, etc) en conjuntos denominados egagrópilas. No hay registro de producción de estas estructuras en las chuñas y aunque la asignación de egagrópilas a un productor extinguido es muy cuestionable, Nasif et al., (2009) sostienen explícitamente que los forrracos podrían ser productores de las mismas.

Presas de mayor tamaño requerían un mayor tiempo de procesado. Como se mencionó previamente, las características del pico, alto y terminado en gancho de los fororracos resulta muy resistente a fuerzas dirigidas caudalmente y por lo tanto son adecuados para desgarrar pedazos de músculo de sus presas.

De acuerdo al estudio realizado en esta tesis, parece indiscutible que los fororracos eran depredadores activos y que perseguían y mataban a sus presas a picotazos. Pero ¿cuáles eran sus posibles presas? Marshall (1994) propuso que los ungulados nativos (como Typotheria o Litopterna) serían la presa predilecta de los fororracos. Murray y Vickers-Rich (2004) establecen que los Notoungulata, si bien muy diversos, habrían sido herbívoros de selección $\mathrm{k}$ y por lo tanto, no habrían sido muy abundantes y las formas más grandes habrían sido demasiado masivas para los fororracos. Proponen entonces que los fororracos depredaban roedores hystricomorfos, muy diversificados en el Mioceno temprano. Blanco y Jones (2005) proponen que Mesembriornis habría ocupado un nicho particular: se alimentaba de médula de los huesos a la cual accedería rompiendo los huesos por medio de patadas o pisotones, e incluso se ha llegado a postular que estas formas utilizaban sus fuertes miembros para romper corazas de mulitas y gliptodontes (Blanco y Jones, 2005; Blanco et al., 2009). Tonni y Noriega (1998) propusieron que esta especie podría haber sido carroñera y competido con otras aves carroñeras como Dryornis pampeanus.

Como fuese mencionado previamente, tanto el tamaño del depredador como de la presa representan factores críticos al momento de evaluar posibles relaciones depredador-presa. En esta tesis, se discriminaron tres tamaños de fororracos: (1) fororracos pequeños, donde se incluye a los Psilopterinae con una altura hasta el dorso de entre 38 y $60 \mathrm{~cm}$ y una masa que no superaba los $15 \mathrm{~kg}$; (2) fororracos medianos con una altura de 70-75 cm hasta el dorso y una masa corporal de entre 15 y $40 \mathrm{~kg}$, incluyen a los Patagornithinae y al Taxón nuevo A y (3) fororracos grandes-gigantes que superaban la altura de $75 \mathrm{~cm}$ hasta el dorso y la masa corporal de $40 \mathrm{~kg}$, incluyen a Mesembriornis milneedwardsi, a los Phorusrhacinae y Physornithinae. En pocas de las localidades donde se han encontrado fororracos se evidencia la coexistencia de los tres tamaños, pero siempre hay al menos dos (figura 2.3) (véase más adelante). 
La morfología del pico de los fororracos y el alto valor de stress calculado para esfuerzos laterales parecen indicar que presas de gran tamaño podrían ser perjudiciales. En tanto las aves no pueden utilizar los miembros anteriores para manipular sus presas y solo dependen del accionar de la cabeza, cuello y patas, puede inferirse que los fororracos consumían presas de menor tamaño que ellos mismos. Parece evidente que estaba planteada una repartición de nichos respecto al tamaño de las presas entre fororracos de diferentes tallas. Las presas más pequeñas como los roedores podrían ser devoradas por los psilopterinos; los mamíferos de masa de hasta 10 o $20 \mathrm{~kg}$ estarían al alcance de los patagornitinos mientras que los de mayor masa y talla serían posibles presas de los mesembriornitinos y forusrracinos (Figura 10.1) que probablemente podrían perseguir y matar animales como Theosodon de 100-130 kg (Cassini, 2011). Formas de kilaje superior a $130 \mathrm{~kg}$, como los Toxodontidae o los Homalodotheriidae (Cassini, 2011; Vizcaíno et al., 2010) probablemente eran inaccesibles a los fororracos. Por dar un ejemplo, la fauna del Santacrucense de la Formación Santa Cruz (Mioceno temprano tardío) estaba compuesta por una gran cantidad de mamíferos con masas de 0,16 kg hasta más de $1000 \mathrm{~kg}$ (Cassini, 2011; Vizcaíno et al., 2010). De estos mamíferos, muchos presentan menos de $10 \mathrm{~kg}$ de peso, en menor proporción entre $10 \mathrm{y}$ 100 y las mayores a $100 \mathrm{~kg}$ representan solo el $15 \%$ de la diversidad de mamíferos (Vizcaíno et al., 2010). De todos ellos descartamos como posibles presas de los fororracos a los Glyptodontidae (por ser animales acorazados grandes) y los Borhyenidae de $20 \mathrm{~kg}$ (por ser mamíferos carnívoros), quedando igualmente un abanico enorme de presas potenciales: los animales menores a $10 \mathrm{~kg}$ serían presa de Psilopterinae y Patagornithinae (tamaños 1 y 2), mientras que las formas de más de 10 kg serían presa de los Phorusrhacinae (tamaño 3).

\subsection{Ecomorfos}

Los análisis ecomorfológicos y biomecánicos brindan herramientas útiles a los efectos de identificar ecomorfos e inferir nichos (Ibañez, 2006). Un ecomorfo es un constructo de un objeto biológico independiente de su origen sistemático, pero de acuerdo a la relación con parámetros ambientales. Cualquier estudio ecomorfológico tiene como fin último discriminar nichos específicos dentro de los hábitats en base a rasgos como alimentación, locomoción o cualquier otra característica que se refleje en la morfología. En otras palabras, la morfología define el nicho (Keast, 1970). 
En el caso particular de los fororracos, Tonni (1977) reconoció tres ecomorfos de acuerdo a su locomoción y hábito trófico: graviportales carroñeros, depredadores cursores con limitada capacidad de vuelo y depredadores cursores con nula capacidad de vuelo. Tambussi (1997) restringió estos tres ecomorfos a solo dos: graviportales carroñeros y depredadores cursores con limitada o nula capacidad de vuelo. Luego, Tonni y Noriega (1998) establecieron que estos tipos adaptativos no habrían sido excluyentes, sino más bien complementarios dentro del papel de consumidores primarios de las cadenas tróficas del Cenozoico.

La evidencia morfo-funcional analizada en esta tesis no permite la discriminación de ecomorfos aunque si de dos patrones morfológicos tanto para el cráneo como para la pelvis: el tipo "psilopterino" y el tipo "terror bird”. Sin embargo, estos dos morfotipos habrían tenido un funcionamiento muy similar. Si bien el tipo "terror bird" parece una especialización evolutiva en el sentido de Ferry-Graham et al. (2002), la forma y función de ambos complejos (trófico y apendicular) evidencian que las facultades de ambos morfotipos eran golpear con el pico y correr respectivamente, por lo cual se infiere que el rol biológico final es la adaptación a un tipo de cacería muy particular, persiguiendo y matando a picotazos. En otras palabras, todos los fororracos son similares desde el punto de vista ecomorfológico y desempeñaban el papel de activos depredadores cursoriales.

Además, la evidencia encontrada aquí no permite establecer con certeza que los fororracos de portes gigantes hayan sido incapaces de correr o que fueran carroñeros.

Es evidente que los ecomorfos son constructos subjetivos y la adición de nuevos rasgos contribuirá a la delimitación o eliminación de los mismos. Por ejemplo, teniendo en cuenta las características del módulo locomotor anterior estaría incorporándose una variable, la capacidad de vuelo, ligada al desarrollo diferencial de este módulo. En este caso, muy posiblemente Psilopterus bachmanni y P. lemoinei se diferenciarían ecomorfológicamente de los fororracos sin la capacidad de desplazamiento en el aire. Asimismo, la masa corporal y su relación con el tamaño de las presas potenciales podría ser otro criterio que permita discriminar depredadores pequeños, medianos y grandes.

\subsection{Los fororracos y la división de nichos tróficos}

Un hecho que merece ser destacado acerca de los hallazgos de fororracos (Figura 2.3) es que en prácticamente todos los yacimientos aparece más de una especie $y$, en particular, se asocian fororracos grandes (tamaño 3 ) con fororracos pequeños o 
medianos (tamaño 1 y 2). Por lo tanto puede pensarse como probable una partición de los nichos carnívoros que afecte, por ejemplo, los tamaños de las presas blanco.

Es sabido que las aves presentan comportamientos muy dispares en tierra y aire. En el aire, las aves más pequeñas (e.g., Passeriformes) se atreven a enfrentar aves de mucho mayor porte que ellas (e.g., Polyborus). En tierra en cambio, el predominio lo ejercen las aves voladoras más grandes y que se alimentan primero, tal como ocurre con el jote real, el jote de cabeza negra y el jote de cabeza roja en las Yungas y con los albatros y petreles, skúas y gaviotas en la Antártida. Sin embargo, no se conocen ecosistemas actuales donde aves terrestres se disputen el alimento y por lo tanto estos ejemplos no son completamente comparables.

Dos escenarios parecen plausibles:

(1) en el cual los fororracos más grandes mataban a las presas, comían hasta saciarse y abandonaban el resto que era aprovechado a su vez por los fororracos de mediano porte y por último los más pequeños. Sin embargo, los fororracos medianos y pequeños también eran capaces de matar y perseguir sus propias presas de mediano y pequeño porte. Inferir un hábito depredador para Psilopterus está robustamente sustentado por todos los análisis realizados aunque puede suponerse que también se haya comportado como un oportunista. Depredadores y oportunistas es el rol de algunas aves rapaces vivientes.

(2) en el cual los fororracos depredaran presas de diversos tamaños y los forrracos gigantes (tamaño 3) como Phorusrhacos o Kelenken eran kleptoparásitos aprovechando las presas subyugadas por fororracos de menor tamaño como los Patagornithinae o que éste a su vez también lo fuera aprovechándose y robándole presas a los Psilopterinae.

No hay evidencias como para seleccionar uno u otro escenario.

\subsection{Contraste de hipótesis}

Cuando fue elaborado este proyecto se pretendió contrastar siete hipótesis que rigieron cada una de las acciones que se llevaron a cabo, la selección de las metodologías a aplicar y el recorte que se iba a realizar del conjunto a analizar. Asimismo y como toda investigación científica está enmarcada en determinados marcos teóricos y parte de supuestos más o menos explícitos. En este caso, se asumió que forma y función son dos dimensiones inseparables de los rasgos fenotípicos del animal que 
conforman el complejo forma-función. El análisis de este complejo da cuenta del estilo de vida del animal, es decir, de su facultad y rol biológico.

Para determinar este significado biológico se eligió testear las hipótesis enunciadas con datos provenientes de la morfología funcional y biomecánicos en un contexto filogenético apropiado. Luego se confrontaron los factores ambientales y espaciales en los que se habrían desarrollado los atributos estudiados para inferir finalmente la historia morfológica de un rasgo determinado en un linaje.

A continuación, se desarrolla cada una de ellas.

\section{H1. Los Phorusrhacidae exhiben tres patrones morfológicos dados por el desarrollo diferencial muscular y óseo del cráneo y del complejo apendicular posterior.}

El estudio aquí realizado permite rechazar esta hipótesis. Los fororracos exhiben solamente dos patrones morfológicos osteológicos. El morfotipo I (tipo "psilopterino") incluye fororracos pequeños y medianos (Psilopterinae y Mesembriornithinae), con ausencia de movilidad palatal en el cráneo y pelvis relativamente ancha, mientras que el morfotipo II (tipo "terror bird") incluye formas medianas y grandes (Patagornithinae, Phorusrhacinae y posiblemente Physornithinae), con inmovilidad palatal y ausencia de zona flexoria craniofascialis y pelvis muy angostas. No parece haber diferencias sustanciales en los patrones musculares.

H2. Los patrones morfológicos y funcionales encontrados se corresponden con aquellos de aves de reconocidos hábitos carnívoros.

La hipótesis se rechaza. Si bien la forma del cráneo de un fororraco es concordante con la de un ave carnívora, su funcionamiento exhibe total pérdida de la capacidad quinética y por lo tanto, el patrón funcional es diferente al de un ave carnívora actual como los halcones o los búhos. Desde un punto de vista funcional está más cerca de las chuñas que muestran evidencia de inmovilización palatal.

\section{H3. Los Phorusrhacinae, Patagornithinae, Mesembriornithinae y Psilopterinae son} capaces de desarrollar desplazamientos veloces típicos de aves cursoriales y depredadoras.

La hipótesis se acepta. El complejo apendicular posterior de los fororracos presenta similitudes morfo-funcionales con aves terrestres. Mientras que el miembro refleja una morfología de ave terrestre caminadora capaz de correr (e.g., Otididae), la 
pelvis presenta una morfología que se asemeja a la de aves con capacidad cursora, como Rhea y Dromaius. Esto les permitiría perseguir presas de forma activa.

H4. La graviportalidad se restringe a Phorusrhacidae de masas corporales grandes (mayores a $200 \mathrm{~kg}$.) y hábitos necrófagos.

La hipótesis no puede ser testeada. Ya fue discutido que la graviportalidad no es un término aplicable a las aves. En este sentido, la hipótesis debe ser rechazada. Entendiendo que fue formulada bajo el concepto clásico de graviportalidad, podemos hacer algunas consideraciones. En ningún caso se obtuvieron masas mayores a los 160 kilos para ningún fororraco (e.g. Devicenzia o Paraphysornis de unos $180 \mathrm{~kg}$ sensu Alvarenga y Höfling, 2003), pero aún así pueden ser consideradas aves de gran porte y caminadoras, quizás menos ágiles aunque no incapaces de correr. La posibilidad de que pudieran desarrollar hábitos necrófagos no pudo ser contrastada por ninguna de las metodologías aquí aplicadas.

H5. En ningún momento del Cenozoico ni en ningún lugar se verifica la coexistencia de los tres ecomorfos propuestos por Tonni (1977).

La hipótesis se rechaza. En esta tesis se postula que los fororracos pertenecen a un único ecomorfo. Sin embargo, es destacable la existencia de fororracos de distintos tamaños coexistiendo en el espacio y en el tiempo. Esto podría indicar que había una segregación de tamaño de presa por parte de fororracos de diferentes tamaños.

\section{H6. Los Phorusrhacidae muestran una tendencia al incremento de tamaño y a la terrestrialidad.}

La hipótesis se acepta. Todas los fororracos eran aves terrestres y en su mayoría, incapaces de volar. Muestran una amplia gama de tamaños, desde animales de $5 \mathrm{~kg}$ hasta $180 \mathrm{~kg}$ y varias subfamilias han alcanzado grandes tamaños (e.g., Mesembriornithinae, Phorusrhacinae y Physornithinae). Incluso los linajes con representantes más pequeños, los Psilopterinae, incluyen especies de mayor talla incapaces de volar (e.g., Procariama). Esto denota la tendencia intrafamiliar a alcanzar grandes tallas, la cual podría haberse dado de forma paralela en varios taxones.

H7. Solo los Phorusrhacinae habrían sido capaces de manipular presas del tamaño del mamifero Paedotherium. 
La hipótesis se rechaza. La manipulación implica varios fenómenos como la matanza, desmembramiento y deglución de las partes. Animales como Paedotherium ( $\sim 4 \mathrm{~kg})$, que presentaban el tamaño de una mara patagónica, serían accesibles y fácilmente manipulables por fororracos de la talla de Mesembriornis, Patagornithinae y Phorusrhacinae. Los Phorusrhacinae, en particular, quizás tendrían acceso a presas mucho mayores $(\sim 100 \mathrm{~kg})$. 


\section{Perspectivas}

Durante el desarrollo de estas tesis se han subrayado algunas dificultades específicas y cuestiones pendientes surgidas en el transcurso de las distintas etapas de investigación; dificultades y cuestiones que dejan abiertas posibles vías de continuación para futuras investigaciones. Asimismo, a partir de los resultados alcanzados es posible identificar otras posibles líneas de investigación que complementarán y fortalecerán el conocimiento de la paleobiología, evolución y sistemática de los fororracos. Se resumen a continuación las más significativas:

1) Los estudios de la musculatura mandibular y apendicular de Cariamidae permitirán ajustar las reconstrucciones musculares realizadas en esta tesis y realizar un análisis biomecánico profundo de la contribución de cada músculo del complejo apendicular posterior a la velocidad o a la fuerza.

2) Un análisis en profundidad del complejo apendicular de Paraphysornis brasiliensis, cuyo material original no pudo ser abordado en profundidad durante el transcurso de esta tesis, permitirá establecer si era efectivamente capaz de moverse ágilmente.

3) Realizar análisis de elementos finitos en ambos morfotipos craneanos permitirá establecer si existen diferencias en el comportamiento mecánico de los distintos tipos de cráneos.

4) Realizar un análisis descriptivo y biomecánico del complejo apendicular anterior permitirá establecer las capacidades de vuelo de las diferentes especies de Psilopterinae.

5) La base de datos osteológica obtenida en esta tesis permitirá realizar un análisis filogenético intrafamiliar de los fororracos y estudiar la evolución y diversificación de los Phorusrhacidae.

6) Estudiar mediante tomografías computadas el endocráneo de los fororracos (e.g., cerebro y oído) permitirá establecer sus capacidades somato-sensoriales.

7) De la misma manera, la estimación de volumen ocular a través de los anillos escleróticos y reconstrucciones del nervio oftálmico permitirá evaluar las capacidades visuales de los Phorusrhacidae. 
8) Estudiar la interacción de los Phorusrhacidae con otras aves fósiles con las que cohabitaron (e.g., Cariamidae, Accipitridae, Falconidae) a fin de elucidar en profundidad las diversas interacciones depredador-presa y subdivisión de nichos. 


\section{Referencias bibliográficas}

Abourachid, A. 2001. Kinematic parameters of terrestrial locomotion in cursorial (ratites), swimming (ducks), and striding birds (quail and guinea fowl). Comparative Biochemistry and Physiology Part A, 131, 113-119.

Abourachid, A. y Renous, S. 2000. Bipedal locomotion in ratites (Paleognatiform): examples of cursorial birds. Ibis, 142, 538-549.

Abourachid, A.; Höfling, E. y Renous, S. 2005. Walking kinematics parameters in some paleognathous and neognathous neotropical birds. Ornitología Neotropical, 16, 471-479.

Ackerly, D.D. 2000. Taxon sampling, correlated evolution, and independent contrast. Evolution, 54, 1480-1492.

Acosta Hospitaleche, C. 2002. Nuevo registro de Hermosiornithinae (Cariamidae) del Mioceno tardíotemprano (Chasiquense) de Argentina. Ameghiniana, 39(2), 251-254.

Acosta Hospitaleche, C. y Tambussi, C. 2005. Phorusrhacidae Psilopterinae (Aves) en la formación Sarmiento de la localidad de Gran Hondanada (Eoceno Superior), Patagonia, Argentina. Revista Española de Paleontología, 20, 127-132.

Acosta Hospitaleche, C. y Tambussi, C.P. 2006. Skull morphometry of Pygoscelis (Sphenisciformes): inter- and intraspecific variations. Polar Biology, 29, 728-734.

Adams D.C.; Rohlf, F.J. y Slice, D.E. 2004. Geometric morphometrics: ten years of progress following the 'revolution'. Italian Journal of Zoology, 71, 5-16.

Agnolín, F. 2006. Posición sistemática de algunas aves fororracoideas (Ralliformes; Cariamae) Argentinas. Revista del Museo de Ciencias Naturales 8(1), 27-33.

Agnolín, F.L. 2007. Brontornis burmeisteri Moreno \& Mercerat, un Anseriformes (Aves) gigante del Mioceno Medio de Patagonia, Argentina. Revista del Museo Argentino de Ciencias Naturales, 9(1), 1525.

Agnolín, F.L. 2009. Sistemática y filogenia de las aves fororracoideas (Gruiformes: Cariamae). Monografías Fundación Azara/Adrián Giacchino, 79 pp.

Alexander, R.M. 1975. The chordates. Cambridge University press, Cambridge, 480 pp.

Alexander, R. M. 1979. Allometry of the limb bones of mammals from shrews (Sorex) to elephant (Loxodonta). Journal of Zoology, 189, 305-314.

Alexander, R.M. 1983. Animals Mechanichs. Blackwell Scientific Publications. Oxford, 312 pp.

Alexander, R.McN. 1984. Elastic energy stores in running vertebrates. American Zoologist, 24, 85-94.

Alexander, R.M. 1985. The legs of Ostrichs (Struthio) and Moas (Pachyornis). Acta Biotheoretica, 34, 165-174.

Alexander, R.M. 1989. Dynamics of dinosaurs and other extinct giants. Columbia University Press, New York, $167 \mathrm{pp}$.

Alexander, R. M. 1991. Energy-saving mechanisms in walking and running. Journal of Experimental Biology, 160, 55-69.

Alexander, R. M. 2004. Bipedal animals, and their differences from humans. Journal of Anatomy, 204, 321-330. 
Alexander, R.M.; Jayes, A.S.; Maloiy, G.M.O. y Wathuta, E.M. 1979. Allometry of the limb bones of mammals from shrews (Sorex) to elephant (Loxodonta). Journal of Zoology, 189, 305-314.

Alvarenga, H.M.F. 1982. Uma gigantesca ave fóssil do Cenozóico brasileiro: Physornis brasiliensis sp. $\mathrm{n}$. Anais da Academia Brasileira de Ciências, 54, 697-712.

Alvarenga, H.M.F. 1985. Um novo Psilopteridae (Aves: Gruiformes) dos sedimentos Terciários de Itaboraí, Rio de Janeiro, Brasil. Anais do Congresso Brasileiro de Paleontologia, 8, Série Geologia, 27, $17-20$.

Alvarenga, H.M.F. y Höfling, E. 2003. Systematic revision of the Phorusrhacidae (Aves: Ralliformes). Papeis Avulsos de Zoologia, Museu de Zoologia da Universidade de Sao Paulo, 43, 55-91.

Alvarenga, H.M.F., Jones, W.W. y Rinderknecht, A. 2010. The youngest record of phorusrhacid birds (Aves, Phorusrhacidae) from the late Pleistocene of Uruguay. Neues Jahrbuch für Geologie und Paläontologie, Abhandlungen, 256, 229-234.

Alvarenga, H.M.F., Chiappe, L.M. y Bertelli, S. 2011. Phorusrhacids: the Terror Birds. Pp 187-208 en G. Dyke y G. Kaiser (eds) Living Dinosaurs: The Evolutionary History of Modern Birds. John Wiley \& Sons, Ltd.

Amadon, D. 1947. An estimated weight of the largest known bird. The Condor, 49, 159-164.

Amaral, A.R.; Coelhoa, M.M.; Marugán-Lobón, J. yRohlf, J.F. 2009. Cranial shape differentiation in three closely related delphinid cetacean species: Insights into evolutionary history. Zoology, 112(1), 3847.

Ameghino, F. 1887. Enumeración sistemática de las especies de mamíferos fósiles coleccionados por Carlos Ameghino en los terrenos Eocenos de la Patagonia austral y depositados en el Museo de La Plata. Boletín del Museo La Plata, 1, 1-26.

Ameghino, F. 1889. Los mamíferos fósiles de la República Argentina. Actas de la Academia Nacional de Ciencias de Córdoba, 6, 1-1028.

Ameghino, F. 1891a. Caracteres diagnósticos de cincuenta especies nuevas de mamíferos fósiles argentinos. Revista Argentina de Historia Natural, 1, 129-167.

Ameghino, F. 1891b. Mamíferos y aves fósiles argentinas: especies nuevas, adiciones y correcciones. Revista Argentina de Historia Natural, 1, 240-259.

Ameghino, F. 1895. Sobre las aves fósiles de Patagonia. Boletín del Instituto Geográfico de Argentina, $15,501-602$.

Ameghino, F. 1899. Sinopsis geológico-paleontológica de la Argentina. Segundo Censo de la República Argentina, 1, 112-255.

Anderson, J.F.; Hall-Martin, A. y Russel, D.A. 1985. Long-bone circumference and weight in mammals, birds and dinosaurs. Journal of Zoology, 207, 53-61.

Anderson, R.A.; McBrayer, L.D. y Herrel, A. 2008. Bite force in vertebrates: opportunities and caveats for use of a nonpareil whole-animal performance metric. Biological Journal of the Linnean Society of London, 93, 709-720.

Andors, A.V. 1992. Reapparaisal of the Eocene groundbird Diatryma (Aves: Anserimorphae). Science Series Natural History Museum of Los Angeles County, 36, 109-125.

Andrews, C. 1896. Remarks on the Stereornithes, a group of extinct birds from Patagonia. Ibis, 7, 1-12.

Andrews, C. 1899. On the extinct birds of Patagonia, I, the Skull and skeleton of Phororhacos inflatus Ameghino. Transactions of the Zoological Society of London, 15, 55-86. 
Arnold, S. J. 1983. Morphology, performance and fitness. American Zoologist, 23, 347-361.

Barbosa, A., Moreno, E., 1999. Hindlimb morphology and locomotor performance in waders. An evolutionary approach. Biological Journal of the Linnean Society, 67, 313-330.

Bargo, M.S.; Vizcaíno, S.F.; Archuby, F.M. y Blanco, E.R. 2000. Limb bone proportions, strength and digging in some Lujanian (Late Pleistocene-Early Holocene) mylodontid ground sloths (Mammalia, Xenarthra). Journal of Vertebrate Paleontology, 20, 743-754.

Bargo, M.S., y Vizcaíno S.F. 2008. Paleobiology of Pleistocene ground sloths (Xenarthra, Tardigrada): biomechanics, morphogeometry and ecomorphology applied to the masticatory apparatus. Ameghiniana, 45, 175-196.

Baskin, J.A.1995.the giant flightless bird Titanis walleri (Aves: Phorusrhacidae) from the Pleistocene coastal plain of south Texas. Journal of Vertebrate Paleontology, 15(4), 842-844.

Baumel, J.J. y Raikow, R.J. 1993. Arthrologia. Pp 133-188 en J.J. Baumel, A.S. King, J.E. Breazile, H.E. Evans y J.C. Vanden Berge (eds) Handbook of avian anatomy: nomina anatomica avium. Cambridge, Massachusetts.

Baumel, J.J. y Witmer, L.M. 1993. Osteologia. Pp 45-132 en J.J. Baumel, A.S. King, J.E. Breazile, H.E. Evans y J.C. Vanden Berge (eds) Handbook of avian anatomy: nomina anatomica avium. Cambridge, Massachusetts.

Beecher, W.J. 1962. The biomechanics of the bird skull. Bulletin of the Chicago Academy of Sciences, $11(2), 10-33$.

Benjamin, M.; Toumi, H.; Ralphs, J.R.; Bydder, G.; Best, T.M. y Milz, S. 2006. Where tendons and ligaments meet bone: attachment sites ('entheses') in relation to exercise and/or mechanical load. Journal of Anatomy, 208, 471-490.

Bennet, A.F. 1989. Integrated studies of locomotor performance. Pp 191-202 en Wake, D.B. y Roth, G. (eds) Complex organismal functions: integration and evolution in vertebrates. John Wiley sons, New York.

Bennett, M.B. 1996. Allometry of the legs muscles of birds. Journal of Zoology of London, 238, 435-443.

Berger, A.J. 1952. The comparative functional morphology of the pelvic appendage in three genera of Cuculidae. American Midland Naturalist, 47, 513-605.

Bertelli, S., Chiappe, L.M. y Tambussi, C.P. 2007. A new phorusrhacid (Aves, Cariamae) from the middle Miocene of Patagonia, Argentina. Journal of Vertebrate Paleontology, 27, 409-419.

Bertelli, S.; Lindow, B.E.K.; Dyke, G.J. y Chiappe, L.M. 2010. A well-preserved 'charadriiform-like' fossil bird from the early Eocene fur formation of Denmark. Palaeontology, 53(3), 507-531.

Bhattacharyya, B.N. 1980. The morphology of the jaw and tongue musculature of the common pigeon. Columba livia, in relation to its feeding habit. Proceedings of the Zoological Society (Calcutta), 31, 95 126.

Bhattacharyya, B.N. 1989. Functional morphology of the jaw muscles of two species of imperial pigeons, Duculaenea nicobarica and Ducula badia insignis. Gegenbauers Morphologisches Jahrbuch, 135, 573618.

Bhattacharyya, B.N. 1994. Diversity of feeding adaptations in certain columbid birds: a functional morphological approach. Journal of Biosciences, 19, 415-427.

Biewener, A.A. 2005. Biomechanical consequences of scaling. Journal of Experimental Biology, 208, 1665-1676. 
Biewener, A.; McGowan, C.; Card, G. y Baudinette, R. 2004. Dynamics of leg muscle function in tammar wallabies (M. eugenii) during level versus incline hopping. Journal of Experimental Biology, 207, 211223.

Bierregaard, R.O.1978. Morphological analysis of community structure in birds of prey. Tesis Doctoral, University of Pennsylvania, USA. 293 pp.

Binder, W.J. y Van Valkenburgh, B. 2000. Development of bite strength and feeding behaviour in juvenile spotted hyena (Crocuta crocuta). Journal of Zoology of London, 252, 273-283.

Blanco, R.E. y Jones, W.W. 2005. Terror birds on the run: A mechanical model to estimate its maximum running speed. Proceedings of the Royal Society B, 272, 1769-1773.

Blanco, R.E., Jones, W.W. y Rinderknecht, A. 2009. The sweet spot of a biological hammer: the centre of percussion of glyptodont (Mammalia: Xenarthra) tail clubs. Proceedings of Royal Society B, 276, 39713978.

Blob, R.W. 2001. Evolution of hindlimb posture in nonmammalian therapsids: Biomechanical tests of paleontological hypotheses. Paleobiology, 27(1), 14-38.

Bock, W.J. 1964. Kinetics of the avian skull. Journal of Morphology, 114(1), 1-41.

Bock W.J. 1974 The avian skeletomuscular system. Avian Biology, 4, 119-257.

Bock, W.J. 1980. The definition and recognition of biological adaptation. American Zoologist, 20, $217-$ 227.

Bock W.J. 1990 From biologische anatomic to ecomorphology. Netherlands Journal of Zoology, 40, 254277.

Bock, W.J. 1993 Selection and fitness; definitions and uses; 1859 and now. Proceedings of the Zoological Society of Calcutta, pp 7-26.

Bock, W. J. 1994. Concepts and methods in ecomorphology. Journal of Biosciences, 19(4), 403-413.

Bock, W. J. 1999. Functional and evolutionary explanations in morphology. Netherlands Journal of Zoology, 49, 45-65.

Bock, W.J.; Von Wahlert, Y.G. 1965. Adaptation and the from-function complex. Evolution, 19, 269299.

Bonaparte, C.L. 1853. Classification ornithologique par series. Compte Rendus Hebdomadaire des Séances de Académie des Sciences, 37, 641-647.

Bonaparte, C.L. 1854. Conspectus systematis ornithologiae. Annales des Sciences Naturelle/Zoologie, $1(4), 105-152$.

Bookstein, E.L., 1991. Morphometric tools for landmark data: geometry and biology. Cambridge University Press, New York, 456 pp.

Bookstein F.L.; Chernoff, B.; Elder, R.L.; Humphries, J.M. Jr.; Smith, G.R.; Strauss, R.E. 1985. Morphometrics in evolutionary biology. Academy of Natural Sciences Press, Philadelphia, 277 pp.

Bourke, J.; Wroe, S.; Moreno, K.; McHenry, C. y Clausen, P. 2008. Effects of gape and tooth position on bite the Dingo (Canis lupus dingo) using a 3-D finite element approach. PLoS ONE, 3, 1-5.

Bout, R.G. 1997. Postures of the avian cranio-cervical column. Journal of Morphology, 231, 287-295. Bout, R.G. y Zweers, G.A. 2001. The role of cranial kinesis in birds. Comparative Biochemistry and Physiology A 131(1), 197-205. 
Bowman, R.I. 1961. Morphological differentiation and adaptation in the Galápagos finches. University of California Publications in Zoology, 58, 1-326.

Box, E.O. 1981. Macroevolution and Plant Forms: An Introduction to Predictive Modeling in Phytogeography. Tasks for Vegetation Science, Vol. 1. Dr. W. Junk Publishers, The Hague.

Box, E.O. 1996. Plant functional types and climate at the global scale. Journal of Vegetation Science, 7, $309-20$.

Brodkorb, P. 1963. A giant flightless bird from the Pleistocene of Florida. The Auk, 80, 111-115.

Brodkorb, P. 1967. Catalogue of fossil birds, Part III (Ralliformes, Ichthyornithiformes, Charadriiformes). Bulletin of Florida State Museum, 2, 99-220.

Bryant, H.N. y Russell, A.P. 1992. The role of phylogenetic analysis in the inference of unpreserved attributes of extinct taxa. Philosophical Transactions of the Royal Society London, 337, 405-418.

Bryant, H.N. y Seymour, K.N. 1990. Observations and comments on the reliability of muscle reconstruction in fossil vertebrates. Journal of Morphology, 206,109-117.

Bühler, P. 1981. Functional anatomy of the avian jaw apparatus. Pp 439-468. en A. S. King y J. McClelland (eds.) Form and Function in Birds, Volume 2. Academic Press, New York.

Burmeister, H. 1854. Beitr. Z. Naturgesch. D. Seriema. Abh. nat. Ges. z. Halle, i, pp. 11.

Burton, A.M. y Alford, R.A. 1994.Morphometric comparison of two sympatricgoshawks from the Australian wet tropics. Journal of Zoology, London, 232, 525-538.

Camin, J.H. y Sokal, R.R. 1965. A method for deducing branching sequences in phylogeny. Evolution, $19,311-326$.

Campbell, K.E.,Jr. y Marcus, L. 1992. The relationship of hindlimb bone dimensions to body weight in birds. Science Series Natural History Museum of Los Angeles County, 36, 395-412.

Carr, J. A. 2008. Muscle function during swimming and running in aquatic, semiaquatic and cursorial birds. Tesis Doctoral, Northeastern University, Boston, Massachusetts. 181 pp.

Carrano, M.T. 1997. Morphological indicators of foot posture in mammals: a statistical and biomechanical analysis. Zoological Journal of the Linnean Society, 121, 77-104.

Carrano M.T. y Biewener, A.A. 1999. Experimental alteration of limb posture in the chicken (Gallus gallus) and its bearing on the use of birds as analogs for dinosaur locomotion. Journal of Morphology, 240, 237-249.

Carrano, M.T. y Hutchinson, J.R. 2002. Pelvic and hindlimb musculature of Tyrannosaurus rex (Dinosauria: Theropoda). Journal of Morphology, 253, 207-228.

Carril, J. 2010. Análisis de la fuerza de mordida y diseño del cráneo en Aves. Tesis de Licenciatura, Universidad CAECE, Buenos Aires, 77 pp. Inédita.

Case, J.; Woodbourne, M. y Chaney, D. 1987. A gigantic phororhacoid (?) bird from Antartica. Journal of Paleontology, 61, 1280-1284.

Case, J.; Reguero, M.; Martin, J y Cordes-Person, A. 2006. A cursorial bird from the Maastrictian of Antarctica. Journal of Vertebrate Paleontology, 26 (3, Supl.), 48A.

Casinos, A. y Cubo, J. 2001. Avian long bones, flight and bipedalism. Comparative Biochemistry and Physiology - A Molecular and Integrative Physiology, 131(1), 159-167. 
Cassini, G.H. 2011. Paleobiología de ungulados de la Formación Santa Cruz (Mioceno temprano-medio), Patagonia, Argentina: una aproximación morfométrica y morfofuncional al estudio del aparato masticatorio. Tesis Doctoral. Universidad Nacional de La Plata, Argentina, 320 pp. Inédita.

Chandler, R.M. 1994. The wing of Titanis walleri (Aves: Phorusrhacidae) from the late Blancan of Florida. Bulletin of Florida Museum of Natural History, 36, 175-180.

Chandler, R. 1997. New discoveries of Titanis walleri (Aves: Phorusrhacidae) and a new phylogenetic hipótesis for the Phorusrhacids. Journal of Vertebrate Paleontology, 17(3, Supl.), 36A-37A.

Chiappe, L.M. y Walker, C.A. 2002. Skeletal morphology and systematics of the Cretaceous Euenantiornithines (Ornithothoraces: Enantiornithines). Pp 240-267 en L.M. Chiappe y L.M. Witmer (eds) Mesozoic birds, over the heads of the dinosaurs. University of California Press, Berkeley.

Chiappe, L.M. y Bertelli, S. 2006. Skull morphology of giant terror birds. Nature, 443, 929.

Christiansen, P. y Adolfssen, J.S. 2005. Bite forces, canine strengths and skull allometry in extant carnivores (Mammalia, Carnivora). Journal of Zoology of London, 266, 1-19.

Christiansen, P. y Wroe, S. 2007. Bite forces and evolutionary adaptations to feeding ecology in carnivores. Ecology, 88(2), 347-358.

Cleuren, J., Aerts, P. y de Vree, F. 1995. Bite and joint force analysis in Caiman crocodilus. Belgian Journal of Zoology, 125, 79-94.

Collar, J. 1996. Family Otididae (Bustards). Pp 240-273 en J. del Hoyo, A. Elliot and J. Sargatal (eds) Handbook of Birds of the world, Volume 3: Hoatzin to Auks. Lynx, Barcelona.

Coombs, W.P. 1978. Theoretical aspects of cursorial adaptations in Dinosaurs. The Quarterly Review of Biology, 53, 393-418.

Cracraft, J. 1968. A review of the Bathornithidae (Aves, Gruiformes), with remarks on the relationships of the suborder Cariamae. American Museum Novitates, 2326, 1-46.

Cracraft, J. 1971. Systematics and evolution of the Gruiformes (Class Aves) 2. Additional comments on the Bathornithidae, with descriptions of new species. American Museum Novitates, 2449, 1-14.

Cracraft, J. 1988. The major clades of birds. Pp 339-361 en M.J. Benton (ed) The phylogeny and classification of the tetrapods, volume 1. Clarendon Press, Oxford.

Cracraft, J. y Clarke, J.A. 2001. The basal clades of modern birds. Pp 143-156 en J. Gauthier y Gall, L.F. (eds) New Perspectives on the Origin and Early Evolution of Birds. Peabody Museum of Natural History, New Haven, CT.

Cracraft, J., Keith Barker, F., Braun, M., Harshman, J., Dyke, G., Feinstein, J., Stanley, S., Cibois, A., Schikler, P., Beresford, P., García-Moreno, J., Sorenson, M.D., Yuri, T. y Mindell, D.P. 2004. Phylogenetic relationships among modern birds (Neornithes): Toward an Avian Tree of Life. Pp 468-489 en J. Cracraft, y M.J. Donoghue (eds) Assembling the Tree of Life. Oxford University Press, New York.

Cubo, J. y Casinos, A. 1998. Biomechanical significance of cross-sectional geometry of avian long bones. European Journal of Morphology, 36(1), 19-28.

Curtis, E.L. y Miller, R.C. 1938. The sclerotic ring in North American birds. The Auk, 55, 225-243.

Damuth, J.D.; Jablonski, D.; Harris, J.A.; Potts, R.; Stucky, R.K.; Sues, H.D. y Weishampel, D.B.1992. Taxon-free characterization of animal communities. Pp 183-203 en A.K. Behrensmeyer, J.D. Damuth, W.A. DiMichele, R. Potts, H.D. Sues y S.L. Wing (eds) Terrestrial Ecosystems Through Time: Evolutionary Paleoecology of Terrestrial Plants and Animals. University of Chicago Press, Chicago. 
Degrange, F.J. 2007. Mandible muscle reconstruction in Phorusrhacid birds (Aves, Gruiformes, Cariamae). Ciencias Morfológicas, 9(12), 36.

Degrange, F.J. 2008. M. adductor mandibulae externus de Andalgalornis steulleti (Aves, Phorusrhacidae): Reconstrucción y biomecánica. Actas del III Congreso Latinoamericano de Paleontología de Vertebrados, 76.

Degrange, F.J. y Tambussi, C.P. 2008. Estructura interna del pico de los Psilopterinae (Aves, Gruiformes, Phorusrhacidae). Journal of Morphology, 26(3), 746.

Degrange, F.J.; Tambussi, C.P.; Moreno, K.; Wroe, S. y Witmer, L. 2008. Andalgalornis steulleti (Aves, Phorusrhacidae): respuesta biomecánica del cráneo ante acción de fuerzas extrínsecas. Actas del III Congreso Latinoamericano de Paleontología de Vertebrados, 77.

Degrange, F.J. y Tambussi, C.P. 2009. Análisis de elementos finitos aplicados en aves: beneficios y limitaciones. Ameghiniana, 46 (4, Supl.), 19-20R.

Degrange, F.J. y Picasso, M.B.J. 2010. Skull geometric morphometrics of the Tinamidae (Aves, Palaeognathae). Zoology, 113(6), 334-338.

Degrange, F.J., Tambussi, C.P., Moreno, K., Witmer, L.W. y Wroe, S. 2010. Mechanical Analysis of Feeding Behavior in the Extinct "Terror Bird"' Andalgalornis steulleti (Gruiformes: Phorusrhacidae). PLoS ONE, 5(8), e11856.

Degrange, F.J. y Tambussi, C.P. 2011. Re-examination of Psilopterus lemoinei (Moreno and Mercerat 1891), a late early Miocene little terror bird from Patagonia (Argentina). Journal of Vertebrate Paleontology, 31(5), 1-13.

Degrange, F.J.; Noriega, J.I. y Areta, J.I. (en prensa) Diversity and paleobiology of the santacrucian birds. En S.F. Vizcaíno, R.F. Kay y M.S. Bargo (eds.) Early Miocene Paleobiology in Patagonia: high-latitude paleocommunities of the Santa Cruz Formation. Cambridge University Press.

Desojo, J.B. y Vizcaíno, S.F. 2009. Jaw biomechanics in the South American aetosaur Neoaetosauroides engaeus. Paläontologische Zeitschrift, 83(4), 499-510.

de Oliveira, F.B.; Molina, E.C. y Marroig, G. 2008. Paleogeography of the South Atlantic: a route for primates and rodents into the NewWorld? Pp 55-68 en P.A. Garber, A. Estrada, K.B. Strier (eds) South American primates: comparative perspectives in the study of behavior, ecology, and conservation. Springer, New York.

de Pinna, M.C.C. 1991. Concepts and tests of homology in the cladistic paradigm. Cladistics, 7, 367-394.

De Queiroz, K. y Good, D.A. 1988. The scleral ossicles of Opisthocomus and their phylogenetic significance. The Auk, 105, 29-35.

del Hoyo, J., Elliot, A. y Sargatal, J. 1996. Handbook of Birds of the world, Volume 3: Hoatzin to Auks. Lynx, Barcelona, 752 pp.

Dial, K.P. 2003. Evolution of avian locomotion: correlates of fligth style, locomotor modules, nesting biology, body size, development, and the origin of flapping flight. The Auk, 120, 941-952.

Dolgopol de Saez, M. 1927. Las aves corredoras fósiles del Santacrucense. Anales de la Sociedad Científica Argentina, 103, 145-64.

Dryden, I.L. y Mardia, K.V. 1998. Statistical shape analysis. John Wiley \& Sons, Chichester, 345 pp.

Dullemeijer, P. 1951. The correlation between muscle system and skull structure in Phalacrocorax carbo sinensis (Shaw and Nodder): I-III. Proceedings of the Koninklijke Nederlandse Akademie van Wetenschappen, Series C, 54, 247-259, 400-404, 533-536. 
Dullemeijer, P. 1952. The correlation between muscle system and skull structure in Phalacrocorax carbo sinensis (Shaw and Nodder): IV. Proceedings of the Koninklijke Nederlandse Akademie van Wetenschappen Series C, 55, 95-102.

Dullemeijer P 1974 Concepts and approaches in animal morphology Van Gorcum and Comp B V Assen, The Netherlands, 264 pp.

Dzemski, G. y Christian, A. 2007. Flexibility along the neck of the Ostrich (Struthio camelus) and consequences for the reconstruction of dinosaurs with extreme neck length. Journal of Morphology, 268, 701-714.

Ellerby, D.J.; Henry, H.T.; Carr, J.A.; Buchanan, C.I. y Marsh, R.L. 2005. Blood flow in guinea fowl Numida meleagris as an indicator of energy expenditure by individual muscles during walking and running. Journal of Physiology, 564, 631-648.

Elzanowski, A. 1987. Cranial and eyelid muscles and ligaments of the tinamous (Aves: Tinamiformes). Zoologische Jahrbuch für Anatomie, 116, 63-118.

Emerson S.B. y Arnold, S.J. 1989. Intra- and interspecific relationships between morphology, performance, and fitness. Pp 295-314 en D.B. Wake y G. Roth (eds) Complex organismal functions: integration and evolution in vertebrates. John Wiley and Sons, New York.

Engels, W.L. 1938. Cursorial adaptations in birds. Limb proportions in the skeleton of Geococcyx. Journal of Morphology, 63, 207-217.

Erickson, G.M.; Van Kirk, S.D.; Su, J.; Levenston, M.E.; Caler, W.E. y Carter, D.R. 1996. Bite-force estimation for Tyrannosaurus rex from tooth-marked bones. Nature (London), 382(6593), 706-708.

Ericson, P.G.P. 1997. Systematic relationships of the palaeogene family Presbyornithidae (Aves: Anseriformes). Zoological Journal of the Linnean Society, 121, 429-483.

Ericson, P.G.P., Parsons, T.J. y Johansson, U.S. 2001. Morphological and molecular support for nonmonophyly of the Galloanseres. Pp 157-168 en J. Gauthier y L.F. Gall (eds) New Perspectives on the Origin and Early Evolution of Birds. Peabody Museum of Natural History, New Haven, CT.

Ericson, P.G.P.; Anderson, C.L.; Britton, T.; Elzanowski, A.; Johansson, U.S.; Källersjö, M.; Ohlson, J.I.; Parsons, T.J.; Zuccon, D. y Mayr, G. 2006. Diversification of Neoaves: integration of molecular sequence data and fossils. Biology Letters, 2, 543-547.

Eronen, J.T.; David Polly, P.; Fred, M.; Damuth, J.; Frank, D.C.; Mosbrugger,V.; Scheidegger, C.; Stenseth, N.C. y Fortelius, M. 2010. Ecometrics: The traits that bind the past and present together. Integrative Zoology, 5, 88-101.

Fain, M.G. y Houde, P. 2004. Parallel radiations in the primary clades of birds. Evolution, 58(11), 25582573.

Fain, M.G., Krajewski, C. y Houde, P. 2007. Phylogeny of "core Gruiformes" (Aves: Grues) and resolution of the Limpkin-Sungrebe problem. Molecular Phylogenetics and Evolution, 43, 515-529.

Farris, J.S. 1969. A successive approximation approach to character weighting. Systematic Zoology, 18, 374-385.

Farris, J.S. 1989. The retention index and the rescaled consistency index. Cladistics, 5, 417-419.

Feduccia, A. 1999. 1,2,3 - 2,3,4: Accommodating the cladogram. PNAS, 96, 4740-4742.

Feduccia, A. 2003. 'Big bang' for tertiary birds? TRENDS in Ecology and Evolution, 18(4), 172-176.

Felsenstein, J. 1985. Phylogenies and the comparative method, The American Naturalist, 125, 1-15. 
Ferry-Graham, L.; Bolnick, D.I. y Wainwright, P.C. 2002. Using functional morphology to examine the ecology and evolution of specialization. Integrative and Comparative Biology, 42, 265-277.

Fisher, H.I. 1955. Some aspects of the kinetics in the jaws of birds. The Wilson Bulletin, 67(3), 175-188.

Fisher, H.I. y Goodman, D.C. 1955. The myology of the Whooping Crane, Grus americana. Monografias Urbana, Illinois: University of Illinois Press, 24, 127pp.

Freeman, S. y Jackson, W.M. 1990. Univariate metrics are not adequate to measure avian body size. The Auk, 107, 69-74.

Gallina, P.A. 2011. Estudio anatómico, sistemático y paleobiológico de Bonitasaura salgadoi (Dinosauria, Sauropoda): su importancia en el contexto de la evolución de los titanosaurios del Cretácico superior de la Argentina. Tesis Doctoral. Universidad Nacional de La Plata, Argentina, 340 pp. Inédita.

Garland Jr., T. y Janis, C.M. 1993. Does metatarsal/femur ratio predict maximal running speed in cursorial mammals? Journal of Zoology, London, 229, 133-151.

Garland Jr, T.; Dickerman, A.W.; Janis, C.M. y Jones, J.A. 1993. Phylogenetic analysis of covariance by computer simulation. Systematic Biology, 42, 265-292.

Garland Jr, T.A.; Bennet, F. y Rezende, E. 2005. Phylogenetic approaches in comparative physiology. The Journal of Experimental Biology, 208, 3015-3035.

Garrod, A.H. 1873. On the value in classification of a peculiarity in the anterior margin of the nasal bones in certain birds. Proceedings of the Zoological Society of London, 1873, 33-38.

Gatesy, S.M. 1990. Caudofemoral musculature and the evolution of theropod locomotion. Paleobiology, $16,170-186$.

Gatesy, S.M. 1991. Hind limb movements of the American alligator (Alligator mississippiensis) and postural grades. Journal of Zoology, 224, 577-588.

Gatesy SM. 1994. Neuromuscular diversity in archosaur deep dorsal thigh muscles. Brain Behavior and Evolution, 43, 1-14.

Gatesy, S.M. 1999a. Guineafowl hind limb function. I. Cineradiographic analysis and speed effects. Journal of Morphology, 240, 115-125.

Gatesy, S.M. 1999b. Guineafowl hind limb function. II. Electromyographic analysis and motor pattern evolution. Journal of Morphology, 240, 127-142.

Gatesy, S.M. y Biewener, A.A. 1991. Bipedal locomotion: effects of speed, size and limb posture in birds and humans. Journal of Zoology of London, 224,127-147.

Gatesy, S.M. y Dial, K.P. 1996. Locomotor modules and the evolution of avian flight. Evolution, 50, 331340 .

Gatesy, S.M. y Middleton, K.M. 1997. Bipedalism, and the evolution of theropod diversity. Journal of Vertebrate Paleontology, 17, 308-329.

Gatesy, S.M.; Bäker, M. y Hutchinson, J.R. 2009. Constraint-based exclusion of limb poses for reconstructing theropod dinosaur locomotion. Journal of Vertebrate Paleontology, 29(2), 535-544.

Gaunt, A.S. 1969. Myology of the leg in swallows. The Auk, 85, 41-53.

Gauthier, J. 1986. Saurischian monophyly and the origin of birds. Pp 1-55 en K. Padian (eds) The Origin of Birds and the Evolution of Flight. Memoirs of the California Academy of Sciences 8. 
Gebo, D.L. y Rose, K.D. 1993. Skeletal morphology and locomotor adaptation in Prolimnocyon atavus, an early Eocene hyaenodontid creodont. Journal of Vertebrate Paleontology, 13, 125-144.

George, J.C. y Berger, A.J. 1966. Avian Myology. Academic Press, New York, 500 pp.

Giannini, N. P. 2003. Canonical Phylogenetic Ordination. Systematic Biology, 52, 684-695.

Giardina, M.A. 2006. Anatomía económica de Rheidae. Intersecciones en Antropología, 7, 263-276.

Goloboff, P. A. 1993. Estimating character weights during tree search. Cladistics, 9, 83-92.

Goloboff, P.A.; Farris, J.S y Nixon, K.C. 2000. T.N.T. Tree Analysis Using New Technology. Version 1.1. Program and documentation available from the authors, and at www.zmuc.dk/public/phylogeny.

Gonzaga, L.P. 1996. Family Cariamidae (Seriemas). Pp 234-239 en J. Del Hoyo, A. Elliott y J. Sargatal (eds) Handbook of Birds of the world, Volume 3: Hoatzin to Auks. Lynx, Barcelona.

Goodman, D.C. y Fisher, H.I. 1962. Functional anatomy of the feeding apparatus in waterfowl (Aves: Anatidae). Monografias Urbana, Illinois: University of Illinois Press, 193 pp.

Goswami, A.; Milne, N. y Wroe, S. 2011. Biting through constraints: cranial morphology, disparity and convergence across living and fossil carnivorous mammals. Proceedings of the Royal Society B, 278, 1831-1839.

Goussard, F.; Germain, D.; Delmer, C. y Moreno, K. 2010. Finite element analysis: A promising tool for the reconstruction of extinct vertebrate graviportal taxa. A preliminary study based on the metacarpal arrangement of Elephas maximus. Comptes Rendus Palevol, 9, 455-461.

Grafen, A. 1995. The phylogenetic regression. Philosophycal Transactions of the Royal Society of London, Series B, Biological Sciences, 326, 119-157.

Gregory, W.K. 1912. Notes on the principles of quadrupedal locomotion and on the mechanism of he limbs in hoofed animals. Annals of the New York Academy of Sciences, 22, 267-294.

Grzimek B. 1968. Grzimeks Tierleben. Vögel. Band I. München, DTV. 86 pp.

Gussekloo, W.S.; Vosselman, M.G. y Bout, R.G. 2001. Three-dimensional kinematics of skeletal elements in avian prokinetic and rhynchokinetic skulls determined by roentgen stereophotogrammetry. Journal of Experimental Biology, 204, 1735-1744.

Gussekloo, S.W. y Bout, R.G. 2005a. The kinematics of feeding and drinking in palaeognathous birds in relation to cranial morphology. Journal of Experimental Biology, 208, 3395-3407.

Gussekloo, W.S. y Bout, R.G. 2005b. Cranial kinesis in palaeognathus birds. Journal of Experminetal Biology, 208, 3409-3419.

Haas, G. 1969. On the jaw musculature of Ankylosaurus. American Museum Novitates, 2399, 1-11.

Habib, M.B. y Ruff, C.B. 2008. The effects of locomotion on the structural characteristics of avian limb bones. Zoological Journal of the Linnean Society, 153, 601-624.

Hackett, S.J.; Kimball, R.T.; Reddy, S.; Bowie, R.C.K.; Braun, E.L.; Braun, M.J.; Chojnowski, J.L.; Andrew Cox, W.; Han, K.; Harshman, J.; Huddleston, C.J.; Marks, B.D.; Miglia, K.J.; Moore, W.S.; Sheldon, F.H.; Steadman, D.W.; Witt, C.C. y Yuri, T. 2008. A phylogenomic study of birds reveals their evolutionary history. Science, 320, 1763-1768.

Hall, B.K. 1988. The embryonic development of bone. American Scientist, 76, 174-181.

Hall, M.I. 2008. The anatomical relationships between the avian eye, orbit and sclerotic ring: Implications for inferring activity patterns in extinct birds. Journal of Anatomy, 212(6), 781-794. 
Hall, M.I. 2009. The Relationship Between the Lizard Eye and Associated Bony Features: A Cautionary Note for Interpreting Fossil Activity Patterns. The Anatomical Record, 292, 798-812.

Hamershock, D.M., Seamans, T.W. y Bernhardt, G.E. 1993. Determination of body density for twelve bird species. Reports of the Wright Laboratory, $20 \mathrm{pp}$.

Hartman, F.A. 1961. Locomotor mechanisms of birds. Smithonian Miscellaneus Collections, 143, 1-91.

Hennig, W. (1968) Elementos de una sistemática filogenética. EUDEBA, Buenos Aires, 353 pp.

Herrel, A.; Van Damme, R.; Vanhooydonck, B. y de Vree, F. 2001. The implications of bite performance for diet in two species of lacertid lizards. Canadian Journal of Zoology, 79, 662-670.

Herrel, A.; O’Reilly, J.C. y Richmond, A.M. 2002. Evolution of bite force in turtles. Jounal of Evolutionary Biology, 15, 1083-1094.

Herrel, A.; Podos, J.; Huber, S.K. y Hendry, A.P. 2005a. Bite performance and morphology in a population of Darwin's finches: implications for the evolution of beak shape. Functional Ecology, 19, 4348.

Herrel, A.; Podos, J.; Huber, S.K. y Hendry, A.P. 2005b. Evolution of bite force in Darwin's finches: a key role for head width. Journal of Evolutionary Biology, 18, 669-675.

Hertel F. 1994. Diversity in body size and feedingmorphology within past and present vulture assemblages. Ecology, 75, 1074-1084.

Hertel F. 1995. Ecomorphological indicators of feeding behavior in recent and fossil raptors. The Auk, $112,890-903$.

Hertel, F. y Campbell, K.E. 2007. The antitrochanter of birds: form and function in balance. The Auk, 124(3), 789-805.

Hildebrand, M. 1985. Digging of quadrupeds. Pp 90-108 en M. Hildebrand, D.M. Bramble, K.F. Liem y D.B. Wake (eds.). Functional Vertebrate Morphology. Cambridge: Belknap Press of Harvard University.

Hildebrand, M. 1988. Analysis of vertebrate structure. Jhon Wiley \& Sons, Inc., New York, 701 pp.

Hildebrand, M. y Goslow, G. 2001. Analysis of Vertebrate Structure. New York: Wiley, 635 pp.

Hoese, W.J. y Westneat, M.W. 1996. Biomechanics of cranial kinesis in birds: testing linkage models in the White-throated Sparrow Zonotrichia albicollis. Journal of Morphology, 227, 305-320.

Hofer, H. 1950. Zur Morphologie der Kiefermuskulatur der Vögel. Abteilung für Anatomie und Ontogenie der Tiere, 70, 427-556.

Hofer,H. 1953. Die Kiefermuskulatur der Papageien als evolutionsproblem. Biologisches Zentralblatt, $72(5 / 6), 225-232$.

Höfling, E. y Gasc, J.P. 1984. Biomécanique du crâne et du bec chez Ramphastos (Ramphastidae, Aves). Gegenbaurs morphologisches Jahrbuch, 130(2), 235-262.

Holliday C.M. 2006. Evolution and function of the jaw musculature and adductor chamber of archosaurs (crocodilians, dinosaurs, and birds). Tesis Doctoral. Ohio University, Athens, Ohio. 325 pp.

Holliday, C.M. 2009. New insights into dinosaur jaw muscle anatomy. The Anatomical Record, 292, 1246-1265.

Holliday, C.M. y Witmer, L.M. 2007. Archosaur adductor chamber evolution: integration of musculoskeletal and topological criteria in jaw muscle homology. Journal of Morphology, 268, 457-484. 
Holliday, C.M. y Witmer, L.M. 2008. Cranial kinesis in dinosaurs: intracranial joints, protractor muscles, and their significance for cranial evolution and function in diapsids. Journal of Vertebrate Paleontology, 28, 1073-1088.

Holtz, T.R. 1994. The phylogenetic position of the Tyrannosauridae: implications for theropod systematics. Journal of Paleontology, 68(5), 1100-1117.

Hudson, G.E. 1937. Studies on the muscles of the pelvic appendage in birds. American Midland Naturalist, 18, 1-108.

Hudson, G.E. 1948. Studies on the Muscles of the Pelvic Appendage in Birds II: The Heterogeneous Order Falconiformes. American Midland Naturalist, 39, 102- 127.

Huey, R.B. y Stevenson, R. 1979. Integrative and Comparative Biology. American Zoologist, 19(1), $357-$ 366.

Hunt, K.H. 1978. Kinematic geometry of mechanisms. Clarendon Press; Oxford University Press, New York, $465 \mathrm{pp}$.

Hurlburt, G. 1999. Comparison of body mass estimation techniques, using recent reptiles and the pelycosaur Edaphosaurus boanerges. Journal of Vertebrate Paleontology, 19(2), 338-350.

Hurum, J.H. y Currie, P.J. 2000. The crushing bite of tyrannosaurids. Journal of Vertebrate Paleontology, 20(4), 619-621.

Hutchinson, J.R. 2001a. The evolution of femoral osteology and soft tissues on the line to extant birds. Zoological Journal of the Linnaean Society, 131, 169-197.

Hutchinson, J.R. 2001b. The evolution of pelvic osteology and soft tissues on the line to extant birds. Zoological Journal of the Linnaean Society, 131, 123-168.

Hutchinson, J.R. 2004. Biomechanical modeling and sensitivity analysis of bipedal running ability. I. Extant Taxa. Journal of Morphology, 262, 421-440.

Hutchinson, J.R. y Gatesy, S.M. 2000. Adductors, aductors, and the evolution of arhosaur locomotion. Paleobiology, 26, 734-751.

Hutchinson, J.R. y Gatesy, S.M. 2001. Bipedalism. Pp 1-6. Enyclopedia of Life Sciences. Macmillan, London.

Hutchinson, J.R. y García, M. 2002. Tyrannosaurus was not a fast runner. Nature, 415, 1018-1021.

Hutchinson, J.R.; Anderson, F.C.; Blemker, S. y Delp, S.L. 2005. Analysis of hindlimb muscle moment arms in Tyrannosaurus rex using a three-dimensional musculoskeletal computer model. Paleobiology, 31, 676-701.

Huxley, T.H. 1867. On the classification of birds, and on the taxonomic value of the modifications of certain of the cranial bones observable in that class. Proceedings of the Zoological Society, 27, 415-472.

Ibañez, B. 2006. Ecomorfología de aves habitantes de humedales de la región Pampeana, Argentina. Tesis de grado. Universidad CAECE, 129 pp. Inédita.

Iordansky, N.N. 1990. Evolution of cranial kinesis in lower tetrapods. Netherlands Journal of Zoology, $40(1-2), 32-54$.

Irschick, D. y Losos, J. 1998. A comparative analysis of the ecological significance of maximal locomotor performance in caribbean Anolis lizards. Evolution, 52(1), 219-226. 
Jacobson, R.D. y Hollyday, M. 1982. A behavioral and electromyographic study of locomotion in the chick. Journal of Neurophysiology, 48, 238-256.

Jimenez, J. y Jaksic, F. 1990. Historia natural del águila Geranoaetus melanoleucus: una revisión. El Hornero, 13, 97-110.

Jones, W.W. 2010. Nuevos aportes sobre la paleobiología de los fororrácidos (Aves: Phorusrhacidae) basados en el análisis de estructuras biológicas. Tesis Doctoral. Universidad de Ciencias, Uruguay, 213 pp. Inédita.

Kardong, K.V. 1998. Vertebrados: Anatomía comparada, function, evolución (2da. Ed.). McGraw Hill, California, $732 \mathrm{pp}$

Karr, J.R. y James, F.C. 1975. Eco-morphological configurations and convergent evolution of species and communities. Pp 258-291 en M.L. Cody y J.M. Diamond (eds) Ecology and Evolution of Communities. Harvard University Press, Massachusetts.

Keast, A. 1970. Adaptive evolution and shifts in nicho occupation in island birds. Biotropica, 2, 61-75.

Klingenberg, C.P. 2011. MorphoJ: an integrated software package for geometric morphometrics. Molecular Ecology Resources, 11, 353-357.

Kluge, A. 1997. Testability and the refutation and corroboration of cladistics hypotheses. Cladistics, 13, 81-96.

Kluge, A.G. y Farris, J.S. 1969. Quantitative phyletics and the evolution of anurans. Systematic Zoology, $18,1-32$.

Koehl, M.A.R. 1996. When does morphology matter? Annual Reviews in Ecology and Systematics, 27, 501-542.

Kraglievich, L. 1920. Sobre las aves fósiles de la República Argentina. El Hornero, 2(1), 49-55.

Kraglievich, L. 1932. Una gigantesca ave fósil del Uruguay, Devincenzia gallinali n. gen. n. sp., tipo de una nueva familia, Devincenziidae, del Orden Stereornithes. Anales del Museo Historia Natural de Montevideo, 3, 323-55.

Kraglievich, L. 1940. Descripción del gran ave pliocena "Mesembriornis milneedwardsi”. Obras de Geología y Paleontología, 3, 639-666.

Kraglievich, L. 1946. Noticia preliminar acerca de un nuevo y gigantesco estereornito de la fauna Chapadmalense. Anales de la Sociedad Científica Argentina, 142(3), 104-121.

Kulemeyer, C.; Asbahr, K.; Gunz, P.; Frahnert, S.y Bairlein, F. 2009. Functional morphology and integration of corvid skulls - a 3D geometric morphometric approach. Frontiers in Zoology, 6(2), 1-14.

Lauder, G.V. 1986. Homology, analogy, and the evolution of behavior.Pp 9-40 en M. Nitecki y J. Kitchell (eds) The evolution of behavior. Oxford University Press, New York.

Lauder, G.V. 1990. Functional morphology and systematics: studying functional patterns in an historical context. Annual Review of Ecology and Systematics, 21, 317-340.

Lauder, G.V. 1991. Biomechanics and evolution: integrating physical and historical biology in the studyof complex systems. Pp 1-19 en J.M.V. Rayner y R.J. Wootton (eds) Biomechanics and Evolution. Cambridge University Press, New York.

Lauder, G.V. 1995. On the inference of function from structure. Pp 1-18 en J.J. Thomason (eds) Functional Morphology in Vertebrate Paleontology. Cambridge, University Press, New York.

Lemmrich, W. 1931. Der Skleralring der Vögel. Jenaische Zeitschrift für Naturwissenschaft, 65, 513-586. 
Leiber, R.L. 1992. Skeletal Muscle Structure and Function: Implications for Rehabilitation and Sports Medicine. Williams and Wilkins, Baltimore, 303 pp.

Leisler, B. y Winkler, H. 1985. Ecomorphology. Current Ornithology, 2, 155-186.

Liem, K.F.; Bemis, W.E.; Walker, W.F. y Grande, L. 2001. Functional Anatomy of the Vertebrates. Harcourt College Publisher, Orlando, 703 pp.

Lima, FC.; Vieira, LG.; Santos, A.L.Q.; De Simone, S.B.S.; Hirano, L.Q.L.; Silva, J.M.M. y Romão, M.F. 2009. Anatomy of the scleral ossicles in brazilian birds. Brazilian Journal of Morphology Sciences, 26(3-4), 165-169.

Livezey, B.C. 1989. Morphometric patterns in Recent and fossil penguins (Aves, Sphenisciformes). Journal of Zoology (London), 219, 269-307.

Livezey, B.C. 1993a. Morphology of flightlessness in Chendytes, fossil seaducks (Anatidae: Mergini) of California. Journal of Vertebrate Paleontology, 13, 185-199.

Livezey, B.C. 1993b. An ecomorphological review of the dodo (Raphus cucullatus) and solitaire (Pezophaps solitaria), flightless Columbiformes of the Mascarene Islands. Journal of Zoology (London), 230, 247-292.

Livezey, B.C. 1998. A phylogenetic analysis of the Gruiformes (Aves) based on morphological characters, with an emphasis on the rails (Rallidae). Philosophical Transactions of the Royal Society of London B, 353, 2077-2151.

Livezey, B.C. y Zusi, R.L. 2001. Higher-order phylogenetics of modern Aves based on comparative anatomy. Netherlands Journal of Zoology, 51, 179-205.

Livezey, B.C. y Zusi, R.L. 2006. Higher-order phylogeny of modern birds (Theropoda, Aves: Neornithes) based on comparative anatomy. I. Methods and characters. Bulletin of the Carnegie Museum of Natural History, 37, 1-544.

Livezey, B.C. y Zusi, R.L. 2007. Higher-order phylogeny of modern birds (Theropoda, Aves: Neornithes) based on comparative anatomy. II. Analysis and discussion. Zoological Journal of the Linnean Society, $149,1-95$.

Lucas, F.A. 1901. The animals of the past. McClure, Phillips \& Co., New York, 258 pp.

Lydekker, R. 1893. On the extinct giant birds of Argentina. Ibis, 5, 40-47.

MacFadden, B.J.; Labs-Hochstein, J. y Hulbert Jr., R.C. 2007. Revised age of the late Neogene terror bird (Titanis) in North America during the Great American Interchange. Geology, 35(2), 123-126.

Marinelli, W. 1928. Über den Schädel der Schnepfe. Palaeobiologica, 1, 135-160.

Marshall, L.G. 1978. The Terror Bird. Field Museum of Natural history Bulletin, 49(9), 6-15.

Marshall, L. 1994. The terror birds of South America. Scientific American, 270, 90-95.

Martins, E.P. 2000. Adaptation and the comparative method. TREE, 15(7), 296-299.

Marugán-Lobón, J. y Buscalioni, A.D. 2003. Disparity and geometry of the skull in Archosauria (Reptilia: Diapsida). Biological Journal of the Linnean Sociey, 80, 67-88.

Marugán-Lobón, J. y Buscalioni, A.D. 2006. Avian skull morphological evolution: exploring exo- and endocranial covariation with two-block partial least squares. Zoology, 109, 217-230. 
Mayr, G. 2002. A new specimen of Salmila robusta (Aves: Gruiformes: Salmilidae n. fam.) from the Middle Eocene of Messel. Paläontologische Zeitschrift, 76(2), 305-316.

Mayr, G. 2005. "Old World phorusrhacids" (Aves: Phorusrhacidae): a new look at Strigogyps (“Aenigmavis") sapea (Peters 1987). PaleoBios, 25(1), 11-16.

Mayr, G. 2008. Avian higher-level phylogeny: well-supported clades and what we can learn from a phylogenetic analysis of 2954 morphological characters. Journal of Zoological Systematics and Evolutionary Research, 46(1), 63-72.

Mayr, G. 2009. Paleogene Fossil Birds. Springer-Verlag, Berlin Heidelberg, 262 pp.

Mayr, G. y Clarke, J. 2003. The deep divergences of Neornithine birds: a phylogenetic analysis of morphological characters. Cladistics, 19, 527-553.

Mazzetta, G.; Christiansen, P.V. y Fariña, R.A. 2004. Giants and Bizarres: Body Size of Some Southern South American Cretaceous Dinosaurs. Historical Biology, 65(2-4), 1-13.

McDowell, S. 1948. The bony palate of birds: Part I the Palaeognathae. The Auk, 65(4), 520-549.

McGowan, C. 1979. The hind limb musculature of the Brown kiwi, Apteryx australis mantelli. Journal of Morphology, 160, 33-74.

McHenry, C.R.; Clausen, P.D.; Daniel, W.J.T.; Meers, M.B. y Pendharkar, A. 2006. The biomechanics of the rostrum in crocodilians: a comparative analysis using finite element modelling. The Anatomical Record, 288, 827-849.

McHenry, C.R.; Wroe, S.; Clausen, P.D.; Moreno, K. y Cunningham, E. 2007. Supermodeled sabercat, predatory behaviour in Smilodon fatalis revealed by high resolution 3-D computer simulation. PNAS, $104,16010-16015$.

McKitrick, M.C. 1985. Pelvic morphology of the kingbirds and their allies (Aves: Tyrannidae). Annals of the Carnegie museum, 54, 275-317.

McIntyre, S.; Lavorel, S.; Landsberg, J. y Forbes, T.D.A. 1999. Response in vegetation: Towards a global perspective on functional traits. Journal of Vegetation Science, 10, 621-30.

Meekangvan, P.; Barhosrst, A.A.; Chatterjee, S. y Schovanec, L. 2006. Nonlinear dynamical model of avian cranial kinesis. Journal of Theoretical Biology, 240, 32-47.

Meers, M.B. 2002. Maximum bite force and prey size of Tyrannosaurus rex and their relationships to the inference of feeding behaviour. Historical Biology, 16(1), 1-12.

Middleton, K.M. y Gatesy, S.M. 2000. Theropod forelimb design and evolution. Zoological Journal of the Linnean Society, 28(2), 149-187.

Miles, D.B.; Ricklefs, R.E. y Travis, J. 1987. Concordance of ecomorphological relationships in three assemblages of passerine birds. American Naturalist, 129, 347-364.

Mittelbach, G.G. 1984. Predation and resource partitioning in two sunfishes (Centrarchidae). Ecology, $65,499-513$.

Mittelbach, G.G. y Osenberg, C.W. 1994. Using foraging theory to study trophic interactions. Pp 45-59 en D.J. Stouder, K.L. Fresh y R.J. Feller (eds.) Theory and application in fish feeding ecology. University of South Carolina Press, Columbia, South Carolina.

Moazen, M; Curtis, N; O’Higgins, P.; Jones, M.E.H. Evans SE, y Fagan, M.J. 2009a. Assessment of the role of sutures in a lizard skull: a computer modelling study. Proceedings of the Royal Society B, 276, 3946. 
Moazen, M.; Curtis, N.; O’Higgins, P., Evans, S.E. y Fagan, M.J. 2009b. Biomechanical assessment of evolutionary changes in the lepidosaurian skull. PNAS, 106, 8273-8277.

Montenegro, F.; Jones, W.W.; Lecuona, G.; Toriño, P.; Batista, A.; García, G. y Ubilla, D. 2010. Nuevos aportes al conocimiento de los Phorusrhacinae (Aves, Phorusrhacidae) del Pleistoceno tardío. Libro de Resúmenes del X Congreso Argentino de Paleontología y Bioestratigrafía y VII Congreso Latinoamericano de Paleontología, 186.

Moreno, F.P. y Mercerat, A. 1891. Catálogo de los pájaros fósiles de la República Argentina conservados en el Museo de La Plata. Anales del Museo de La Plata, 1, 7-71.

Moreno, K.; Wroe, S.; Clausen, P.D.; McHenry, C.R.; D’Amore, D.C.; Rayfield, E.J. y Cunningham, E. 2008. Cranial performance in the Komodo dragon (Varanus komodoensis) as revealed by high-resolution 3-D finite element analysis. Journal of Anatomy, 212, 736-746.

Morgan, C. 2009. Análisis de la diversidad morfológica vinculada a la capacidad fosorial en especies del género Ctenomys (Rodentia, Octodontidae). Tesis Doctoral. Universidad Nacional de La Plata, Argentina, 198 pp. Inédita.

Mourer-Chauviré, C. 1981. Première indication de la présence de Phorusrhacidés, famille d'oiseaux géants d'Amérique du Sud, dans le Tertiaire Européen: Ameghinornis nov. gen. (Aves, Ralliformes) des Phosphorites du Quercy, France. Geóbios, 14, 637-647.

Mourer-Chauviré, C. 1983. Les Gruiformes (Aves) des Phosphorites du Quercy (France). I. Sous-ordre Cariamae (Cariamidae et Phorusrhacidae) systématique et biostratigraphie. Paleovertebrata, 13, 83-143.

Mourer-Chauviré, C.; Tabuce, R.; Mahboubi, M.; Adaci, M. y Bensalah, M. 2011. A Phororhacoid bird from the Eocene of Africa. Naturwissenschaften. DOI 10.1007/s00114-011-0829-5.

Murray, P.F. y Vickers-Rich, P. 2004. Magnificent Mihirungs: The colossal flightless birds of the Australian dreamtime. Indiana University Press, Indiana, 410 pp.

Nasif, N.L.; Esteban, G.I. y Ortiz, P.E. 2009. Novedoso hallazgo de egagrópilas en el Mioceno tardío, Formación Andalhuala, provincia de Catamarca, Argentina. Temas de Paleontología I, Serie Correlación Geológica, 25, 105-114.

Noriega, J. 2001 . Body mass estimation and locomotion of the Miocene pelecaniform bird Macranhinga. Acta Paleontologica Polonica, 46(2), 115-128.

Nudds, R.L., Dyke, G.J. y Rayner, J.M.V. 2004. Forelimb proportions and the evolutionary radiation of Neornithes. Proceedings of the Royal Society of London, Series B, 271(Suppl. 5), 324-327.

Nudds, R.L., Dyke, G.J. y Rayner, J.M.V. 2007. Avian brachial index and wing kinematics: Putting movement back into bones. Journal of Zoology, 272(2), 218-226.

Nuijens, F.W. y Bout, R.G. 1998. The role of two jaw ligaments in the evolution of passerines. Zoology, $101,24-33$

O’Connor, P.M. 2006. Postcranial pneumaticity: an evaluation of soft-tissue influences on the postcranial skeleton and the reconstruction of pulmonary anatomy in archosaurs. Journal of Morphology, 267, 11991226 .

Olmos, M.; Casinos, A. y Cubo, J. 1996. Limb allometry in birds. Annales des sciences naturelles, Zoologie, 17, 39-49.

Olson, S. 1985. The fossil record of birds. Pp 79-252 en D. Farner, J. King, y K. Parkes (eds) Avian Biology. New York, Academic Press.

Orians, G. 1971. Ecological aspects of behavior. Pp 513-546 en D.S. Farner y J.R. King (eds) Avian Biology. Academic Press, New York. 
Osborn, H.F. 1916. Skeletal adaptations of Ornitholestes, Struthiomimus, Tyrannosaurus. Bulletin of the American Museum of Natural History, 35(43), 733-771.

Osborn, H.F. 1929. The Titanotheres of ancient Wyoming, Dakota, and Nebraska. Monograph U.S. Geological Survey, 55, 1-953.

Ostrom, J.H. 1976. Archaeopteryx and the origin of birds. Biological Journal of the Linnean Society, 8, 91-182.

Otero, A. y Vizcaíno, S.F. 2008. Hindlimb musculature and function of Neuquensaurus australis Lydekker (Sauropoda: Titanosauria). Ameghiniana, 45, 333-348.

Otero, A. 2011. Saurópodos Saltasaurinae del territorio argentino: reconstrucción de la musculatura y función del esqueleto apendicular. Tesis Doctoral. Universidad Nacional de La Plata, Argentina, 388 pp. Inédita.

Patterson, C.1982. Morphological characters and homology. Pp 21-74 en K.A. Joysay y A.E. Friday (eds) Problems of phylogenetic reconstruction. Academic Press, London.

Patterson, B. y Kraglievich, L. 1960. Sistemática y nomenclatura de las aves fororracoideas del Plioceno Argentino. Publicación del Museo Municipal Ciencias Naturales y Tradicionales de Mar del Plata, 1, 151.

Paul, G. S. 2002. Dinosaurs of the air: the evolution and loss of flight in dinosaurs and birds. Johns Hopkins Press, Baltimore, 460 pp.

Payne, R.C.; Hutchinson, J.R.; Robilliard, J.J.; Smith, N.C. y Wilson, A.M. 2005. Functional specialization of pelvic limb anatomy in horses (Equus caballus). Journal of Anatomy, 206, 557-574.

Pennycuick, C.J. 1989. Bird Flight Performance. Oxford University Press, Oxford, 153 pp.

Pennycuik, C.J. 2007. Modelling the flying bird. Academic Press, London, 496 pp.

Perry, S.F. y Sander, P.M. 2004. Reconstruction of the evolution of the respiratory apparatus in dinosaurs and other tetrapods using a two-step deductive process. Respiratory Physiology and Neurobiology, 144, 125-139.

Peters, R.H. 1983. The ecological implications of body size. Cambridge University Press, Cambridge, $329 \mathrm{pp}$.

Picasso. M.B.J. 2010a. Crecimiento y desarrollo de los componentes musculares y óseos asociados a la locomoción durante la vida postnatal de Rhea americana (Aves: Palaeognathae). Tesis Doctoral. Universidad Nacional de La Plata, Argentina, 229 pp. Inédita.

Picasso, M.B.J. 2010b. The hindlimb muscles of Rhea americana (Aves, Palaeognathae, Rheidae). Anatomia, Histologia, Embryolgia, 39, 462-472.

Plotnick, R. y Baumiller, T.K. 2000. Invention by evolution: functional analysis in paleobiology. Paleobiology, 26, 305-321.

Prange, H.D.; Anderson, J.F. y Rahn, H. 1979. Scaling of skeletal mass to body mass in birds and mammals. American Naturalist, 113, 103-122.

Preuschoft, H. y Witzel, U. 2002. Biomechanical investigations on the skulls of reptiles and mammals. Senckenbergiana Lethaea, 82(1), 207-222.

Preuschoft, H. y Witzel, U. 2004. Functional structure of the skull in hominoidea. Folia Primatologica, 75, 219-52. 
Preuschoft, H. y Witzel, U. 2005. Functional shape of the skull in vertebrates: which forces determine skull morphology in lower primates and ancestral synapsids? The Anatomical Record Part A, 283, 402413.

Radinsky, L.B. 1987. The evolution of vertebrate desing. University of Chicago Press, Chicago, 188 pp.

Raikow, R.J. 1978 Appendicular myology and relationships of the New World, nine-primaried oscines (Aves: Passeriformes). Bulletin of the Carnegie Museum of Natural History, 7, 1-43.

Raikow, R.J. 1985. Locomotor system. Pp 57-147 en A.S. King y J. McLelland (eds) Form and Function in birds, Vol. 3, Academic Press, London.

Raikow, R.J. 1987. Hindlimb myology and evolution of the Old World suboscine passerine birds (Acanthisittidae, Pittidae, Philepittidae, Eurylaimidae). Ornithological Monographs, 41, 1-81.

Rayfield, E.J. 2001 Cranial design and function in a large theropod dinosaur: a study using finite element analysis. Tesis Doctoral, University of Cambridge, UK, 300 pp.

Rayfield, E.J. 2004. Cranial mechanics and feeding in Tyrannosaurus rex. Proceedings of the Royal Society B, 271, 1451-1459.

Rayfield, E.J. 2005a. Using finite-element analysis to investigate suture morphology: a case study using large carnivorous dinosaurs. The Anatomical Record, 283A, 349-365.

Rayfield E.J. 2005b. Aspects of comparative cranial mechanics in the theropod dinosaurs Coelophysis, Allosaurus and Tyrannosaurus. Zoological Journal of the Linnean Society, 144, 309-16.

Rayfield, E.J. 2007. Finite element analysis and understanding the biomechanics and evolution of living and fossil organisms. Annual Review of Earth and Planetary Sciences, 35, 541-576.

Rayfield, E.J.; Norman, D.B.; Horner, C.C.; Horner, J.R.; May Smith, P.; Thomason, J.J. y Upchurch, P. 2001. Cranial design and function in a large theropod dinosaur. Nature, 409, 1033-1037.

Rayfield, E.J.; Milner, A.C.; Xuan, V.B. y Young, P.G. 2007. Functional morphology of spinosaur 'crocodile-mimic' dinosaurs. Journal of Vertebrate Paleontology, 27(4), 892-901.

Rayner, J.M.V. 1985. Linear relations in biomechanics: the statistics of scaling functions. Journal of Zoology of London (A), 206, 415-439.

Reid, J. 1835. Anatomical description of the Patagonian penguin. Proceedings of the Zoological Society of London, 3, 132-148.

Richmond, B.G.; Wright, B.W.; Grosse, L.; Dechow, P.C.; Ross, C.F.; Spencer, M.A. y Strait, D.S. 2005. Finite element analysis in functional morphology. The Anatomical Record A, 283, 259-274.

Ricklefs, R.E. y Travis, J. 1980. A morphological approach to the study of avian community organization. The Auk, 97, 321-338.

Ricklefs, R.E. y Miles, D.B. 1994. Ecological and evolutionary inferences from morphology: An Ecological Perspective. Pp 13-41 en P.C. Wainwright y S.M. Reilly (eds) Ecological Morphology: integrative organismal biology. The University of Chicago Press, Chicago.

Rieppel, O. 1988. Fundamentals of Comparative Biology. Birkhäuser Verlag, Basel, 202 pp.

Rieppel, O. 2002. Feeding mechanics in Triassic stem group sauropterygians: the anatomy of a successful invasion of Mesozoic seas. Zoological Journal of the Linnean Society, 135, 33-63.

Rising, J.D. y Somers, K.M. 1989. The measurement of overall body size in birds. The Auk, 106, 666674. 
Rohlf, F.J. 1993. Relative warp analysis and an example of its application to mosquito wings. Pp 131-158 en L.F. Marcus, E. Bello y A. Garcia-Valdecasas (eds.) Contributions to Morphometrics. Museo Nacional de Ciencias Naturales, Madrid.

Rohlf, F.J. 2003. TpsRelw, version 1.35. Department of Ecology and Evolution, State University of New York, Stony Brook, New York.

Rohlf, F.J., 2005. TpsDig, version 2.04. Department of Ecology and Evolution, State University of New York, Stony Brook, New York.

Rohlf, F.J. y Slice, D., 1990. Extensions of the Procrustes method for the optimal superimposition of landmarks. Systematic Zoology, 39, 40-59.

Rohlf, F.J. y Marcus L.F. 1993. A revolution in morphometrics. Trends in Ecology and Evolution, 8, 129132.

Ross, C.F.; Patel, B.A.; Slice, D.E.; Strait, D.S.; Dechow, P.C.; Richmond, B.G. y Spencer, M.A. 2005. Modeling masticatory muscle force in finite element analysis: sensitivity analysis using principal coordinates analysis. The Anatomical Record, 283A, 288-299.

Rosser, B.W.C.; Secoy, D.M. y Riegert, P.W. 1982. The leg muscles of the American coot (Fulica americana Gmelin). Canadian Journal of Zoology, 60, 1236-1256.

Rovereto, C. 1914. Los estratos araucanos y sus fósiles. Anales del Museo Nacional de Historia Natural de Buenos Aires, 25, 1-247.

Rubenson, J.; Lloyd, D.G.; Besier, T.F.; Heliams, D.B. y Fournier, P.A. 2007. Running in ostriches (Struthio camelus): three-dimensional joint axes alignment and joint kinematics. Journal of Experimental Biology, 210, 2548-2562.

Schmidt, E.V. 1996. Morphological and molecular variation in four species of migrating raptors from North America. Ph.D. dissertation. Las Vegas: University of Nevada.

Schmidt-Nielsen, K. 1984. Scaling: Why is animal size so important? Cambridge University Press, Cambridge, $256 \mathrm{pp}$.

Schoones, J. 1963. Some aspects of the cranial morphology of Colius indicus. Annale Universiteit van Stellenbosch, 38(7), 215-246.

Sereno, P.C.; Dutheil, D.B.; Iarochene, M.; Larsson, H.C.E.; Lyon, G.H.; Magwene, P.M.; Sidor, C.A.; Varricchio, D.J. y Wilson, J.A. 1996. Predatory dinosaurs from the Sahara and Late Cretaceous faunal differentiation. Science, 272, 986-991.

Sherman, P.T. 1996. Family Psophiidae (Trumpeters). Pp 96-107 en J. del Hoyo, A. Elliot y J. Sargatal (eds) Handbook of Birds of the world, Volume 3: Hoatzin to Auks. Lynx, Barcelona.

Sibley, C.G. y Ahlquist, J.E. 1990. Phylogeny and Classification of Birds: A Study in Molecular Evolution. Yale University Press, New Haven. 1008 pp.

Sims, S.W. 1955. The morphology $\mathrm{f}$ the head of the hawfinch (Coccothraustes coccothraustes). Bulletin of the British Museum, Zoology, 2(13), 371-393.

Sinclair, A.G. y Alexander, R.McN. 1987. Estimates of forces exerted by the jaw muscles of some reptiles. Journal of Zoology of London, 213, 107-115.

Sinclair, W. y Farr, M. 1932. Aves of the Santa Cruz beds. Pp 157-191 en W. Scott (eds) Reports of the Princeton University expeditions to Patagonia (1896-1899).Volume 7. Princeton Univesity, New Jersey.

Smith, R.J. 1993. Categories of allometry: Body size versus biomechanics. Journal of Human Evolution, 24, 173-182. 
Smith, J.M. y Savage, R.J.G. 1956. Some locomotory adaptations in mammals. Journal of the Linnean Society (Zoology), 42, 603-622.

Smith, N.C., Wilson A.M., Jespers K.J. y Payne R.C. 2006. Muscle architecture and functional anatomy of the pelvic limb of the ostrich (Struthio camelus). Journal of Anatomy, 209, 765-779.

Snively, E. y Russell, A.P. 2007. Functional variation of neck muscles and their relation to feeding style in Tyrannosauridae and other large theropod dinosaurs. The Anatomical Record, 290, 934-957.

Stanley, S.M. 1970. Relation of the Shell form to life habits in the bivalvia. Memoirs of the Geological Society of America, 125, 1-296.

Stannius, H. Lehrbuch der Anatomie der Wirbeltiere, Zweite Aufl., Zweites Buch. Amphibien, 1856.

Starck, D. y Barnikol, A. 1954. Beiträg zur Morphologie der Trigeminusmuskulatur der Vögel (besonders der Accipitres, Cathartidae, Striges und Anseres). Gegenbaurs Morphologisches Jahrbuch, 94(1-2), 1-64.

Steffen, W.L.; Walker, B.H.; Ingram, J.S.I. y Koch, G.W. 1992. Global change and terrestrial ecosystems: The operational plan. The International Geosphere-Biosphere Programme, Report no. 21, Stockholm, SE.

Stein, B.R. y Casinos, A. 1997. What is a cursorial mammal? Journal of Zoology, 242(1), 185-192.

Storer, R.W. 1971. Adaptative radiation of birds. Pp 149-188 en D.S. Farner y J.R. King (eds) Avian Biology. Academic Press, New York.

Strait, D.S.;Wang, Q.; Dechow, P.C.; Ross, C.F.; Richmond, B.G.; Spencer, M.A. y Patel, B.A. 2005. Modeling elastic properties in finite element analysis: how much precision is needed to produce an accurate model? The Anatomical Record, 283A, 275-287.

Sustaita, D. 2008. Musculoskeletal underpinnings to differences in killing behavior between North american accipiters (Falconiformes: Accipitridae) and falcons (Falconidae). Journal of Morphology, 269, 283-301.

Sustaita, D. y Hertel, F. 2010. In vivo bite and grip forces, morphology and prey-killing behavior of North American accipiters (Accipitridae) and falcons (Falconidae). Journal of Experimental Biology, 213, 26172628.

Symonds, M.R.E. 2002. The effects of topological error in evolutionary trees on the phylogenetic comparative method of independent contrasts. Systematic Biology, 54, 541-553.

Tambussi, C.P. 1989. Las aves del Plioceno tardío-Plesitoceno temprano de la Provincia de Buenos Aires. Tesis doctoral. Facultad de Ciencias Naturales y Museo, Universidad Nacional de La Plata, Argentina, 285 pp. Inédita.

Tambussi, C.P. 1997. Algunos aspectos biomecánicos de la locomoción de los fororracos (Aves, Gruiformes). Ameghiniana, 34(4), 541.

Tambussi, C.P. 2011. Paleoenvironmental and faunal inferences based upon the avian fossil record of Patagonia and Pampa: what works and what does not. Biological Journal of the Linnean Society, 103(2), 458-474.

Tambussi, C.P. y Noriega, J.I. 1996. Summary of the Avian Fossil Record from Southern South America. Pp 245-264 en G. Arratia (eds) Contributions of the southern south America to vertebrate paleontology. Müncher Geowissenschaftliche Abhandlungen.

Tambussi, C.P. y Hoffman, F. 1998. Some biomechanic aspects of the jaw apparatus of the extinct phorusrhacoids (Aves, Gruiformes) and its dietary implications. Libro de Resúmenes del VII Congreso Argentino de Paleontología y Bioestratigrafía, 118. 
Tambussi, C.P., Ubilla, M. y Perea, D. 1999. The youngest large carnassial bird (Phorusrhacidae, Phorusrhacinae) from South America (Pliocene-Early Pleistocene of Uruguay). Journal of Vertebrate Paleontology, 19, 404-406.

Tambussi, C.P. y Acosta Hospitaleche, C. 2007. Antarctic birds (Neornithes) during the CretaceousEocene times. Revista de la Asociación Geológica Argentina, 62(4), 604-617.

Tambussi, C.P. y Acosta Hospitaleche, C. 2008. Skull shape analysis and diet of South American fossil penguins (Sphenisciformes). Oryctos, 7, 137-145.

Tambussi, C.P.; Picasso, M.B.J. y Mosto, M.C. 2010. Graviportalidad en aves ¿sí o no? Libro de resúmenes del X Congreso Argentino de Paleontología y Bioestratigrafía y VII Congreso Latinoamericano de Paleontología, 214.

Thomason, J.J. 1991 Cranial strength in relation to estimated biting forces in some mammals. Canadian Journal of Zoology, 69, 2326-2333.

Tinbergen, N. 1963. On aims and methods of ethology. Zeitschrift für Tierpsychologie, 20, 410-433.

Tizzard, A.; Horesh, L.; Yerworth, R.J.; Holder, D.S. y Bayford, R.H. 2005. Generating accurate finite element meshes for the forward model of the human head in EIT. Physiological Measurement, 26, 251253.

Toledo, N. 2009. La reconstrucción muscular en Tardigrada (Xenarthra: Mammalia) fósiles: aplicabilidad y restricciones del EPB (Extant Phylogenetic Brackets). Ameghiniana, 46(4 Supl.), 51R.

Tonni, E.P. (1977). El rol ecológico de algunas aves fororracoideas. Ameghiniana, 14, 316.

Tonni, E.P. y Tambussi, C.P.1986. Las aves del Cenozoico de la República Argentina. IV Congreso Argentino de Paleontología y Bioestratigrafía, Actas 2, 131-142.

Tonni, E.P. y Tambussi, C.P. 1988. Un nuevo Psilopterinae (Aves: Ralliformes) del Mioceno tardío de la provincia de Buenos Aires, República Argentina. Ameghiniana, 25,155-160.

Tonni, E. y Noriega, J.I. 1998. Los cóndores (Ciconiformes, Vulturidae) de la región pampeana de la Argentina durante el Cenozoico tardío: distribución, interacciones y extinciones. Ameghiniana, 35, 141 150.

van der Meij, M.A.A. y Bout, R.G. 2004. Scaling of jaw muscle size and maximal bite force in finches. Journal of Experimental Biology, 207, 2745-2753.

van der Meij, M.A.A. y Bout, R.G. 2006. Seed husking time and maximal bite forces in finches. Journal of Experimental Biology, 209, 3329-3335.

van der Meij, M.A.A. y Bout, R.G. 2008. The relationship between shape of the skull and bite force in finches. Journal of Experimental Biology, 211, 1668-1680.

Van der Klaauw, C.J. 1948. Ecological studies and reviews. IV. Ecological Morphology, Bibliographia Biotheoretica, 4, 23-111.

Van Gennip, E.M.S.J. y Berkhoudt, H. 1992. Skull mechanics in the pigeon, Columba livia, a threedimensional kinetic model. Journal of Morphology, 213, 197-224.

Van Remsen, J.V. 2007. Recognize Cariamidae in their own Order, Cariamiformes. http://www.museum.lsu.edu/ remsen/SACCprop290.html.

Vanden Berge, J.C. y Zweers, G.A. 1993. Myologia. Pp 189-247 en J.J. Baumel, A.S. King, J.E. Breazile, H.E. Evans y J.C. Vanden Berge (eds) Handbook of avian anatomy: Nomina Anatomica Avium. Cambridge, Massachusetts. 
Verstappen, M.; Aerts, P. y De Vree, F. 1998. Functional morphology of the hindlimb musculature of the black-billed magpie, Pica pica (Aves, Corvidae). Zoomorphology, 118, 207-223.

Versluys, J. 1910. Sterptostylie bei Dinosaureirn, nebst Bemerkungen über die Verwandtschaft der Vögel und Dinosaurier. Zoologischer Jarbusch Anatomie, 30, 175-260.

Versluys, J. 1912. Das streptosylie-problem und die bewegung im schädel bei Sauropsida. Zoologischer Jarbusch, 15(2), 545-716.

Vizcaíno, S.F.; de Iuliis, G. y Bargo, M.S. 1998. Skull shape, masticatory apparatus, and diet of Vassallia and Holmesina (Mammalia: Xenarthra: Pampatheriidae). When anatomy constrains destiny. Journal of Mammalian Evolution, 5, 291-322.

Vizcaíno, S.F. y de Iuliis, G. 2003. Evidence for advanced carnivory in fossil armadillos (Mammalia Xenarthra, Dasypodidae). Paleobiology, 29, 123-1388.

Vizcaíno, S.F.; Bargo, M.S.; Kay, R.; Fariña, R.A.; Di Giacomo, M.; Perry, J.M.G.; Prevosti, F.J.; Toledo, N.; Cassini, G.H.; Fernicola, J.C. 2010. A baseline paleoecological study for the Santa Cruz Formation (late-early Miocene) at the Atlantic coast of Patagonia, Argentina. Palaeogeography, Palaeoclimatology, Palaeoecology, 292, 507-519.

Wainwright, P.C. 1991. Ecomorphology: experimental functional anatomy for ecological problems. American Zoologist, 31, 680-693.

Wainwright, P.C. 1994. Functional morphology as a tool in ecological research. Pp 42-59 en P.C. Wainwright y S.M. Reilly (eds) Ecological morphology: integrative organismal biology. University of Chicago Press, Chicago.

Wainwright, P.C. y Reilly, S.M. 1994. Ecological Morphology: Integrative Organismal Biology. The University of Chicago Press, Illinois, 376 pp.

Wake, M.H. 1992. Morphology, the study of form and function, in modern evolutionary biology. Pp 289346 en D. Futuyma y J. Antonovics (eds) Oxford Surveys in Evolutionary Biology. Oxford University Press, New York.

Wartheit, K.I.; Good, D.G. y De Queiroz, K. 1989. Variation in numbers of scleral ossicles and their phylogenetic transformations within the Pelecaniformes. The Auk, 106, 383-388.

Warton, D.I.; .Wrigth, I.J.; Falster, D.S. y Westoby, M. 2006. Bivariate line-fitting methods for allometry. Biological Reviews, 81, 259-291.

Webb, M. 1957. The ontogeny of the cranial bones, cranial peripheral and cranial parasympathetic nerves, together with a study of the visceral muscles of Struthio. Acta Zoologica, 38, 81-203.

Wedden, S.E.; Ralphs, J.R. y Tickle, C. 1988. Pattern formation in the facial primordial. Development, 103(Supl.), 31-40.

Wheelwright, N.T. 1985. Fruit size, gape width, and the diet of fruit-eating birds. Ecology, 66, 808-818.

Witmer, L.M. 1992. Ontogeny, phylogeny and air sacs: the importance of soft-tissue inferences in the interpretation of facial evolution in Archosauria. Tesis Doctoral, John Hopkins University, Baltimore, 922 pp. Inédita.

Witmer, L.M. 1995a. Homology of facial structures in extant archosaurs (Birds and Crocodilians), with special reference to paranasal pneumaticity and nasal conchae. Journal of Morphology, 225, 269-327.

Witmer, L.M. 1995b. The Extant Phylogenetic Bracket and the importance of reconstructing soft tissues in fossils. Pp 19-33 en J.J. Thomason (eds) Functional Morphology in Vertebrate Paleontology. Cambridge, University Press, New York. 
Witmer, L.M. 1997. The evolution of the antorbital cavity of Archosaurs: a study in soft-tissue reconstruction in the fossil record with an analysis of the function of pneumaticity. Society of Vertebrate Paleontology, Memoir 3, 1-73.

Witmer, L.M. y Rose, K.D. 1991. Biomechanics of the jaw apparatus of the gigantic Eocene bird Diatryma: implications for diet and mode of life. Paleobiology, 17, 95-120.

Witmer, L.M. y Ridgely, R. 2008. The paranasal air sinuses of predatory and armored dinosaurs (Archosauria: Theropoda and Ankylosauria) and their contribution to cephalic structure. The Anatomical Record, 291, 1362-1388.

Witzel, U. 1985. Zur Biomechanik der ossaeren Schafteinbettung von Hueftendoprothesen, 5. Symposium ueber isoelastische RM-Hueftprothesen, Mathys, Bettlach, Schweiz.

Witzel, U. y Preuschoft, H. 1999. The bony roof of the nose in humans and other primates. Zoologische Anzeiger, 238,103-15.

Witzel, U. y Preuschoft, H. 2002. Function-dependent shape characteristics of the human skull. Anthropologischer Anzeiger, 60, 113-135.

Witzel, U. y Preuschoft, H. 2005. Finite-element model construction for the virtual synthesis of the skulls in vertebrates: case study of Diplodocus. The Anatomical Record, 283A, 391-401.

Wolff, R.G. 1991. Functional Chordate Anatomy. D.C. Heath and Co., Massachusetts, 88 pp.

Wolpert, L. 1983. Constancy and change in the development and evolution pattern. Pp 47-57 en B.C. Goodwin, N. Holder y C.C. Wylie (eds.) Development and Evolution. Cambridge University Press.

Wroe, S. 2008. Cranial mechanics compared in extinct marsupial and extant African lions using a finiteelement approach. Journal of Zoology, 274, 332-339.

Wroe, S.; McHenry, C. y Thomason, J. 2005. Bite club: comparative bite force in big biting mammals and the prediction of predatory behaviour in fossil taxa. Proceedings of the Royal Society B, 272, 619625.

Wroe, S.; Moreno, K.; Clausen, P.D. y McHenry, C.R. 2007a. High-resolution computer simulation of hominid cranial mechanics. The Anatomical Record, 290, 1248-1255.

Wroe, S.; Clausen, P.D.; McHenry, C.R.; Moreno, K. y Cunningham, E. 2007b. Computer simulation of feeding behaviour in the thylacine and dingo: a novel test for convergence and niche overlap. Proceedings of the Royal Society of London B, Biological Sciences, 274, 2819-2828.

Wroe, S.; Huber, D.R.; Lowry, M.; McHenry, C.; Moreno, K.; Clausen, P.; Ferrara, T.L.; Cunningham, E.; Dean, M.N. y Summers, A.P. 2008. Three dimensional computer analysis of white shark jaw mechanics: how hard can a great white bite? Journal of Zoology, 276, 336-342.

Yudin, K.A. 1961. On the mechanism of the jaw in Charadriiformes, Procellariiformes and some other birds. Academy of sciences of USSR, Trudy Zoologischeskogo Instituto, 29, 257-302.

Zeffer, A. y Lindhe Norberg, U.M.L. 2003. Leg morphology and locomotion in birds: Requirements for force and speed during ankle flexion. Journal of Experimental Biology, 206, 1085-1097.

Zeffer, A.; Johansson, L.C. y Marmebro, A. 2003. Functional correlation between habitat use and leg morphology in birds (Aves). Biological Journal of the Linnean Society, 79, 461-484.

Zelditch, M.L.; Swiderski, D.L.; Sheets, H.D. y Fink, W.L. 2004. Geometric Morphometrics for Biologists: A Primer. Elsevier Academic Press, San Diego, 416 pp.

Zusi, R.L. 1959. The function of the depressor mandibulae muscle in certain passerine birds. The Auk, 76(4), 537-539. 
Zusi, R.L. 1967. The Role of the depressor mandibulae muscle in kinesis of the avian skull. Proceedings of the United States National Museum, 123(3607), 1-28.

Zusi, R.L. 1984. A functional and evolutionary analysis of rhynchokinesis in birds. Smithsonian Contributions in Zoology, 395, 1-38.

Zusi, R.L. 1993. Patterns of diversity in the avian skull. Pp 391-437 en J. Hanken y B.K. Hall (eds) The skull. Volume 2: Patterns of structural and systematic diversity. The University of Chicago Press, Chicago.

Zusi, R.L. y Storer, R.W. 1969. Osteology and myology of the head and neck of the pied-billed grebes (Podilymbus). Miscellaneous Publications Museum of Zoology University of Michigan, 139, 1-49.

Zusi, R.L. y Bentz, G.D. 1984. Myology of the Purple-throated carib (Eulampis jugalaris) and other hummingbirds (Aves: Trochilidae). Smithsonian Contributions to Zoology, 385, 1-70.

Zusi, R.L. y Warheit, L.I. 1992. On the evolution of intraramal Mandibular joints in Pseudodontorns (Aves: Odontopterygia). Science Series Natural History Museum of Los Angeles County, 36, 351-360.

Zusi, R.L. y Livezey, B.C. 2000. Homology and phylogenetic implications of some enigmatic cranial features in galliform and anseriform birds. Annals of the Carnegie Museum, 69(3), 157-193.

Zusi, R.L. y Livezey, B.C. 2006. Variation in the os palatinum and its structural relation to the palatum osseum of birds (Aves). Annals of Carnegie Museum, 75(3), 137-180.

Zweers, G.A. 1979. Explanation of structure by optimization and systemization. Netherlands Journal of Zoology, 29, 41-440.

Zweers, G.A.; Berkhoudt, H. y Vanden Berge, J.C. 1994. Behavioral mechanisms of avian feeding. Pp 241-279 en V.L. Bels, M. Chardon y P. Vandewalle (eds) Bio-mechanics of Feeding in Vertebrates. Advances in comparative and environmental physiology, Volume 18. Springer-Verlag, Berlin.

Zweers, G.A. y Vanden Berge, J.C., 1997. Birds at geological boundaries. Zoology, 100, 183-202.

Zweers, A.G., Vanden Berge, J.C. y Berkhoudt, H., 1997. Evolutionary patterns of avian trophic diversification. Zoology, 100, 25-57.

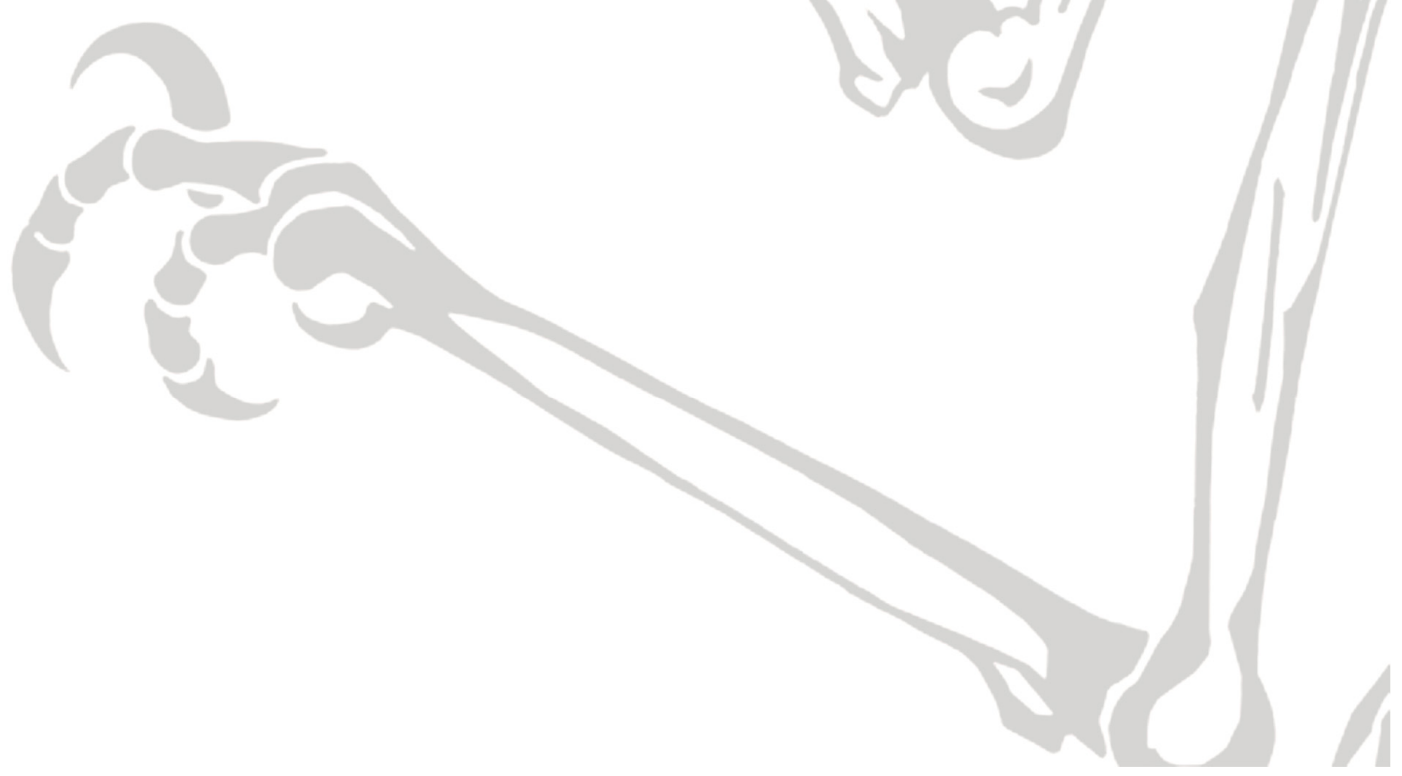




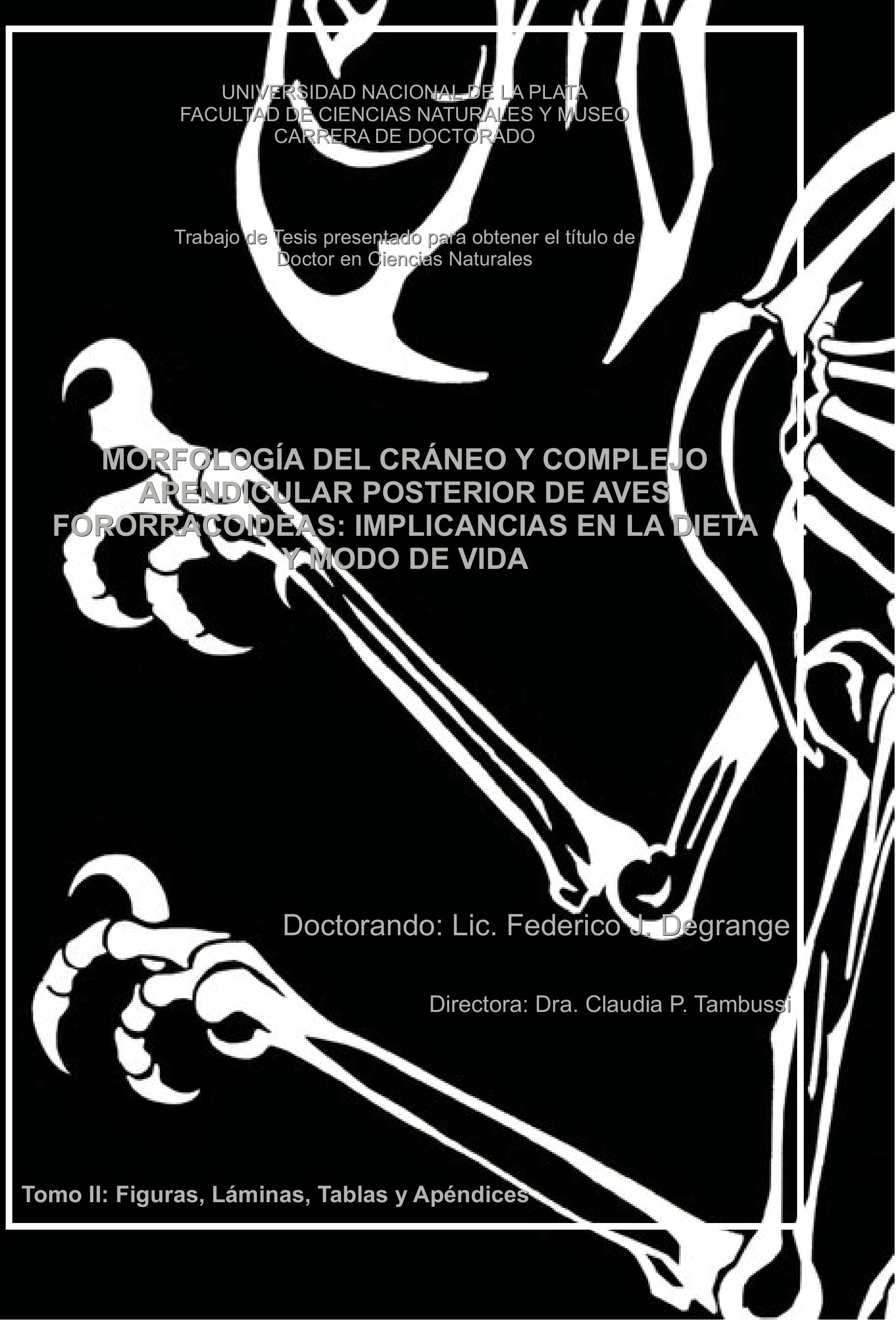


Figura 1.1. Concepción popular de los fororracos como "terror birds"

Figura 2.1. Brontornis burmeisteri

Figura 2.2. Distribución estratigráfica de los Phorusrhacidae 214

Figura 2.3. Distribución geográfica de los Phorusrhacidae en Argentina 215

Figura 2.4. Módulos locomotores en aves 216

$\begin{array}{lr}\text { Figura 4.1. Cráneo de fororraco } & 217\end{array}$

$\begin{array}{lr}\text { Figura 4.2. Mandíbula de fororraco } & 219\end{array}$

Figura 4.3. Región occipital de los Phorusrhacidae 220

Figura 4.4. Processi basipterygoideus $\quad 222$

Figura 4.5. Región ótica de Psilopterus lemoinei 222

Figura 4.6. Zona flexoria craniofascialis $\quad 224$

Figura 4.7. Detalle de las zonae flexoria 225

Figura 4.8. Región orbital de los Phorusrhacidae 226

Figura 4.9. Annulus ossicularis sclerae 226

Figura 4.10. Os lacrimale y os lacrimale communicans 227

Figura 4.11. Esquema del pico y paladar 228

Figura 4.12. Estructura interna del pico de Andalgalornis steulleti 229

Figura 4.13. Estructura interna del pico de Psilopterus lemoinei 230

$\begin{array}{ll}\text { Figura 4.14. Ossa palati } & 231\end{array}$

Figura 4.15. Os quadratum $\quad 232$

Figura 4.16. Extremo caudal de la mandíbula de Psilopterus lemoinei 233

$\begin{array}{ll}\text { Figura 4.17. Pelvis de fororracos } & 234\end{array}$

Figura 4.18. Proceso del margen caudal del foramen ilioischiadicum 235

Figura 4.19. Comparación de la pelvis de algunos Phorusrhacidae

\begin{tabular}{ll} 
Figura 4.20. Extremo distal de tibiotarso en vista craneal & 235 \\
\hline
\end{tabular}

$\begin{array}{ll}\text { Figura 4.21. Fíbula de Phorusrhacidae } & 237\end{array}$

$\begin{array}{ll}\text { Figura 4.22. Hypotarsus de Phorusrhacidae } & 237\end{array}$

Figura 4.23. Extremo distal de tarsometatarso de Phorusrhacidae 239

$\begin{array}{ll}\text { Figura 4.24. Pata de algunos Phorusrhacidae } & 240\end{array}$

Figura 5.1. Propuestas filogenéticas de los Phorusrhacidae 241

\begin{tabular}{lr} 
Figura 5.2. Árbol consenso & 242 \\
\hline
\end{tabular}

Figura 5.3. Relaciones intrafamiliares de los Phorusrhacidae 243

Figura 6.1. Cálculo de altura y postura de los fororracos $\quad 244$

Figura 7.1. Extant Phylogenetic Brackeet (EPB) 245

Figura 7.2. Niveles de inferencia del EPB 246

Figura 7.3. Organización neuromuscular de la cámara aductora de los diápsidos $\quad 247$

Figura 7.4. Músculos mandibulares de Neornithes 248

Figura 7.5. Sitios de origen e inserción de la musculatura mandibular de Andalgalornis steulleti 249

Figura 7.6. Anatomía de la musculatura mandibular de Andalgalornis steulleti $\quad 250$ 
Figura 7.7. Sitios de origen de la musculatura apendicular en la pelvis de los fororracos

Figura 7.8. Sitios de origen e inserción de la musculatura apendicular en el fémur de Psilopterus lemoinei

Figura 7.9. Sitios de origen e inserción de la musculatura apendicular en el tibiotarso, fíbula y tarsometatarso de Psilopterus lemoinei

Figura 8.1. Quinesis craneana de los Neornithes: Tipos 254

Figura 8.2. Quinesis craneana de los Neornithes: Zonas flexorias 255

Figura 8.3. Pasos involucrados en un análisis de elementos finitos 256

Figura 8.4. Modelos de Andalgalornis $\quad 257$

Figura 8.5. Regresión del logaritmo de la masa corporal y de la fuerza de mordida 257

Figura 8.6. Distribución del stress en los modelos de elementos finitos 258

Figura 8.7. Sistema de palanca de tercer orden $\quad 259$

Figura 8.8. Brazos de momento y líneas de acción de los diferentes músculos mandibulares de Geranoaetus, Taxón nuevo A y Andalgalornis $\quad 259$

Figura 8.9. Evolución de la aquinesis en los Phorusrhacidae 261

$\begin{array}{lr}\text { Figura 9.1. Medidas tomadas en el fémur } & 262\end{array}$

Figura 9.2. Medidas tomadas en el tibiotarso 263

Figura 9.3. Medidas tomadas en el tarsometatarso 264

Figura 9.4. Proporciones de los miembros posteriores de las Neornithes 265

Figura 9.5. Análisis de componentes principales del fémur 266

Figura 9.6. Análisis de componentes principales del tibiotarso 267

Figura 9.7. Análisis de componentes principales del tarsometatarso 268

Figura 9.8. Análisis de componentes principales del miembro posterior $\quad 269$

Figura 9.9. Análisis de componentes principales de los índices del

$\begin{array}{ll}\text { miembro posterior } & 270\end{array}$

Figura 9.10. Análisis discriminante del tarsometatarso 271

Figura 9.11. Análisis discriminante del miembro posterior 272

Figura 9.12. Landmarks utilizados en el estudio del neurocráneo de los fororracos

Figura 9.13. Estudio del neurocráneo de los fororracos 273

Figura 9.14. Grillas de visualización de los cambios de la forma 274

Figura 9.15. Landmarks utilizados en el estudio del cráneo de las aves 275

$\begin{array}{ll}\text { Figura 9.16. RW de cráneo dorsal } & 276\end{array}$

Figura 9.17. Grillas de visualización de los cambios de la forma del cráneo $\quad 276$

$\begin{array}{ll}\text { Figura 9.18. RW de cráneo lateral } & 277\end{array}$

Figura 9.19. Grillas de visualización de los cambios de la forma del cráneo $\quad 278$

$\begin{array}{lr}\text { Figura 9.20. Cráneo de carnívoros } & 279\end{array}$

Figura 9.21. Esplacnocráneo 280

$\begin{array}{ll}\text { Figura 9.22. Pico } & 281\end{array}$

Figura 9.23. Landmarks utilizados en el estudio de la pelvis de las aves $\quad 282$

Figura 9.24. RW de pelvis dorsal $\quad 283$

Figura 9.25. Grillas de visualización de los cambios de la forma 284

Figura 9.26. RW de Pelvis lateral 285

Figura 9.27. Grillas de visualización de los cambios de la forma 286

Figura 10.1. Relaciones depredador-presa de los fororracos 287 
Lámina 4.1. Cráneo de Psilopterus bachmanni 288

Lámina 4.2. Cráneo de Psilopterus lemoinei 289

Lámina 4.3. Cráneo de Psilopterus lemoinei 290

Lámina 4.4. Cráneo de Psilopterus lemoinei 291

Lámina 4.5. Cráneo de Procariama simplex 292

Lámina 4.6. Cráneo de Taxón nuevo A 293

Lámina 4.7. Mandíbula de Taxón nuevo A 294

Lámina 4.8. Cráneo de Andalgalornis steulleti 295

Lámina 4.9. Mandíbula de Andalgalornis steulleti 296

Lámina 4.10. Cráneo de Patagornis marshi 297

Lámina 4.11. Mandíbula de Patagornis marshi 298

Lámina 4.12. Cráneo y mandíbula de Andrewsornis abbotti 299

Lámina 4.13. Fragmentos craneanos de Phorusrhacos longissimus 300

Lámina 4.14. Cráneo de Kelenken guillermoi 301

Lámina 4.15. Mesembriornis milneedwardsi 302

Lámina 4.16. Cráneo de Devincenzia pozzi 303

Lámina 4.17. Pelvis de Psilopterus bachmanni 304

Lámina 4.18. Pelvis de Psilopterus lemoinei 305

Lámina 4.19. Pelvis de Psilopterus lemoinei 306

Lámina 4.20. Cráneo de Procariama simplex 307

Lámina 4.21. Pelvis de Mesembriornis milneedwardsi 308

Lámina 4.22. Pelvis de Taxón nuevo A 309

Lámina 4.23. Pelvis de Andalgalornis steulleti 310

Lámina 4.24. Pelvis de Patagornis marshi 311

Lámina 4.25. Fémur derecho de Psilopterus lemoinei 312

Lámina 4.26. Fémur de Psilopterinae $\quad 313$

Lámina 4.27. Fémur de Mesembriornithinae $\quad 314$

Lámina 4.28. Fémur de Patagornithinae y Phorusrhacinae 315

Lámina 4.29. Tibiotarso de Psilopterus lemoinei 316

Lámina 4.30. Tibiotarso de Psilopterinae $\quad 317$

Lámina 4.31. Tibiotarso de Mesembriornithinae 318

Lámina 4.32. Tibiotarso de Patagornis marshi 319

Lámina 4.33. Tibiotarso de Phorusrhacinae 320

Lámina 4.34. Tarsometatarso de Psilopterus lemoinei 321

Lámina 4.35. Tarsometatarso de Psilopterinae 322

Lámina 4.36. Tarsometatarso de Mesembriornithinae 323

Lámina 4.37. Tarsometatarso de Patagornis marshi $\quad 324$

Lámina 4.38. Tarsometatarso de Phorusrhacinae 325 
Tabla 6.1. Altura estimada de los fororracos

Tabla 6.2. Estimación de masa de los fororracos

Tabla 6.3. Estimación de fuerza de mordida de los fororracos de acuerdo a la masa corporal

Tabla 6.4. Estimación de fuerza de mordida de los fororracos

Tabla 7.1. Niveles de inferencia de los orígenes e inserciones de los músculos mandibulares de los Phorusrhacidae

Tabla 7.2. Niveles de inferencia de los orígenes e inserciones de los músculos del complejo apendicular posterior de los Phorusrhacidae

Tabla 8.1. Stress promedio calculado en tres especies de aves bajo tres condiciones de carga.

Tabla 8.2. Brazos de momento estandarizados e índices de velocidad

Tabla 9.1. Matriz de medidas del fémur tomadas en las Neornithes

Tabla 9.2. Matriz de medidas del fémur tomadas en los Phorusrhacidae

Tabla 9.3. Individuos promedio para cada especie de fororraco en base a las medidas del fémur

Tabla 9.4. Matriz de medidas del tibiotarso tomadas en las Neornithes 343

Tabla 9.5. Matriz de medidas del tibiotarso tomadas en los Phorusrhacidae $\quad 349$

Tabla 9.6. Individuos promedio para cada especie de fororraco

en base a las medidas del tibiotarso

Tabla 9.7. Matriz de medidas del tarsometatarso tomadas en las Neornithes $\quad 352$

Tabla 9.8. Matriz de medidas del tarsometatarso tomadas en los Phorusrhacidae $\quad 360$

Tabla 9.9. Individuos promedio para cada especie de fororraco

en base a las medidas del tarsometatarso

Tabla 9.10. Análisis de componentes principales para el conjunto de aves actuales y fororracos analizados mediante el fémur

Tabla 9.11. Análisis de componentes principales para el conjunto de aves actuales y fororracos analizados mediante el tibiotarso

Tabla 9.12. Análisis de componentes principales para el conjunto de aves actuales y fororracos analizados mediante el tarsometatarso

Tabla 9.13. Análisis de componentes principales para el conjunto de aves actuales y fororracos analizados mediante el miembro posterior completo

Tabla 9.14. Análisis de componentes principales para el conjunto de aves actuales y fororracos analizados mediante los índices del miembro posterior

Tabla 9.15. Análisis de componentes principales del neurocráneo de los fororracos en vista dorsal

Tabla 9.16. Análisis de componentes principales del neurocráneo de los fororracos en vista lateral

Tabla 9.17. Análisis de componentes principales del cráneo de las aves en vista dorsal

Tabla 9.18. Análisis de componentes principales del cráneo de las aves en vista lateral 
Tabla 9.19. Análisis de componentes principales del cráneo de las aves carnívoras en vista lateral

Tabla 9.20. Análisis de componentes principales del cráneo del esplacnocráneo en vista lateral

Tabla 9.21. Análisis de componentes principales del cráneo del pico en vista lateral

Tabla 9.22. Análisis de componentes principales de la pelvis en vista dorsal

Tabla 9.23. Análisis de componentes principales de la pelvis en vista lateral

Tabla 10.1. Medidas del miembro anterior, proporciones e índice braquial 
Índice de apéndices

Apendice 5.1. Matriz de 148 caracteres morfológicos para los cuatro Phorusrhacidae

Apéndice 6.1. Datos de masa corporal en kg. y fuerza de mordida en Newtons $(\mathrm{N})$ utilizados para estimar la fuerza de mordida

Apéndice 9.1. Correlación variable-componente de los tres primeros componentes principales del análisis del fémur

Apéndice 9.2. Correlación variable-componente de los tres primeros componentes principales del análisis del tibiotarso

Apéndice 9.3. Correlación variable-componente de los tres primeros componentes principales del análisis del tarsometatarso

Apéndice 9.4. Correlación variable-componente de los tres primeros componentes principales del análisis del miembro posterior

Apéndice 9.5. Correlación variable-componente de los tres primeros componentes principales del análisis de los índices del miembro posterior 

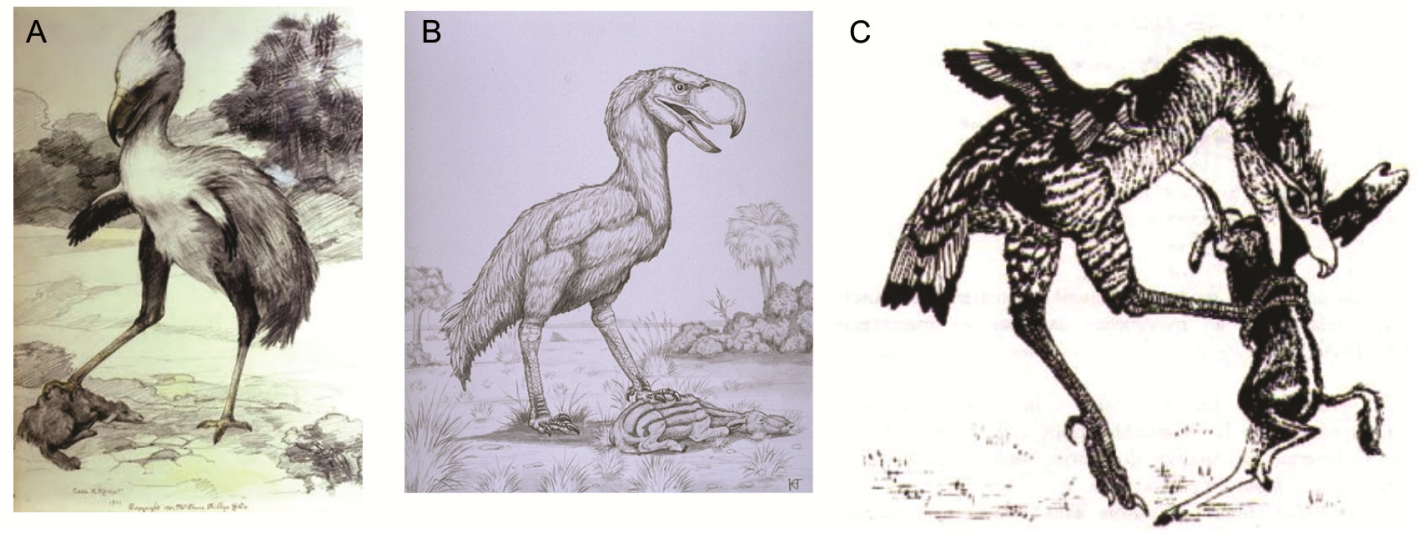

Figura 1.1. Concepción popular de los fororracos como "terror birds". A-B, Phorusrhacos; C, Andalgalornis. A, ilustración realizada por C. Knight, tomado de Lucas, 1901; B, ilustración realizada por K. Taylor (reproducido con permiso); C, ilustración realizada por B. Dalzell, tomada de Marshall, 1978. 

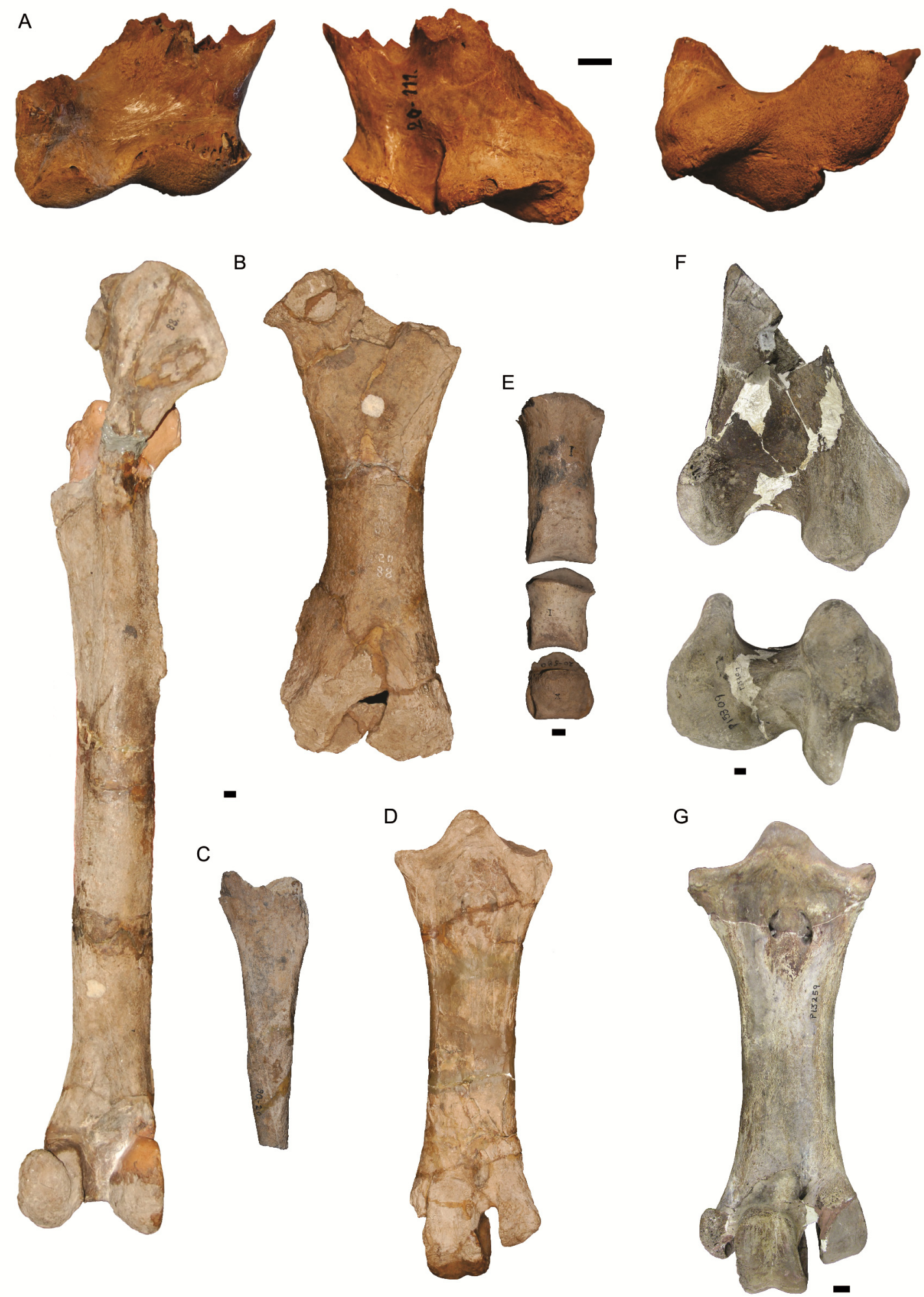

Figura 2.1. Brontornis burmeisteri. A, MLP 20-111, os quadratum en vista craneal, caudal y distal. B-G, elementos del miembro posterior; B, MLP 20-88, fémur y tibiotarso izquierdos; C, MLP 20-90, fíbula izquierda; D, MLP 20-91, tarsometatarso izquierdo; E, MLP 20-574, 20-575 y 20-580, falanges 1, 2 y 3 del dedo III; F, FMP15309, extremo distal de fémur izquierdo en vista craneal y distal; G, FM-P15259, tarsometatarso izquierdo. 


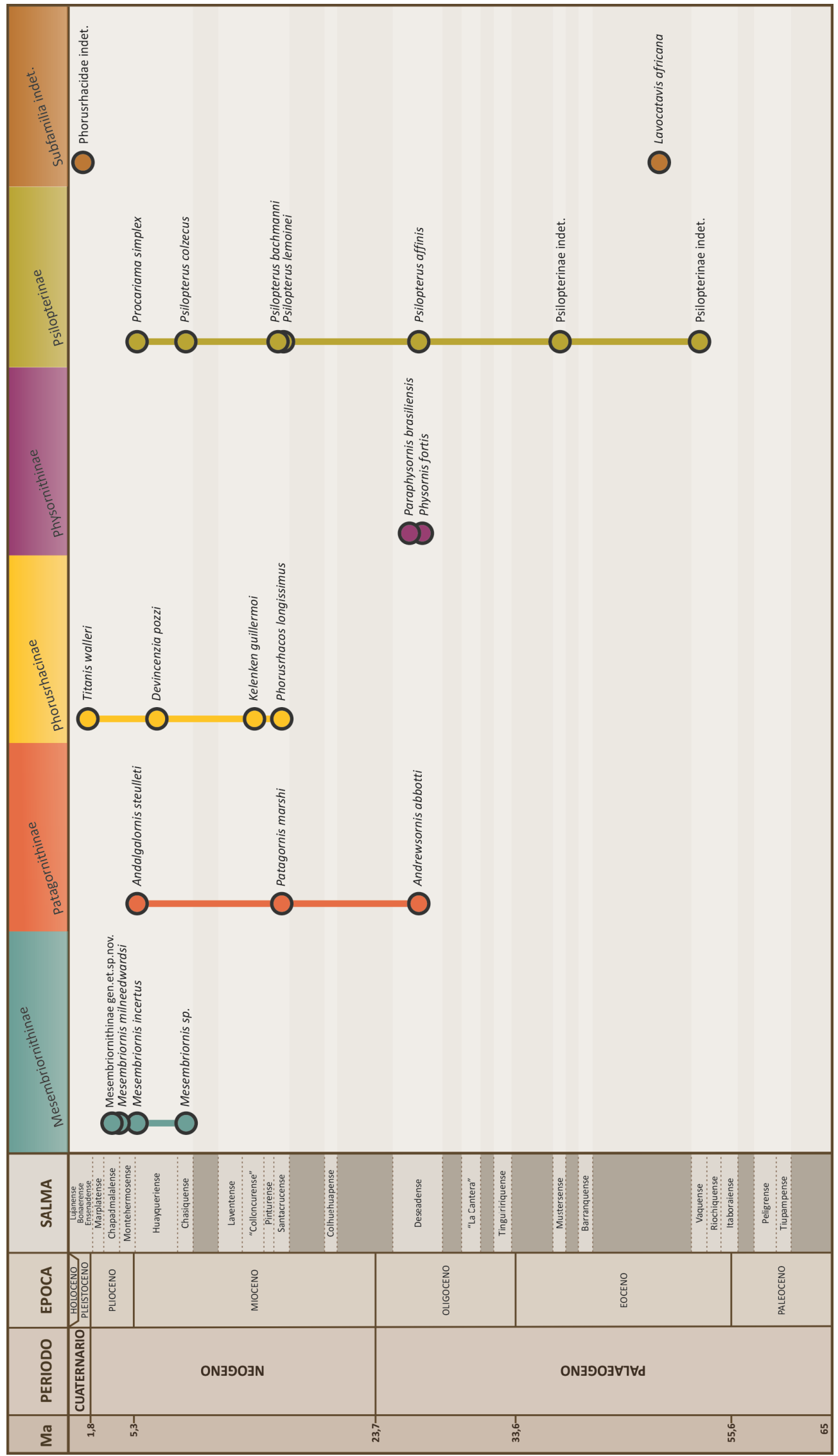

Figura 2.2. Distribución estratigráfica de los Phorusrhacidae. 


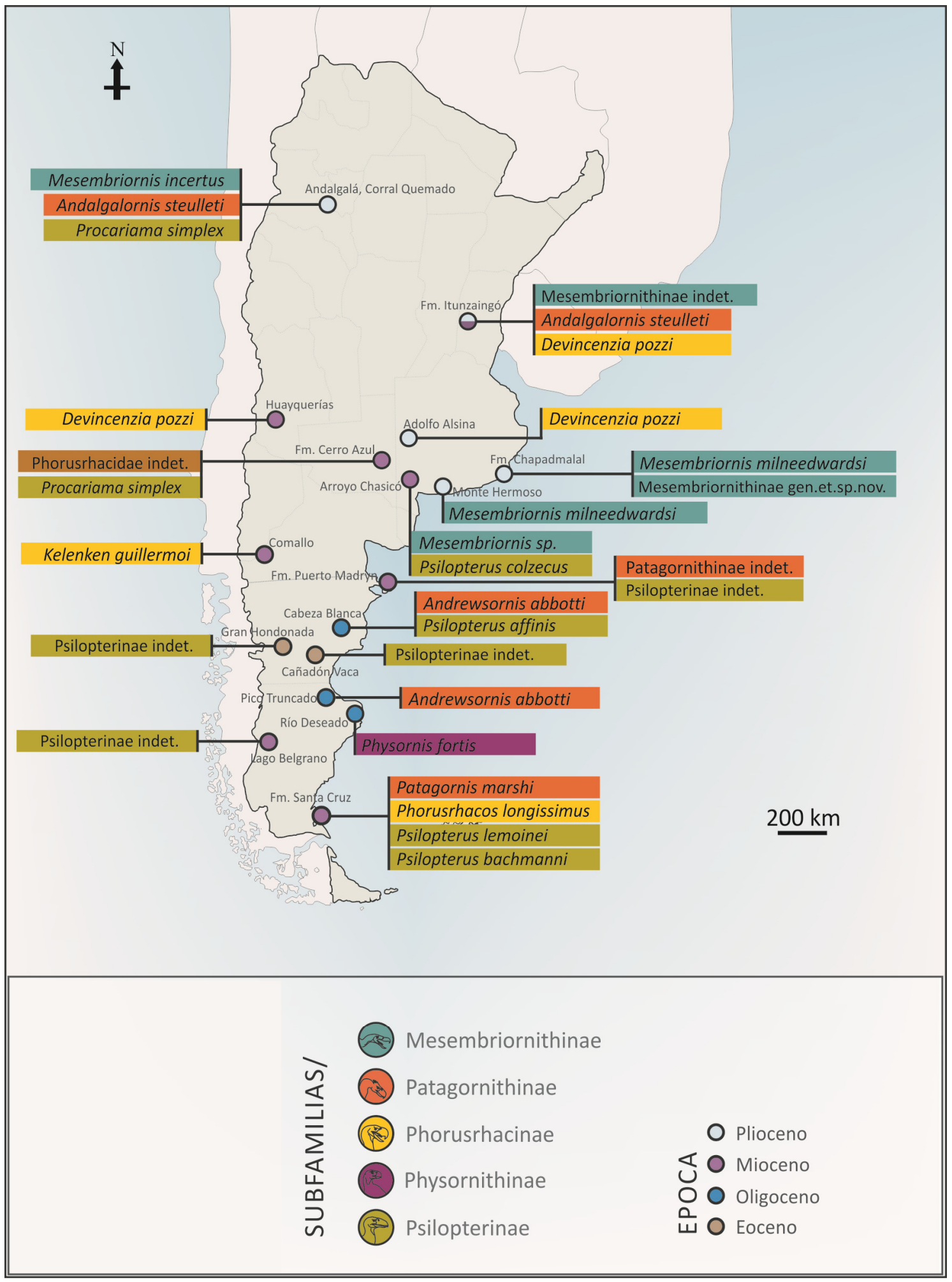

Figura 2.3. Distribución geográfica de los Phorusrhacidae en Argentina. 
A

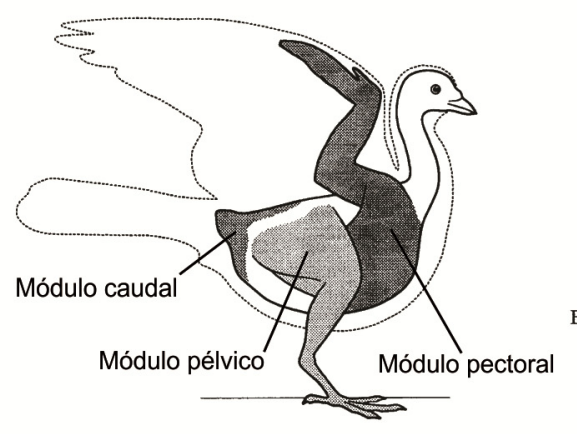

B Hummingbirds, Hummingbirds,
Nighthawks, Nighthawks,

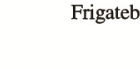

Figura 2.4. Módulos locomotores en aves. A, ubicación; B, diversidad locomotora aviana como resultado de la diferenciación en el desarrollo de los diferentes módulos locomotores. Modificado de Gatesy y Dial (1996). 
A

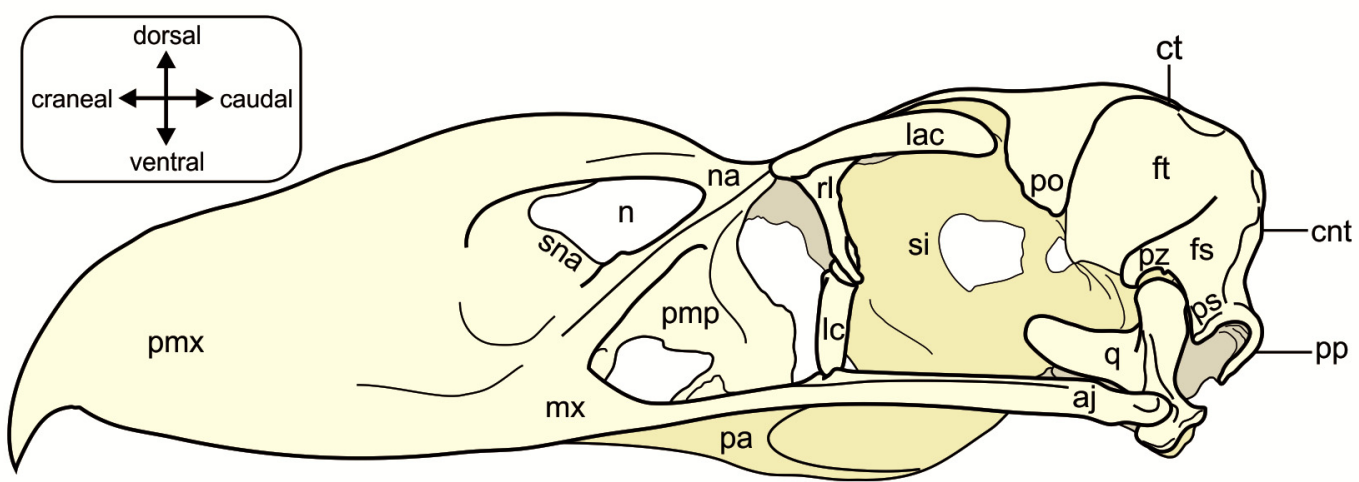

B

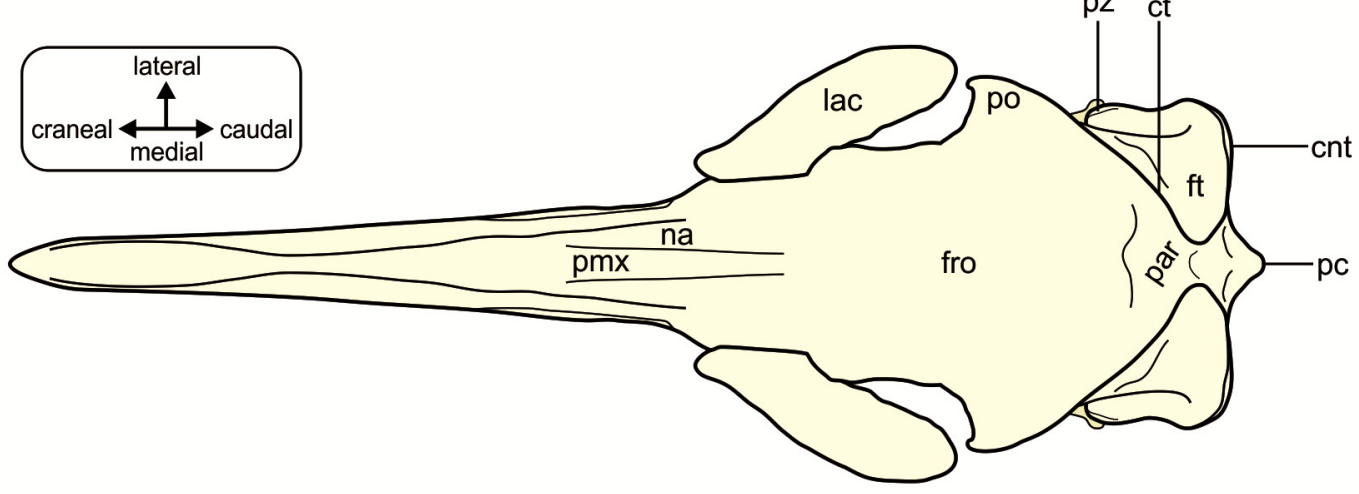

C

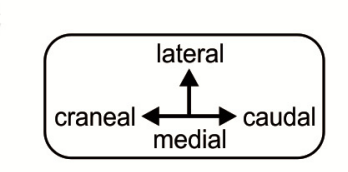

D

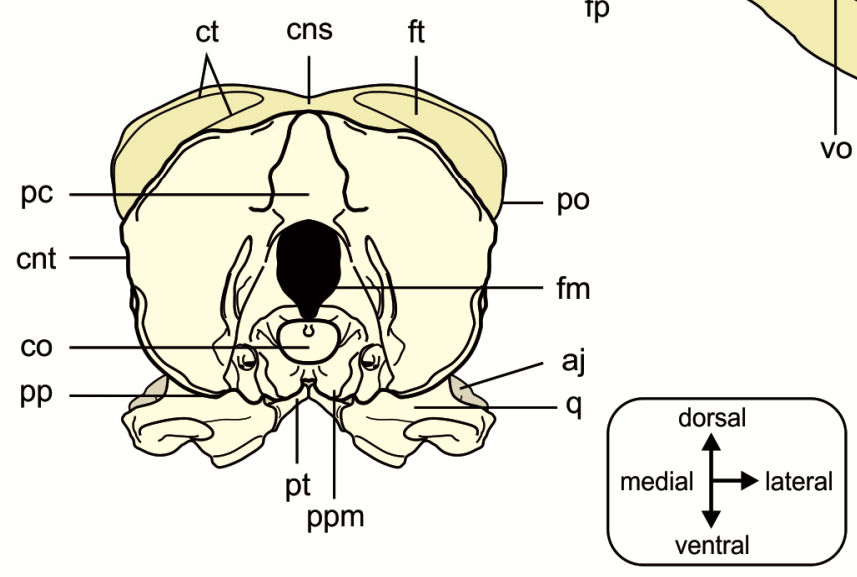


Figura 4.1. (Página anterior) Cráneo de fororraco. A, vista lateral; B, vista dorsal; $C$, vista ventral; D, vista caudal. Abreviaturas: aj, arcus jugalis; b, os basisphenoidale; ca, coanas; cns, crista nuchalis sagitalis; cnt, crista nucalis transversa; co, condylus occipitalis; $\mathbf{c t}$, crista temporalis; $\mathbf{f m}$, foramen magnum; fp, fenestra palatalis; fro, ossa frontalis; fs, fossa subtemporalis; $\mathbf{f t}$, fossa temporalis; lac, os lacrimale; lat, os laterosphenoidale; lc, os lacrimale communicans; $\mathbf{m x}$, os maxillare; $\mathbf{n}$, narinas; na, os nasale; pa, os palatinum; par, oss a parietalis; pc, prominentia cerebellaris; pmp, processus maxillopalatinus; pmx, os premaxillare; po, processus postorbitalis; $\mathbf{p p}$, processus paraoccipitalis; ppm, processus parasphenoidalis medialis; ps, processus suprameaticus; pt, os pterygoideum; pz, processus zygomaticus; q, os quadratum; rl, rama descendente del os lacrimale; si, septum interorbitale; sna, septum nasi osseum; vo, vómer. 


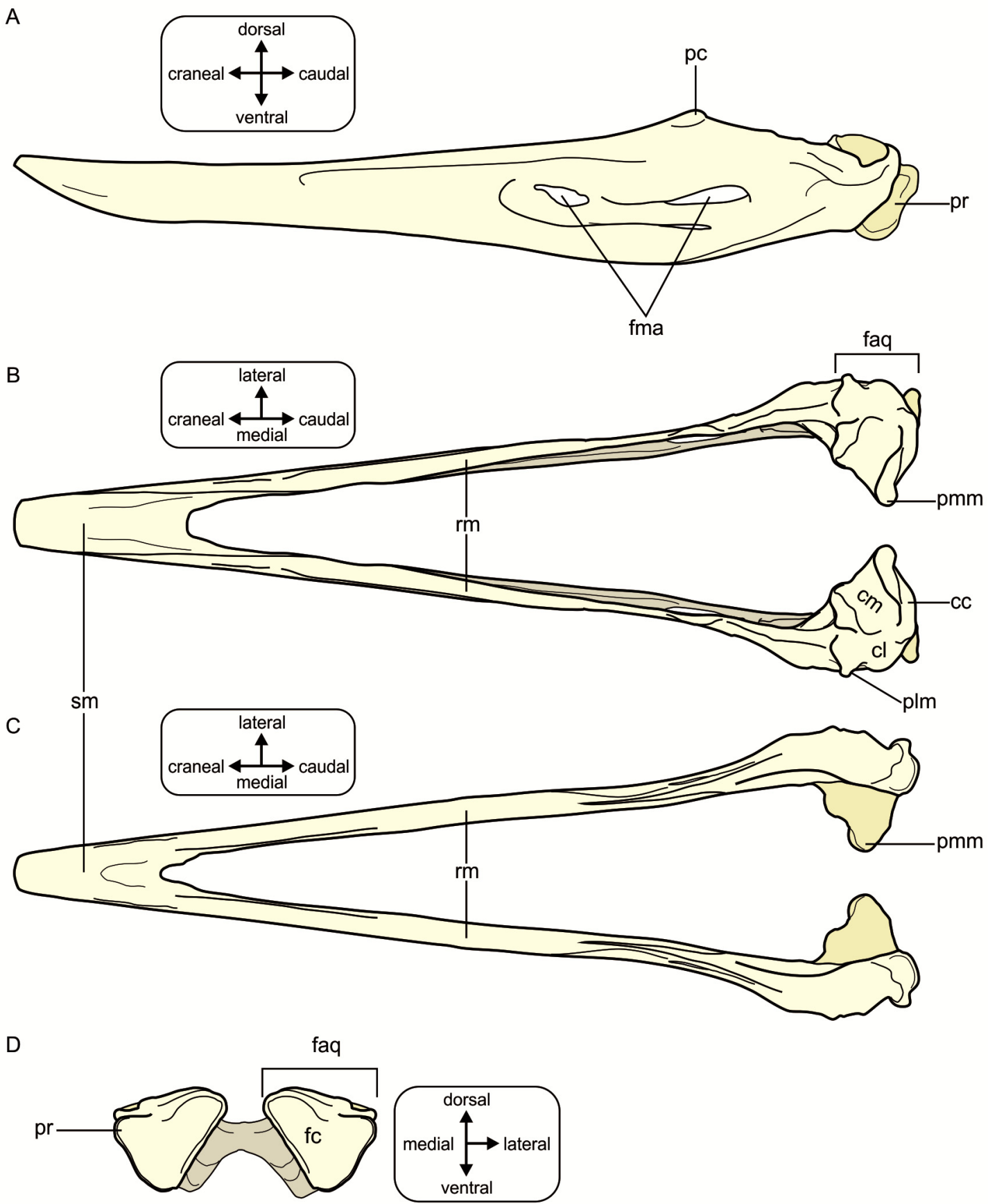

Figura 4.2. Mandíbula de fororraco. A, vista lateral; B, vista dorsal; C, vista ventral; D, vista caudal. Abreviaturas: cc, cotyla caudalis; $\mathbf{c l}$, cotyla lateralis; $\mathbf{c m}$, cotyla medialis; faq, fossa articularis quadratica; fc, fossa caudalis; fma, fenestra mandibulae; pc, processus coronoideus; plm, processus lateralis mandibulae; $\mathbf{p m m}$, processus medialis mandibulae; pr, processus retroarticularis; $\mathbf{r m}$, rami mandibulae; $\mathbf{s m}$, symphysis mandibularis. 
Figura 4.3. (Página siguiente) Región occipital de los Phorusrhacidae. A, Psilopterus lemoinei AMNH 9257; B, Procariama simplex MACN Pv 8225; C, Andalgalornis steulleti FM-P14357; D, Taxón nuevo A MMP5050. Abreviaturas: cnt, crista nucalis transversa; co, condylus occipitalis; fh, foramen nervus hypoglossi; fm, foramen magnum; fp, fossa parabasalis; fv, foramen nervus vagi; occ, ostium canalis carotici; pc, prominentia cerebelaris; $\mathbf{p p}$, processus paraoccipitalis; $\mathbf{p p m}$, processi

parasphenoidalis medialis; voe, foramen vena occipitalis externa. Escala $=1 \mathrm{~cm}$. 


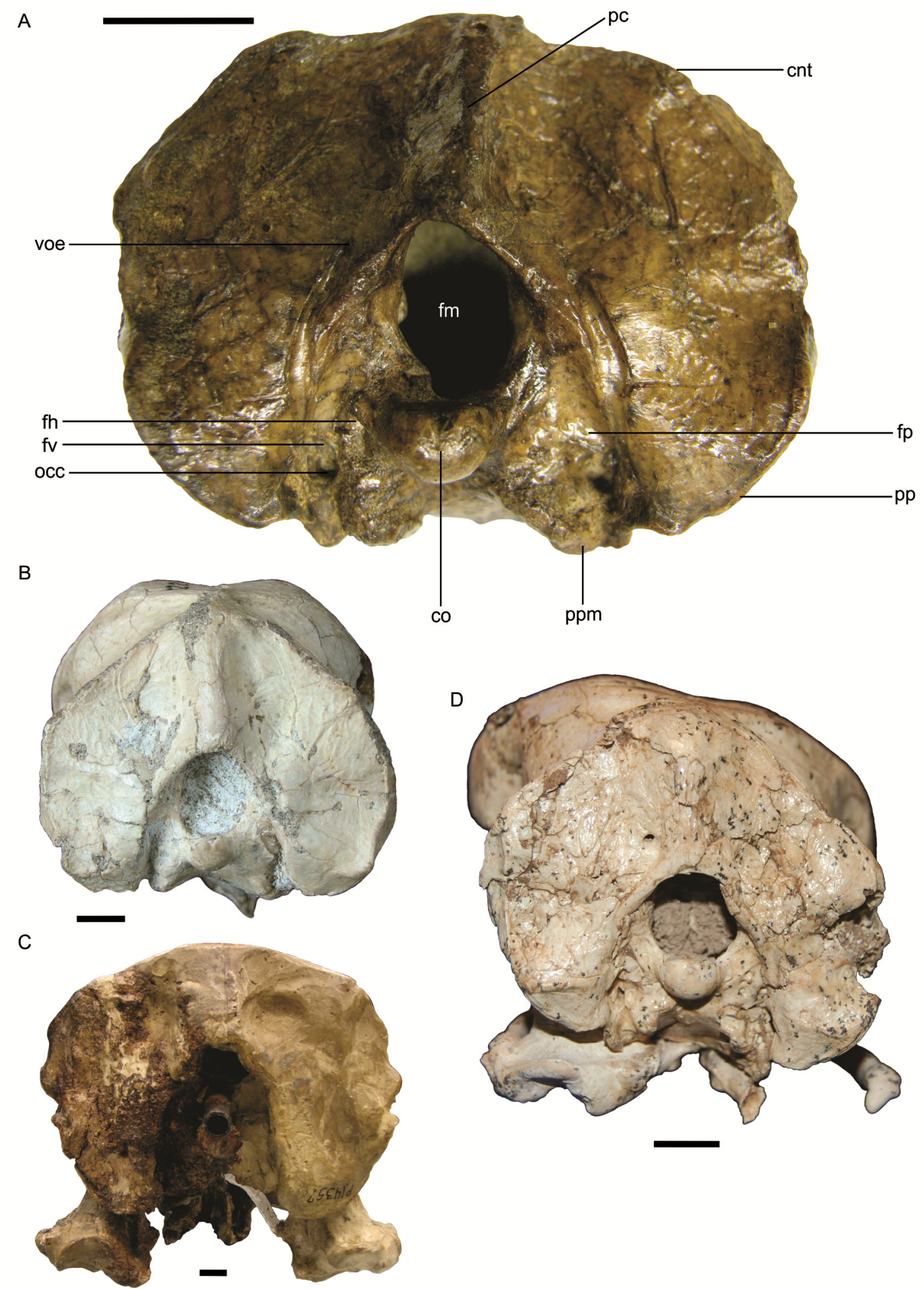




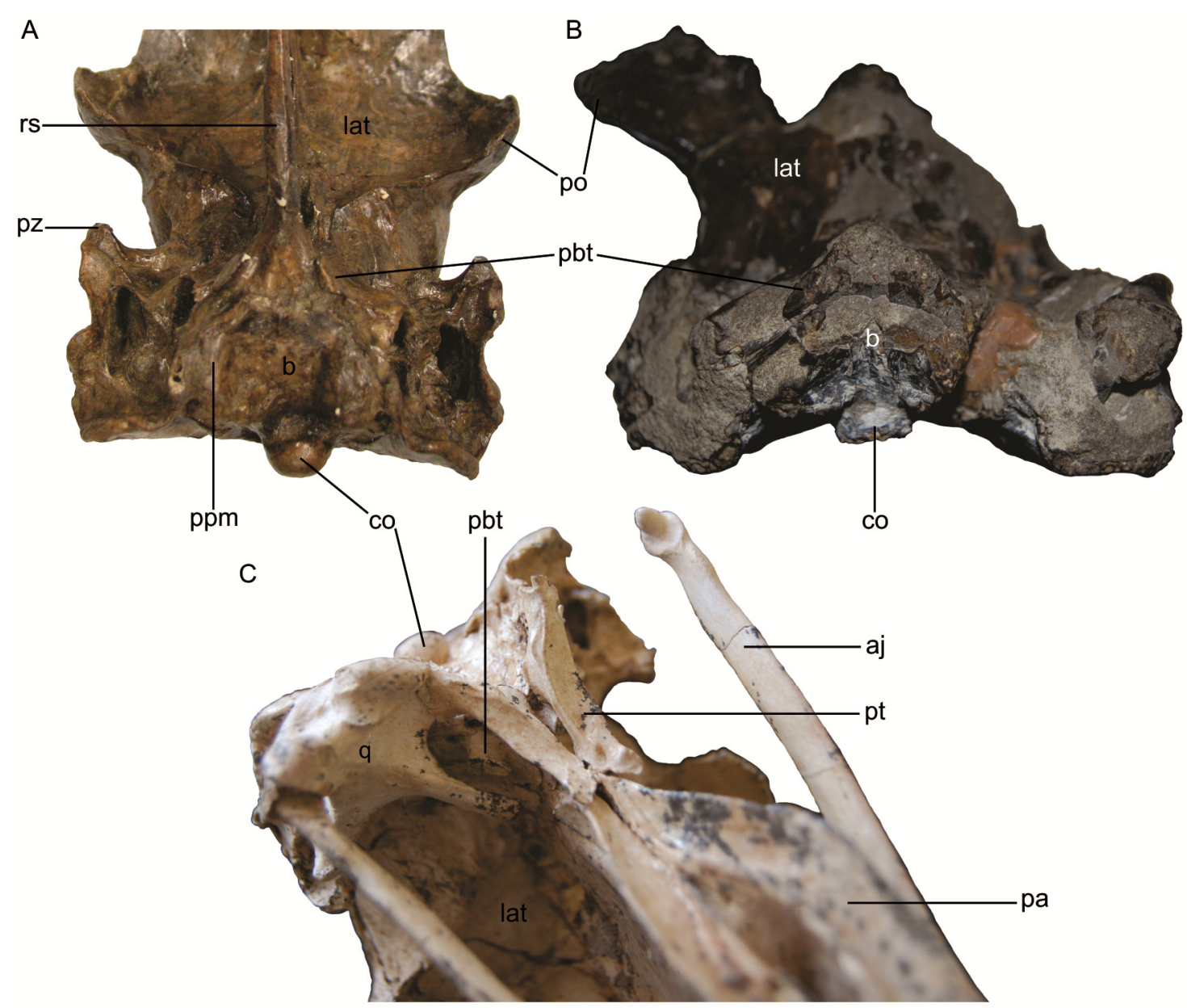

Figura 4.4. Processi basipterygoideus. A, Psilopterus lemoinei AMNH 9257; B, Patagornis marshi MLP 20-122; C, Taxón nuevo A MMP5050. Abreviaturas: aj, arcus jugalis; b, os basiesfenoidale; co, condylus occipitalis; lat, os laterosphenoidale; pbt, processus basipterygoideus; pa, os palatinum; po, processus postorbitalis; ppm, processus parasphenoidalis medialis; $\mathbf{p t}$, os pterygoideum; pz, processus zygomaticus; q, os quadratum; rs, rostrum parasphenoidalis. Escala $=1 \mathrm{~cm}$.

Figura 4.5. (Página siguiente) Región ótica de Psilopterus lemoinei AMNH 9257. A, vista ventral del neurocráneo; $B$, detalle de la zona ótica en vista ventral; $C$, detalle de la zona ótica en vista ventrolateral. Abreviaturas: b, os basiesfenoidale; co, condylus occipitalis; cqo, cotyla quadratica otici; $\mathbf{c q s}$, cotyla quadratica squamosi; $\mathbf{f v}$, fenestra vestibularis; $\mathbf{f c}$, fenestra cochelaris; $\mathbf{f}_{\mathbf{I I}}$, foramen nervus ophthalmicus; $\mathbf{f}_{\mathbf{V 2}-\mathbf{3}}$, foramen maxillomandibularis; $\mathbf{f}_{\mathbf{V I I}}$, foramen nervus facialis; pbt, processus basipterygoideus; po, processus postorbitalis; pp, processus paraoccipitalis; ppm, processus parasphenoidalis medialis; ps, processus suprameaticus; pz, processus zygomaticus; rc, recessus columellae; $\mathbf{r t d}$, recesus tympanicus dorsalis; $\mathbf{r t r}$, recessus tympanicus rostralis. Escala $=1 \mathrm{~cm}$. 


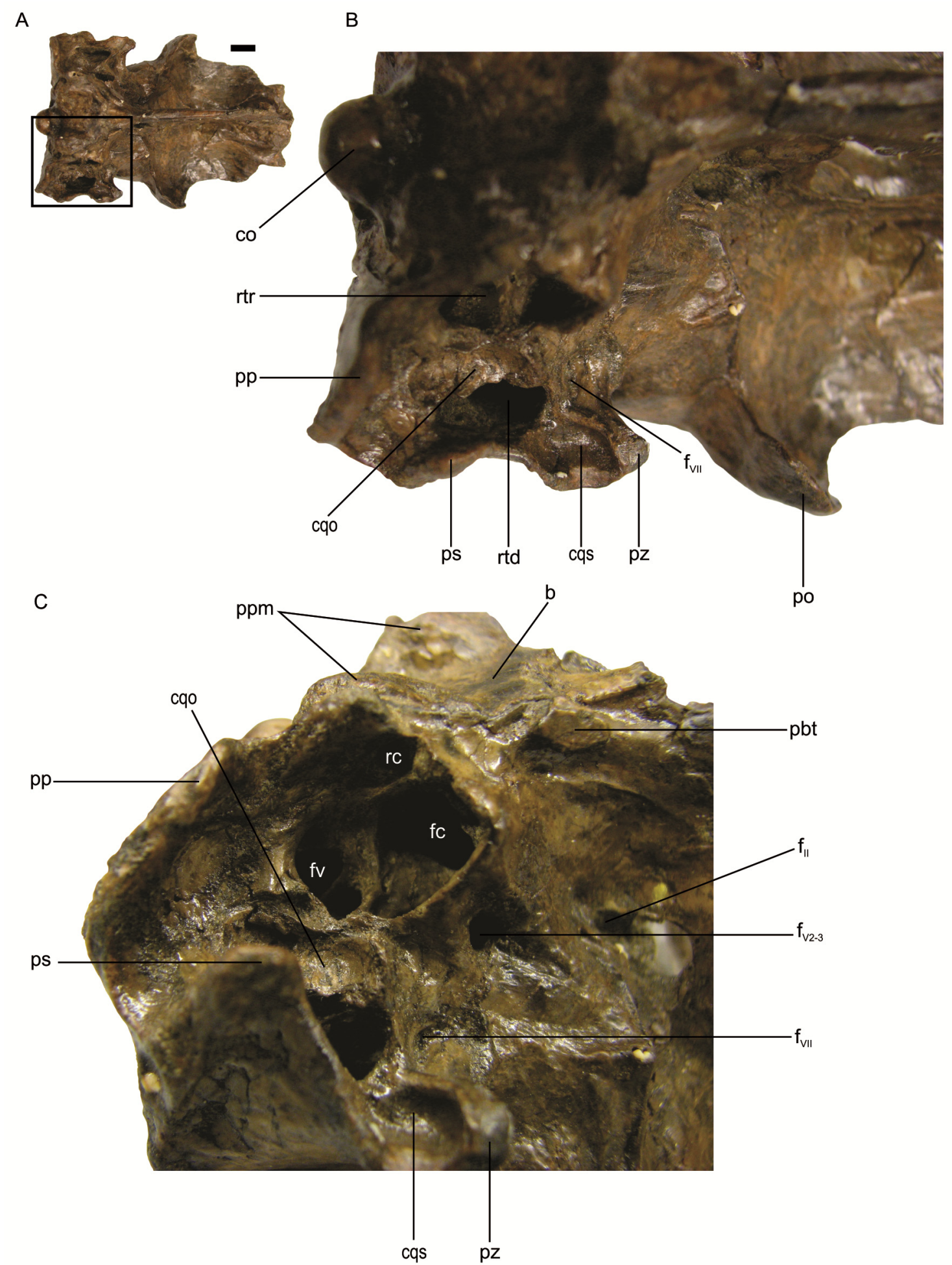


A

B
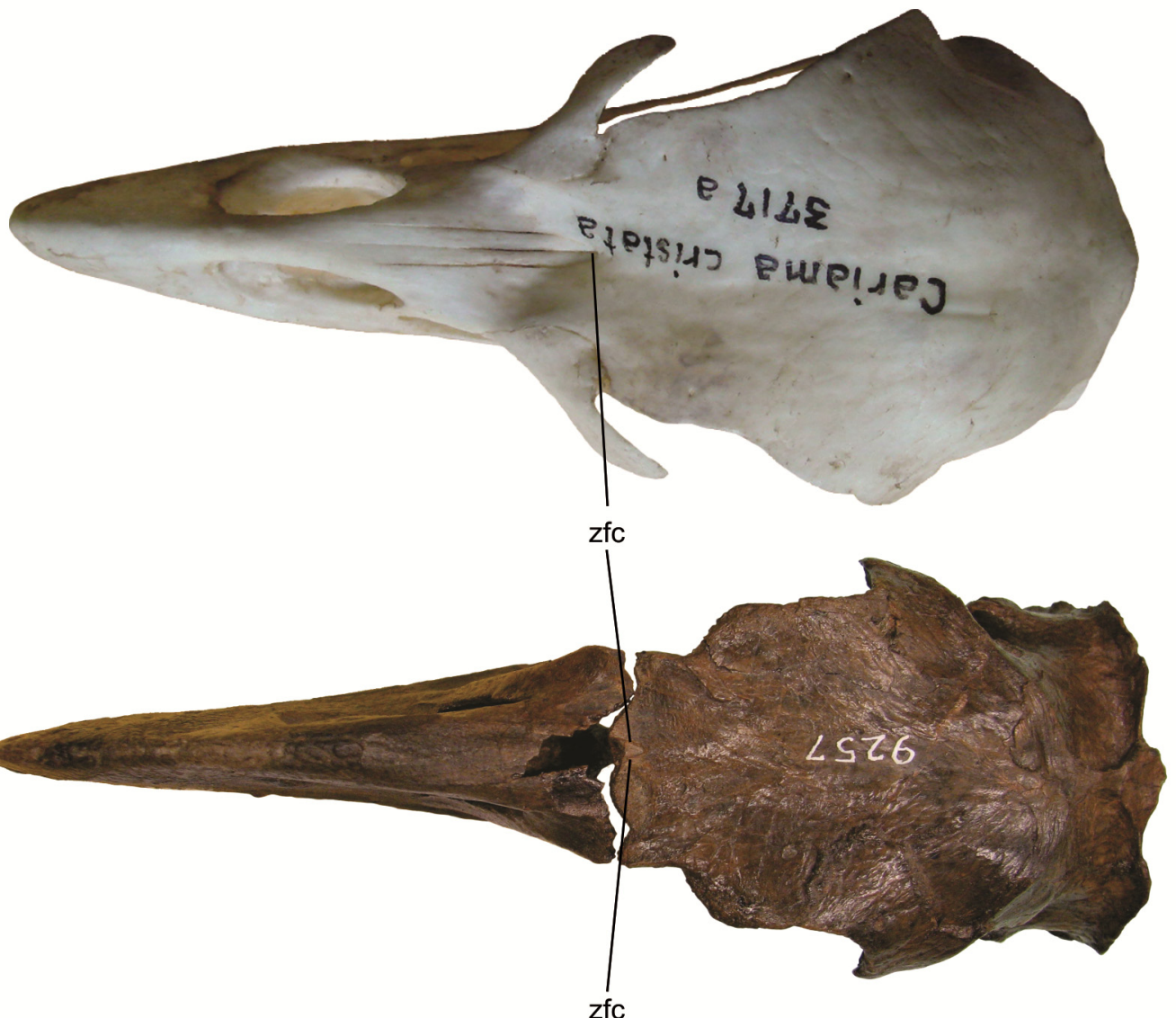

C

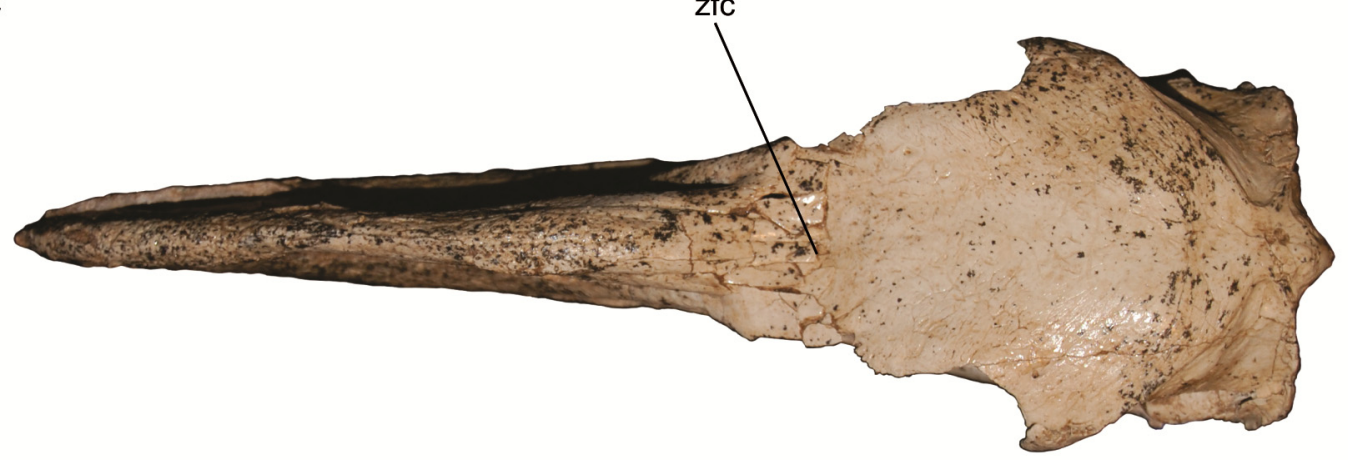

D

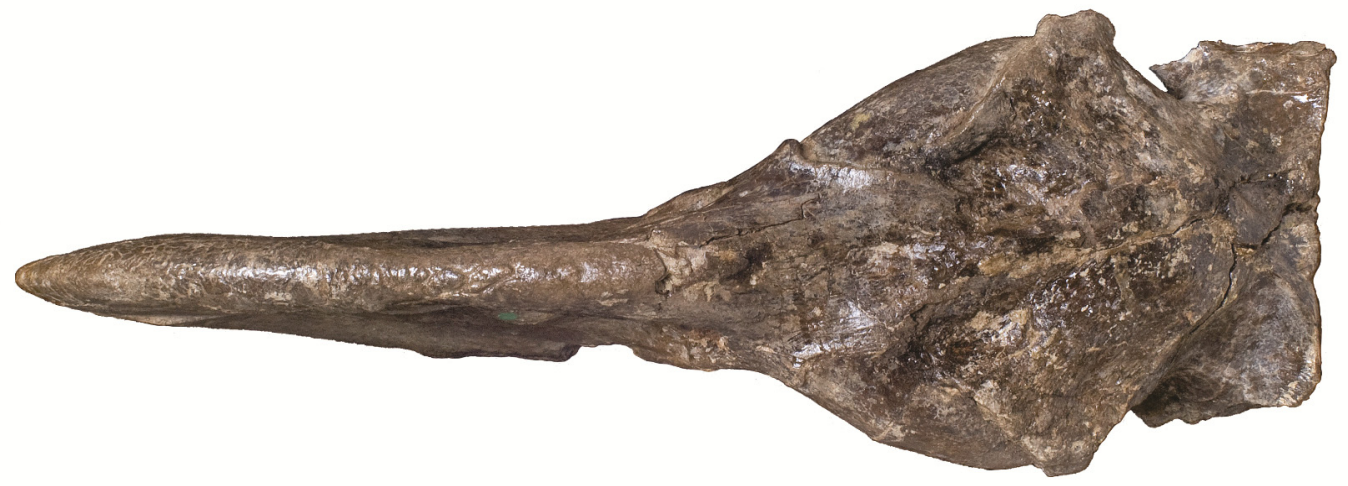

Figura 4.6. Zona flexoria craniofascialis. A, Cariama cristata MACN 3717a; B, Psilopterus lemoinei AMNH 9257; C, Taxón nuevo A MMP5050; D, Patagornis marshi BMNH-A516. Abreviaturas: zfc, zona flexoria craniofascialis. No a escala. 


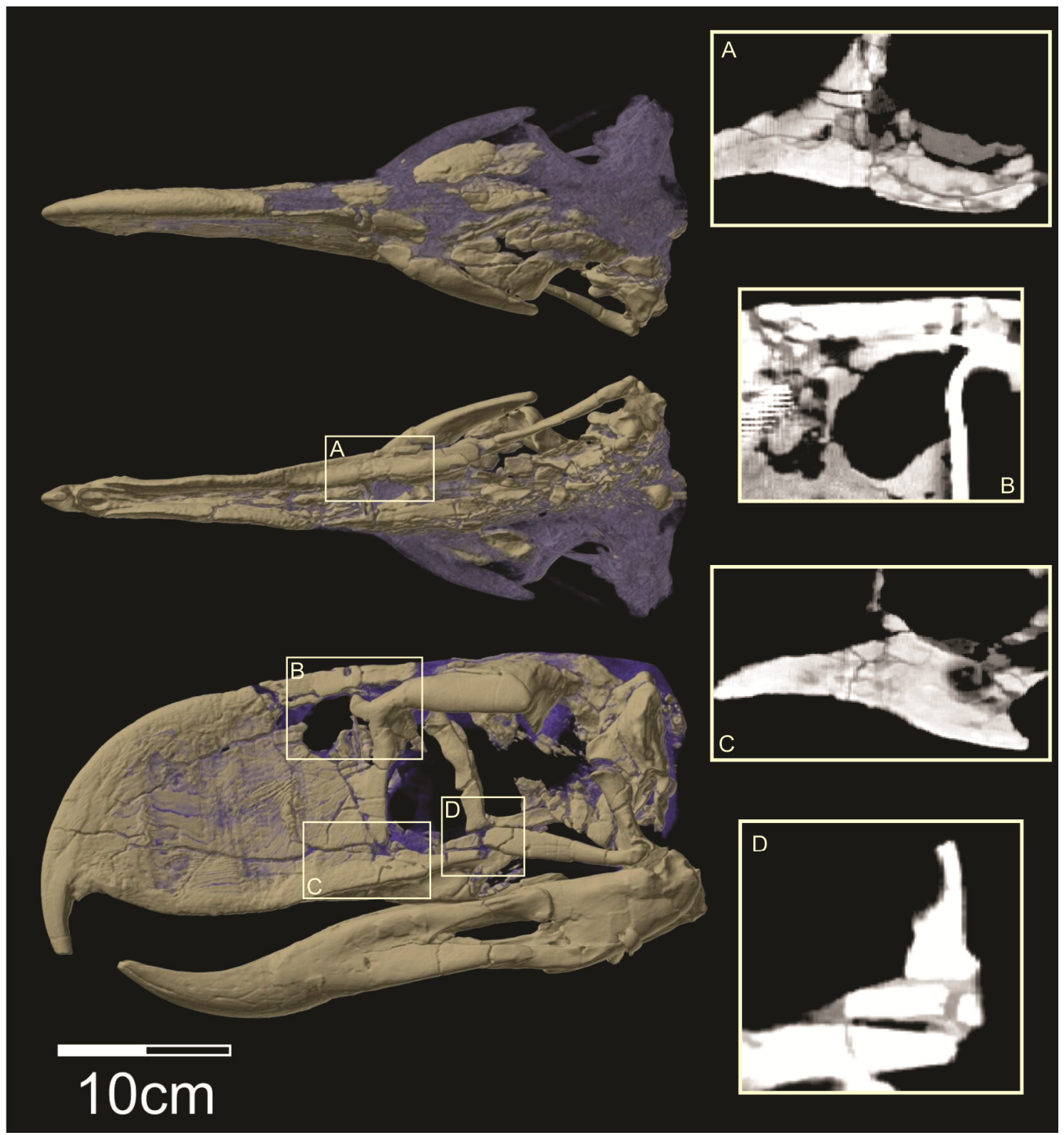

Figura 4.7. Detalle de las zonae flexoria en corte lateral de un Phorusrhacidae obtenidos a partir de cortes tomográficos: Modelo de Andalgalornis steulleti FMP14357 construido a partir de tomografías computadas en vista dorsal, ventral y lateral izquierda. En marrón claro se observa el hueso, mientras que el color azulado marca las zonas donde el material está reconstruido. A, zona flexoria palatina; $\mathrm{B}$, zona flexoria craniofascialis; $\mathrm{C}$, zona flexoria arcus jugalis; $\mathrm{D}$, contacto entre el os lacrimale y el arcus jugalis. Escala $=10 \mathrm{~cm}$. 
A

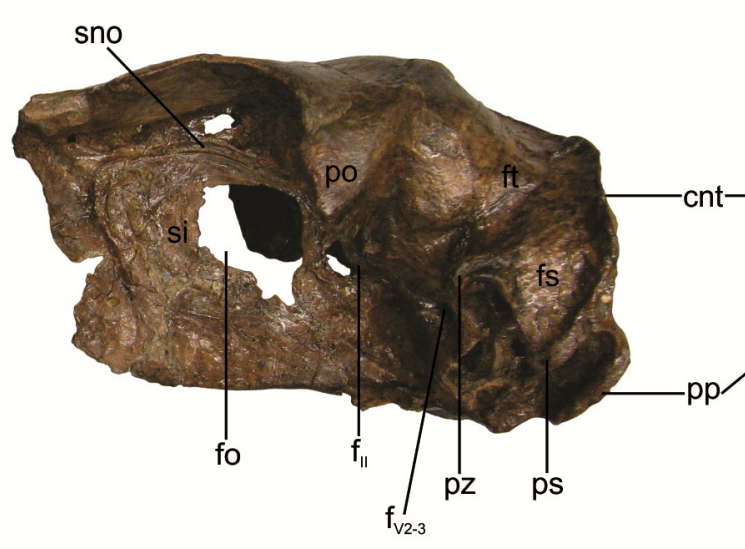

B

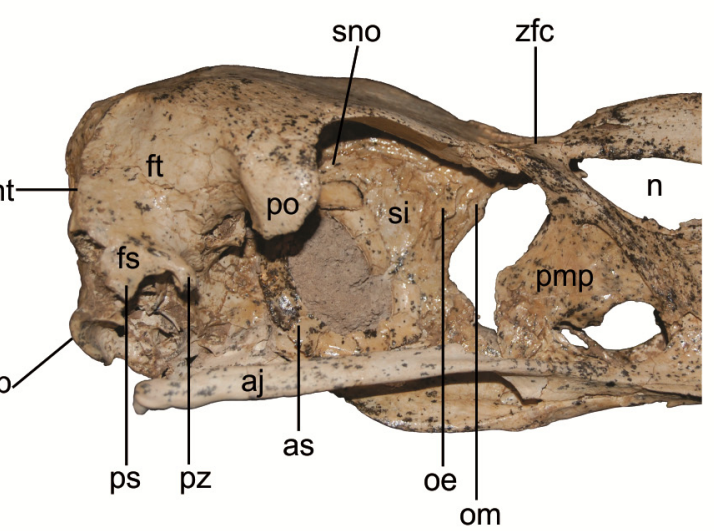

Figura 4.8. Región orbital de los Phorusrhacidae. A, Psilopterus lemoinei AMNH 9257; B, Taxón nuevo A MMP5050. Abreviaturas: aj, arcus jugalis; as, Annulus ossicularis sclerae; cnt, crista nucalis transversa; fo, fontanela orbitocraneana; fs, fossa subtemporalis; $\mathbf{f t}$, fossa temporalis; $\mathbf{f}_{\mathbf{I I}}$, foramen nervus ophthalmicus; $\mathbf{f}_{\mathbf{V} 2-\mathbf{3}}$, foramen maxillomandibularis; $\mathbf{n}$, narinas; oe, os ectethmoidale; $\mathbf{o m}$, os mesethmoidale; pmp, processus maxillopalatinus; po, processus postorbitalis; pp, processus paraoccipitalis; ps, processus suprameaticus; pz, processus zygomaticus; $\mathbf{s i}$, septum interorbitale; sno, sulcus nervus olfactorii; zfc, zona flexoria craniofascialis. No a escala.

A

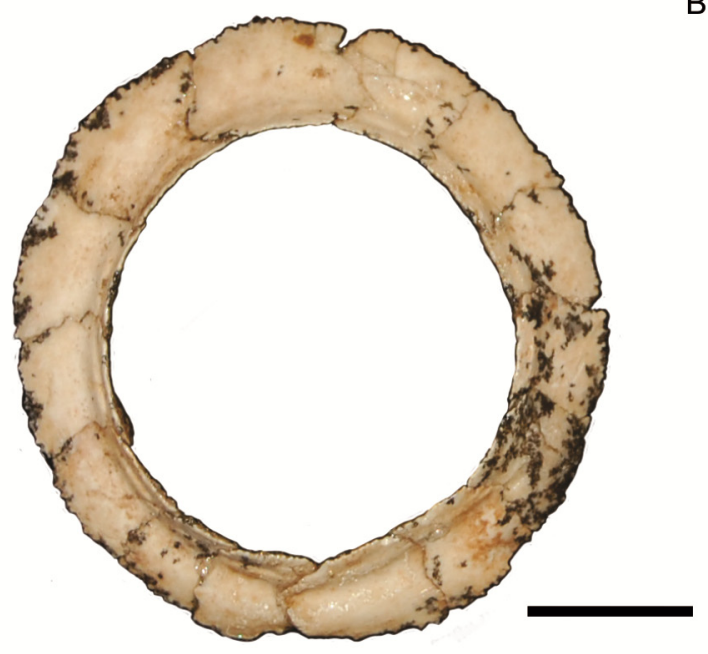

B

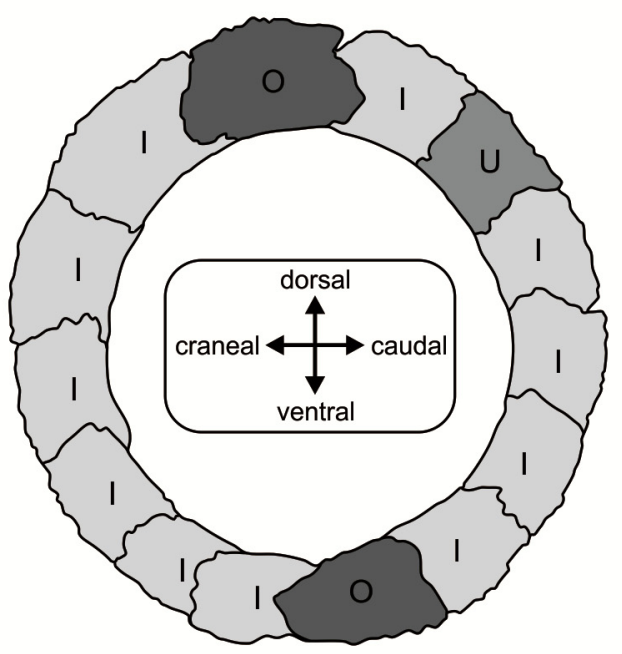

Figura 4.9. Annulus ossicularis sclerae de Taxón nuevo A MMP 5050. A, annulus ossicularis sclerae izquierdo; B, esquema. Abreviaturas: i, interlocking plates; o, overplates; $\mathbf{u}$, underplates. Escala $=1 \mathrm{~cm}$. 
A

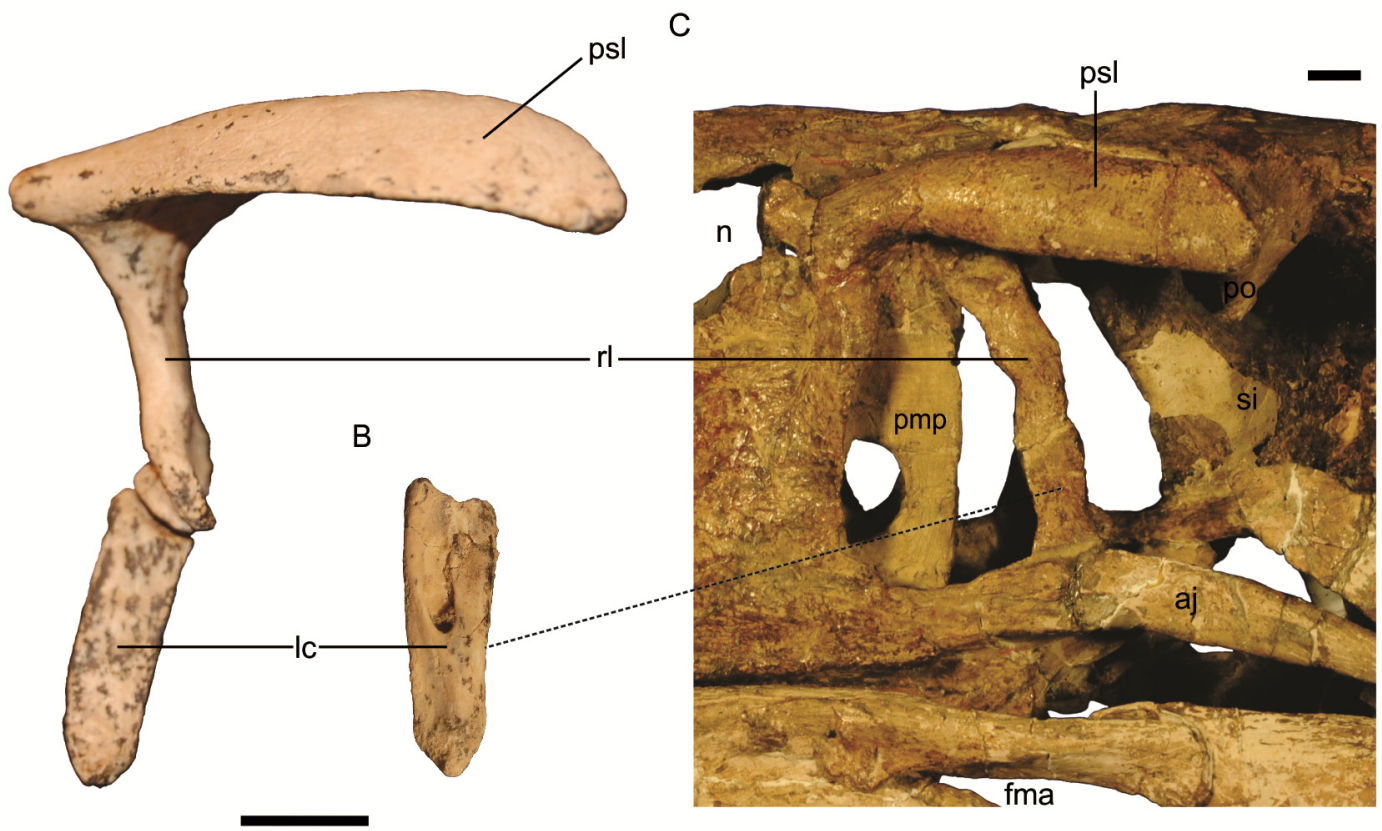

Figura 4.10. Os lacrimale y os lacrimale communicans de los Phorusrhacidae. A-B, Taxón nuevo A MMP 5050. A, vista lateral del os lacrimale y os lacrimale communicans; B, vista medial del os lacrimale communicans; C, Andalgalornis steulleti FM-P14357, os lacrimale y os lacrimale communicans fusionados. Abreviaturas: aj, arcus jugalis; fma, fenestra mandibularis; lc, os lacrimale communicans; $\mathbf{n}$, narinas pmp, processus maxillopalatinus; $\mathbf{p o}$, processus postorbitalis; $\mathbf{p s l}$, processus supraorbitalis del os lacrimale; rl, rama descendente del os lacrimale; si, septum interorbitale. Escala $=1 \mathrm{~cm}$. 
A

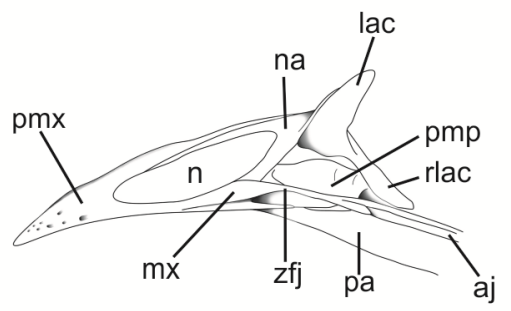

B
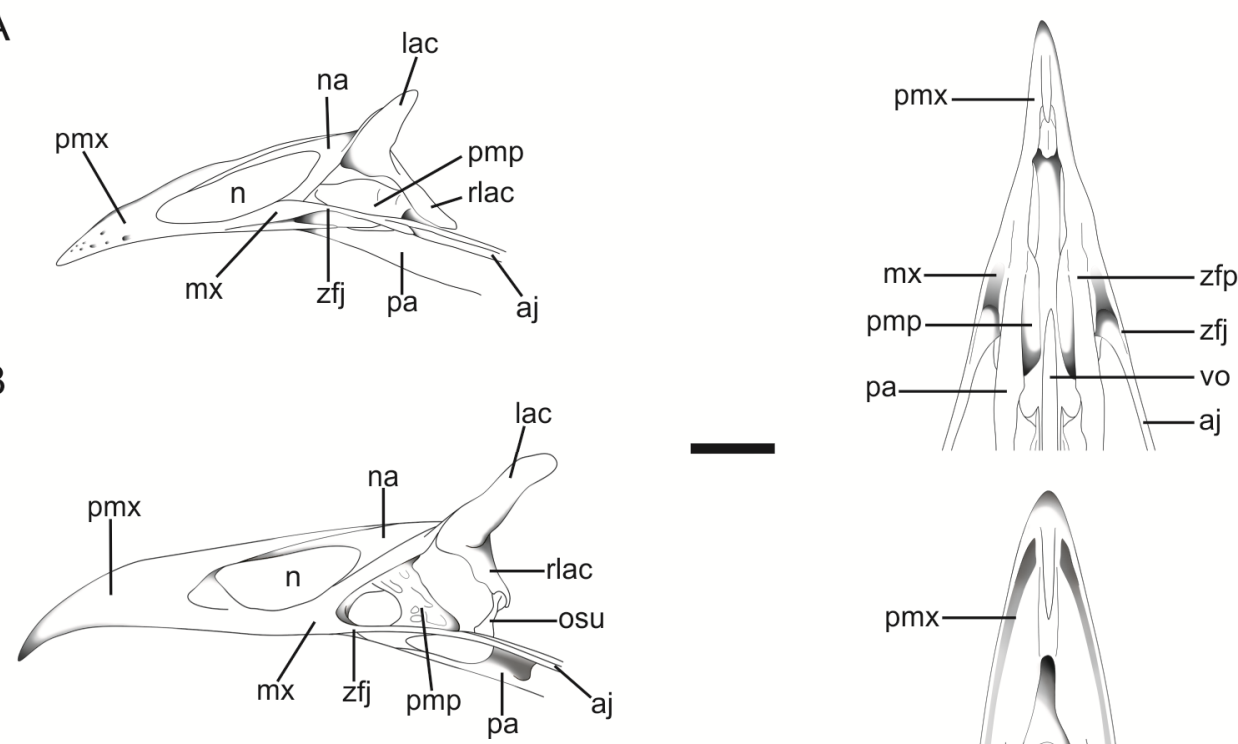

$E$

C
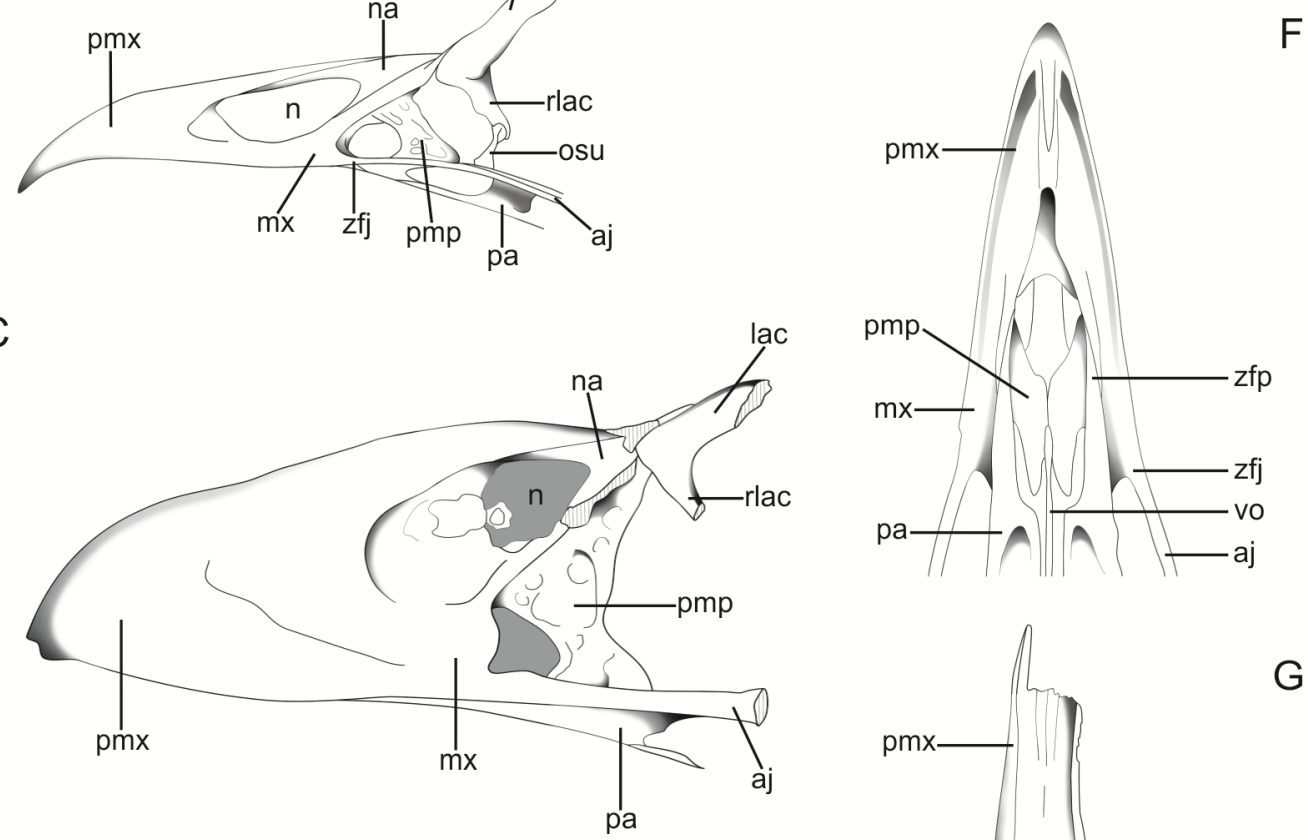

D
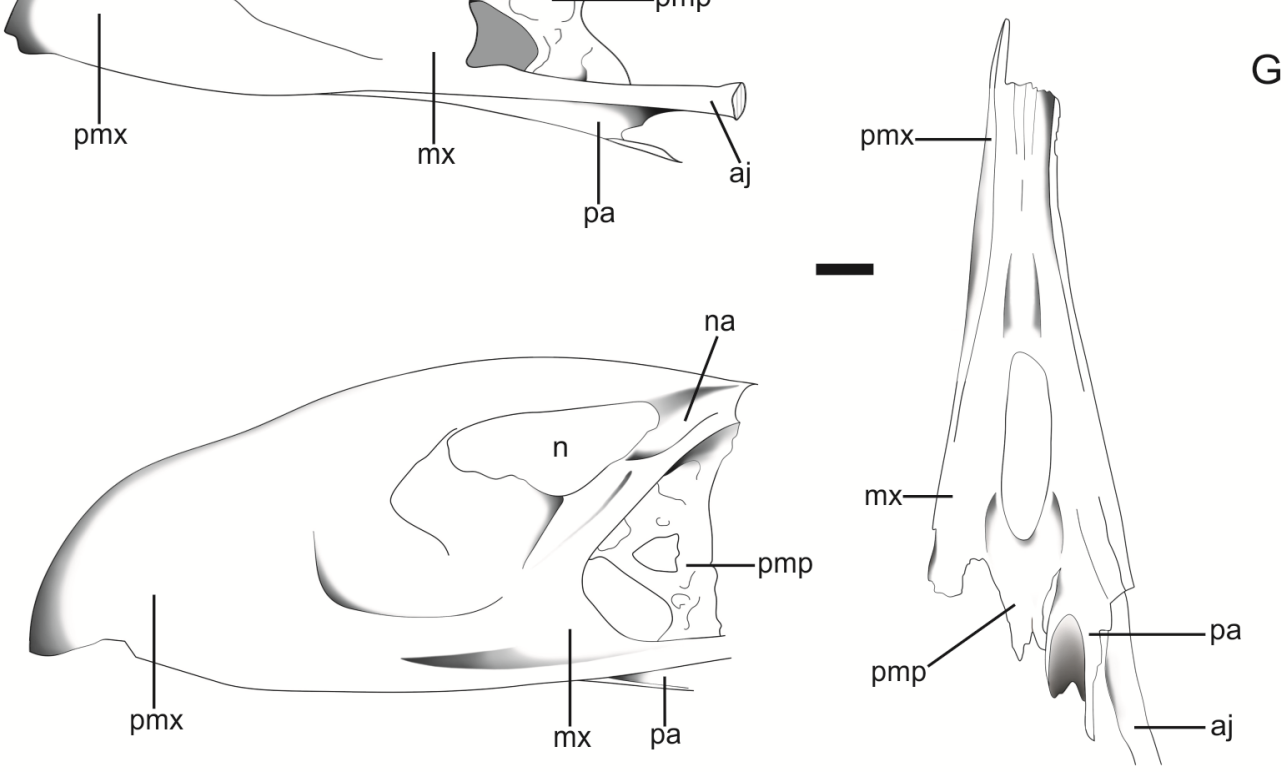

Figura 4.11. Ilustración esquemática del pico (columna izquierda) y paladar (columna derecha) de A y E, Psophia crepitans; B y F, Chunga burmeisteri; C, D y G, Psilopterus lemoinei. Los dibujos C, D, G están basados en los materiales YMPPU15402, AMNH 9257 y MPM-PV3649 respectivamente. Abreviaturas: aj, arcus jugalis; lac, os lacrimale; $\mathbf{m x}$, os maxillare; $\mathbf{n}$, nares; na, os nasale; pa, os palatinum; pmp, processus maxillopalatinus; pmx, os premaxillare; rlac, descending ramus of the os lacrimale; osu, os lacrimale communicans; vo, vomer; $\mathbf{z f j}$, zona flexoria arcus jugale; $\mathbf{z f p}$, zona flexoria palatina. Escala $=1 \mathrm{~cm}$. Tomada de Degrange y Tambussi (2011). 


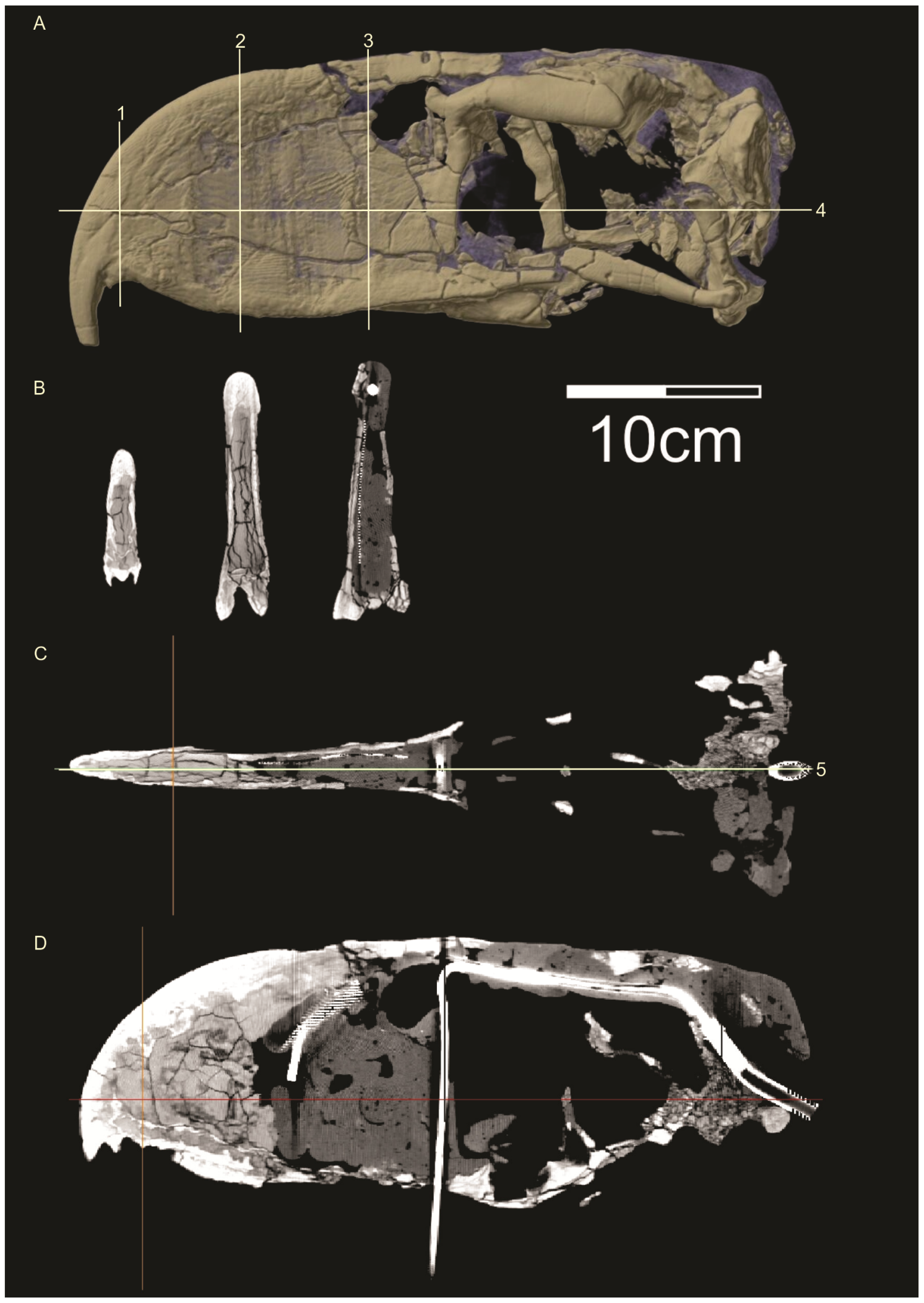

Figura 4.12. Estructura interna del pico de Andalgalornis steulleti FM-P14357. A, Vista lateral izquierda indicando los planos de corte transversales 1-3 y el plano horizontal 4; B, secciones 1-3; C, estructura interna observada a través del plano de corte 4, indicando la ubicación del plano de corte vertical 5; D, corte del cráneo utilizando el plano 5 . Escala $=10 \mathrm{~cm}$. 


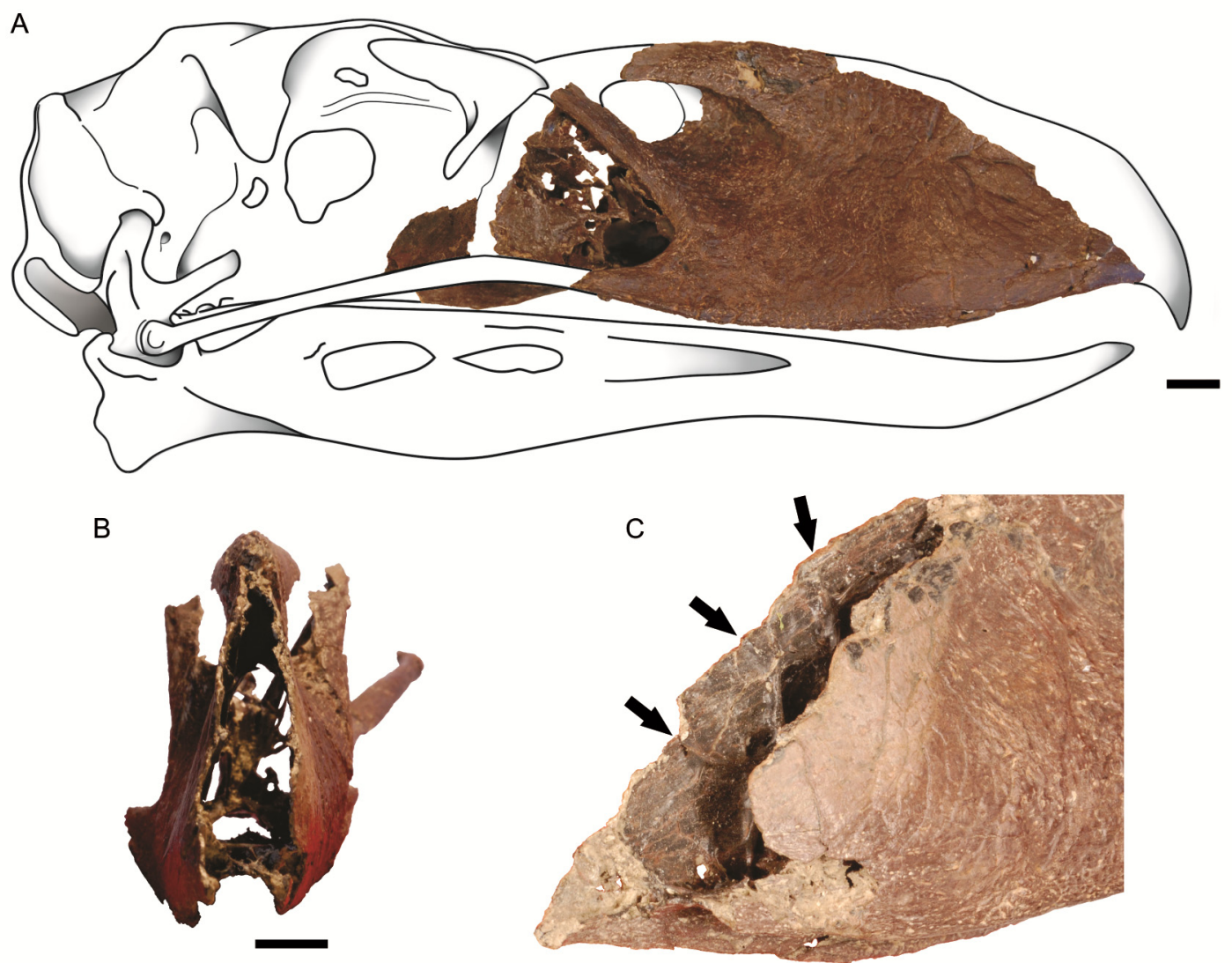

Figura 4.13. Estructura interna del pico de Psilopterus lemoinei MPM-PV3649. A, vista lateral derecha; $\mathrm{B}$, vista craneal; $\mathrm{C}$, detalle de las trabéculas internas (flechas). Escala $=1 \mathrm{~cm}$. C no a escala. Modificada de Degrange y Tambussi (2011). 


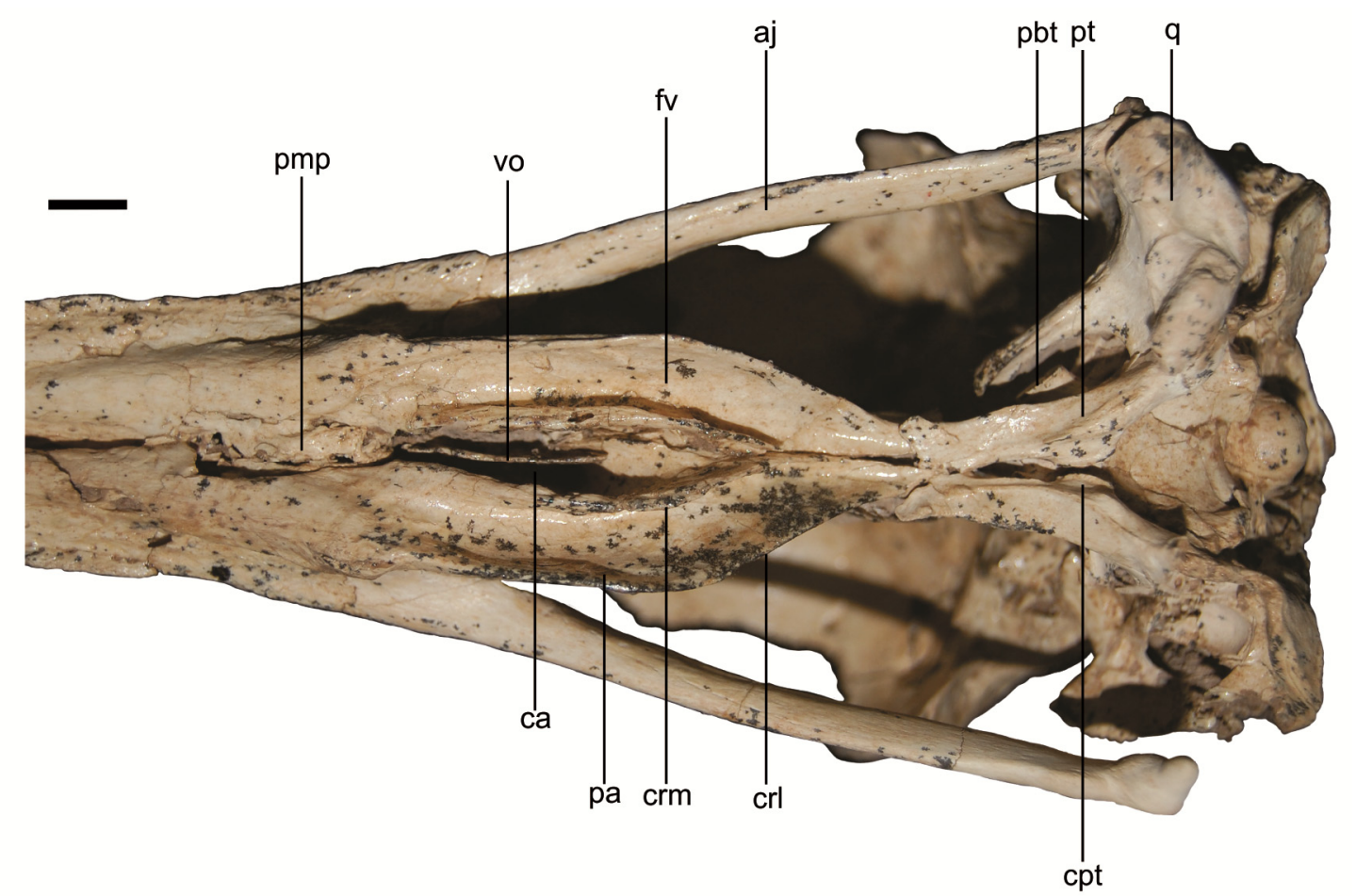

Figura 4.14. Ossa palati de Taxón nuevo A MMP 5050. Abreviaturas: aj, arcus jugalis; ca, coanas; crl, crista lateralis; crm, crista medialis; cpt, proceso del os pterygoideum de articulación con los processi basipterygoideus del os basisphenoidale; $\mathbf{f v}$, fossa ventralis; pa, os palatinum; pbt, processus basipterygoideus; pmp, processus maxillopalatinus; $\mathbf{p t}$, os pterygoideum; $\mathbf{q}$, os quadratum; vo, vómer. Escala $=1 \mathrm{~cm}$.

Figura 4.15. (Página siguiente) Os quadratum de los Phorusrhacidae. A, Psilopterus lemoinei YPM-PU15402, vistas medial, lateral, caudal, craneal, distal y proximal; B, Psilopterus bachmanni YPM-PU15904, vista distal; C, Procariama simplex FMP14353, vista distal; D, Patagornis marshi BMNH-A516, vistas lateral, medial, caudal, distal y craneal; E, Andalgalornis steulleti FM-P14357, vistas medial y lateral. Abreviaturas: cc, condylus caudalis; cl, condylus lateralis; $\mathrm{cm}$, condylus medialis; co, capitulum oticum; coq, corpus ossa quadrati; cp, condylus pterygoideus; cq, cotyla quadratojugalis; cs, capitulum squamosum; fp, foramen pneumaticum; ii, incisura intercapitularis; pm, processus mandibularis; por, processus orbitalis; pot, processus oticus. Escala $=1 \mathrm{~cm}$. 
A
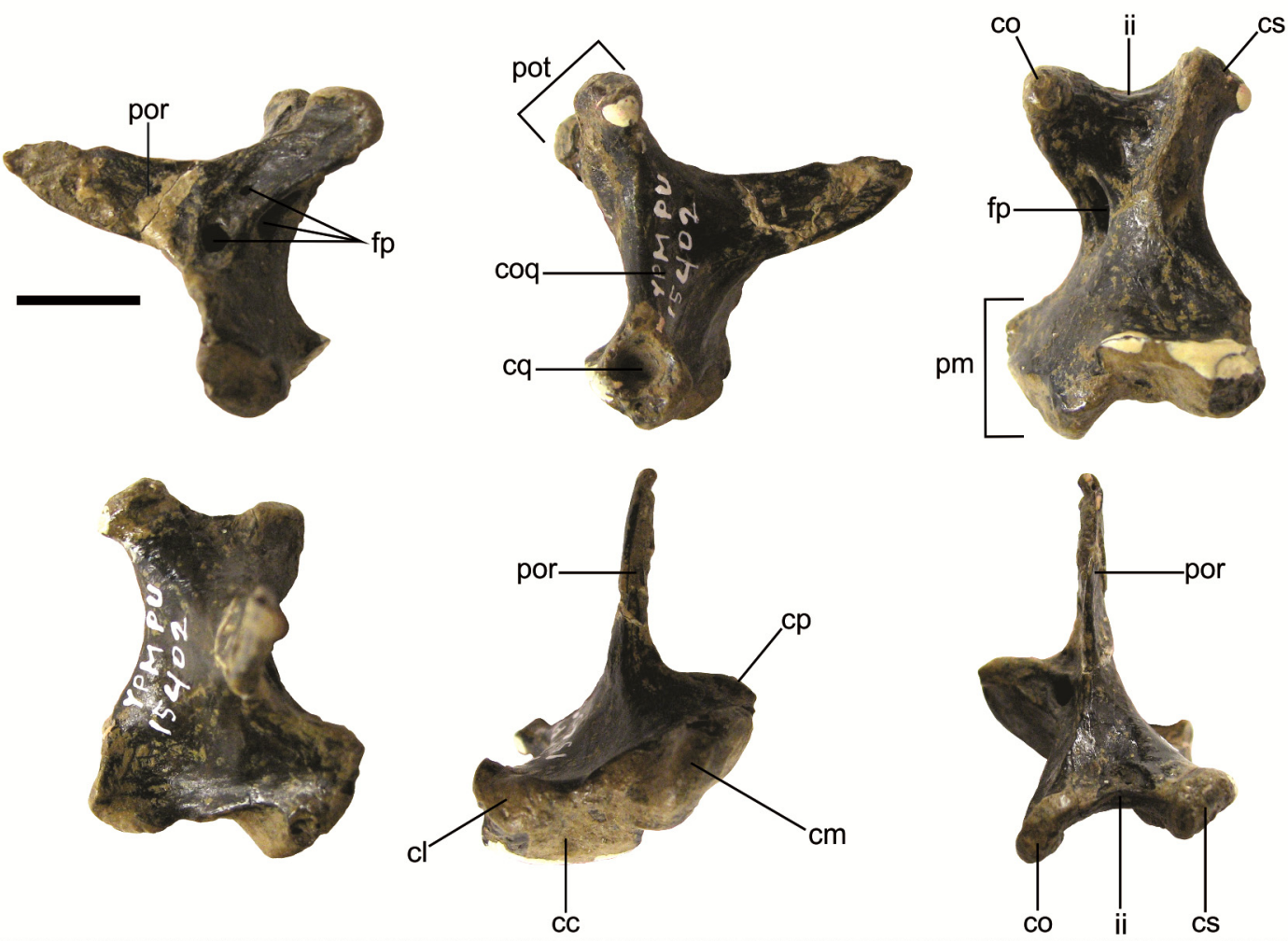

B

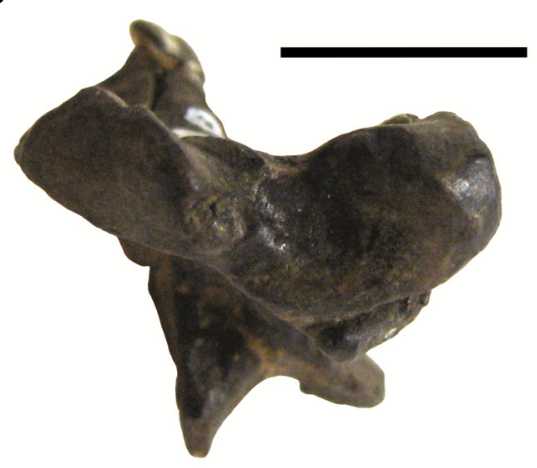

C
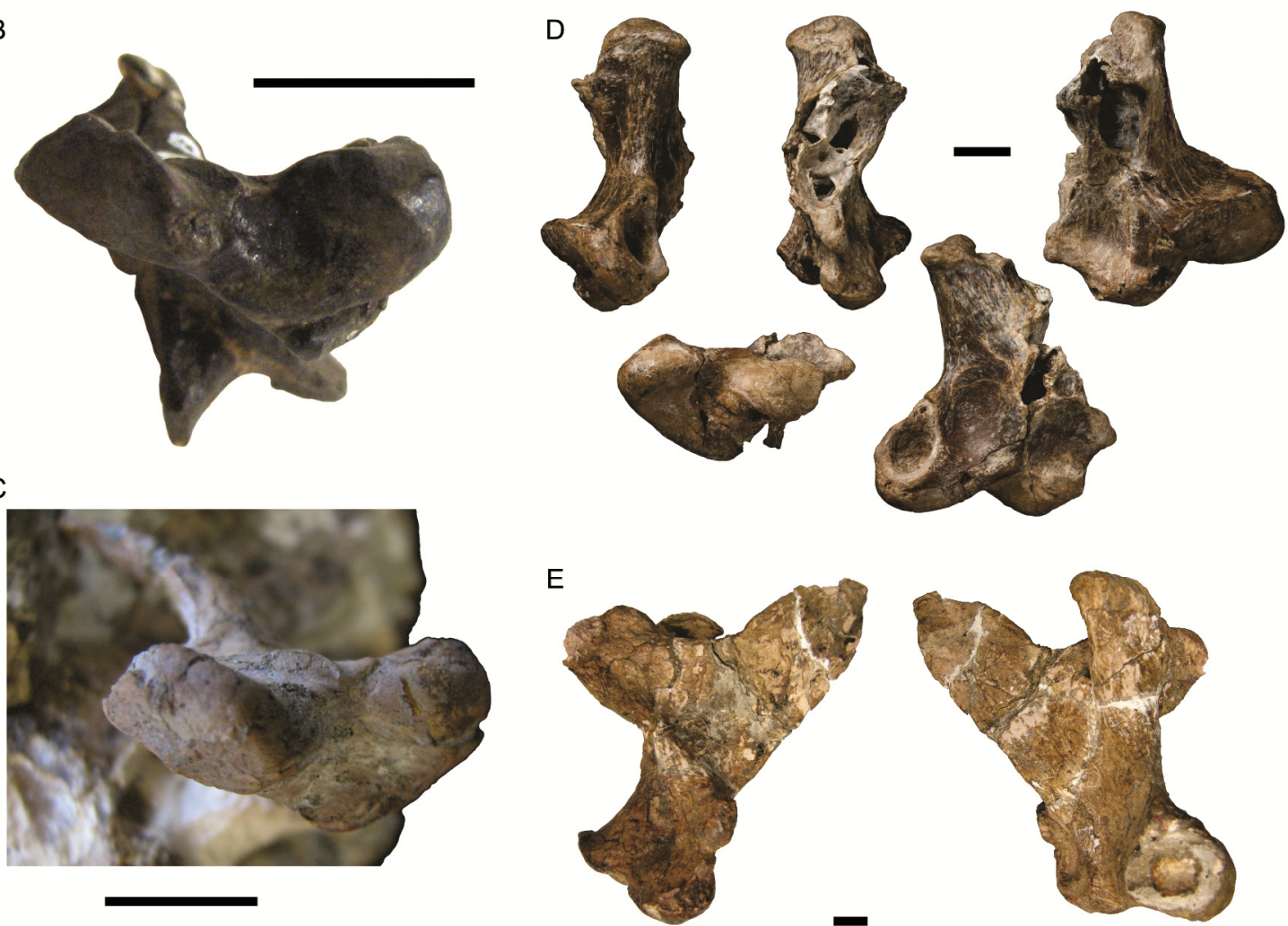
A

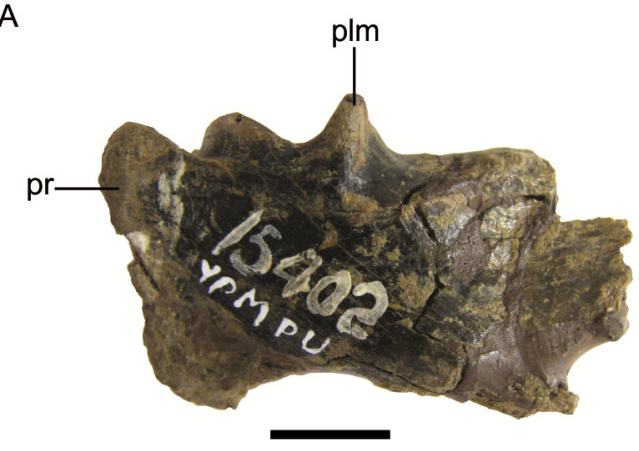

B

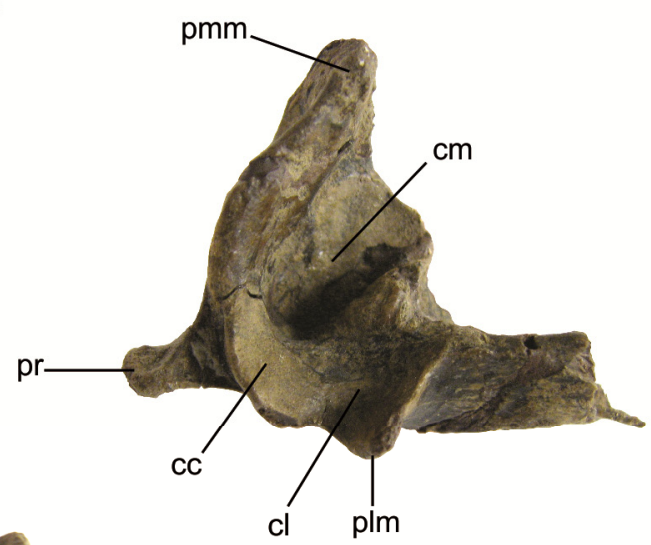

C

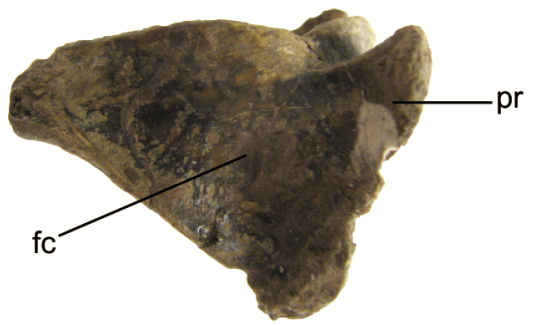

Figura 4.16. Extremo caudal de la hemimandíbula derecha de Psilopterus lemoinei YPM-PU15402. A, vista lateral derecha; B, vista dorsal; C, vista caudal. Abreviaturas: cc, cotyla caudalis; $\mathbf{c l}$, cotyla lateralis; $\mathbf{c m}$, cotyla medialis; fc, fossa caudalis; fma, fenestra mandibulae; pc, processus coronoideus; plm, processus lateralis mandibulae; pmm, processus medialis mandibulae; pr, processus retroarticularis. Escala $=1 \mathrm{~cm}$. 
A

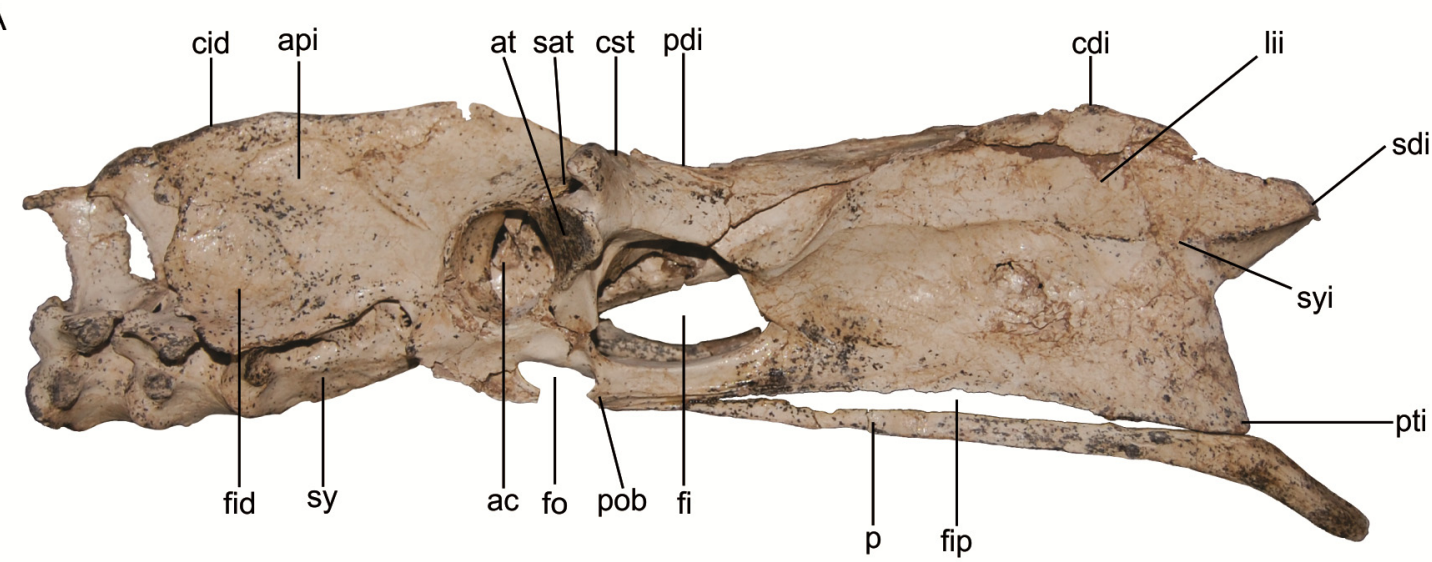

B

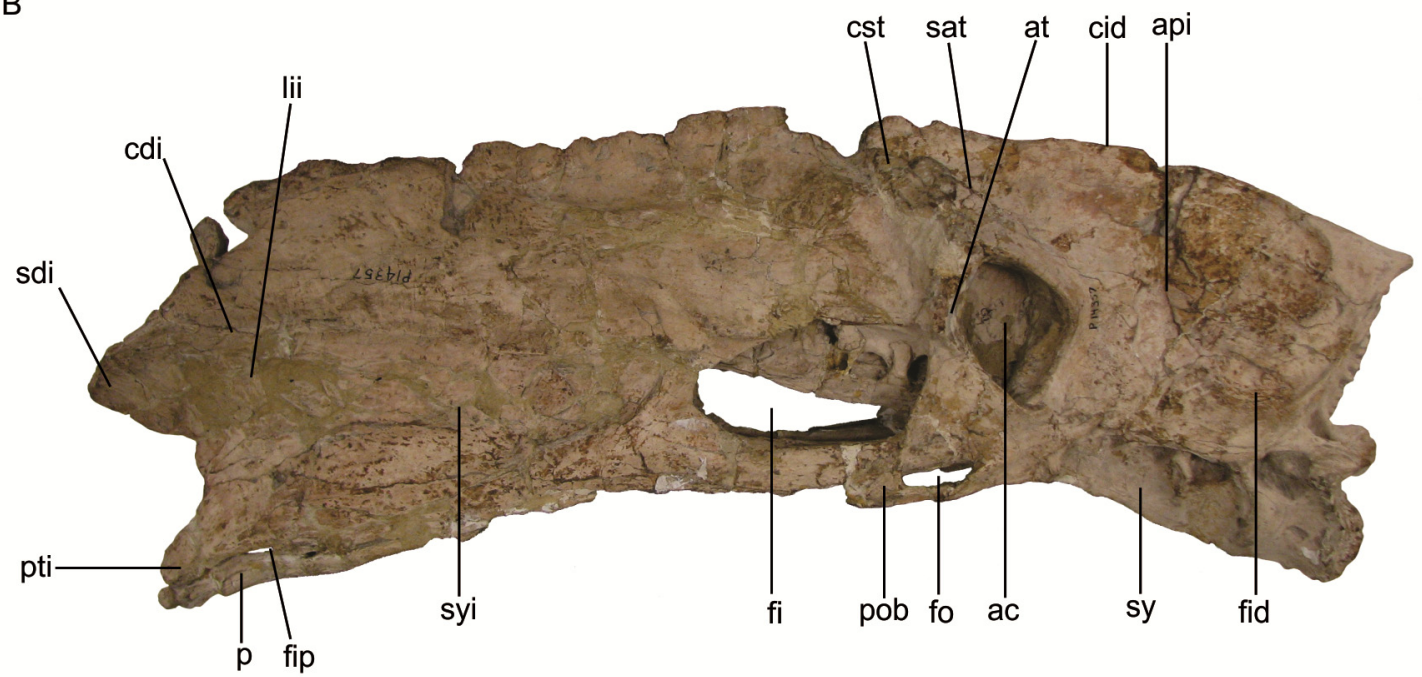

Figura 4.17. Pelvis de fororracos. A, Taxón nuevo A MMP 5050, vista lateral izquierda; B, Andalgalornis steulleti FM-P14357, vista lateral derecha. Abreviaturas: ac, acetabulum; api, ala preacetabularis ilii; at, antitrochanter; cdi, crista dorsolateralis ilii; cid, crista iliaca dorsalis; cst, crista supratrochanterica; fi, foramen ilioischiadicum; fid, fossa iliaca dorsalis; fip, fenestra ischiopubica; fo, foramen obturatum; lii, lamina infracristalis ilii; p, pubis; pdi, plataforma dorsal iliaca; pob, processus obturatorius; pti, processus terminalis ischii; sat, sulcus antitrochantericus; sdi, spina dorsolateralis ilii; sy, synsacrum; syi, synchondrosis ilioischiadica. Escala = $1 \mathrm{~cm}$. 
A

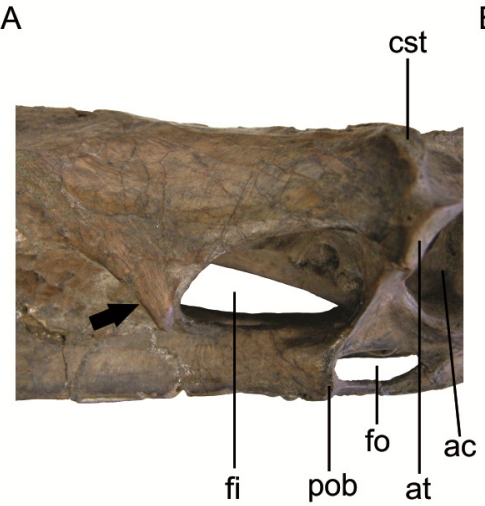

B

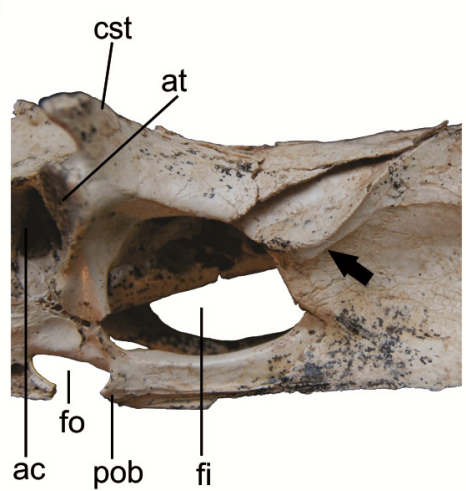

C

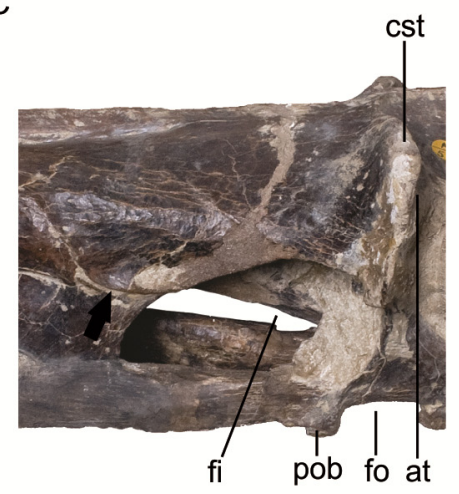

Figura 4.18. Proceso (flecha) ubicado sobre el margen caudal del foramen ilioischiadicum. A, Psilopterus lemoinei AMNH 9257, vista lateral derecha; B, Taxón nuevo A MMP 5050, vista lateral izquierda; C, Patagornis marshi BMNH-A516, vista lateral derecha. Abreviaturas: ac, acetabulum; at, antitrochanter; cst, crista supratrochanterica; fi, foramen ilioischiadicum; fo, foramen obturatum; pob, processus obturatorius. No a escala.

A

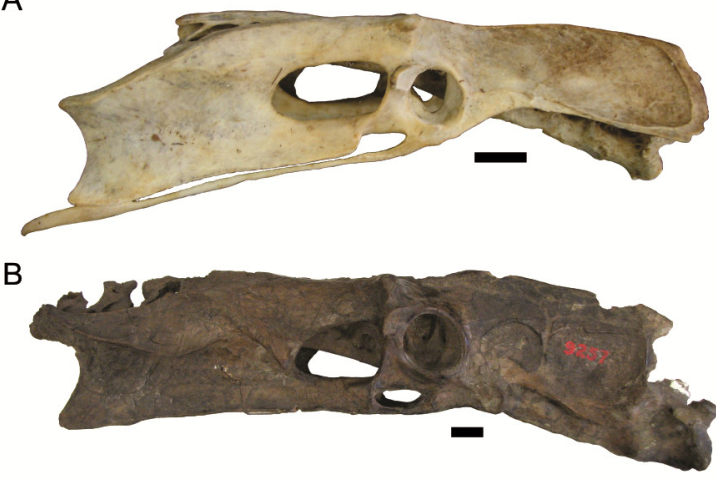

C

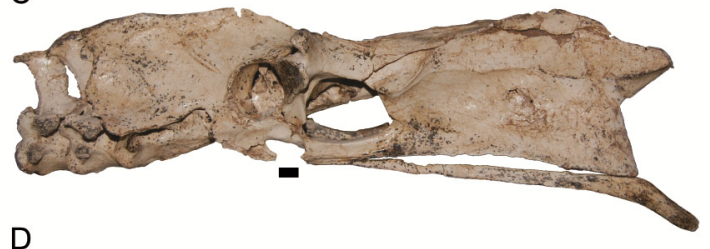

D

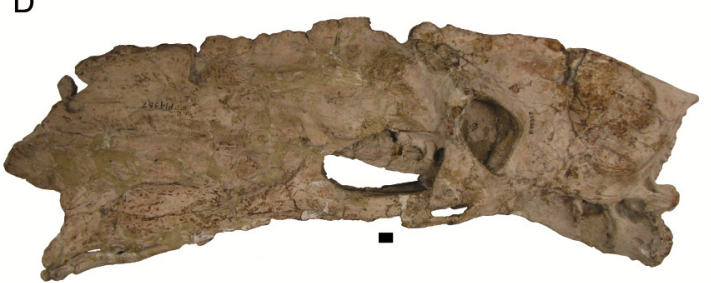

Figura 4.19. Comparación de la pelvis de algunos Phorusrhacidae con Cariamidae. A, Cariama cristata AMNH 8604, vista lateral derecha; B, Psilopterus lemoinei AMNH 9257, vista lateral derecha; C, Taxón nuevo A MMP 5050, vista lateral izquierda; D, Andalgalornis steulleti FM-P14357, vista lateral derecha. Escala $=1 \mathrm{~cm}$. 

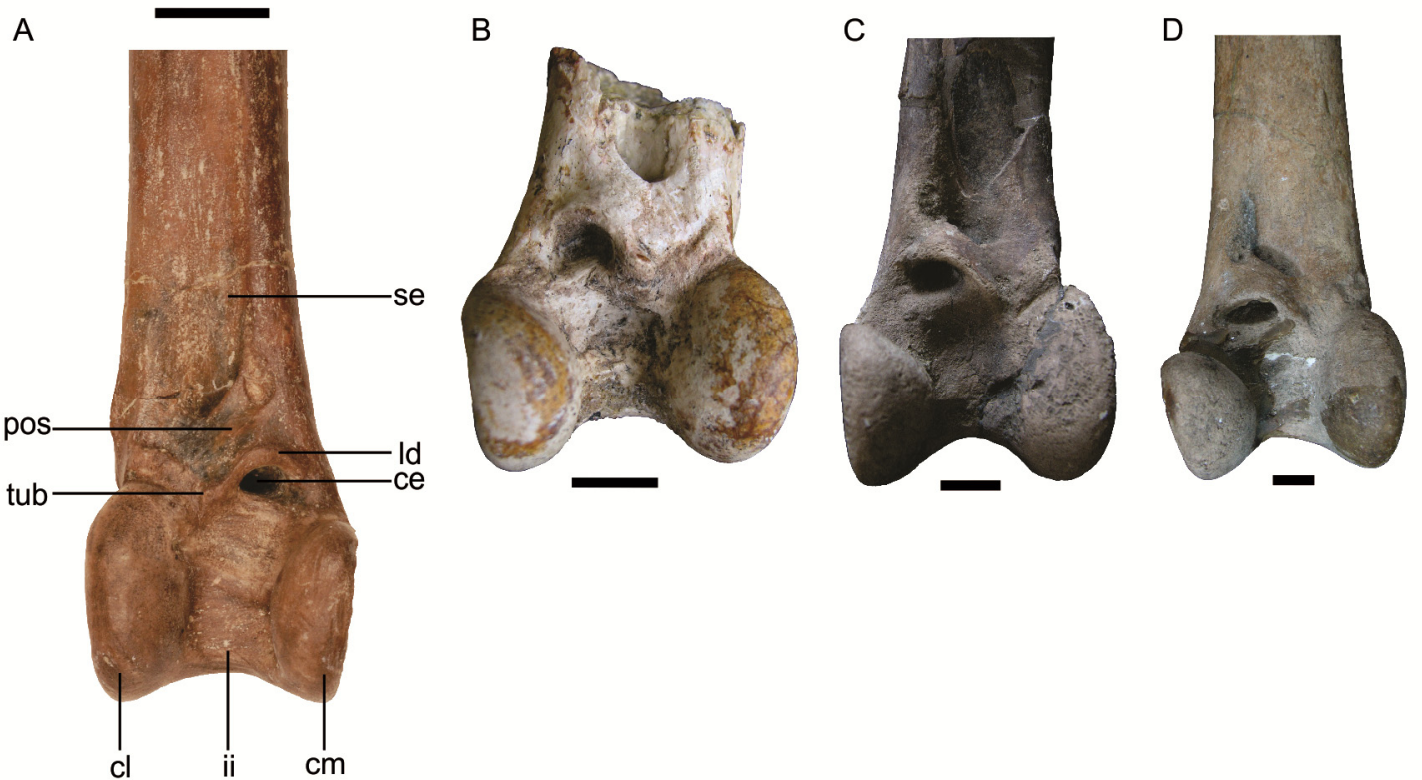

Figura 4.20. Extremo distal de tibiotarso en vista craneal. A, Psilopterus lemoinei MPM-PV3650, tibiotarso derecho; Procariama simplex FM-P14525, tibiotarso izquierdo; Patagornis marshi AMNH 9254, tibiotarso izquierdo; Mesembriornis milneedwardsi MACN Pv 5944, tibiotarso izquierdo. Abreviaturas: ce, canalis extensorius; $\mathbf{c l}$, condylus lateralis; $\mathbf{c m}$, condylus medialis; $\mathbf{i i}$, incisura intercondylaris; ld, labio distal; pos, pons supratendineus; se, sulcus extensorius; tub, tubérculo. Escala $=1 \mathrm{~cm}$. 
A

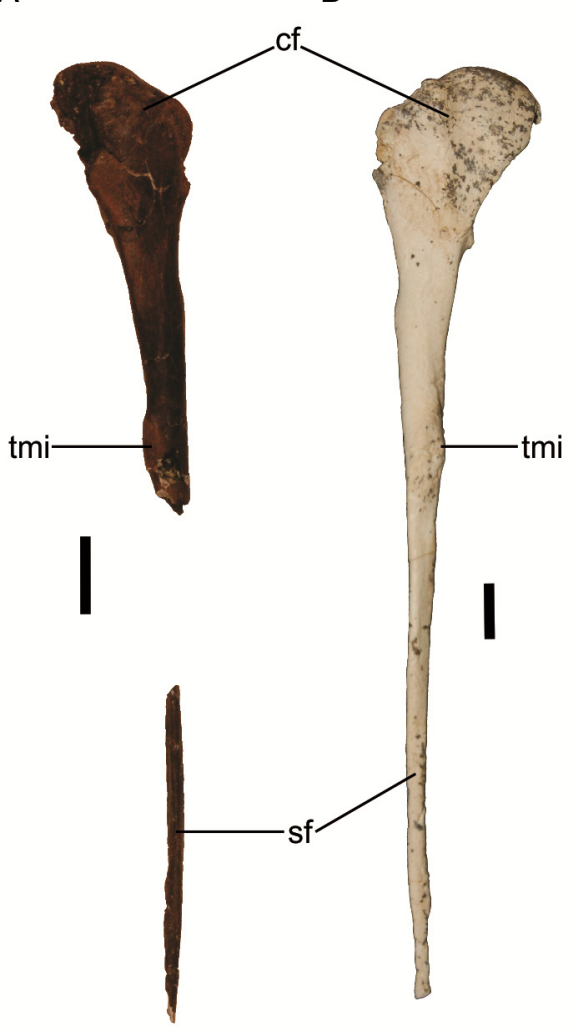

C

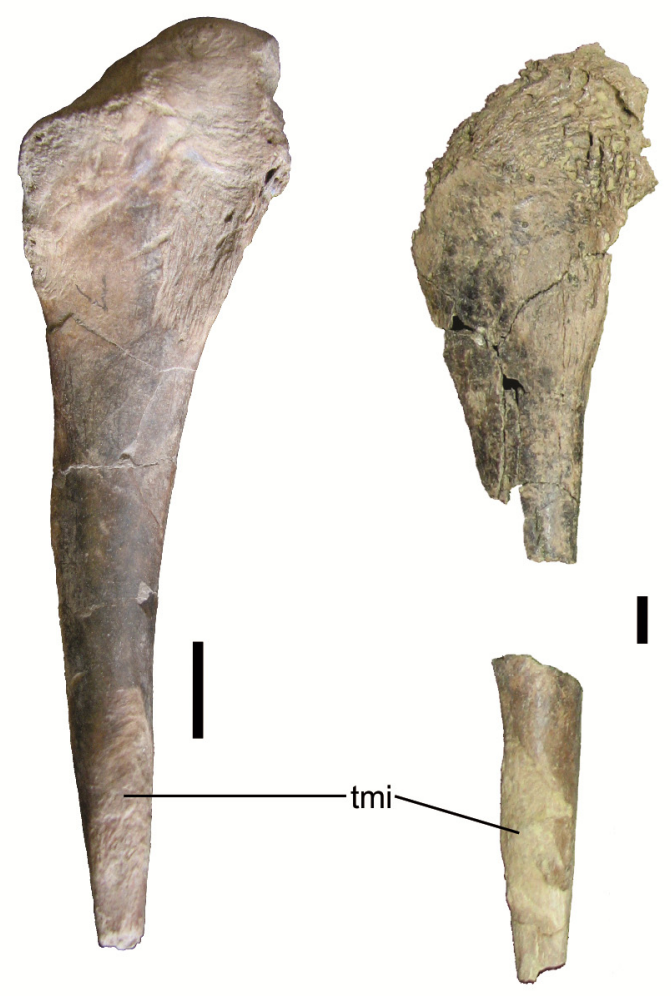

Figura 4.21. Fíbula de Phorusrhacidae. A, Psilopterus lemoinei MPM-PV3650, fíbula derecha; B, Taxón nuevo A MMP 5050, fíbula izquierda; C, Patagornis marshi AMNH 9254, fíbula izquierda; D, Phorusrhacos longissimus MPM-PV4241, fíbula izquierda. Abreviaturas: cf, caput fibulae; sf, spina fibulae; tmi, tuberculum m. iliofibularis. Escala $=1 \mathrm{~cm}$.

Figura 4.22. (Página siguiente) Hypotarsus de Phorusrhacidae, Cariama y Paleopsilopterus. A, Cariama cristata; B, Paleopsilopterus itaboraiensis; C, Psilopterus lemoinei; D, Procariama simplex; E, Taxón nuevo A; F, Mesembriornis milneedwardsi; G, Patagornis marshi; H, Phorusrhacos longissimus; I, Physornis fortis. A, D-F y H-I corresponden a hypotarsus izquierdos, mientras que B-C y G son derechos. Las áreas rayadas representan áreas faltantes. Abreviaturas: cl, cotyla lateralis; $\mathbf{c m}$, cotyla medialis; $\mathbf{c m p}$, crista medianoplantaris; ei, eminentia intercotylaris; fvp, foramina vascularia proximalia; hy, hypotarsus. Escala $=1 \mathrm{~cm}$. 
A
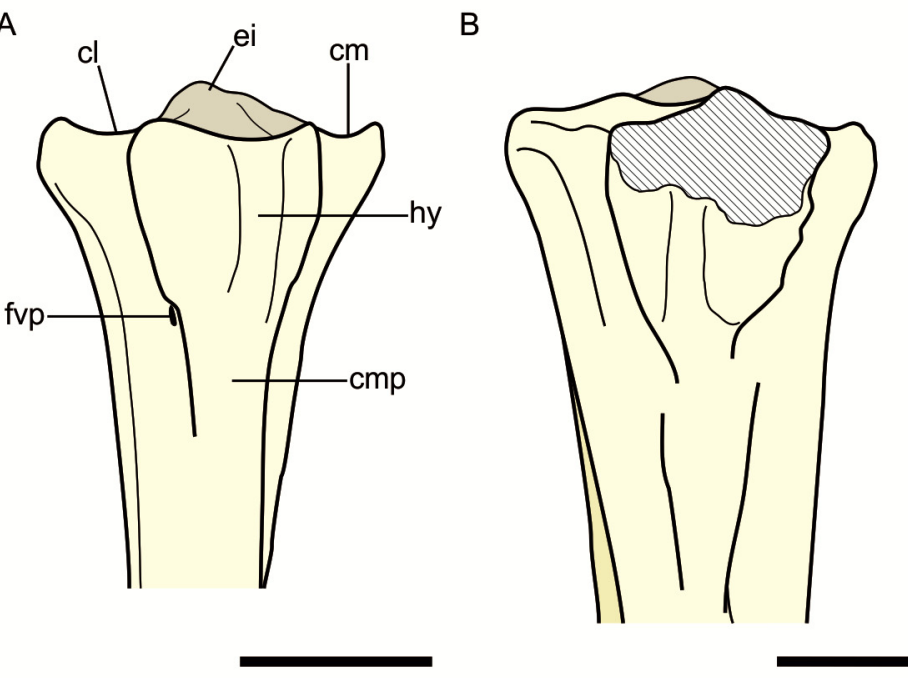

E
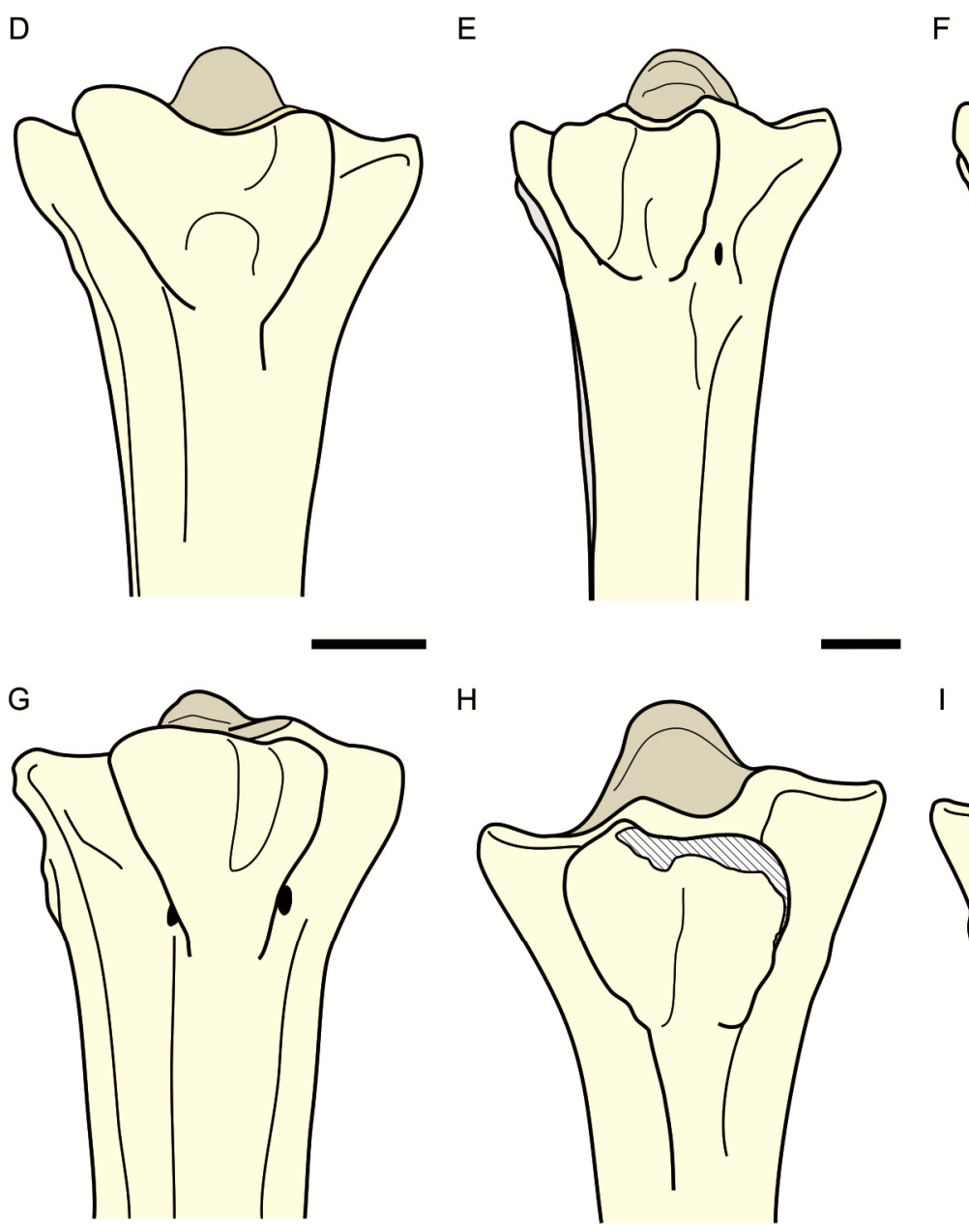

C

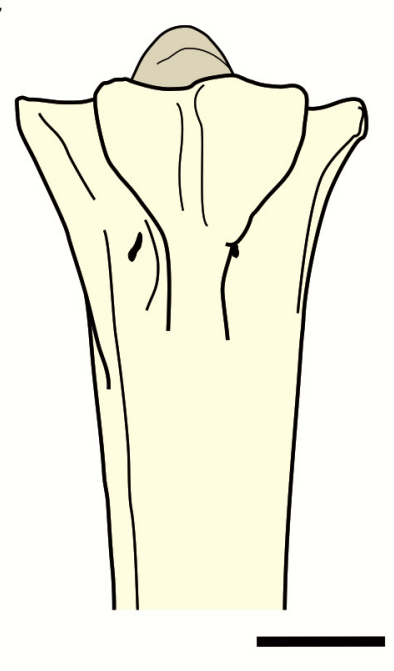

F
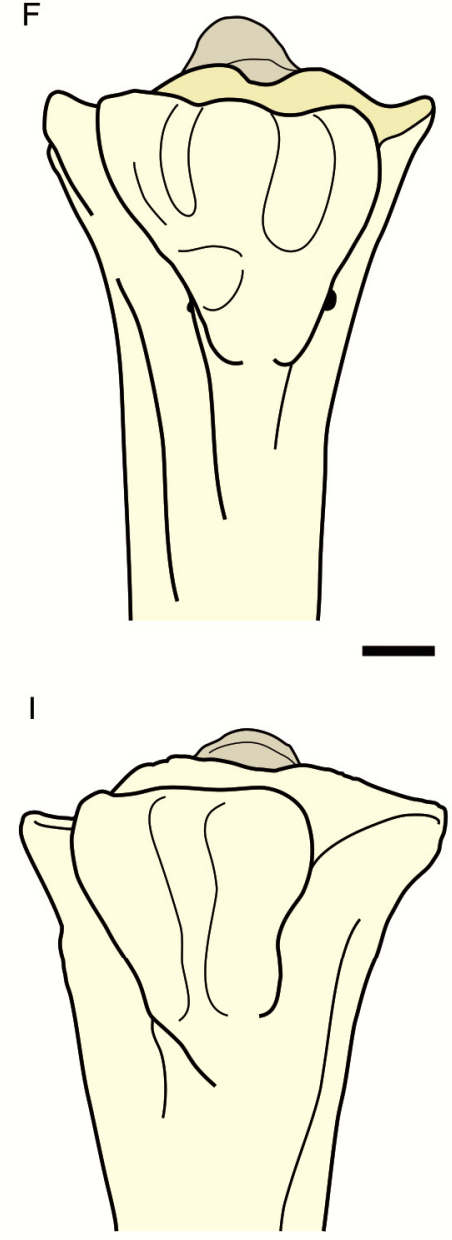

- 

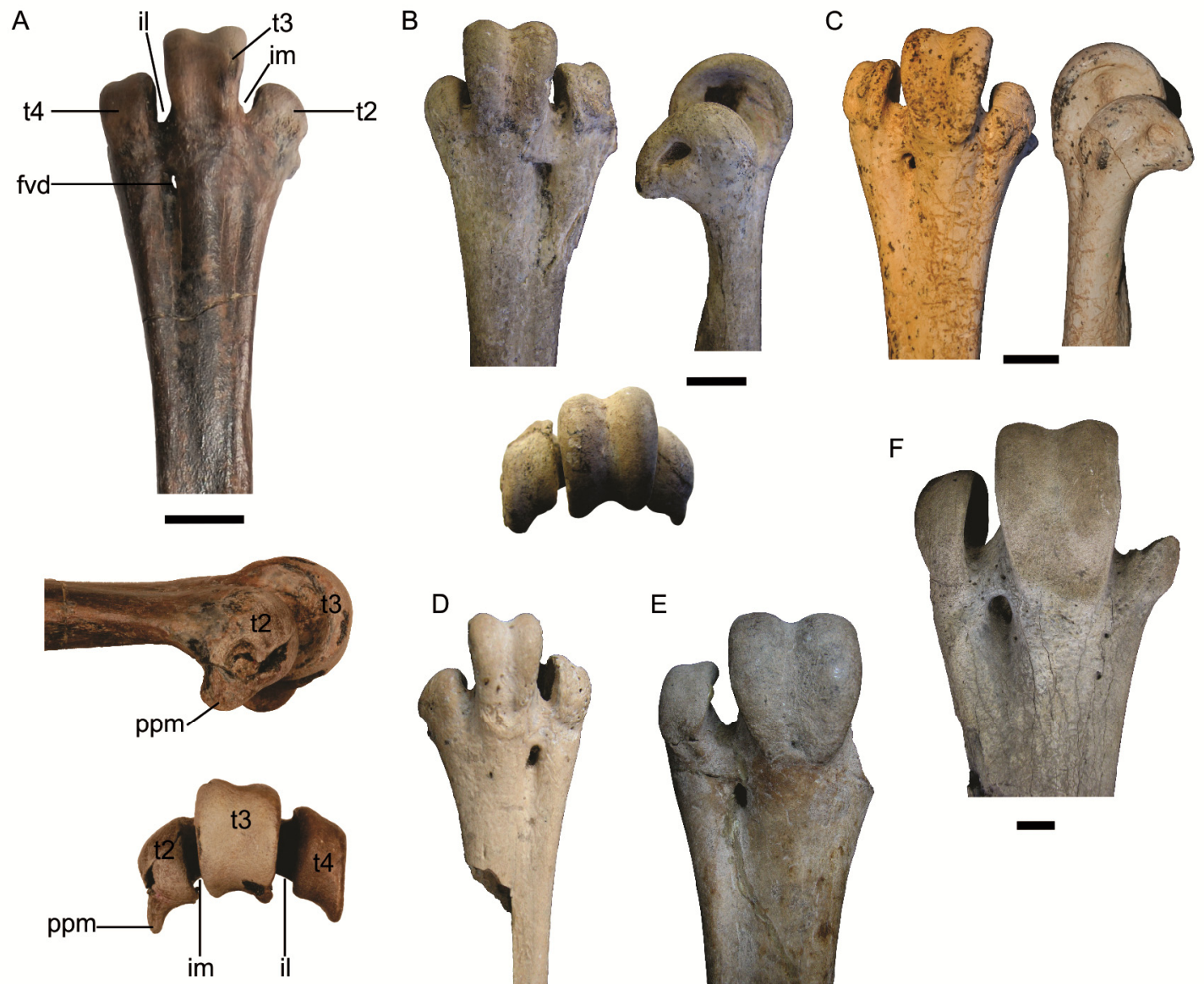

Figura 4.23. Extremo distal de tarsometatarso de Phorusrhacidae. A, Psilopterus lemoinei MPM-PV3650, tarsometatarso izquierdo; B, Procariama simplex FM-P14525, tarsometatarso derecho; C, Taxón nuevo A MMP 5050, tarsometatarso izquierdo; D, Psilopterus affinis MACN A 52-184, tarsometatarso derecho; E, Mesembriornis milneedwardsi MACN Pv 5944, tarsometatarso izquierdo; F, Phorusrhacos longissimus AMNH 9146, tarsometatarso izquierdo. Abreviaturas: fvd, foramen vasculare distale; il, incisura intertrochlearis lateralis; im, incisura intertrochlearis medialis; ppm, proceso posteromedial de la trochlea metatarsi II; $\mathrm{t} 2$, trochlea metatarsi II; $\mathrm{t} 3$, trochlea metatarsi III; $\mathrm{t} 4$, trochlea metatarsi $I V$. Escala $=1 \mathrm{~cm}$. 
A

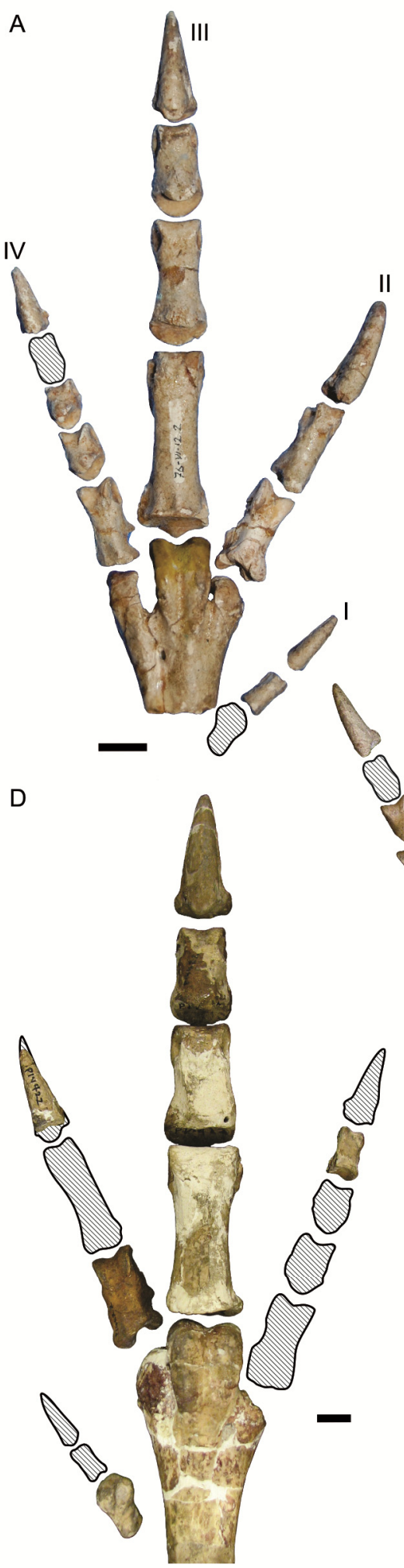

B

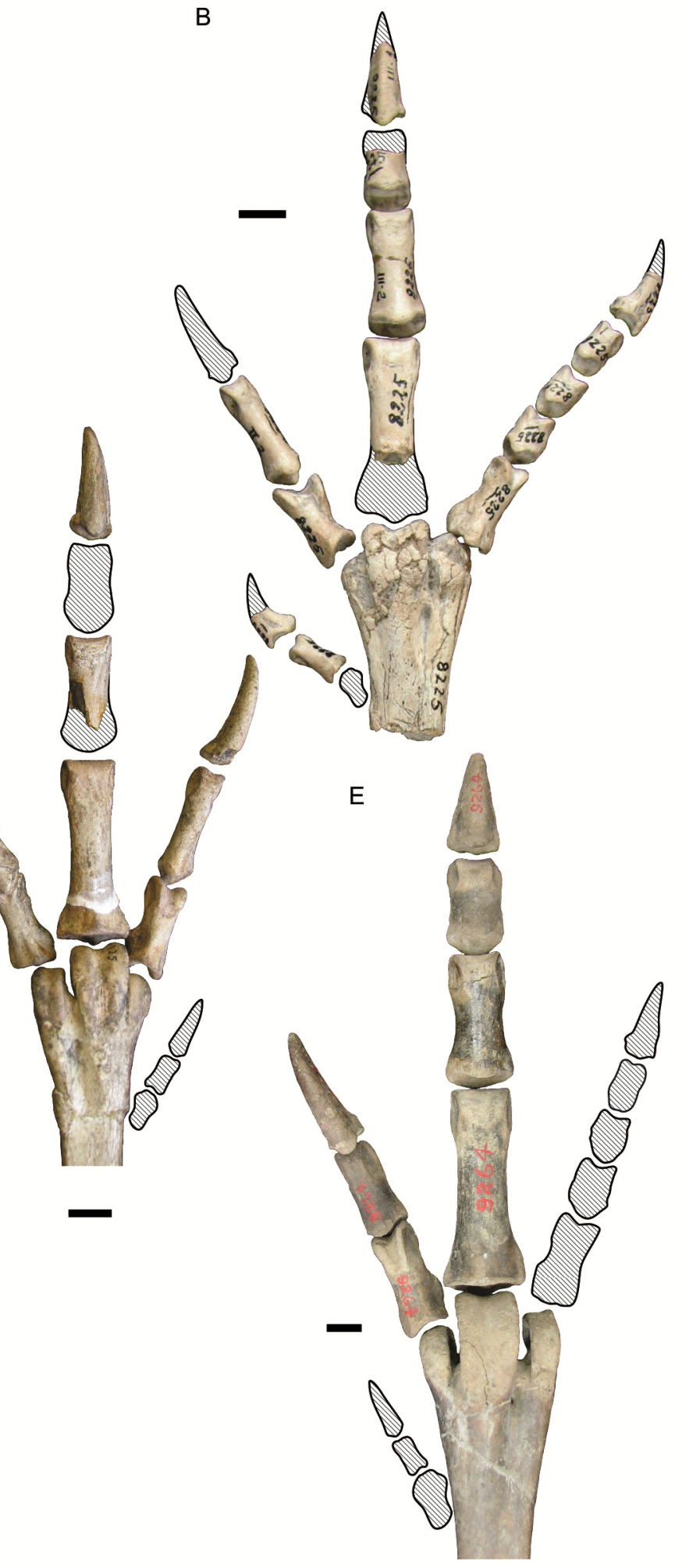

Figura 4.24. Pata de algunos Phorusrhacidae. A, Psilopterus colzecus MLP 76-VI-12-2; B, Procariama simplex MACN Pv 8225; C, Procariama simplex FM-P14525; D, Mesembriornis incertus FM-P14422; E, Patagornis marshi AMNH 9264. A y C son patas izquierdas, B y D-E son derechas. Las áreas rayadas representan áreas faltantes. Los números romanos en $\mathrm{A}$ indican el número de dedo. Escala $=1 \mathrm{~cm}$. 
A

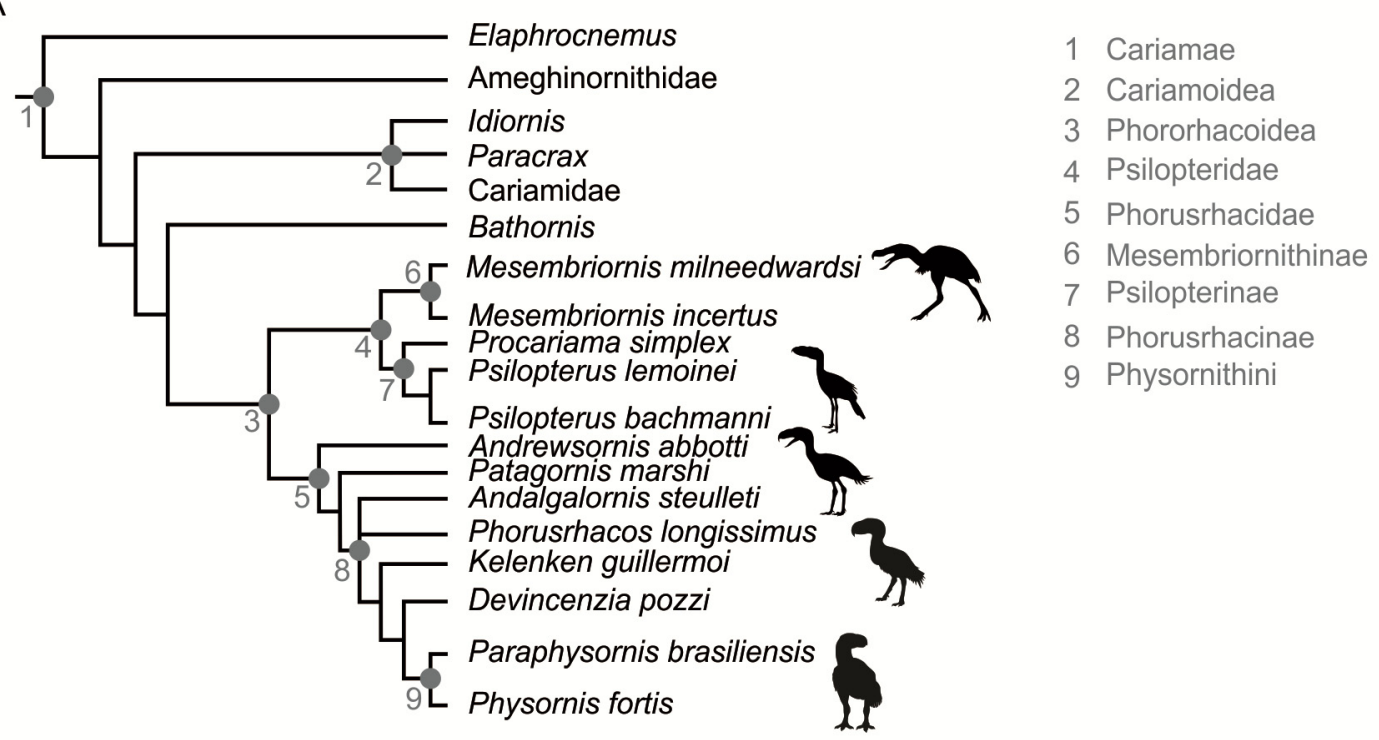

B

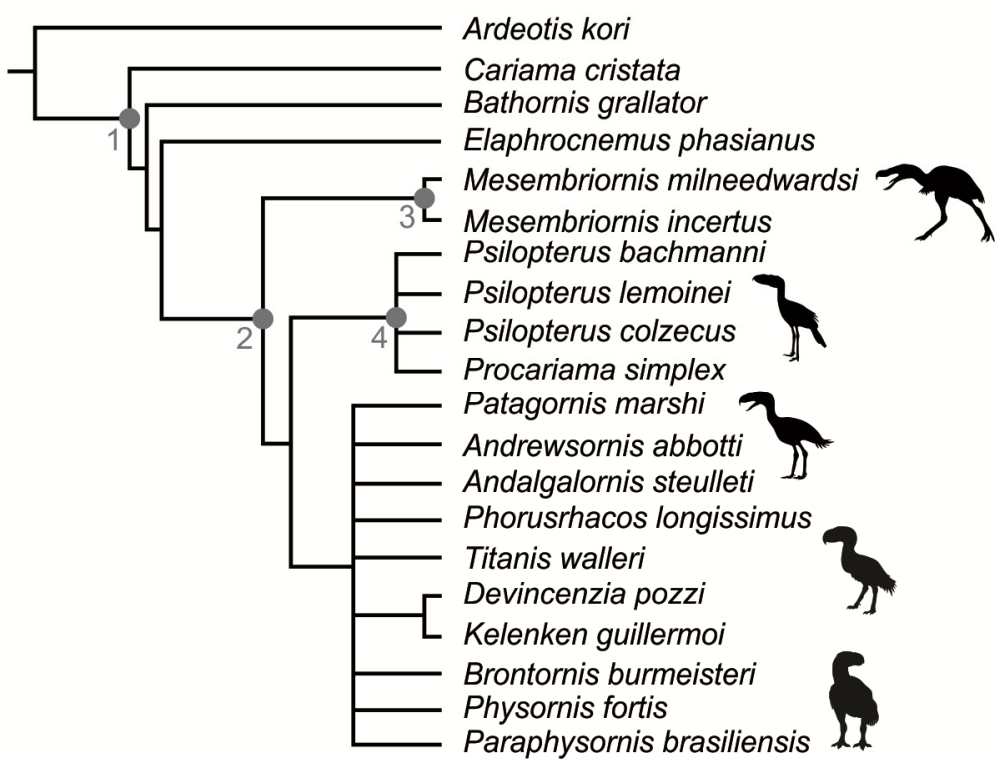

1 Cariamae

2 Phorusrhacidae

3 Mesembriornithinae

4 Psilopterinae

Figura 5.1. Propuestas filogenéticas de los Phorusrhacidae. A, Agnolín (2009); B, Alvarenga et al. (2011). 


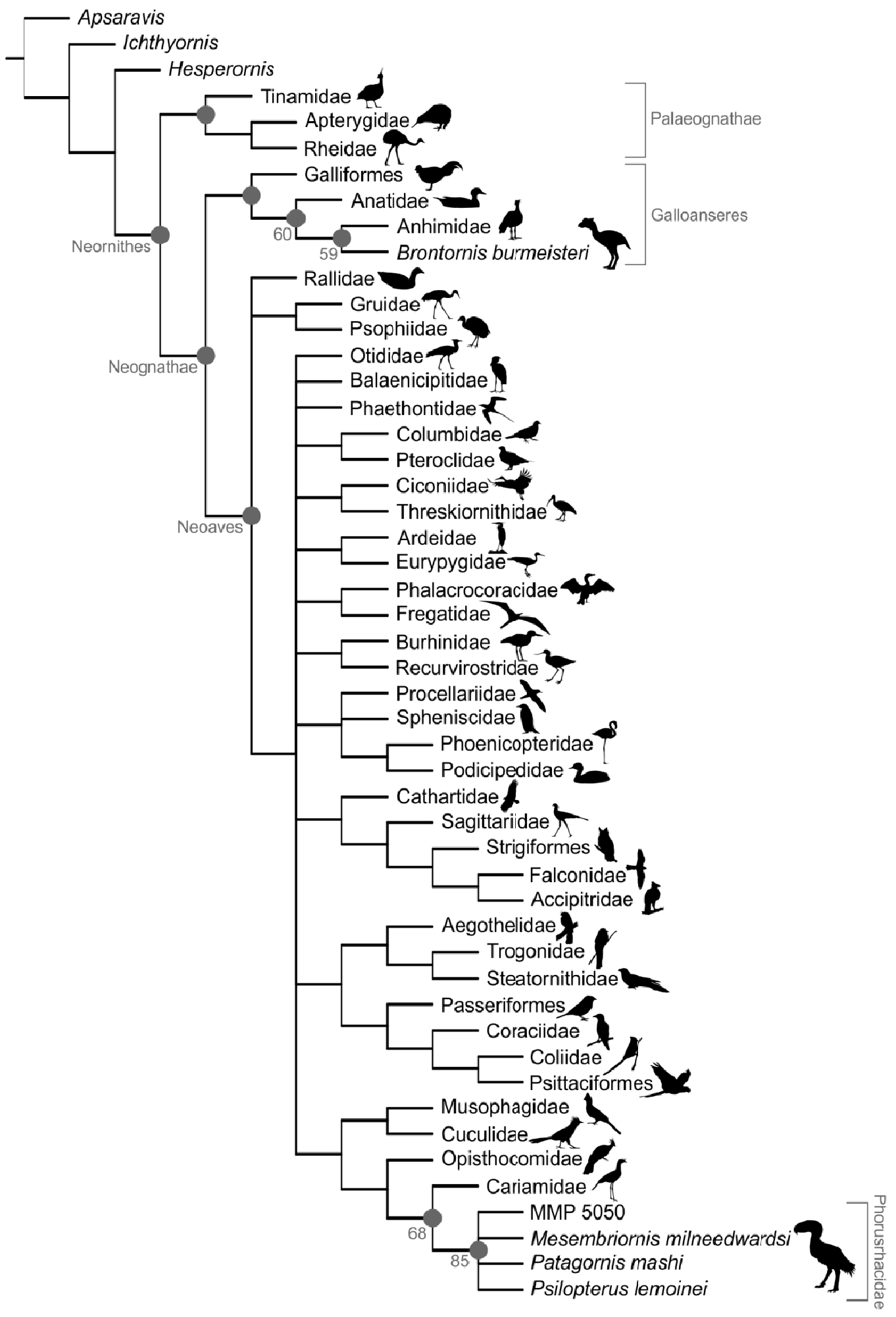

Figura 5.2. Árbol consenso resultado del análisis de la matriz de caracteres de Mayr y Clarke (2003), con la adición de cuatro especies de Phorusrhacidae y el Anseriformes Brontornis. Los caracteres 55, 71 y 91 se codificaron como ordenados y se excluyó del análisis a los Gaviidae. Longitud $=806$ pasos, $\mathrm{CI}=0,20596, \mathrm{RI}=0,45399$. 
A

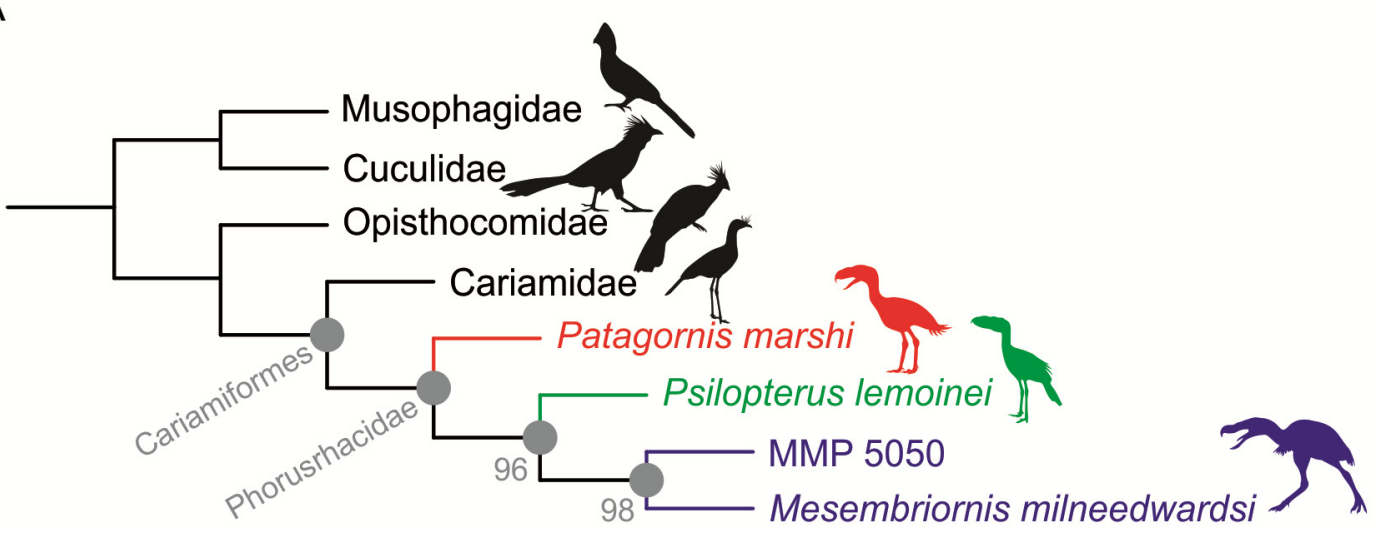

B

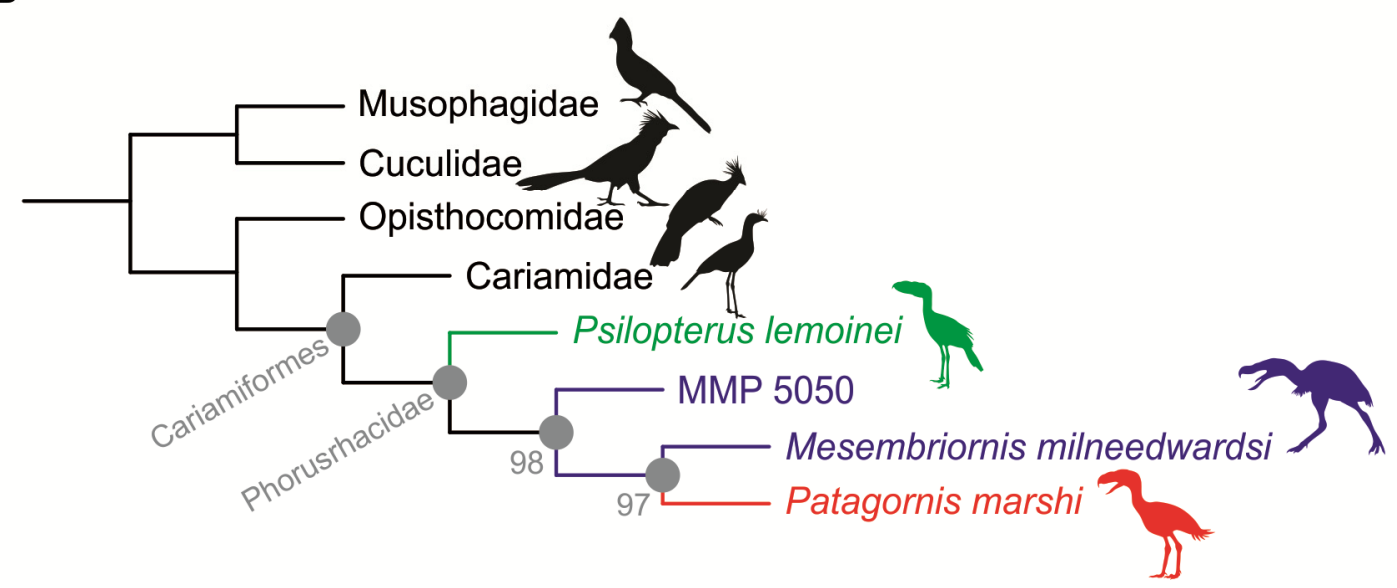

Figura 5.3. Hipótesis sobre las relaciones intrafamiliares de los Phorusrhacidae. A, Mesembriornithinae + Psilopterus constituyen un grupo monofilético y Patagornis constituye una forma más basal; B, Psilopterus + Mesembriornithinae constituyen un grupo parafilético, basal y hermano de Patagornis marshi que representaría una forma derivada. Los números corresponden a los números de nodo (véase el texto). 
A

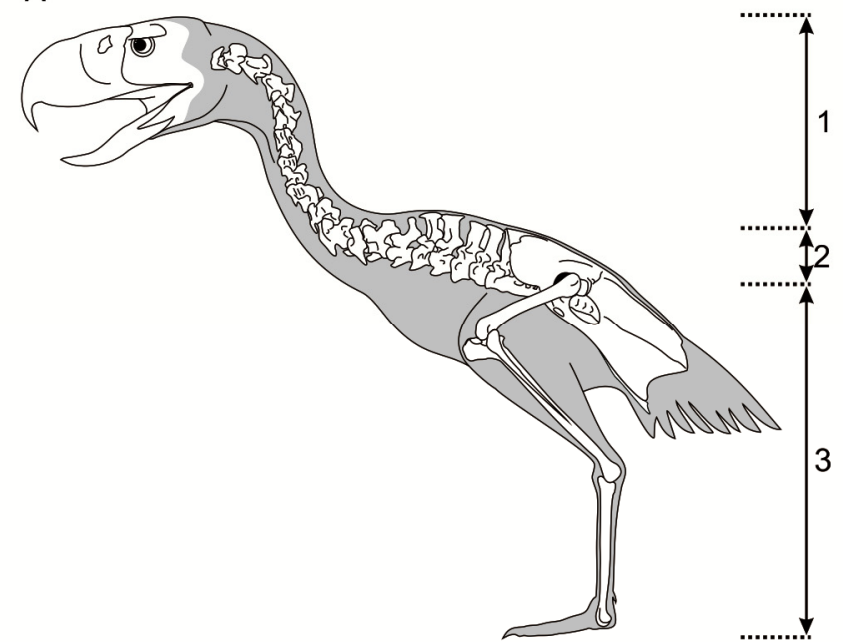

B

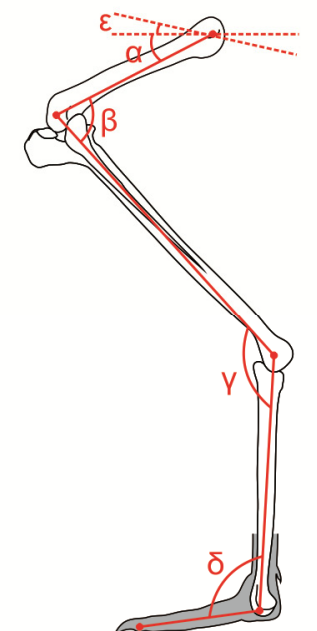

Figura 6.1. Cálculo de altura y postura de los fororracos. A, cálculo de altura; B, postura de los miembros. $1=$ alto del cuello y cabeza; $2=$ alto de la pelvis; $3=$ alto del miembro posterior, $\alpha$ = ángulo fémur - horizontal, $\beta=$ ángulo fémur - tibiotarso, $\gamma=$ ángulo tibiotarso - tarsometatarso, $\delta$ = ángulo tarsometatarso - falanges, $\varepsilon=$ ángulo de la pelvis - horizontal. 

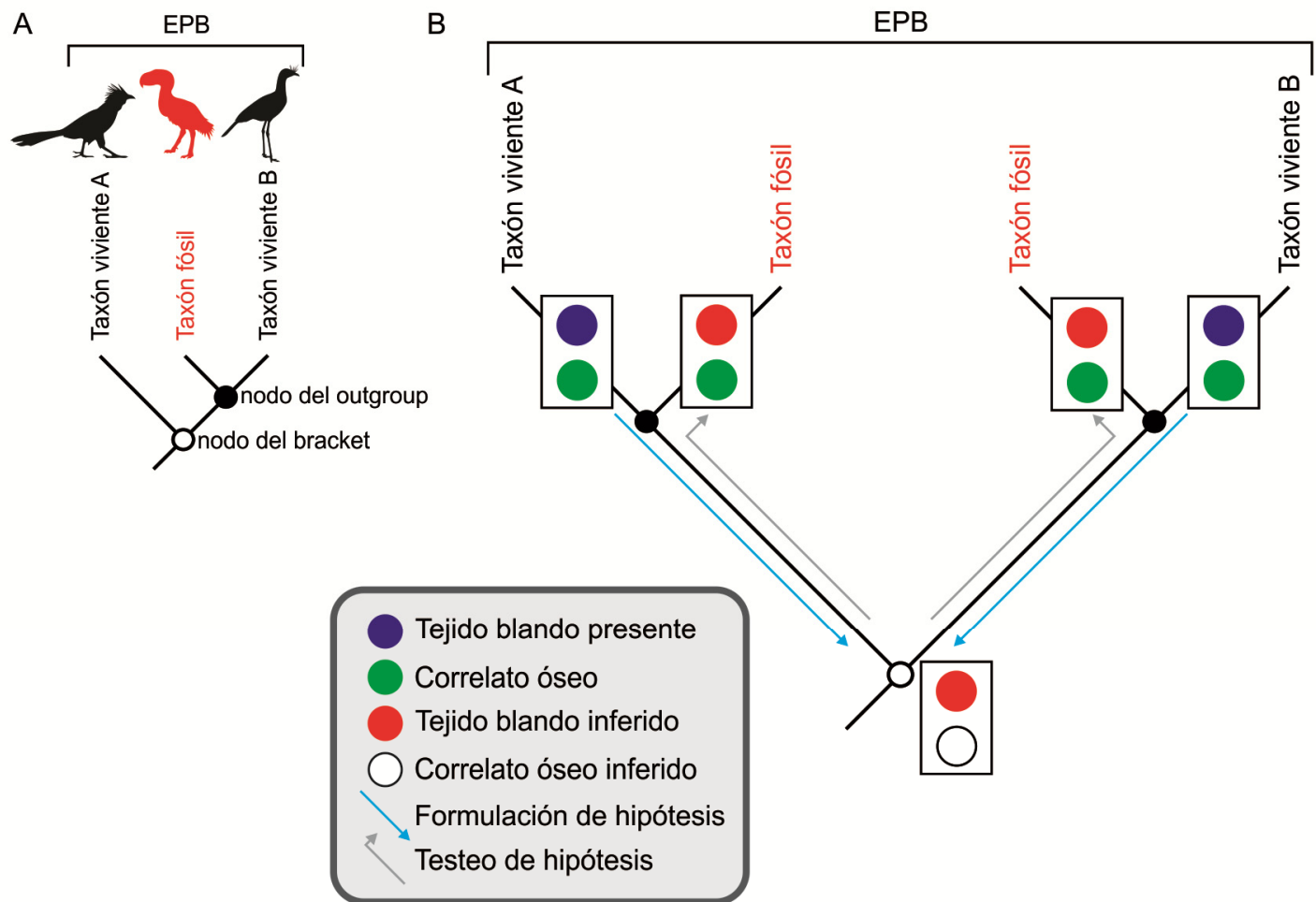

Figura 7.1. Extant Phylogenetic Bracket (EPB). A, relaciones filogenéticas del taxón fósil de interés y sus grupos hermanos vivientes más próximos. $\mathrm{B}$, formulación y testeo de hipótesis mediante EPB. La presencia de tejidos blando en los taxones actuales es hipotetizada como presente en su ancestro común (flechas celestes). Si los taxa fósiles poseen el correlato osteológico, la hipótesis de homología se acepta (flechas grises) y se infiere la presencia de los tejidos blando en las formas fósiles. Modificado de Witmer (1995b, 1997). 
A

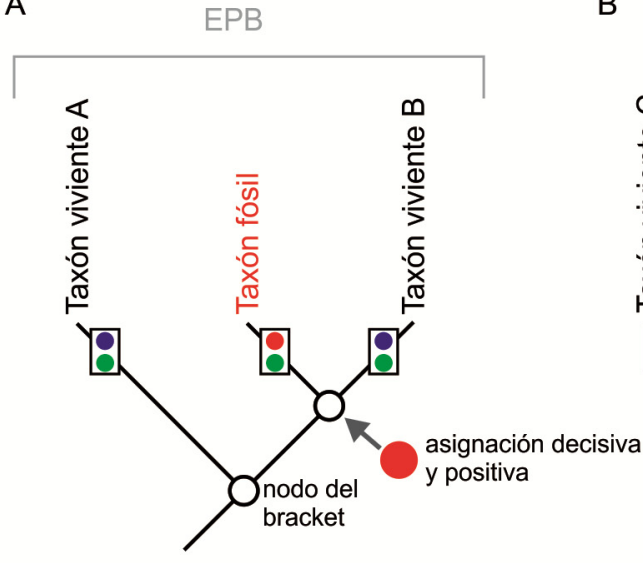

nivel de inferencia I

C

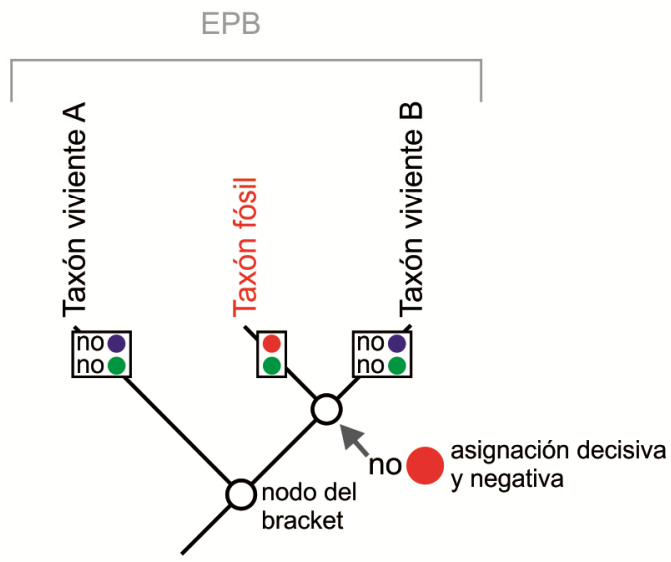

nivel de inferencia III

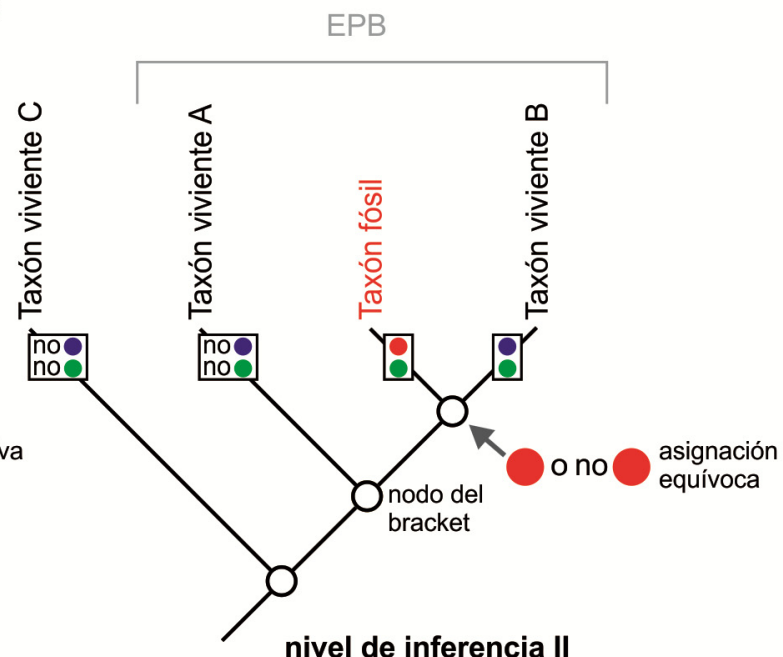

nivel de inferencia II

Correlato óseo

Tejido blando inferido

Figura 7.2. Niveles de inferencia del EPB. A, nivel I: asignación decisiva y positiva, cuando ambos grupos actuales poseen el carácter blando (y su correspondiente correlato óseo) inferido en el taxón fósil; B, nivel II: asignación equívoca, cuando sólo uno de los grupos actuales posee el atributo blando; C, nivel III: asignación decisiva y negativa, cuando ninguna de las formas actuales posee el tejido blando. Modificado de Witmer (1995b, 1997). 

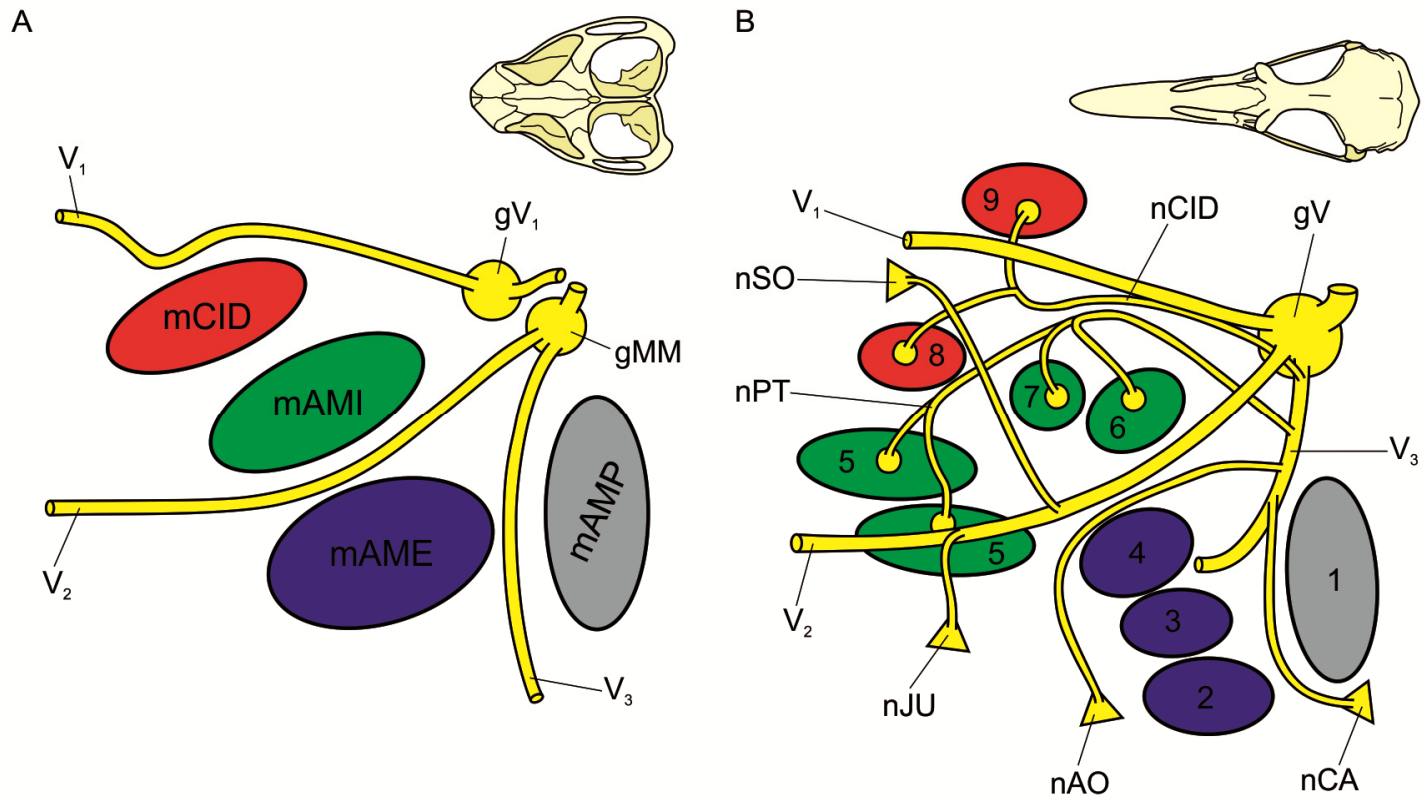

Figura 7.3. Organización neuromuscular de la cámara aductora de los diápsidos en vista dorsal. A, principales grupos musculares definidos de acuerdo a su posición respecto del nervio trigémino en Sphenodon; B, patrón topológico de los músculos individuales y nervios en las Neornithes. Abreviaturas: $\mathbf{g V}$, ganglio trigémino; gV1, ganglio oftálmico; gMM, ganglio maxillomandibular; mAME, M. adductor mandibulae externus; mAMI, M. adductor mandibulae internus; mAMP, M. adductor mandibulae posterior; mCID, M. constrictor internus dorsalis; nAO, ramus anguli oris del nervio maxilar; nCA, ramus caudal del nervio mandibular; nCID, rama motora del nervio mandibular que inerva los músculos derivados del M. constrictor internus dorsalis; $\mathbf{n J U}$, rama jugal del nervio maxilar; nPT, rama pterigoidea del nervio mandibular; nSO, rama supraorbital del nervio maxilar; $\mathbf{V}_{\mathbf{1}}$, nervio oftálmico; $\mathbf{V}_{\mathbf{2}}$, nervio maxilar; $\mathbf{V}_{\mathbf{3}}$, nervio mandibular; $\mathbf{1}$, M. adductor mandibulae posterior; 2, M. adductor mandibulae externus superficialis; $\mathbf{3}$, M. adductor mandibulae externus medialis; 4, M. adductor mandibulae externus profundus; 5, M. pterygoideus (ventralis y dorsalis); 6, M. pseudotemporalis superficialis; 7, M. pseudotemporalis profundus; 8 , M. protractor pterygoideus et quadrati; 9, M. tensor periorbitae. Modificado de Holliday y Witmer (2007).

Figura 7.4. (Página siguiente) Músculos mandibulares de Neornithes. A, Guira guira; B, Chauna torquata; C, Geranoaetus melanoleucus. Abreviaturas: amep, M. adductor mandibulae externus profundus; ames, $M$. adductor mandibulae externus superficialis; amp, M. adductor mandibulae posterior; dm, M. depressor mandibulae; pqt, $\mathrm{M}$. protractor pterygoideus et quadrati; psp, M. pseudotemporalis profundus; pss, $\mathrm{M}$. pseudotemporalis superficialis; ptd, M. pterygoideus dorsalis; ptv, M. pterygoideus ventralis; Ipo, ligamentum postorbitale. 

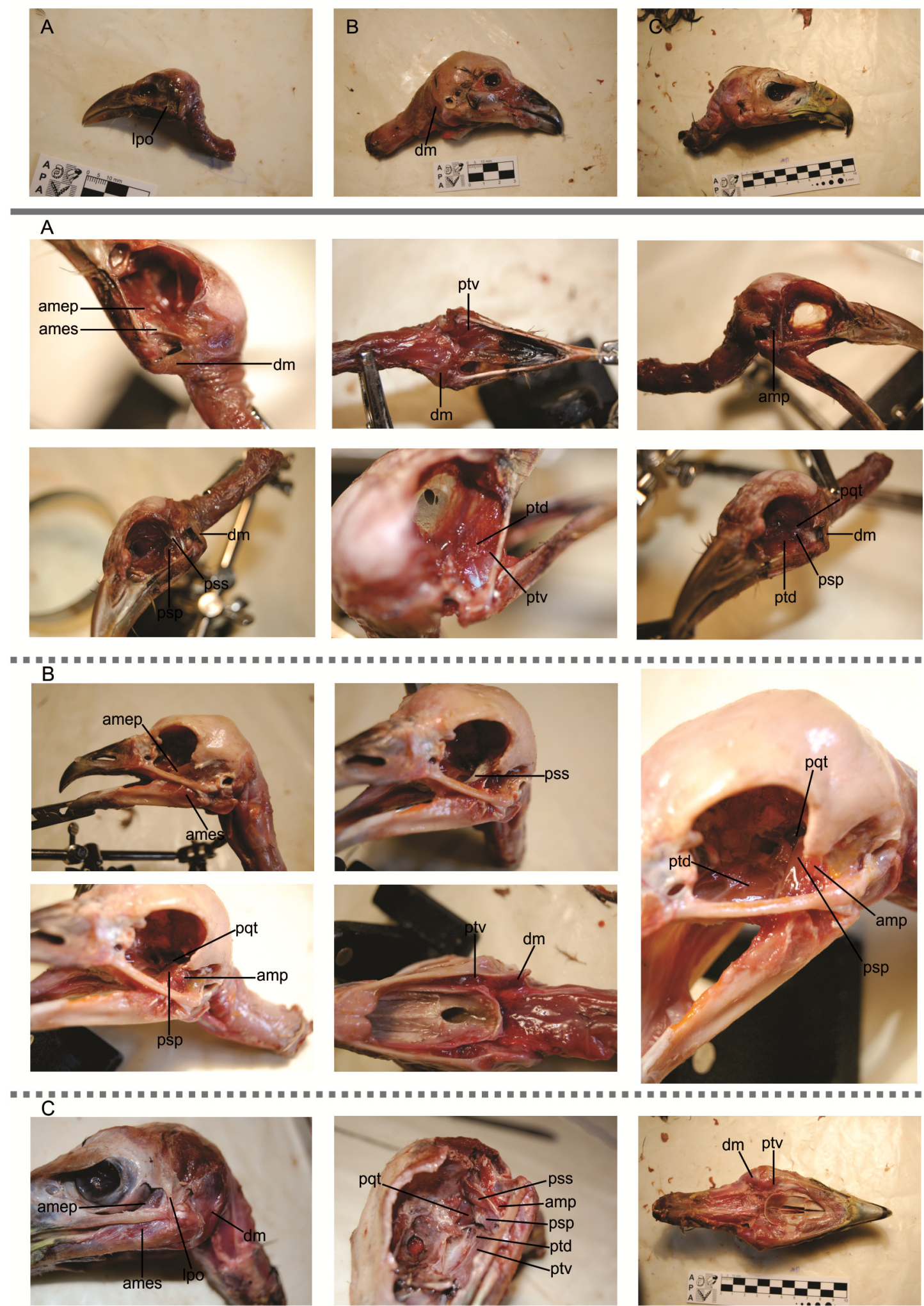

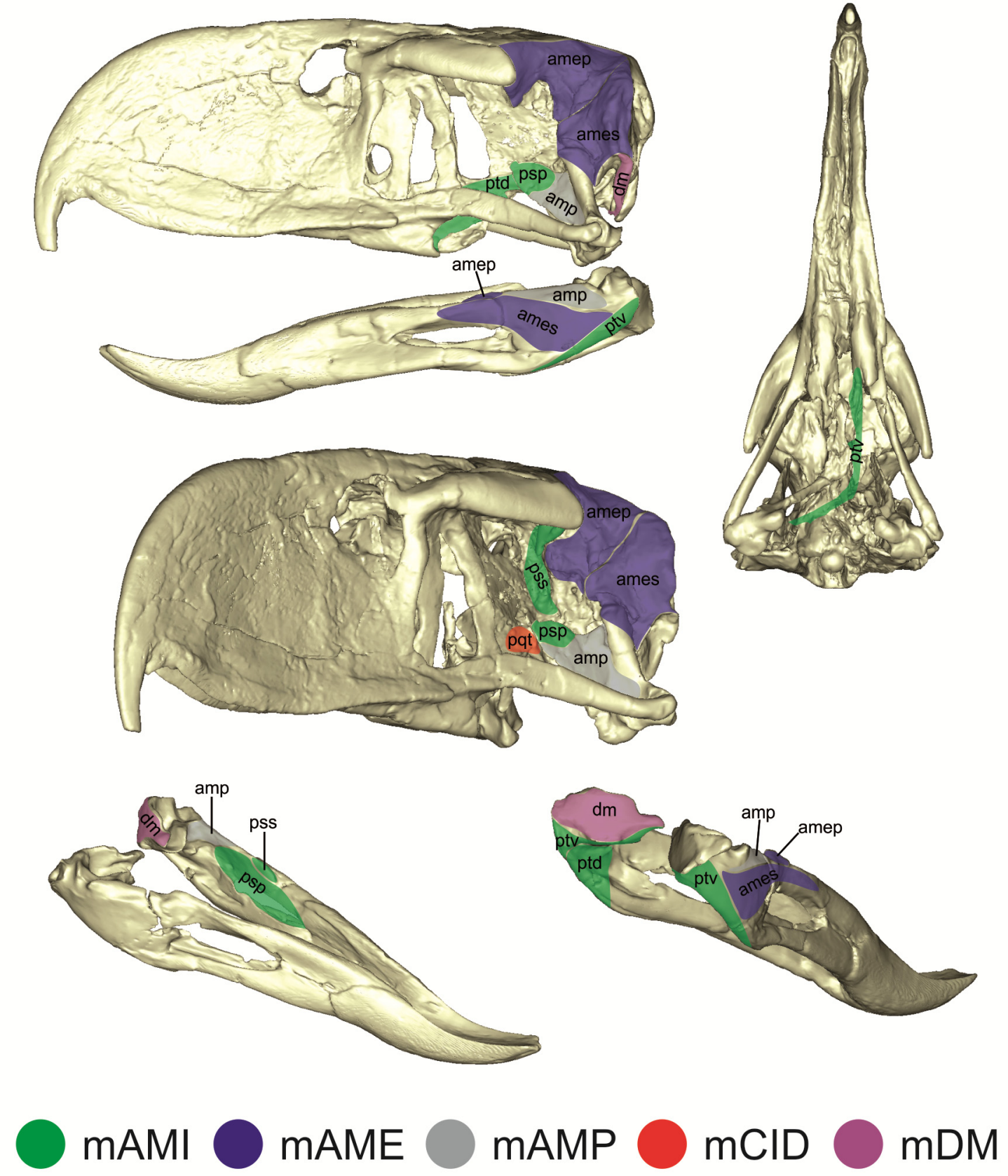

Figura 7.5. Sitios de origen e inserción de la musculatura mandibular de Andalgalornis steulleti. Abreviaturas: mAME, M. adductor mandibulae externus; mAMI, M. adductor mandibulae internus; mAMP, M. adductor mandibulae posterior; mCID, M. constrictor internus dorsalis; mDM, musculatura depresora, amep, M. adductor mandibulae externus profundus; ames, M. adductor mandibulae externus superficialis; amp, M. adductor mandibulae posterior; pqt, $\mathrm{M}$. protractor pterygoideus et quadrati; psp, $\mathrm{M}$. pseudotemporalis profundus; pss, M. pseudotemporalis superficialis; ptd, M. pterygoideus dorsalis; ptv, M. pterygoideus ventralis. 
A

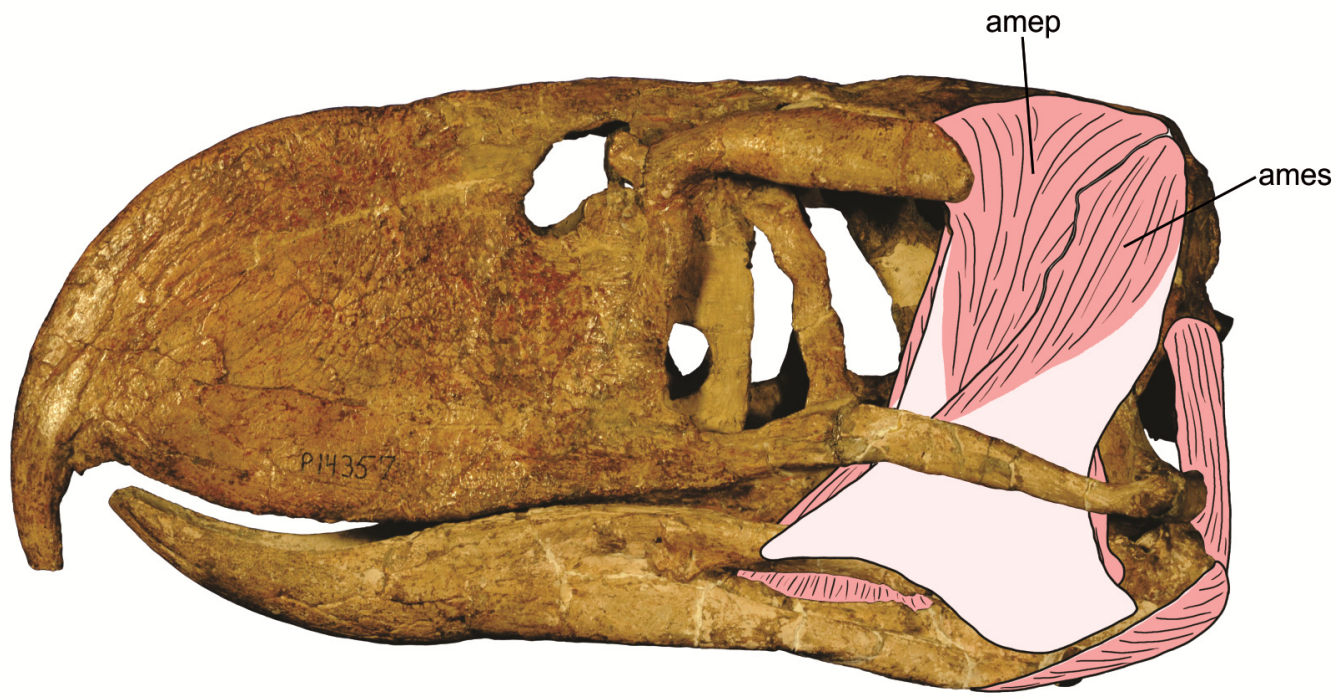

B

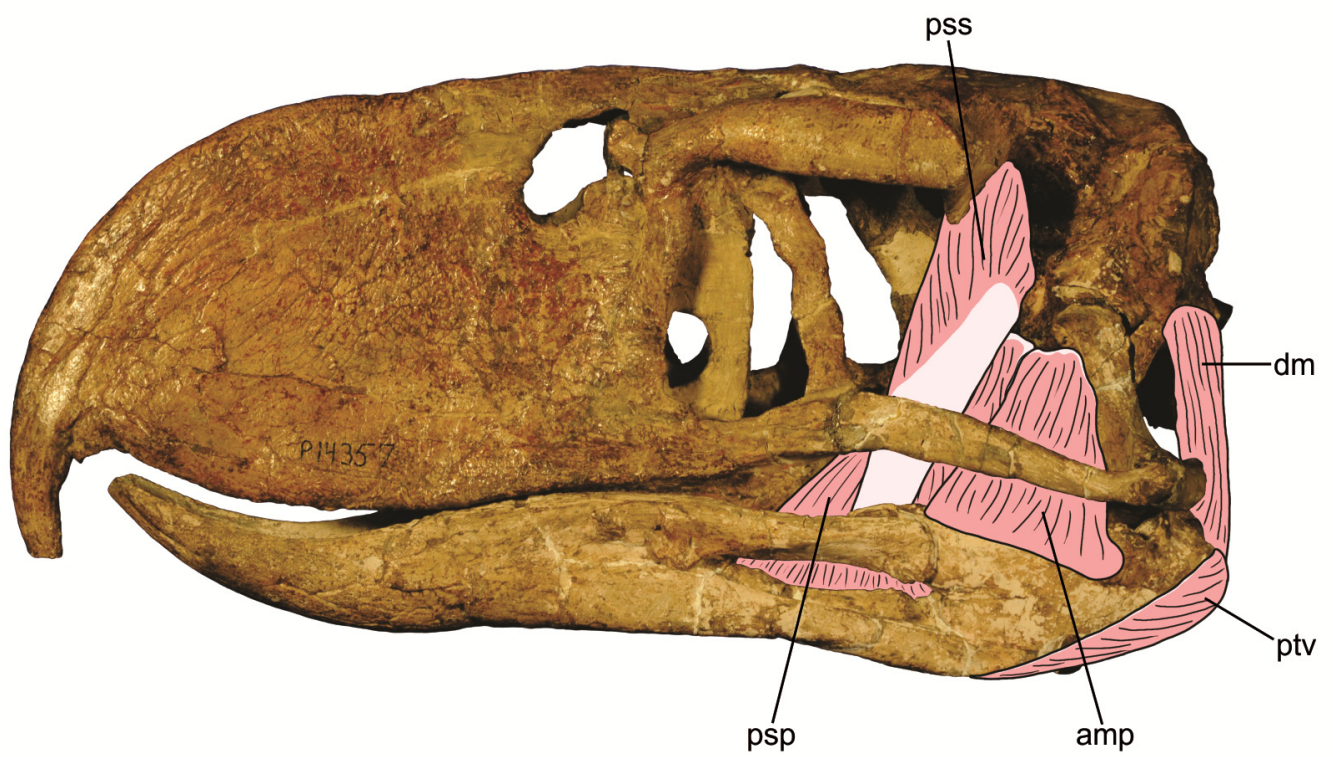

Figura 7.6. Anatomía de la musculatura mandibular de Andalgalornis steulleti. A, músculos superficiales; $\mathrm{B}$, músculos profundos. Abreviaturas: amep, $\mathrm{M}$. adductor mandibulae externus profundus; ames, $M$. adductor mandibulae externus superficialis; amp, M. adductor mandibulae posterior; pqt, M. protractor pterygoideus et quadrati; psp, M. pseudotemporalis profundus; pss, M. pseudotemporalis superficialis; ptv, M. pterygoideus ventralis. 
A
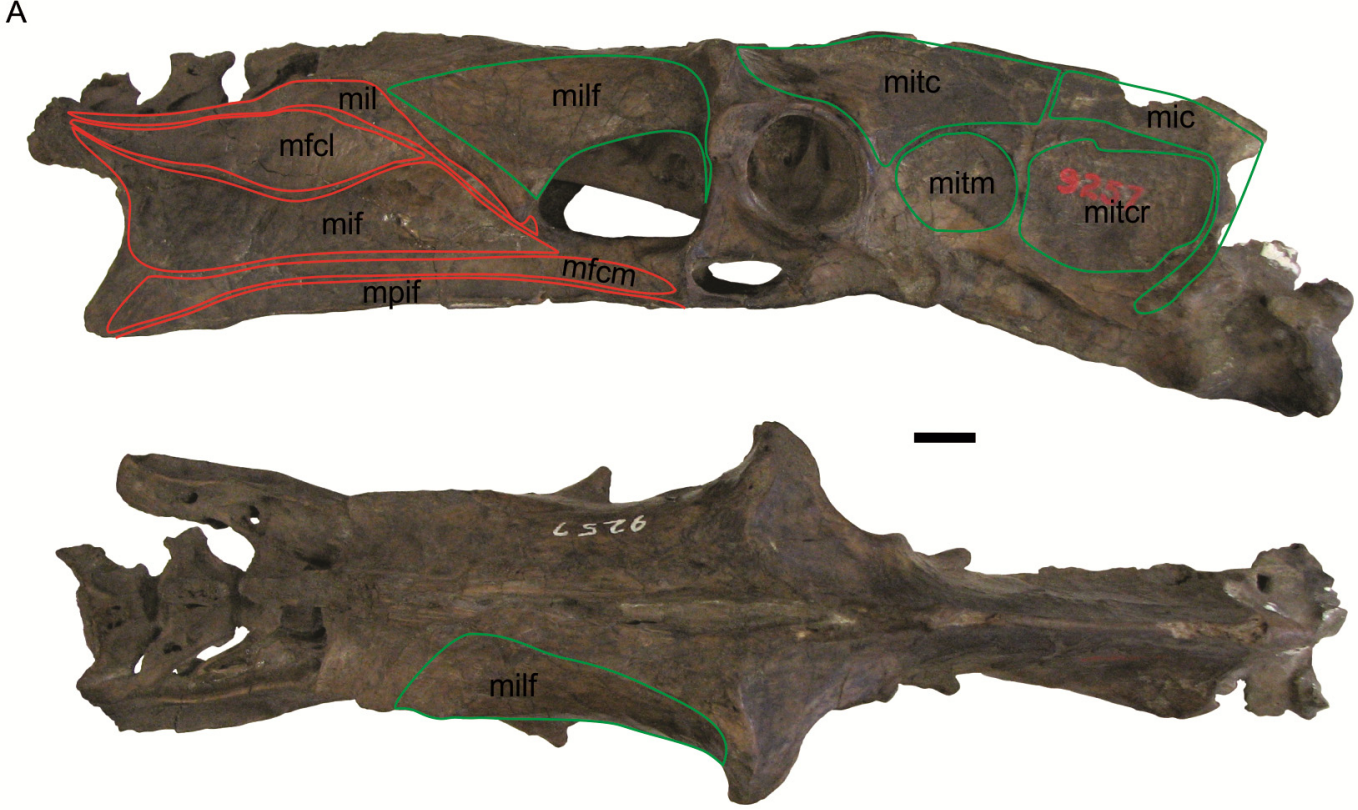

B

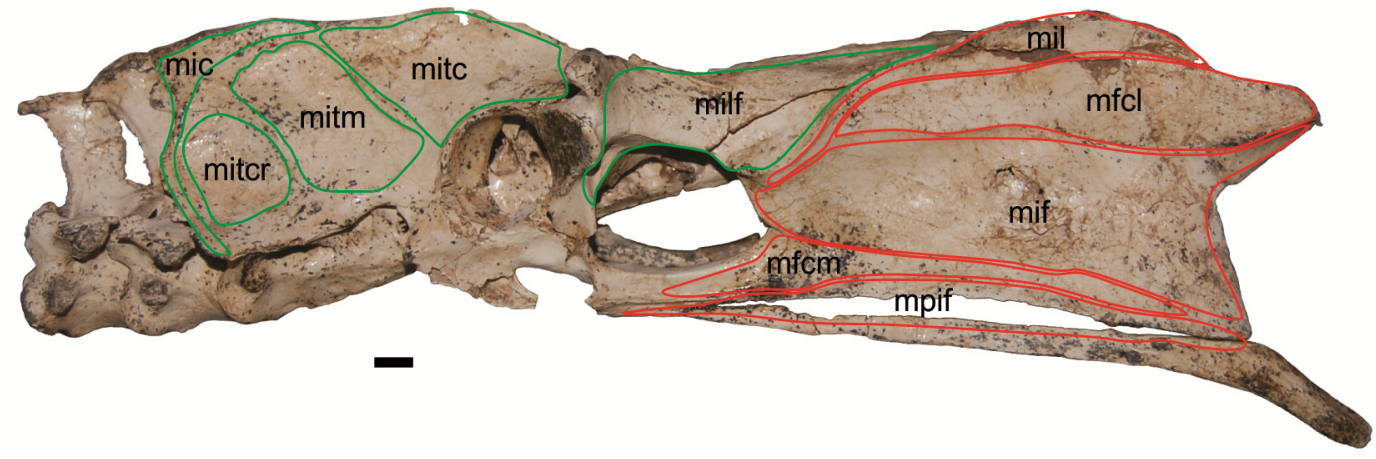

Figura 7.7. Sitios de origen de la musculatura apendicular en la pelvis de los fororracos. A, Psilopterus lemoinei AMNH 9257 en vista lateral derecha y dorsal; B, Taxón nuevo A MMP 5050 en vista lateral izquierda. Musculatura extensora en rojo y flexora en verde. Abreviaturas: $\mathbf{m f c l}, \mathbf{m}$. flexor cruris lateralis; $\mathbf{m f c m}, \mathbf{m}$. flexor cruris medialis; mic, m. iliotibialis cranialis; mif, m. ischiofemoralis; mil, m. iliotibialis lateralis; milf, m. iliofibularis; mitc, m. iliotrochantericus caudalis; mitcr, m. iliotrochantericus cranialis; mitm, m. iliotrochantericus medialis; mpif, m. puboischiofemoralis. Escala = $1 \mathrm{~cm}$. 

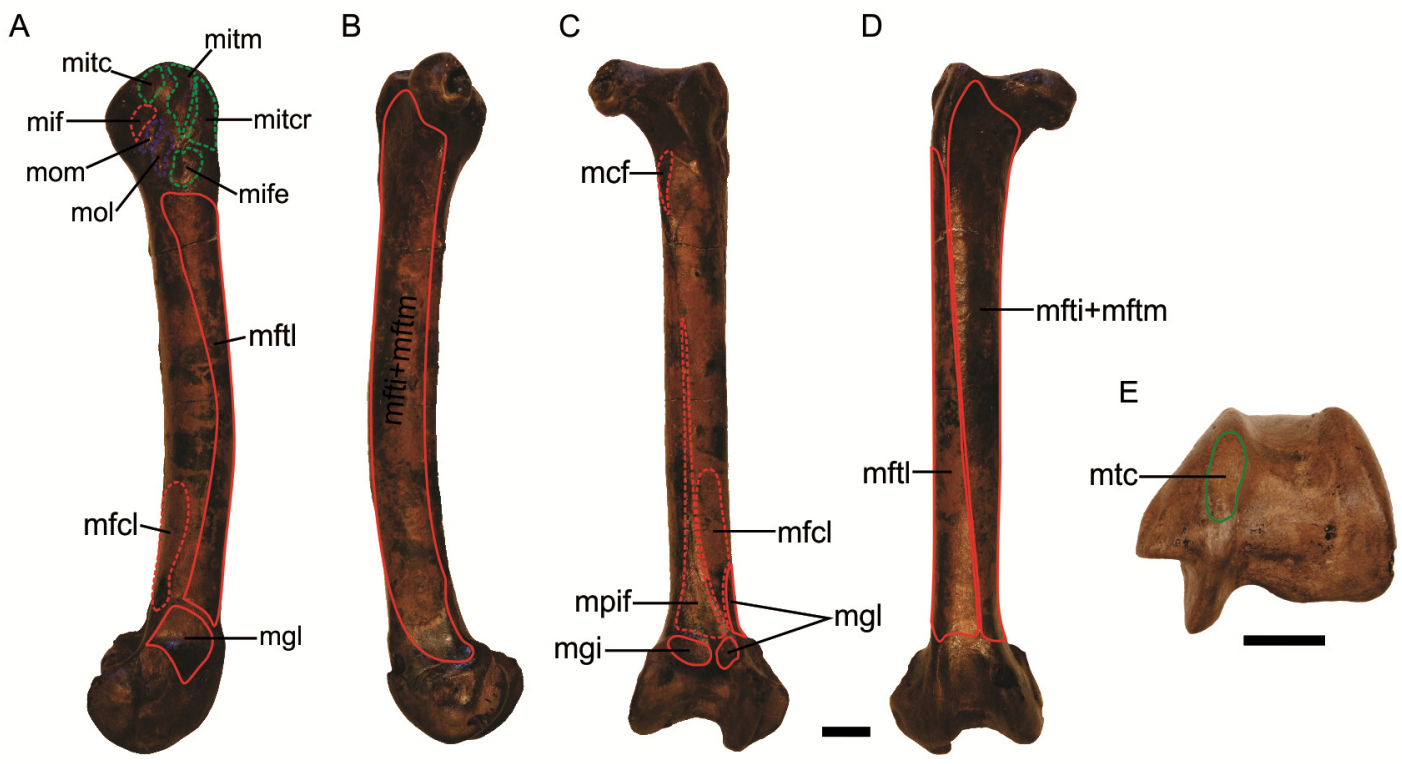

Figura 7.8. Sitios de origen e inserción de la musculatura apendicular en el fémur de Psilopterus lemoinei AMNH 9257. A, vista lateral; B, vista medial; C, vista caudal; D, vista craneal; E, vista distal. Musculatura extensora en rojo, flexora en verde y rotadora en azul; origen, línea continua; inserción, línea discontinua. Abreviaturas: mcf, m. caudofemoralis; mfcl, $\mathbf{m}$. flexor cruris lateralis; mfti, m. femorotibialis intermedius; mftl, m. femorotibialis lateralis; mftm, m. femorotibialis medialis; mgi, m. gastrocnemius pars intermedia; mgl, m. gastrocnemius pars lateralis; mif, m. ischiofemoralis; mife, m. iliofemoralis externus; mitc, m. iliotrochantericus caudalis; mitcr, m. iliotrochantericus cranialis; mitm, m. iliotrochantericus medialis; mol, m. obturatorius lateralis; mom, m. obturatorius medialis; mpif, m. puboischiofemoralis; mtc, $\mathrm{m}$. tibialis cranialis. Escala $=1 \mathrm{~cm}$.

Figura 7.9. (Página siguiente) Sitios de origen e inserción de la musculatura apendicular en el tibiotarso, fíbula y tarsometatarso de Psilopterus lemoinei AMNH 9257. A-E, vistas caudal, craneal, medial, lateral y proximal del tibiotarso; F-H, vistas caudal, craneal y medial del tarsometatarso; H-I, vista lateral y medial de la fíbula. Musculatura extensora en rojo, flexora en verde y de función desconocida en negro; origen, línea continua; inserción, línea discontinua. Abreviaturas: medl, m. extensor digitorum longus; mehl, $\mathrm{m}$. extensor hallucis longus; $\mathbf{m f c m}, \mathrm{m}$. flexor cruris medialis; mfdl, $\mathrm{m}$. flexor digitorum longus; $\mathbf{m f l}$, $\mathrm{m}$. fibularis longus; $\mathbf{m f t i}, \mathrm{m}$. femorotibialis intermedius; $\mathbf{m f t l}, \mathbf{m}$. femorotibialis lateralis; $\mathbf{m f t m}, \mathbf{m}$. femorotibialis medialis; $\mathbf{m g}, \mathbf{m}$. gastrocnemius; mgm, m. gastrocnemius pars medialis; mic, m. iliotibialis cranialis; mil, m. iliotibialis lateralis; milf, m. iliofibularis; mp, m. popliteus; mtc, m. tibialis cranialis. Escala $=1 \mathrm{~cm}$. 
A

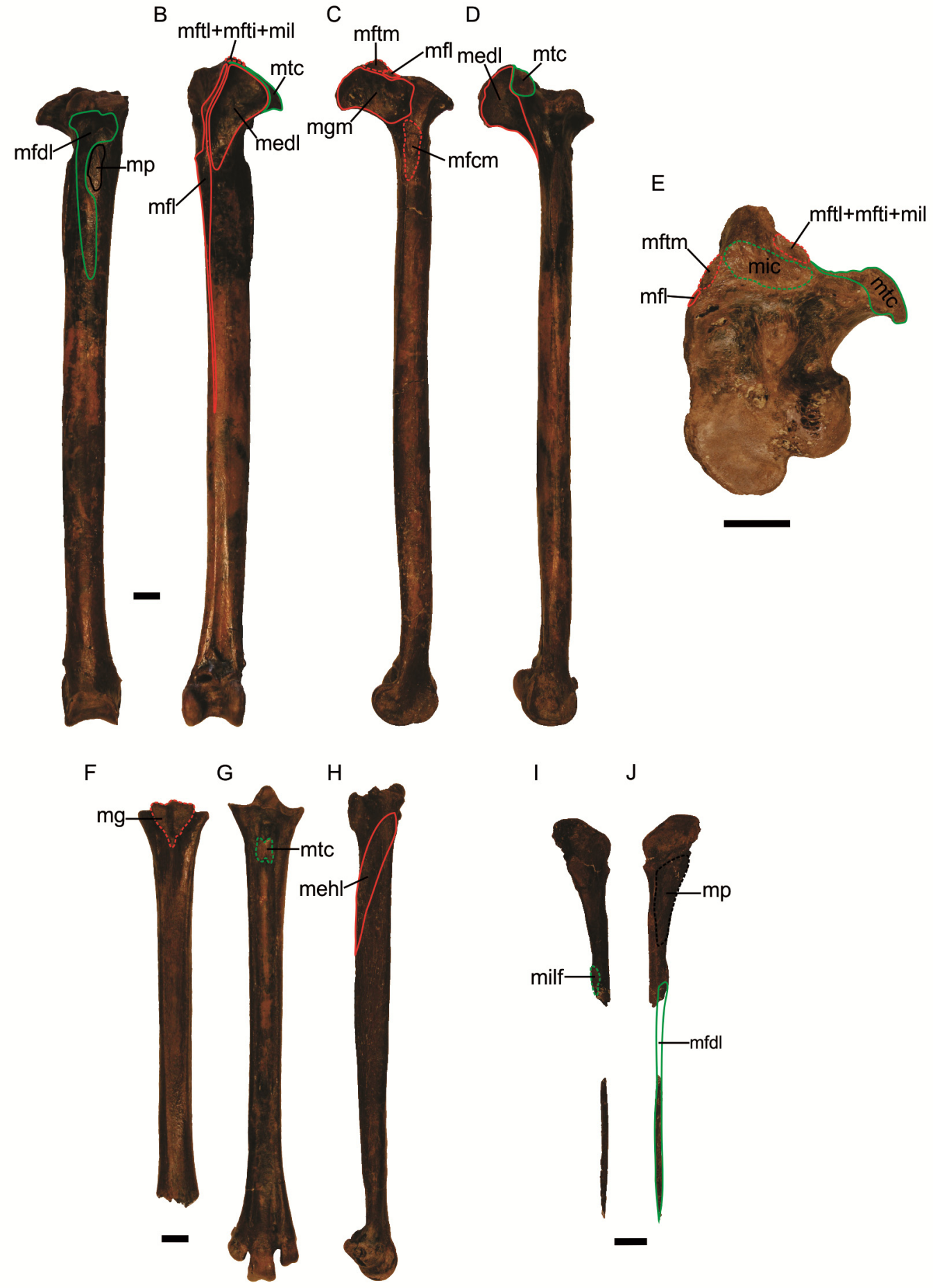


A

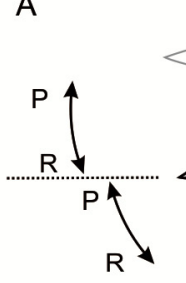

C

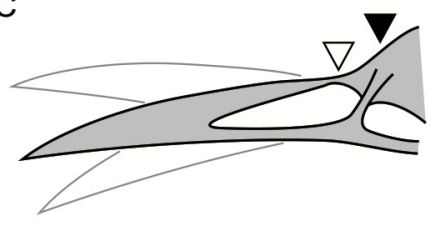

$\mathrm{F}$

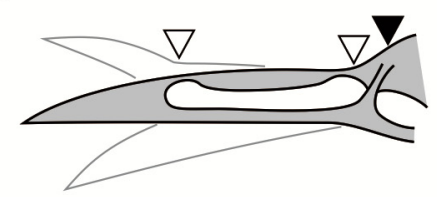

B

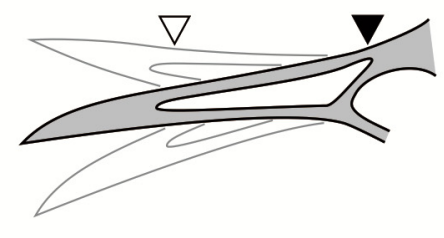

$\mathrm{E}$
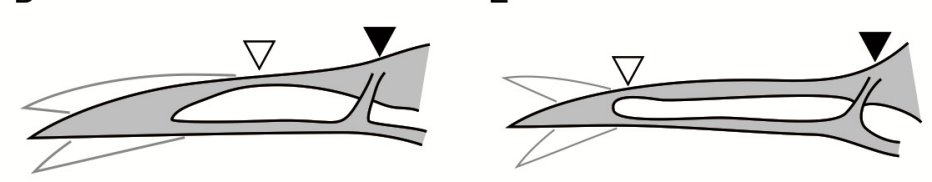

G

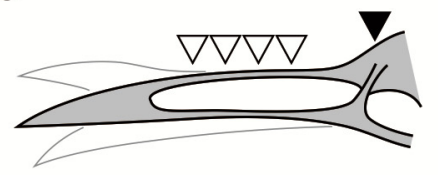

Figura 8.1. Quinesis craneana de los Neornithes: Tipos. A, proquinesis; B, anfiquinesis; $\mathrm{C}$, rincoquinesis proximal; $\mathrm{D}$, rincoquinesis central; $\mathrm{E}$, rincoquinesis distal; $\mathrm{F}$, rincoquinesis doble; G, rincoquinesis extensiva. Abreviaturas: P, protracción; R, retracción. Los triángulos negros señalan la zona flexoria craniofascialis, mientras que los triángulos vacíos señalan zonas flexorias adicionales. Modificado de Zusi (1984) y Gussekloo (2000). 


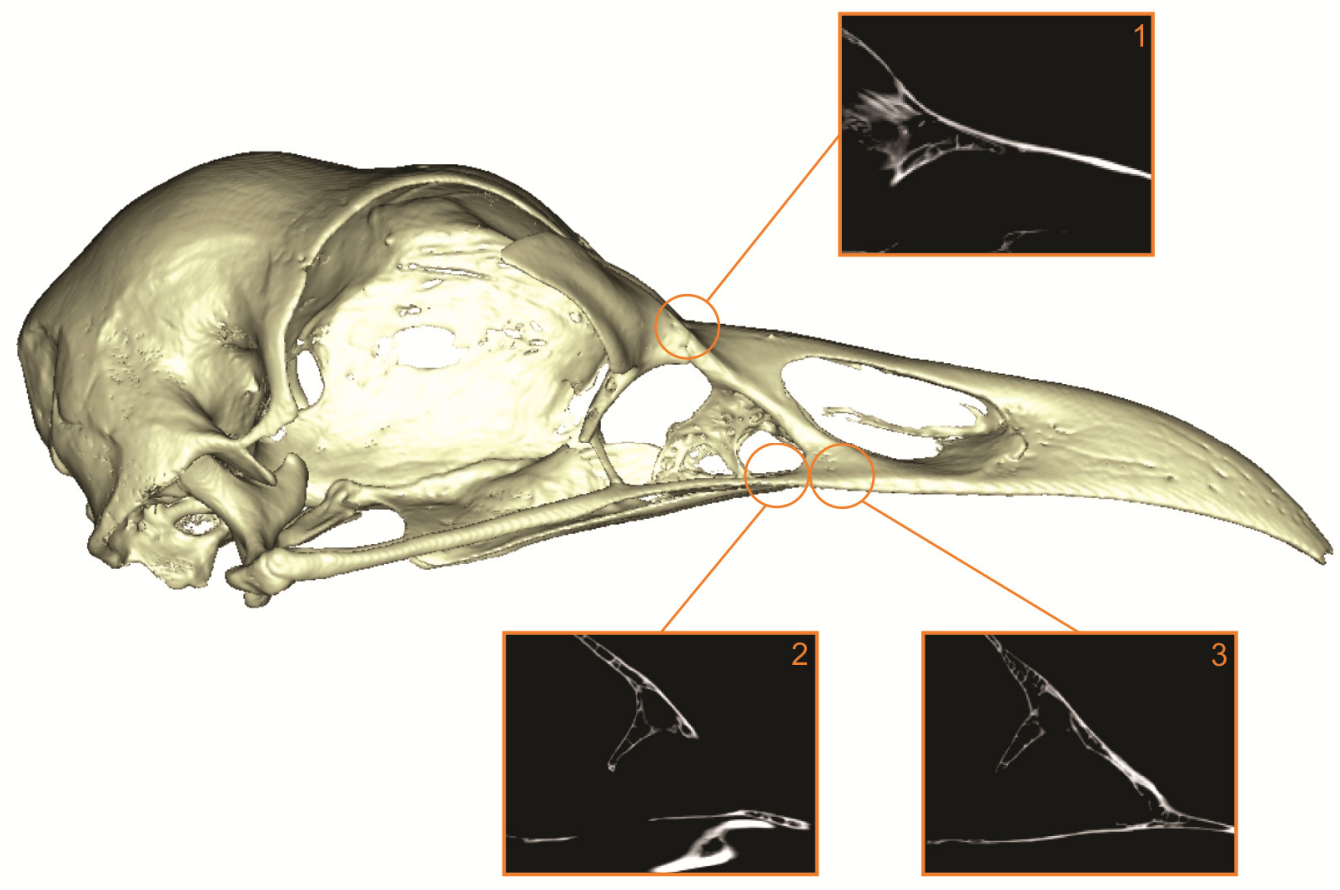

Figura 8.2. Quinesis craneana de los Neornithes: Zonas flexorias de Cariama cristata. 1, zona flexoria craniofascialis; 2, zona flexoria arcus jugalis; 3 , zona flexoria palatina. 


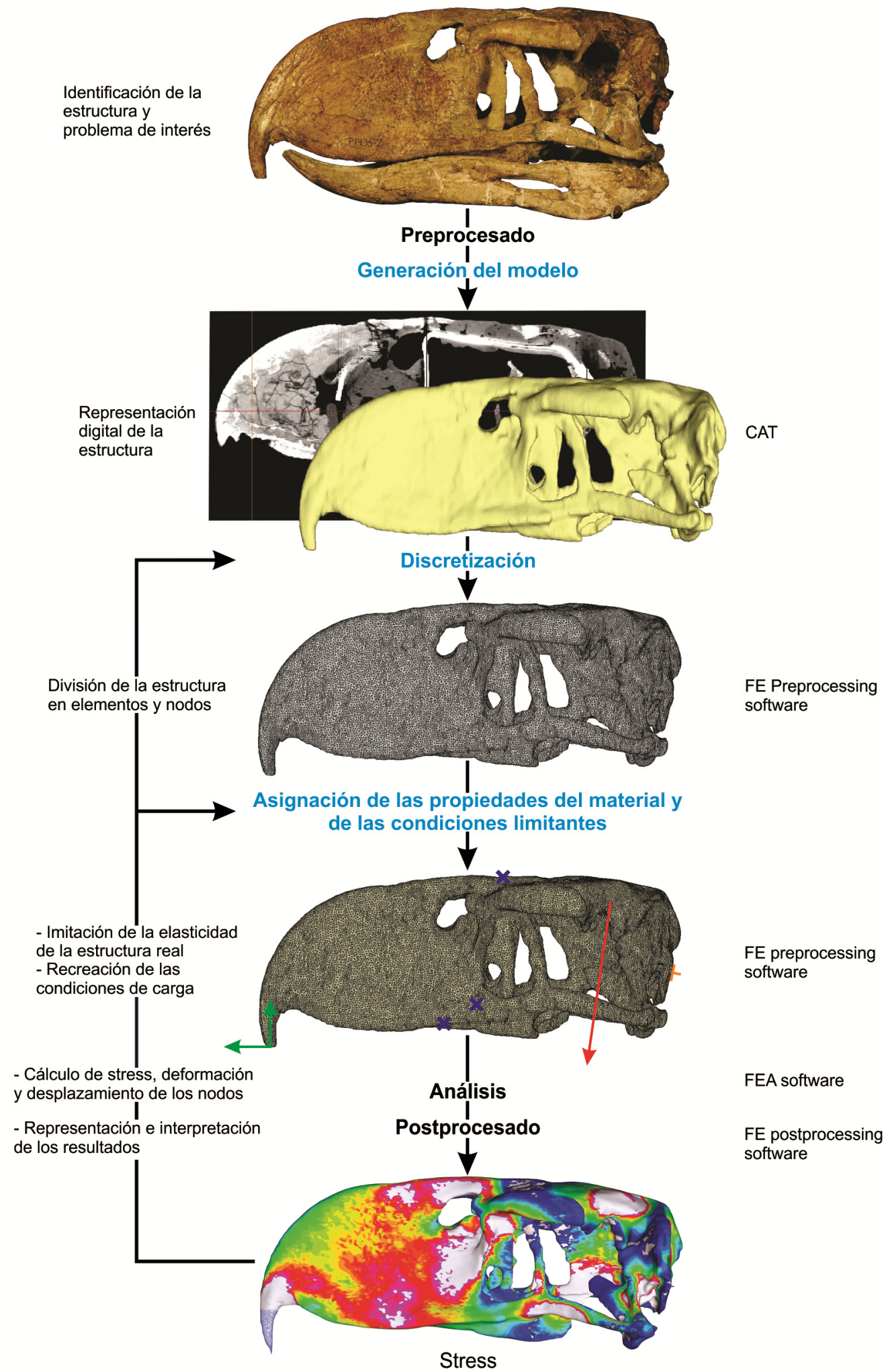

Figura 8.3. Pasos involucrados en un análisis de elementos finitos. Modificado de Rayfield (2007). 
A

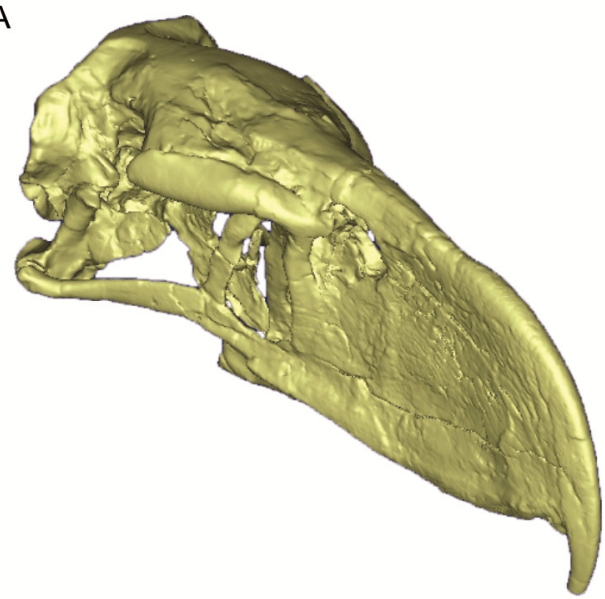

B

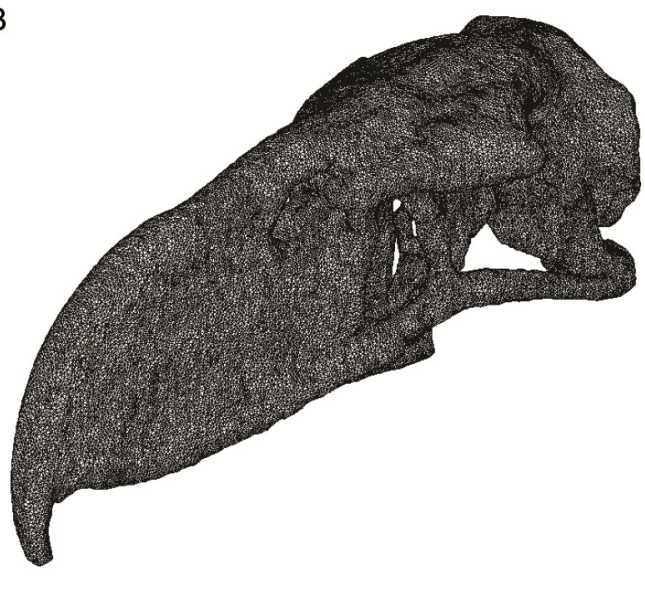

Figura 8.4. Modelos de Andalgalornis utilizado en el análisis de elementos finitos. A, modelo sólido. B, enmallado. Modificado de Degrange et al. (2010).

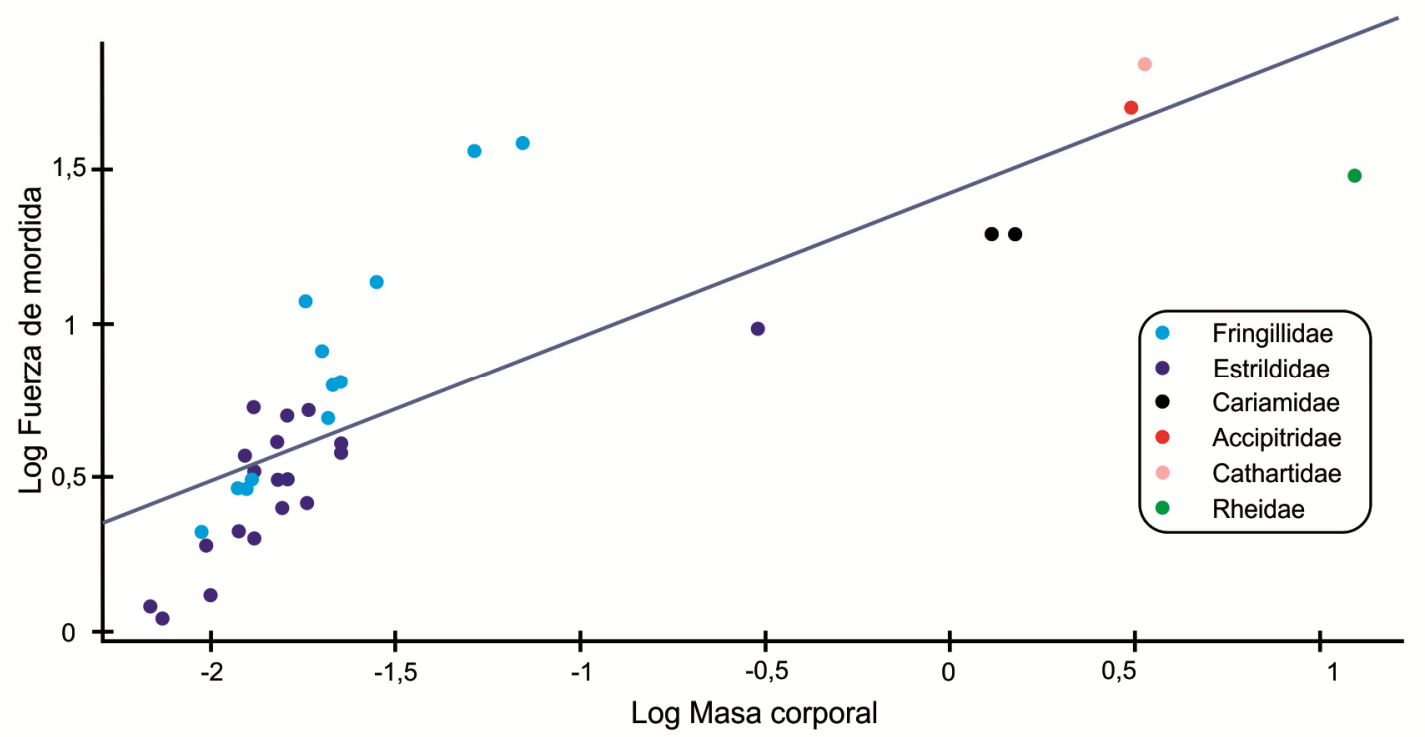

Figura 8.5. Regresión del logaritmo de la masa corporal y de la fuerza de mordida. Modificada de Degrange et al. (2010). 


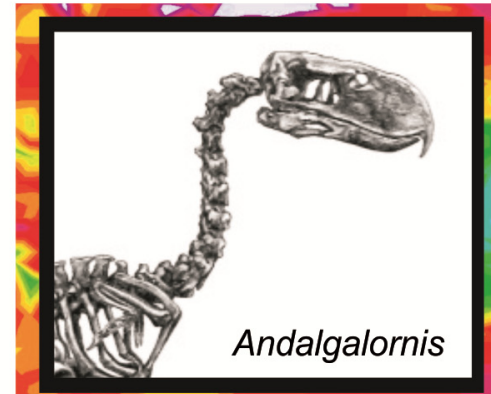

A

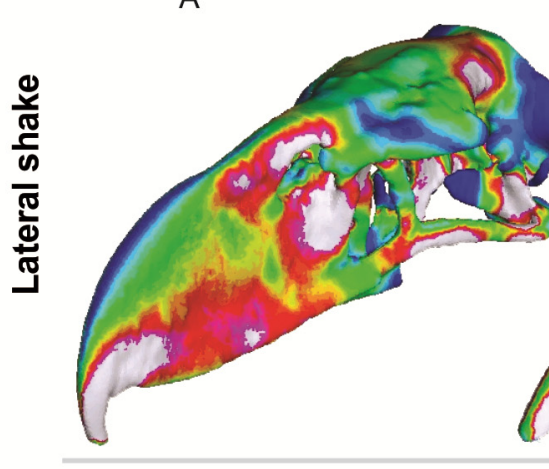

B
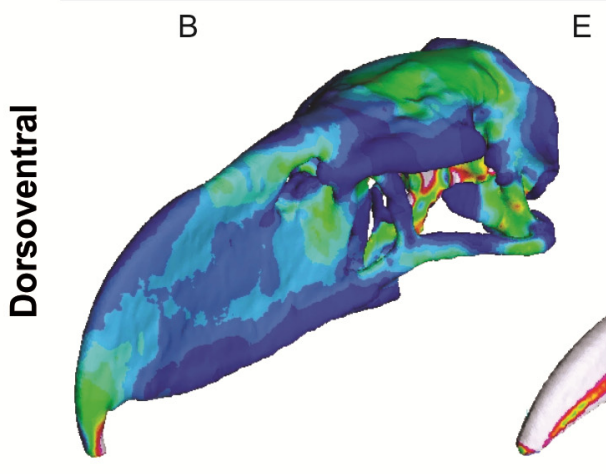

$\mathrm{E}$
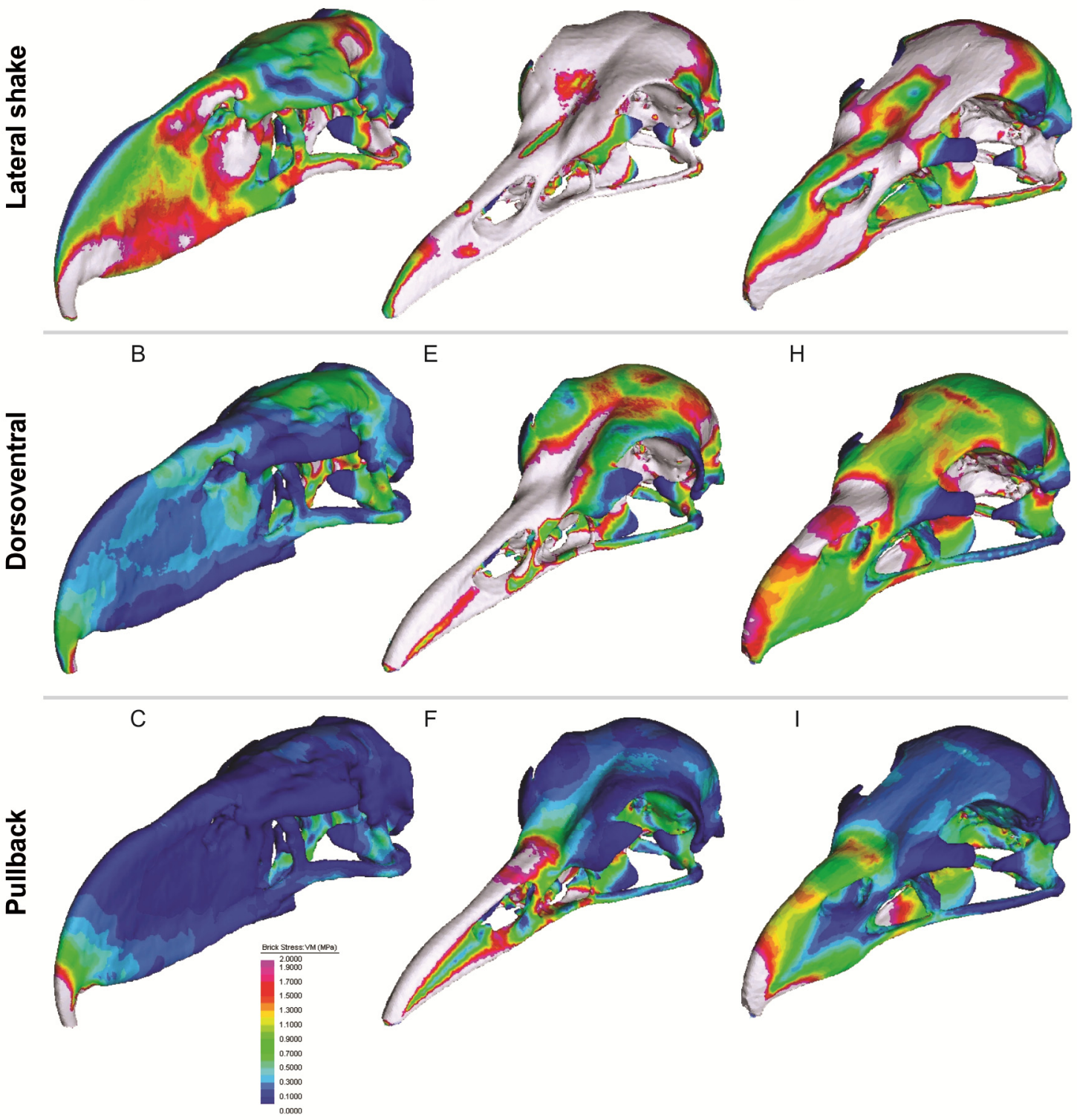

G

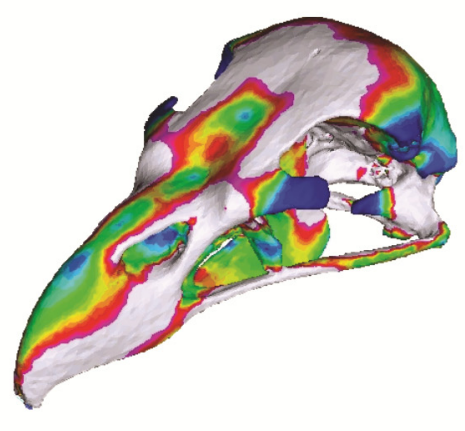

$\mathrm{H}$

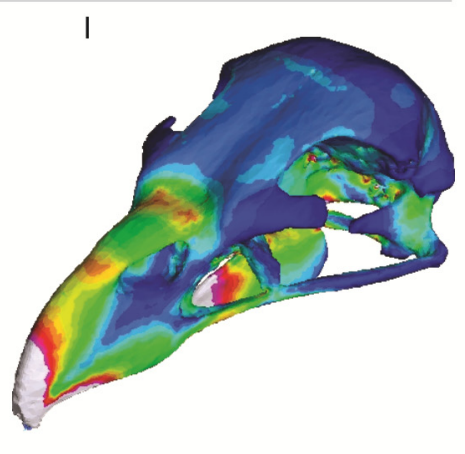

Figura 8.6. Distribución del stress (Von Mises) en los modelos de elementos finitos (AC) Andalgalornis steulleti, (D-F) Cariama cristata y (G-I) Haliaeetus albicilla bajo tres condiciones de carga. (A, D, G) lateral shake, (B, E, H) normal bite, (C, F, I) pullback. $\mathrm{VM}=$ Von Mises; MPa, mega pascals. Las zonas blancas indican donde los valores de VM sobrepasan la máxima escala (2 MP) en ésas áreas. Modificada de Degrange et al. (2010). 


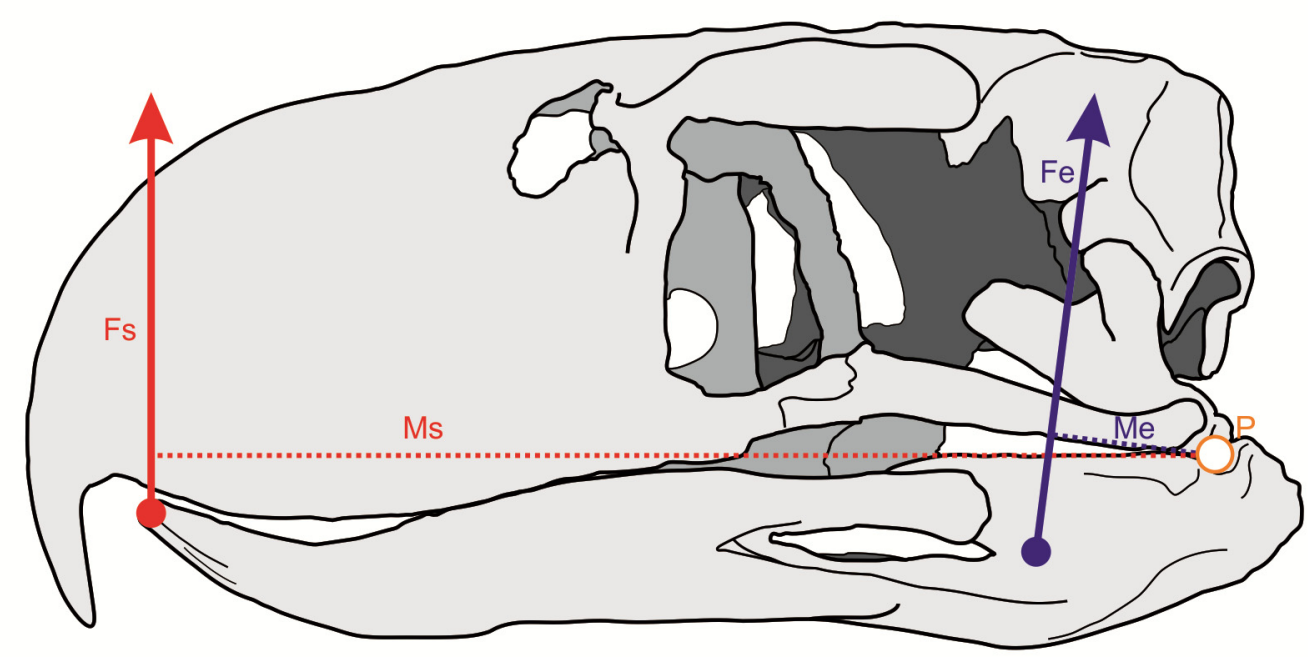

Figura 8.7. Sistema de palanca de tercer orden: cierre de la mandíbula durante la contracción del $m$. adductor mandibulae externus de Andalgalornis. Abreviaturas: Fe, fuerza de entrada; Fs, fuerza de salida; Me, brazo de entrada; Ms, brazo de salida, P, pivot.

Figura 8.8. (Página siguiente) Brazos de momento (línea punteada) y líneas de acción (flechas) de los diferentes músculos mandibulares de Geranoaetus, Taxón nuevo A y Andalgalornis. Abreviaturas: AME, M. adductor mandibulae externus; AMP, M. adductor mandibulae posterior; DM, M. depresor mandibulae; PSP, M. pseudotemporalis profundus; PSS, M. pseudotemporalis superficialis; PTD, M. pterygoideus dorsalis; PTV, M. pterygoideus ventralis. No a escala. 
PTD
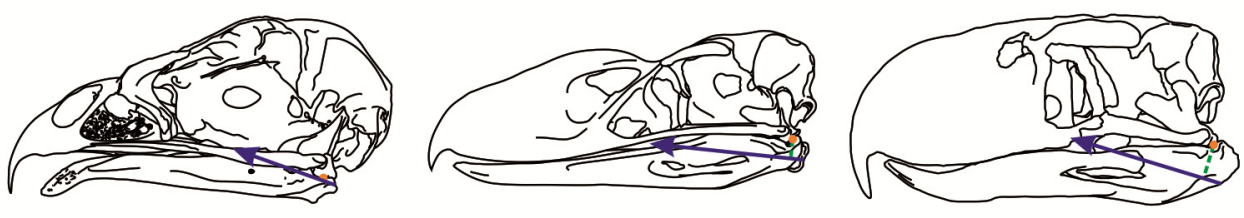

PTV
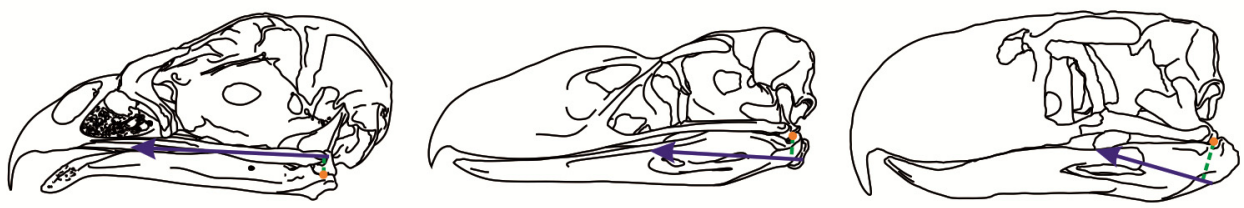

PSS
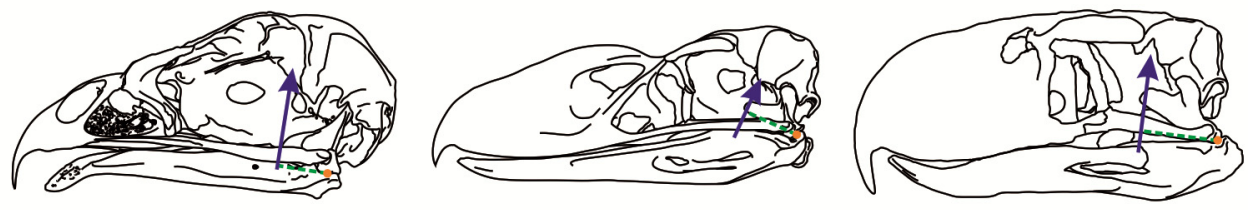

PSP
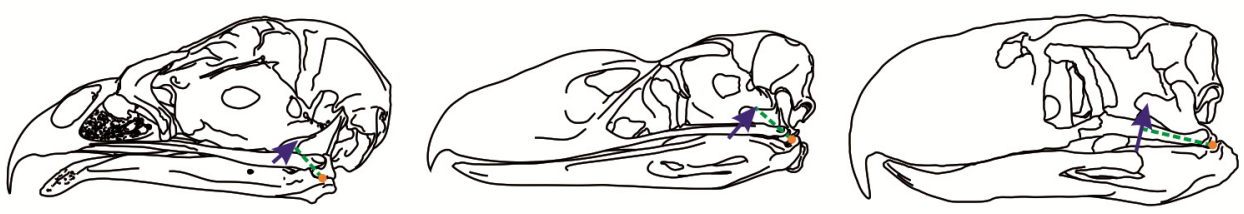

AME
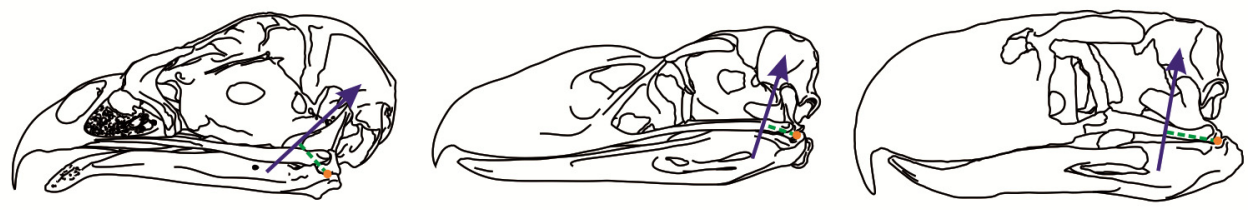

AMP
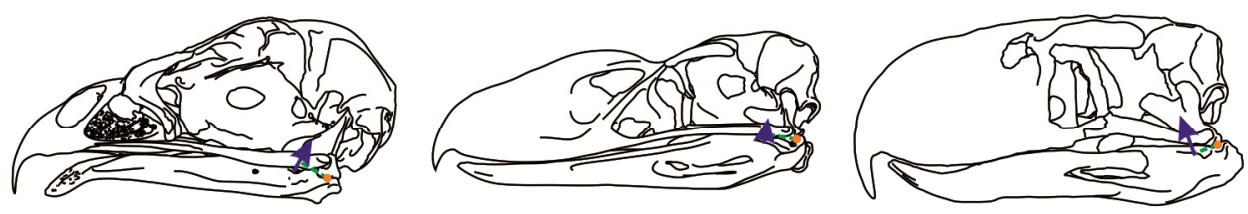

DM
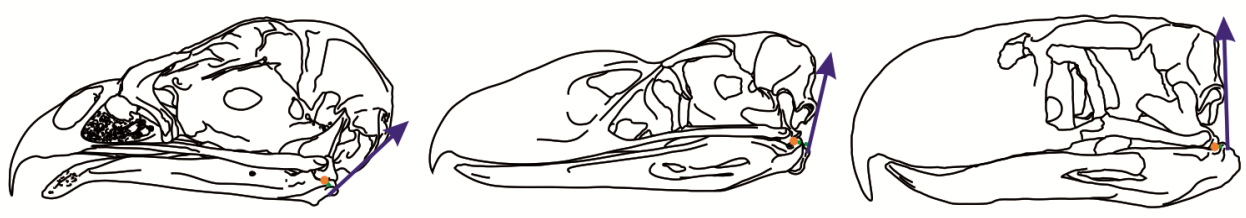


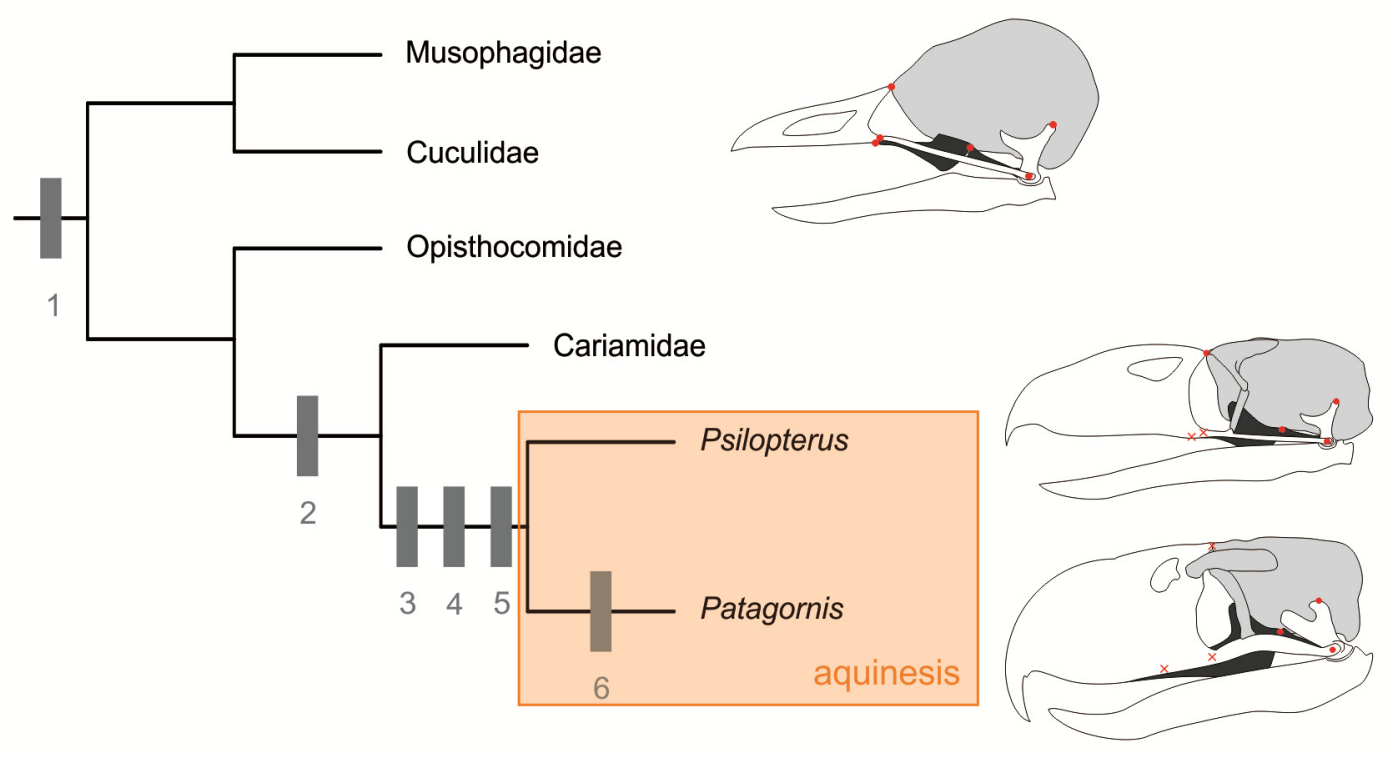

Figura 8.9. Evolución de la aquinesis en los Phorusrhacidae. Los círculos rojos indizan zonas móviles, mientras que las cruces rojas indican puntos inmóviles. 1, quinesis; 2 , zonas flexorias palatales poco móviles; 3 , presencia de processi basipterygoideus; 4 , zona flexoria palatina ausente; 5, zona flexoria arcus jugalis ausente; 6 , zona flexoria craniofascialis ausente. 
A

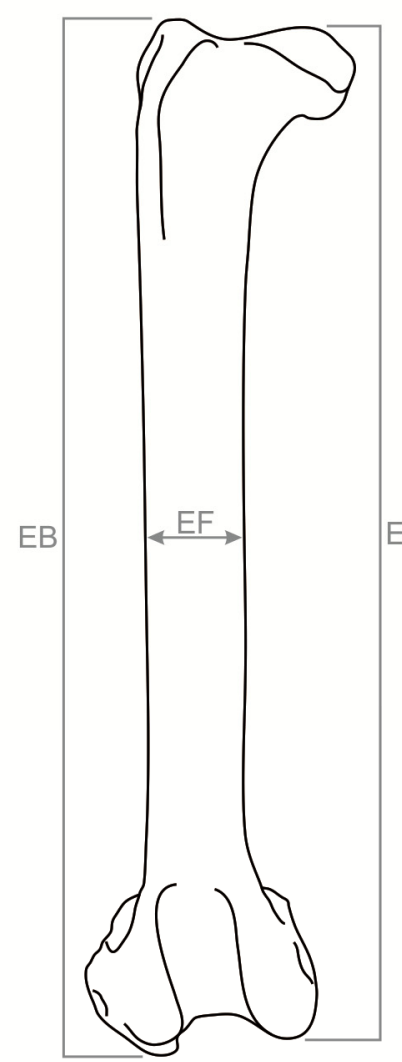

B

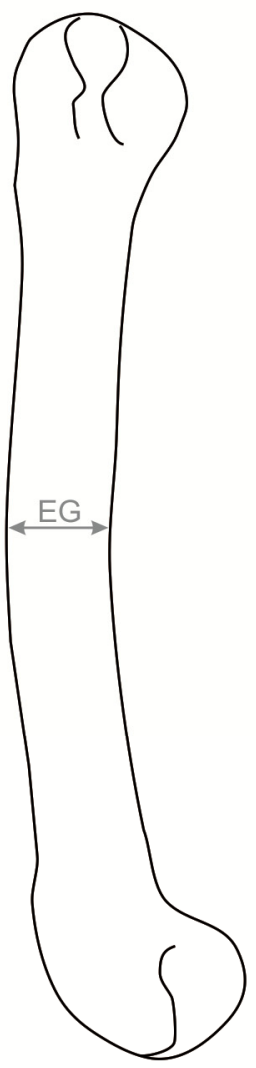

C

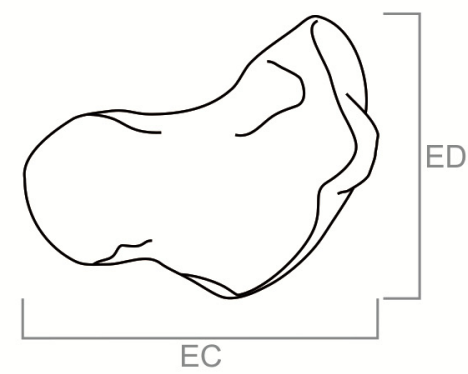

D

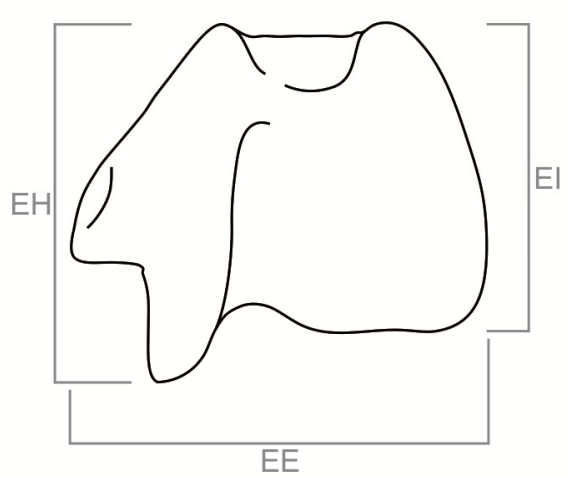

Figura 9.1. Medidas tomadas en el fémur. A, vista craneal; B, vista lateral; C, vista proximal; D, vista distal. 
A

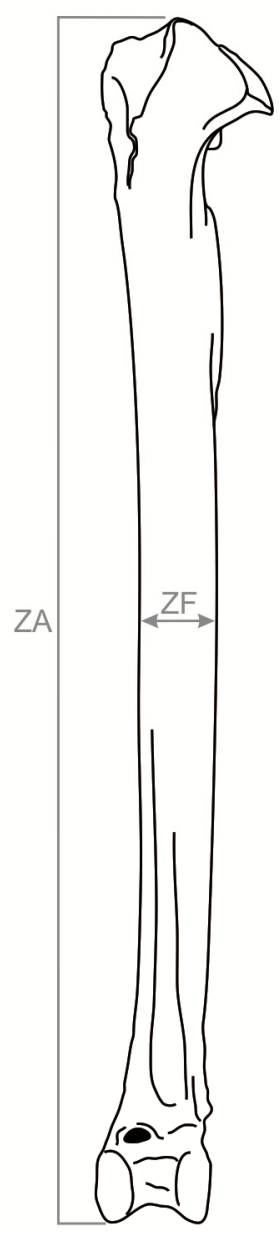

B

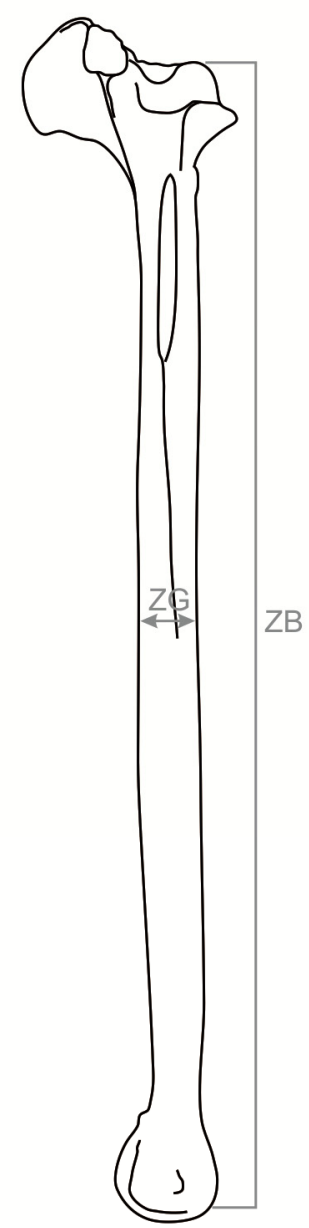

C

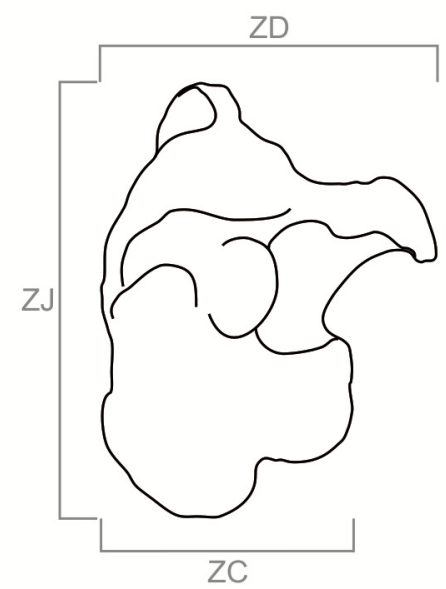

D

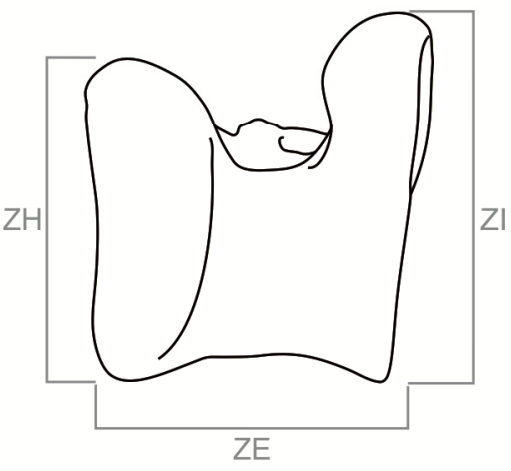

Figura 9.2. Medidas tomadas en el tibiotarso. A, vista craneal; B, vista lateral; C, vista proximal; D, vista distal. 


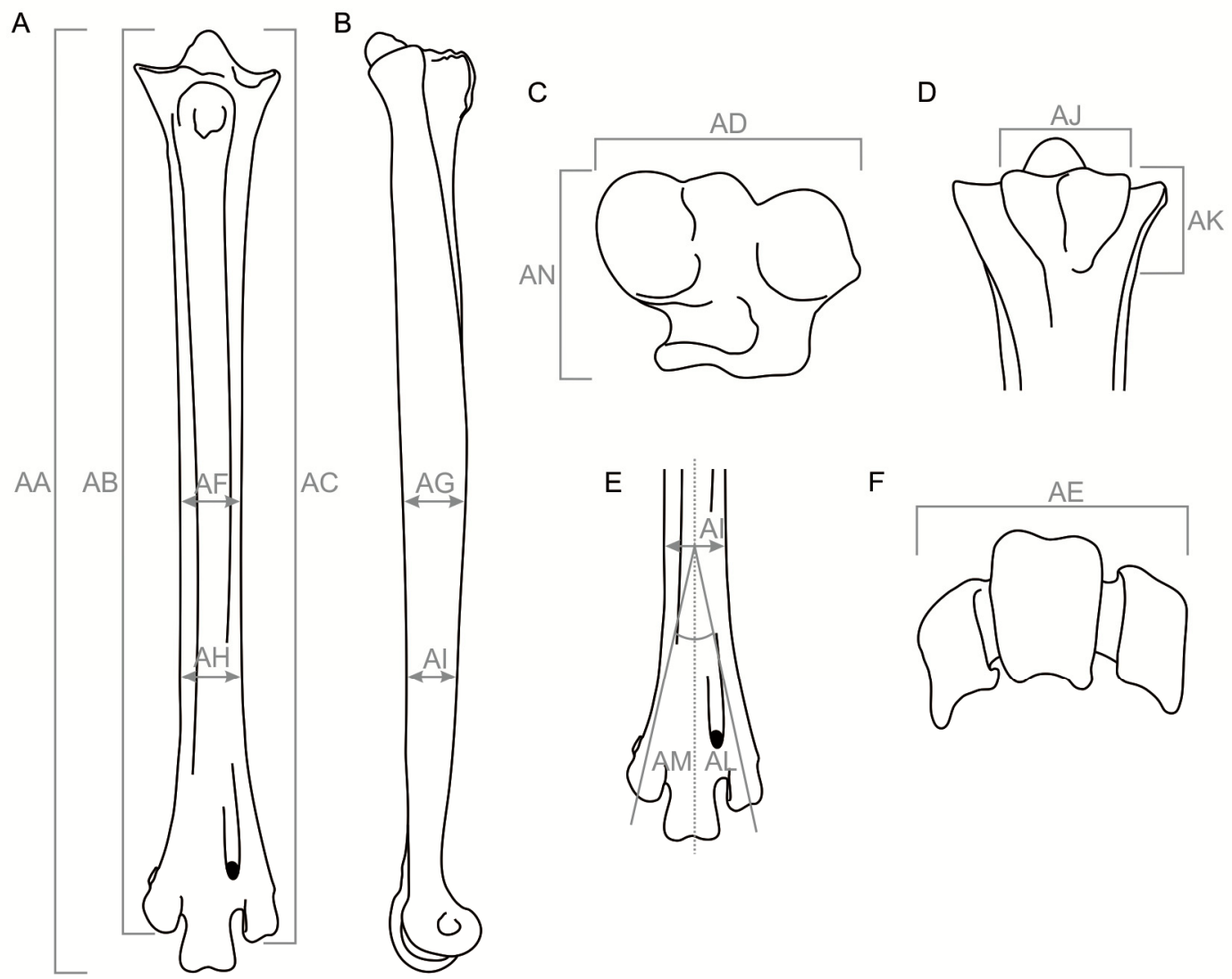

Figura 9.3. Medidas tomadas en el tarsometatarso. A, vista craneal; B, vista lateral; $\mathrm{C}$, vista proximal; D, vista caudal, medidas del hypotarsus; E, vista craneal, divaricación troclear; F, vista distal. 


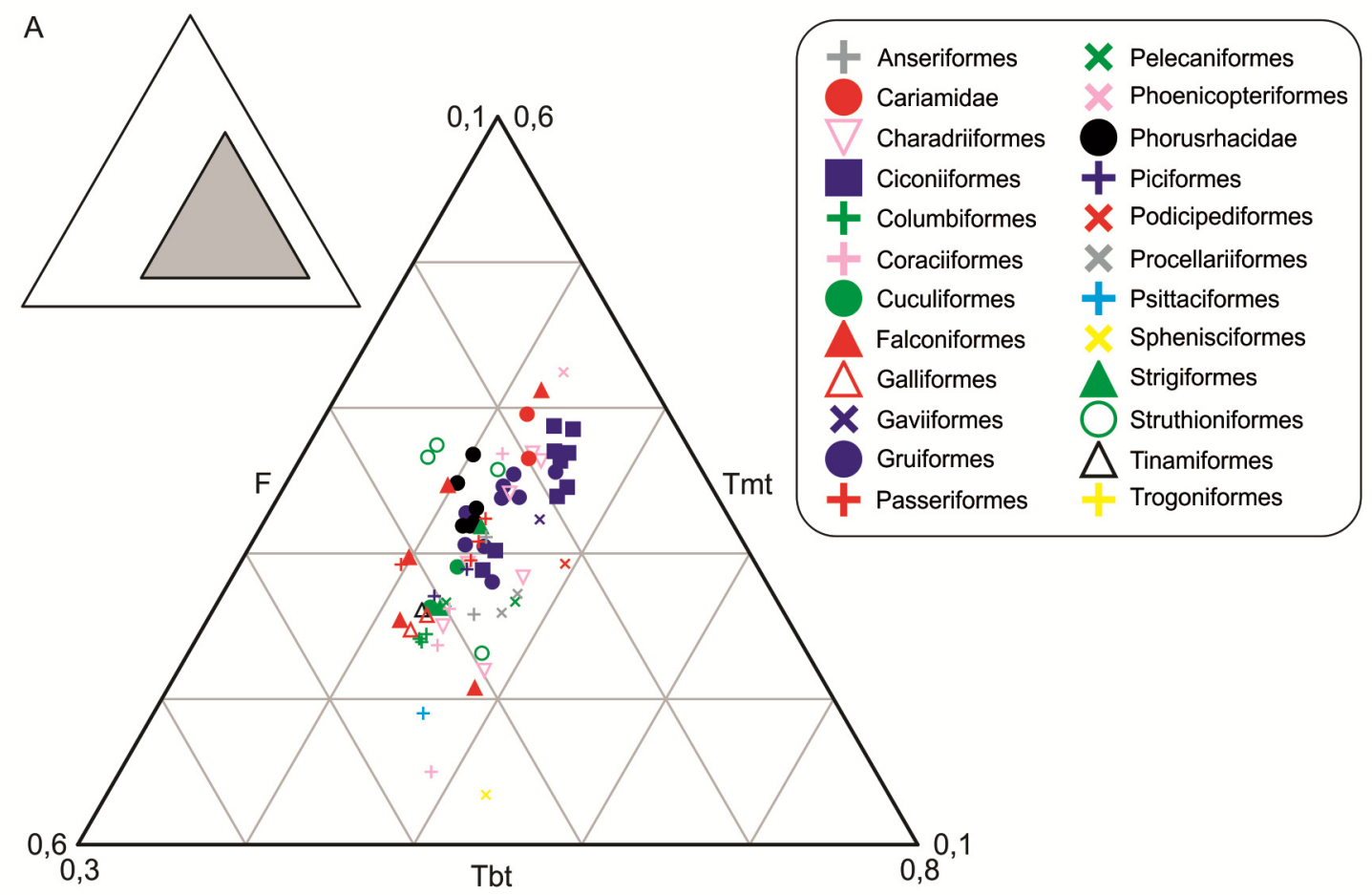

B

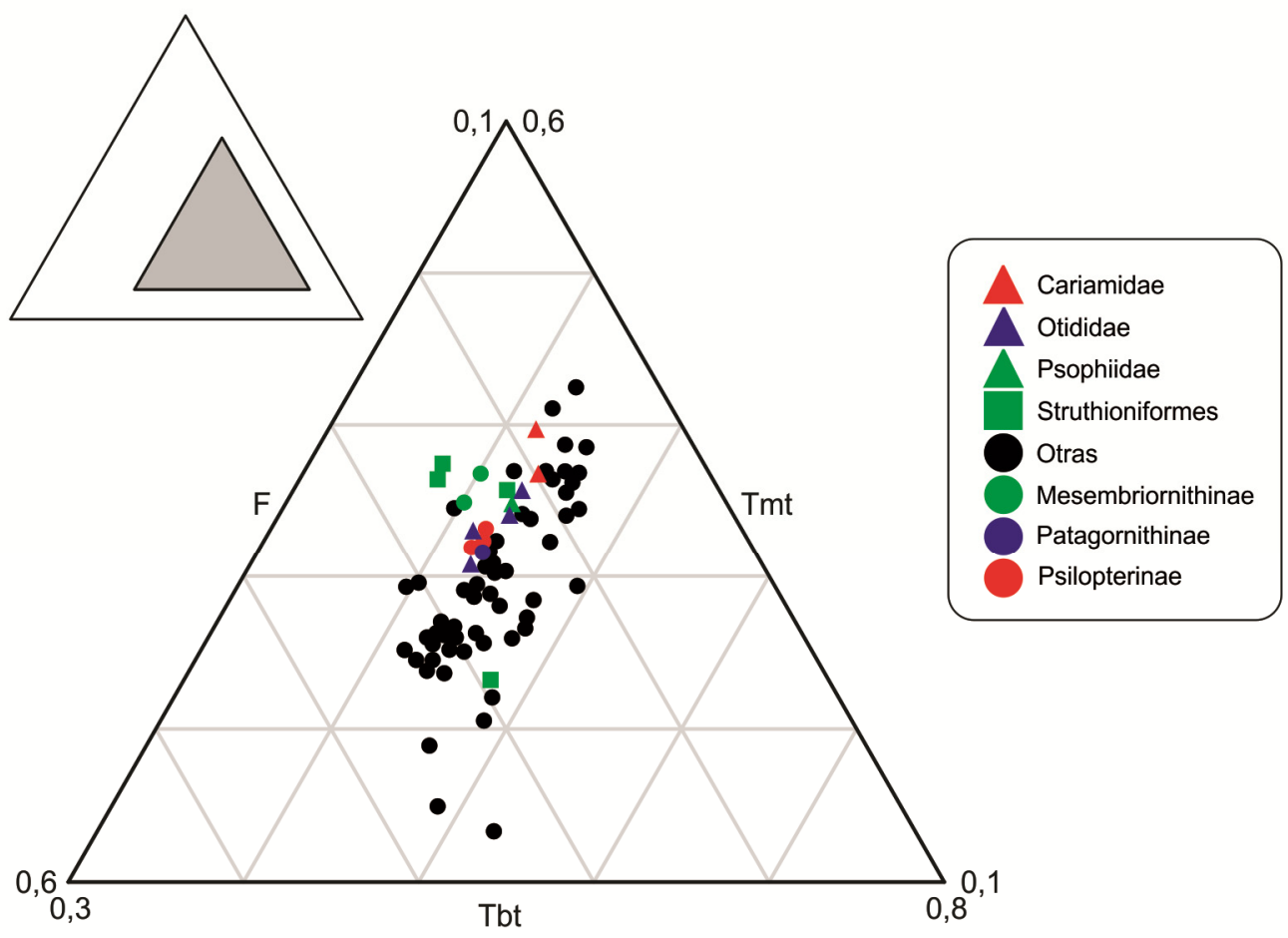

Figura 9.4. Proporciones de los miembros posteriores de las Neornithes en un morfoespecio ternario. A, gráfico mostrando el área que ocupan los fororracos; B, gráfico simplificado con las subfamilias de fororracos discriminadas. Abreviaturas: $\mathrm{F}$, fémur; Tbt, tibiotarso; Tmt, tarsometatarso. 


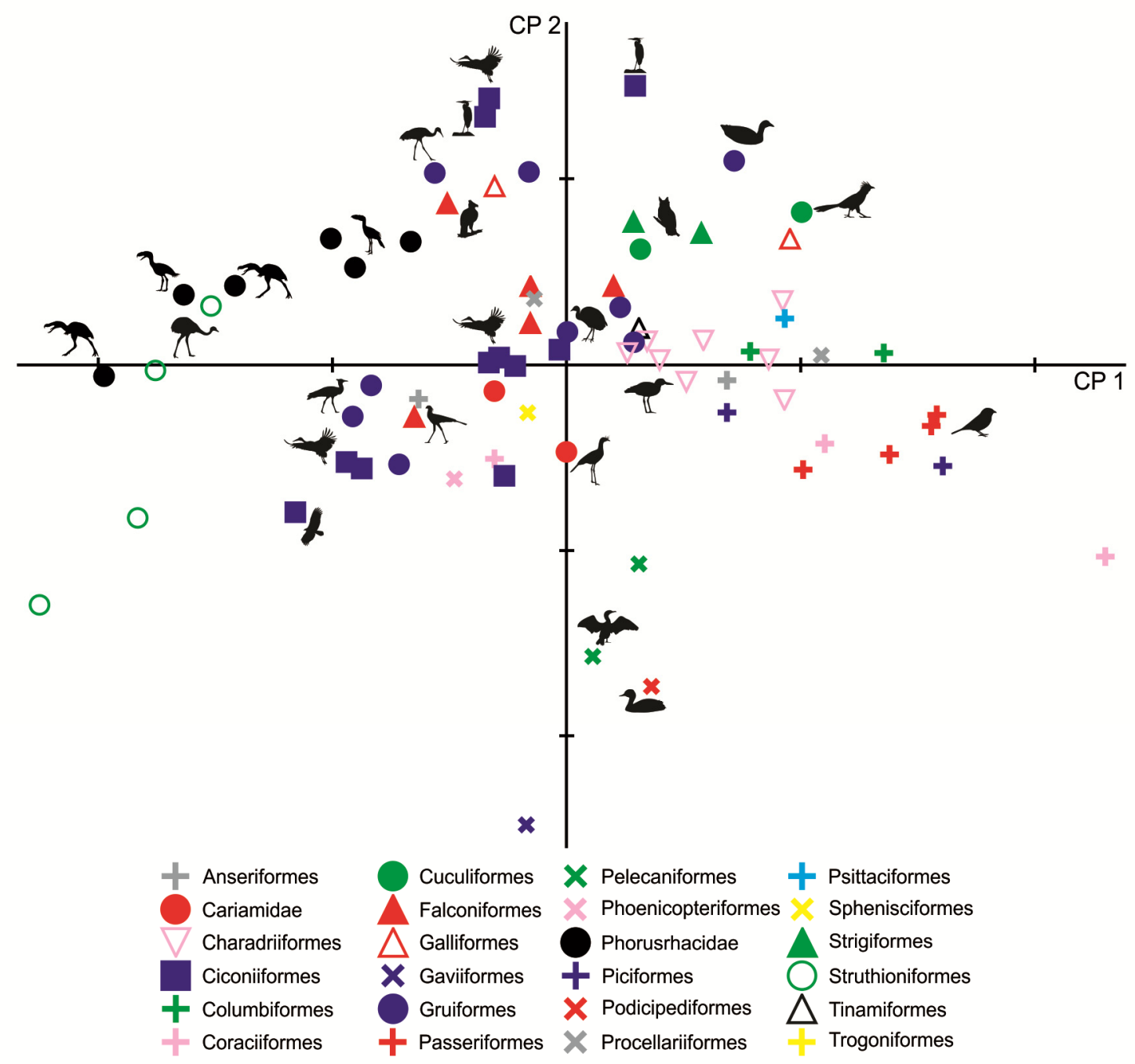

Figura 9.5. Análisis de componentes principales del fémur: distribución de los taxones en el morfoespacio definido por CP1 y CP2. 


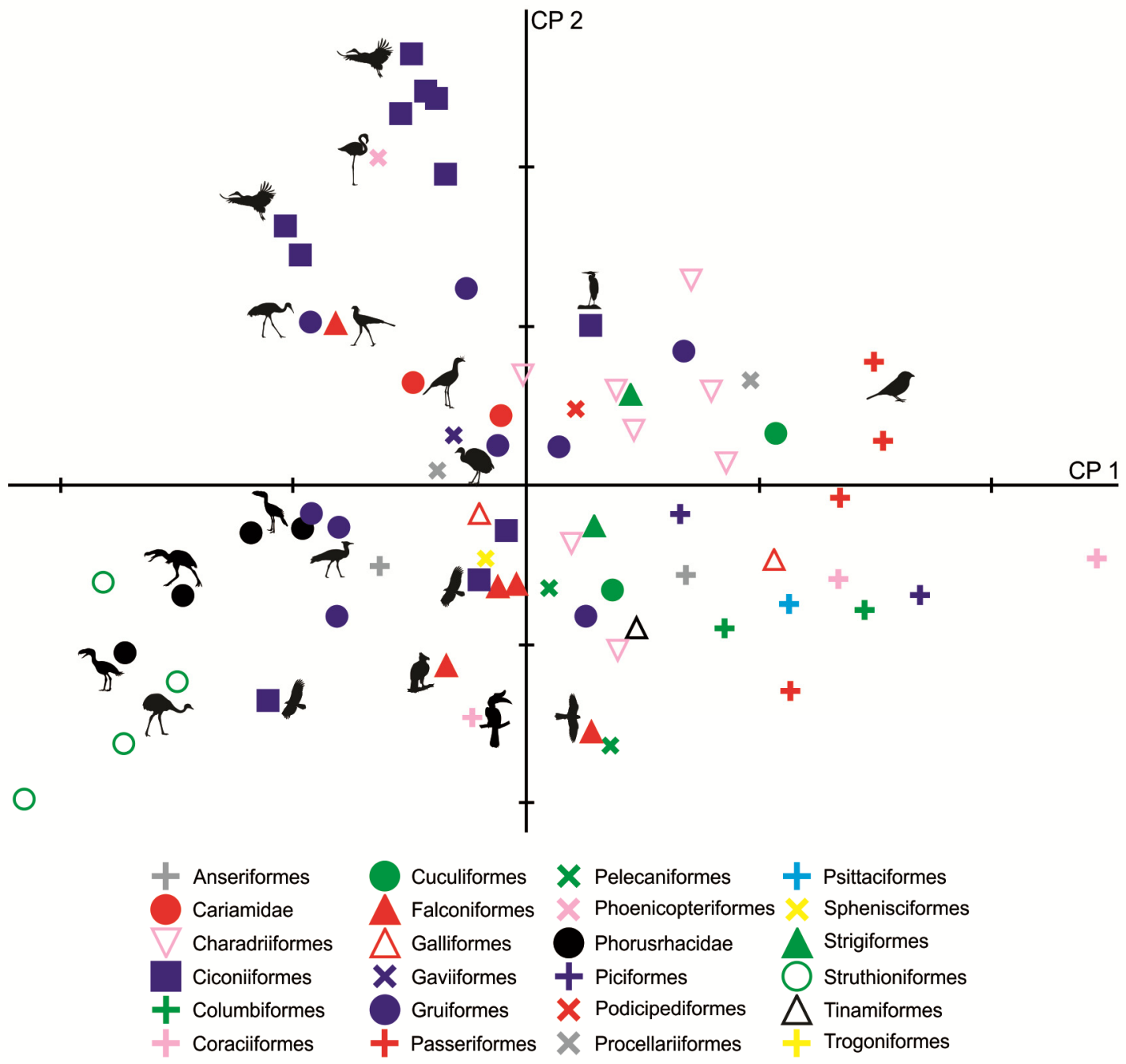

Figura 9.6. Análisis de componentes principales del tibiotarso: distribución de los taxones en el morfoespacio definido por CP1 y CP2. 


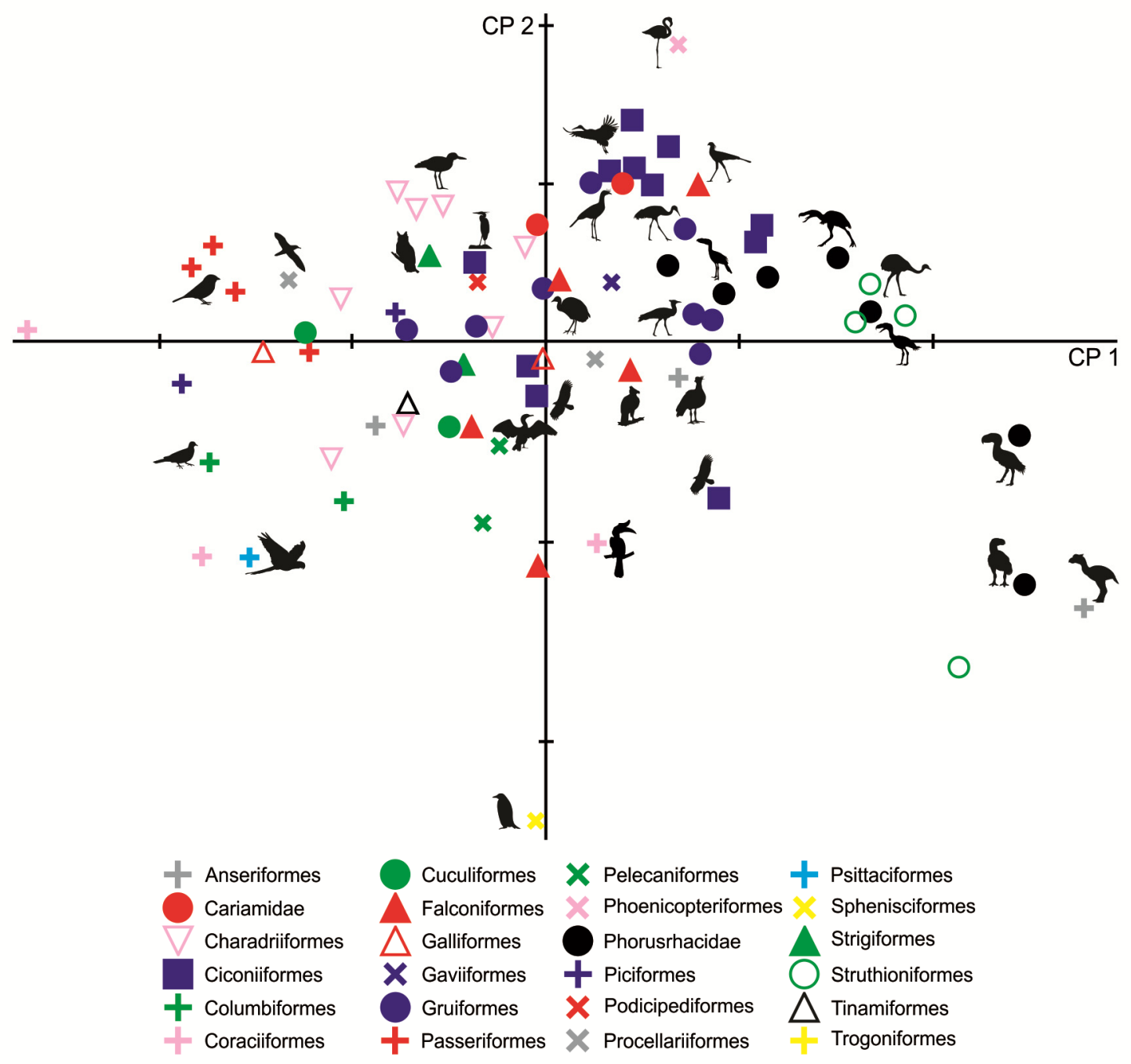

Figura 9.7. Análisis de componentes principales del tarsometatarso: distribución de los taxones en el morfoespacio definido por CP1 y CP2. 


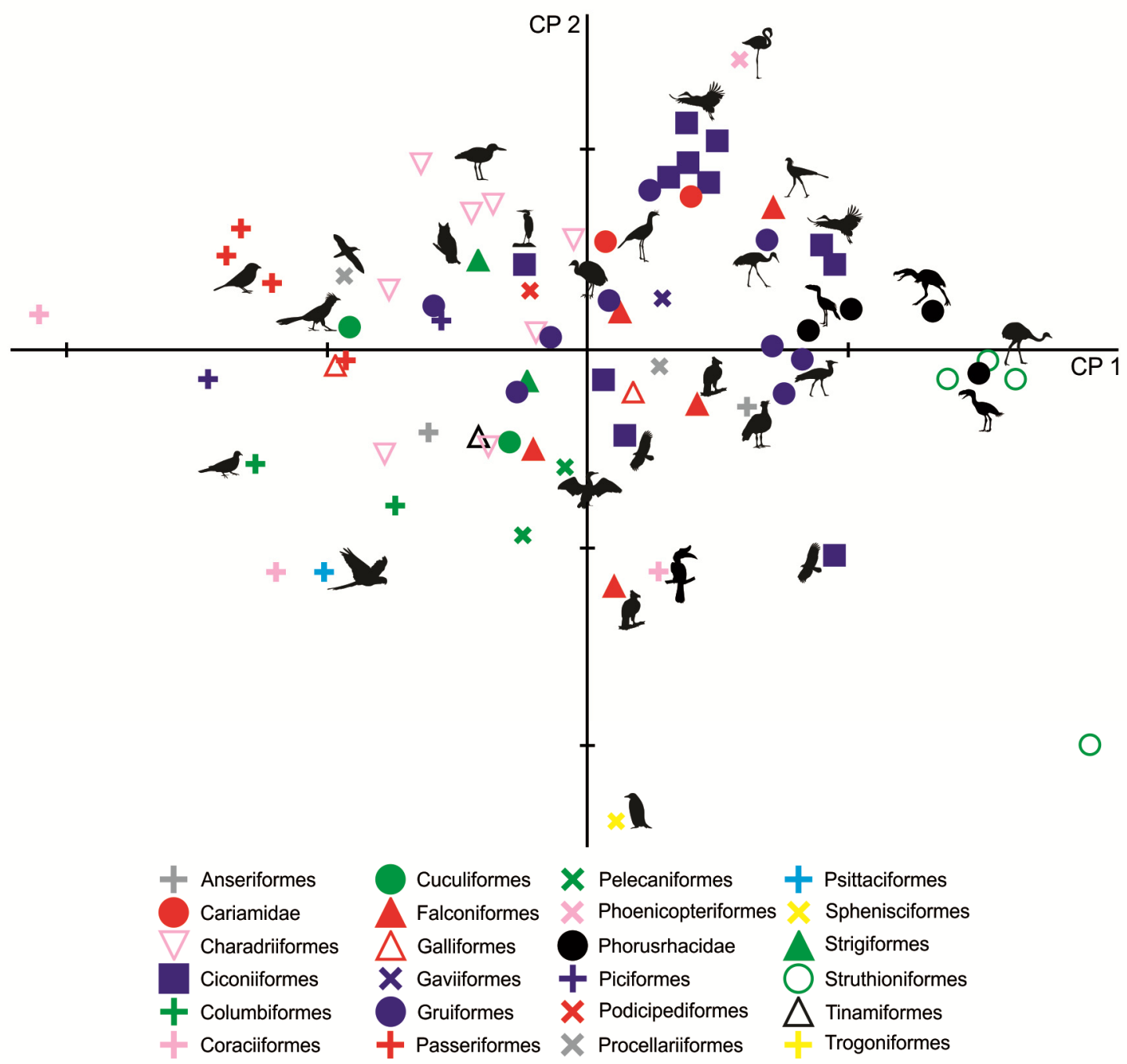

Figura 9.8. Análisis de componentes principales del miembro posterior: distribución de los taxones en el morfoespacio definido por CP1 y CP2. 

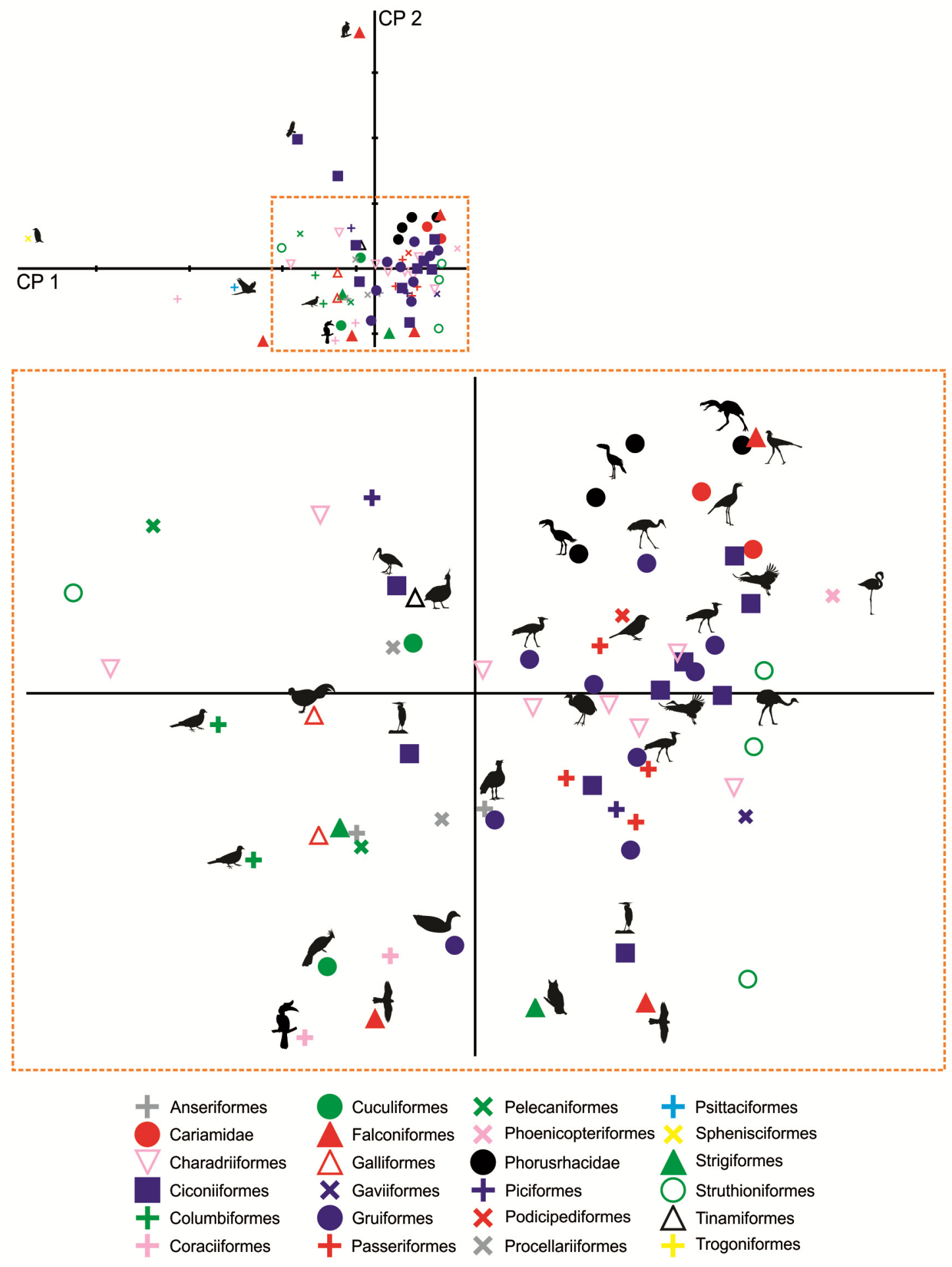

Figura 9.9. Análisis de componentes principales de los índices del miembro posterior: distribución de los taxones en el morfoespacio definido por CP1 y CP2. 


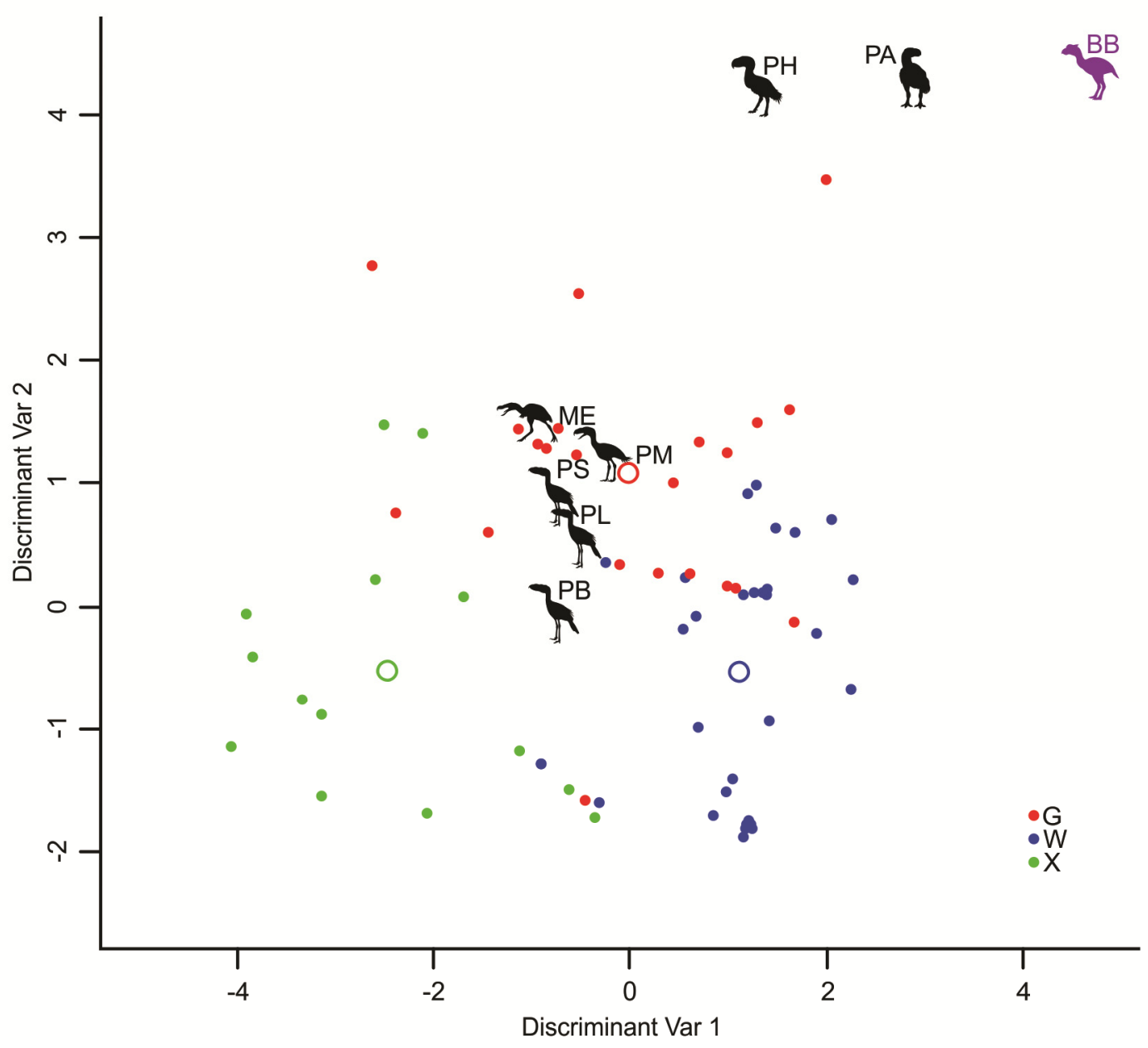

Figura 9.10. Análisis discriminante del tarsometatarso: distribución de los taxones en el morfoespacio definido por las variables discriminantes 1 y 2 . BB, Brontornis burmeisteri; ME, Taxón nuevo A; PA, Paraphysornis brasiliensis; PB, Psilopterus bachmanni; PH, Phorusrhacos longissimus; PL, Psilopterus lemoinei; PM, Patagornis marshi; PS, Procariama simplex. 


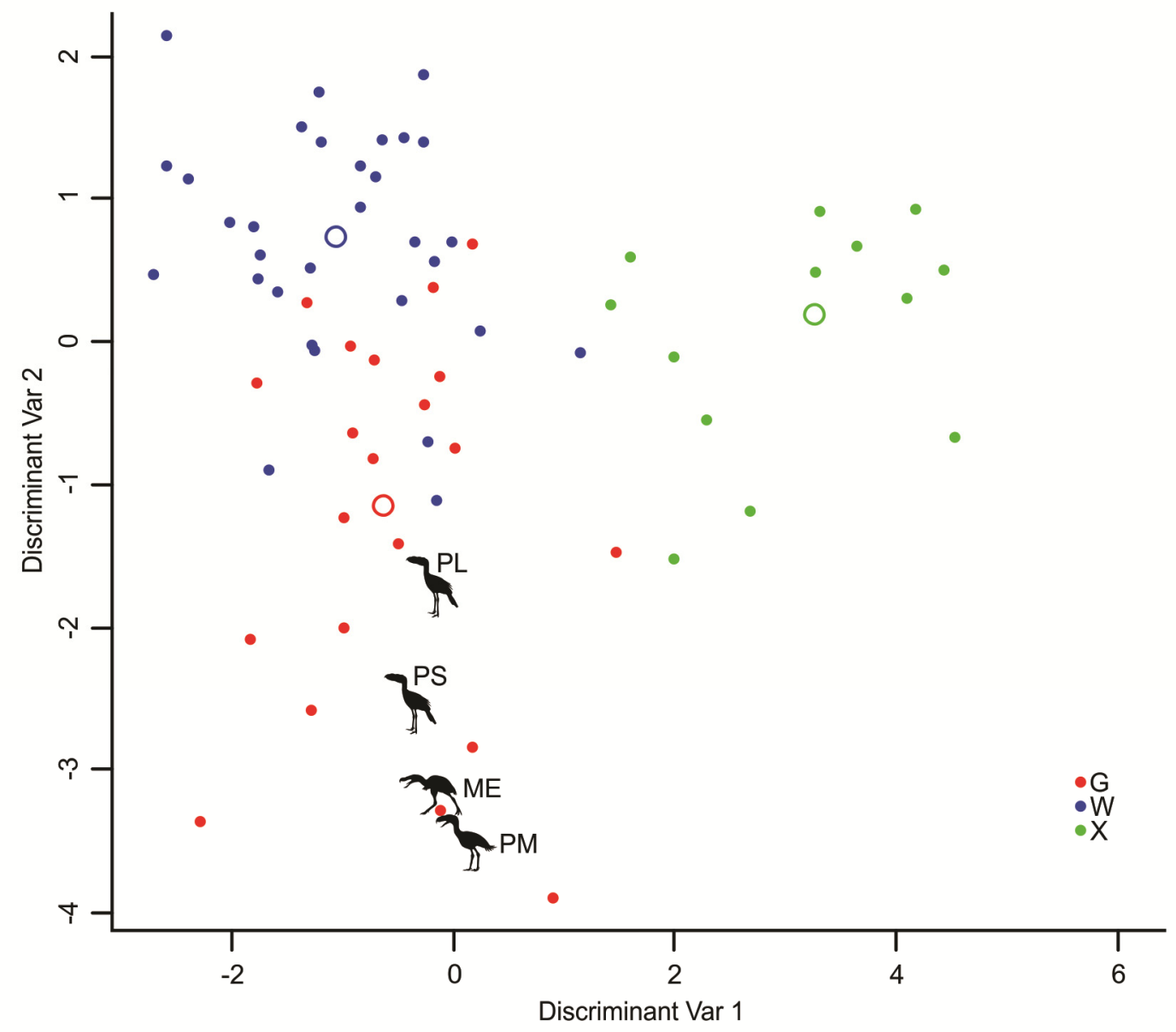

Figura 9.11. Análisis discriminante del miembro posterior: distribución de los taxones en el morfoespacio definido por las variables discriminantes 1 y 2. ME, Taxón nuevo A; PL, Psilopterus lemoinei; PM, Patagornis marshi; PS, Procariama simplex. 
A

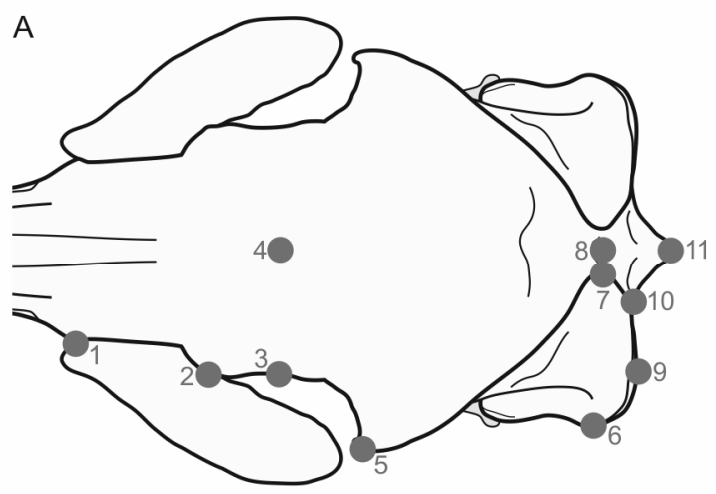

B

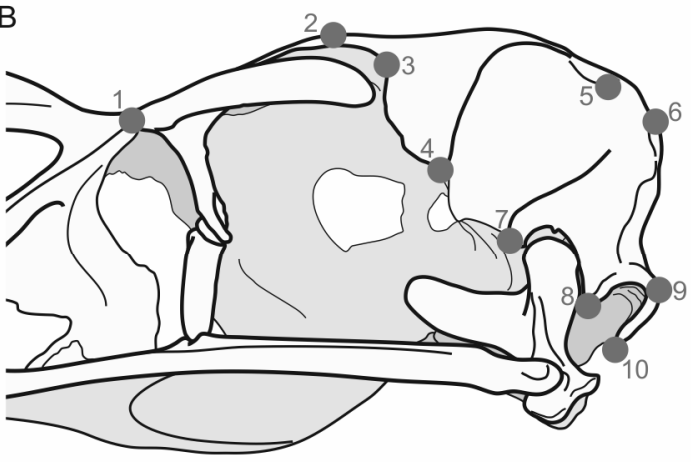

Figura 9.12. Landmarks utilizados en el estudio del neurocráneo de los fororracos. A, vista dorsal; B, vista lateral.

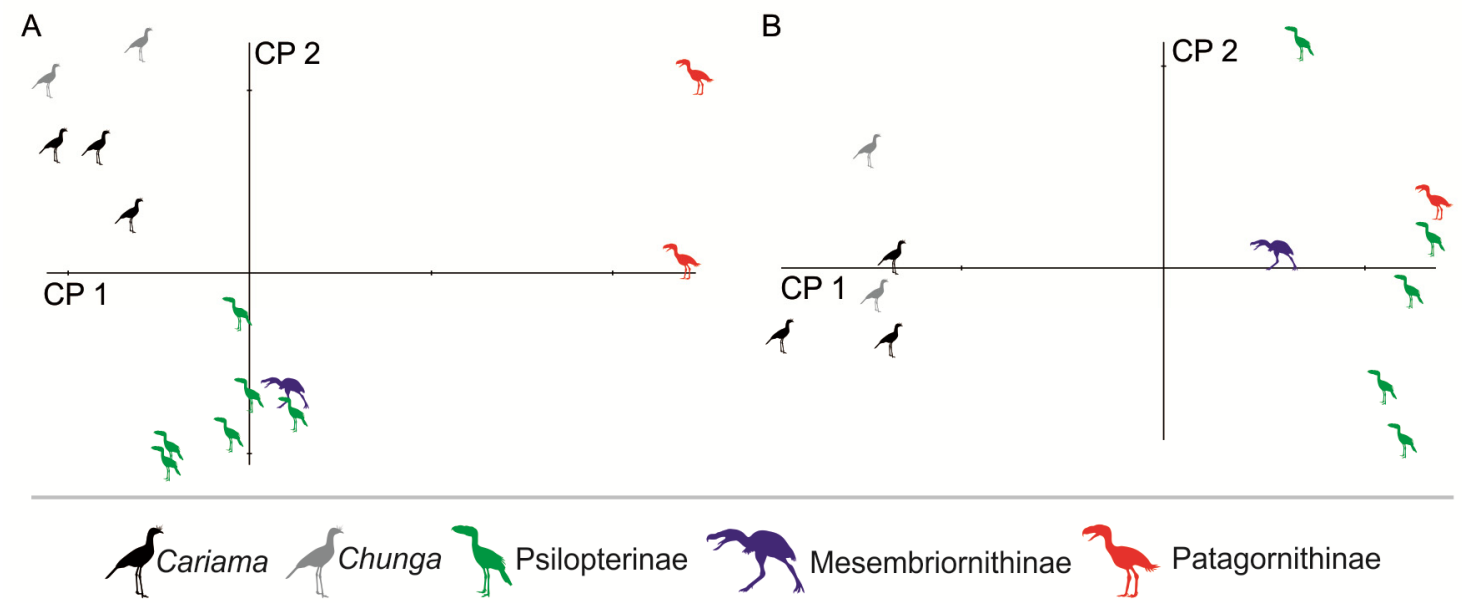

Figura 9.13. Estudio del neurocráneo de los fororracos: distribución de los taxones de Phorusrhacidae y Cariamidae en el morfoespacio de los dos primeros relative warps. A, dorsal; B, lateral. 
A
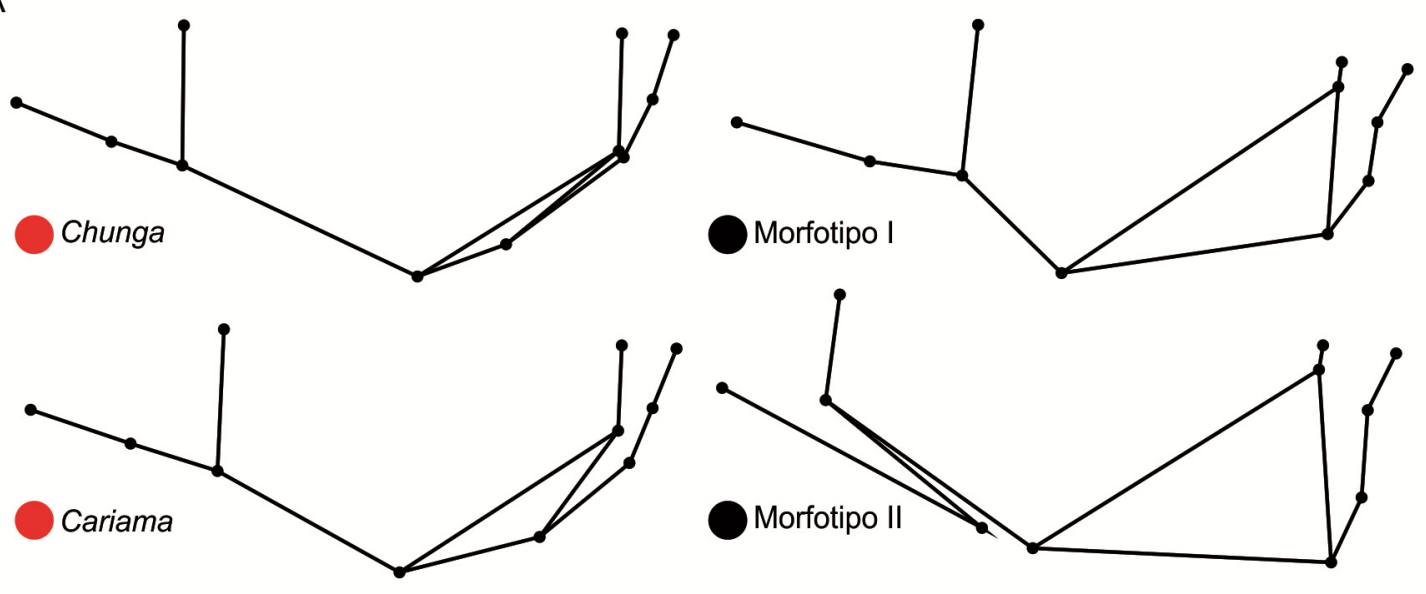

B

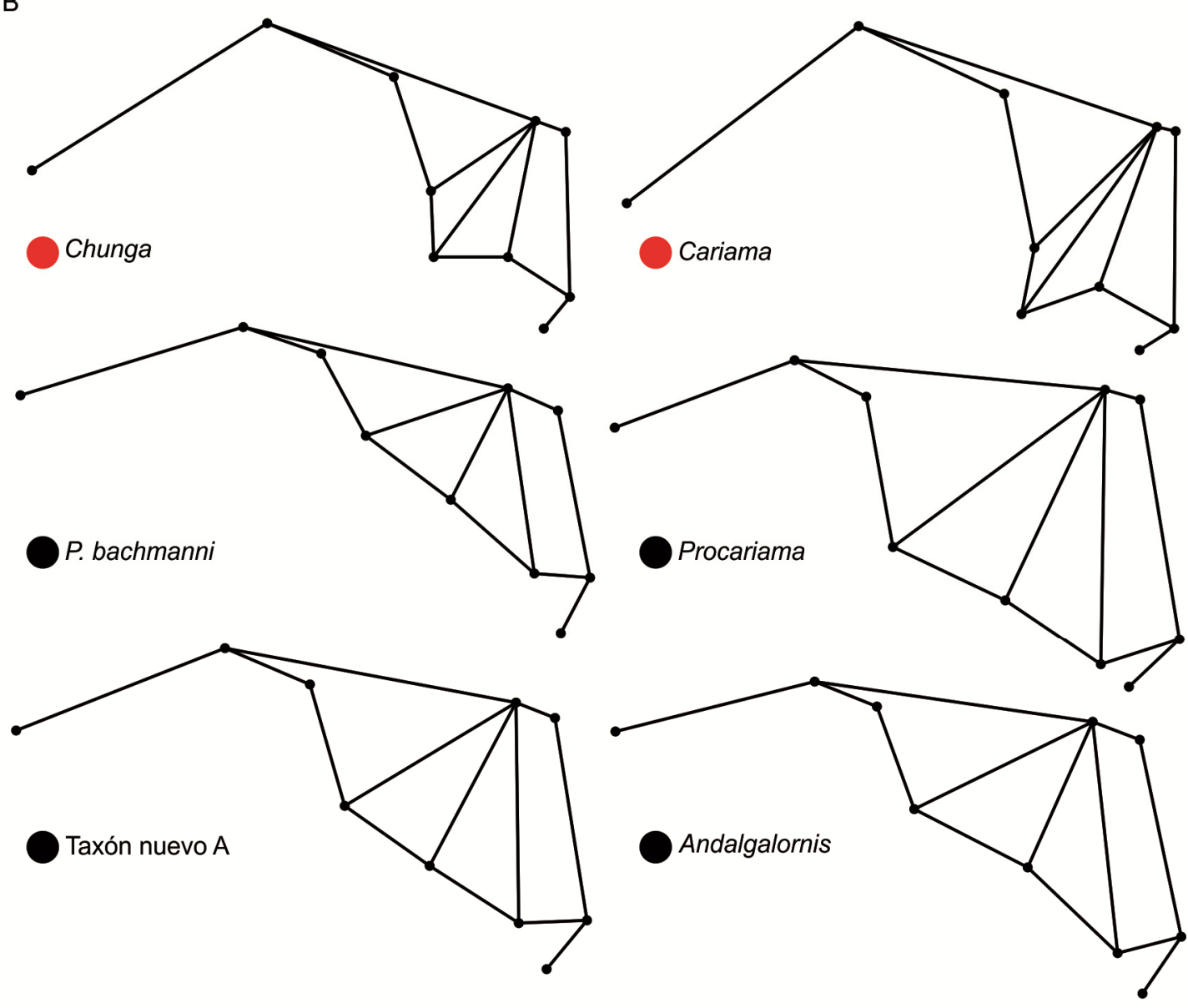

Figura 9.14. Grillas de visualización de los cambios de la forma del neurocráneo en distintas especies. A, dorsal; B, lateral. 
A

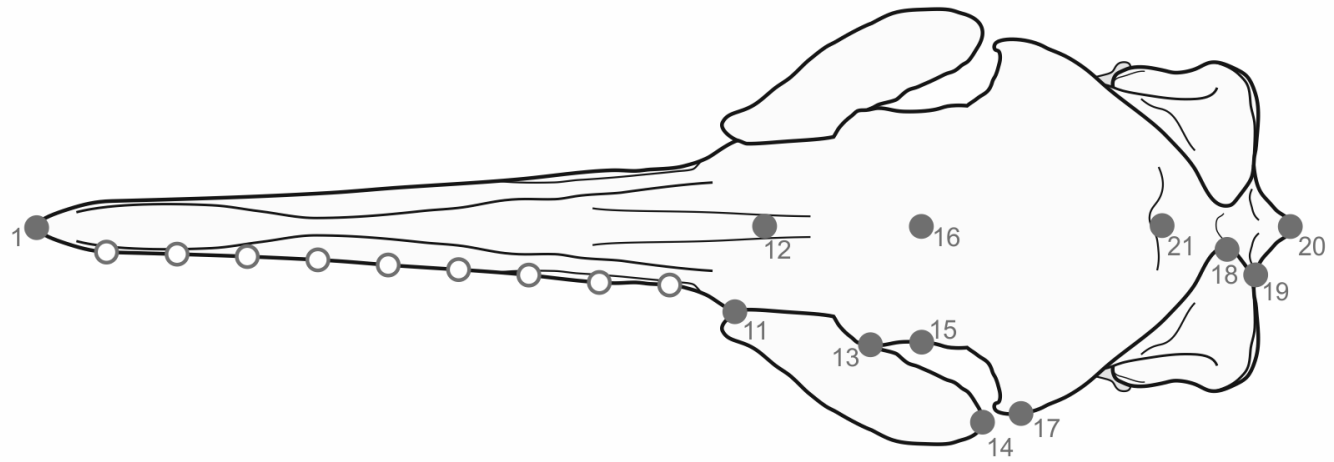

B

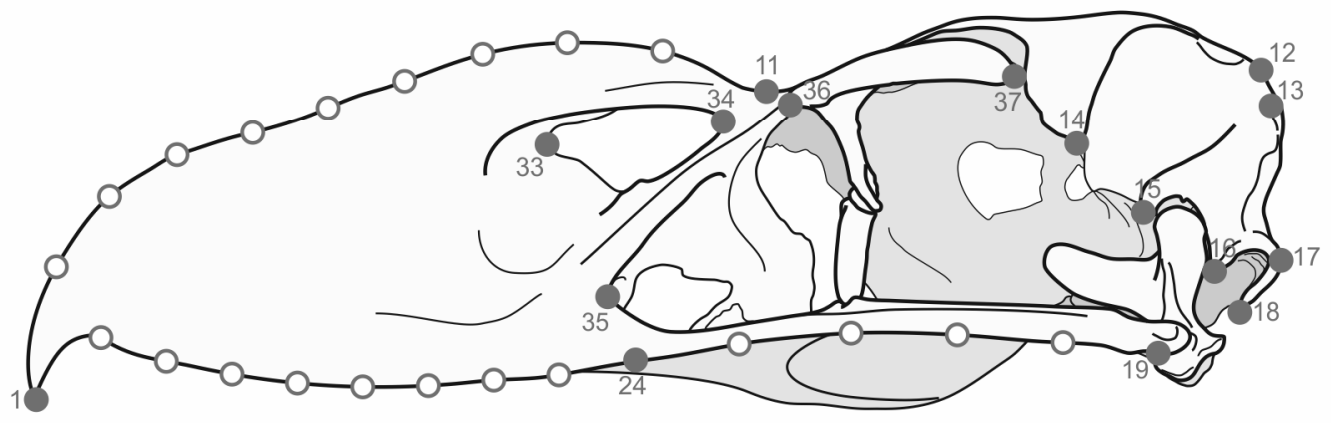

Figura 9.15. Landmarks utilizados en el estudio del cráneo de las aves. A, vista dorsal; $\mathrm{B}$, vista lateral. 


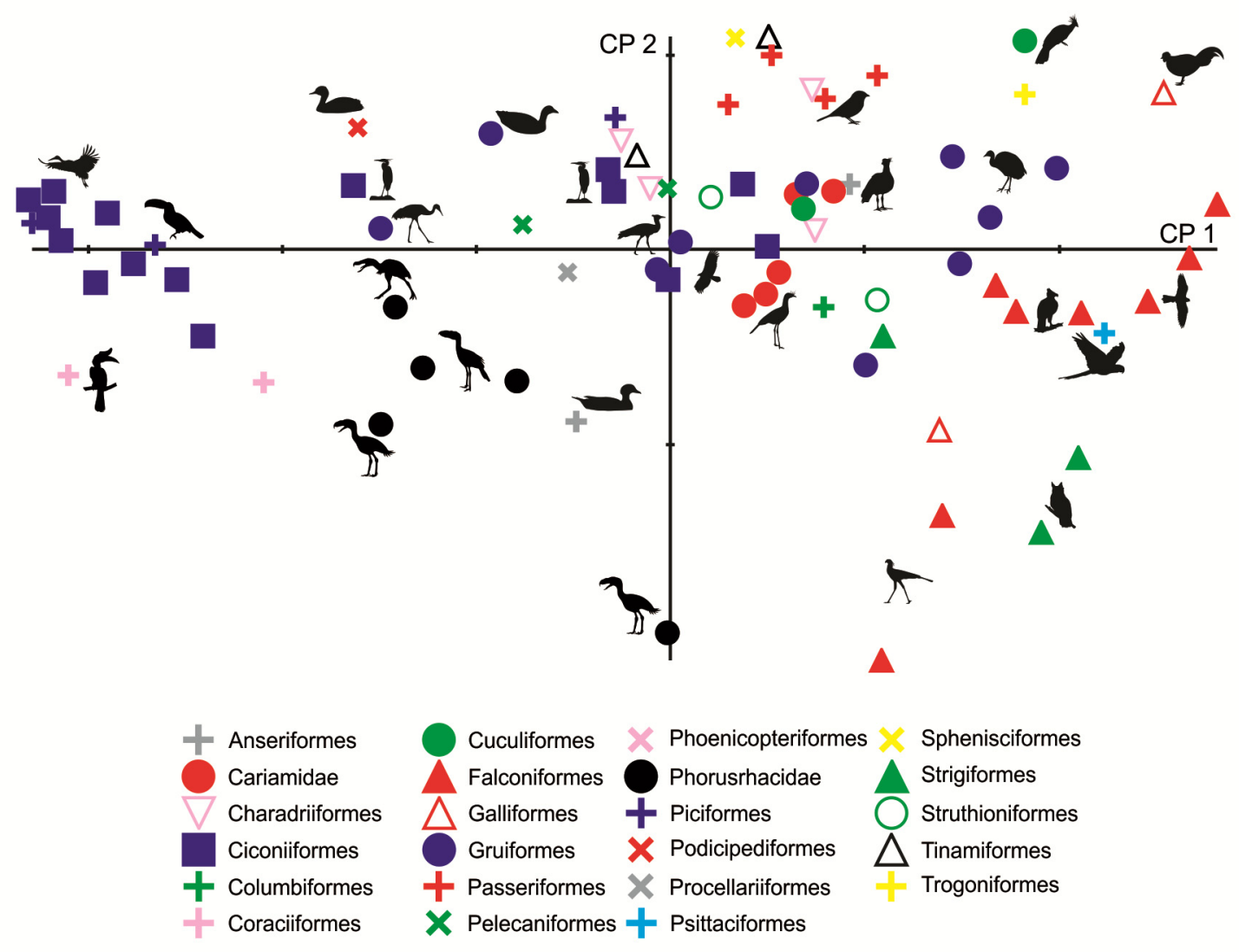

Figura 9.16. Cráneo: distribución de los taxones estudiados (actuales y fósiles) en el morfoespacio definido por CP1 y CP2 en vista dorsal.
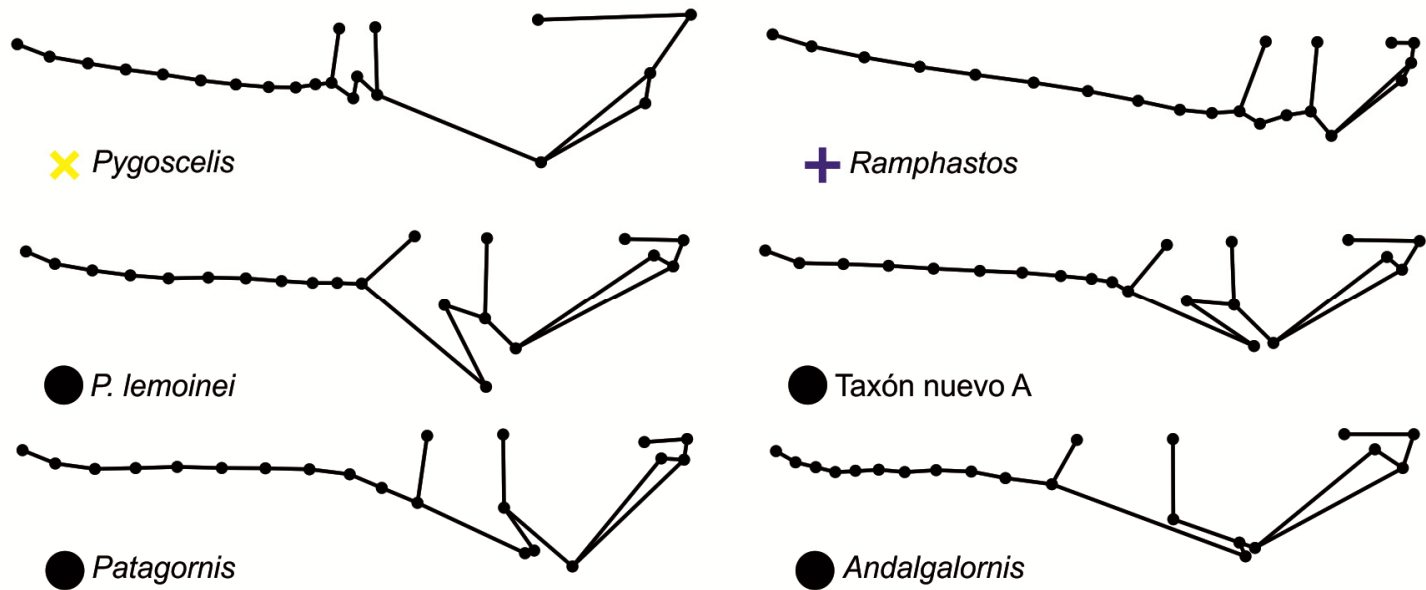

Figura 9.17. Grillas de visualización de los cambios de la forma del cráneo en distintas especies en vista dorsal. 


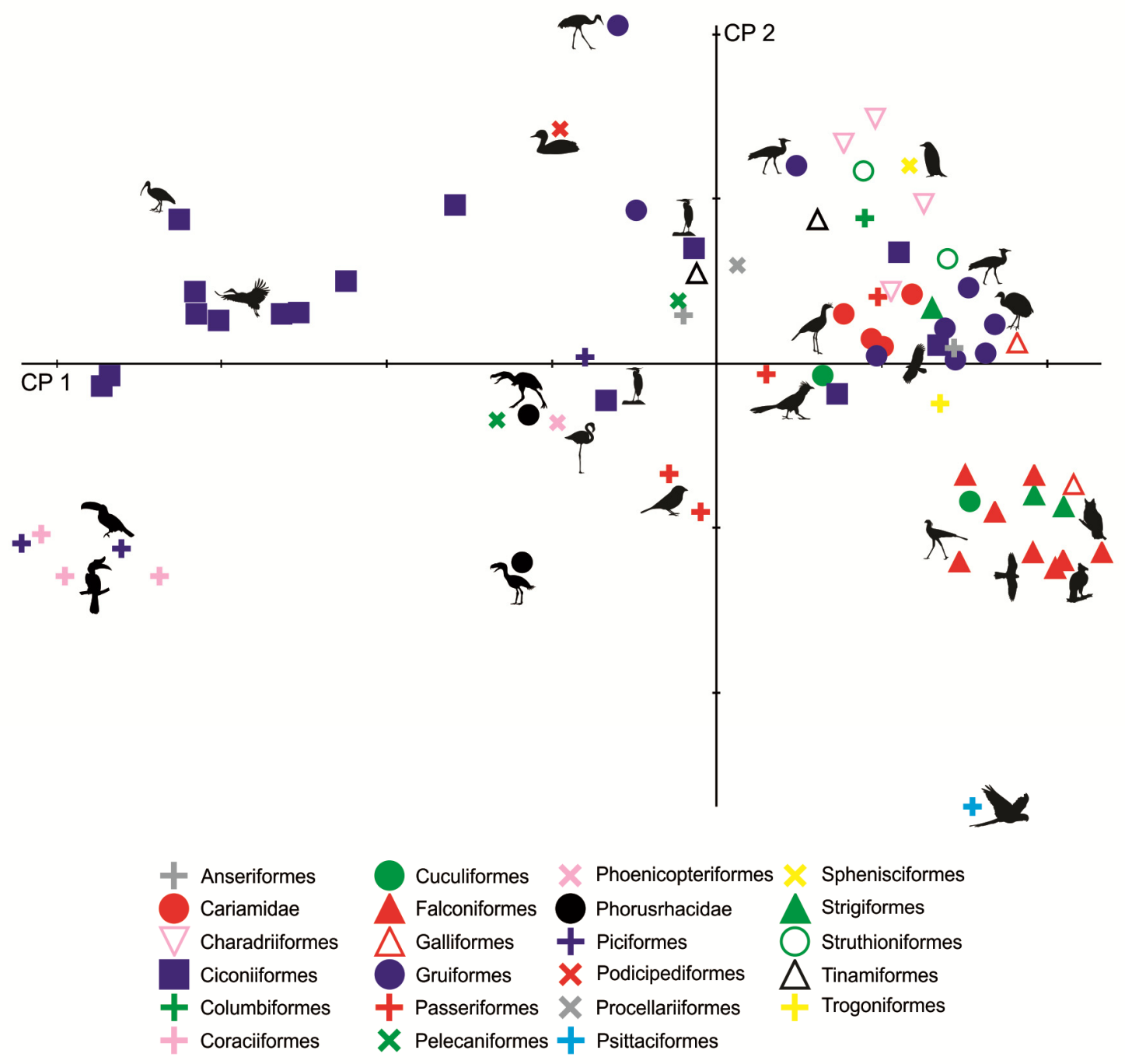

Figura 9.18. Cráneo: distribución de los taxones estudiados (actuales y fósiles) en el morfoespacio definido por CP1 y CP2 en vista lateral. 

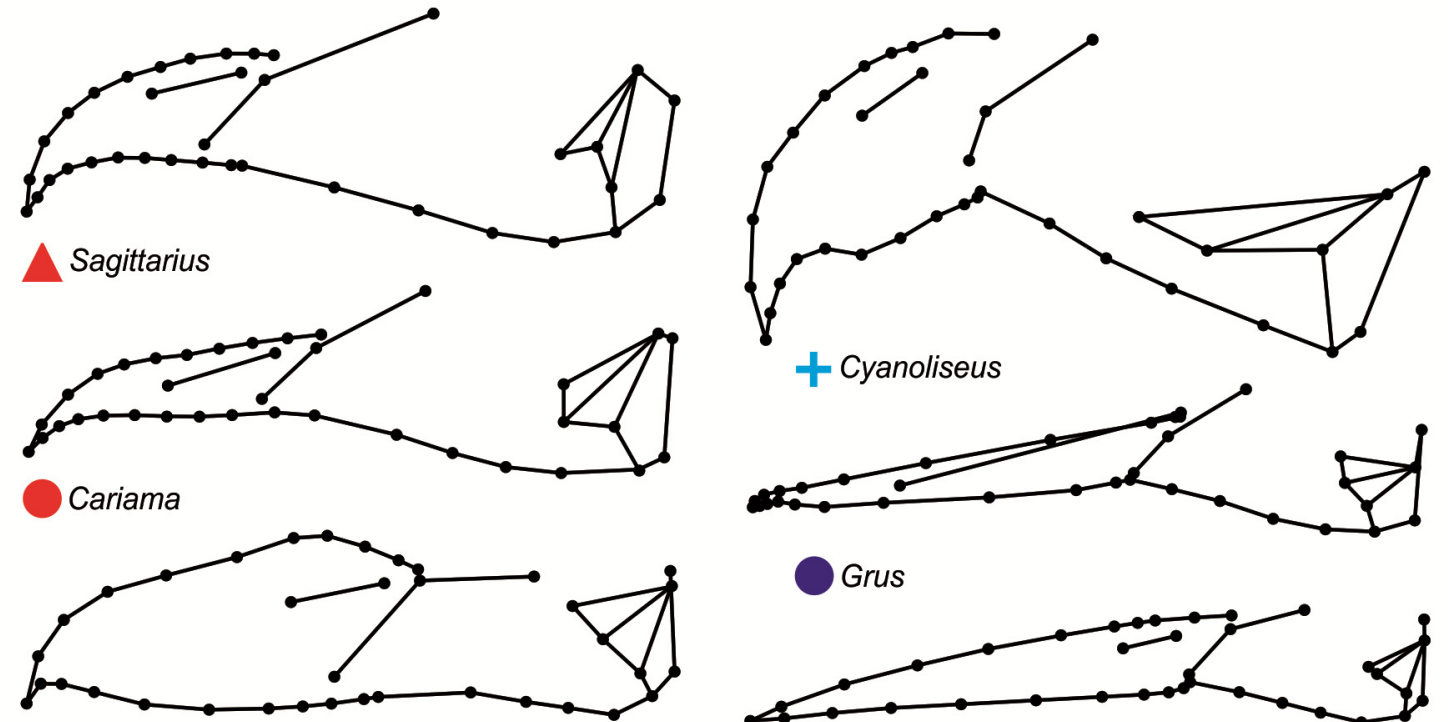

Taxón nuevo $A$
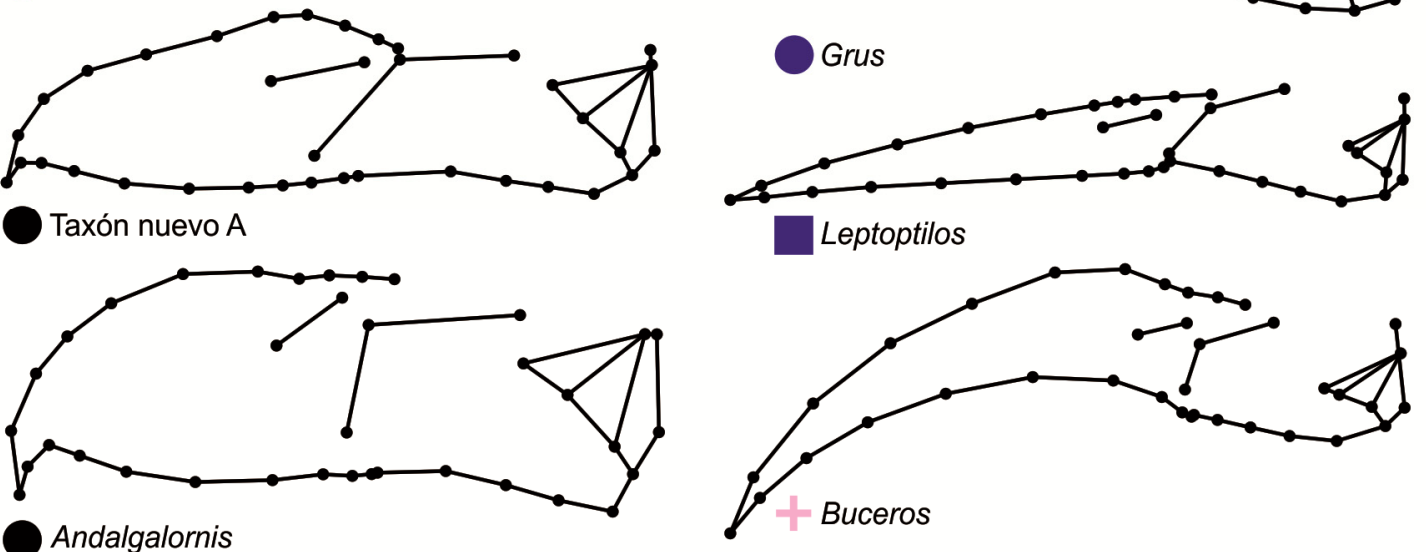

Figura 9.19. Grillas de visualización de los cambios de la forma del cráneo en distintas especies en vista lateral. 


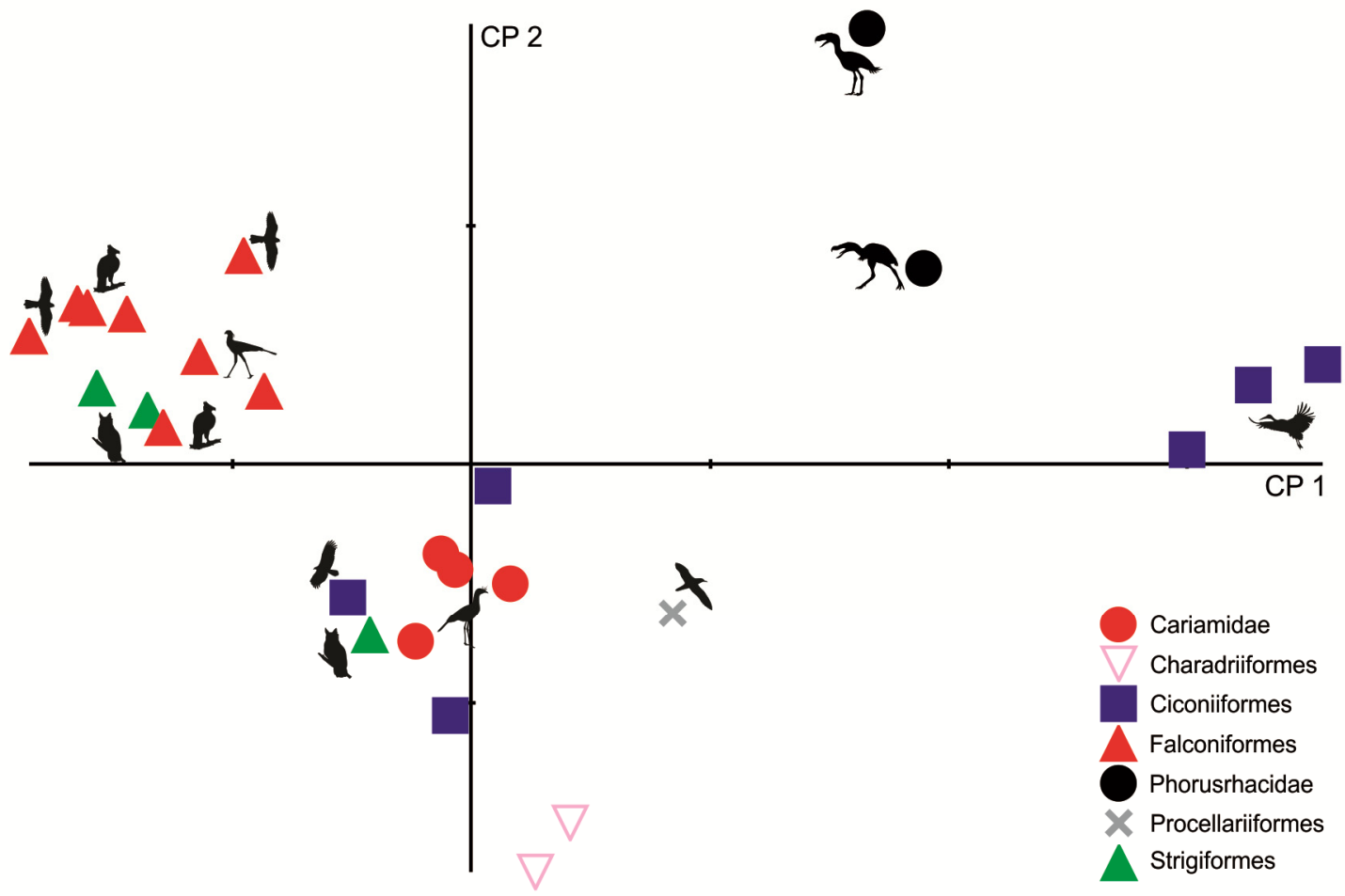

Figura 9.20. Cráneo: distribución de los taxones carnívoros en el morfoespacio definido por CP1 y CP2 en vista lateral. 


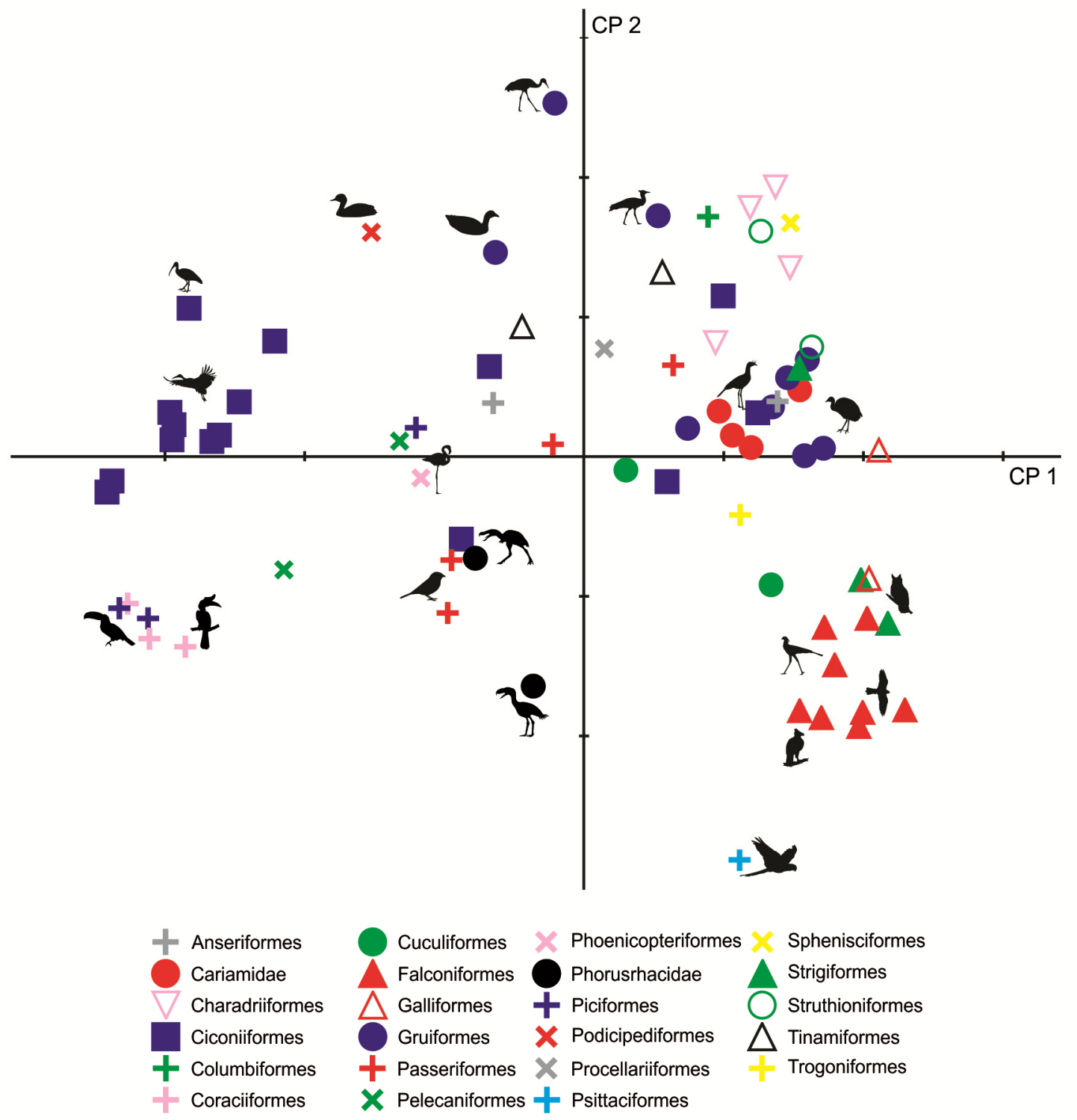

Figura 9.21. Esplacnocráneo: distribución de los taxones estudiados (actuales y fósiles) en el morfoespacio definido por CP1 y CP2 en vista lateral. 


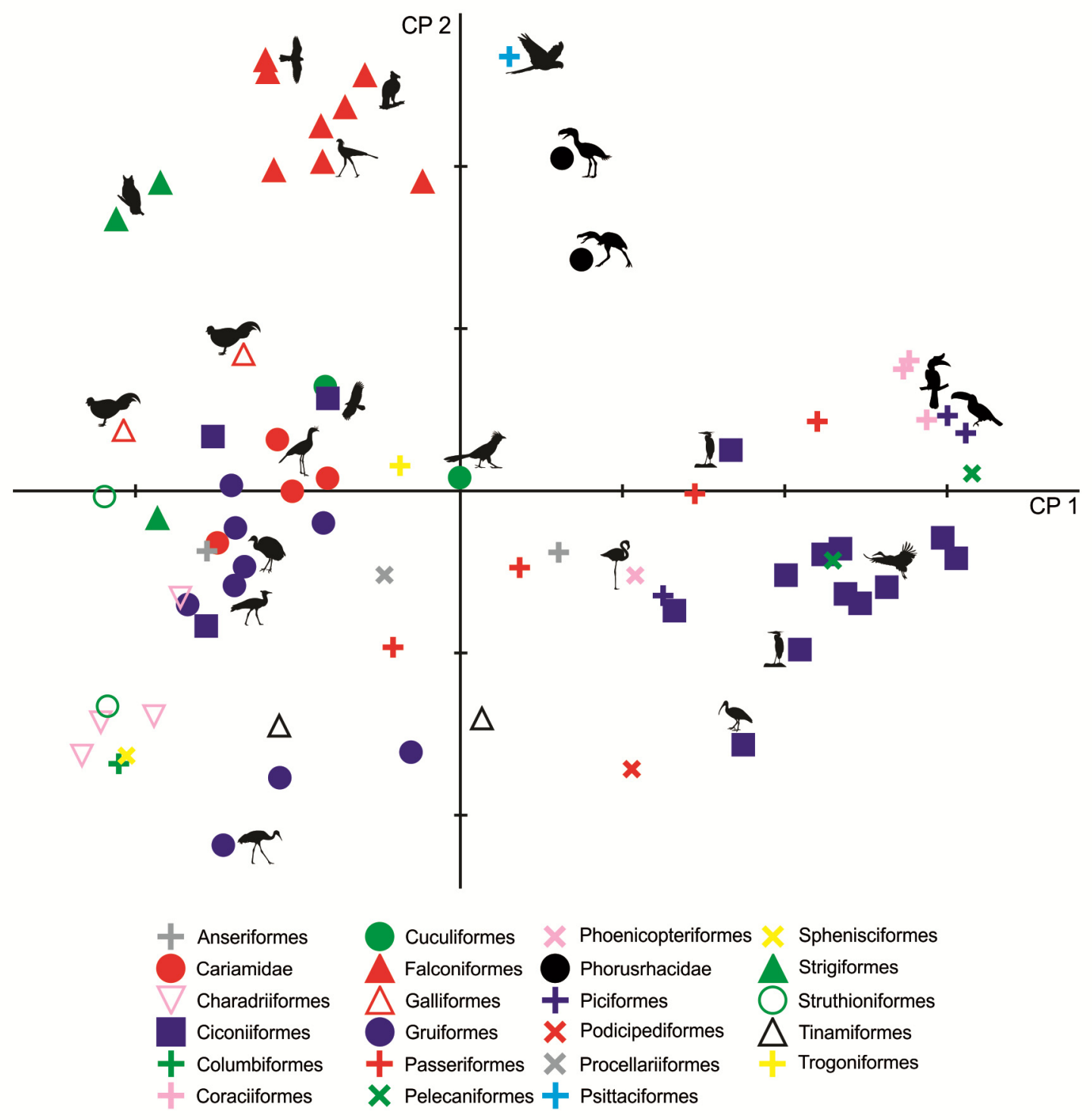

Figura 9.22. Pico: distribución de los taxones estudiados (actuales y fósiles) en el morfoespacio definido por CP1 y CP2 en vista lateral. 
A

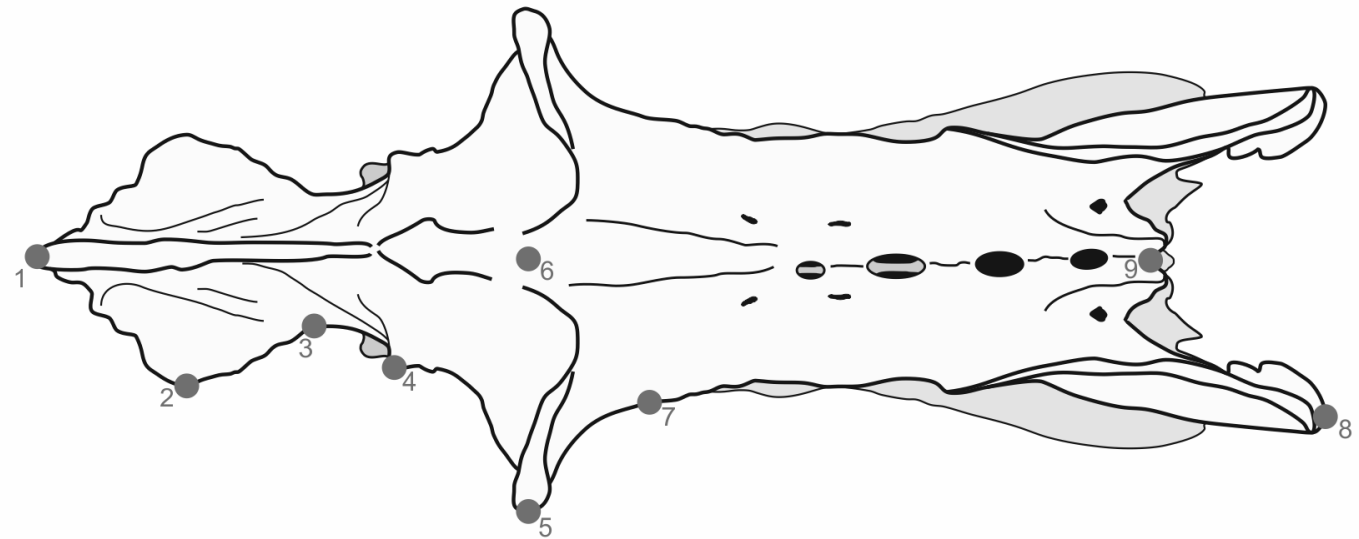

B

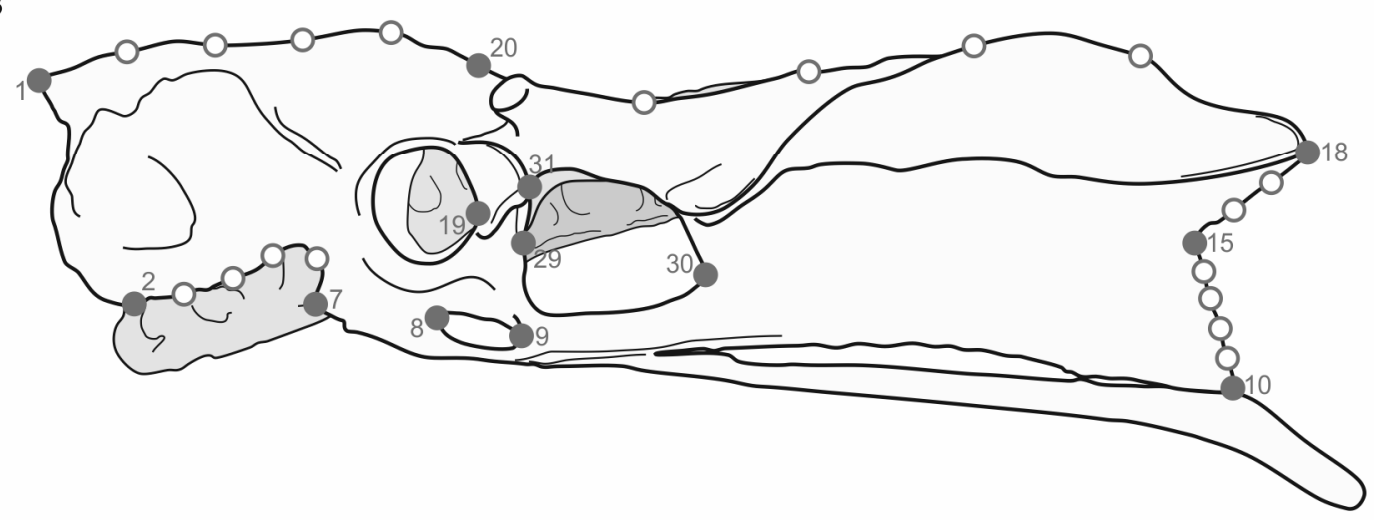

Figura 9.23. Landmarks utilizados en el estudio de la pelvis de las aves. A, vista dorsal; $\mathrm{B}$, vista lateral. 


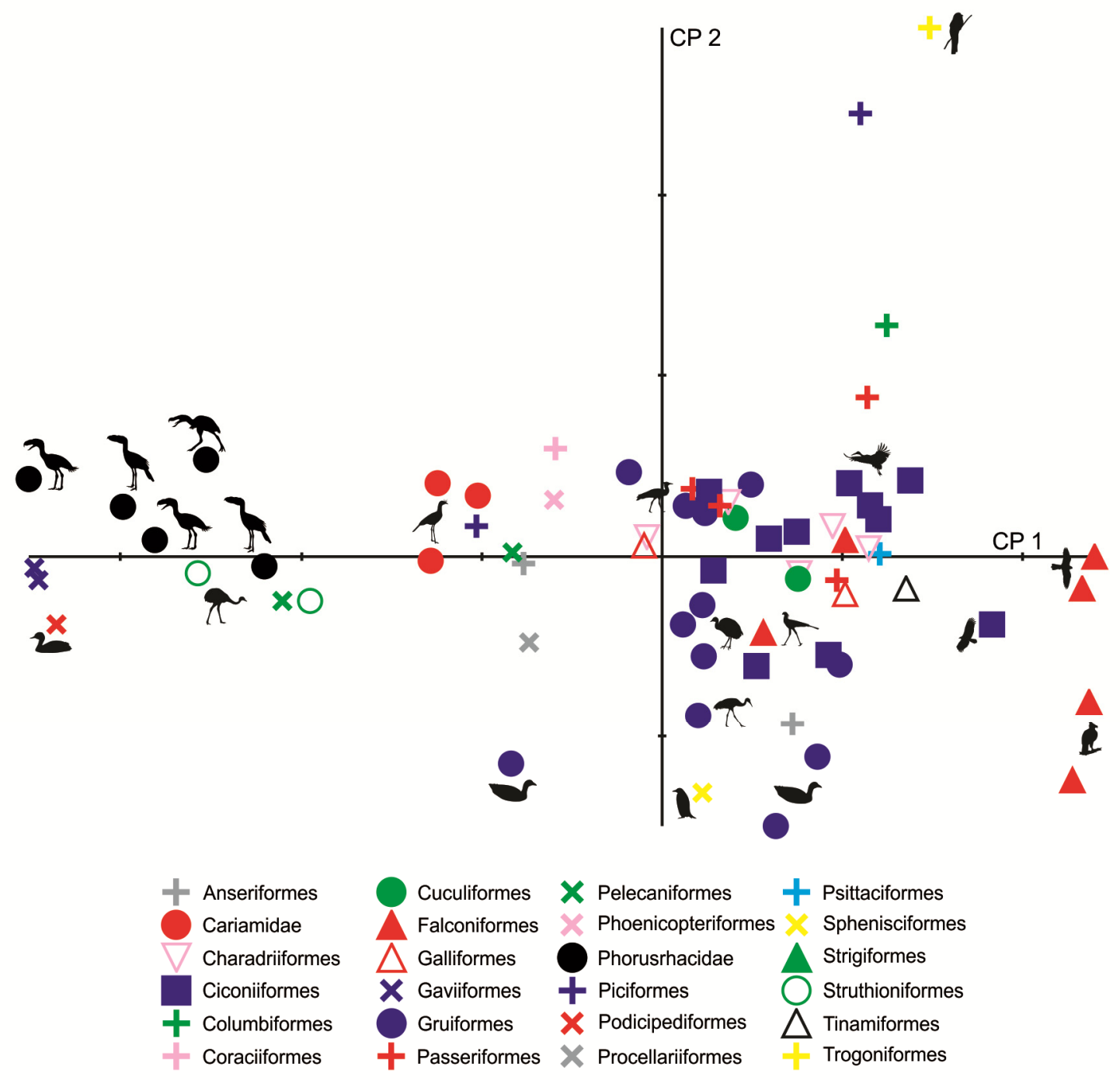

Figura 9.24. Pelvis: distribución de los taxones estudiados (actuales y fósiles) en el morfoespacio definido por CP1 y CP2 en vista dorsal. 

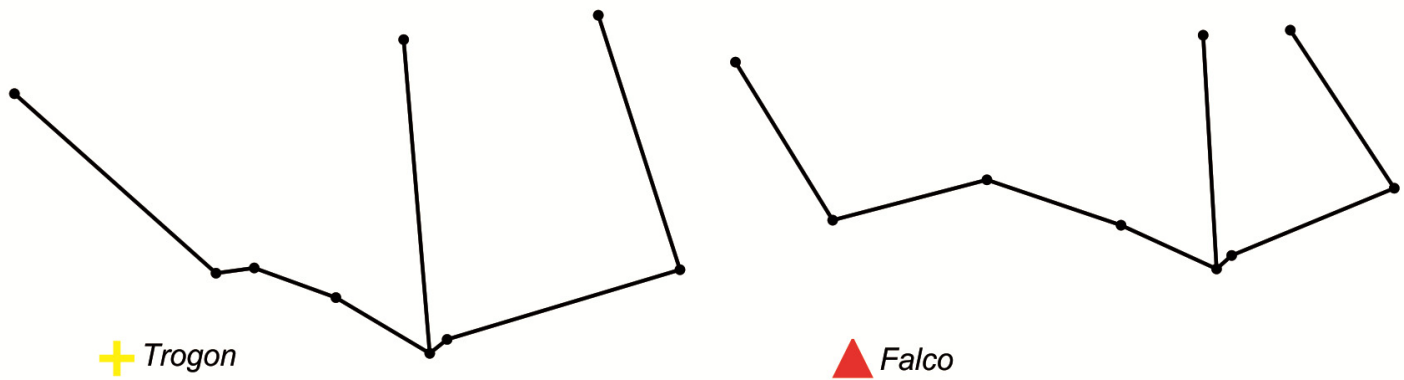

$\triangle$ Falco
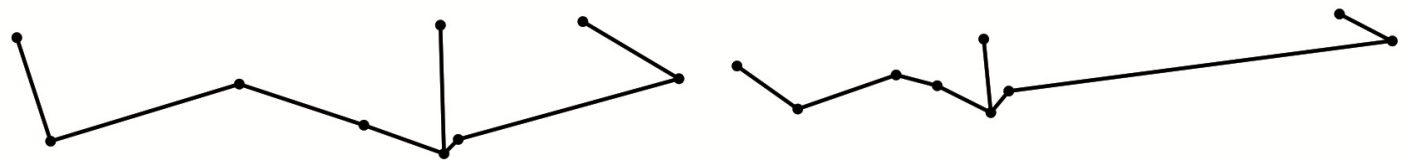

Rallus

X Gavia
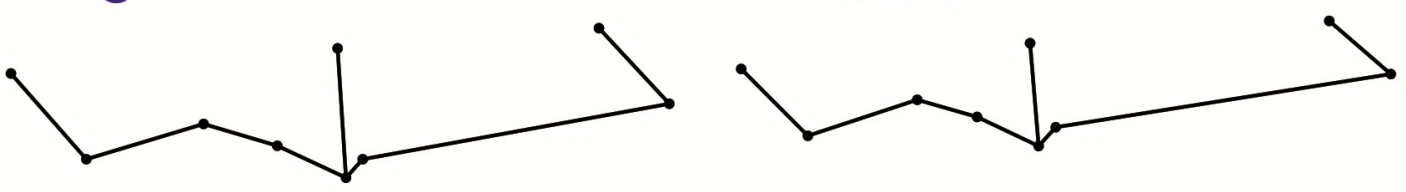

Cariama

P. lemoinei

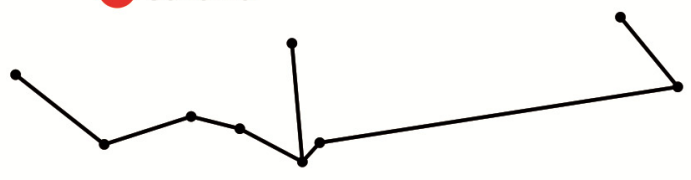

Taxón nuevo A

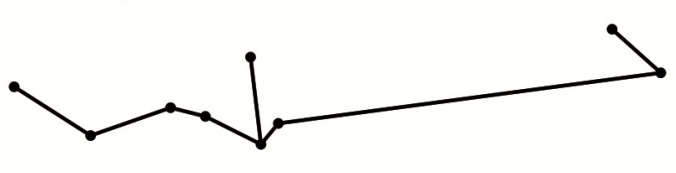

Andalgalornis

Figura 9.25. Grillas de visualización de los cambios de la forma de la pelvis en distintas especies en vista dorsal. 


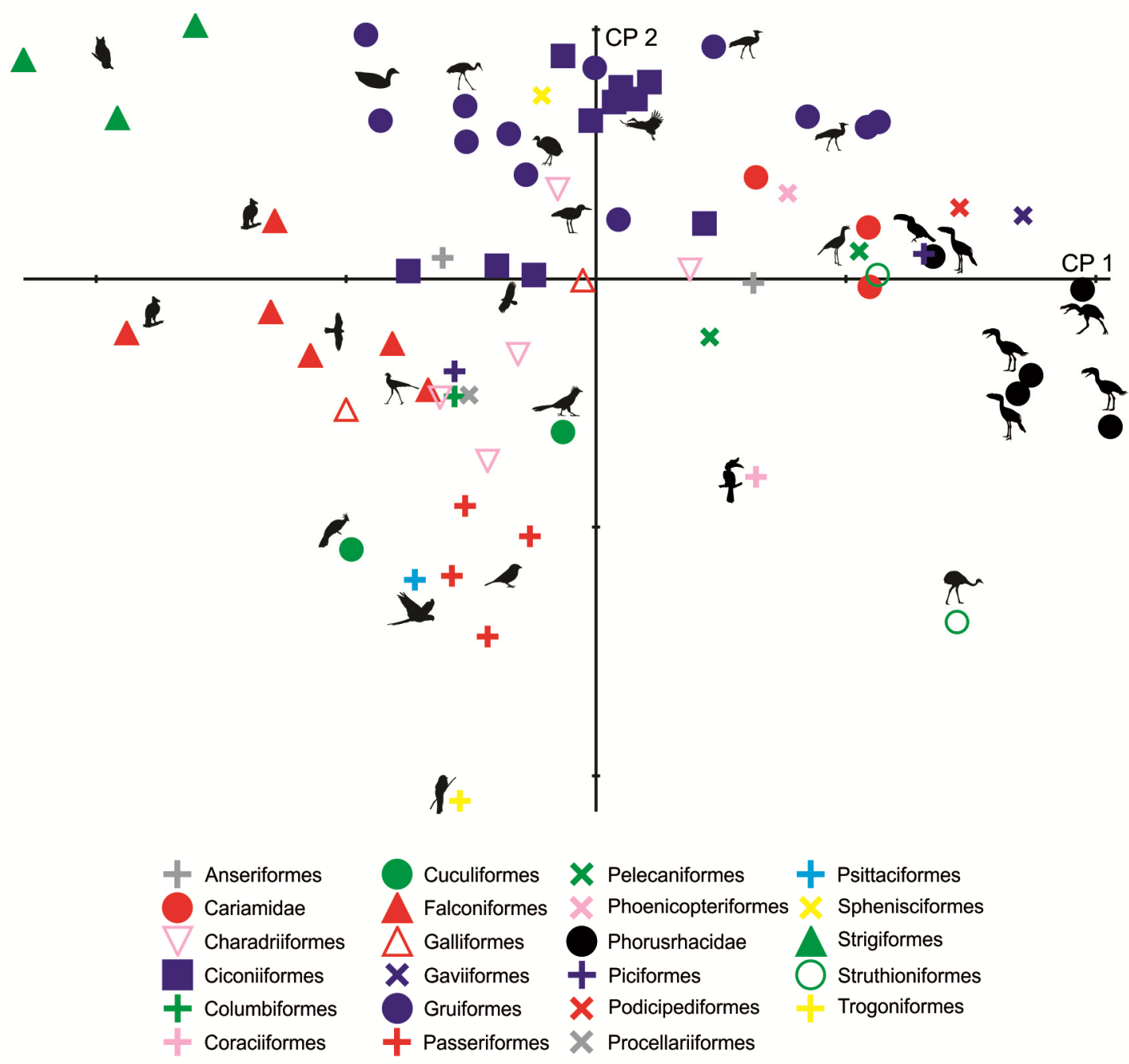

Figura 9.26. Pelvis: distribución de los taxones estudiados (actuales y fósiles) en el morfoespacio definido por CP1 y CP2 en vista lateral. 


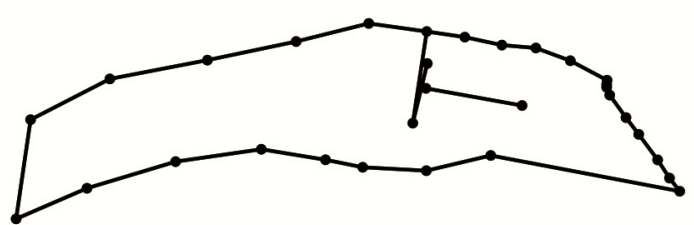

Bubo

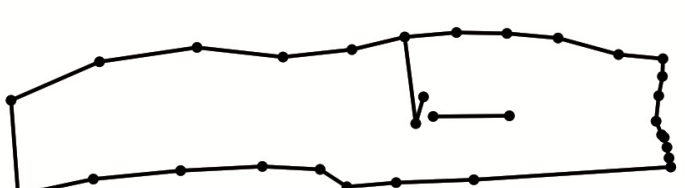

Rallus

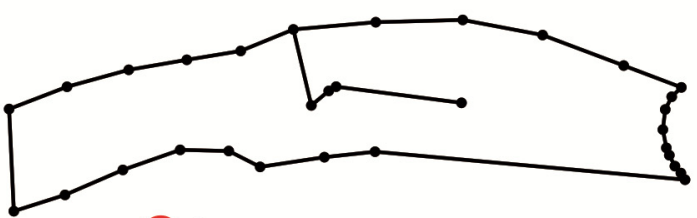

Cariama

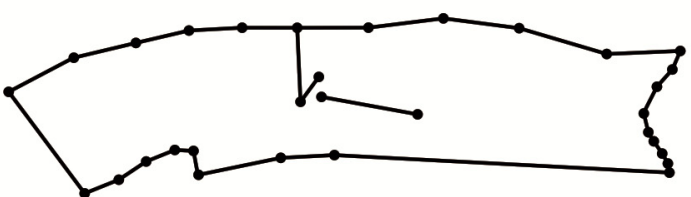

P. lemoinei
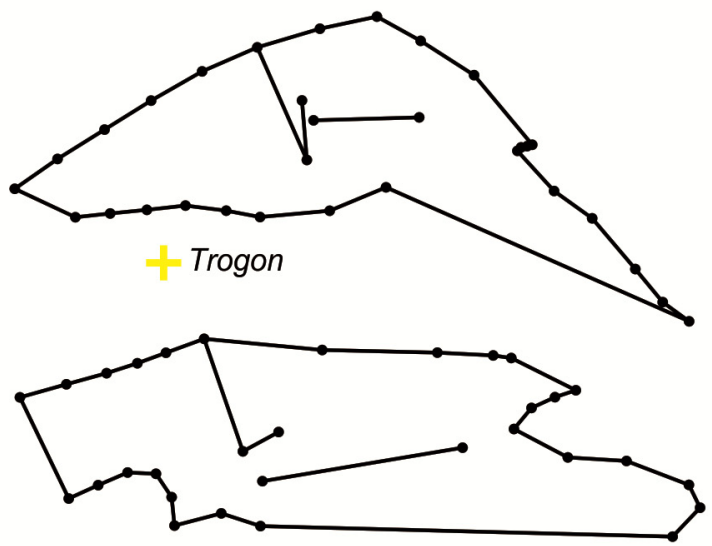

Rhea

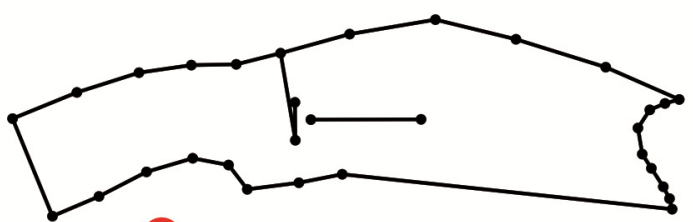

Chunga

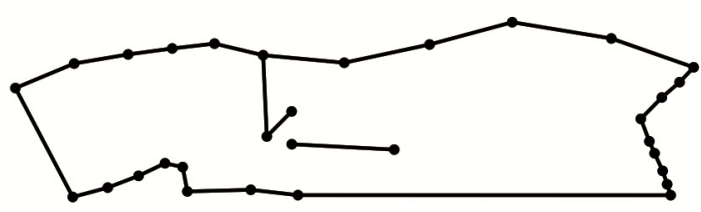

Taxón nuevo A

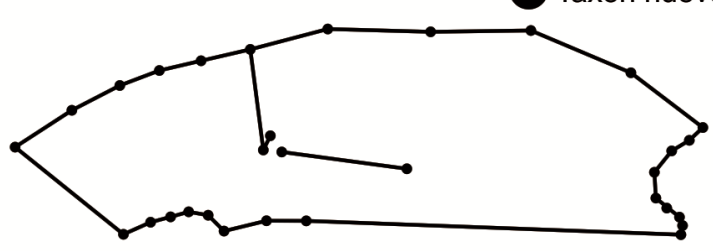

Andalgalornis

Figura 9.27. Grillas de visualización de los cambios de la forma de la pelvis en distintas especies en vista lateral. 


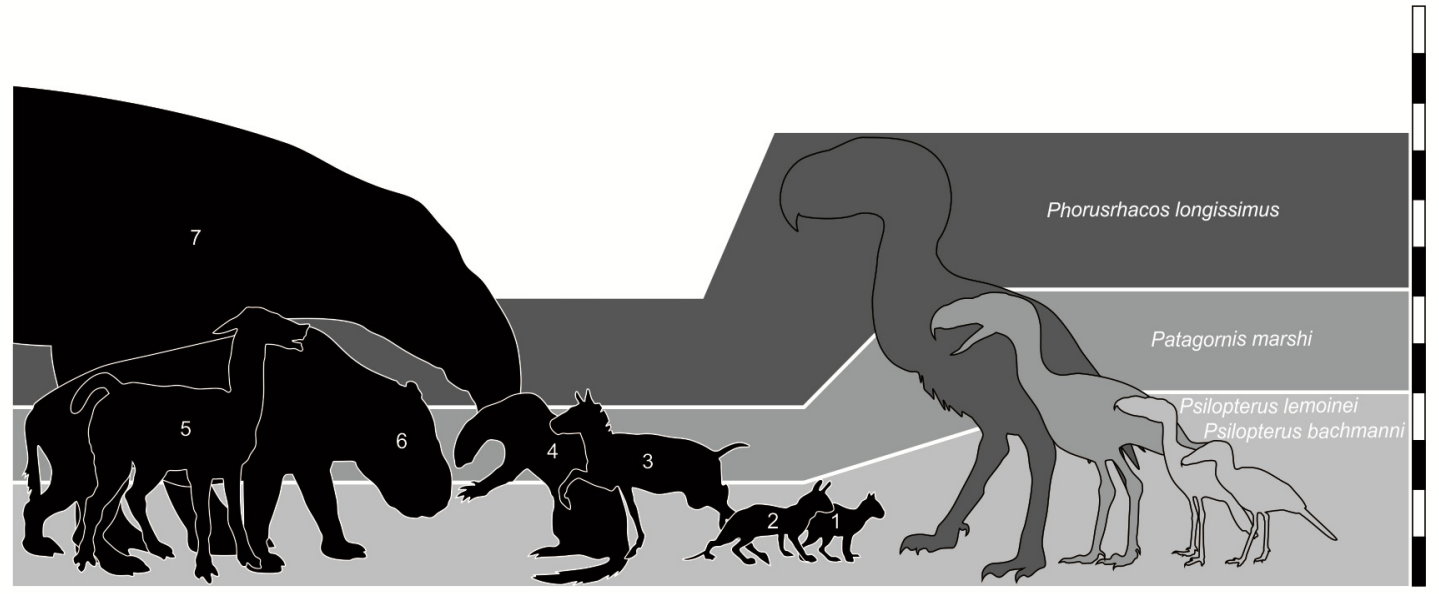

Figura 10.1. Relaciones depredador-presa de los fororracos ejemplificada con la fauna santacrucense. Cada una de las franjas de color representa el tamaño máximo de presa disponible. Las presas más pequeñas como los roedores podrían ser devoradas por los psilopterinos; los mamíferos de masa de hasta 10 o $20 \mathrm{~kg}$ estarían al alcance de los patagornitinos mientras que los de mayor masa y talla serían posibles presas de los forusracinos. Formas de kilaje superior a $130 \mathrm{~kg}$, como los Toxodontidae o los Homalodotheriidae probablemente eran inaccesibles a los fororracos.1, Eocardia; 2, Protypotherium; 3, Thoaterium; 4, Hapalops; 5, Theosodon; 6, Nesodon; 7, Astrapotherium. Escala $=3 \mathrm{mts}$. 


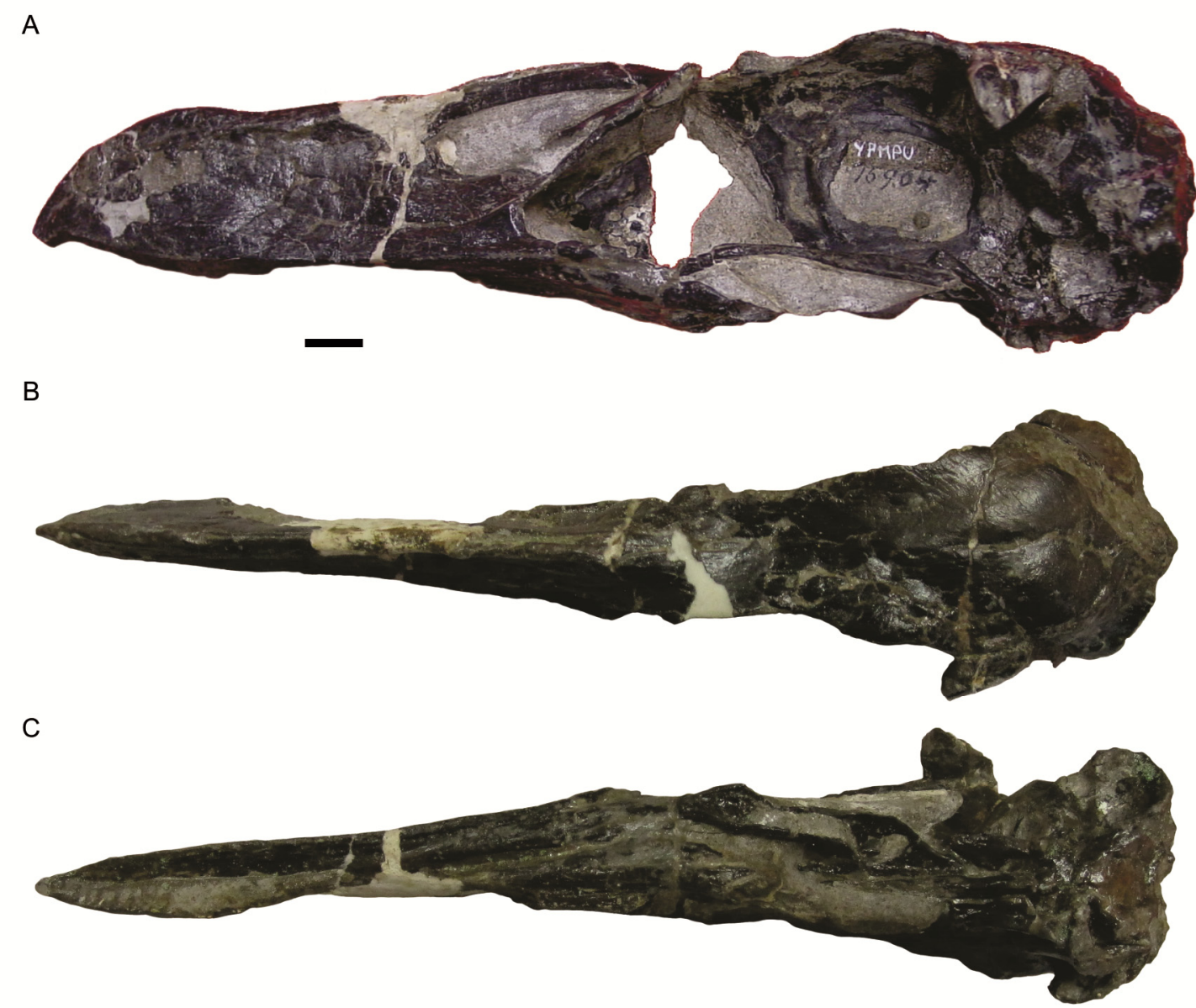

Lámina 4.1. Cráneo de Psilopterus bachmanni YPM-PU15904. A, vista lateral izquierda; B, vista dorsal; $\mathrm{C}$, vista ventral. Escala $=1 \mathrm{~cm}$. 
A

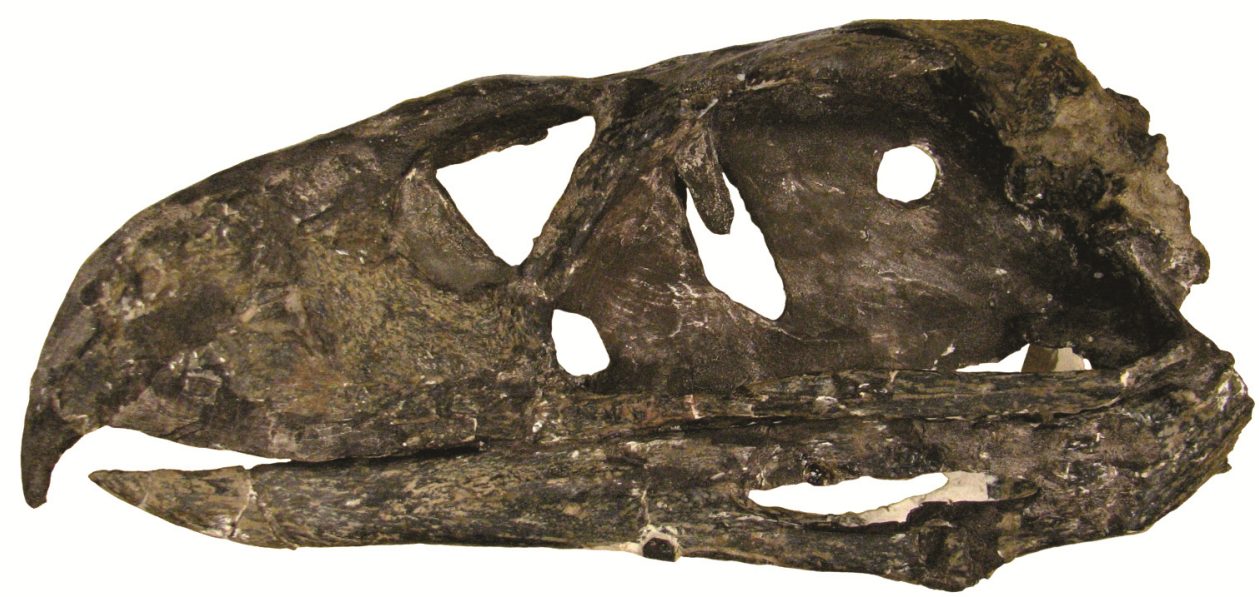

B
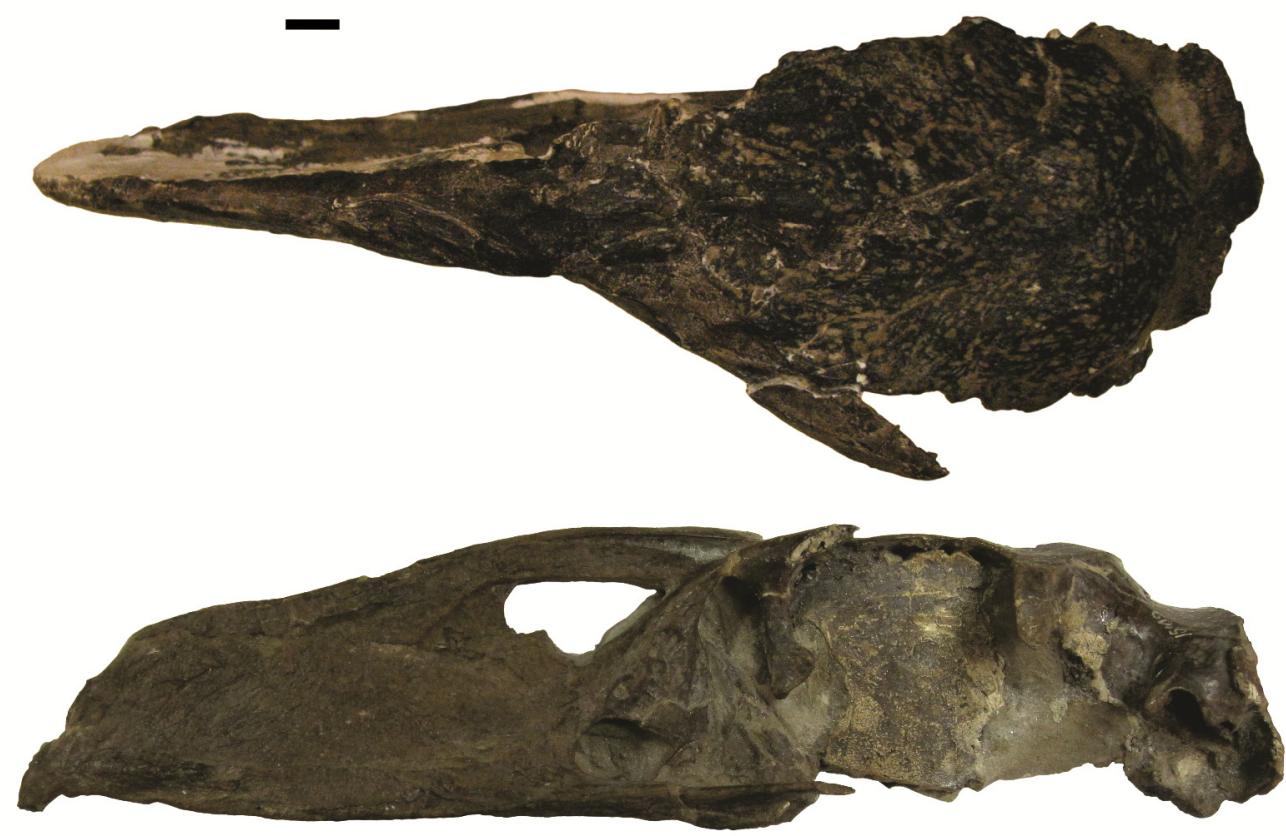

C

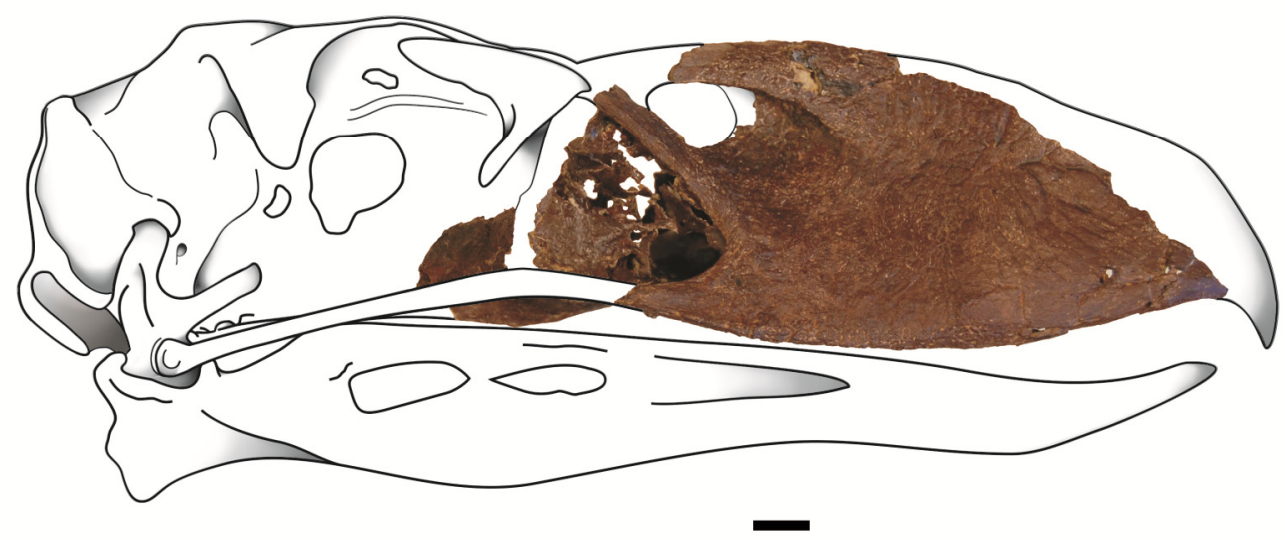

Lámina 4.2. Cráneo de Psilopterus lemoinei. A, vista lateral izquierda y dorsal de FMP13257; B, vista lateral izquierda de YPM-PU15109; C, vista lateral derecha de la porción preservada MPM-PV3649 en una reconstrucción de cráneo completo. Escala = $1 \mathrm{~cm}$. 
A
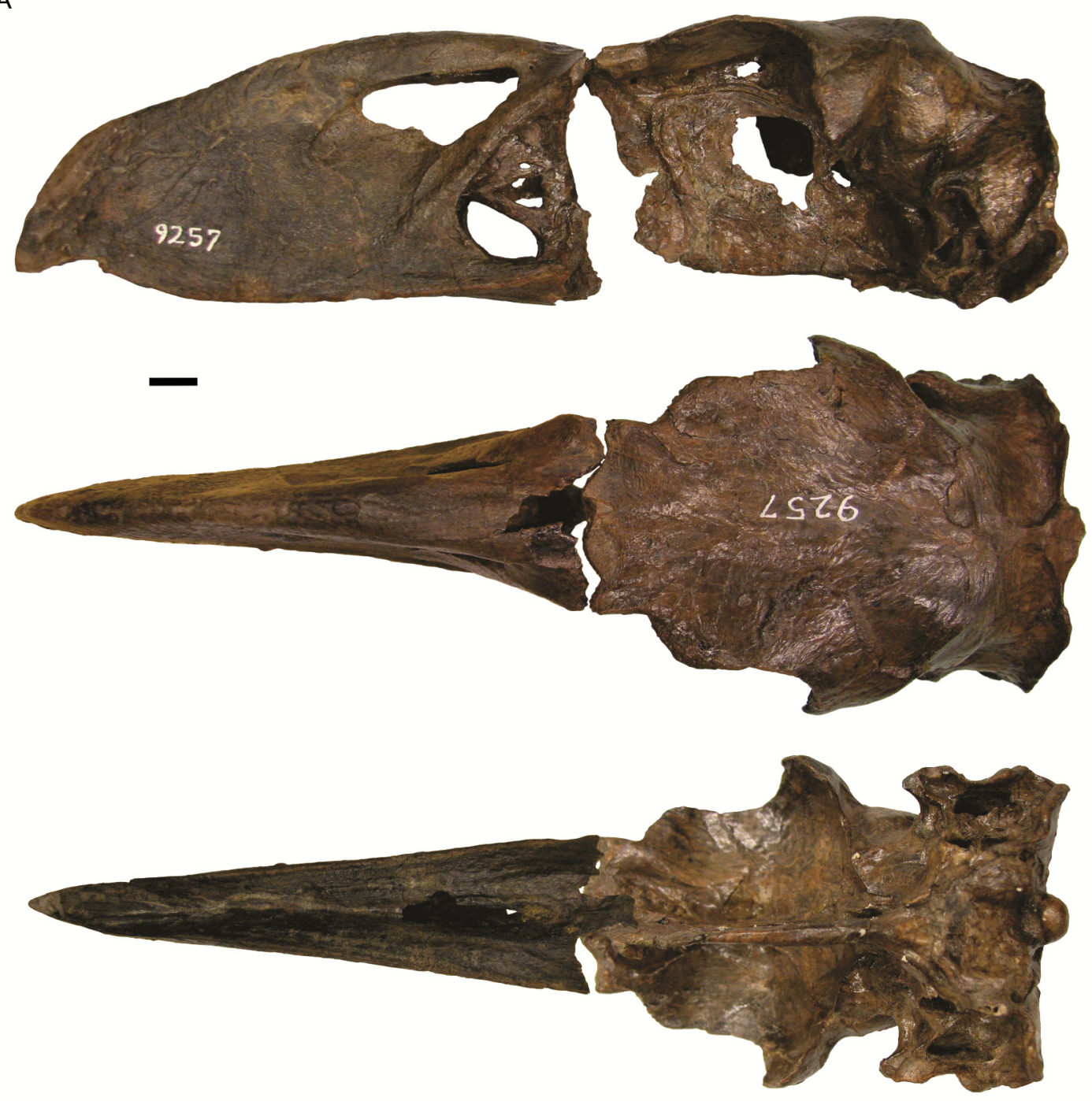

B

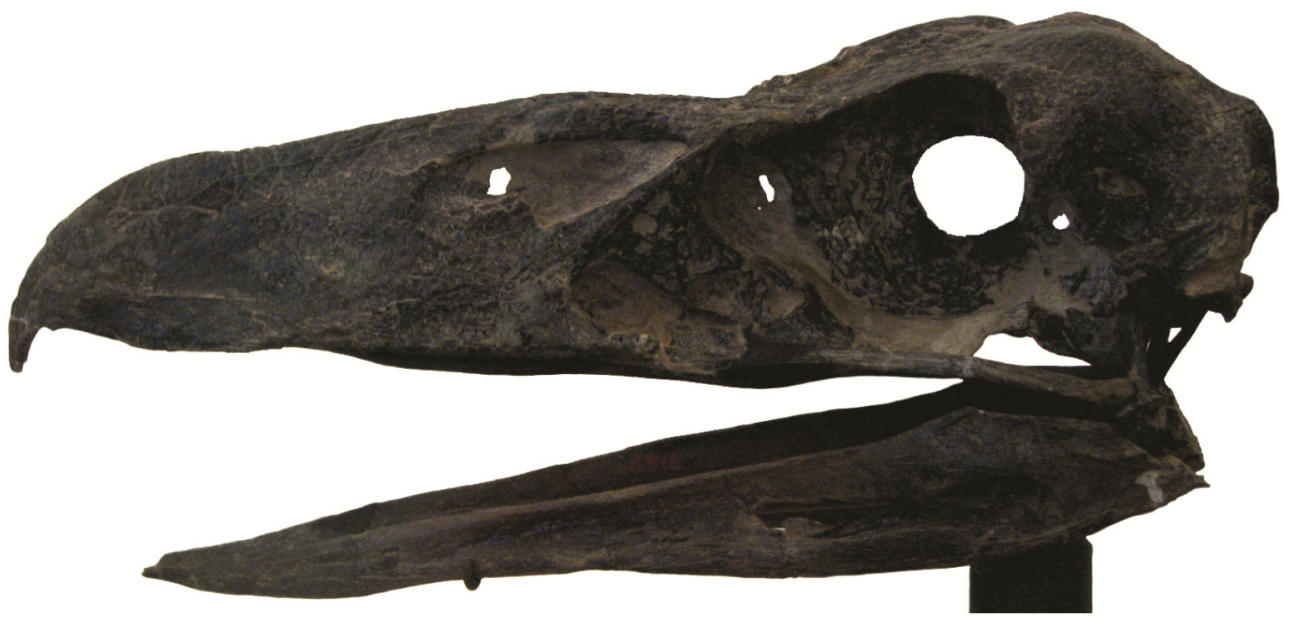

Lámina 4.3. Cráneo de Psilopterus lemoinei. A, vista lateral izquierda, dorsal y ventral de $A M N H$ 9257, Escala $=1 \mathrm{~cm}$. B, vista lateral izquierda de AMNH 9157 no a escala. 
A

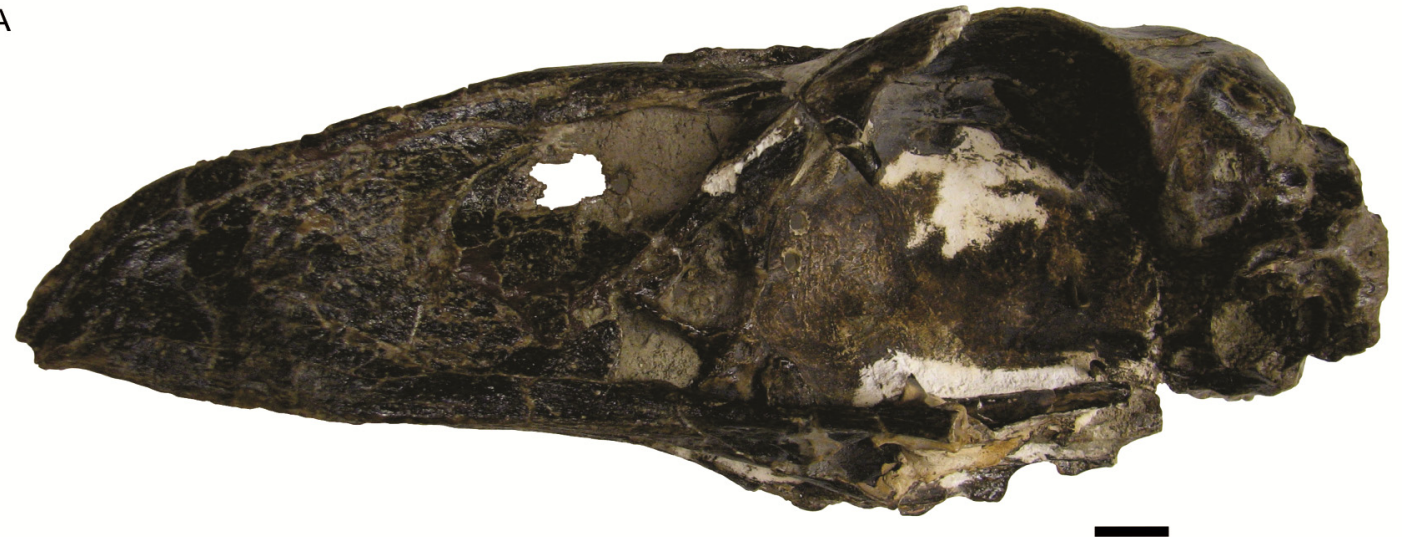

B

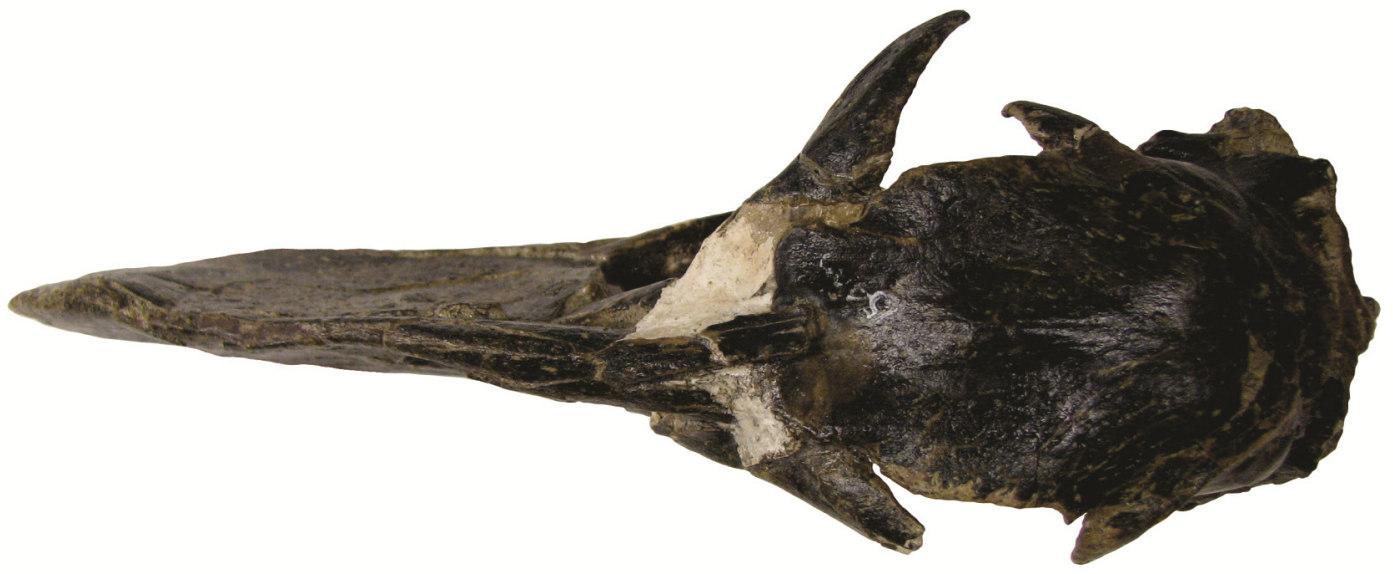

C

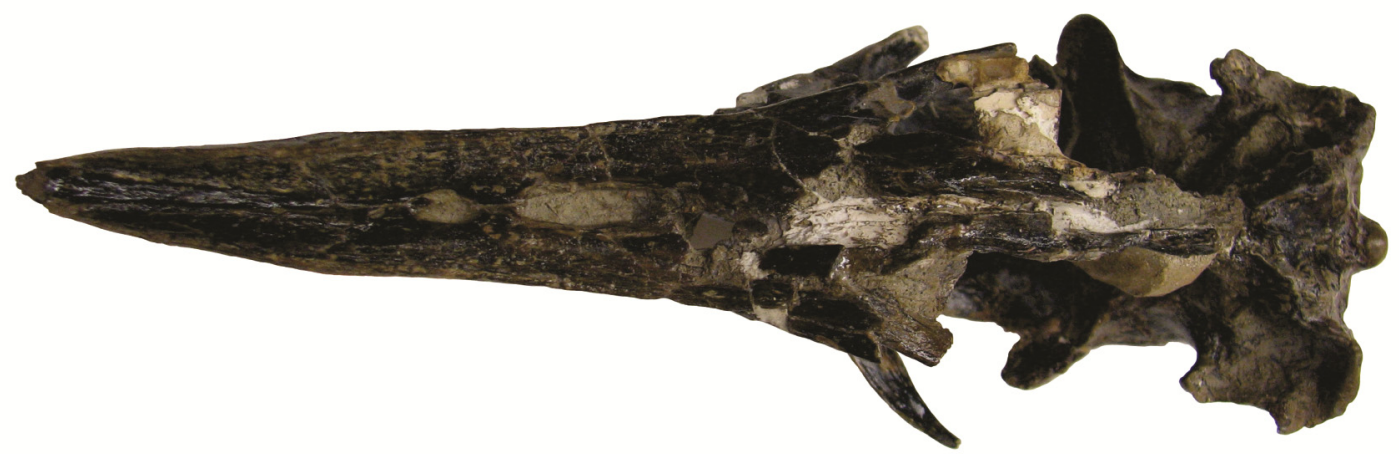

Lámina 4.4. Cráneo de Psilopterus lemoinei YPM-PU15402. A, vista lateral izquierda; $\mathrm{B}$, vista dorsal; $\mathrm{C}$, vista ventral. Escala $=1 \mathrm{~cm}$. 
A
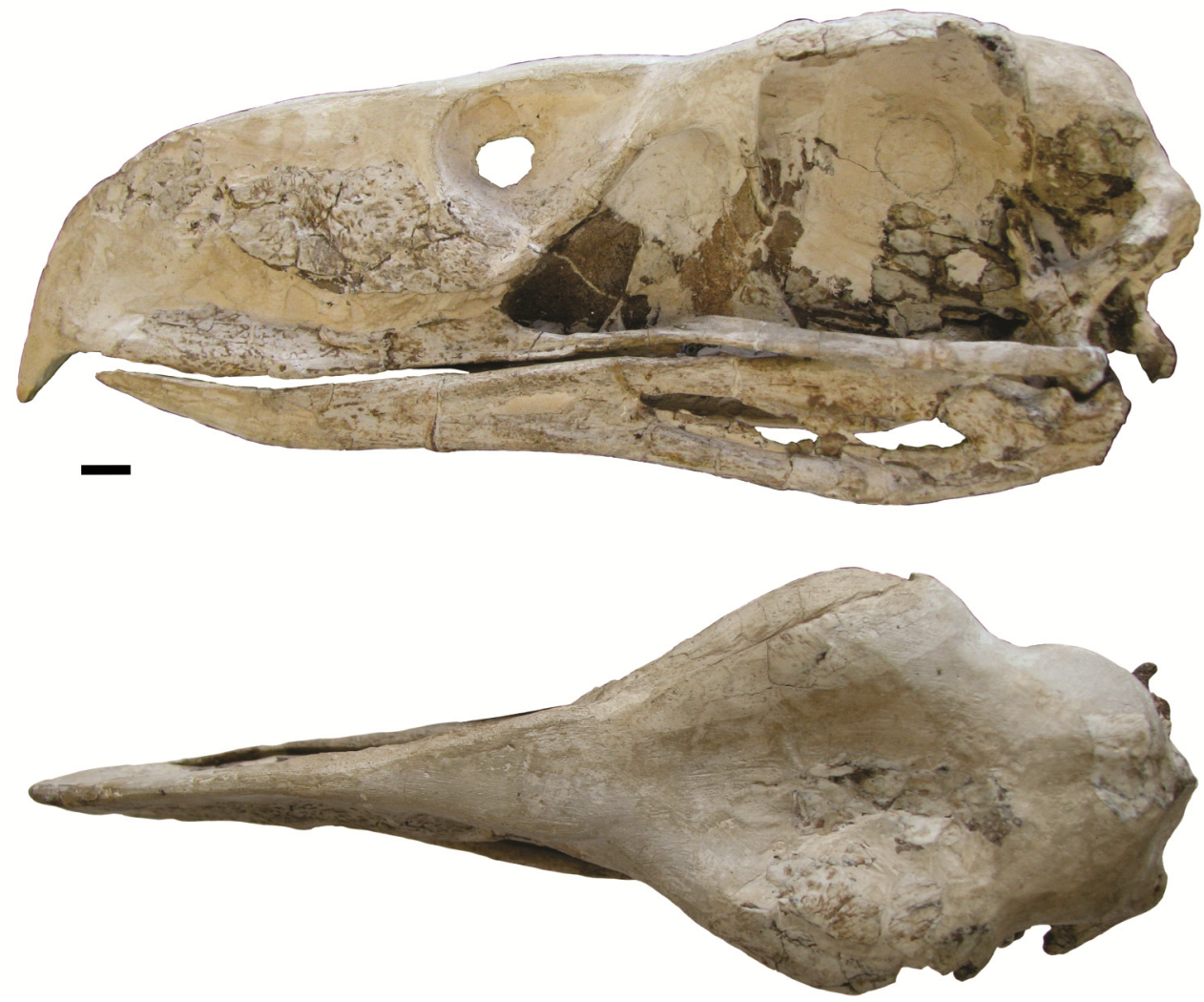

B
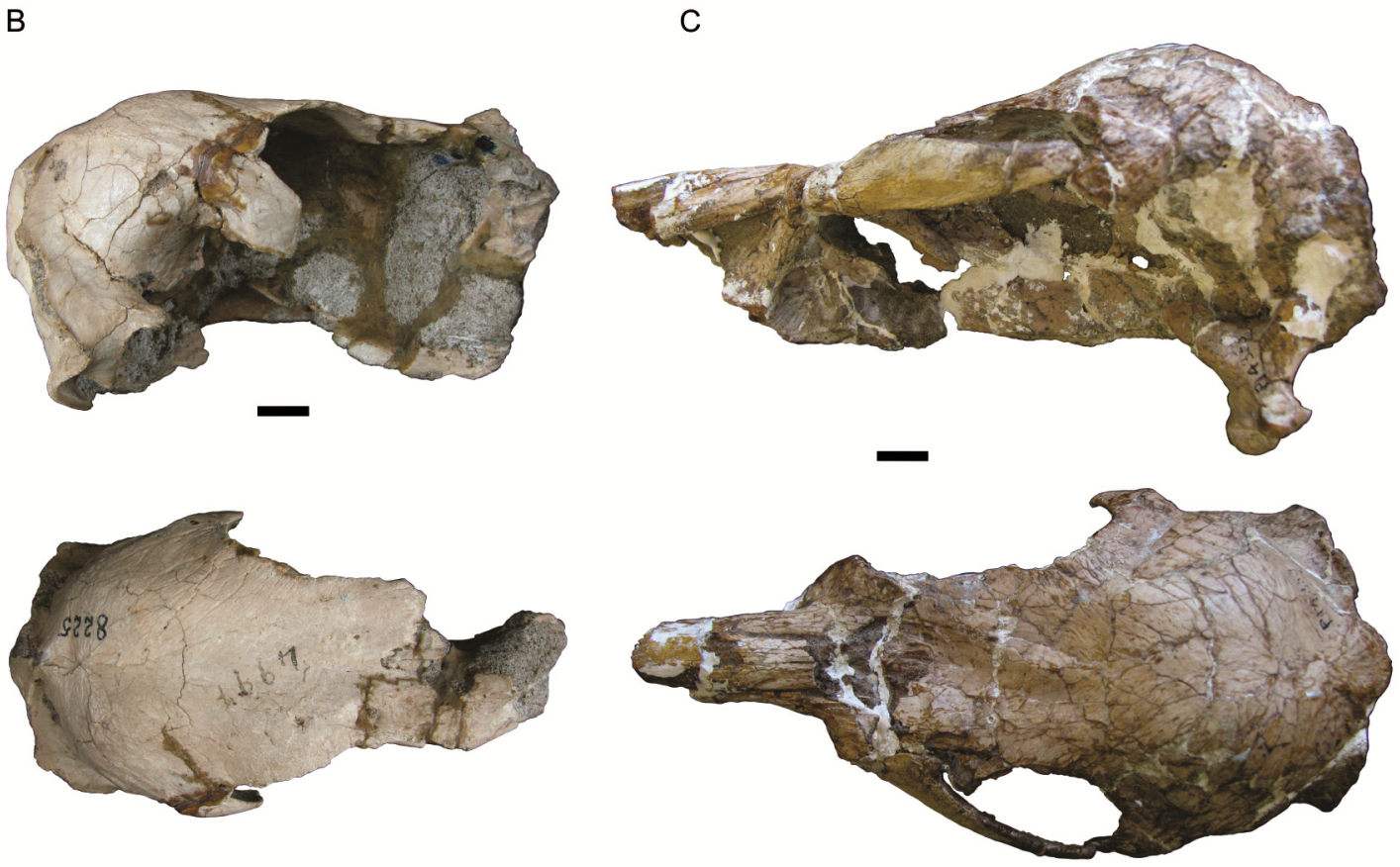

Lámina 4.5. Cráneo de Procariama simplex. A, vista lateral izquierda y dorsal de FMP14525; B, vista lateral izquierda y dorsal de MACN Pv 8225; C, vista lateral izquierda $\mathrm{y}$ dorsal de FM-P14353. Escala $=1 \mathrm{~cm}$. 
A

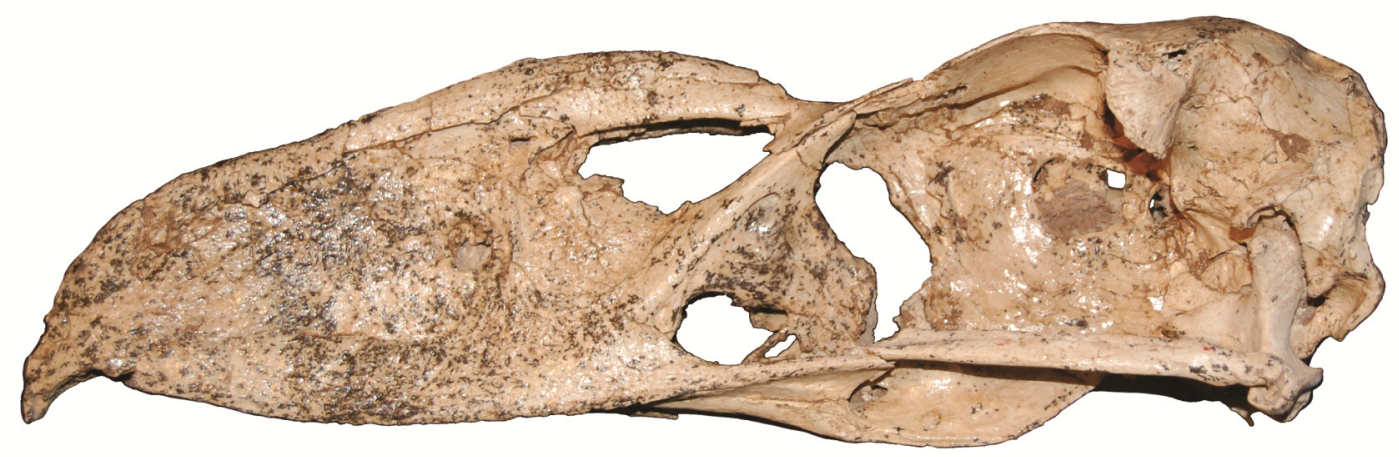

B

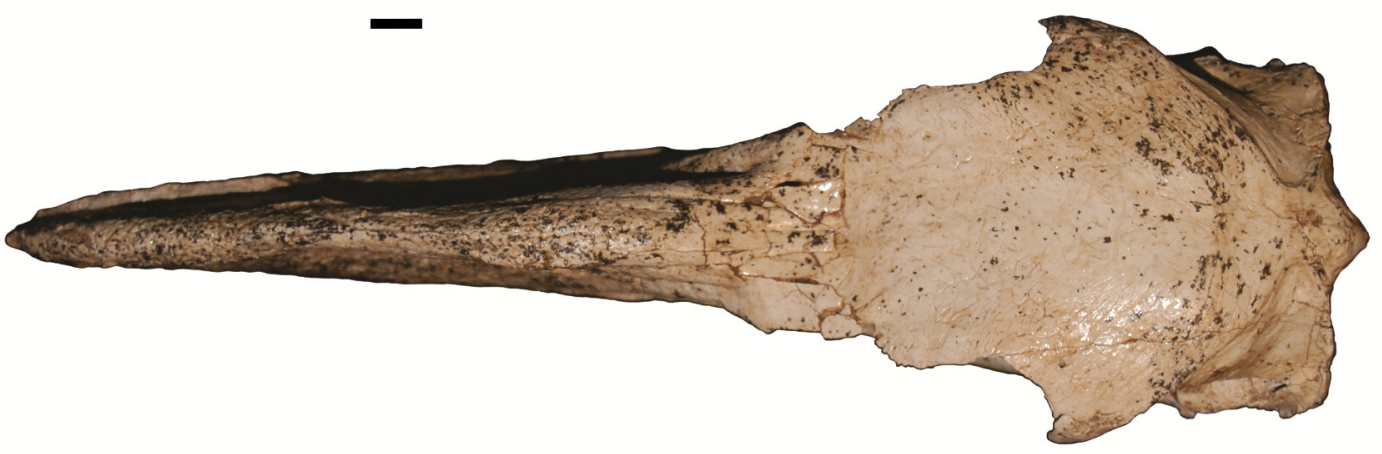

C

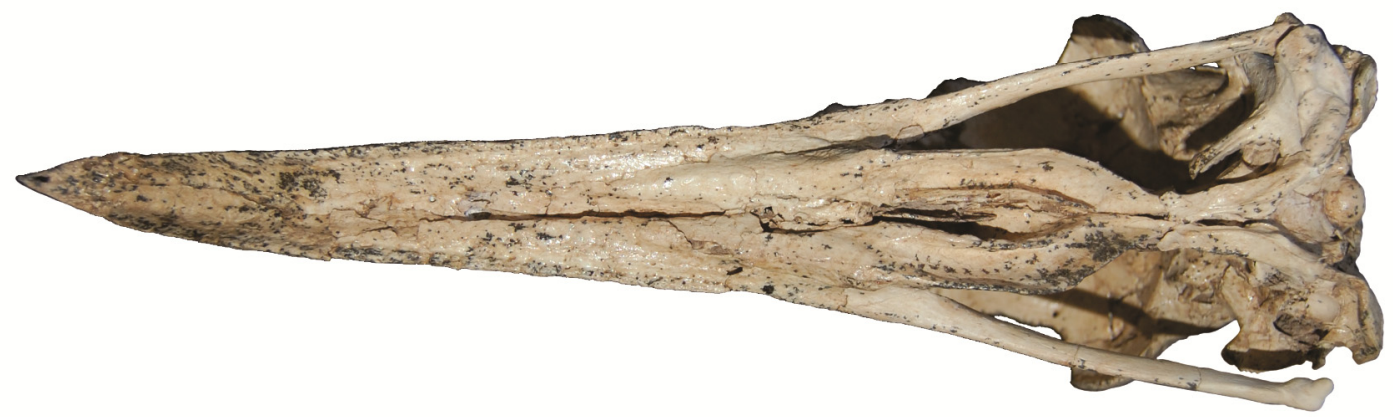

Lámina 4.6. Cráneo de Taxón nuevo A MMP 5050. A, vista lateral izquierda; $B$, vista dorsal; $\mathrm{C}$, vista ventral. Escala $=1 \mathrm{~cm}$. 
A

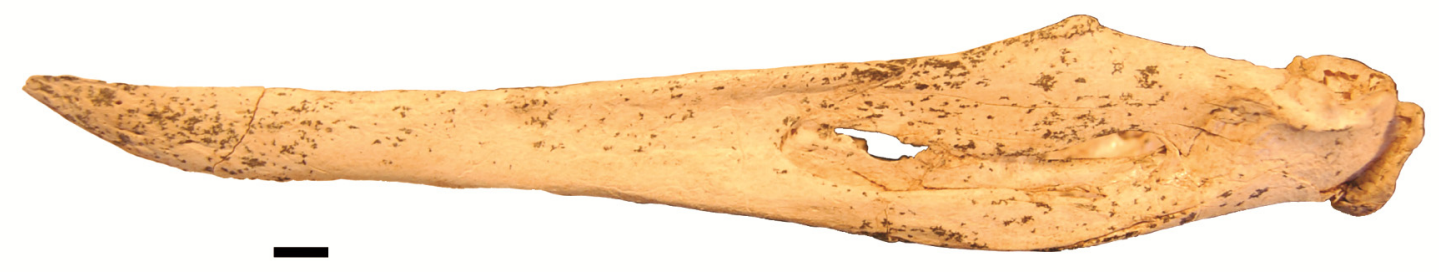

B

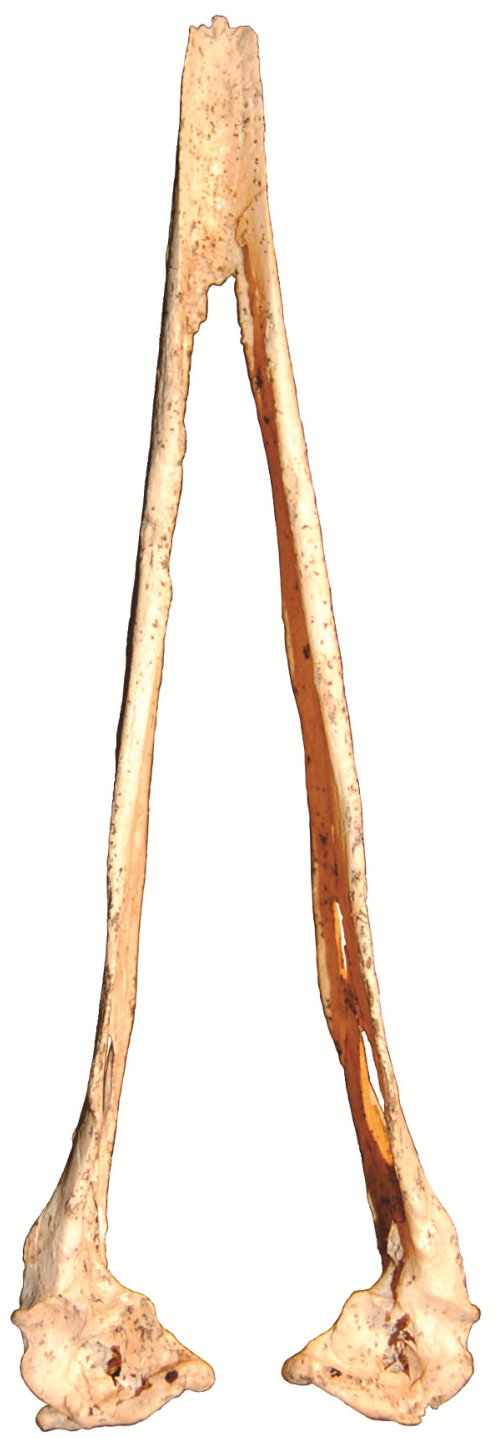

C

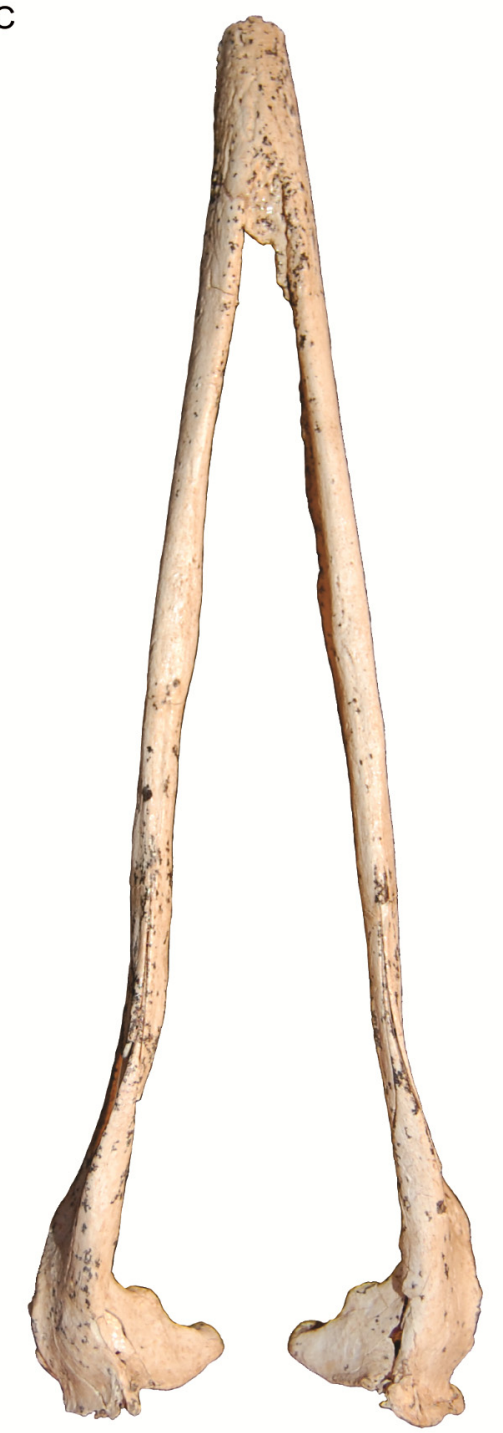

Lámina 4.7. Mandíbula de Taxón nuevo A MMP 5050. A, vista lateral izquierda; B, vista dorsal; $\mathrm{C}$, vista ventral. Escala $=1 \mathrm{~cm}$. 


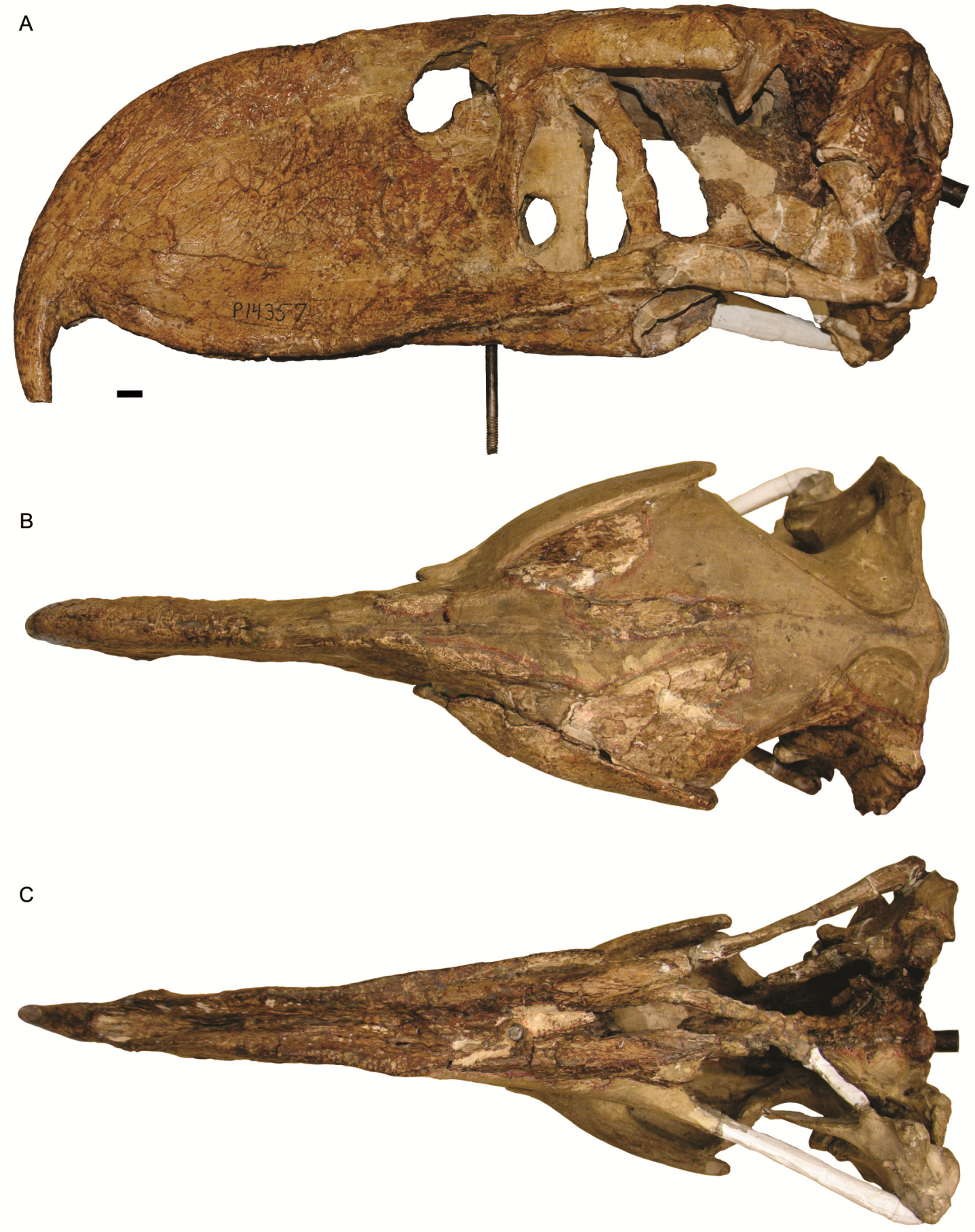

Lámina 4.8. Cráneo de Andalgalornis steulleti FM-P14357. A, vista lateral izquierda; $B$, vista dorsal; $C$, vista ventral. Escala $=1 \mathrm{~cm}$. 
A
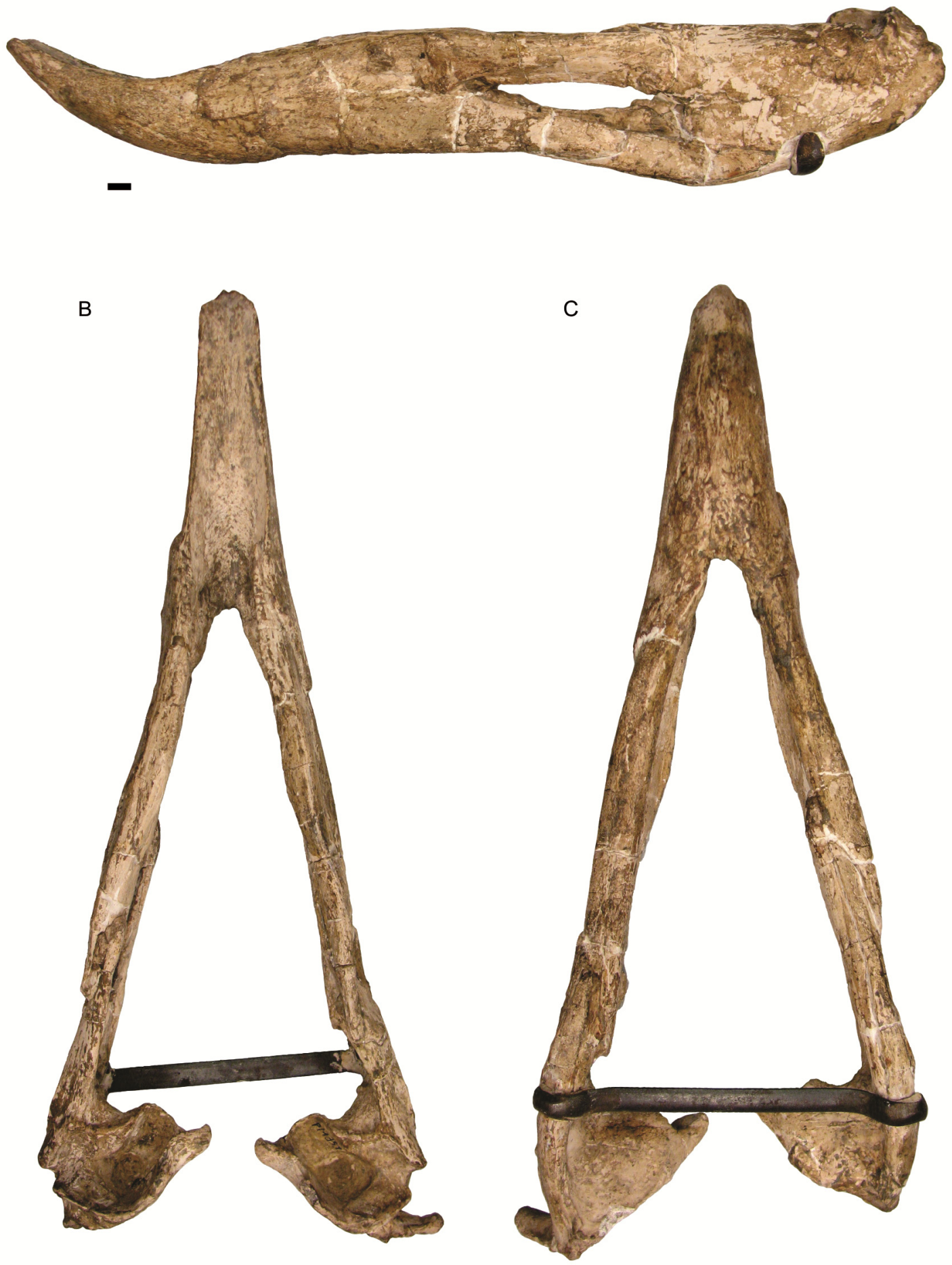

Lámina 4.9. Mandíbula de Andalgalornis steulleti FM-P14357. A, vista lateral izquierda; B, vista dorsal; C, vista ventral. Escala $=1 \mathrm{~cm}$. 
A
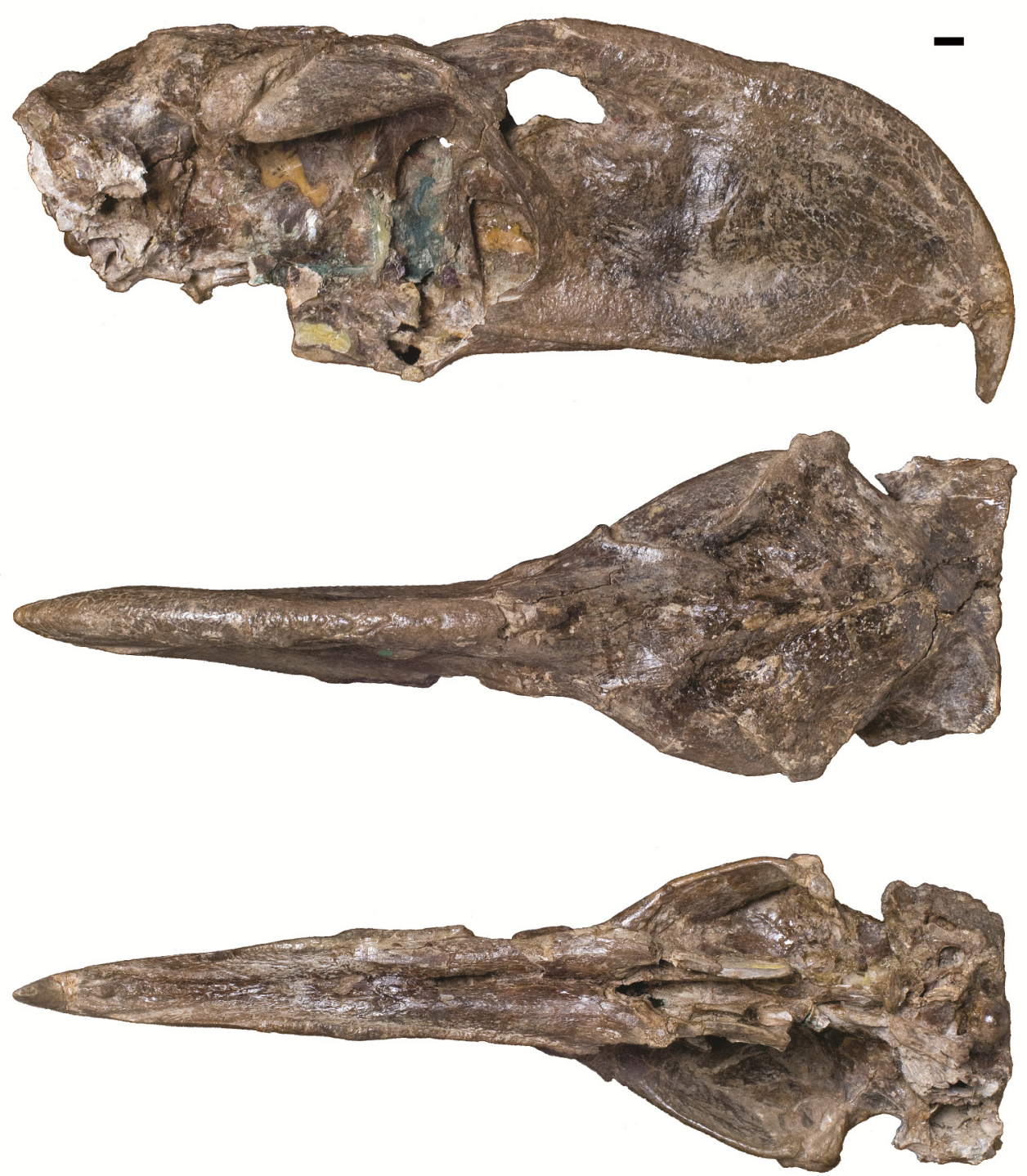

B

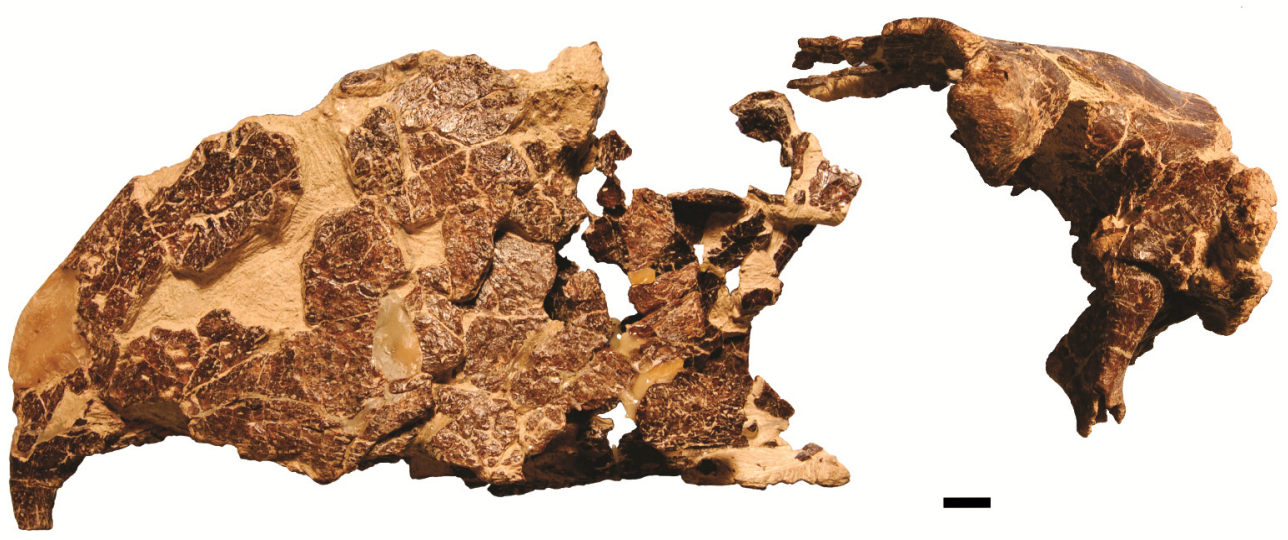

Lámina 4.10. Cráneo de Patagornis marshi. A, vista lateral derecha, dorsal y ventral de BMNH-A516; B, vista lateral izquierda de MLP 84-II-9-21. Escala = $1 \mathrm{~cm}$. 
A

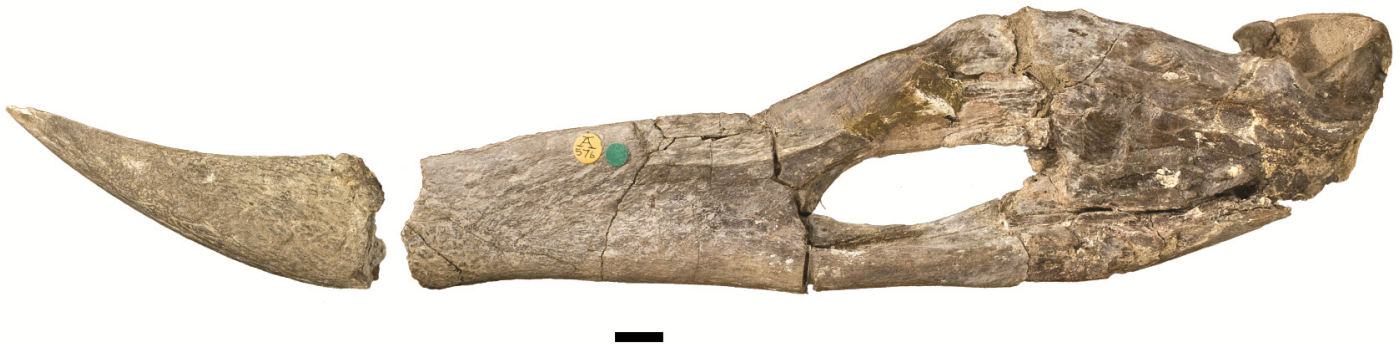

B
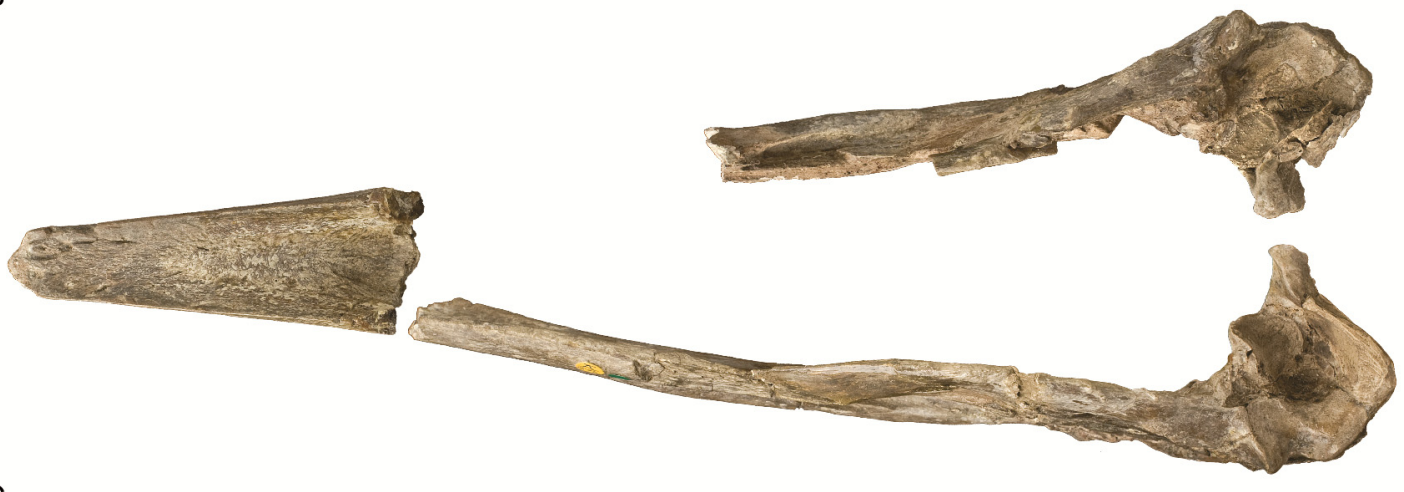

C

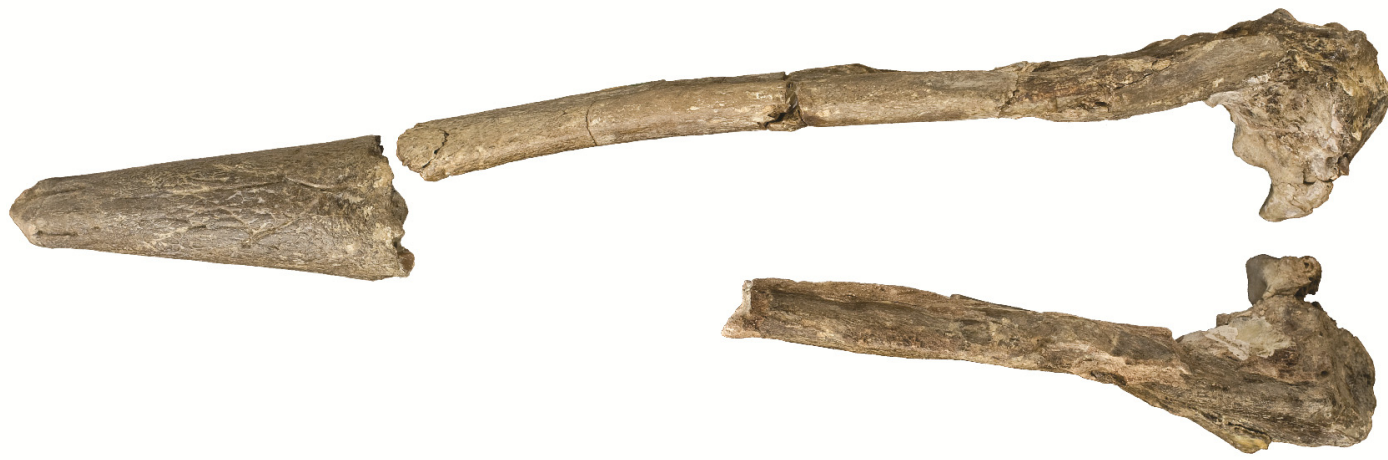

D

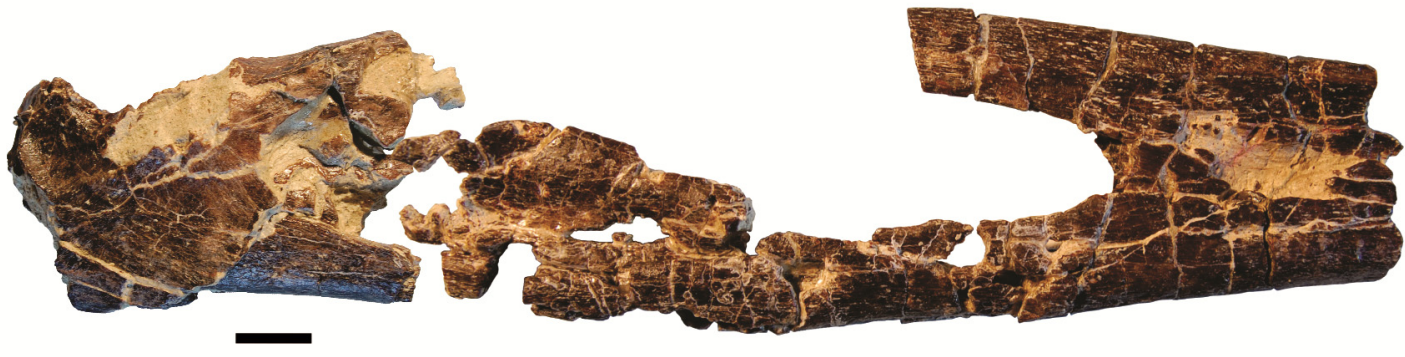

Lámina 4.11. Mandíbula de Patagornis marshi. A, vista lateral izquierda, dorsal y ventral de BMNH-A516; B, vista lateral derecha de MLP 84-II-9-21. Escala $=1 \mathrm{~cm}$. 


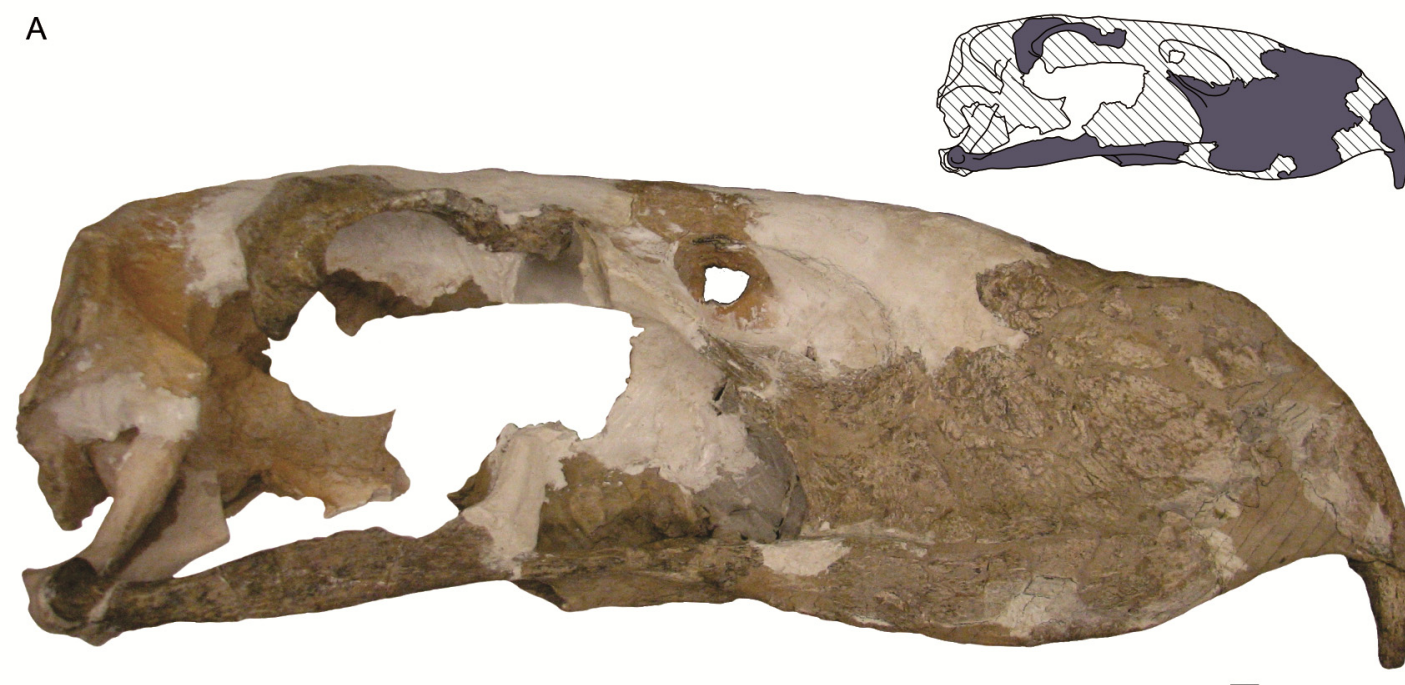

B

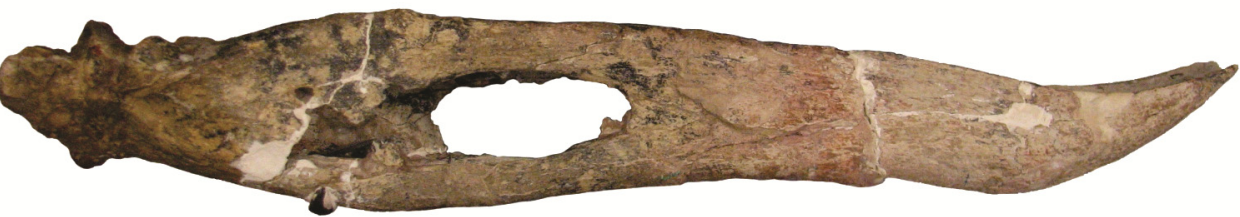

C
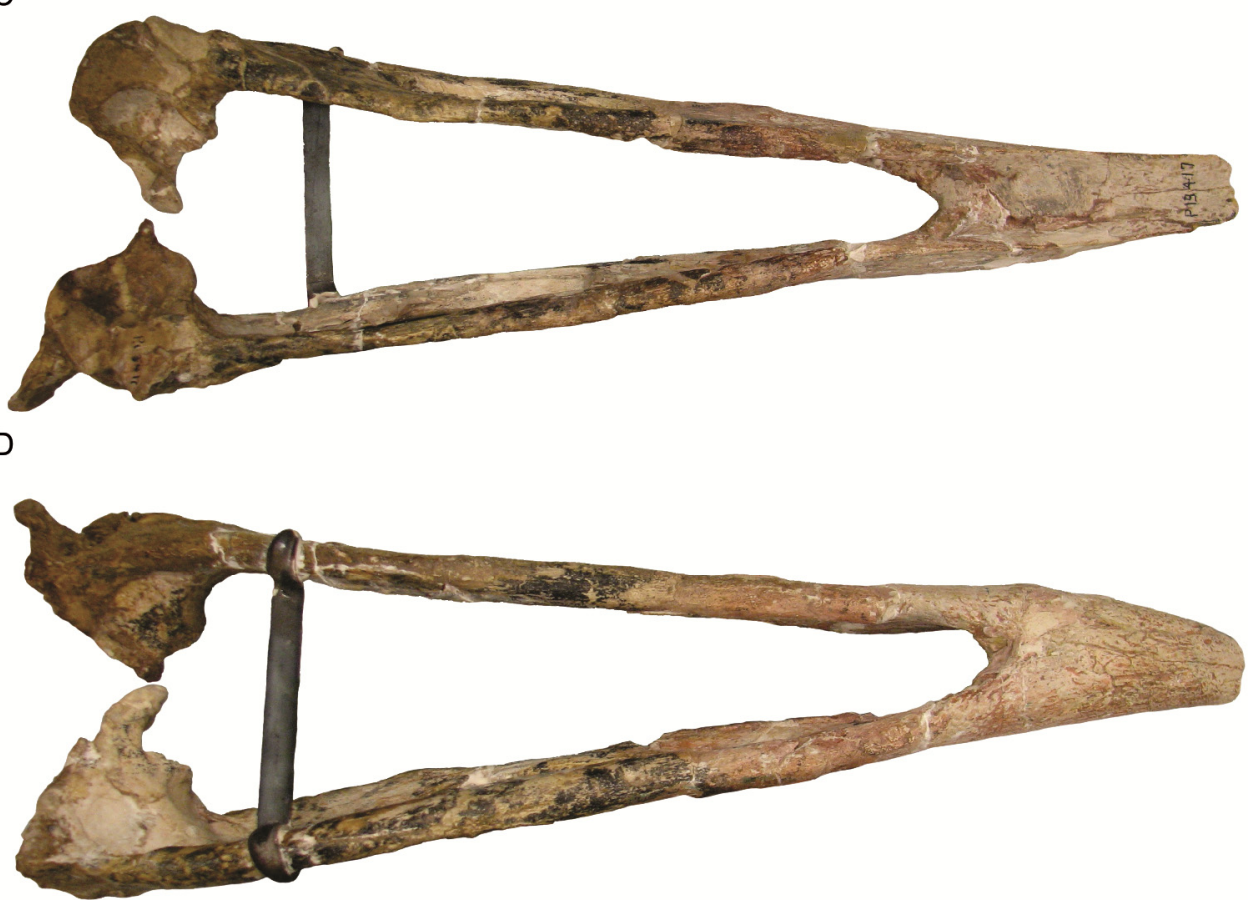

Lámina 4.12. Cráneo y mandíbula de Andrewsornis abbotti FM-P13417. A, vista lateral derecha del cráneo, el esquema muestra en las zonas no preservadas o reconstruidas en rayado. B, C y D, mandíbula. B, vista lateral derecha; C, vista dorsal; $\mathrm{D}$, vista ventral. Escala $=1 \mathrm{~cm}$. 


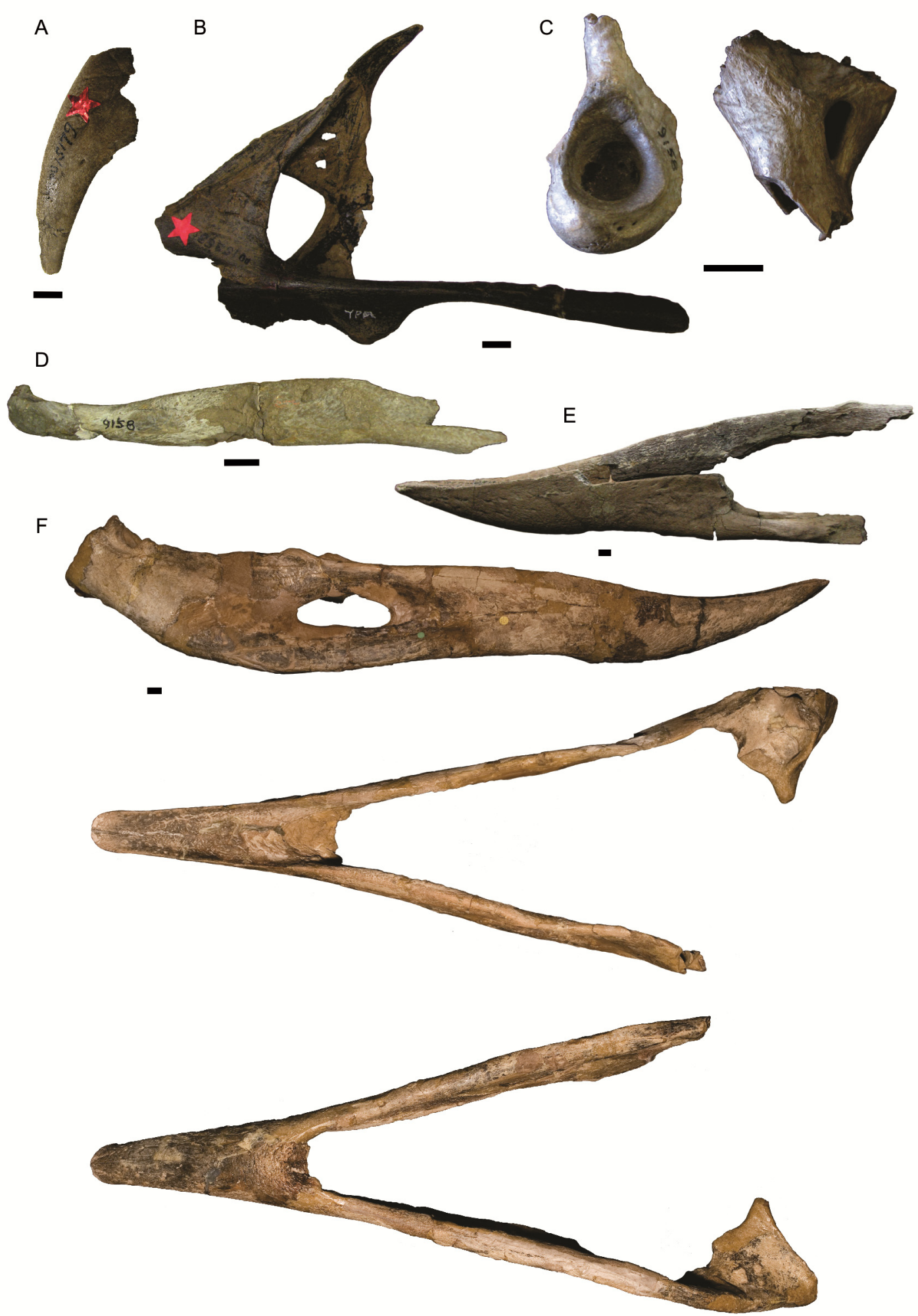

Lámina 4.13. Fragmentos craneanos de Phorusrhacos longissimus. A, YPM-PU15179, fragmento maxila, correspondiente a la punta del pico izquierda; B, YPM-PU15353, fragmento correspondiente a la región de la fenestra antorbitalis. C y D, AMNH 9158; $\mathrm{C}$, restos fragmentarios de os quadratum; D, arcus jugalis derecho. E, MPM-PV4241, fragmento mandibular; $\mathrm{F}$, vista lateral derecha, dorsal y ventral de mandíbula BMNHA529. Escala $=1 \mathrm{~cm}$. 
A
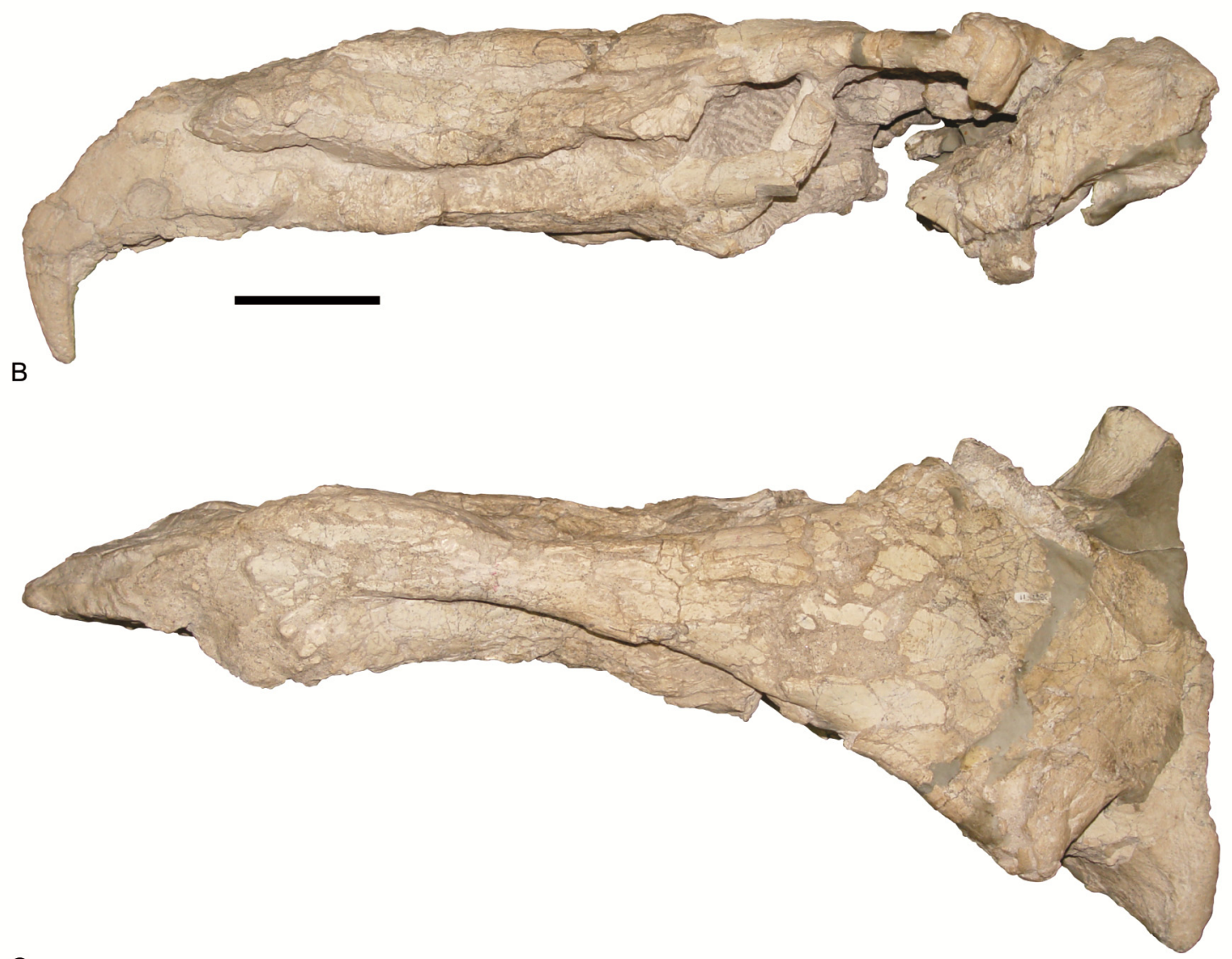

C

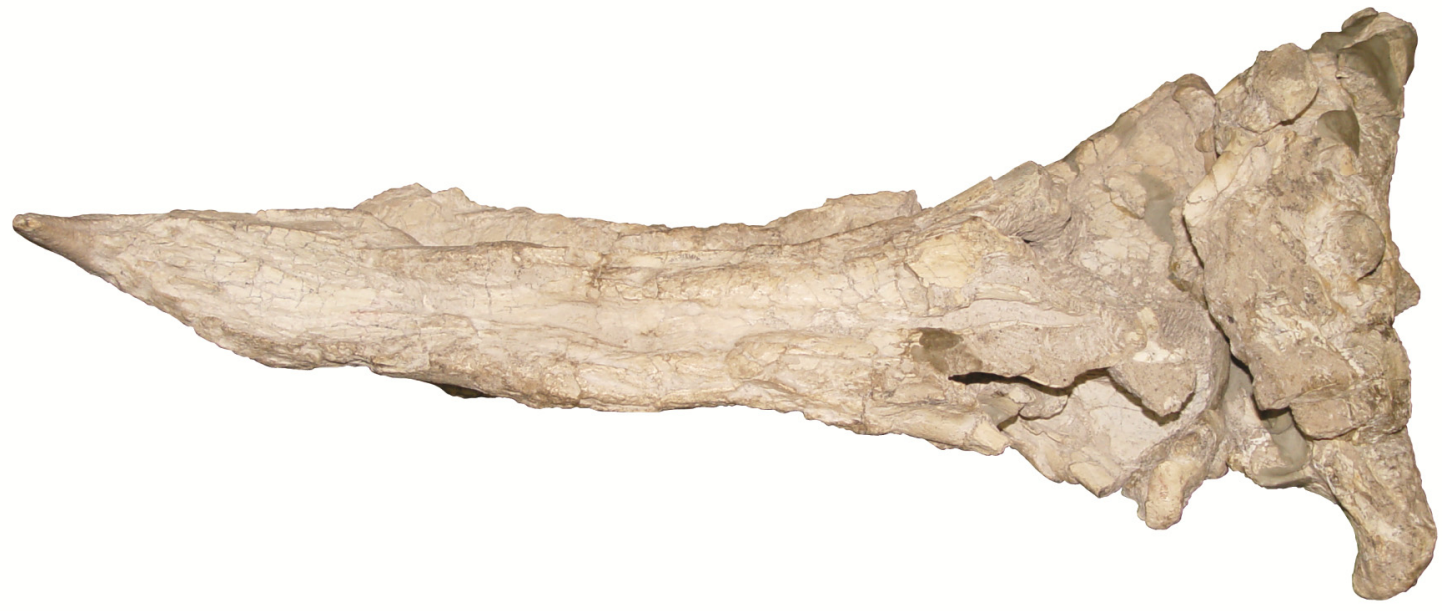

Lámina 4.14. Cráneo de Kelenken guillermoi BAR 3877-11. A, vista lateral izquierda; $B$, vista dorsal; $C$, vista ventral. Escala $=10 \mathrm{~cm}$. 
A
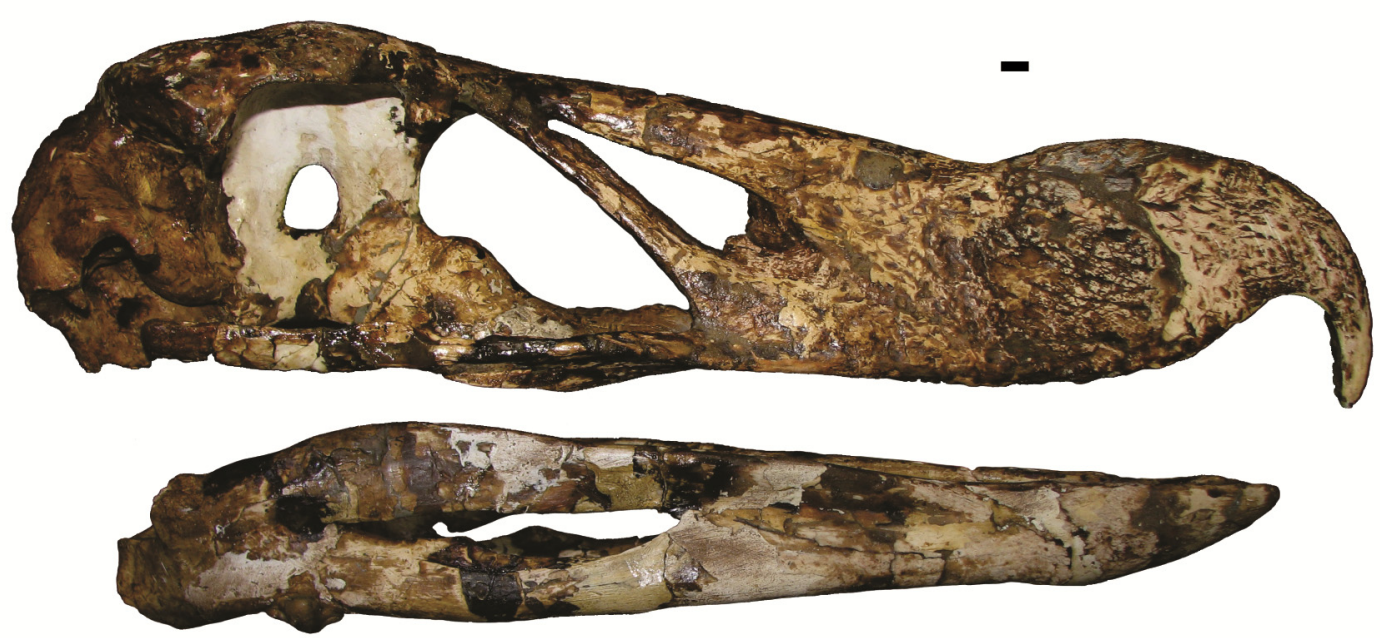

B

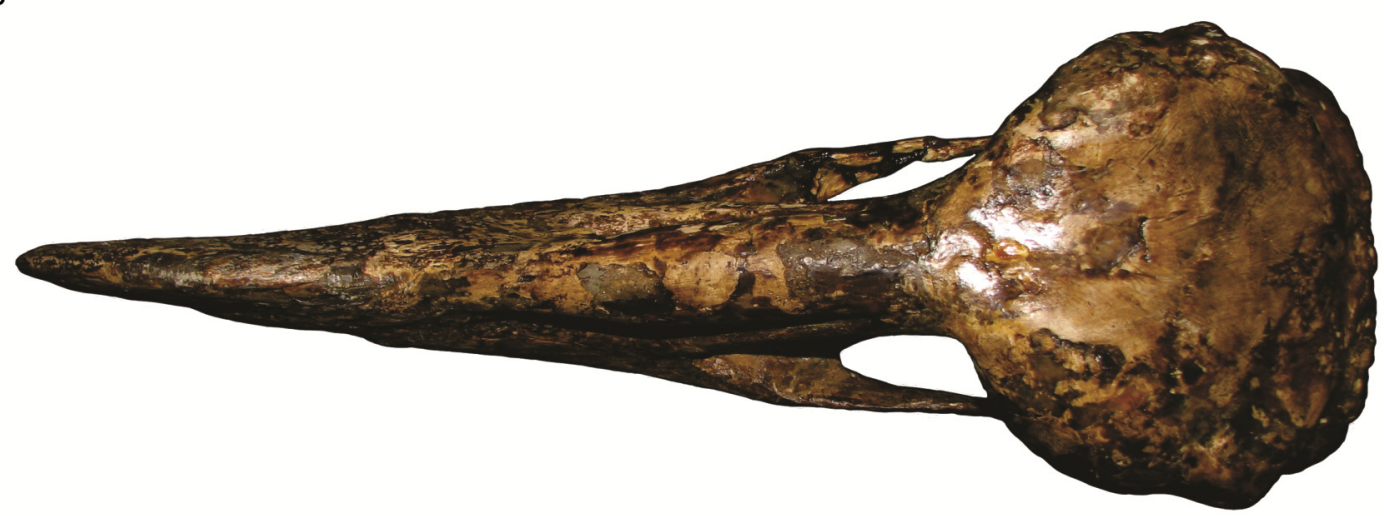

C

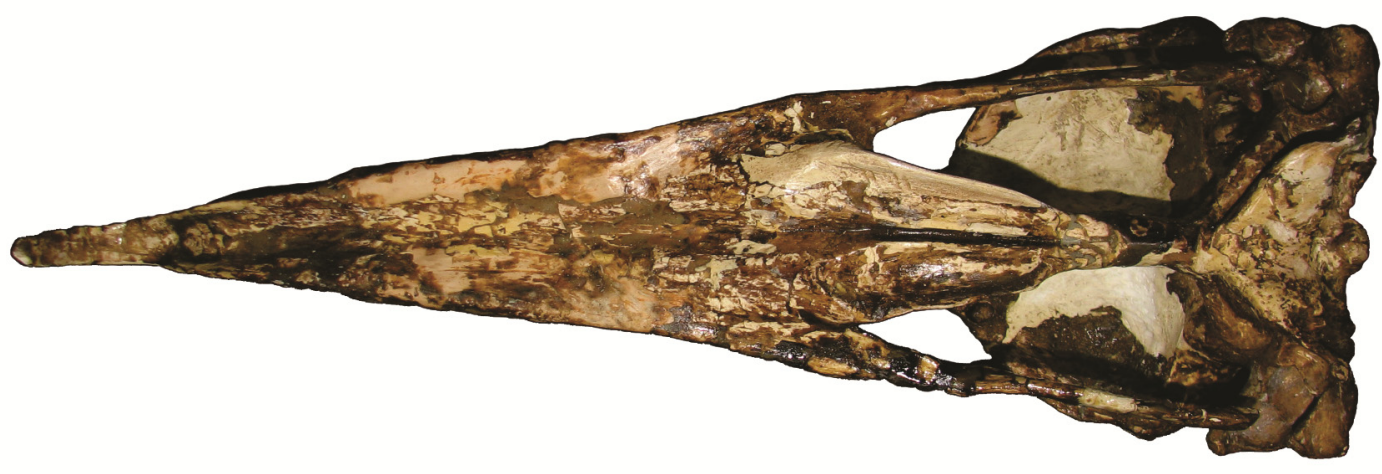

Lámina 4.15. Mesembriornis milneedwardsi MMP 155-S. A, vista lateral derecha de cráneo y mandíbula; $\mathrm{B}$, vista dorsal del cráneo; $\mathrm{C}$, vista ventral del cráneo. Escala $=1$ $\mathrm{cm}$. 
A

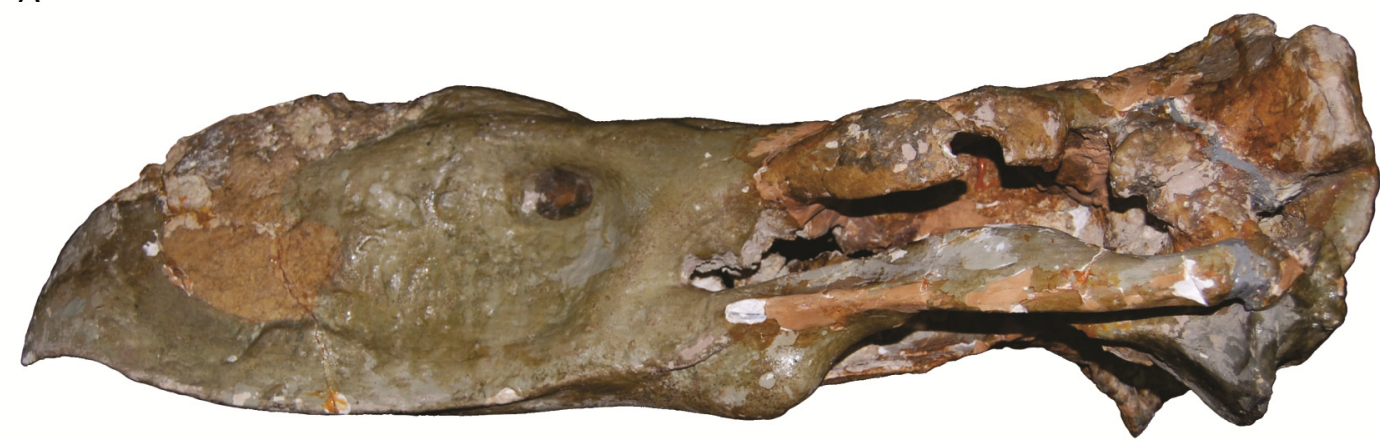

B

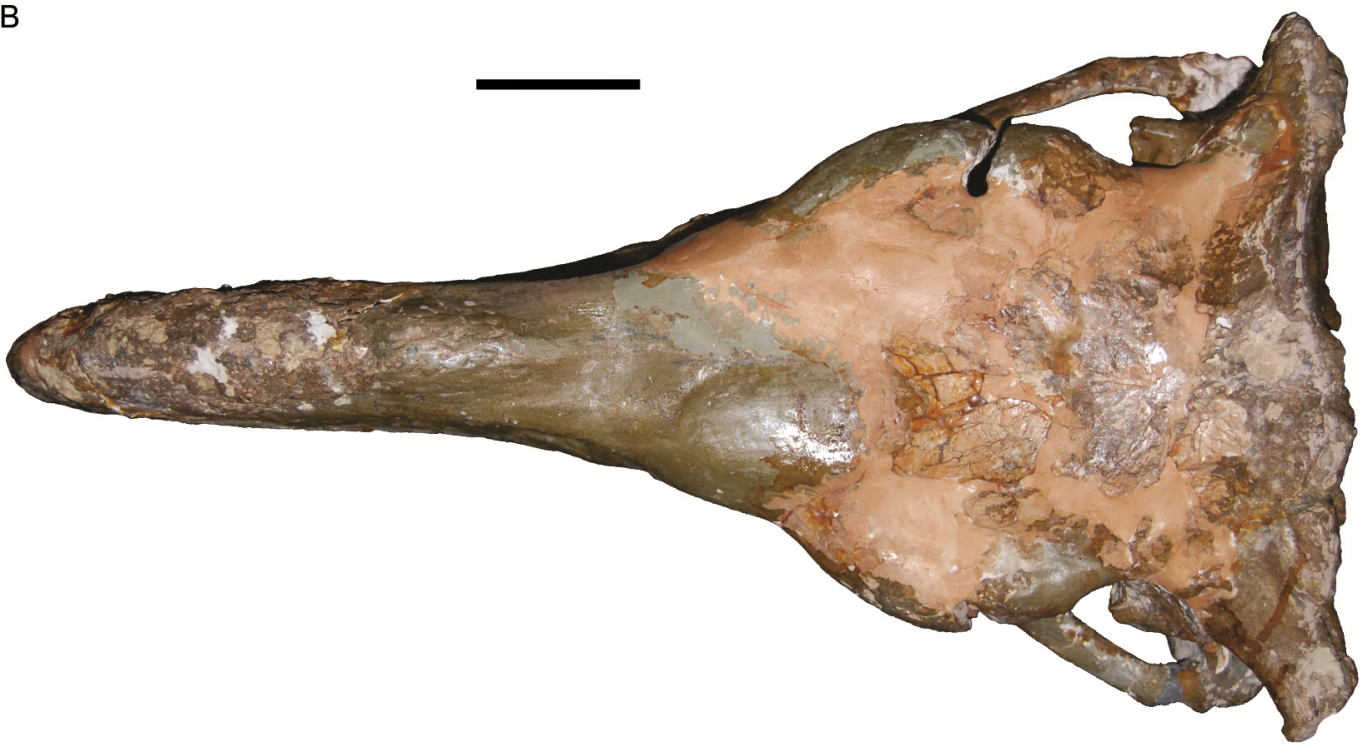

C

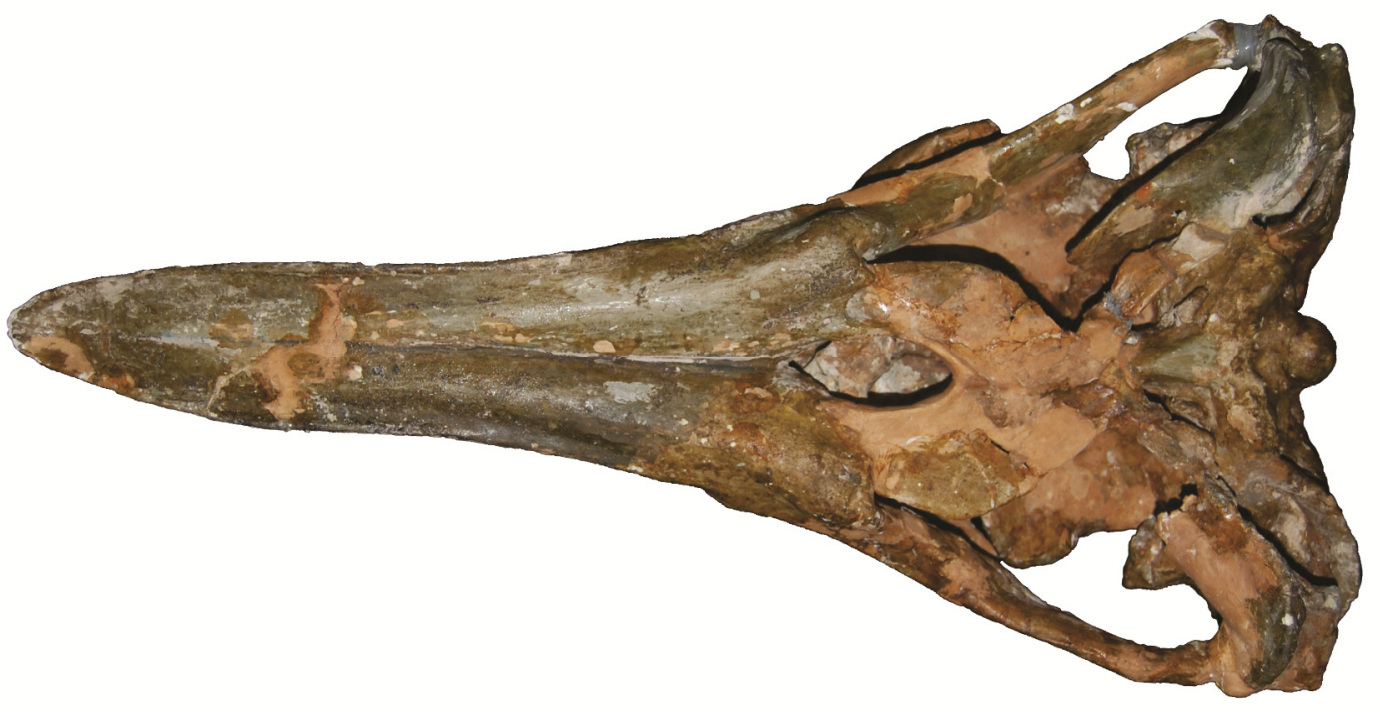

Lámina 4.16. Cráneo de Devincenzia pozzi MLP 37-III-7-83. A, vista lateral izquierda; $B$, vista dorsal; $C$, vista ventral. Escala $=10 \mathrm{~cm}$. 
A

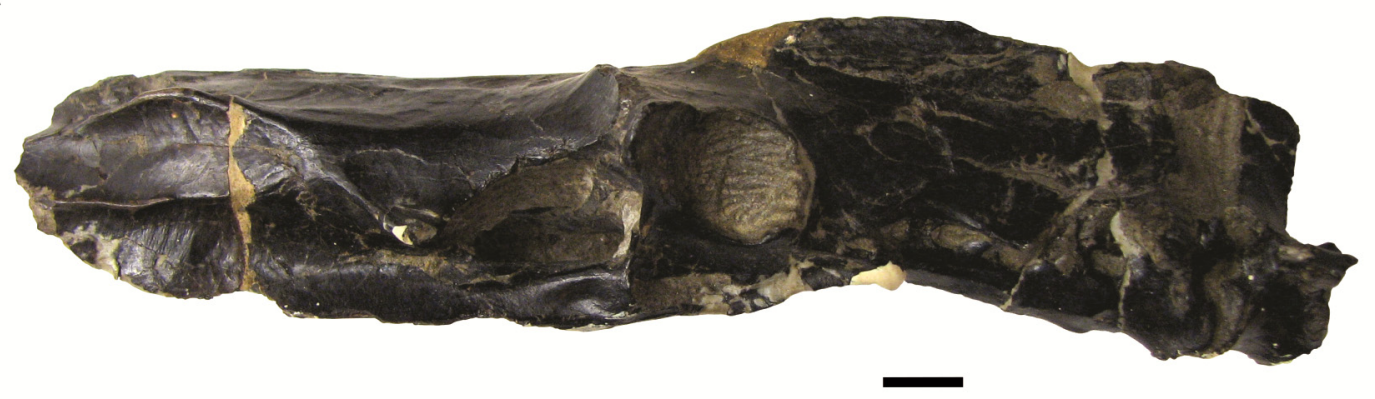

B

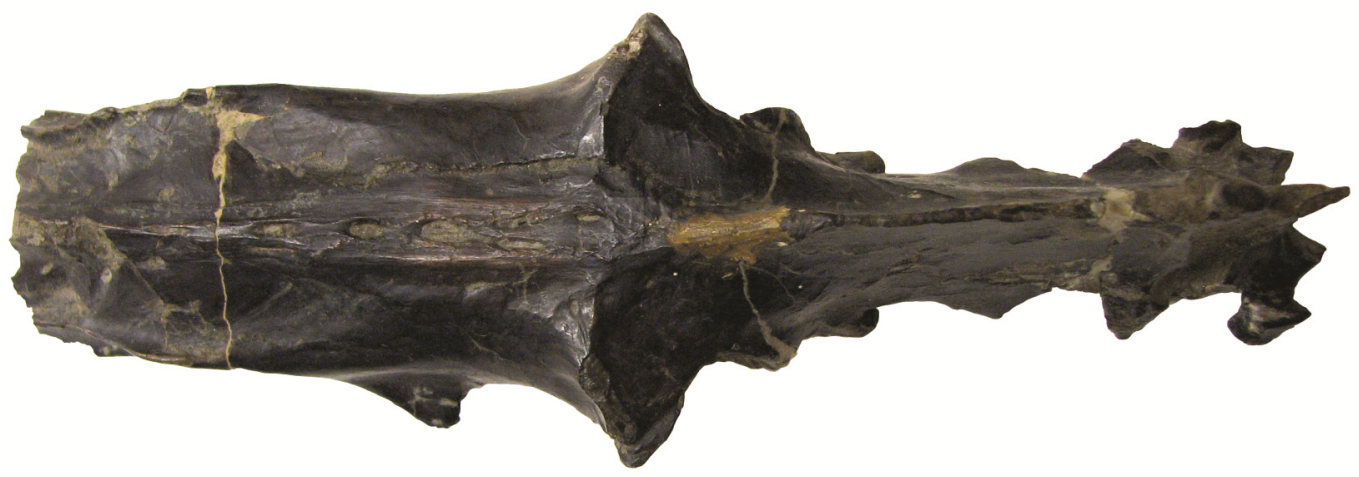

C

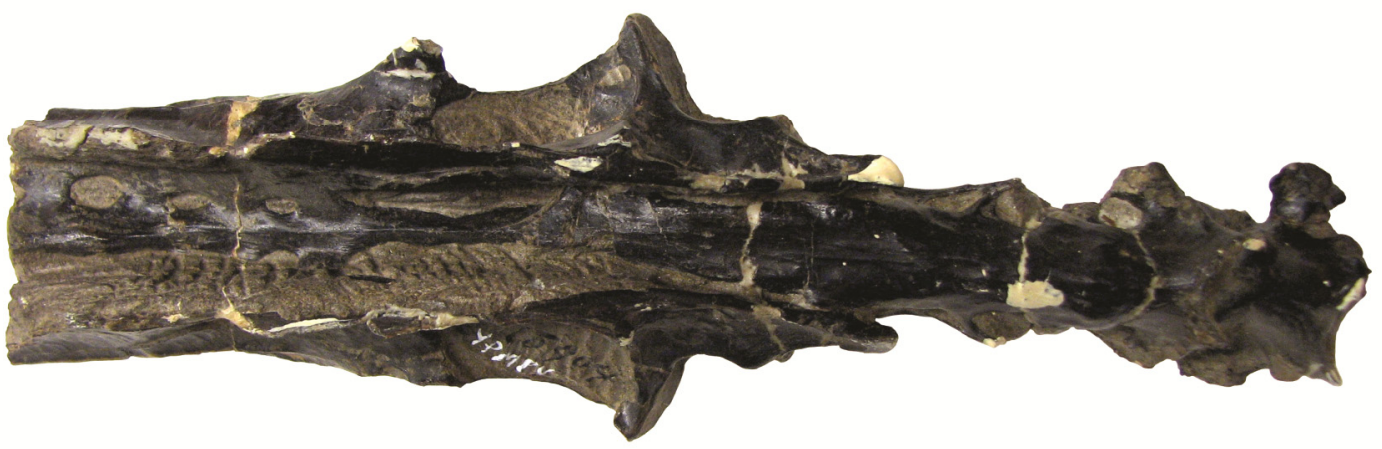

Lámina 4.17. Pelvis de Psilopterus bachmanni YPM-PU15904. A, vista lateral derecha; B, vista dorsal; C, vista ventral. Escala $=1 \mathrm{~cm}$. 
A
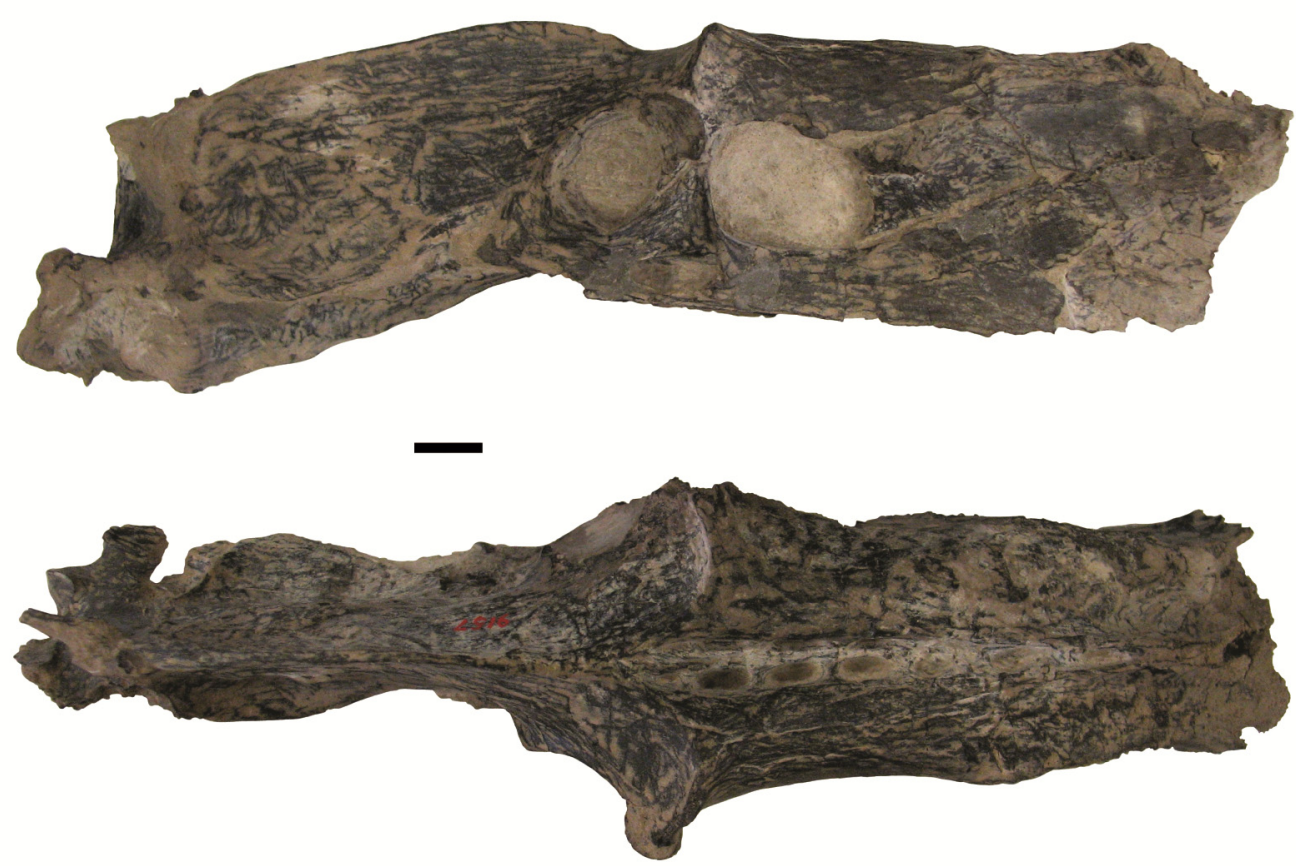

B
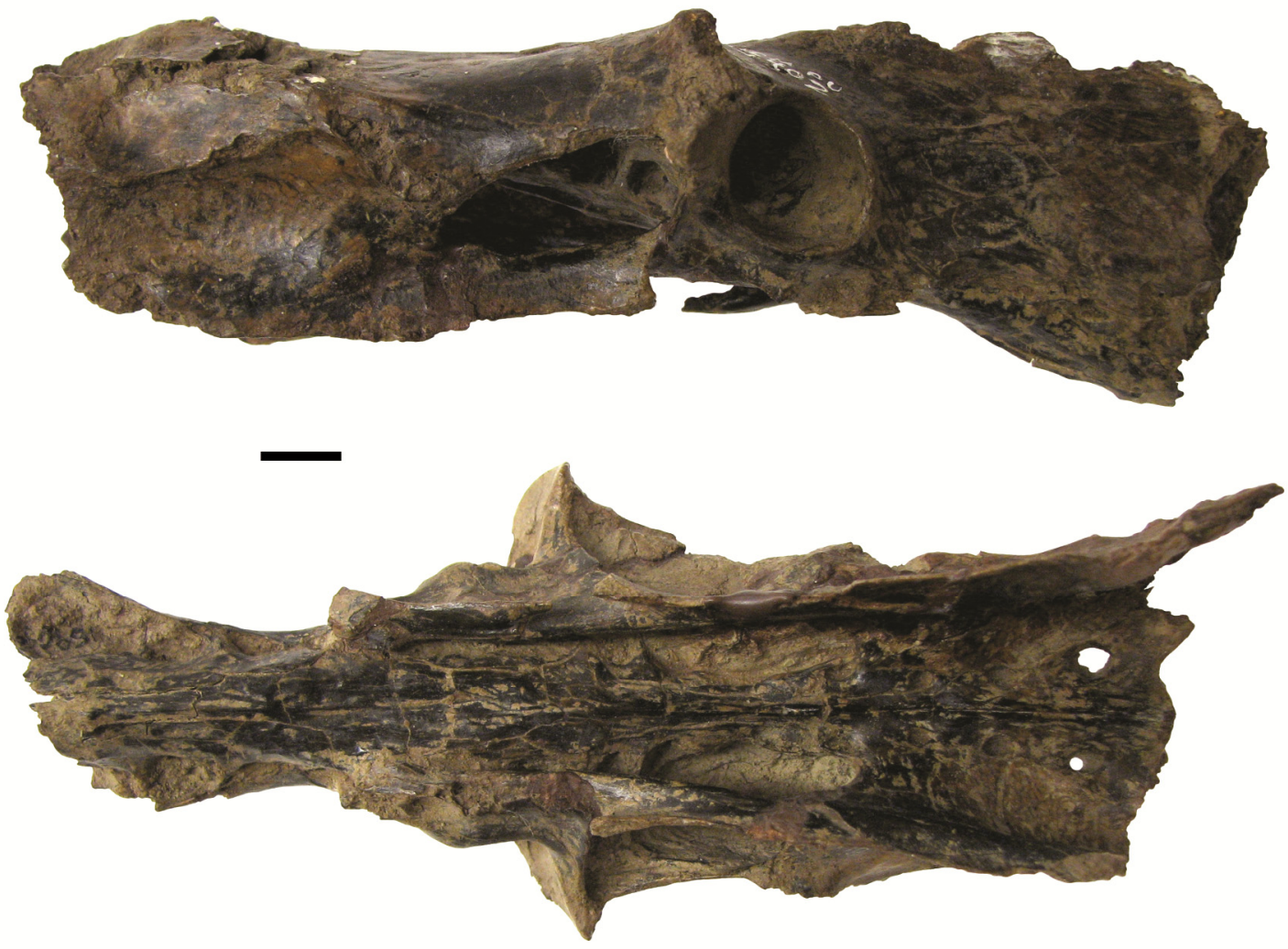

Lámina 4.18. Pelvis de Psilopterus lemoinei. A, vista lateral izquierda y dorsal de AMNH 9157; B, vista lateral derecha y dorsal de YPM-PU15402. Escala $=1 \mathrm{~cm}$. 
A

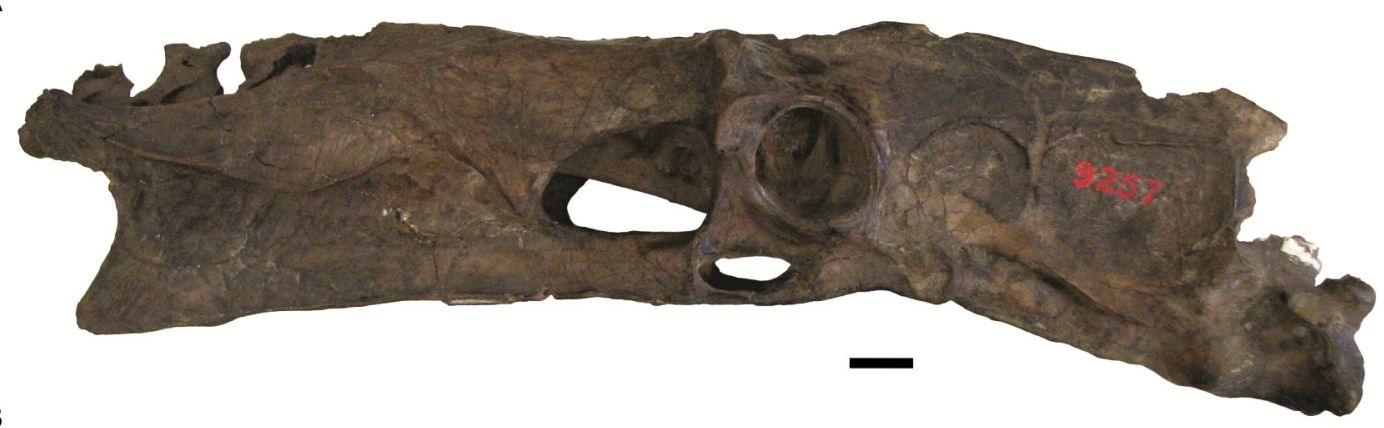

B

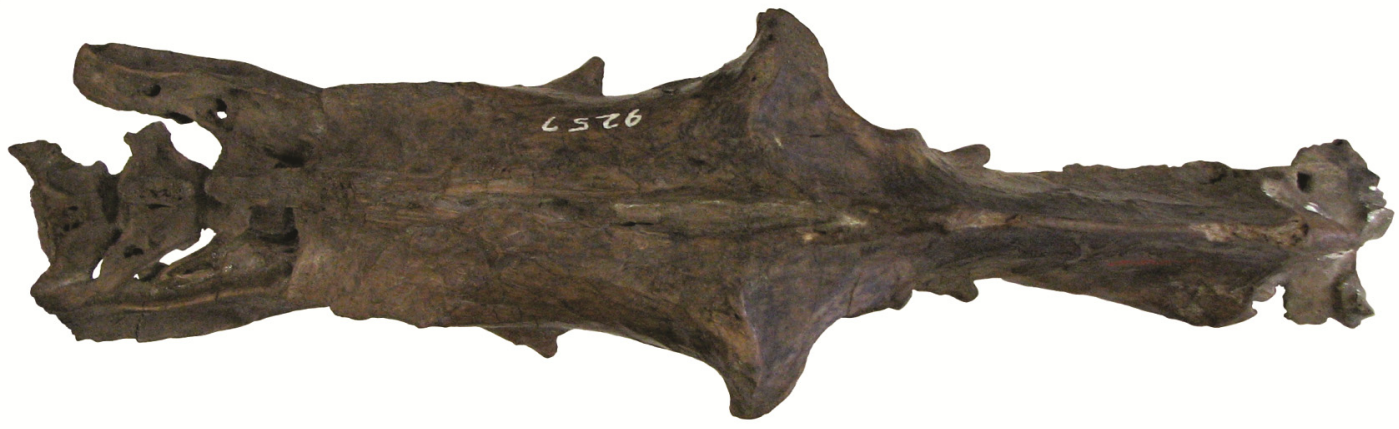

C

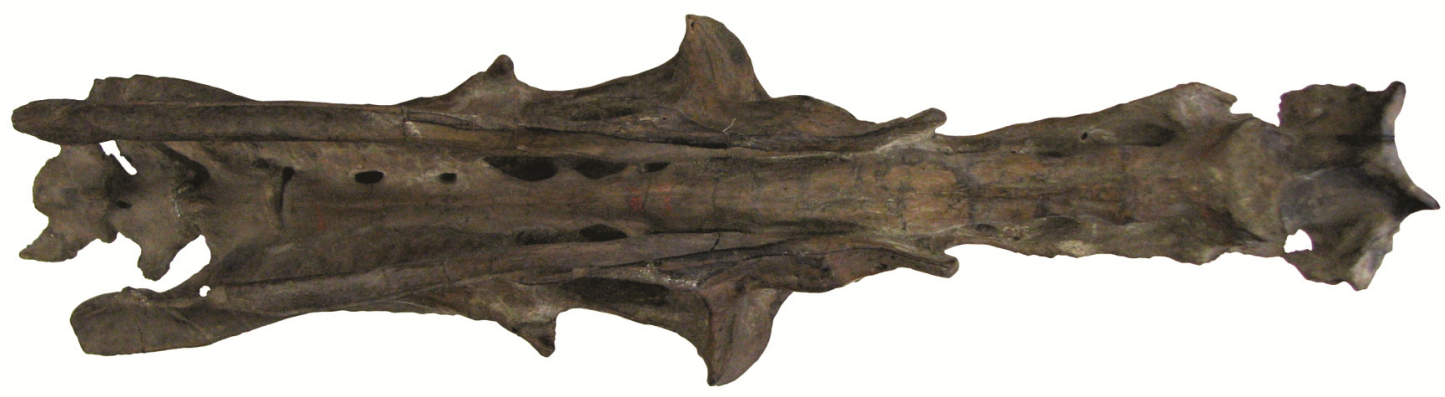

Lámina 4.19. Pelvis de Psilopterus lemoinei AMNH 9257. A, vista lateral izquierda; B, vista dorsal; $C$, vista ventral. Escala $=1 \mathrm{~cm}$. 
A
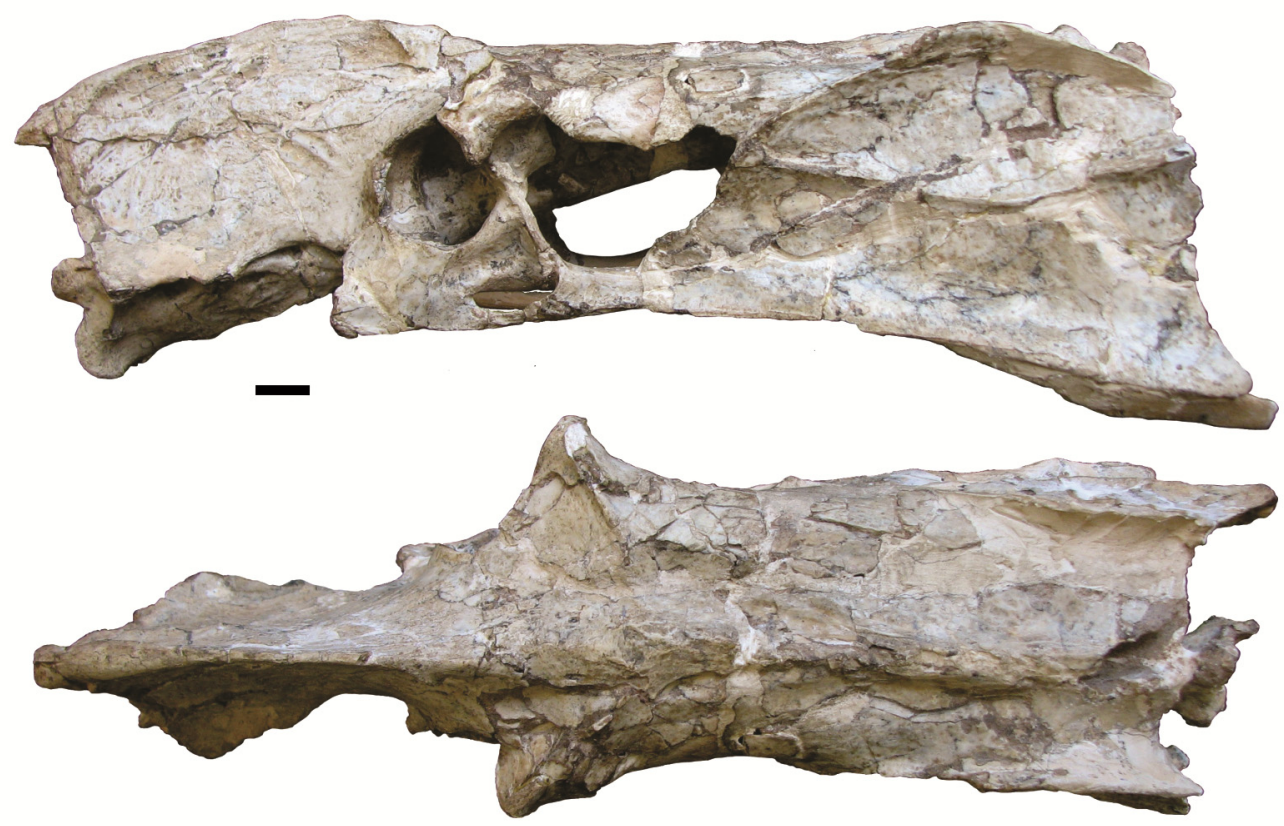

B
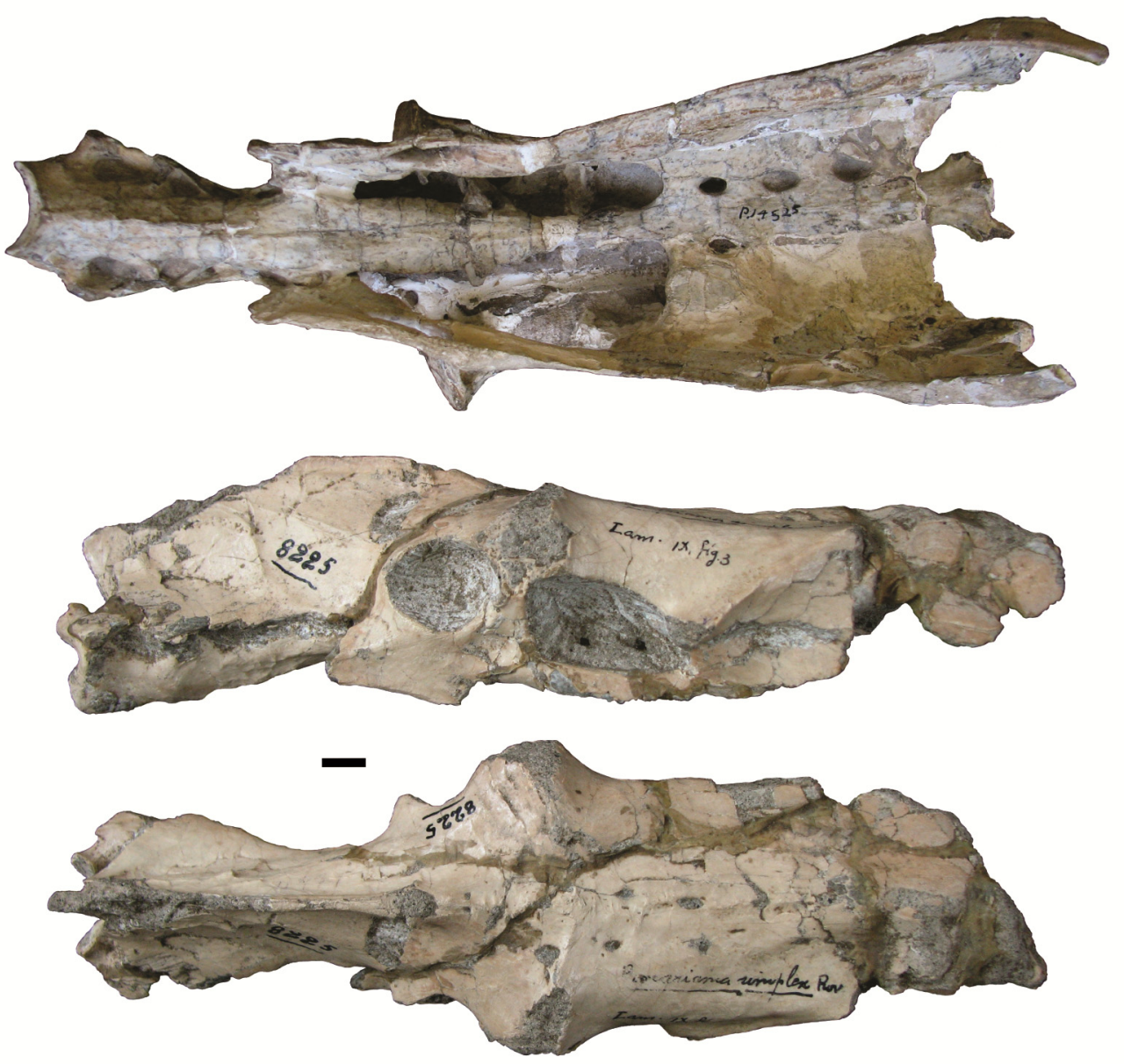

Lámina 4.20. Pelvis de Procariama simplex. A, vista lateral izquierda, dorsal y ventral de FM-P14525; B, vista lateral izquierda y dorsal de MACN Pv 8225. Escala $=1 \mathrm{~cm}$. 
A

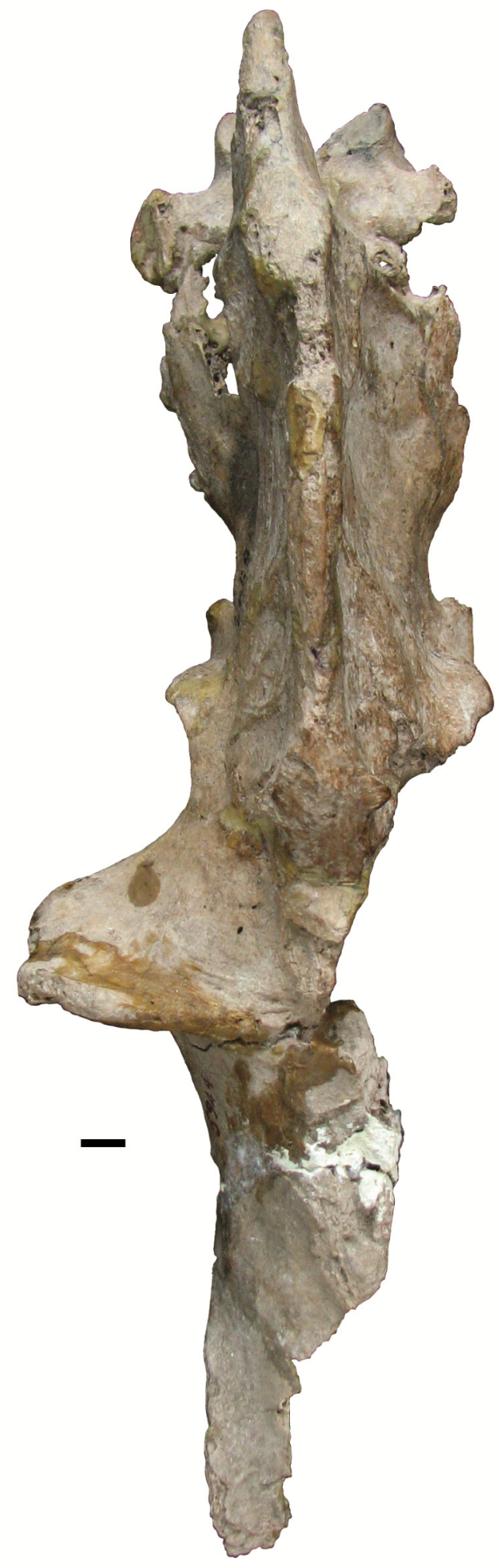

B

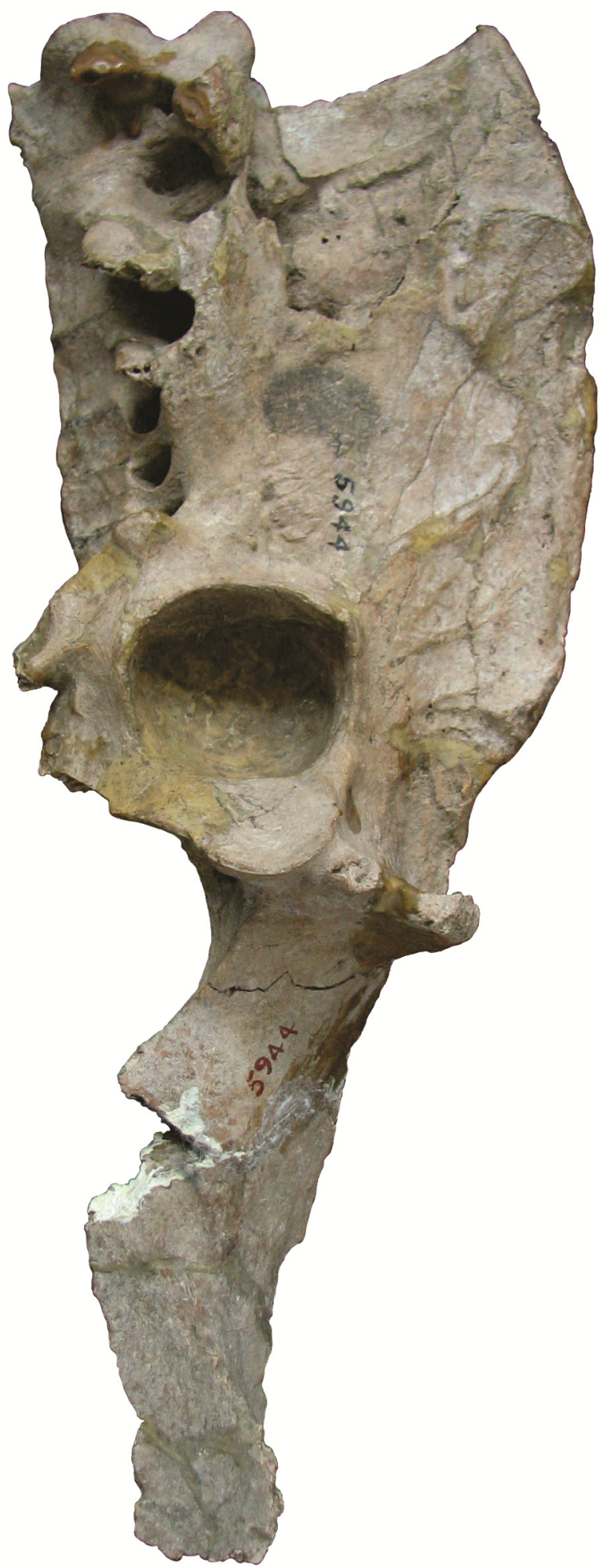

Lámina 4.21. Pelvis de Mesembriornis milneedwardsi MACN Pv 5944. A, vista dorsal; $\mathrm{B}$, vista lateral izquierda. Escala $=1 \mathrm{~cm}$. 
A

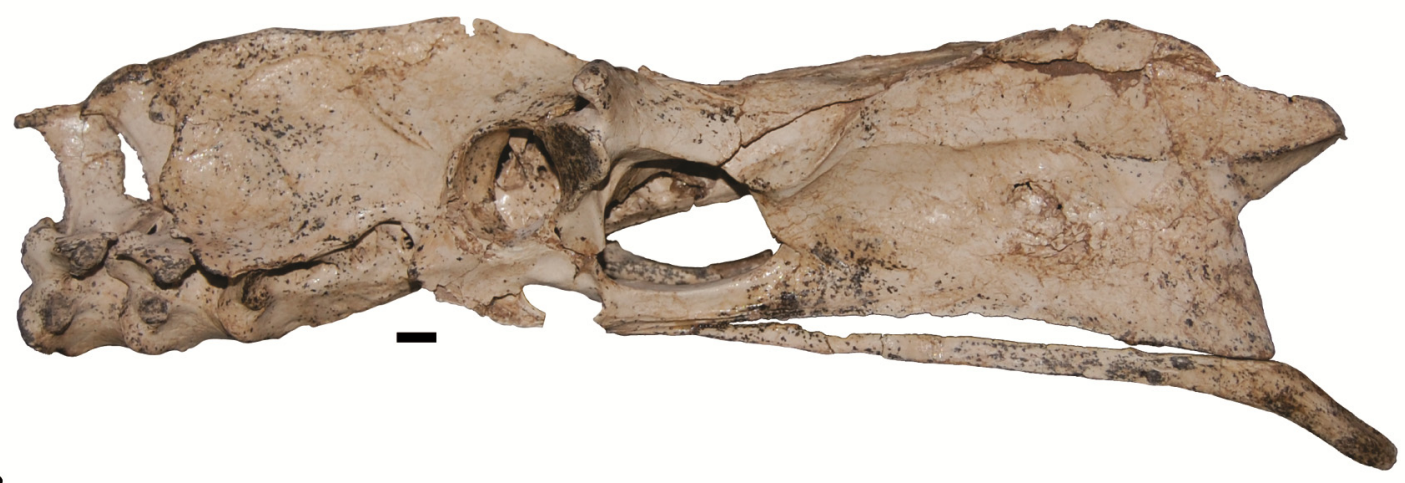

B

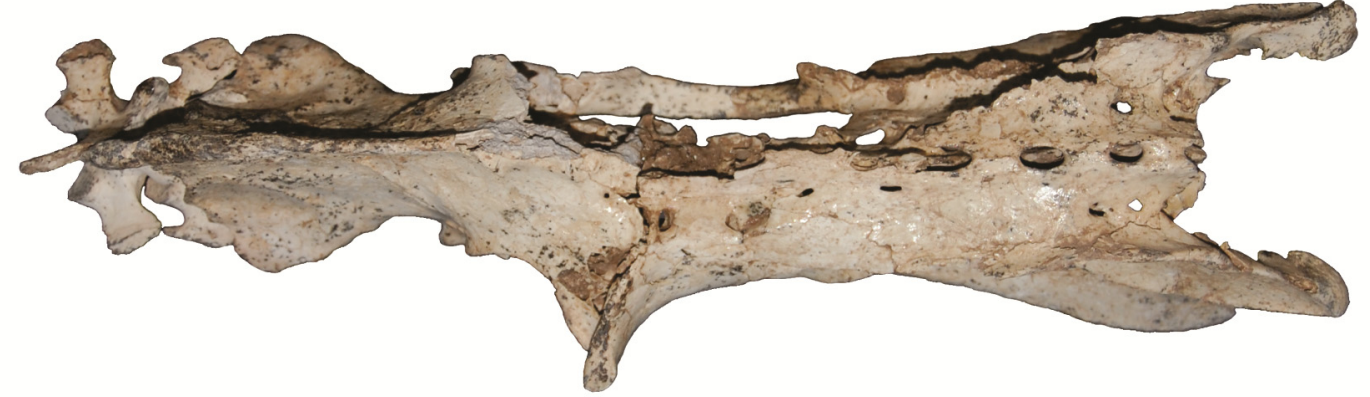

C

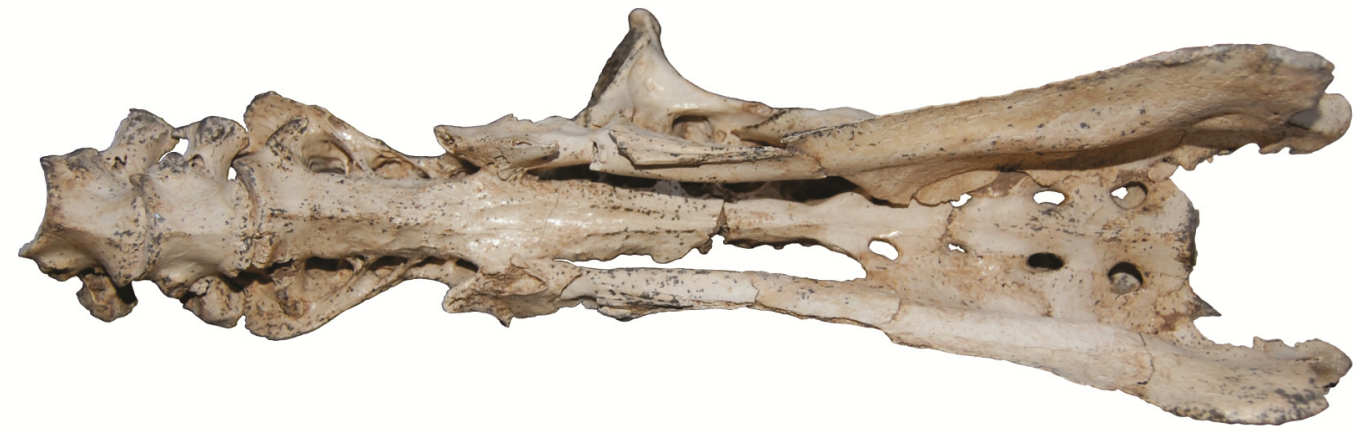

Lámina 4.22. Pelvis de Taxón nuevo A MMP 5050. A, vista lateral izquierda; B, vista dorsal; C, vista ventral. Escala: $1 \mathrm{~cm}$. 
A

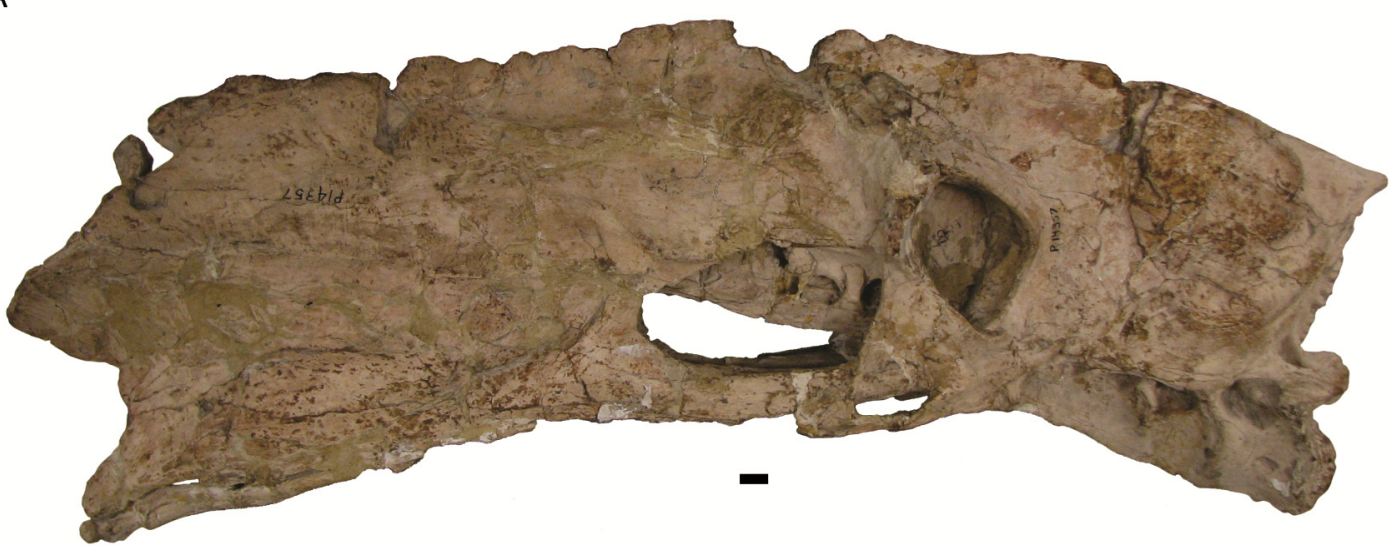

B

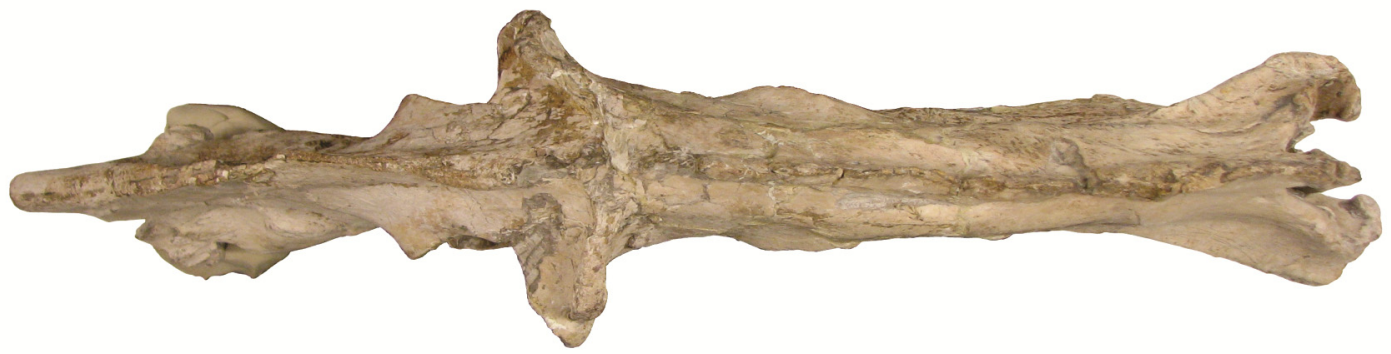

C

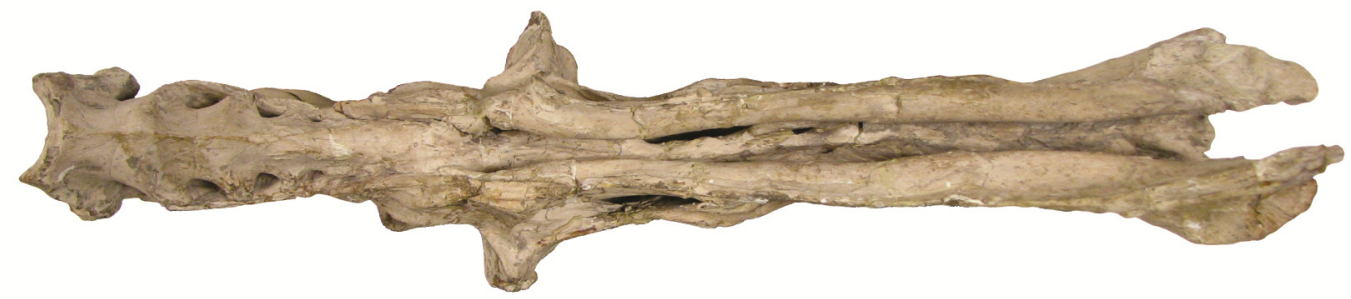

Lámina 4.23. Pelvis de Andalgalornis steulleti FM-P14357. A, vista lateral derecha; B, vista dorsal; $C$, vista ventral. Escala $=1 \mathrm{~cm}$. 
A

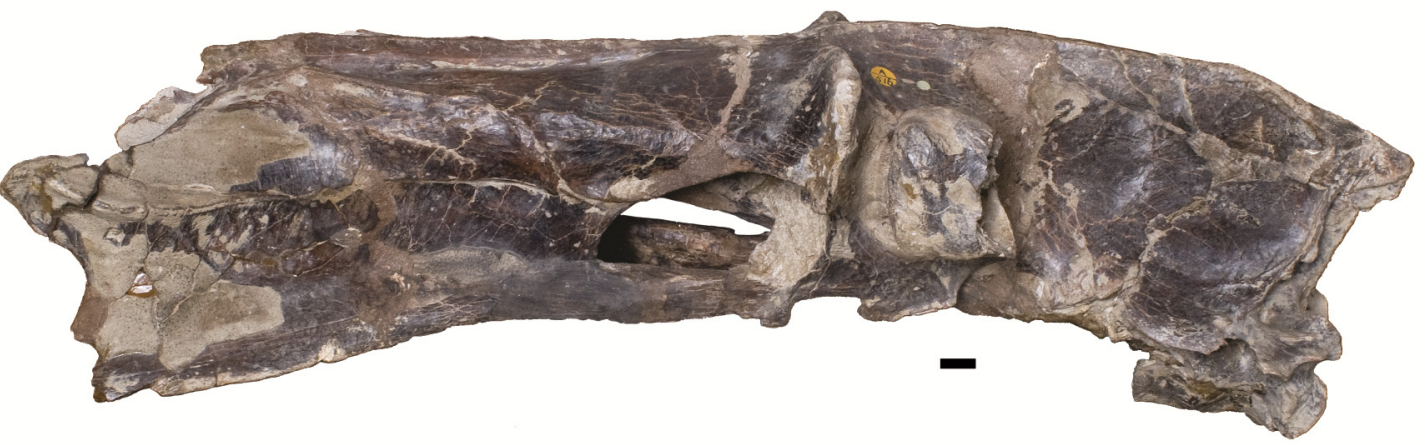

B

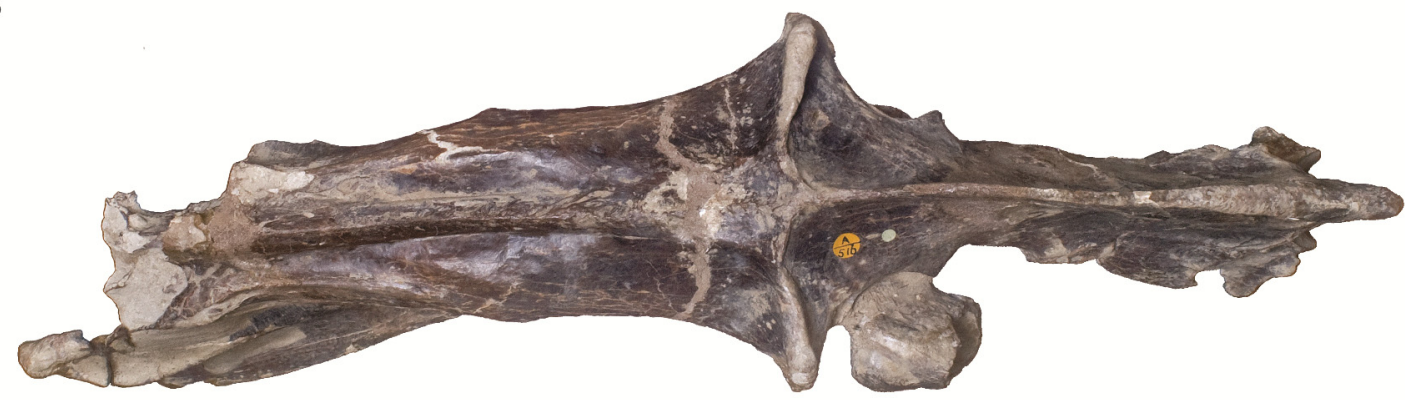

C

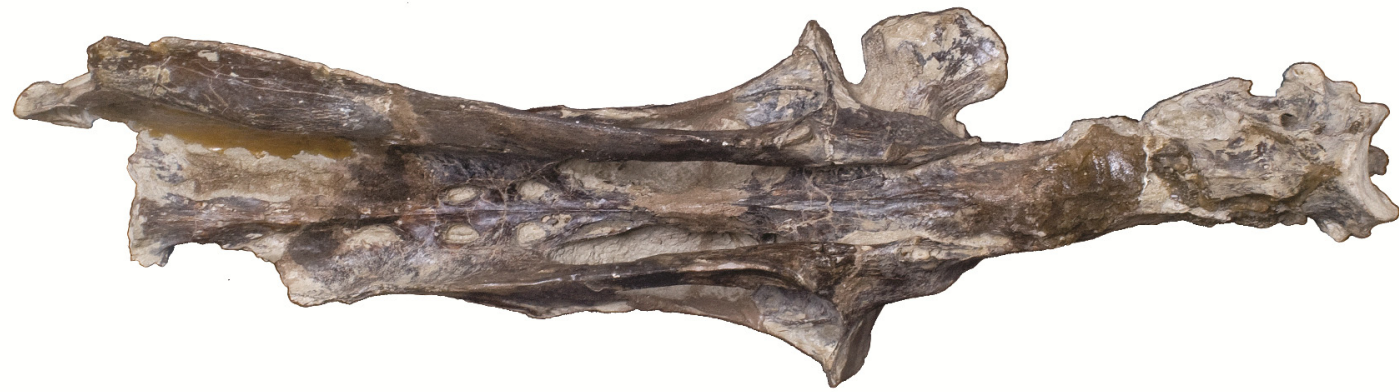

Lámina 4.24. Pelvis de Patagornis marshi BMNH-A516. A, vista lateral derecha; B, vista dorsal; $\mathrm{C}$, vista ventral. Escala $=1 \mathrm{~cm}$. 

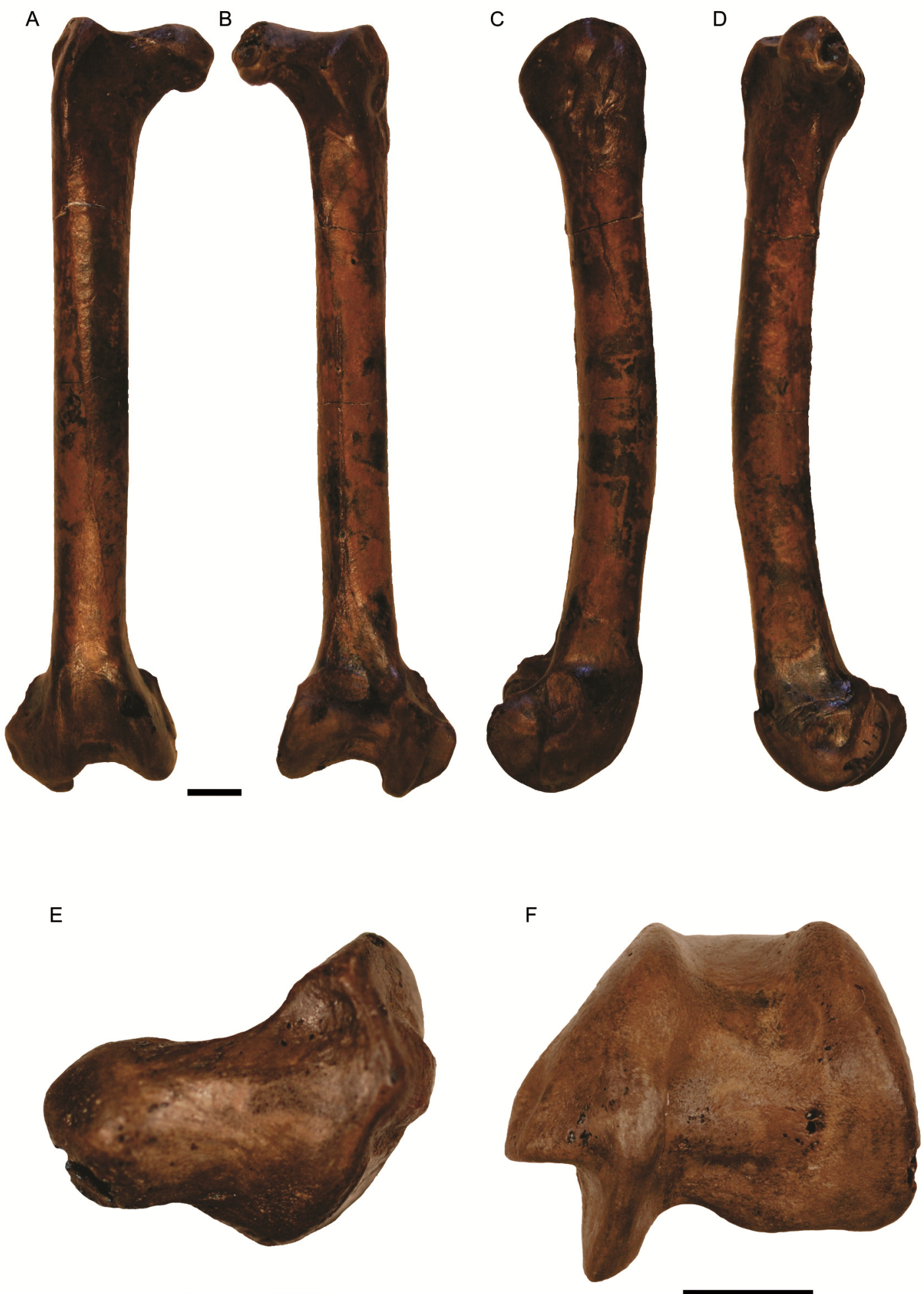

Lámina 4.25. Fémur derecho de Psilopterus lemoinei MPM-PV3650. A, vista craneal; $\mathrm{B}$, vista caudal; $\mathrm{C}$, vista lateral; D, vista medial; E, vista proximal; F, vista distal. Escala $=1 \mathrm{~cm}$. 
A

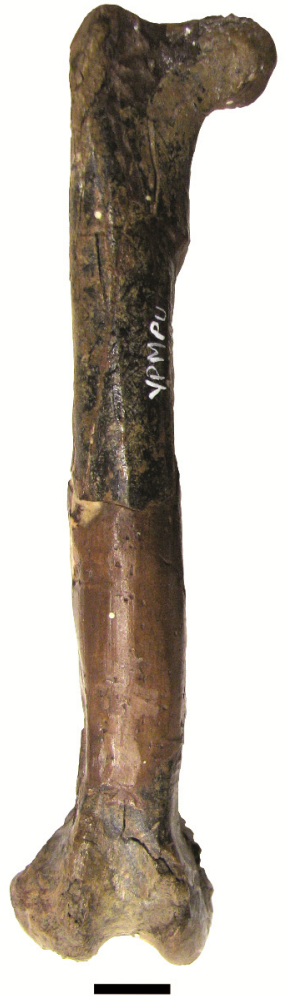

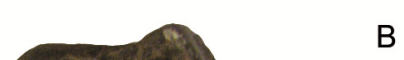

(1)
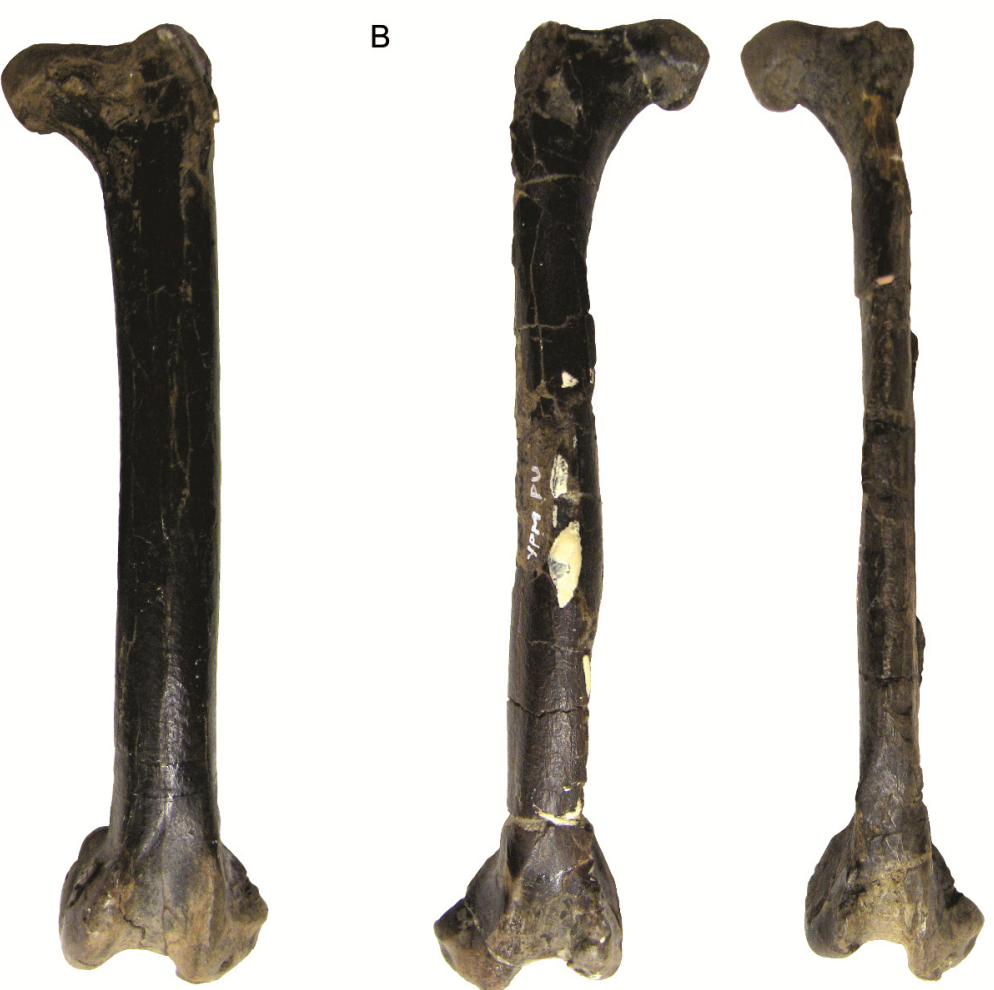

C
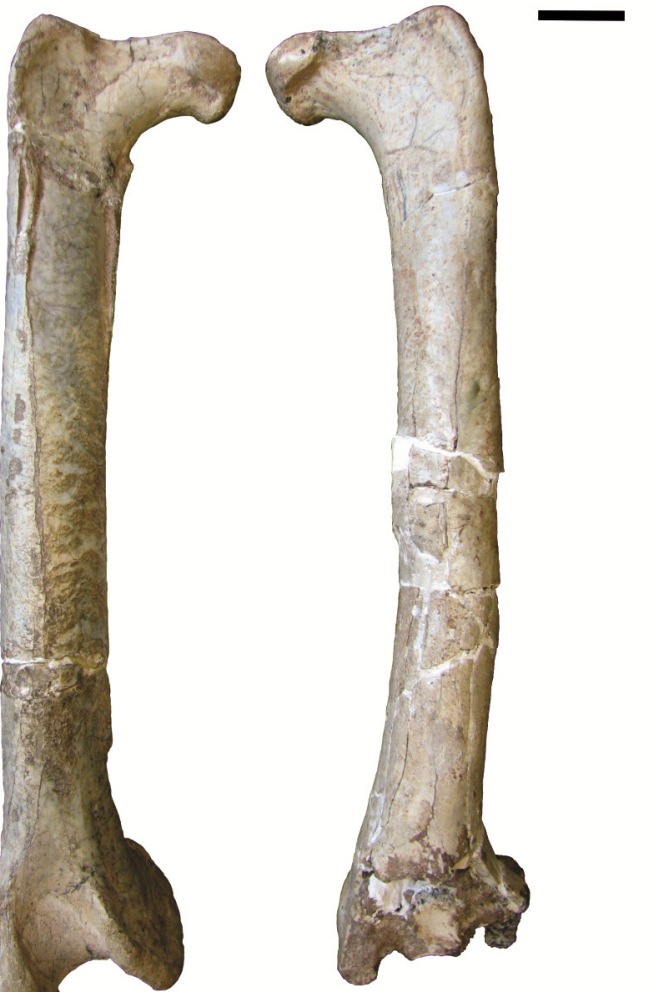

Lámina 4.26. Fémur de Psilopterinae. A, Psilopterus lemoinei YPM-PU15402; B, Psilopterus bachmanni YPM-PU15904; C, Procariama simplex FM-P14525. Escala $=1$ $\mathrm{cm}$. 
A

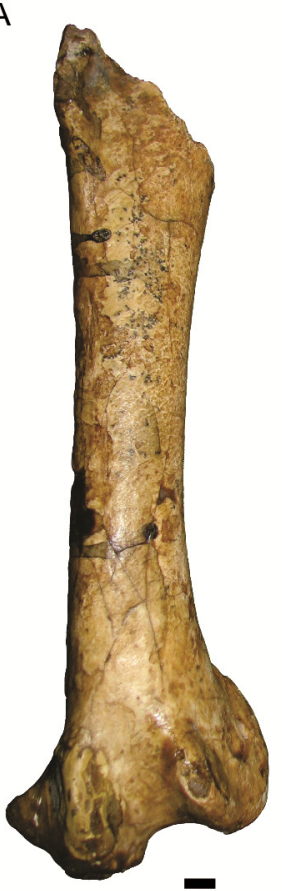

B
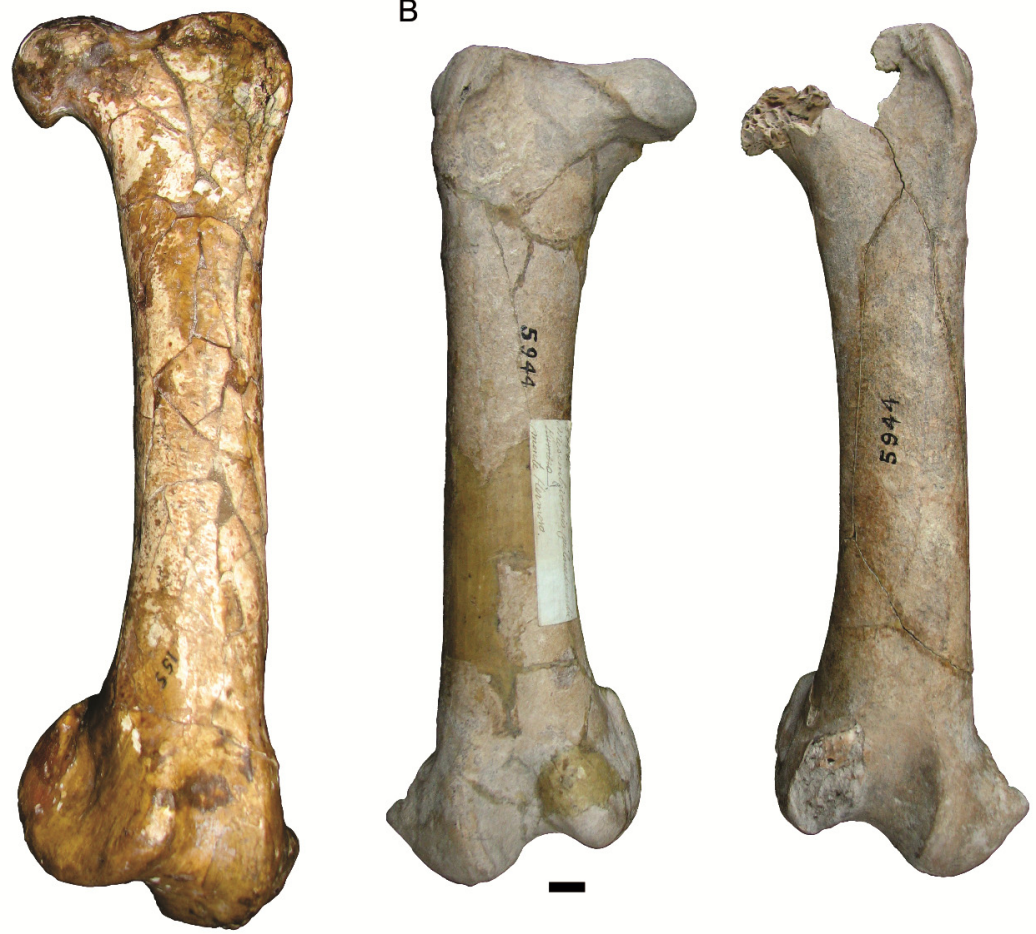
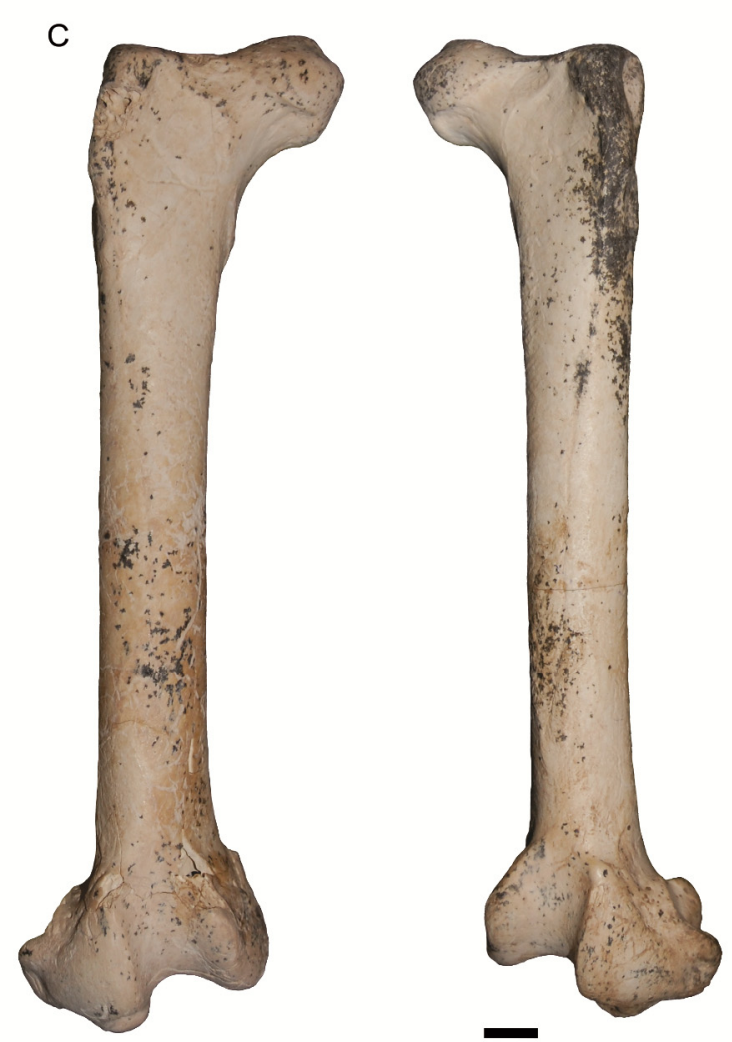

Lámina 4.27. Fémur de Mesembriornithinae. A, Mesembriornis milneedwardsi MMP 155-S; B, M. milneedwardsi MACN Pv 5944; C, Taxón nuevo A MMP 5050. Escala = $1 \mathrm{~cm}$. 
A

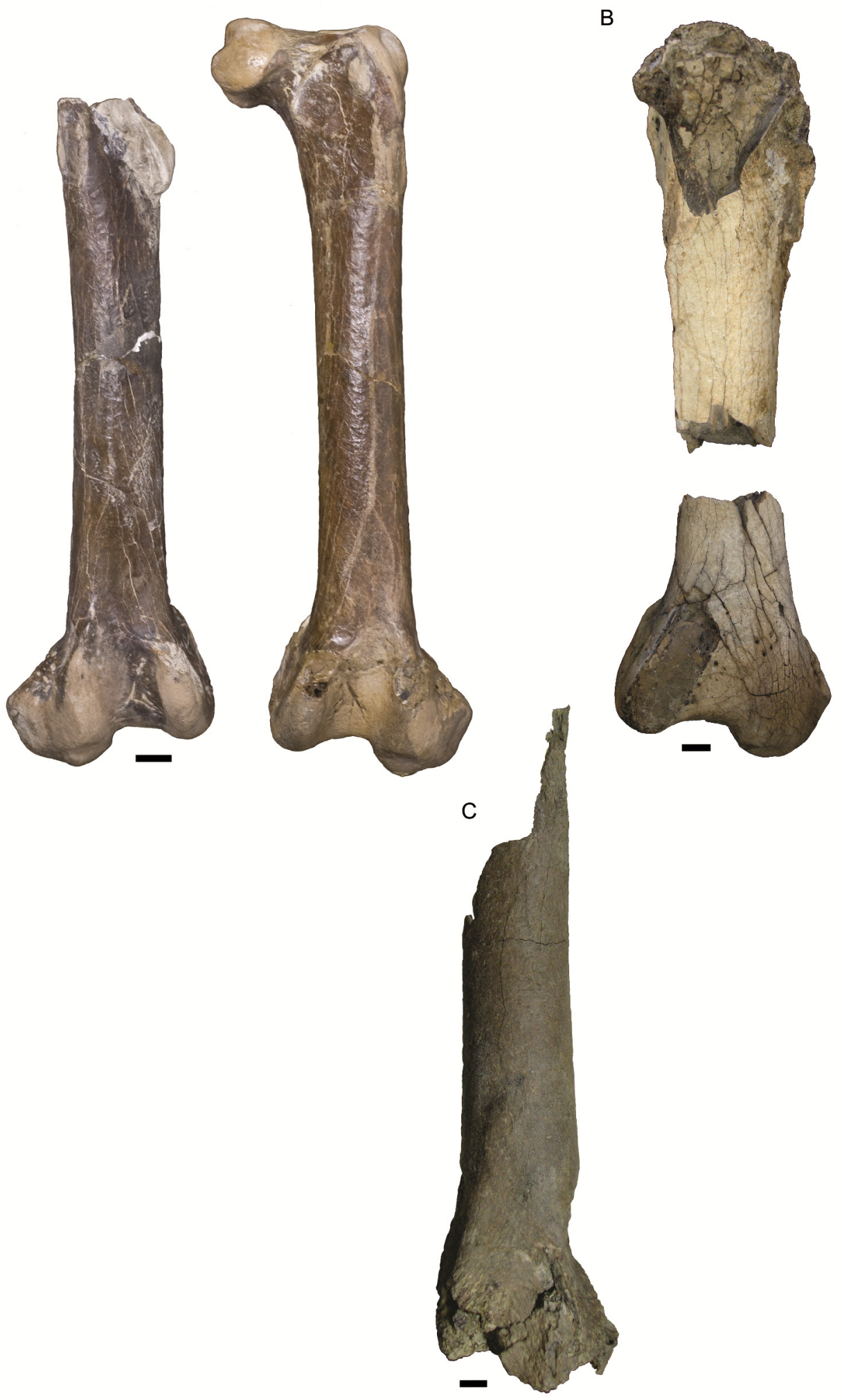

Lámina 4.28. Fémur de Patagornithinae y Phorusrhacinae. A, Patagornis marshi BMNH-A516; B, Phorusrhacos longissimus AMNH 9497; C, Phorusrhacos longissimus MPM-PV4241. Escala $=1 \mathrm{~cm}$. 

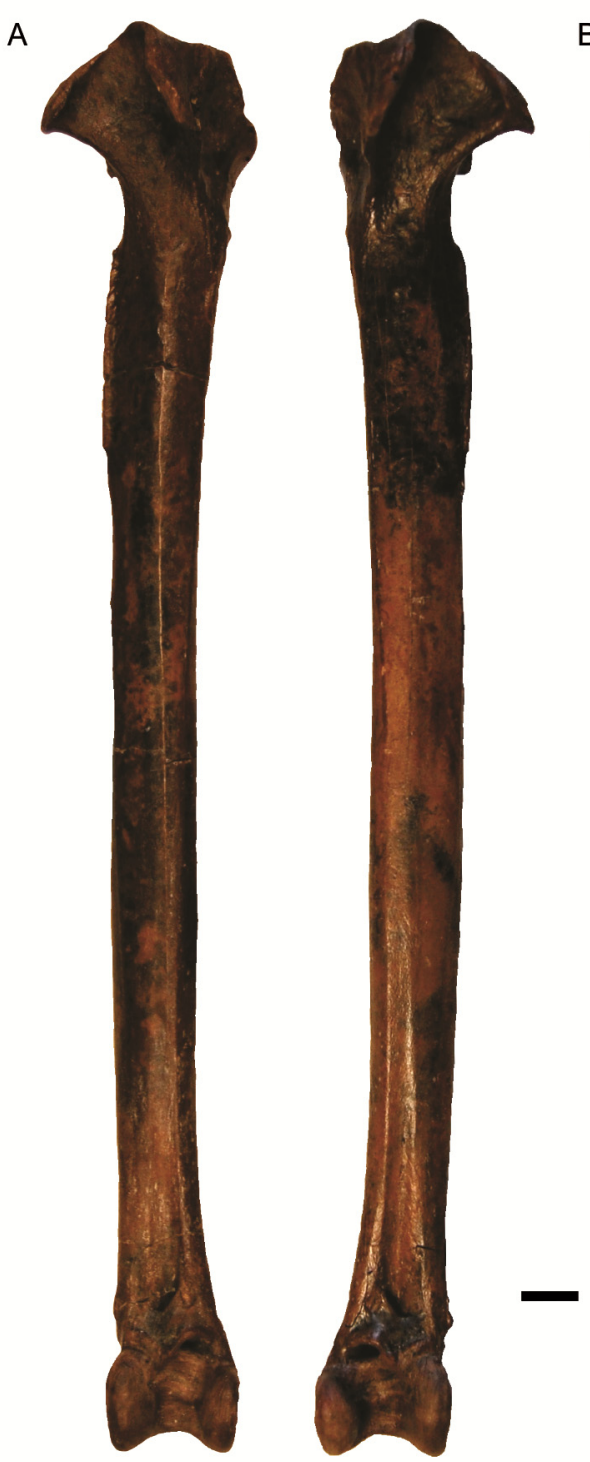

B

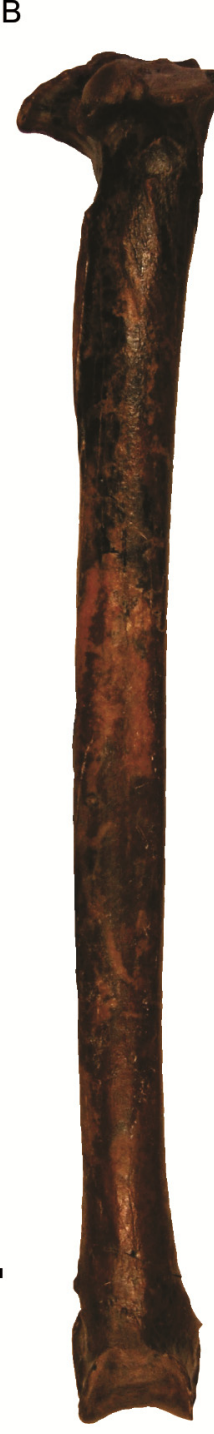

C
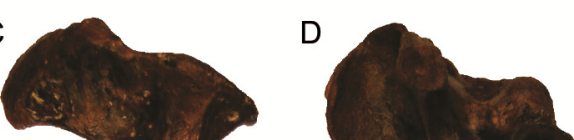

E
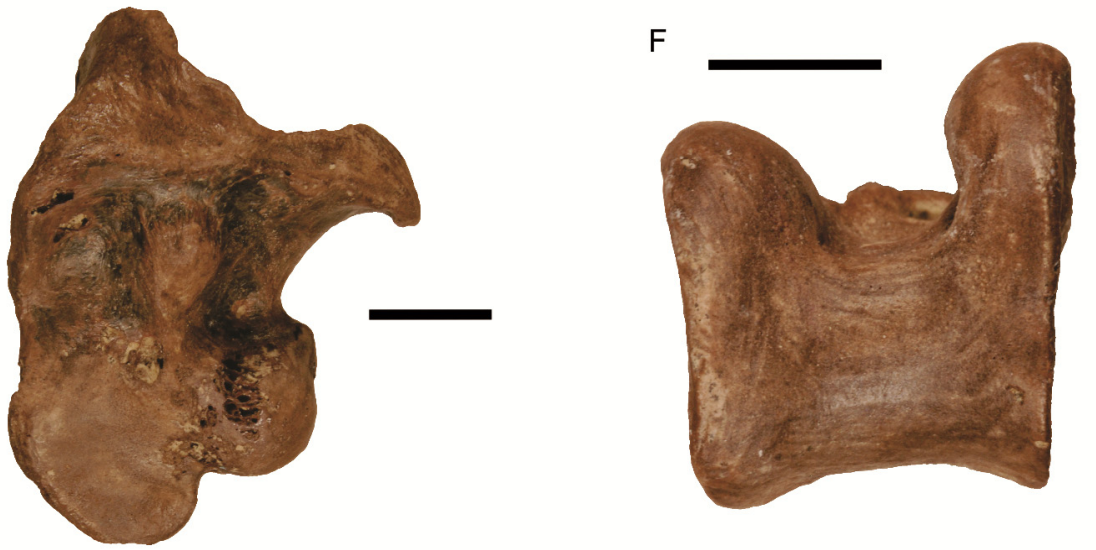

Lámina 4.29. Tibiotarso de Psilopterus lemoinei MPM-PV3650. A, vista craneal de ambos tibiotarsos; B, vista caudal de tibiotarso izquierdo; C, vista medial de tibiotarso derecho; D, vista lateral de tibiotarso izquierdo; E, vista proximal de tibiotarso derecho; $\mathrm{F}$, vista distal de tibiotarso derecho. Escala $=1 \mathrm{~cm}$. 


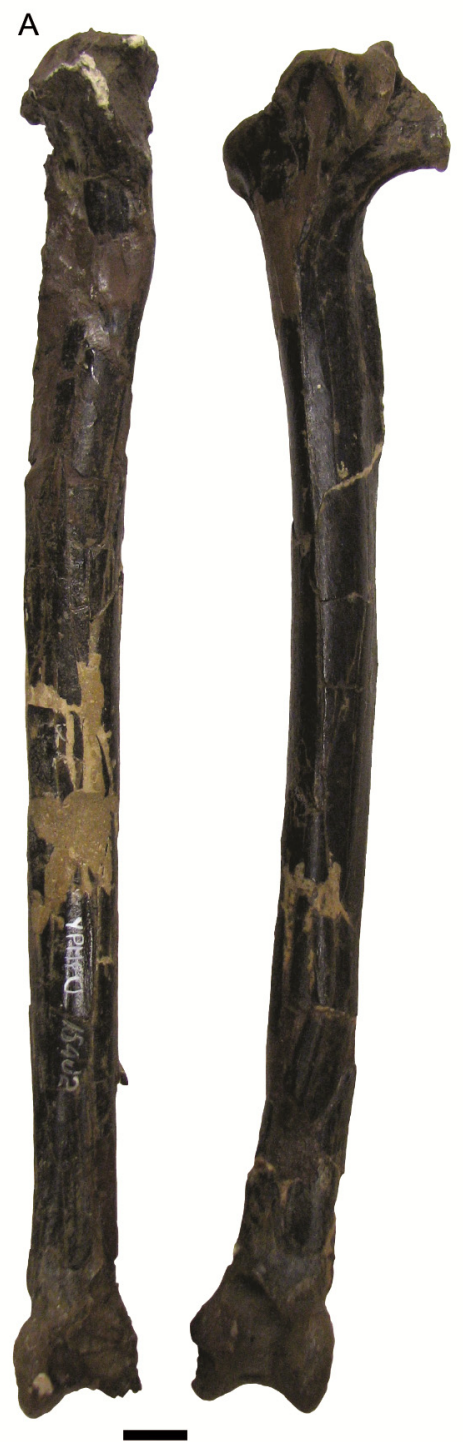

B

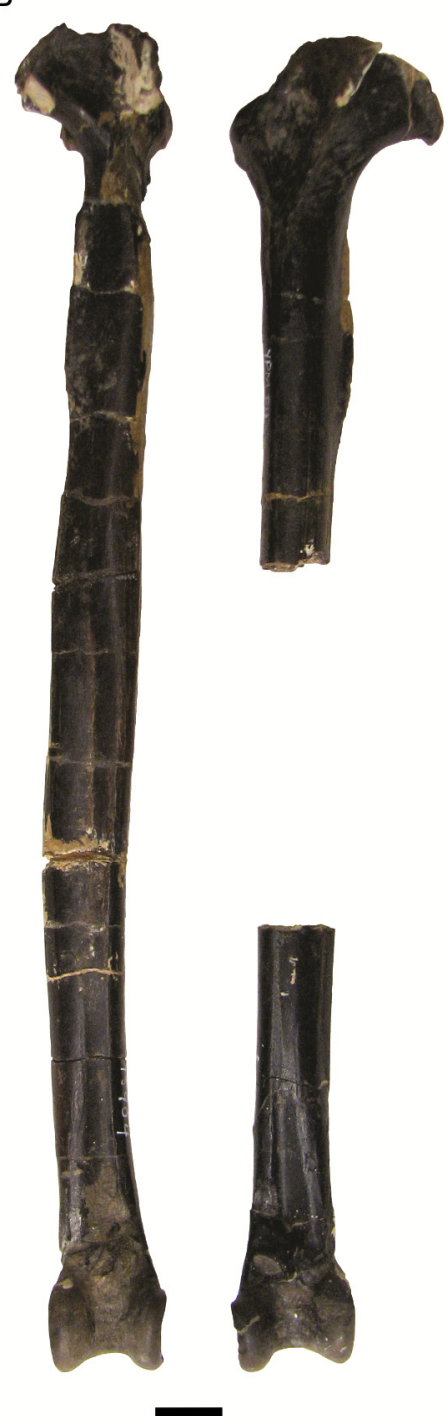

C

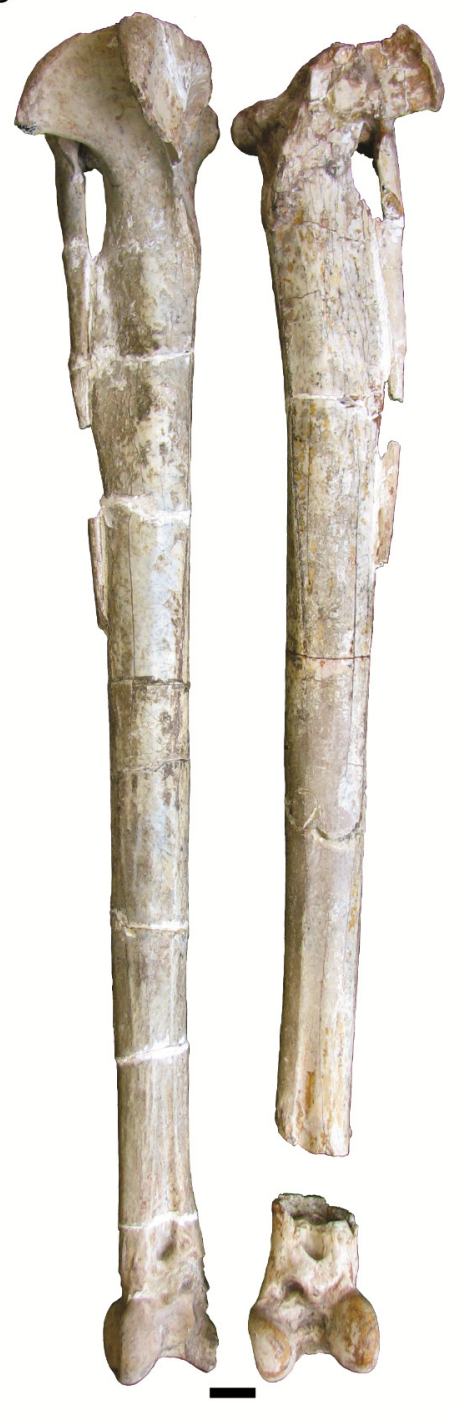

Lámina 4.30. Tibiotarso de Psilopterinae. A, Psilopterus lemoinei YPM-PU15402; B, Psilopterus bachmanni YPM-PU15904; C, Procariama simplex FM-P14525. Escala = 1 $\mathrm{cm}$. 
A

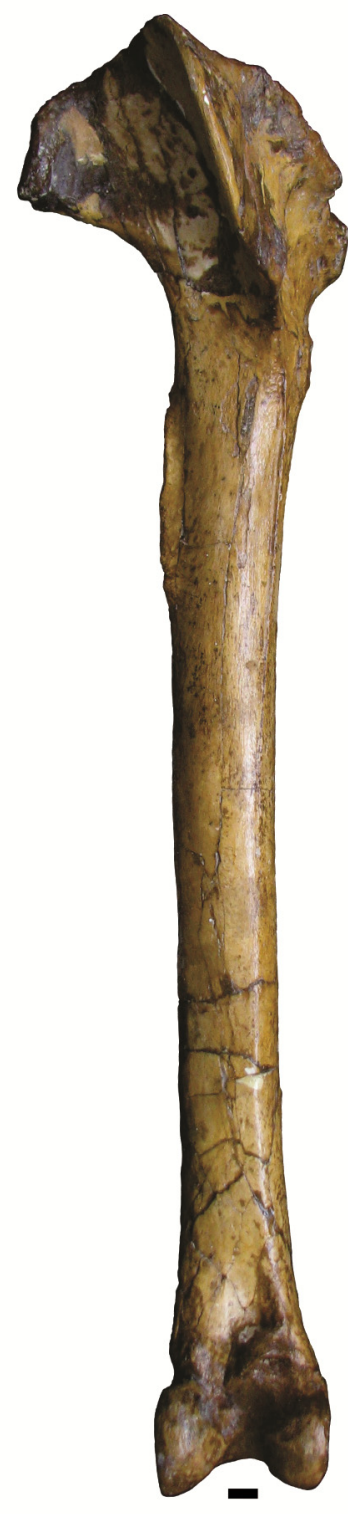

B

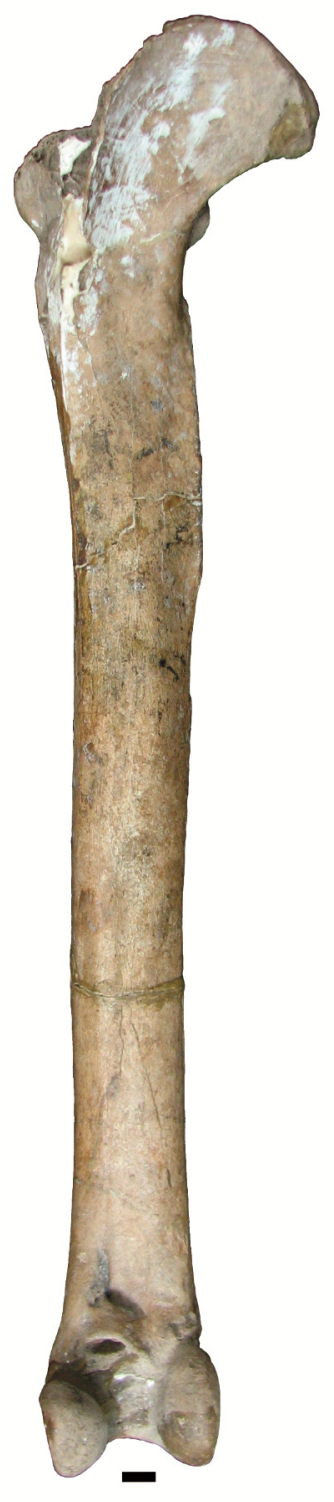

C

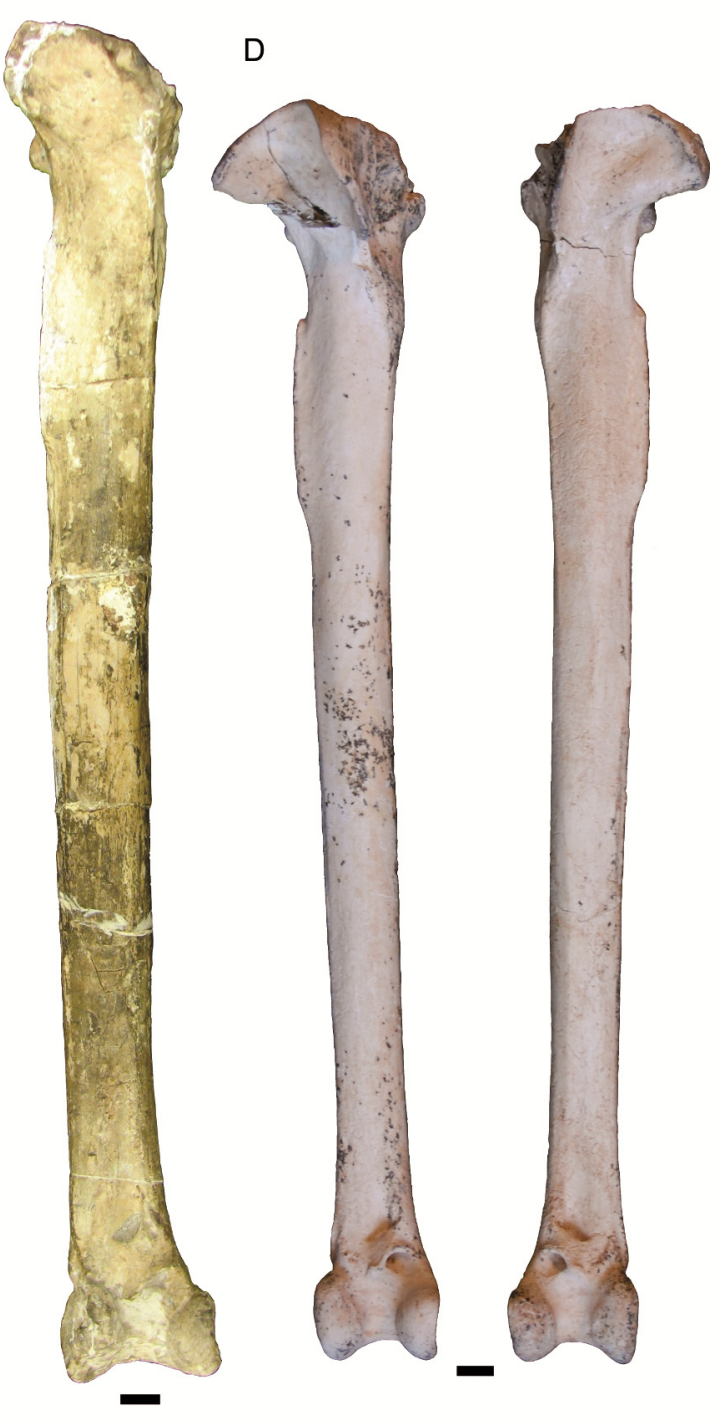

Lámina 4.31. Tibiotarso de Mesembriornithinae. A, Mesembriornis milneedwardsi MMP 155-S, tibiotarso derecho; B, M. milneedwardsi MACN Pv 5944, tibiotarso izquierdo; C, Mesembriornis incertus FM-P14422, tibiotarso derecho; D, ambos tibiotarsos de Taxón nuevo A MMP 5050. Escala $=1 \mathrm{~cm}$. 
A

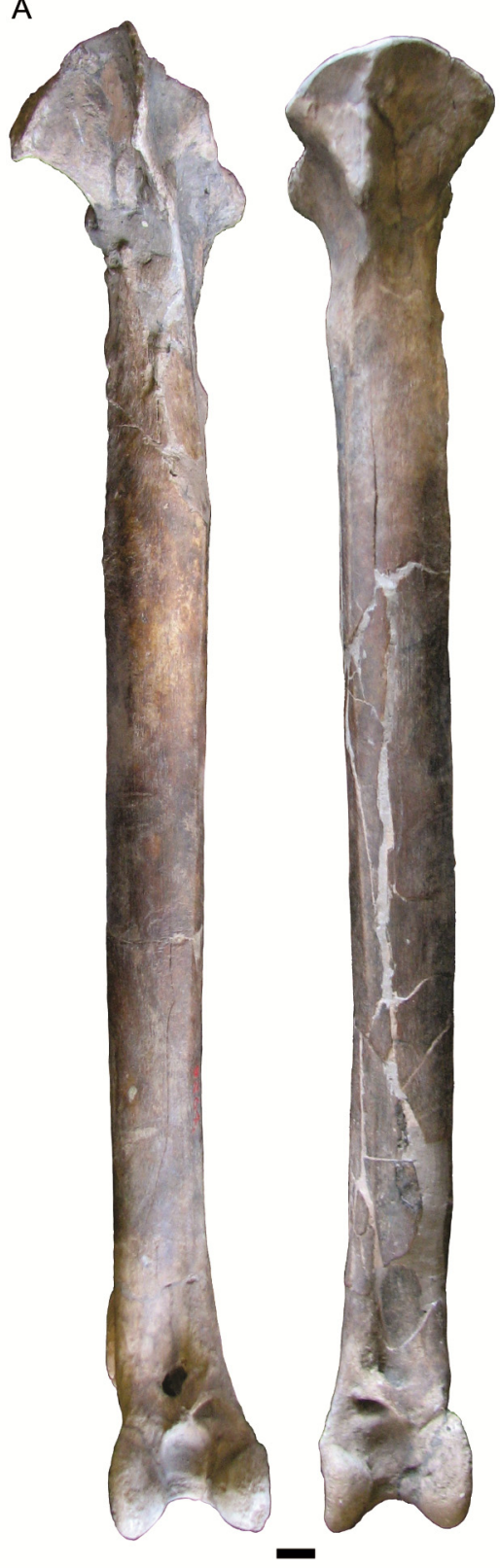

B

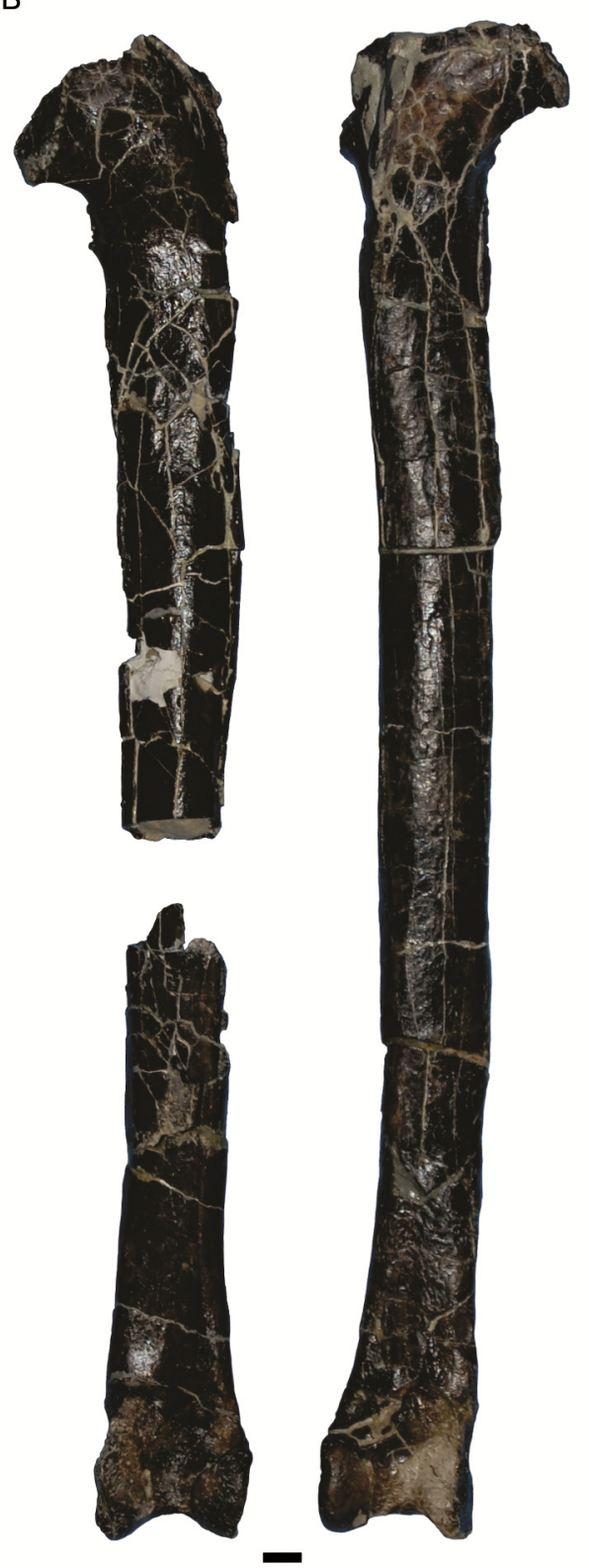

C

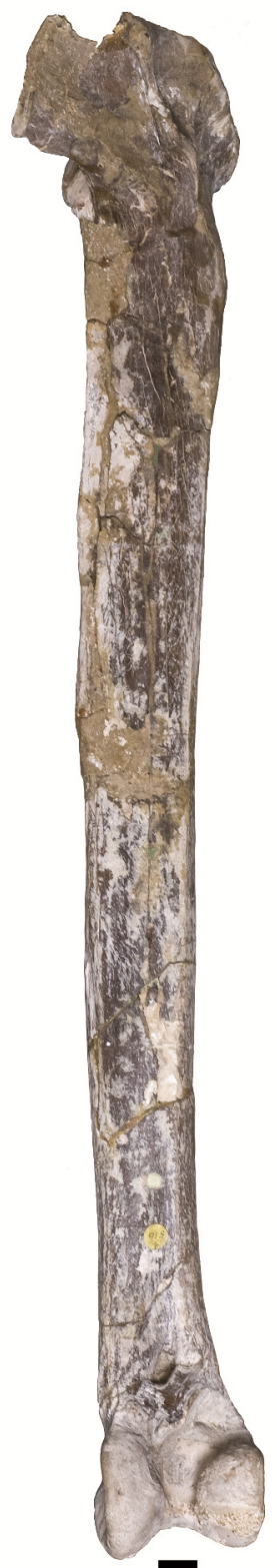

Lámina 4.32. Tibiotarso del Patagornithinae Patagornis marshi. A, AMNH 9264; MLP 84-II-9-21; C, BMNH-A516, tibiotarso derecho. Escala $=1 \mathrm{~cm}$. 
A

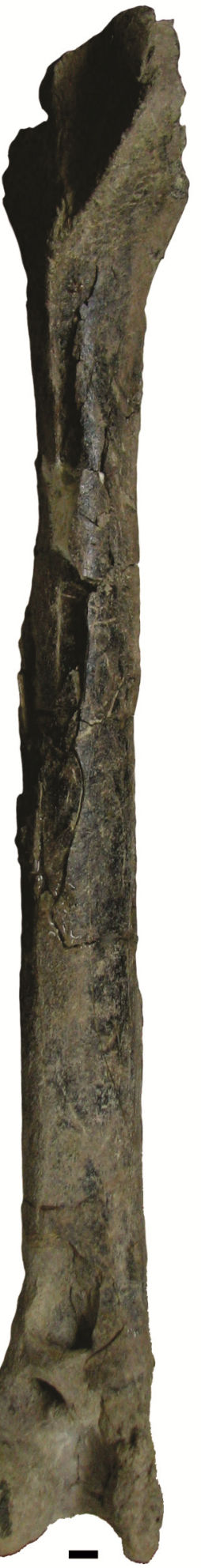

C

\section{B}

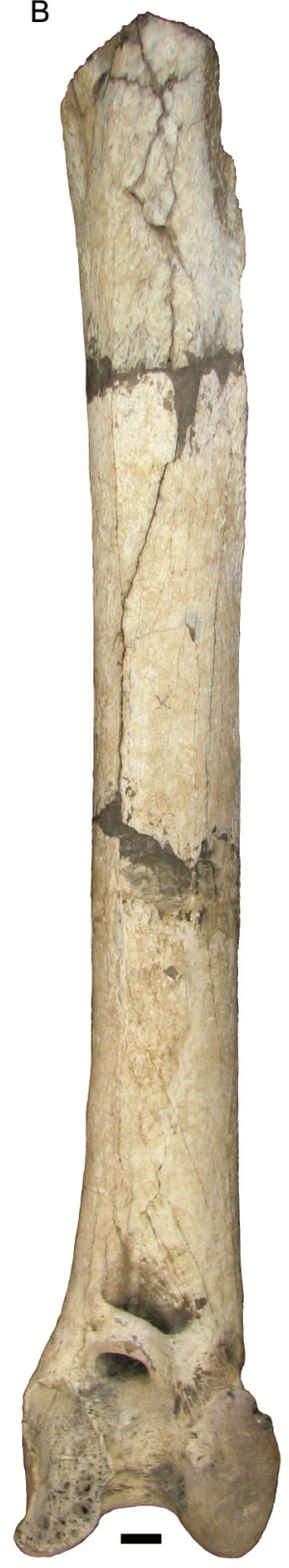

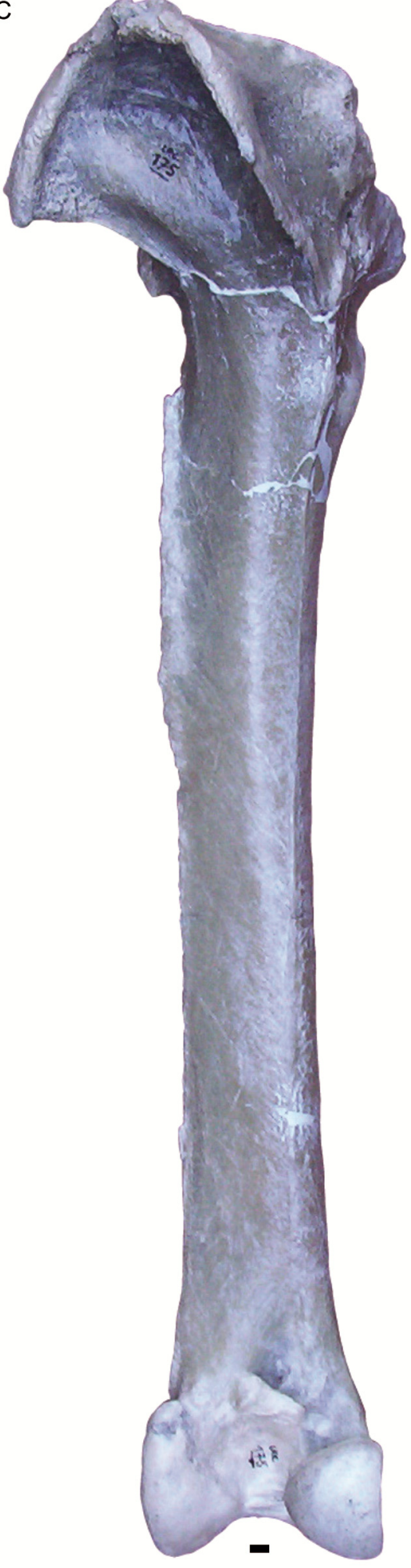

Lámina 4.33. Tibiotarso de Phorusrhacinae. A y B, Phorusrhacos longissimus; $\mathrm{C}$, Phorusrhacinae indet. A, MPM-PV4241; B, AMNH 9497; C, MNHN-1563. Escala = 1 $\mathrm{cm}$. 
A
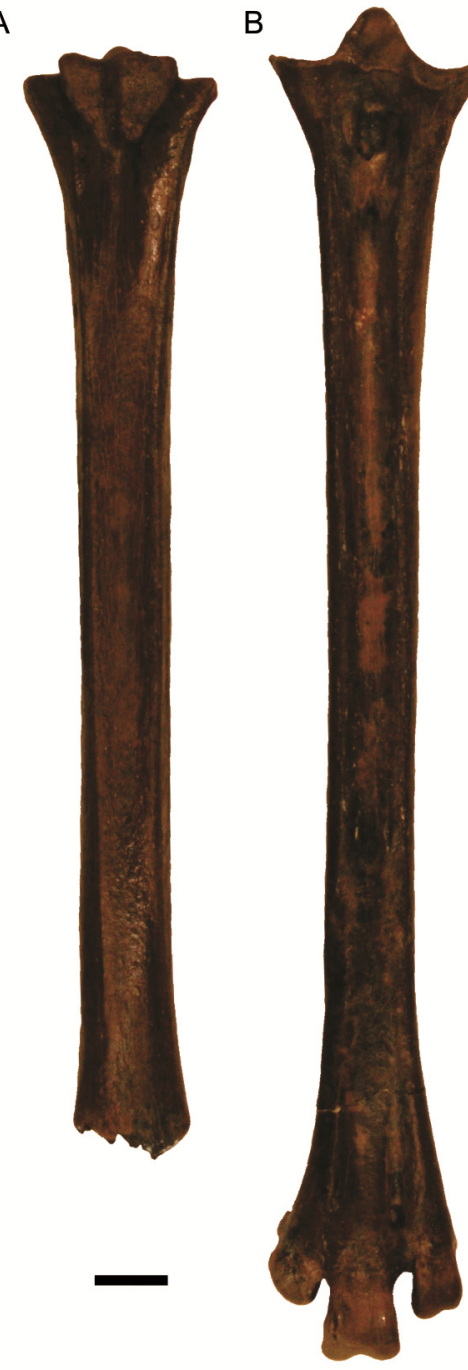

$\mathrm{F}$

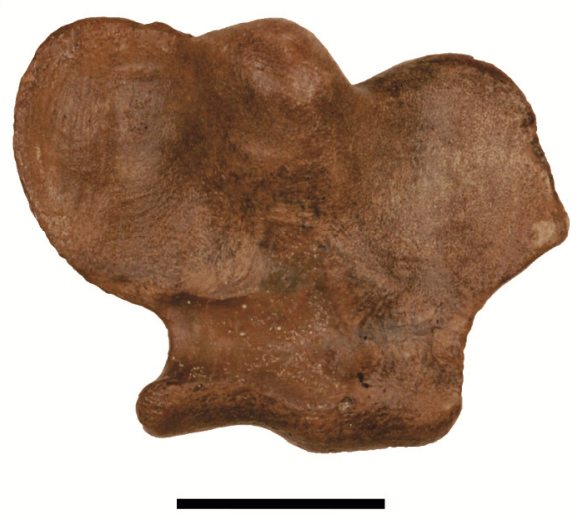

B
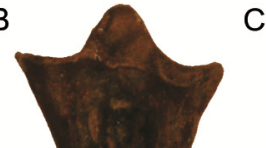

10

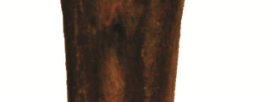

(1)

D

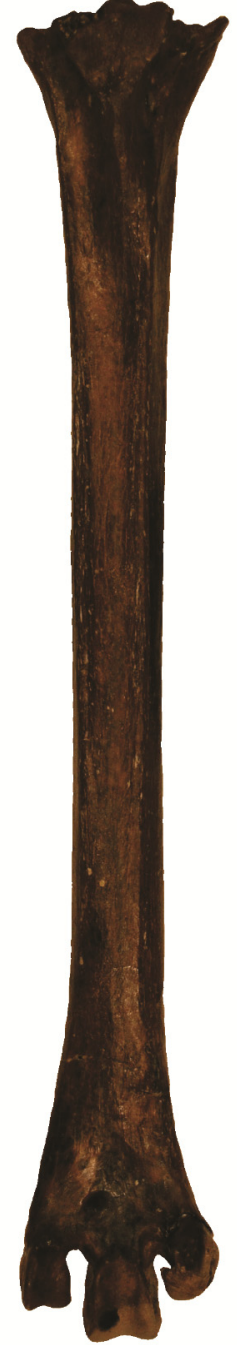

D

$E$

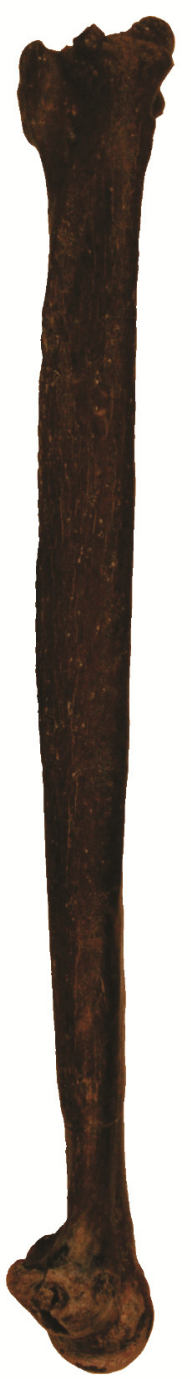

G
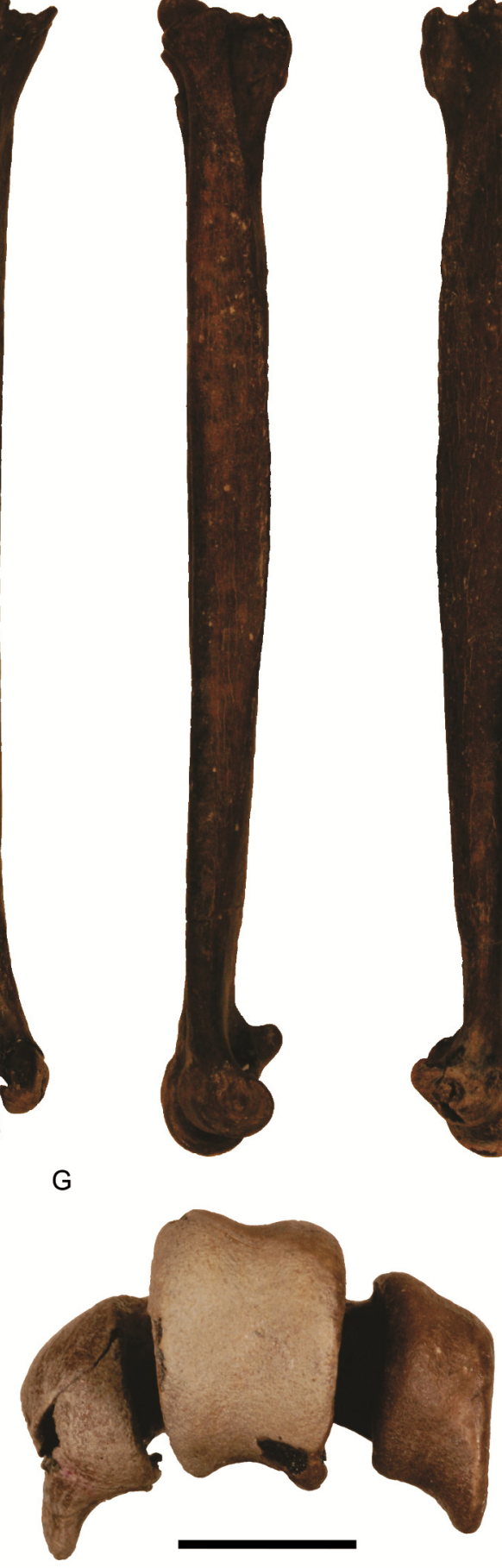

Lámina 4.34. Tarsometatarso de Psilopterus lemoinei MPM-PV3650. A, vista caudal de tarsometatarso izquierdo (nótese el hypotarsus). B-D, tarsometatarso derecho; B, vista craneal; $\mathrm{C}$, vista caudal; $\mathrm{D}$, vista lateral; E, vista medial; F, vista proximal de tarsometatarso izquierdo; $\mathrm{G}$, vista distal del tarsometatarso izquierdo. Escala $=1 \mathrm{~cm}$. 

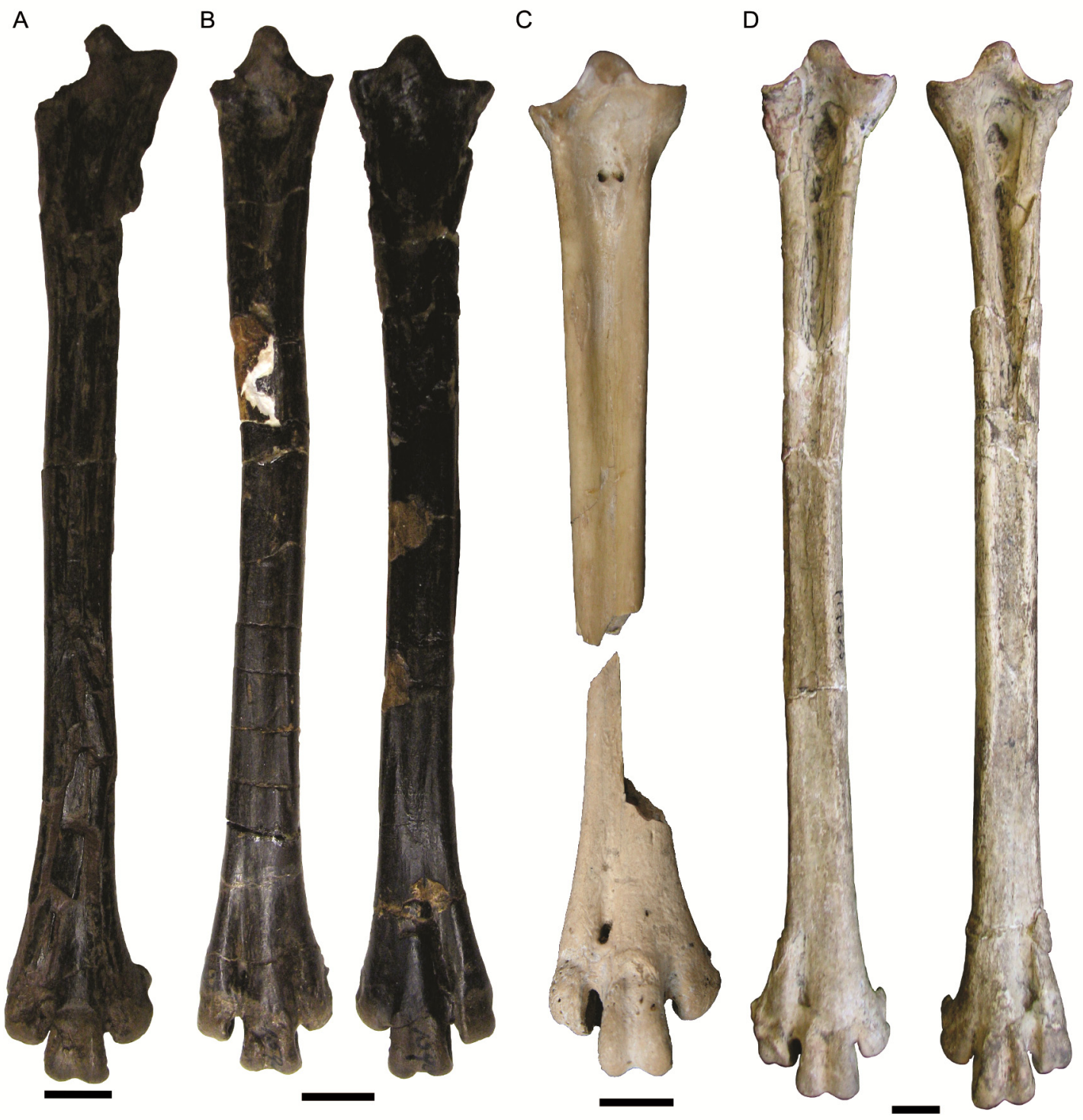

Lámina 4.35. Tarsometatarso de Psilopterinae. A, Psilopterus lemoinei YPMPU15402; B, Psilopterus bachmanni YPM-PU15904; C, Psilopterus affinis MACN A 52-184; D, Procariama simplex FM-P14525. Escala $=1 \mathrm{~cm}$. 
A

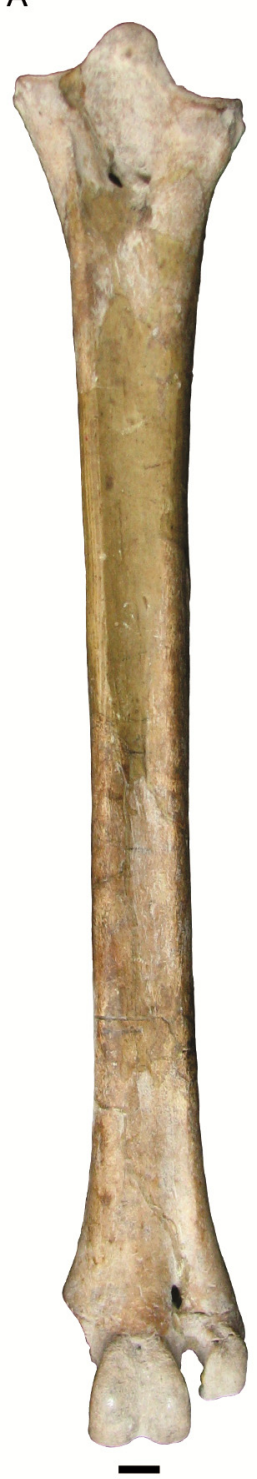

B

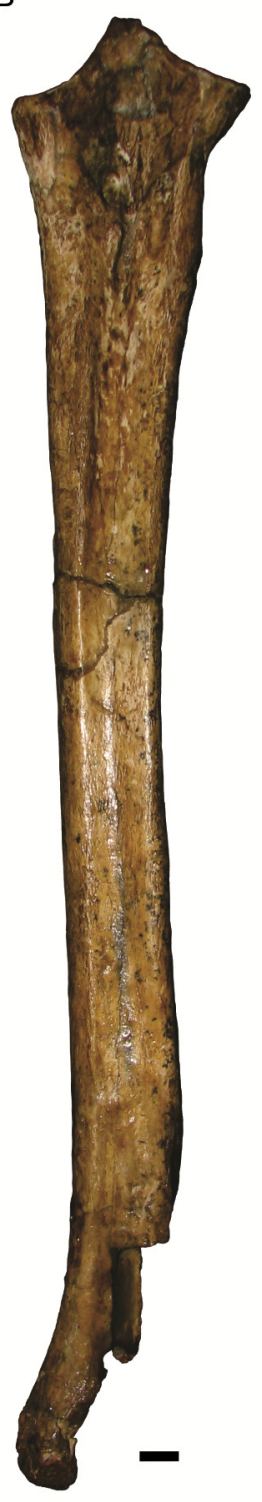

C

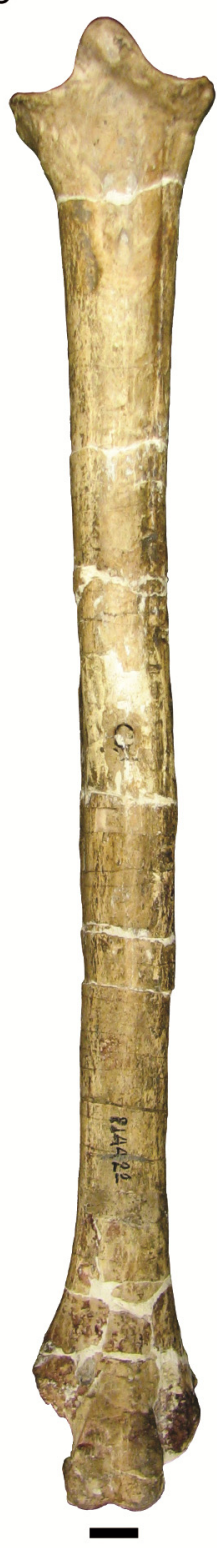

D

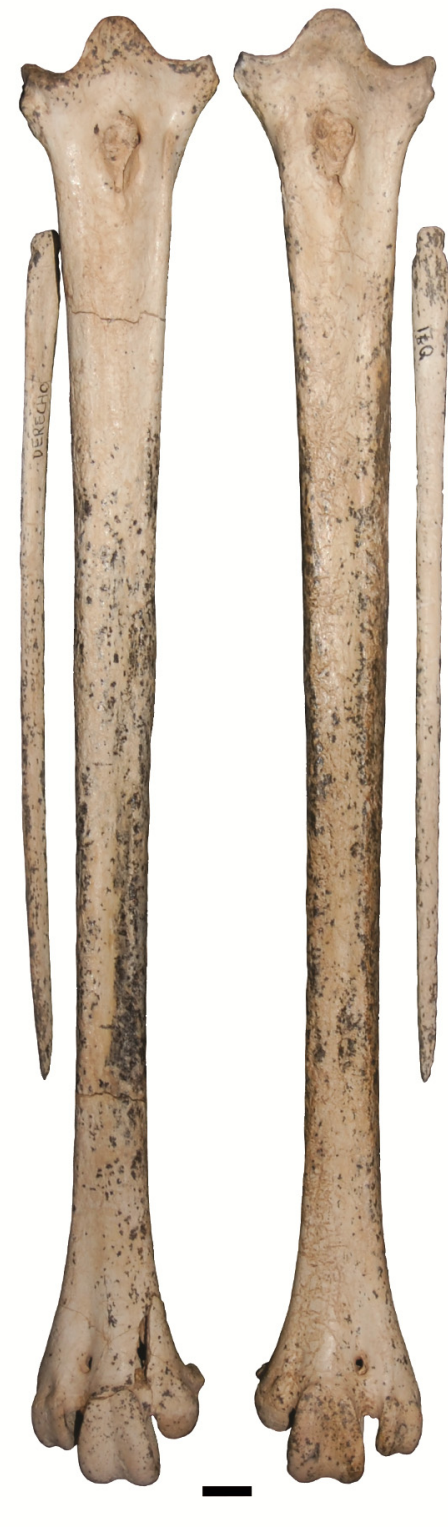

Lámina 4.36. Tarsometatarso de Mesembriornithinae. A, Mesembriornis milneedwardsi MACN Pv 5944, tarsometatarso izquierdo; B, M. milneedwardsi MMP 155-S, tarsometatarso derecho; C, Mesembriornis incertus FM-P14422, tarsometatarso derecho; D, ambos tarsometatarsos y tendones osificados de Taxón nuevo A MMP 5050. Escala $=1 \mathrm{~cm}$. 
A

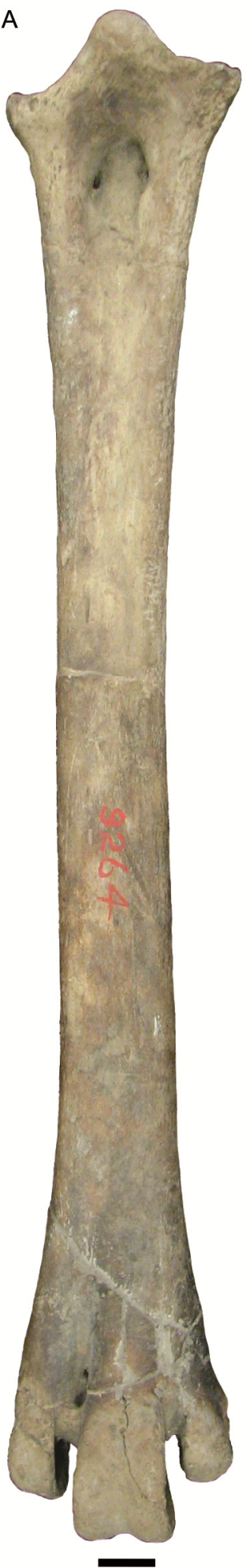

B

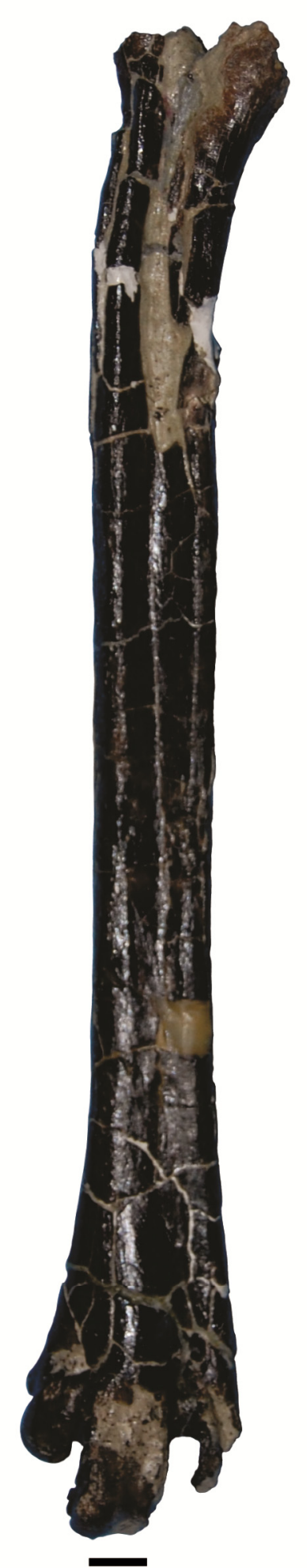

C
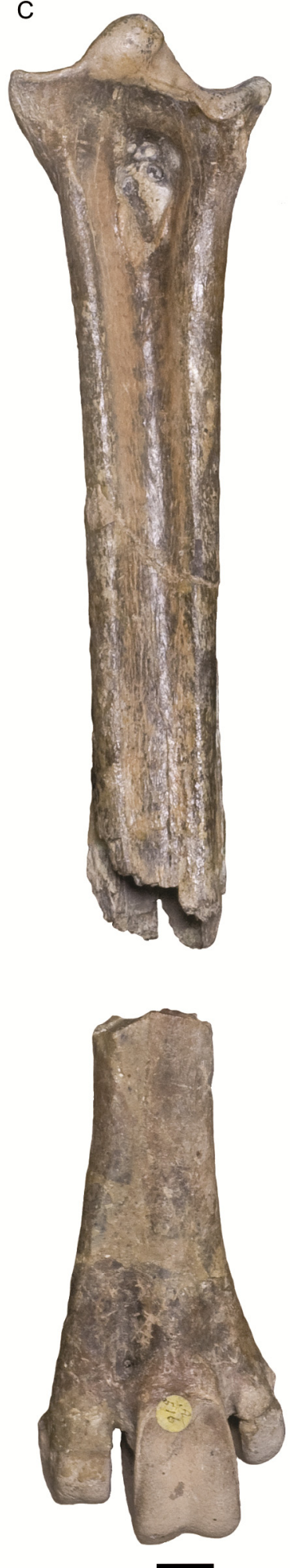

Lámina 4.37. Tarsometatarso del Patagornithinae Patagornis marshi. A, AMNH 9264, tarsometatarso derecho; MLP 84-II-9-21, tarsometatarso izquierdo; C, BMNH-A516, tarsometatarso derecho. Escala $=1 \mathrm{~cm}$. 
A

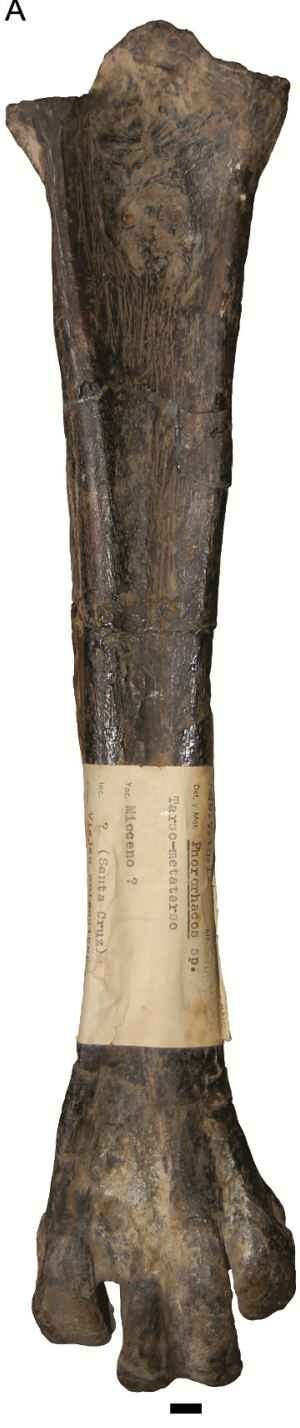

B

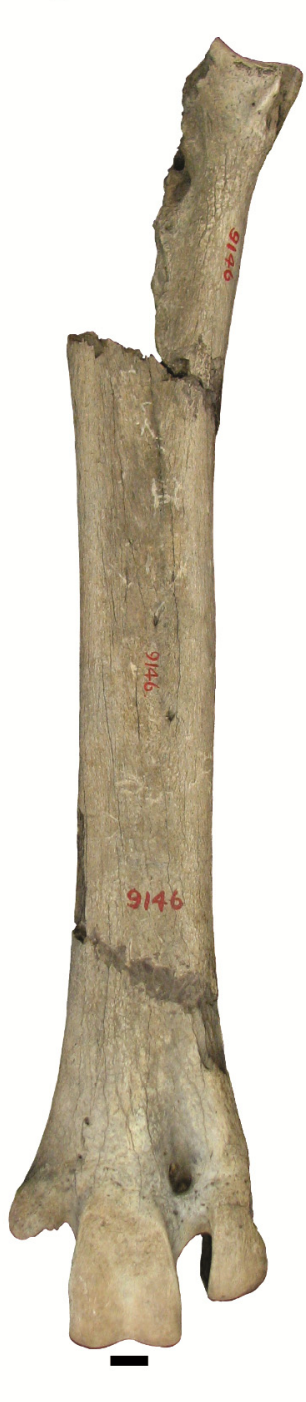

C

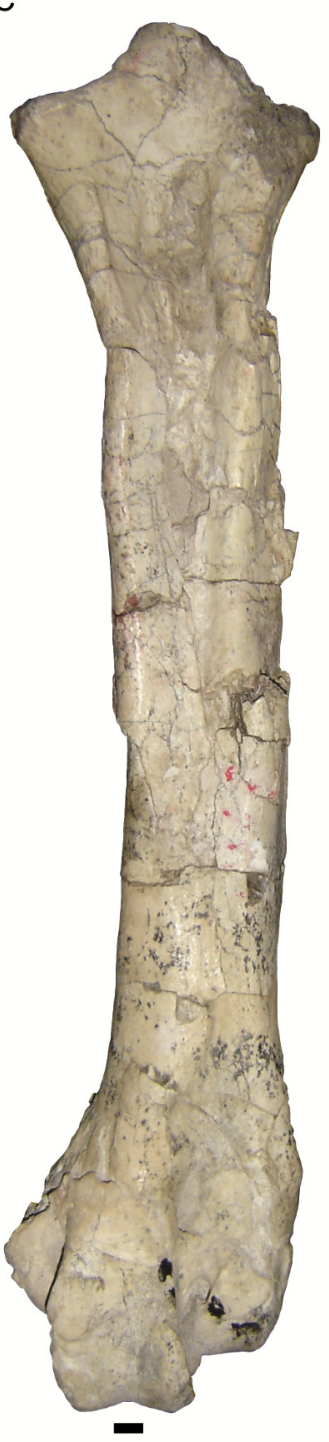

D

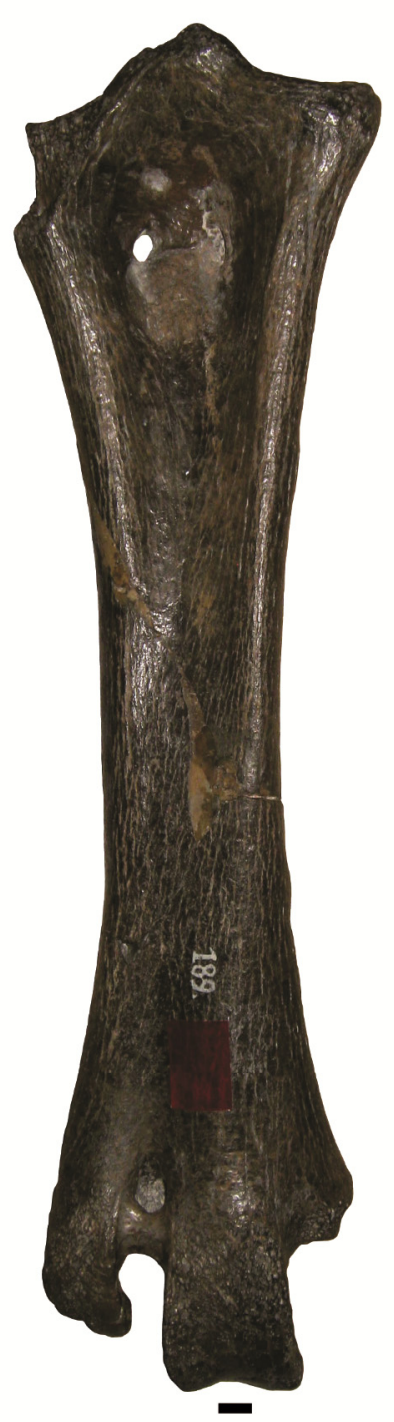

Lámina 4.38. Tarsometatarso de Phorusrhacinae. A y B, Phorusrhacos longissimus; A, MLP 76-V-10-11, tarsometatarso derecho; B, AMNH 9146, tarsometatarso izquierdo. C, Kelenken guillermoi BAR 3877-11, tarsometatarso izquierdo; D, Devincenzia pozzi MNHN-N-189, tarsometatarso derecho. Escala $=1 \mathrm{~cm}$. 
Tabla 6.1. Altura estimada (cm.) de los fororracos. $1=$ alto del cuello y cabeza; $2=$ alto de la pelvis; $3=$ alto del miembro posterior; $\mathrm{T}_{0}=$ altura total cuando el ángulo de la pelvis con la horizontal es $0^{\circ} ; \mathrm{T}_{15}=$ cuando dicho ángulo es igual a $15^{\circ} ; \mathrm{T}_{30}=$ ángulo igual a $30^{\circ} ; \mathrm{T}_{45^{\prime}}=$ ángulo igual a $45^{\circ}$.

\begin{tabular}{lccccccc}
\hline \multicolumn{1}{c}{ Especie } & \multicolumn{1}{c}{ Altura } \\
& 1 & 2 & 3 & $\mathrm{~T}_{0}$ & $\mathrm{~T}_{15}$ & $\mathrm{~T}_{30}$ & $\mathrm{~T}_{45}$ \\
\hline Psilopterus lemoinei & -- & 2,3 & 43,73 & -- & -- & -- & -- \\
Psilopterus bachmanni & -- & 2,1 & 35,96 & -- & -- & -- & -- \\
Procariama simplex & 28,6 & 4,5 & 51,15 & 84,15 & 88,54 & 92,65 & 96,17 \\
Mesembriornis milneedwardsi & 60 & 12 & 81,17 & 153,17 & 162,71 & 170,67 & 177,91 \\
Andalgalornis steulleti & 40 & 10,5 & $\sim 66,27$ & 116,77 & 125,41 & 133,47 & 140,47 \\
Patagornis marshi & -- & 6,2 & 66,27 & -- & -- & -- & -- \\
Taxón nuevo A & -- & 6 & 63,72 & -- & -- & -- & -- \\
\hline \hline
\end{tabular}


Tabla 6.2. Estimación de masa (kg.) de los fororracos y del Anseriformes Brontornis realizada en función del fémur y tibiotarso. Perímetro en mm. Abreviaturas: AL, all birds; LL, long-legged birds; gsr, general structural relation; OLS, ordinary least square; RMA, reduced major axis regression; aa, Andrewsornis abbotti; as, Andalgalornis steulleti; bb, Brontornis burmeisteri; dp, Devincenzia pozzi; m, Taxón nuevo A; mi, Mesembriornis incertus; mm, Mesembriornis milneedwardsi; $\mathrm{pb}$, Psilopterus bachmanni; pc, Psilopterus colzecus; pl, Phorusrhacos longissimus; ple, Psilopterus lemoinei; pm, Patagornis marshi; ps, Procariama simplex.

\begin{tabular}{|c|c|c|c|c|c|c|c|c|c|}
\hline \multirow{3}{*}{$\begin{array}{c}\text { Elemento } \\
\text { del CAP }\end{array}$} & \multirow{3}{*}{ Ejemplar } & \multirow{3}{*}{ Perímetro } & \multicolumn{7}{|c|}{ Métodos } \\
\hline & & & \multicolumn{2}{|c|}{ GSR } & \multicolumn{2}{|c|}{ RMA } & \multirow[t]{2}{*}{ OLS } & \multicolumn{2}{|c|}{ Fórmula } \\
\hline & & & $\mathrm{AL}$ & $\mathrm{LL}$ & $\mathrm{AL}$ & $\mathrm{LL}$ & & $\mathrm{AL}$ & $\mathrm{LL}$ \\
\hline \multirow[t]{11}{*}{ Fémur } & aa MLP 59-II-26-82 & 65,500 & 22,385 & 20,765 & 22,667 & 21,027 & 20,604 & 18,452 & 17,294 \\
\hline & bb MLP20-88 & 228,580 & 484,433 & 470,067 & 492,392 & 477,789 & 419,412 & 347,534 & 319,464 \\
\hline & pb MLP20-166 & 37,100 & 5,529 & 5,025 & 5,589 & 5,080 & 5,233 & 4,855 & 4,591 \\
\hline & ple MPM-PV3650 & 47,190 & 9,992 & 9,161 & 10,109 & 9,267 & 9,347 & 8,543 & 8,047 \\
\hline & pm MLP 84-III-9-21 & 78,210 & 34,628 & 32,328 & 35,084 & 32,754 & 31,598 & 27,988 & 26,158 \\
\hline & ps MACN Pv 6939 & 46,280 & 9,525 & 8,726 & 9,635 & 8,827 & 8,918 & 8,161 & 7,690 \\
\hline & ps MACN Pv 8225 & 50,640 & 11,887 & 10,925 & 12,027 & 11,054 & 11,080 & 10,083 & 9,488 \\
\hline & mm MACN Pv 5944 & 106,570 & 74,128 & 69,980 & 75,174 & 70,968 & 66,624 & 57,887 & 53,845 \\
\hline & pl MPM-PV4241 & 134,900 & 132,382 & 126,040 & 134,344 & 127,909 & 117,614 & 100,705 & 93,331 \\
\hline & m MMP5050 & 62,115 & 19,646 & 18,189 & 19,890 & 18,416 & 18,130 & 16,290 & 15,280 \\
\hline & pl AMNH 9497 & 117,165 & 93,593 & 88,658 & 94,940 & 89,934 & 83,728 & 72,322 & 67,173 \\
\hline \multirow[t]{17}{*}{ Tibiotarso } & bb MLP20-110 & 165,530 & 343,907 & 513,496 & 347,439 & 503,109 & 284,811 & 355,326 & 241,361 \\
\hline & bb MLP20-88 & 192,940 & 503,816 & 784,037 & 509,147 & 767,705 & 412,918 & 521,307 & 350,024 \\
\hline & mi FM-P14422 & 66,200 & 35,041 & 40,852 & 35,336 & 40,172 & 30,886 & 35,889 & 26,130 \\
\hline & mm MLP20-141 & 107,080 & 116,154 & 154,189 & 117,245 & 151,334 & 99,086 & 119,512 & 83,902 \\
\hline & pc MLP76-VI-12-2 & 41,180 & 10,735 & 11,009 & 10,815 & 10,847 & 9,772 & 10,945 & 8,260 \\
\hline & pl MLP 20-130 & 128,440 & 182,760 & 254,818 & 184,543 & 249,917 & 153,989 & 188,371 & 130,436 \\
\hline & pl MLP 20-137 & 137,410 & 216,243 & 307,048 & 218,382 & 301,061 & 181,366 & 223,026 & 153,645 \\
\hline & ple MPM-PV3650 & 43,390 & 12,229 & 12,720 & 12,321 & 12,529 & 11,093 & 12,474 & 9,377 \\
\hline & pm MLP 84-III-9-21 & 74,560 & 47,129 & 56,736 & 47,537 & 55,766 & 41,205 & 48,324 & 34,868 \\
\hline & dp MACN Pv 13243 & 131,140 & 192,485 & 269,889 & 194,371 & 264,675 & 161,953 & 198,434 & 137,187 \\
\hline & ps MACN Pv 8225 & 45,260 & 13,584 & 14,292 & 13,688 & 14,075 & 12,287 & 13,863 & 10,388 \\
\hline & mm MACN Pv 5944 & 106,600 & 114,861 & 152,288 & 115,938 & 149,470 & 98,013 & 118,177 & 82,993 \\
\hline & pl MPM-PV4241 & 122,700 & 163,080 & 224,589 & 164,656 & 220,310 & 137,835 & 168,014 & 116,742 \\
\hline & ple MPM-PV4240 & 50,460 & 17,813 & 19,299 & 17,954 & 18,999 & 15,994 & 18,197 & 13,524 \\
\hline & as MLP 88-IX-20-16 & 66,120 & 34,936 & 40,715 & 35,230 & 40,039 & 30,795 & 35,781 & 26,053 \\
\hline & m MMP5050 & 60,025 & 27,454 & 31,171 & 27,680 & 30,665 & 24,360 & 28,092 & 20,605 \\
\hline & pb YPM-PU15904 & 33,282 & 6,315 & 6,114 & 6,359 & 6,029 & 5,832 & 6,425 & 4,928 \\
\hline
\end{tabular}


Tabla 6.3. Estimación de fuerza de mordida de los fororracos de acuerdo a la masa corporal de todas las aves analizadas como predictor. $(y=0,4246 x+1,3198 ; R=0,77912$; $\left.\mathrm{R}^{2}=0.607 ; \mathrm{p}=0.0000\right)$ y utilizando únicamente la masa corporal de aves carnívoras como predictor. $\left(\mathrm{y}=0,9946 \mathrm{x}+1,2241 ; \mathrm{R}=0.91653 ; \mathrm{R}^{2}=0.84002 ; \mathrm{p}=0.0000\right)$. Fuerza de mordida (FM) en Newtons (N) y masa corporal en kg (estimadas en función del fémur). aa, Andrewsornis abbotti; as, Andalgalornis steulleti; m, Taxón nuevo A; mm, Mesembriornis milneedwardsi; pb, Psilopterus bachmanni; pl, Phorusrhacos longissimus; pm, Patagornis marshi; ps, Procariama simplex.

\begin{tabular}{lccccc}
\hline & \multirow{2}{*}{ Masa } & \multicolumn{4}{c}{ Fuerza de mordida estimada } \\
\cline { 3 - 6 } Ejemplar & corporal & Masa corporal & \multicolumn{2}{c}{ Carnívoros } \\
\cline { 3 - 6 } & & OLS & RMA & OLS & RMA \\
\hline aa MLP 59-II-26-82 & 20,6 & 75,46 & 152,42 & 339,6 & 459,31 \\
pb MLP20-166 & 5,23 & 42,17 & 72,23 & 86,89 & 103,8 \\
ple MPM-PV3650 & 9,35 & 53,94 & 99,07 & 154,71 & 194,78 \\
pm MLP 84-III-9-21 & 31,6 & 90,48 & 192,41 & 519,59 & 730,51 \\
ps MACN Pv 6939 & 8,92 & 52,88 & 96,57 & 147,65 & 185,11 \\
ps MACN Pv 8225 & 11,08 & 57,98 & 108,7 & 183,23 & 234,28 \\
mm MACN Pv 5944 & 66,62 & 124,2 & 288,93 & 1091,14 & 1641,35 \\
pl MPM-PV4241 & 117,61 & 158,09 & 393,82 & 1920,34 & 3041,32 \\
m MMP5050 & 18,13 & 71,47 & 142,16 & 299,02 & 399,77 \\
pl AMNH 9497 & 83,73 & 136,85 & 327,24 & 1369,58 & 2103,3 \\
as & $40^{*}$ & 100,01 & 218,8 & 656,91 & 943,53 \\
\hline \hline
\end{tabular}

*Estimación de C.P. Tambussi (inédito). Véase texto. 
Tabla 6.4. Estimación de fuerza de mordida de los fororracos utilizando el ancho craneano como predictor. ( $\left.y=2,8705 x-0,5706 ; R=0,96518 ; R^{2}=0.93157 ; p=0.0004\right)$. Fuerza de mordida (FM) en Newtons (N); Ancho craneano (AC) en cm. as, Andalgalornis steulleti; dp, Devincenzia pozzi; ke, Kelenken guillermoi; m, Taxón nuevo A; pb, Psilopterus bachmanni; pm, Patagornis marshi; ps, Procariama simplex.

\begin{tabular}{lcc}
\hline \hline Ejemplar & AC & FM \\
\hline ke BAR 3877-11 & 22,11 & 1945,55 \\
dp MLP 37-III-7-8 & 25,65 & 2979,79 \\
as FM-P14357 & 15,46 & 696,67 \\
pm BMNH-A516 & 11,80 & 320,80 \\
pm MLP N20-122 & 12,18 & 351,36 \\
pm MLP 84-III-9-21 & 12,37 & 367,32 \\
ple AMNH 9257 & 7,08 & 74,03 \\
ple YPM-PU15402 & 5,85 & 42,81 \\
pb YPM-PU15904 & 5,36 & 33,30 \\
ps FM-P14353 & 6,97 & 70,78 \\
ps MACN Pv 8225 & 6,40 & 55,40 \\
m MMP 5050 & 8,13 & 110,11 \\
\hline \hline
\end{tabular}


Tabla 7.1. Niveles de inferencia de los orígenes e inserciones de los músculos mandibulares de los Phorusrhacidae. Grupos de comparación: Anhimidae, Phoenicopteridae, Falconidae, Accipitridae y Cuculidae.

\begin{tabular}{lcc}
\hline \hline \multirow{2}{*}{ Músculos mandibulares } & \multicolumn{2}{c}{ Niveles de inferencia } \\
\cline { 2 - 3 } & Origen & Inserción \\
\hline m. pterygoideus dorsalis & $\mathrm{I}$ & $\mathrm{I}$ \\
m. pterygoideus ventralis & $\mathrm{I}$ & $\mathrm{I}$ \\
m. pseudotemporalis profundus & $\mathrm{I}^{\prime}$ & $\mathrm{I}^{\prime}$ \\
m. pseudotemporalis superficialis & $\mathrm{I}$ & $\mathrm{I}^{\prime}$ \\
m. adductor mandibulae externus profundus & $\mathrm{I}$ & $\mathrm{I}$ \\
m. adductor mandibulae externus superficialis & $\mathrm{I}$ & $\mathrm{I}$ \\
m. adductor mandibulae posterior & $\mathrm{I}^{\prime}$ & $\mathrm{I}$ \\
m. protractor pterygoideus et quadrati & $\mathrm{I}$ & $\mathrm{I}$ \\
m. depressor mandibulae & $\mathrm{I}$ & $\mathrm{I}$ \\
\hline \hline
\end{tabular}


Tabla 7.2. Niveles de inferencia de los orígenes e inserciones de los músculos del complejo apendicular posterior de los Phorusrhacidae. Grupos de comparación: Rheidae, Tinamidae, Tytonidae, Falconidae y Cuculidae.

\begin{tabular}{|c|c|c|}
\hline \multirow{2}{*}{ Músculos apendiculares posteriores } & \multicolumn{2}{|c|}{ Niveles de inferencia } \\
\hline & Origen & Inserción \\
\hline m. iliotibialis lateralis & $\mathrm{I}$ & I \\
\hline m. flexor cruris lateralis & I & $\mathrm{I}^{\prime}$ \\
\hline m. flexor cruris medialis & $\mathrm{I}^{\prime}$ & I \\
\hline m. ischiofemoralis & $\mathrm{I}$ & I \\
\hline m. puboischiofemoralis & $\mathrm{I}^{\prime}$ & $\mathrm{I}$ \\
\hline m. iliotibialis cranialis & $\mathrm{I}$ & $\mathrm{I}$ \\
\hline m. iliotrochantericus caudalis & $\mathrm{I}$ & I \\
\hline m. iliotrochantericus cranialis & $\mathrm{I}$ & $\mathrm{I}^{\prime}$ \\
\hline m. femorotibialis lateralis & $\mathrm{I}$ & $\mathrm{I}$ \\
\hline m. femorotibialis intermedius & $\mathrm{I}^{\prime}$ & $\mathrm{I}$ \\
\hline m. femorotibialis medialis & $\mathrm{I}^{\prime}$ & I \\
\hline m. iliofibularis & I & I \\
\hline m. fibularis longus & I & $\mathrm{I}^{\prime}$ \\
\hline m. gastrocnemius pars lateralis & I & I \\
\hline m. gastrocnemius pars intermedia & $\mathrm{I}$ & I \\
\hline m. gastrocnemius pars medialis & I & $\mathrm{I}$ \\
\hline m. tibialis cranialis & $\mathrm{I}$ & I \\
\hline $\mathrm{m}$. extensor digitorum longus & $\mathrm{I}^{\prime}$ & I \\
\hline m. extensor hallucis longus & $\mathrm{I}$ & I \\
\hline m. flexor hallucis longus & $\mathrm{I}^{\prime}$ & I \\
\hline m. flexor digitorum longus & $\mathrm{I}$ & $\mathrm{I}$ \\
\hline
\end{tabular}


Tabla 8.1. Stress promedio (von Misses, VM) calculado en tres especies de aves bajo tres condiciones de carga. $\mathrm{L}=$ lateral shake, $\mathrm{N}=$ normal bite, $\mathrm{P}=$ pullback.

\begin{tabular}{lccc}
\hline & Andalgalornis & Haliaeetus & Cariama \\
\hline Número de elementos & 1.080 .137 & 860.757 & 775.698 \\
Lateral shake & 1,028 & 2,272 & 3,285 \\
Normal Bite & 0,570 & 2,412 & 3,235 \\
Pullback & 0,234 & 0,678 & 0,833 \\
Indice L/N & 1,803 & 0,941 & 1,015 \\
Indice L/P & 4,393 & 3,351 & 3,943 \\
\hline \hline
\end{tabular}


Tabla 8.2. Brazos de momento estandarizados (Me) e índices de velocidad (Iv) calculados para el $m$. adductor mandibulae externus (MAME), m. adductor mandibulae posterior (MAMP), m. pseudotemporalis profundus (PSP), m. pseudotemporalis superficialis (PSS), m. pterygoideus dorsalis (PTD), m. pterygoideus ventralis (PTV), suma de la musculatura adductora (MA) y $m$. depressor mandibulae (MDM). Los valores entre paréntesis indican el porcentaje de contribución a la musculatura adductora total.

\begin{tabular}{lcccccc}
\hline \hline & \multicolumn{2}{c}{ Mesembriornithinae } & \multicolumn{2}{c}{ Andalgalornis } & \multicolumn{2}{c}{ Geranoaetus } \\
\cline { 2 - 7 } & Me & Iv & Me & Iv & Me & Iv \\
\hline PTD & $0,04(8,87)$ & 17,37 & $0,08(11,47)$ & 9,98 & $0,05(10,59)$ & 12,47 \\
PTV & $0,06(11,32)$ & 13,61 & $0,08(11,44)$ & 10,01 & $0,04(8,01)$ & 16,49 \\
PSS & $0,15(26,93)$ & 5,72 & $0,21(27,81)$ & 4,12 & $0,13(24,48)$ & 5,39 \\
PSP & $0,12(21,42)$ & 7,2 & $0,17(22,2)$ & 5,16 & $0,1(18,98)$ & 6,96 \\
MAME & $0,1(18,45)$ & 8,35 & $0,12(16,81)$ & 6,81 & $0,12(21,76)$ & 6,07 \\
MAMP & $0,07(12,98)$ & 11,87 & $0,07(10,25)$ & 11,17 & $0,09(16,16)$ & 8,18 \\
MA & 0,56 & 1,54 & 0,76 & 1,14 & 0,55 & 1,32 \\
MDM & 0,02 & 36,02 & 0,02 & 36,99 & 0,02 & 30,72 \\
\hline \hline
\end{tabular}


Tabla 9.1. Matriz de medidas del fémur $(\mathrm{cm}$.) tomadas en las Neornithes actuales utilizadas en esta tesis.

\begin{tabular}{|c|c|c|c|c|c|c|c|c|}
\hline Catálogo & Especie & Orden & Familia & EA & EB & $\mathrm{EC}$ & ED & $\mathrm{EE}$ \\
\hline MLP 569 & Chauna torquata & Anseriformes & Anhimidae & 9,911 & 10,603 & 2,480 & 2,254 & 2,606 \\
\hline MLP 84 & Anas platalea & Anseriformes & Anatidae & 4,140 & 4,319 & 0,911 & 0,820 & 0,889 \\
\hline MLP 533 & Cariama cristata & Cariamiformes & Cariamidae & 7,969 & 8,521 & 1,883 & 1,671 & 2,071 \\
\hline MLP 535 & Chunga burmeisteri & Cariamiformes & Cariamidae & 6,018 & 6,452 & 1,629 & 1,427 & 1,673 \\
\hline MLP 615 & Vanellus chilensis & Charadriiformes & Charadriidae & 3,788 & 4,093 & 0,718 & 0,604 & 0,840 \\
\hline MLP 814 & Larus maculipennis & Charadriiformes & Laridae & 3,671 & 3,899 & 0,729 & 0,656 & 0,758 \\
\hline MLP 412 & Chionis alba & Charadriiformes & Chionididae & 5,233 & 5,672 & 1,104 & 1,054 & 1,207 \\
\hline MLP 871 & Catharacta maccormicki & Charadriiformes & Stercorariidae & 5,922 & 6,195 & 1,223 & 1,020 & 1,300 \\
\hline YPM 111287 & Burhinus capensis & Charadriiformes & Burhinidae & 4,670 & 5,070 & 0,920 & 0,860 & 1,110 \\
\hline YPM 102096 & Burhinus grallarius & Charadriiformes & Burhinidae & 5,590 & 6,010 & 1,290 & 0,970 & 1,360 \\
\hline MLP 531 & Burhinus oedicnemus & Charadriiformes & Burhinidae & 4,457 & 4,755 & 0,933 & 0,774 & 1,022 \\
\hline MACN 22325 & Fratercula corniculata & Charadriiformes & Alcidae & 4,030 & 4,096 & 0,844 & 0,592 & 0,790 \\
\hline MLP 474 & Theristicus melanopis & Ciconiiformes & Threskiornithidae & 6,857 & 7,212 & 1,520 & 1,321 & 1,706 \\
\hline MLP 344 & Coragyps atratus & Ciconiiformes & Cathartidae & 8,356 & 8,533 & 1,796 & 1,564 & 1,984 \\
\hline MLP 804 & Nycticorax nycticorax & Ciconiiformes & Ardeidae & 7,032 & 7,152 & 1,248 & 0,924 & 1,192 \\
\hline MLP 712 & Ciconia maguari & Ciconiiformes & Ciconiidae & 10,480 & 10,766 & 1,832 & 1,462 & 1,902 \\
\hline MLP 807 & Vultur gryphus & Ciconiiformes & Cathartidae & 13,972 & 14,892 & 3,632 & 3,178 & 3,982 \\
\hline Prom. YPM & $\begin{array}{l}\text { Leptoptilos } \\
\text { crummeniferus }\end{array}$ & Ciconiiformes & Ciconiidae & 11,230 & 12,245 & 3,065 & 2,155 & 2,960 \\
\hline YPM 102102 & Leptoptilos dubius & Ciconiiformes & Ciconiidae & 11,610 & 12,730 & 3,000 & 2,320 & 3,110 \\
\hline YPM 105903 & Mycteria americana & Ciconiiformes & Ciconiidae & 7,670 & 8,310 & 1,820 & 1,270 & 1,800 \\
\hline YPM 105272 & Mycteria ibis & Ciconiiformes & Ciconiidae & 7,810 & 8,360 & 1,880 & 1,340 & 1,780 \\
\hline YPM 102099 & Mycteria leucocephala & Ciconiiformes & Ciconiidae & 8,370 & 9,060 & 1,890 & 1,310 & 1,950 \\
\hline MACN 20958 & Ardea cocoi & Ciconiiformes & Ardeidae & 10,634 & 10,912 & 1,914 & 1,422 & 1,992 \\
\hline MLP 399 & Columba picazuro & Columbiformes & Columbidae & 4,242 & 4,463 & 0,865 & 0,634 & 0,805 \\
\hline MLP 261 & Zenaida auriculata & Columbiformes & Columbidae & 2,781 & 2,925 & 0,563 & 0,443 & 0,542 \\
\hline
\end{tabular}




\begin{tabular}{|c|c|c|c|c|c|c|c|c|}
\hline YPM 103256 & Buceros bicornis & Coraciiformes & Bucerotidae & 8,350 & 8,700 & 1,980 & 1,640 & 1,790 \\
\hline MLP 319 & Galbula ruficauda & Coraciiformes & Galbulidae & 1,338 & 1,393 & 0,294 & 0,210 & 0,268 \\
\hline MLP 6 & Ceryle torquata & Coraciiformes & Alcedinidae & 3,259 & 3,280 & 0,704 & 0,537 & 0,682 \\
\hline MLP 97 & Guira guira & Cuculiformes & Cuculidae & 3,875 & 3,951 & 0,680 & 0,546 & 0,662 \\
\hline MLP 536 & Opisthocomus hoazin & Cuculiformes & Opisthocomidae & 6,332 & 6,461 & 1,301 & 0,892 & 1,247 \\
\hline MLP 696 & $\begin{array}{l}\text { Geranoaetus } \\
\text { melanoleucus }\end{array}$ & Falconiformes & Accipitridae & 10,772 & 11,087 & 2,156 & 1,473 & 2,442 \\
\hline MLP 438 & Falco peregrinus & Falconiformes & Falconidae & 6,548 & 6,842 & 1,311 & 0,685 & 1,364 \\
\hline MLP 62 & Polyborus plancus & Falconiformes & Falconidae & 7,554 & 7,856 & 1,832 & 1,286 & 1,776 \\
\hline YPM 111125 & Sagittarius serpentarius & Falconiformes & Sagittariidae & 9,710 & 10,510 & 2,470 & 2,020 & 2,510 \\
\hline MACN 26366 & Pandion haliaetus & Falconiformes & Accipitridae & 7,726 & 7,958 & 1,634 & 1,474 & 1,726 \\
\hline MLP 364 & Lophortyx californica & Galliformes & Odontophoridae & 3,943 & 4,202 & 0,792 & 0,546 & 0,722 \\
\hline MACN 343438 & Penelope purpurascens & Galliformes & Cracidae & 9,626 & 10,204 & 1,940 & 1,556 & 1,826 \\
\hline OUVC 10563 & Gavia immer & Gaviiformes & Gaviidae & 6,118 & 6,696 & 2,155 & 1,252 & 2,118 \\
\hline MLP 49 & Fulica armillata & Gruiformes & Rallidae & 6,251 & 6,631 & 1,308 & 1,085 & 1,244 \\
\hline YPM 102540 & Ardeotis arabs & Gruiformes & Otididae & 9,340 & 10,370 & 2,760 & 2,310 & 2,590 \\
\hline YPM 105866 & Ardeotis kori & Gruiformes & Otididae & 11,200 & 12,130 & 3,210 & 2,560 & 3,370 \\
\hline YPM 102227 & Otis tarda & Gruiformes & Otididae & 10,460 & 11,870 & 2,820 & 2,800 & 2,720 \\
\hline Prom. YPM & Psophia crepitans & Gruiformes & Psophiidae & 6,676 & 7,373 & 1,520 & 1,226 & 1,516 \\
\hline YPM 102062 & Tetrax tetrax & Gruiformes & Otididae & 5,340 & 5,780 & 1,250 & 1,030 & 1,150 \\
\hline MLP 403 & Porphyrula martinica & Gruiformes & Rallidae & 4,877 & 5,020 & 0,949 & 0,697 & 0,863 \\
\hline YPM 102538 & Grus canadensis & Gruiformes & Gruidae & 10,710 & 11,750 & 2,080 & 1,850 & 2,370 \\
\hline MACN 63320 & Aramus guarauna & Gruiformes & Aramidae & 8,558 & 8,932 & 1,692 & 1,446 & 1,712 \\
\hline MLP 178 & Xiphocolaptes major & Passeriformes & Furnariidae & 3,445 & 3,631 & 0,776 & 0,528 & 0,739 \\
\hline MLP 126 & Pseudoseisura lophotes & Passeriformes & Furnariidae & 2,632 & 2,792 & 0,584 & 0,338 & 0,596 \\
\hline MLP 777 & Turdus rufiventris & Passeriformes & Turdidae & 2,604 & 2,746 & 0,492 & 0,296 & 0,488 \\
\hline MLP 141 & Pitangus sulphuratus & Passeriformes & Tyraniidae & 2,500 & 2,652 & 0,456 & 0,298 & 0,498 \\
\hline MLP 476 & Phalacrocorax albiventer & Pelecaniformes & Phalacrocoracidae & 5,535 & 5,818 & 1,580 & 1,196 & 1,638 \\
\hline MLP 482 & Sula leucogaster & Pelecaniformes & Sulidae & 5,188 & 5,292 & 1,184 & 1,060 & 1,239 \\
\hline
\end{tabular}




\begin{tabular}{|c|c|c|c|c|c|c|c|c|}
\hline MLP 564 & Phoenicopterus chilensis & Phoenicopteriformes & Phoenicopteridae & 8,044 & 9,129 & 2,193 & 1,835 & 2,406 \\
\hline MLP 314 & Ramphastos vitellinus & Piciformes & Ramphastidae & 4,572 & 4,772 & 0,964 & 0,669 & 0,984 \\
\hline MLP 330 & Monasa nigrifrons & Piciformes & Bucconidae & 2,301 & 2,394 & 0,472 & 0,333 & 0,473 \\
\hline MLP 522 & Podiceps major & Podicipediformes & Podicipedidae & 4,343 & 4,737 & 1,370 & 0,798 & 1,526 \\
\hline MLP 488 & Pagodroma nivea & Procellariiformes & Procellariidae & 3,715 & 3,759 & 0,778 & 0,438 & 0,694 \\
\hline MLP 812 & Macronectes giganteus & Procellariiformes & Procellariidae & 8,310 & 8,490 & 1,872 & 1,209 & 1,896 \\
\hline MLP 65 & Cyanoliseus patagonus & Psittaciformes & Psittacidae & 3,834 & 3,979 & 0,763 & 0,535 & 0,730 \\
\hline MLP 469 & Pygoscelis adeliae & Sphenisciformes & Spheniscidae & 8,084 & 8,298 & 1,904 & 1,149 & 1,706 \\
\hline MLP 53 & Tyto alba & Strigiformes & Tytonidae & 5,409 & 5,610 & 1,041 & 0,593 & 1,001 \\
\hline MLP 401 & Bubo virginianus & Strigiformes & Strigidae & 6,687 & 7,055 & 1,296 & 0,831 & 1,274 \\
\hline MLP 685 & Dromaius novahollandie & Struthioniformes & Casuariidae & 18,833 & 21,433 & 6,021 & 6,000 & 7,258 \\
\hline MLP 878 & Rhea americana & Struthioniformes & Rheidae & 19,603 & 22,393 & 5,804 & 5,354 & 6,451 \\
\hline MLP 86-VI-15-1 & Emeus crassus & Struthioniformes & Dinornithidae & 24,129 & 27,080 & 10,322 & 8,270 & 11,472 \\
\hline Prom. MLP & Pterocnemia pennata & Struthionifromes & Rheidae & 18,085 & 19,843 & 4,634 & 4,638 & 5,306 \\
\hline MLP 327 & Eudromia elegans & Tinamiformes & Tinamidae & 5,286 & 5,678 & 1,263 & 1,080 & 1,233 \\
\hline
\end{tabular}

\begin{tabular}{|c|c|c|c|c|c|c|c|}
\hline Catálogo & Especie & Orden & Familia & $\mathrm{EF}$ & $\mathrm{EG}$ & $\mathrm{EH}$ & EI \\
\hline MLP 569 & Chauna torquata & Anseriformes & Anhimidae & 1,132 & 1,143 & 1,950 & 2,240 \\
\hline MLP 84 & Anas platalea & Anseriformes & Anatidae & 0,336 & 0,444 & 0,687 & 0,829 \\
\hline MLP 533 & Cariama cristata & Cariamiformes & Cariamidae & 0,921 & 0,840 & 1,502 & 1,774 \\
\hline MLP 535 & Chunga burmeisteri & Cariamiformes & Cariamidae & 0,680 & 0,650 & 1,210 & 1,342 \\
\hline MLP 615 & Vanellus chilensis & Charadriiformes & Charadriidae & 0,292 & 0,326 & 0,550 & 0,693 \\
\hline MLP 814 & Larus maculipennis & Charadriiformes & Laridae & 0,333 & 0,343 & 0,504 & 0,637 \\
\hline MLP 412 & Chionis alba & Charadriiformes & Chionididae & 0,499 & 0,476 & 0,805 & 0,982 \\
\hline MLP 871 & Catharacta maccormicki & Charadriiformes & Stercorariidae & 0,530 & 0,575 & 0,884 & 1,065 \\
\hline YPM 111287 & Burhinus capensis & Charadriiformes & Burhinidae & 0,460 & 0,470 & 0,760 & 0,970 \\
\hline YPM 102096 & Burhinus grallarius & Charadriiformes & Burhinidae & 0,550 & 0,510 & 0,930 & 1,210 \\
\hline
\end{tabular}




\begin{tabular}{|c|c|c|c|c|c|c|c|}
\hline MLP 531 & Burhinus oedicnemus & Charadriiformes & Burhinidae & 0,415 & 0,435 & 0,803 & 0,899 \\
\hline MACN 22325 & Fratercula corniculata & Charadriiformes & Alcidae & 0,334 & 0,368 & 0,546 & 0,722 \\
\hline MLP 474 & Theristicus melanopis & Ciconiiformes & Threskiornithidae & 0,665 & 0,694 & 1,215 & 1,374 \\
\hline MLP 344 & Coragyps atratus & Ciconiiformes & Cathartidae & 0,943 & 0,988 & 1,189 & 1,696 \\
\hline MLP 804 & Nycticorax nycticorax & Ciconiiformes & Ardeidae & 0,482 & 0,482 & 0,976 & 1,076 \\
\hline MLP 712 & Ciconia maguari & Ciconiiformes & Ciconiidae & 0,828 & 0,836 & 1,624 & 1,852 \\
\hline MLP 807 & Vultur gryphus & Ciconiiformes & Cathartidae & 2,026 & 1,952 & 2,638 & 3,388 \\
\hline Prom. YPM & $\begin{array}{l}\text { Leptoptilos } \\
\text { crummeniferus }\end{array}$ & Ciconiiformes & Ciconiidae & 1,600 & 1,535 & 2,305 & 3,035 \\
\hline YPM 102102 & Leptoptilos dubius & Ciconiiformes & Ciconiidae & 1,640 & 1,680 & 2,510 & 3,180 \\
\hline YPM 105903 & Mycteria americana & Ciconiiformes & Ciconiidae & 0,930 & 0,830 & 1,480 & 1,910 \\
\hline YPM 105272 & Mycteria ibis & Ciconiiformes & Ciconiidae & 0,960 & 0,880 & 1,620 & 1,870 \\
\hline YPM 102099 & Mycteria leucocephala & Ciconiiformes & Ciconiidae & 1,000 & 0,960 & 1,590 & 1,680 \\
\hline MACN 20958 & Ardea cocoi & Ciconiiformes & Ardeidae & 0,812 & 0,846 & 1,546 & 1,764 \\
\hline MLP 399 & Columba picazuro & Columbiformes & Columbidae & 0,396 & 0,392 & 0,608 & 0,684 \\
\hline MLP 261 & Zenaida auriculata & Columbiformes & Columbidae & 0,238 & 0,234 & 0,410 & 0,414 \\
\hline YPM 103256 & Buceros bicornis & Coraciiformes & Bucerotidae & 1,020 & 1,020 & 1,380 & 1,600 \\
\hline MLP 319 & Galbula ruficauda & Coraciiformes & Galbulidae & 0,118 & 0,126 & 0,164 & 0,196 \\
\hline MLP 6 & Ceryle torquata & Coraciiformes & Alcedinidae & 0,303 & 0,300 & 0,451 & 0,507 \\
\hline MLP 97 & Guira guira & Cuculiformes & Cuculidae & 0,308 & 0,295 & 0,578 & 0,583 \\
\hline MLP 536 & Opisthocomus hoazin & Cuculiformes & Opisthocomidae & 0,493 & 0,522 & 0,860 & 1,077 \\
\hline MLP 696 & $\begin{array}{l}\text { Geranoaetus } \\
\text { melanoleucus }\end{array}$ & Falconiformes & Accipitridae & 0,970 & 1,078 & 2,037 & 2,066 \\
\hline MLP 438 & Falco peregrinus & Falconiformes & Falconidae & 0,635 & 0,683 & 1,103 & 1,156 \\
\hline MLP 62 & Polyborus plancus & Falconiformes & Falconidae & 0,792 & 0,748 & 1,454 & 1,572 \\
\hline YPM 111125 & Sagittarius serpentarius & Falconiformes & Sagittariidae & 1,270 & 1,220 & 2,110 & 2,430 \\
\hline MACN 26366 & Pandion haliaetus & Falconiformes & Accipitridae & 0,762 & 0,762 & 1,494 & 1,506 \\
\hline MLP 364 & Lophortyx californica & Galliformes & Odontophoridae & 0,315 & 0,312 & 0,595 & 0,544 \\
\hline MACN 343438 & Penelope purpurascens & Galliformes & Cracidae & 0,778 & 0,882 & 1,512 & 1,762 \\
\hline
\end{tabular}




\begin{tabular}{|c|c|c|c|c|c|c|c|}
\hline OUVC 10563 & Gavia immer & Gaviiformes & Gaviidae & 0,898 & 1,161 & 0,971 & 1,539 \\
\hline MLP 49 & Fulica armillata & Gruiformes & Rallidae & 0,540 & 0,586 & 0,895 & 1,183 \\
\hline YPM 102540 & Ardeotis arabs & Gruiformes & Otididae & 1,340 & 1,250 & 2,380 & 2,310 \\
\hline YPM 105866 & Ardeotis kori & Gruiformes & Otididae & 1,430 & 1,430 & 2,790 & 2,740 \\
\hline YPM 102227 & Otis tarda & Gruiformes & Otididae & 1,310 & 1,360 & 2,580 & 2,720 \\
\hline Prom. YPM & Psophia crepitans & Gruiformes & Psophiidae & 0,723 & 0,726 & 1,276 & 1,426 \\
\hline YPM 102062 & Tetrax tetrax & Gruiformes & Otididae & 0,530 & 0,550 & 1,040 & 1,000 \\
\hline MLP 403 & Porphyrula martinica & Gruiformes & Rallidae & 0,341 & 0,341 & 0,683 & 0,793 \\
\hline YPM 102538 & Grus canadensis & Gruiformes & Gruidae & 1,020 & 1,010 & 2,100 & 2,320 \\
\hline MACN 63320 & Aramus guarauna & Gruiformes & Aramidae & 0,712 & 0,696 & 1,408 & 1,666 \\
\hline MLP 178 & Xiphocolaptes major & Passeriformes & Furnariidae & 0,361 & 0,305 & 0,426 & 0,636 \\
\hline MLP 126 & Pseudoseisura lophotes & Passeriformes & Furnariidae & 0,262 & 0,232 & 0,352 & 0,474 \\
\hline MLP 777 & Turdus rufiventris & Passeriformes & Turdidae & 0,232 & 0,216 & 0,262 & 0,392 \\
\hline MLP 141 & Pitangus sulphuratus & Passeriformes & Tyraniidae & 0,214 & 0,212 & 0,268 & 0,412 \\
\hline MLP 476 & Phalacrocorax albiventer & Pelecaniformes & Phalacrocoracidae & 0,647 & 0,828 & 0,916 & 1,071 \\
\hline MLP 482 & Sula leucogaster & Pelecaniformes & Sulidae & 0,630 & 0,641 & 0,795 & 0,999 \\
\hline MLP 564 & Phoenicopterus chilensis & Phoenicopteriformes & Phoenicopteridae & 1,100 & 0,980 & 1,656 & 2,380 \\
\hline MLP 314 & Ramphastos vitellinus & Piciformes & Ramphastidae & 0,434 & 0,410 & 0,556 & 0,782 \\
\hline MLP 330 & Monasa nigrifrons & Piciformes & Bucconidae & 0,204 & 0,211 & 0,287 & 0,354 \\
\hline MLP 522 & Podiceps major & Podicipediformes & Podicipedidae & 0,543 & 0,617 & 0,743 & 1,064 \\
\hline MLP 488 & Pagodroma nivea & Procellariiformes & Procellariidae & 0,310 & 0,292 & 0,415 & 0,540 \\
\hline MLP 812 & Macronectes giganteus & Procellariiformes & Procellariidae & 0,728 & 0,776 & 1,270 & 1,451 \\
\hline MLP 65 & Cyanoliseus patagonus & Psittaciformes & Psittacidae & 0,367 & 0,326 & 0,590 & 0,595 \\
\hline MLP 469 & Pygoscelis adeliae & Sphenisciformes & Spheniscidae & 0,873 & 0,913 & 1,188 & 1,567 \\
\hline MLP 53 & Tyto alba & Strigiformes & Tytonidae & 0,446 & 0,430 & 0,698 & 0,949 \\
\hline MLP 401 & Bubo virginianus & Strigiformes & Strigidae & 0,558 & 0,519 & 0,841 & 1,091 \\
\hline MLP 685 & Dromaius novahollandie & Struthioniformes & Casuariidae & 2,942 & 2,998 & 5,073 & 7,021 \\
\hline MLP 878 & Rhea americana & Struthioniformes & Rheidae & 2,587 & 2,618 & 5,093 & 6,361 \\
\hline
\end{tabular}


MLP 86-VI-15-1 Emeus crassus

Prom. MLP

Pterocnemia pennata

MLP 327
Struthioniformes

Struthionifromes

Tinamiformes
Dinornithidae

Rheidae

Tinamidae
3,910

2,119

4,204

2,108

0,540
7,035

4,209

0,933
7,912

5,135 
Tabla 9.2. Matriz de medidas del fémur (cm.) tomadas en los Phorusrhacidae disponibles.

\begin{tabular}{|c|c|c|c|c|c|c|c|c|c|c|}
\hline Catálogo & Especie & EA & EB & $\mathrm{EC}$ & ED & $\mathrm{EE}$ & $\mathrm{EF}$ & $\mathrm{EG}$ & $\mathrm{EG}$ & EI \\
\hline FM-P14678 & Andrewsornis abbotti & & 20,316 & 4,714 & 4,668 & & 2,408 & 2,128 & & \\
\hline MLP 59-II-26-82 & Andrewsornis abbotti? & & & 4,535 & 3,854 & & & & & \\
\hline MMP 155-5 & Mesembriornis milneedwardsi & 25,692 & 26,944 & 8,2 & 4,734 & 7,736 & 3,432 & 3,292 & 6,644 & 6,886 \\
\hline MLP 20-170 & Mesembriornis milneedwardsi & & & & & & & & & \\
\hline MACN Pv 5944 & Mesembriornis milneedwardsi & 23,134 & 24,786 & 7,068 & 5,912 & 7,626 & 3,527 & 3,096 & 5,944 & 6,38 \\
\hline AMNH 9264 & Patagornis marshi & & & 4,734 & 4,452 & 5,528 & 2,272 & 2,376 & & \\
\hline MLP 20-151 & Patagornis marshi & & & 5,572 & 4,53 & & & & & \\
\hline MLP 20-152 & Patagornis marshi & & & & & 6,398 & & & 4,697 & 5,142 \\
\hline MLP 84-III-9-21 & Patagornis marshi & & & & & & 2,585 & 2,444 & & \\
\hline BMNH - A516 & Patagornis marshi & 21,2 & 21,71 & 5,71 & 3,89 & 5,98 & 2,58 & 2,405 & 4,635 & 5,17 \\
\hline AMNH 9497 & Phorusrhacos longissimus & & & & & 9,166 & & & & \\
\hline MACN Pv 6932 & Phorusrhacos longissimus & & & & & & & & & 4,542 \\
\hline MPM-PV4241 & Phorusrhacos longissimus & & & & & & 4,106 & 4,176 & & \\
\hline FM-P14525 & Procariama simplex & 15,406 & 16,242 & 3,569 & 2,564 & 3,698 & 1,602 & 1,589 & 2,558 & 2,842 \\
\hline FM-P14535 & Procariama simplex & & & 3,142 & 2,782 & & 1,466 & 1,492 & & \\
\hline MACN Pv 8225 & Procariama simplex & & & & 2,868 & 3,6 & & & 2,846 & 3,216 \\
\hline MACN Pv 6939 & Procariama simplex & & & 2,872 & 2,512 & 2,902 & & & 2,272 & 2,622 \\
\hline YPM-PU15904 & Psilopterus bachmanni & 11,392 & 11,725 & 2,314 & & 2,35 & 0,914 & 1,202 & 1,93 & 2,314 \\
\hline MLP 20-165 & Psilopterus bachmanni & & & 2,635 & 2,035 & & & & & \\
\hline MLP 20-166 & Psilopterus bachmanni & & & & & 2,632 & & & 1,982 & 2,307 \\
\hline MPM-PV4243 & Psilopterus bachmanni & & & 2,902 & 2,132 & 2,994 & & & 2,398 & 2,702 \\
\hline FM-PA-6 & Psilopterus lemoinei & & & 2,784 & 2,002 & & & & & \\
\hline YPM-PU15477 & Psilopterus lemoinei & & & 3,256 & 2,518 & & 1,414 & 1,712 & & \\
\hline YPM-PU15402 & Psilopterus lemoinei & 13,396 & 13,502 & 2,943 & 2,134 & 3,02 & 1,406 & 1,442 & 2,287 & 2,463 \\
\hline AMNH 9257 & Psilopterus lemoinei & 14,672 & 14,78 & 3,202 & 2,452 & 3,296 & 1,34 & 1,572 & & 2,694 \\
\hline
\end{tabular}




\begin{tabular}{|c|c|c|c|c|c|c|c|c|c|c|}
\hline AMNH 9157 & Psilopterus lemoinei & 13,8 & 13,972 & 2,44 & 2,15 & 2,662 & & & 2,622 & 2,244 \\
\hline MLP 20-161 & Psilopterus lemoinei & & & & & & & & & 2,283 \\
\hline MPM-PV3650 & Psilopterus lemoinei & 14,917 & 15,286 & 2,944 & 2,576 & 3,468 & 1,453 & 1,56 & 2,659 & 2,936 \\
\hline MMP 5050 & Taxón Nuevo A & 17,883 & 18,469 & 3,896 & 4,985 & 4,842 & 1,971 & 1,912 & 3,772 & 4,395 \\
\hline
\end{tabular}


Tabla 9.3. Individuos promedio para cada especie de fororraco en base a las medidas del fémur $(\mathrm{cm}$.).

\begin{tabular}{|c|c|c|c|c|c|c|c|c|c|}
\hline Especie & EA & EB & $\mathrm{EC}$ & ED & $\mathrm{EE}$ & $\mathrm{EF}$ & EG & $\mathrm{EH}$ & EI \\
\hline \multicolumn{10}{|l|}{ Andalgalornis steulleti } \\
\hline Andrewsornis abbotti & & 20,316 & 4,625 & 4,261 & & 2,408 & 2,128 & & \\
\hline \multicolumn{10}{|l|}{ Devincenzia pozzi } \\
\hline \multicolumn{10}{|l|}{ Kelenken guillermoi } \\
\hline \multicolumn{10}{|l|}{ Mesembriornis incertus } \\
\hline Mesembriornis milneedwardsi & 24,413 & 25,865 & 7,634 & 5,323 & 7,681 & 3,480 & 3,194 & 6,294 & 6,633 \\
\hline \multicolumn{10}{|l|}{ Paraphysornis brasiliensis } \\
\hline Patagornis marshi & 21,200 & 21,710 & 5,339 & 4,291 & 5,969 & 2,479 & 2,408 & 4,666 & 5,156 \\
\hline Phorusrhacos longissimus & & & & & 9,166 & 4,106 & 4,176 & & 4,542 \\
\hline \multicolumn{10}{|l|}{ Physornis fortis } \\
\hline Procariama simplex & 15,406 & 16,242 & 3,194 & 2,682 & 3,400 & 1,534 & 1,541 & 2,559 & 2,893 \\
\hline \multicolumn{10}{|l|}{ Psilopterus affinis } \\
\hline Psilopterus bachmanni & 11,392 & 11,725 & 2,617 & 2,084 & 2,659 & 0,914 & 1,202 & 2,103 & 2,441 \\
\hline \multicolumn{10}{|l|}{ Psilopterus colzecus } \\
\hline Psilopterus lemoinei & 14,196 & 14,385 & 2,928 & 2,305 & 3,112 & 1,403 & 1,572 & 2,523 & 2,524 \\
\hline Taxón nuevo A & 17,883 & 18,469 & 3,896 & 4,985 & 4,842 & 1,971 & 1,912 & 3,772 & 4,395 \\
\hline
\end{tabular}


Tabla 9.4. Matriz de medidas del tibiotarso $(\mathrm{cm}$.) tomadas en las Neornithes actuales utilizadas en esta tesis.

\begin{tabular}{|c|c|c|c|c|c|c|c|c|}
\hline Catálogo & Especie & Orden & Familia & $\mathrm{ZA}$ & ZB & $\mathrm{ZC}$ & ZD & $\mathrm{ZE}$ \\
\hline MLP 569 & Chauna torquata & Anseriformes & Anhimidae & 19,080 & 18,078 & 1,904 & 2,491 & 2,227 \\
\hline MLP 84 & Anas platalea & Anseriformes & Anatidae & 7,277 & 6,918 & 0,768 & 0,887 & 0,754 \\
\hline MLP 533 & Cariama cristata & Cariamiformes & Cariamidae & 20,326 & 19,286 & 1,658 & 2,421 & 1,420 \\
\hline MLP 535 & Chunga burmeisteri & Cariamiformes & Cariamidae & 14,816 & 14,157 & 1,310 & 1,877 & 1,075 \\
\hline MLP 615 & Vanellus chilensis & Charadriiformes & Charadriidae & 9,396 & 9,094 & 0,724 & 0,950 & 0,641 \\
\hline MLP 814 & Larus maculipennis & Charadriiformes & Laridae & 7,983 & 7,598 & 0,602 & 0,812 & 0,641 \\
\hline MLP 412 & Chionis alba & Charadriiformes & Chionididae & 8,503 & 8,130 & 1,052 & 1,399 & 0,850 \\
\hline MLP 871 & Catharacta maccormicki & Charadriiformes & Stercorariidae & 10,571 & 10,010 & 1,086 & 1,305 & 0,978 \\
\hline YPM 111287 & Burhinus capensis & Charadriiformes & Burhinidae & 10,750 & 9,990 & 0,890 & 1,280 & 0,780 \\
\hline YPM 102096 & Burhinus grallarius & Charadriiformes & Burhinidae & 14,860 & 13,830 & 1,140 & 1,550 & 1,190 \\
\hline MLP 531 & Burhinus oedicnemus & Charadriiformes & Burhinidae & 9,707 & 9,362 & 0,998 & 1,073 & 0,719 \\
\hline MACN 22325 & Fratercula corniculata & Charadriiformes & Alcidae & 7,052 & 6,618 & 0,636 & 0,648 & 0,602 \\
\hline MLP 474 & Theristicus melanopis & Ciconiiformes & Threskiornithidae & 13,382 & 12,839 & 1,361 & 1,674 & 1,381 \\
\hline MLP 344 & Coragyps atratus & Ciconiiformes & Cathartidae & 13,922 & 13,457 & 1,638 & 1,932 & 1,300 \\
\hline MLP 804 & Nycticorax nycticorax & Ciconiiformes & Ardeidae & 12,200 & 12,068 & 1,040 & 0,988 & 0,944 \\
\hline MLP 712 & Ciconia maguari & Ciconiiformes & Ciconiidae & 27,134 & 26,756 & 1,590 & 1,508 & 1,532 \\
\hline MLP 807 & Vultur gryphus & Ciconiiformes & Cathartidae & 23,652 & 22,464 & 3,176 & 3,702 & 2,592 \\
\hline Prom. YPM & $\begin{array}{l}\text { Leptoptilos } \\
\text { crummeniferus }\end{array}$ & Ciconiiformes & Ciconiidae & 31,490 & 30,140 & 2,465 & 2,940 & 1,990 \\
\hline YPM 102102 & Leptoptilos dubius & Ciconiiformes & Ciconiidae & 33,660 & 32,770 & 2,540 & 2,420 & 2,170 \\
\hline YPM 105903 & Mycteria americana & Ciconiiformes & Ciconiidae & 21,830 & 20,970 & 1,500 & 1,710 & 1,250 \\
\hline YPM 105272 & Mycteria ibis & Ciconiiformes & Ciconiidae & 24,390 & 23,270 & 1,540 & 1,720 & 1,190 \\
\hline YPM 102099 & Mycteria leucocephala & Ciconiiformes & Ciconiidae & 24,100 & 22,990 & 1,580 & 1,830 & 1,180 \\
\hline MACN 20958 & Ardea cocoi & Ciconiiformes & Ardeidae & 26,592 & 26,228 & 1,622 & 1,928 & 1,600 \\
\hline MLP 399 & Columba picazuro & Columbiformes & Columbidae & 6,042 & 5,952 & 0,708 & 0,838 & 0,622 \\
\hline MLP 261 & Zenaida auriculata & Columbiformes & Columbidae & 4,002 & 3,969 & 0,453 & 0,501 & 0,420 \\
\hline
\end{tabular}




\begin{tabular}{|c|c|c|c|c|c|c|c|c|}
\hline YPM 103256 & Buceros bicornis & Coraciiformes & Bucerotidae & 12,290 & 12,210 & 1,660 & 1,450 & 1,780 \\
\hline MLP 319 & Galbula ruficauda & Coraciiformes & Galbulidae & 2,109 & 2,051 & 0,224 & 0,243 & 0,208 \\
\hline MLP 6 & Ceryle torquata & Coraciiformes & Alcedinidae & 4,385 & 4,363 & 0,527 & 0,522 & 0,428 \\
\hline MLP 97 & Guira guira & Cuculiformes & Cuculidae & 6,165 & 6,090 & 0,599 & 0,658 & 0,528 \\
\hline MLP 536 & Opisthocomus hoazin & Cuculiformes & Opisthocomidae & 9,048 & 8,953 & 1,134 & 1,143 & 0,988 \\
\hline MLP 696 & $\begin{array}{l}\text { Geranoaetus } \\
\text { melanoleucus }\end{array}$ & Falconiformes & Accipitridae & 15,008 & 14,519 & 1,813 & 2,085 & 2,030 \\
\hline MLP 438 & Falco peregrinus & Falconiformes & Falconidae & 8,661 & 8,552 & 1,128 & 1,349 & 1,218 \\
\hline MLP 62 & Polyborus plancus & Falconiformes & Falconidae & 12,288 & 12,148 & 1,408 & 1,542 & 1,336 \\
\hline YPM 111125 & Sagittarius serpentarius & Falconiformes & Sagittariidae & 27,240 & 26,230 & 2,200 & 2,810 & 2,050 \\
\hline MACN 26366 & Pandion haliaetus & Falconiformes & Accipitridae & 12,926 & 12,394 & 1,342 & 1,214 & 1,478 \\
\hline MLP 364 & Lophortyx californica & Galliformes & Odontophoridae & 5,557 & 5,431 & 0,646 & 0,794 & 0,496 \\
\hline MACN 343438 & Penelope purpurascens & Galliformes & Cracidae & 14,198 & 13,984 & 1,600 & 1,688 & 1,152 \\
\hline OUVC 10563 & Gavia immer & Gaviiformes & Gaviidae & 19,472 & 14,506 & 1,426 & 1,741 & 1,458 \\
\hline MLP 49 & Fulica armillata & Gruiformes & Rallidae & 12,330 & 11,490 & 1,109 & 1,363 & 1,018 \\
\hline YPM 102540 & Ardeotis arabs & Gruiformes & Otididae & 22,220 & 21,010 & 2,260 & 2,990 & 2,050 \\
\hline YPM 105866 & Ardeotis kori & Gruiformes & Otididae & 24,800 & 22,960 & 2,380 & 3,470 & 2,160 \\
\hline YPM 102227 & Otis tarda & Gruiformes & Otididae & 20,760 & 19,640 & 2,370 & 3,140 & 2,160 \\
\hline Prom. YPM & Psophia crepitans & Gruiformes & Psophiidae & 14,883 & 14,170 & 1,410 & 1,803 & 1,173 \\
\hline YPM 102062 & Tetrax tetrax & Gruiformes & Otididae & 9,720 & 9,240 & 1,130 & 1,230 & 0,950 \\
\hline MLP 403 & Porphyrula martinica & Gruiformes & Rallidae & 8,902 & 8,631 & 0,751 & 0,925 & 0,675 \\
\hline YPM 102538 & Grus canadensis & Gruiformes & Gruidae & 29,090 & 28,520 & 2,360 & 2,930 & 2,060 \\
\hline MACN 63320 & Aramus guarauna & Gruiformes & Aramidae & 18,454 & 18,094 & 1,404 & 1,822 & 1,262 \\
\hline MLP 178 & Xiphocolaptes major & Passeriformes & Furnariidae & 4,890 & 4,632 & 0,618 & 0,822 & 0,530 \\
\hline MLP 126 & Pseudoseisura lophotes & Passeriformes & Furnariidae & 4,902 & 4,708 & 0,514 & 0,706 & 0,432 \\
\hline MLP 777 & Turdus rufiventris & Passeriformes & Turdidae & 4,910 & 4,772 & 0,474 & 0,458 & 0,328 \\
\hline MLP 141 & Pitangus sulphuratus & Passeriformes & Tyraniidae & 4,382 & 4,290 & 0,416 & 0,474 & 0,328 \\
\hline MLP 476 & Phalacrocorax albiventer & Pelecaniformes & Phalacrocoracidae & 11,624 & 10,825 & 1,216 & 1,343 & 1,248 \\
\hline MLP 482 & Sula leucogaster & Pelecaniformes & Sulidae & 8,117 & 7,772 & 0,987 & 0,967 & 1,208 \\
\hline
\end{tabular}




\begin{tabular}{|c|c|c|c|c|c|c|c|c|}
\hline MLP 564 & Phoenicopterus chilensis & Phoenicopteriformes & Phoenicopteridae & 27,494 & 26,276 & 2,005 & 2,024 & 1,697 \\
\hline MLP 314 & Ramphastos vitellinus & Piciformes & Ramphastidae & 7,820 & 7,598 & 0,835 & 0,927 & 0,726 \\
\hline MLP 330 & Monasa nigrifrons & Piciformes & Bucconidae & 3,480 & 3,383 & 0,390 & 0,457 & 0,346 \\
\hline MLP 522 & Podiceps major & Podicipediformes & Podicipedidae & 13,066 & 10,969 & 1,090 & 0,991 & 1,042 \\
\hline MLP 488 & Pagodroma nivea & Procellariiformes & Procellariidae & 7,196 & 6,646 & 0,559 & 0,681 & 0,540 \\
\hline MLP 812 & Macronectes giganteus & Procellariiformes & Procellariidae & 17,625 & 15,989 & 1,491 & 1,799 & 1,691 \\
\hline MLP 65 & Cyanoliseus patagonus & Psittaciformes & Psittacidae & 5,374 & 5,243 & 0,607 & 0,693 & 0,644 \\
\hline MLP 469 & Pygoscelis adeliae & Sphenisciformes & Spheniscidae & 13,689 & 12,807 & 1,382 & 1,328 & 1,397 \\
\hline MLP 53 & Tyto alba & Strigiformes & Tytonidae & 10,068 & 9,636 & 0,917 & 0,972 & 0,835 \\
\hline MLP 401 & Bubo virginianus & Strigiformes & Strigidae & 10,347 & 9,997 & 1,100 & 1,070 & 1,071 \\
\hline MLP 685 & Dromaius novahollandie & Struthioniformes & Casuariidae & 43,800 & 40,840 & 4,875 & 5,313 & 4,539 \\
\hline MLP 878 & Rhea americana & Struthioniformes & Rheidae & 35,508 & 33,122 & 4,958 & 4,929 & 4,112 \\
\hline $\begin{array}{l}\text { MLP 86-VI-15- } \\
1\end{array}$ & Emeus crassus & Struthioniformes & Dinornithidae & 45,565 & 43,867 & 6,441 & 4,966 & 7,017 \\
\hline Prom. MLP & Pterocnemia pennata & Struthionifromes & Rheidae & 31,384 & 29,900 & 4,464 & 3,995 & 3,211 \\
\hline MLP 327 & Eudromia elegans & Tinamiformes & Tinamidae & 7,934 & 7,734 & 0,902 & 1,195 & 0,804 \\
\hline
\end{tabular}

\begin{tabular}{|c|c|c|c|c|c|c|c|c|}
\hline Catálogo & Especie & Orden & Familia & $\mathrm{ZF}$ & $\mathrm{ZG}$ & $\mathrm{ZH}$ & ZI & $\overline{Z J}$ \\
\hline MLP 569 & Chauna torquata & Anseriformes & Anhimidae & 0,947 & 0,881 & 1,956 & 2,147 & 2,739 \\
\hline MLP 84 & Anas platalea & Anseriformes & Anatidae & 0,387 & 0,333 & 0,737 & 0,854 & 1,107 \\
\hline MLP 533 & Cariama cristata & Cariamiformes & Cariamidae & 1,007 & 0,799 & 1,387 & 1,454 & 3,175 \\
\hline MLP 535 & Chunga burmeisteri & Cariamiformes & Cariamidae & 0,725 & 0,554 & 1,119 & 1,200 & 2,442 \\
\hline MLP 615 & Vanellus chilensis & Charadriiformes & Charadriidae & 0,331 & 0,297 & 0,605 & 0,681 & 1,268 \\
\hline MLP 814 & Larus maculipennis & Charadriiformes & Laridae & 0,352 & 0,307 & 0,617 & 0,658 & 1,202 \\
\hline MLP 412 & Chionis alba & Charadriiformes & Chionididae & 0,514 & 0,409 & 0,738 & 0,873 & 1,652 \\
\hline MLP 871 & Catharacta maccormicki & Charadriiformes & Stercorariidae & 0,561 & 0,446 & 1,027 & 1,174 & 1,816 \\
\hline YPM 111287 & Burhinus capensis & Charadriiformes & Burhinidae & 0,440 & 0,440 & 0,780 & 0,820 & 1,600 \\
\hline
\end{tabular}




\begin{tabular}{|c|c|c|c|c|c|c|c|c|}
\hline YPM 102096 & Burhinus grallarius & Charadriiformes & Burhinidae & 0,630 & 0,530 & 1,010 & 1,140 & 2,200 \\
\hline MLP 531 & Burhinus oedicnemus & Charadriiformes & Burhinidae & 0,437 & 0,391 & 0,724 & 0,843 & 1,598 \\
\hline MACN 22325 & Fratercula corniculata & Charadriiformes & Alcidae & 0,336 & 0,312 & 0,664 & 0,746 & 1,076 \\
\hline MLP 474 & Theristicus melanopis & Ciconiiformes & Threskiornithidae & 0,648 & 0,620 & 1,195 & 1,289 & 1,947 \\
\hline MLP 344 & Coragyps atratus & Ciconiiformes & Cathartidae & 0,863 & 0,653 & 1,236 & 1,341 & 2,058 \\
\hline MLP 804 & Nycticorax nycticorax & Ciconiiformes & Ardeidae & 0,536 & 0,446 & 0,976 & 1,028 & 1,324 \\
\hline MLP 712 & Ciconia maguari & Ciconiiformes & Ciconiidae & 0,904 & 0,830 & 1,678 & 1,754 & 2,114 \\
\hline MLP 807 & Vultur gryphus & Ciconiiformes & Cathartidae & 1,648 & 1,436 & 2,538 & 2,662 & 4,264 \\
\hline Prom. YPM & $\begin{array}{l}\text { Leptoptilos } \\
\text { crummeniferus }\end{array}$ & Ciconiiformes & Ciconiidae & 1,230 & 1,135 & 2,365 & 2,505 & 3,555 \\
\hline YPM 102102 & Leptoptilos dubius & Ciconiiformes & Ciconiidae & 1,330 & 1,330 & 2,530 & 2,660 & 3,680 \\
\hline YPM 105903 & Mycteria americana & Ciconiiformes & Ciconiidae & 0,820 & 0,730 & 1,480 & 1,480 & 2,160 \\
\hline YPM 105272 & Mycteria ibis & Ciconiiformes & Ciconiidae & 0,840 & 0,800 & 1,540 & 1,530 & 2,370 \\
\hline YPM 102099 & Mycteria leucocephala & Ciconiiformes & Ciconiidae & 0,790 & 0,740 & 1,540 & 1,580 & 2,360 \\
\hline MACN 20958 & Ardea cocoi & Ciconiiformes & Ardeidae & 0,902 & 0,846 & 1,730 & 1,824 & 2,184 \\
\hline MLP 399 & Columba picazuro & Columbiformes & Columbidae & 0,377 & 0,325 & 0,678 & 0,717 & 0,878 \\
\hline MLP 261 & Zenaida auriculata & Columbiformes & Columbidae & 0,238 & 0,195 & 0,439 & 0,474 & 0,603 \\
\hline YPM 103256 & Buceros bicornis & Coraciiformes & Bucerotidae & 0,810 & 0,820 & 1,810 & 1,400 & 1,790 \\
\hline MLP 319 & Galbula ruficauda & Coraciiformes & Galbulidae & 0,112 & 0,104 & 0,209 & 0,209 & 0,248 \\
\hline MLP 6 & Ceryle torquata & Coraciiformes & Alcedinidae & 0,238 & 0,225 & 0,488 & 0,547 & 0,597 \\
\hline MLP 97 & Guira guira & Cuculiformes & Cuculidae & 0,267 & 0,258 & 0,571 & 0,582 & 0,794 \\
\hline MLP 536 & Opisthocomus hoazin & Cuculiformes & Opisthocomidae & 0,518 & 0,390 & 0,920 & 1,042 & 1,166 \\
\hline MLP 696 & $\begin{array}{l}\text { Geranoaetus } \\
\text { melanoleucus }\end{array}$ & Falconiformes & Accipitridae & 0,953 & 0,778 & 1,262 & 1,166 & 264 \\
\hline MLP 438 & Falco peregrinus & Falconiformes & Falconidae & 0,566 & 0,558 & 0,913 & 0,906 & 1,261 \\
\hline MLP 62 & Polyborus plancus & Falconiformes & Falconidae & 0,718 & 0,618 & 1,128 & 1,198 & 1,808 \\
\hline YPM 111125 & Sagittarius serpentarius & Falconiformes & Sagittariidae & 1,180 & 1,010 & 1,950 & 2,120 & 2,970 \\
\hline MACN 26366 & Pandion haliaetus & Falconiformes & Accipitridae & 0,786 & 0,770 & 1,356 & 1,424 & 1,846 \\
\hline MLP 364 & Lophortyx californica & Galliformes & Odontophoridae & 0,283 & 0,267 & 0,490 & 0,535 & 0,932 \\
\hline
\end{tabular}




\begin{tabular}{|c|c|c|c|c|c|c|c|c|}
\hline MACN 343438 & Penelope purpurascens & Galliformes & Cracidae & 0,866 & 0,666 & 1,392 & 1,456 & 2,082 \\
\hline OUVC 10563 & Gavia immer & Gaviiformes & Gaviidae & 0,967 & 0,870 & 1,471 & 1,467 & 1,774 \\
\hline MLP 49 & Fulica armillata & Gruiformes & Rallidae & 0,605 & 0,451 & 0,990 & 1,081 & 1,944 \\
\hline YPM 102540 & Ardeotis arabs & Gruiformes & Otididae & 1,170 & 1,040 & 1,980 & 2,230 & 3,450 \\
\hline YPM 105866 & Ardeotis kori & Gruiformes & Otididae & 1,380 & 1,060 & 2,080 & 2,340 & 3,860 \\
\hline YPM 102227 & Otis tarda & Gruiformes & Otididae & 1,230 & 1,020 & 1,970 & 2,270 & 3,440 \\
\hline Prom. YPM & Psophia crepitans & Gruiformes & Psophiidae & 0,723 & 0,660 & 1,090 & 1,176 & 2,183 \\
\hline YPM 102062 & Tetrax tetrax & Gruiformes & Otididae & 0,620 & 0,510 & 0,830 & 0,990 & 1,670 \\
\hline MLP 403 & Porphyrula martinica & Gruiformes & Rallidae & 0,336 & 0,349 & 0,680 & 0,723 & 1,185 \\
\hline YPM 102538 & Grus canadensis & Gruiformes & Gruidae & 1,320 & 1,080 & 1,990 & 2,170 & 3,980 \\
\hline MACN 63320 & Aramus guarauna & Gruiformes & Aramidae & 0,788 & 0,640 & 1,298 & 1,398 & 2,210 \\
\hline MLP 178 & Xiphocolaptes major & Passeriformes & Furnariidae & 0,305 & 0,294 & 0,466 & 0,517 & 0,671 \\
\hline MLP 126 & Pseudoseisura lophotes & Passeriformes & Furnariidae & 0,216 & 0,198 & 0,408 & 0,446 & 0,648 \\
\hline MLP 777 & Turdus rufiventris & Passeriformes & Turdidae & 0,206 & 0,204 & 0,376 & 0,394 & 0,624 \\
\hline MLP 141 & Pitangus sulphuratus & Passeriformes & Tyraniidae & 0,204 & 0,208 & 0,370 & 0,402 & 0,634 \\
\hline MLP 476 & Phalacrocorax albiventer & Pelecaniformes & Phalacrocoracidae & 0,762 & 0,538 & 1,021 & 1,060 & 1,477 \\
\hline MLP 482 & Sula leucogaster & Pelecaniformes & Sulidae & 0,565 & 0,455 & 0,806 & 1,060 & 1,484 \\
\hline MLP 564 & Phoenicopterus chilensis & Phoenicopteriformes & Phoenicopteridae & 0,875 & 0,762 & 1,826 & 1,868 & 3,139 \\
\hline MLP 314 & Ramphastos vitellinus & Piciformes & Ramphastidae & 0,407 & 0,376 & 0,793 & 0,819 & 0,868 \\
\hline MLP 330 & Monasa nigrifrons & Piciformes & Bucconidae & 0,207 & 0,176 & 0,386 & 0,405 & 0,393 \\
\hline MLP 522 & Podiceps major & Podicipediformes & Podicipedidae & 0,671 & 0,542 & 1,078 & 1,056 & 1,123 \\
\hline MLP 488 & Pagodroma nivea & Procellariiformes & Procellariidae & 0,303 & 0,284 & 0,535 & 0,603 & 1,093 \\
\hline MLP 812 & Macronectes giganteus & Procellariiformes & Procellariidae & 0,822 & 0,665 & 1,568 & 1,724 & 2,890 \\
\hline MLP 65 & Cyanoliseus patagonus & Psittaciformes & Psittacidae & 0,277 & 0,273 & 0,430 & 0,551 & 0,677 \\
\hline MLP 469 & Pygoscelis adeliae & Sphenisciformes & Spheniscidae & 0,794 & 0,719 & 1,481 & 1,602 & 2,010 \\
\hline MLP 53 & Tyto alba & Strigiformes & Tytonidae & 0,427 & 0,436 & 0,986 & 1,013 & 1,017 \\
\hline MLP 401 & Bubo virginianus & Strigiformes & Strigidae & 0,553 & 0,498 & 0,942 & 0,926 & 1,346 \\
\hline MLP 685 & Dromaius novahollandie & Struthioniformes & Casuariidae & 2,487 & 2,210 & 4,233 & 4,284 & 8,849 \\
\hline
\end{tabular}




\begin{tabular}{|c|c|c|c|c|c|c|c|c|}
\hline MLP 878 & Rhea americana & Struthioniformes & Rheidae & 2,724 & 2,154 & 3,808 & 3,818 & 9,565 \\
\hline $\begin{array}{l}\text { MLP 86-VI-15- } \\
1\end{array}$ & Emeus crassus & Struthioniformes & Dinornithidae & 4,214 & 2,652 & 5,705 & 7,411 & 10,118 \\
\hline Prom. MLP & Pterocnemia pennata & Struthionifromes & Rheidae & 2,195 & 1,785 & 3,213 & 3,289 & 8,242 \\
\hline MLP 327 & Eudromia elegans & Tinamiformes & Tinamidae & 0,472 & 0,395 & 0,766 & 0,898 & 1,538 \\
\hline
\end{tabular}


Tabla 9.5. Matriz de medidas del tibiotarso $(\mathrm{cm}$.) tomadas en los Phorusrhacidae disponibles.

\begin{tabular}{|c|c|c|c|c|c|c|c|c|c|c|c|}
\hline Catálogo & Especie & ZA & ZB & $\mathrm{ZC}$ & ZD & $\mathrm{ZE}$ & $\mathrm{ZF}$ & $\mathrm{ZG}$ & $\mathrm{ZH}$ & ZI & $\mathrm{ZJ}$ \\
\hline MACN Pv 13243 & Devincenzia pozzi & & & & & 7,432 & & & 7,222 & & \\
\hline FM- P14422 & Mesembriornis incertus & & 35,042 & 4,300 & & 3,506 & 2,566 & 2,094 & & & \\
\hline MMP $155-5$ & Mesembriornis milneedwardsi & 45,452 & 42,330 & & 8,194 & 5,638 & 3,232 & 3,038 & 5,174 & 5,464 & 12,480 \\
\hline MLP 20-141 & Mesembriornis milneedwardsi & & & & & & 3,692 & 3,159 & & & \\
\hline MACN Pv 5944 & Mesembriornis milneedwardsi & & 40,526 & & & 5,133 & 3,464 & 3,208 & 4,808 & 5,364 & \\
\hline AMNH 9264 & Patagornis marshi & 37,122 & 35,104 & 4,226 & 4,624 & 3,448 & 2,570 & 2,116 & 3,668 & 4,159 & 8,022 \\
\hline MLP 20-154 & Patagornis marshi & & & & & & & & 3,876 & & \\
\hline MLP 20-158 & Patagornis marshi & & & 4,816 & & & & & & & \\
\hline MLP 59-XII-14-14 & Patagornis marshi & & & & & 3,455 & & & 3,325 & & \\
\hline MLP 84-III-9-21 & Patagornis marshi & 37,064 & 35,936 & & & 3,696 & 2,806 & 2,038 & 3,402 & 3,836 & \\
\hline BMNH - A516 & Patagornis marshi & 39,130 & 36,470 & 4,780 & 5,840 & 4,100 & 2,890 & 2,580 & 3,970 & 4,480 & \\
\hline AMNH 9497 & Phorusrhacos longissimus & & & & & 5,634 & 3,702 & 3,186 & 5,164 & & \\
\hline MLP 20-119 & Phorusrhacos longissimus & & & & & & & & & & \\
\hline MLP 20-130 & Phorusrhacos longissimus & & & & & & & & & & \\
\hline MLP 20-137 & Phorusrhacos longissimus & & & & & & & & & & \\
\hline MLP 20-171 & Phorusrhacos longissimus & & & & & 7,234 & & & 6,382 & & \\
\hline MLP 20-174 & Phorusrhacos longissimus & & & & & & & & 5,685 & & \\
\hline MLP 20-180 & Phorusrhacos longissimus & & & & & & & & & & \\
\hline MPM-PV4241 & Phorusrhacos longissimus & 52,312 & 49,016 & & & 6,126 & & 4,252 & & & 13,852 \\
\hline AMNH 9158 & Phorusrhacos sp. & & & & & & & & 5,879 & & \\
\hline FM-P14525 & Procariama simplex & 28,930 & 27,540 & 2,796 & 4,034 & 2,710 & 1,713 & 1,338 & 2,496 & 2,768 & 5,402 \\
\hline MACN Pv 6939 & Procariama simplex & & & & & 2,492 & & & 2,302 & 2,492 & \\
\hline MACN Pv 8225 & Procariama simplex & & & & & 2,494 & & & 2,362 & 2,706 & \\
\hline YPM-PU15904 & Psilopterus bachmanni & 19,858 & 19,482 & 1,873 & 2,656 & 1,690 & 1,372 & 0,842 & 1,710 & 1,940 & \\
\hline MLP 20-167 & Psilopterus bachmanni & & & & & 1,759 & & & 1,782 & 1,919 & \\
\hline
\end{tabular}




\begin{tabular}{|c|c|c|c|c|c|c|c|c|c|c|c|}
\hline & & & & & & & & & & & \\
\hline MPM-PV4243 & Psilopterus bachmanni & & & & & 1,882 & & & 2,054 & 2,296 & \\
\hline FM-PA-10 & Psilopterus lemoinei & & & & & 1,762 & & & 1,988 & & \\
\hline FM-PA-7 & Psilopterus lemoinei & & & & & 1,880 & & & 2,100 & 2,276 & \\
\hline YPM-PU15402 & Psilopterus lemoinei & & 22,112 & 2,238 & 3,116 & 1,924 & 1,452 & 1,257 & 2,092 & & 4,100 \\
\hline AMNH 7006 & Psilopterus lemoinei & & & & & 2,072 & & & 2,172 & & \\
\hline AMNH 9257 & Psilopterus lemoinei & 23,876 & 23,558 & & & 2,022 & 1,492 & 1,286 & 2,210 & 2,502 & 4,494 \\
\hline AMNH 9157 & Psilopterus lemoinei & 23,932 & 22,410 & 1,984 & 2,842 & 1,768 & & & 1,842 & 2,040 & 3,928 \\
\hline MLP 20-162 & Psilopterus lemoinei & & & & & 2,022 & & & 2,256 & & \\
\hline MPM-PV3650 & Psilopterus lemoinei & 25,400 & 24,325 & 2,835 & 3,792 & 2,283 & 1,665 & 1,287 & 2,188 & 2,570 & 4,612 \\
\hline MPM-PV4240 & Psilopterus lemoinei & & 25,522 & & & & 1,776 & 1,306 & & & \\
\hline MMP 5050 & Taxón nuevo A & 33,253 & 32,022 & 3,709 & 4,763 & 3,263 & 2,053 & 1,739 & 3,371 & 3,077 & 6,827 \\
\hline
\end{tabular}


Tabla 9.6. Individuos promedio para cada especie de fororraco en base a las medidas del tibiotarso (cm.).

\begin{tabular}{|c|c|c|c|c|c|c|c|c|c|c|}
\hline Especie & ZA & ZB & $\mathrm{ZC}$ & ZD & $\mathrm{ZE}$ & $\mathrm{ZF}$ & $\mathrm{ZG}$ & $\mathrm{ZH}$ & $\overline{Z I I}$ & $\overline{\mathrm{ZJ}}$ \\
\hline \multicolumn{11}{|l|}{ Andalgalornis steulleti } \\
\hline \multicolumn{11}{|l|}{ Andrewsornis abbotti } \\
\hline Devincenzia pozzi & & & & & 7,432 & & & 7,222 & & \\
\hline \multicolumn{11}{|l|}{ Kelenken guillermoi } \\
\hline Mesembriornis incertus & & 35,042 & 4,300 & & 3,506 & 2,566 & 2,094 & & & \\
\hline Mesembriornis milneedwardsi & 45,452 & 41,428 & & 8,194 & 5,386 & 3,463 & 3,135 & 4,991 & 5,414 & 12,480 \\
\hline \multicolumn{11}{|l|}{ Paraphysornis brasiliensis } \\
\hline Patagornis marshi & 37,772 & 35,837 & 4,607 & 5,232 & 3,675 & 2,755 & 2,245 & 3,648 & 4,158 & 8,022 \\
\hline Phorusrhacos longissimus & 52,312 & 49,016 & & & 6,331 & 3,702 & 3,719 & 5,778 & & 13,852 \\
\hline \multicolumn{11}{|l|}{ Physornis fortis } \\
\hline Procariama simplex & 28,930 & 27,540 & 2,796 & 4,034 & 2,565 & 1,713 & 1,338 & 2,387 & 2,655 & 5,402 \\
\hline \multicolumn{11}{|l|}{ Psilopterus affinis } \\
\hline Psilopterus bachmanni & 19,858 & 19,482 & 1,873 & 2,656 & 1,777 & 1,372 & 0,842 & 1,849 & 2,052 & \\
\hline \multicolumn{11}{|l|}{ Psilopterus colzecus } \\
\hline Psilopterus lemoinei & 24,403 & 23,585 & 2,352 & 3,250 & 1,967 & 1,596 & 1,284 & 2,106 & 2,347 & 4,284 \\
\hline Taxón nuevo A & 33,253 & 32,022 & 3,709 & 4,763 & 3,263 & 2,053 & 1,739 & 3,371 & 3,077 & 6,827 \\
\hline
\end{tabular}


Tabla 9.7. Matriz de medidas del tarsometatarso (cm.) tomadas en las Neornithes actuales utilizadas en esta tesis. Las medidas angulares AL y AM se expresan en grados.

\begin{tabular}{|c|c|c|c|c|c|c|c|c|}
\hline Catálogo & Especie & Orden & Familia & $\mathrm{AA}$ & $\mathrm{AB}$ & $\mathrm{AC}$ & $\mathrm{AD}$ & $\mathrm{AE}$ \\
\hline MLP 569 & Chauna torquata & Anseriformes & Anhimidae & 12,794 & 12,444 & 12,396 & 2,376 & 2,490 \\
\hline MLP 84 & Anas platalea & Anseriformes & Anatidae & 3,900 & 3,798 & 3,558 & 0,786 & 0,718 \\
\hline MLP 533 & Cariama cristata & Cariamiformes & Cariamidae & 18,214 & 17,786 & 17,936 & 1,708 & 1,502 \\
\hline MLP 535 & Chunga burmeisteri & Cariamiformes & Cariamidae & 11,942 & 11,700 & 11,776 & 1,368 & 1,158 \\
\hline MLP 615 & Vanellus chilensis & Charadriiformes & Charadriidae & 7,696 & 7,368 & 7,582 & 0,792 & 0,742 \\
\hline MLP 814 & Larus maculipennis & Charadriiformes & Laridae & 4,564 & 4,306 & 4,488 & 0,788 & 0,620 \\
\hline MLP 412 & Chionis alba & Charadriiformes & Chionididae & 4,644 & 4,314 & 4,402 & 1,046 & 1,062 \\
\hline MLP 871 & Catharacta maccormicki & Charadriiformes & Stercorariidae & 6,760 & 6,389 & 6,609 & 1,288 & 1,185 \\
\hline YPM 111287 & Burhinus capensis & Charadriiformes & Burhinidae & 8,780 & 8,490 & 8,650 & 0,910 & 0,890 \\
\hline YPM 102096 & Burhinus grallarius & Charadriiformes & Burhinidae & 11,470 & 11,140 & 11,240 & 1,230 & 1,090 \\
\hline MLP 531 & Burhinus oedicnemus & Charadriiformes & Burhinidae & 7,349 & 7,172 & 7,191 & 0,917 & 0,830 \\
\hline MACN 22325 & Fratercula corniculata & Charadriiformes & Alcidae & 3,032 & 2,716 & 2,918 & 0,750 & 0,736 \\
\hline MLP 474 & Theristicus melanopis & Ciconiiformes & Threskiornithidae & 8,758 & 8,614 & 8,554 & 1,482 & 1,522 \\
\hline MLP 344 & Coragyps atratus & Ciconiiformes & Cathartidae & 7,850 & 7,826 & 7,634 & 1,522 & 1,544 \\
\hline MLP 804 & Nycticorax nycticorax & Ciconiiformes & Ardeidae & 7,798 & 7,766 & 7,648 & 1,070 & 1,024 \\
\hline MLP 712 & Ciconia maguari & Ciconiiformes & Ciconiidae & 19,682 & 19,634 & 19,454 & 1,716 & 1,658 \\
\hline MLP 807 & Vultur gryphus & Ciconiiformes & Cathartidae & 12,486 & 12,342 & 12,108 & 3,034 & 3,210 \\
\hline Prom. YPM & $\begin{array}{l}\text { Leptoptilos } \\
\text { crummeniferus }\end{array}$ & Ciconiiformes & Ciconiidae & 24,825 & 24,280 & 24,245 & 2,450 & 2,725 \\
\hline YPM 102102 & Leptoptilos dubius & Ciconiiformes & Ciconiidae & 26,490 & 26,040 & 26,090 & 2,520 & 2,790 \\
\hline YPM 105903 & Mycteria americana & Ciconiiformes & Ciconiidae & 16,760 & 16,340 & 16,500 & 1,440 & 1,540 \\
\hline YPM 105272 & Mycteria ibis & Ciconiiformes & Ciconiidae & 19,830 & 19,340 & 19,610 & 1,470 & 1,600 \\
\hline YPM 102099 & Mycteria leucocephala & Ciconiiformes & Ciconiidae & 20,290 & 19,850 & 20,000 & 1,510 & 1,680 \\
\hline MACN 20958 & Ardea cocoi & Ciconiiformes & Ardeidae & 19,196 & 19,152 & 18,992 & 1,834 & 1,852 \\
\hline MLP 399 & Columba picazuro & Columbiformes & Columbidae & 3,270 & 3,132 & 3,134 & 0,796 & 0,816 \\
\hline
\end{tabular}




\begin{tabular}{|c|c|c|c|c|c|c|c|c|}
\hline MLP 261 & Zenaida auriculata & Columbiformes & Columbidae & 2,232 & 2,134 & 2,104 & 0,504 & 0,526 \\
\hline YPM 103256 & Buceros bicornis & Coraciiformes & Bucerotidae & 6,490 & 6,400 & 6,330 & 2,030 & 1,960 \\
\hline MLP 319 & Galbula ruficauda & Coraciiformes & Galbulidae & 1,222 & 1,208 & 1,141 & 0,250 & 0,265 \\
\hline MLP 6 & Ceryle torquata & Coraciiformes & Alcedinidae & 1,350 & 1,331 & 1,319 & 0,533 & 0,514 \\
\hline MLP 97 & Guira guira & Cuculiformes & Cuculidae & 4,135 & 4,063 & 3,864 & 0,625 & 0,661 \\
\hline MLP 536 & Opisthocomus hoazin & Cuculiformes & Opisthocomidae & 5,504 & 5,377 & 5,306 & 1,168 & 1,172 \\
\hline MLP 696 & $\begin{array}{l}\text { Geranoaetus } \\
\text { melanoleucus }\end{array}$ & Falconiformes & Accipitridae & 10,768 & 10,842 & 10,708 & 2,038 & 1,954 \\
\hline MLP 438 & Falco peregrinus & Falconiformes & Falconidae & 5,188 & 5,184 & 5,016 & 1,246 & 1,192 \\
\hline MLP 62 & Polyborus plancus & Falconiformes & Falconidae & 10,568 & 10,532 & 10,406 & 1,442 & 1,630 \\
\hline YPM 111125 & Sagittarius serpentarius & Falconiformes & Sagittariidae & 25,590 & 25,390 & 25,310 & 2,210 & 2,020 \\
\hline MACN 26366 & Pandion haliaetus & Falconiformes & Accipitridae & 5,294 & 5,306 & 5,044 & 1,506 & 1,618 \\
\hline MLP 364 & Lophortyx californica & Galliformes & Odontophoridae & 3,132 & 2,926 & 3,048 & 0,562 & 0,574 \\
\hline MACN 343438 & Penelope purpurascens & Galliformes & Cracidae & 8,404 & 8,090 & 8,084 & 1,528 & 1,280 \\
\hline OUVC 10563 & Gavia immer & Gaviiformes & Gaviidae & 10,110 & 8,940 & 9,930 & 1,790 & 1,250 \\
\hline MLP 49 & Fulica armillata & Gruiformes & Rallidae & 7,062 & 6,494 & 6,868 & 1,120 & 1,088 \\
\hline YPM 102540 & Ardeotis arabs & Gruiformes & Otididae & 17,320 & 16,750 & 16,730 & 2,330 & 2,400 \\
\hline YPM 105866 & Ardeotis kori & Gruiformes & Otididae & 18,020 & 17,340 & 17,470 & 2,410 & 2,400 \\
\hline YPM 102227 & Otis tarda & Gruiformes & Otididae & 15,290 & 14,620 & 14,860 & 2,540 & 2,570 \\
\hline Prom. YPM & Psophia crepitans & Gruiformes & Psophiidae & 11,436 & 11,050 & 11,166 & 1,296 & 1,253 \\
\hline YPM 102062 & Tetrax tetrax & Gruiformes & Otididae & 6,650 & 6,300 & 6,350 & 1,130 & 1,140 \\
\hline MLP 403 & Porphyrula martinica & Gruiformes & Rallidae & 5,988 & 5,739 & 5,810 & 0,762 & 0,744 \\
\hline YPM 102538 & Grus canadensis & Gruiformes & Gruidae & 22,260 & 21,140 & 21,830 & 2,150 & 2,050 \\
\hline MACN 63320 & Aramus guarauna & Gruiformes & Aramidae & 13,882 & 13,444 & 13,690 & 1,528 & 1,478 \\
\hline MLP 178 & Xiphocolaptes major & Passeriformes & Furnariidae & 3,418 & 3,366 & 3,448 & 0,566 & 0,586 \\
\hline MLP 126 & Pseudoseisura lophotes & Passeriformes & Furnariidae & 3,340 & 3,350 & 3,320 & 0,464 & 0,356 \\
\hline MLP 777 & Turdus rufiventris & Passeriformes & Turdidae & 3,588 & 3,568 & 3,558 & 0,422 & 0,376 \\
\hline MLP 141 & Pitangus sulphuratus & Passeriformes & Tyraniidae & 2,912 & 2,908 & 2,886 & 0,426 & 0,362 \\
\hline MLP 476 & Phalacrocorax albiventer & Pelecaniformes & Phalacrocoracidae & 6,042 & 5,978 & 6,070 & 1,336 & 1,486 \\
\hline
\end{tabular}




\begin{tabular}{|c|c|c|c|c|c|c|c|c|}
\hline MLP 482 & Sula leucogaster & Pelecaniformes & Sulidae & 4,738 & 4,789 & 4,550 & 1,276 & 1,453 \\
\hline MLP 564 & Phoenicopterus chilensis & Phoenicopteriformes & Phoenicopteridae & 26,136 & 25,568 & 25,920 & 1,982 & 1,952 \\
\hline MLP 314 & Ramphastos vitellinus & Piciformes & Ramphastidae & 5,026 & 4,887 & 4,827 & 0,927 & 0,994 \\
\hline MLP 330 & Monasa nigrifrons & Piciformes & Bucconidae & 2,141 & 2,078 & 2,024 & 0,438 & 0,486 \\
\hline MLP 522 & Podiceps major & Podicipediformes & Podicipedidae & 6,504 & 6,546 & 6,038 & 1,242 & 0,864 \\
\hline MLP 488 & Pagodroma nivea & Procellariiformes & Procellariidae & 3,642 & 3,476 & 3,582 & 0,642 & 0,656 \\
\hline MLP 812 & Macronectes giganteus & Procellariiformes & Procellariidae & 9,148 & 8,690 & 8,898 & 1,873 & 1,759 \\
\hline MLP 65 & Cyanoliseus patagonus & Psittaciformes & Psittacidae & 2,168 & 1,968 & 2,031 & 0,711 & 0,878 \\
\hline MLP 469 & Pygoscelis adeliae & Sphenisciformes & Spheniscidae & 3,254 & 3,108 & 2,947 & 1,634 & 2,266 \\
\hline MLP 53 & Tyto alba & Strigiformes & Tytonidae & 7,102 & 7,162 & 6,980 & 0,992 & 1,142 \\
\hline MLP 401 & Bubo virginianus & Strigiformes & Strigidae & 6,032 & 6,100 & 5,804 & 1,148 & 1,320 \\
\hline MLP 685 & Dromaius novahollandie & Struthioniformes & Casuariidae & 34,642 & 33,372 & 33,800 & 5,434 & 4,712 \\
\hline MLP 878 & Rhea americana & Struthioniformes & Rheidae & 32,184 & 30,952 & 31,119 & 4,219 & 4,076 \\
\hline $\begin{array}{l}\text { MLP 86-VI-15- } \\
1\end{array}$ & Emeus crassus & Struthioniformes & Dinornithidae & 21,404 & 20,620 & 19,366 & 7,970 & 9,868 \\
\hline Prom. MLP & Pterocnemia pennata & Struthionifromes & Rheidae & 29,739 & 28,767 & 29,123 & 4,157 & 4,165 \\
\hline MLP 327 & Eudromia elegans & Tinamiformes & Tinamidae & 4,666 & 4,380 & 4,528 & 0,922 & 1,042 \\
\hline
\end{tabular}

\begin{tabular}{|c|c|c|c|c|c|c|c|c|}
\hline Catálogo & Especie & Orden & Familia & $\mathrm{AF}$ & $\mathrm{AG}$ & $\mathrm{AH}$ & $\mathrm{AI}$ & AJ \\
\hline MLP 569 & Chauna torquata & Anseriformes & Anhimidae & 1,082 & 0,838 & 1,092 & 0,752 & 1,154 \\
\hline MLP 84 & Anas platalea & Anseriformes & Anatidae & 0,432 & 0,354 & 0,422 & 0,302 & 0,474 \\
\hline MLP 533 & Cariama cristata & Cariamiformes & Cariamidae & 0,694 & 0,772 & 0,634 & 0,544 & 0,872 \\
\hline MLP 615 & Vanellus chilensis & Charadriiformes & Charadriidae & 0,318 & 0,258 & 0,312 & 0,224 & 0,444 \\
\hline MLP 814 & Larus maculipennis & Charadriiformes & Laridae & 0,278 & 0,268 & 0,278 & 0,212 & 0,438 \\
\hline
\end{tabular}




\begin{tabular}{|c|c|c|c|c|c|c|c|c|}
\hline YPM 111287 & Burhinus capensis & Charadriiformes & Burhinidae & 0,340 & 0,370 & 0,330 & 0,280 & 0,470 \\
\hline YPM 102096 & Burhinus grallarius & Charadriiformes & Burhinidae & 0,470 & 0,470 & 0,420 & 0,340 & 0,860 \\
\hline MLP 531 & Burhinus oedicnemus & Charadriiformes & Burhinidae & 0,329 & 0,293 & 0,328 & 0,250 & 0,518 \\
\hline MACN 22325 & Fratercula corniculata & Charadriiformes & Alcidae & 0,430 & 0,302 & 0,408 & 0,272 & 0,456 \\
\hline MLP 474 & Theristicus melanopis & Ciconiiformes & Threskiornithidae & 0,674 & 0,468 & 0,668 & 0,408 & 0,794 \\
\hline MLP 344 & Coragyps atratus & Ciconiiformes & Cathartidae & 0,692 & 0,558 & 0,698 & 0,526 & 0,952 \\
\hline MLP 804 & Nycticorax nycticorax & Ciconiiformes & Ardeidae & 0,504 & 0,392 & 0,490 & 0,324 & 0,582 \\
\hline MLP 712 & Ciconia maguari & Ciconiiformes & Ciconiidae & 0,786 & 0,636 & 0,754 & 0,566 & 0,888 \\
\hline MLP 807 & Vultur gryphus & Ciconiiformes & Cathartidae & 1,604 & 1,032 & 1,638 & 0,998 & 1,984 \\
\hline Prom. YPM & $\begin{array}{l}\text { Leptoptilos } \\
\text { crummeniferus }\end{array}$ & Ciconiiformes & Ciconiidae & 1,025 & 0,985 & 0,995 & 1,760 & 1,445 \\
\hline YPM 102102 & Leptoptilos dubius & Ciconiiformes & Ciconiidae & 1,090 & 1,040 & 1,020 & 0,810 & 1,480 \\
\hline YPM 105903 & Mycteria americana & Ciconiiformes & Ciconiidae & 0,610 & 0,660 & 0,610 & 0,520 & 0,880 \\
\hline YPM 105272 & Mycteria ibis & Ciconiiformes & Ciconiidae & 0,660 & 0,670 & 0,640 & 0,550 & 0,960 \\
\hline YPM 102099 & Mycteria leucocephala & Ciconiiformes & Ciconiidae & 0,640 & 0,700 & 0,600 & 0,570 & 0,950 \\
\hline MACN 20958 & Ardea cocoi & Ciconiiformes & Ardeidae & 0,792 & 0,680 & 0,720 & 0,590 & 0,912 \\
\hline MLP 399 & Columba picazuro & Columbiformes & Columbidae & 0,400 & 0,302 & 0,402 & 0,252 & 0,462 \\
\hline MLP 261 & Zenaida auriculata & Columbiformes & Columbidae & 0,236 & 0,180 & 0,242 & 0,152 & 0,244 \\
\hline YPM 103256 & Buceros bicornis & Coraciiformes & Bucerotidae & 0,990 & 0,830 & 0,840 & 0,660 & 0,820 \\
\hline MLP 319 & Galbula ruficauda & Coraciiformes & Galbulidae & 0,111 & 0,089 & 0,111 & 0,089 & 0,123 \\
\hline MLP 6 & Ceryle torquata & Coraciiformes & Alcedinidae & 0,284 & 0,190 & 0,284 & 0,190 & 0,385 \\
\hline MLP 97 & Guira guira & Cuculiformes & Cuculidae & 0,308 & 0,242 & 0,290 & 0,189 & 0,321 \\
\hline MLP 536 & Opisthocomus hoazin & Cuculiformes & Opisthocomidae & 0,493 & 0,349 & 0,480 & 0,322 & 0,508 \\
\hline MLP 696 & $\begin{array}{l}\text { Geranoaetus } \\
\text { melanoleucus }\end{array}$ & Falconiformes & Accipitridae & 0,940 & 1,016 & 0,852 & 0,848 & 1,570 \\
\hline MLP 438 & Falco peregrinus & Falconiformes & Falconidae & 0,586 & 0,540 & 0,548 & 0,426 & 0,432 \\
\hline MLP 62 & Polyborus plancus & Falconiformes & Falconidae & 0,640 & 0,578 & 0,622 & 0,510 & 0,396 \\
\hline YPM 111125 & Sagittarius serpentarius & Falconiformes & Sagittariidae & 0,920 & 1,000 & 0,720 & 0,660 & 1,150 \\
\hline MACN 26366 & Pandion haliaetus & Falconiformes & Accipitridae & 0,980 & 0,508 & 0,938 & 0,588 & 0,702 \\
\hline
\end{tabular}




\begin{tabular}{|c|c|c|c|c|c|c|c|c|}
\hline MLP 364 & Lophortyx californica & Galliformes & Odontophoridae & 0,252 & 0,210 & 0,262 & 0,194 & 0,260 \\
\hline MACN 343438 & Penelope purpurascens & Galliformes & Cracidae & 0,712 & 0,494 & 0,636 & 0,464 & 0,812 \\
\hline OUVC 10563 & Gavia immer & Gaviiformes & Gaviidae & 0,590 & 0,910 & 0,590 & 0,910 & 1,070 \\
\hline MLP 49 & Fulica armillata & Gruiformes & Rallidae & 0,496 & 0,458 & 0,510 & 0,432 & 0,508 \\
\hline YPM 102540 & Ardeotis arabs & Gruiformes & Otididae & 0,840 & 1,010 & 0,780 & 0,780 & 1,370 \\
\hline YPM 105866 & Ardeotis kori & Gruiformes & Otididae & 0,910 & 1,090 & 0,840 & 0,830 & 1,470 \\
\hline YPM 102227 & Otis tarda & Gruiformes & Otididae & 0,940 & 0,930 & 0,890 & 0,850 & 1,330 \\
\hline Prom. YPM & Psophia crepitans & Gruiformes & Psophiidae & 0,620 & 0,513 & 0,546 & 0,403 & 0,743 \\
\hline YPM 102062 & Tetrax tetrax & Gruiformes & Otididae & 0,420 & 0,390 & 0,410 & 0,340 & 0,640 \\
\hline MLP 403 & Porphyrula martinica & Gruiformes & Rallidae & 0,472 & 0,328 & 0,386 & 0,256 & 0,428 \\
\hline YPM 102538 & Grus canadensis & Gruiformes & Gruidae & 0,880 & 0,840 & 0,750 & 0,620 & 1,240 \\
\hline MACN 63320 & Aramus guarauna & Gruiformes & Aramidae & 0,596 & 0,526 & 0,570 & 0,472 & 0,802 \\
\hline MLP 178 & Xiphocolaptes major & Passeriformes & Furnariidae & 0,292 & 0,332 & 0,268 & 0,264 & 0,368 \\
\hline MLP 126 & Pseudoseisura lophotes & Passeriformes & Furnariidae & 0,196 & 0,258 & 0,184 & 0,182 & 0,228 \\
\hline MLP 777 & Turdus rufiventris & Passeriformes & Turdidae & 0,172 & 0,214 & 0,162 & 0,154 & 0,196 \\
\hline MLP 141 & Pitangus sulphuratus & Passeriformes & Tyraniidae & 0,162 & 0,220 & 0,162 & 0,164 & 0,194 \\
\hline MLP 476 & Phalacrocorax albiventer & Pelecaniformes & Phalacrocoracidae & 0,594 & 0,482 & 0,646 & 0,424 & 0,560 \\
\hline MLP 482 & Sula leucogaster & Pelecaniformes & Sulidae & 0,760 & 0,403 & 0,753 & 0,397 & 0,887 \\
\hline MLP 564 & Phoenicopterus chilensis & Phoenicopteriformes & Phoenicopteridae & 0,626 & 0,782 & 0,568 & 0,588 & 1,108 \\
\hline MLP 314 & Ramphastos vitellinus & Piciformes & Ramphastidae & 0,287 & 0,389 & 0,285 & 0,369 & 0,410 \\
\hline MLP 330 & Monasa nigrifrons & Piciformes & Bucconidae & 0,201 & 0,166 & 0,201 & 0,155 & 0,255 \\
\hline MLP 522 & Podiceps major & Podicipediformes & Podicipedidae & 0,358 & 0,550 & 0,366 & 0,488 & 0,812 \\
\hline MLP 488 & Pagodroma nivea & Procellariiformes & Procellariidae & 0,239 & 0,229 & 0,239 & 0,229 & 0,352 \\
\hline MLP 812 & Macronectes giganteus & Procellariiformes & Procellariidae & 0,687 & 0,612 & 0,681 & 0,606 & 1,066 \\
\hline MLP 65 & Cyanoliseus patagonus & Psittaciformes & Psittacidae & 0,336 & 0,199 & 0,336 & 0,199 & 0,267 \\
\hline MLP 469 & Pygoscelis adeliae & Sphenisciformes & Spheniscidae & 1,635 & 0,571 & 1,620 & 0,641 & 1,509 \\
\hline MLP 53 & Tyto alba & Strigiformes & Tytonidae & 0,432 & 0,356 & 0,462 & 0,332 & 0,218 \\
\hline MLP 401 & Bubo virginianus & Strigiformes & Strigidae & 0,540 & 0,432 & 0,578 & 0,396 & 0,424 \\
\hline
\end{tabular}




\begin{tabular}{|c|c|c|c|c|c|c|c|c|}
\hline MLP 685 & Dromaius novahollandie & Struthioniformes & Casuariidae & 2,176 & 2,138 & 1,648 & 1,802 & 1,022 \\
\hline MLP 878 & Rhea americana & Struthioniformes & Rheidae & 1,741 & 2,111 & 1,624 & 1,850 & 1,569 \\
\hline $\begin{array}{l}\text { MLP 86-VI-15- } \\
1\end{array}$ & Emeus crassus & Struthioniformes & Dinornithidae & 4,224 & 2,496 & 4,178 & 2,450 & 3,610 \\
\hline Prom. MLP & Pterocnemia pennata & Struthionifromes & Rheidae & 1,606 & 1,822 & 1,555 & 1,481 & 1,626 \\
\hline MLP 327 & Eudromia elegans & Tinamiformes & Tinamidae & 0,376 & 0,372 & 0,376 & 0,358 & 0,548 \\
\hline
\end{tabular}

\begin{tabular}{|c|c|c|c|c|c|c|c|}
\hline Catálogo & Especie & Orden & Familia & $\mathrm{AK}$ & $\mathrm{AL}$ & $\mathrm{AM}$ & AN \\
\hline MLP 569 & Chauna torquata & Anseriformes & Anhimidae & 1,806 & 12 & 10 & 2,164 \\
\hline MLP 84 & Anas platalea & Anseriformes & Anatidae & 0,706 & 14 & 13 & 0,794 \\
\hline MLP 533 & Cariama cristata & Cariamiformes & Cariamidae & 0,994 & 10 & 8 & 1,398 \\
\hline MLP 535 & Chunga burmeisteri & Cariamiformes & Cariamidae & 0,694 & 11 & 9 & 1,136 \\
\hline MLP 615 & Vanellus chilensis & Charadriiformes & Charadriidae & 0,682 & 8 & 10 & 0,734 \\
\hline MLP 814 & Larus maculipennis & Charadriiformes & Laridae & 0,528 & 10 & 11 & 0,720 \\
\hline MLP 412 & Chionis alba & Charadriiformes & Chionididae & 0,528 & 13 & 16 & 0,829 \\
\hline MLP 871 & Catharacta maccormicki & Charadriiformes & Stercorariidae & 1,029 & 9 & 9 & 1,073 \\
\hline YPM 111287 & Burhinus capensis & Charadriiformes & Burhinidae & 0,900 & 10 & 10 & 0,830 \\
\hline YPM 102096 & Burhinus grallarius & Charadriiformes & Burhinidae & 1,110 & 12 & 12,75 & 1,080 \\
\hline MLP 531 & Burhinus oedicnemus & Charadriiformes & Burhinidae & 0,736 & 7,5 & 9 & 0,794 \\
\hline MACN 22325 & Fratercula corniculata & Charadriiformes & Alcidae & 0,420 & 13,5 & 11 & 0,648 \\
\hline MLP 474 & Theristicus melanopis & Ciconiiformes & Threskiornithidae & 0,784 & 13 & 13 & 1,249 \\
\hline MLP 344 & Coragyps atratus & Ciconiiformes & Cathartidae & 0,612 & 12 & 13 & 1,174 \\
\hline MLP 804 & Nycticorax nycticorax & Ciconiiformes & Ardeidae & 0,706 & 9 & 8 & 1,154 \\
\hline MLP 712 & Ciconia maguari & Ciconiiformes & Ciconiidae & 1,372 & 7 & 11 & 1,964 \\
\hline MLP 807 & Vultur gryphus & Ciconiiformes & Cathartidae & 1,022 & 16,5 & 14 & 2,206 \\
\hline Prom. YPM & $\begin{array}{l}\text { Leptoptilos } \\
\text { crummeniferus }\end{array}$ & Ciconiiformes & Ciconiidae & 1,615 & 8,75 & 8 & 2,410 \\
\hline
\end{tabular}




\begin{tabular}{|c|c|c|c|c|c|c|c|}
\hline YPM 102102 & Leptoptilos dubius & Ciconiiformes & Ciconiidae & 1,890 & 10,75 & 11,25 & 2,510 \\
\hline YPM 105903 & Mycteria americana & Ciconiiformes & Ciconiidae & 1,060 & 8 & 8 & 1,560 \\
\hline YPM 105272 & Mycteria ibis & Ciconiiformes & Ciconiidae & 1,290 & 8,5 & 10 & 1,550 \\
\hline YPM 102099 & Mycteria leucocephala & Ciconiiformes & Ciconiidae & 0,980 & 6,5 & 7 & 1,580 \\
\hline MACN 20958 & Ardea cocoi & Ciconiiformes & Ardeidae & 2,122 & 7 & 5 & 2,112 \\
\hline MLP 399 & Columba picazuro & Columbiformes & Columbidae & 0,498 & 20 & 20 & 0,776 \\
\hline MLP 261 & Zenaida auriculata & Columbiformes & Columbidae & 0,340 & 24 & 16 & 0,492 \\
\hline YPM 103256 & Buceros bicornis & Coraciiformes & Bucerotidae & 1,990 & 20 & 18 & 1,910 \\
\hline MLP 319 & Galbula ruficauda & Coraciiformes & Galbulidae & 0,283 & 8 & 11,5 & 0,210 \\
\hline MLP 6 & Ceryle torquata & Coraciiformes & Alcedinidae & 0,390 & 13 & 16,5 & 0,452 \\
\hline MLP 97 & Guira guira & Cuculiformes & Cuculidae & 0,341 & 10 & 16 & 0,650 \\
\hline MLP 536 & Opisthocomus hoazin & Cuculiformes & Opisthocomidae & 0,951 & 20 & 14 & 1,190 \\
\hline MLP 696 & $\begin{array}{l}\text { Geranoaetus } \\
\text { melanoleucus }\end{array}$ & Falconiformes & Accipitridae & 0,592 & 9 & 12 & 1,588 \\
\hline MLP 438 & Falco peregrinus & Falconiformes & Falconidae & 1,132 & 11 & 16 & 1,042 \\
\hline MLP 62 & Polyborus plancus & Falconiformes & Falconidae & 1,614 & 10 & 11 & 1,285 \\
\hline YPM 111125 & Sagittarius serpentarius & Falconiformes & Sagittariidae & 1,040 & 11,5 & 10 & 1,970 \\
\hline MACN 26366 & Pandion haliaetus & Falconiformes & Accipitridae & 1,462 & 19 & 21 & 1,422 \\
\hline MLP 364 & Lophortyx californica & Galliformes & Odontophoridae & 0,370 & 11 & 13 & 0,598 \\
\hline MACN 343438 & Penelope purpurascens & Galliformes & Cracidae & 0,926 & 12 & 11 & 1,498 \\
\hline OUVC 10563 & Gavia immer & Gaviiformes & Gaviidae & 1,710 & 7 & 7 & 2,120 \\
\hline MLP 49 & Fulica armillata & Gruiformes & Rallidae & 0,838 & 10 & 11 & 1,094 \\
\hline YPM 102540 & Ardeotis arabs & Gruiformes & Otididae & 1,780 & 12,5 & 14 & 2,090 \\
\hline YPM 105866 & Ardeotis kori & Gruiformes & Otididae & 2,030 & 12,5 & 14 & 2,270 \\
\hline YPM 102227 & Otis tarda & Gruiformes & Otididae & 2,310 & 11,5 & 14 & 2,150 \\
\hline Prom. YPM & Psophia crepitans & Gruiformes & Psophiidae & 0,963 & 12,83 & 13,66 & 1,180 \\
\hline YPM 102062 & Tetrax tetrax & Gruiformes & Otididae & 0,780 & 14,5 & 17 & 0,980 \\
\hline MLP 403 & Porphyrula martinica & Gruiformes & Rallidae & 0,825 & 15 & 12 & 0,875 \\
\hline YPM 102538 & Grus canadensis & Gruiformes & Gruidae & 1,420 & 10,7 & 12,5 & 1,700 \\
\hline
\end{tabular}




\begin{tabular}{|c|c|c|c|c|c|c|c|}
\hline MACN 63320 & Aramus guarauna & Gruiformes & Aramidae & 1,542 & 8 & 6 & 1,512 \\
\hline MLP 178 & Xiphocolaptes major & Passeriformes & Furnariidae & 0,504 & 13 & 10 & 0,554 \\
\hline MLP 126 & Pseudoseisura lophotes & Passeriformes & Furnariidae & 0,320 & 18 & 10 & 0,536 \\
\hline MLP 777 & Turdus rufiventris & Passeriformes & Turdidae & 0,256 & 14,5 & 11 & 0,492 \\
\hline MLP 141 & Pitangus sulphuratus & Passeriformes & Tyraniidae & 0,226 & 8 & 15,5 & 0,411 \\
\hline MLP 476 & Phalacrocorax albiventer & Pelecaniformes & Phalacrocoracidae & 0,846 & 16 & 16 & 1,528 \\
\hline MLP 482 & Sula leucogaster & Pelecaniformes & Sulidae & 0,732 & 15 & 17,5 & 1,136 \\
\hline MLP 564 & Phoenicopterus chilensis & Phoenicopteriformes & Phoenicopteridae & 1,354 & 5 & 5 & 1,846 \\
\hline MLP 314 & Ramphastos vitellinus & Piciformes & Ramphastidae & 0,683 & 9 & 12 & 0,880 \\
\hline MLP 330 & Monasa nigrifrons & Piciformes & Bucconidae & 0,215 & 8,5 & 18 & 0,436 \\
\hline MLP 522 & Podiceps major & Podicipediformes & Podicipedidae & 0,834 & 7 & 9 & 1,384 \\
\hline MLP 488 & Pagodroma nivea & Procellariiformes & Procellariidae & 0,350 & 9 & 7,5 & 0,540 \\
\hline MLP 812 & Macronectes giganteus & Procellariiformes & Procellariidae & 1,507 & 12 & 8,5 & 1,851 \\
\hline MLP 65 & Cyanoliseus patagonus & Psittaciformes & Psittacidae & 0,274 & 25 & 20 & 0,507 \\
\hline MLP 469 & Pygoscelis adeliae & Sphenisciformes & Spheniscidae & 0,852 & 34 & 30 & 1,111 \\
\hline MLP 53 & Tyto alba & Strigiformes & Tytonidae & 0,588 & 9 & 10 & 0,966 \\
\hline MLP 401 & Bubo virginianus & Strigiformes & Strigidae & 0,616 & 8 & 15 & 1,108 \\
\hline MLP 685 & Dromaius novahollandie & Struthioniformes & Casuariidae & 7,616 & 11 & 12,5 & 3,972 \\
\hline MLP 878 & Rhea americana & Struthioniformes & Rheidae & 2,256 & 8,5 & 10 & 4,379 \\
\hline $\begin{array}{l}\text { MLP 86-VI-15- } \\
1\end{array}$ & Emeus crassus & Struthioniformes & Dinornithidae & 3,424 & 23,5 & 25 & 5,454 \\
\hline Prom. MLP & Pterocnemia pennata & Struthionifromes & Rheidae & 2,995 & 11,25 & 13 & 3,821 \\
\hline MLP 327 & Eudromia elegans & Tinamiformes & Tinamidae & 0,558 & 15 & 15 & 0,852 \\
\hline
\end{tabular}


Tabla 9.8. Matriz de medidas del tarsometatarso (cm.) tomadas en los Phorusrhacidae disponibles. Las medidas angulares AL y AM se expresan en grados.

\begin{tabular}{|c|c|c|c|c|c|c|c|c|c|}
\hline Catálogo & Especie & $\mathrm{AA}$ & $\mathrm{AB}$ & $\mathrm{AC}$ & $\mathrm{AD}$ & $\mathrm{AE}$ & $\mathrm{AF}$ & $\mathrm{AG}$ & $\mathrm{AH}$ \\
\hline MACN A 11030-68 & cf. Psilopterus lemoinei & & & & & & & & \\
\hline MNHN-M-189 & Devincenzia pozzi & 40,980 & & 39,380 & & & 5,380 & & 5,310 \\
\hline MACN Pv 6554 & Devincenzia pozzi & & & & & & & & \\
\hline BAR 3877-11 & Kelenken guillermoi & 48,520 & 45,140 & 46,480 & 10,850 & 9,900 & 5,900 & 5,170 & 5,700 \\
\hline FM-P14422 & Mesembriornis incertus & 30,976 & 30,464 & & 4,454 & & 1,818 & 2,552 & 1,816 \\
\hline MACN Pv 6737 & Mesembriornis incertus & & & & & 3,896 & & & 1,616 \\
\hline MMP 155-5 & Mesembriornis milneedwardsi & & & 36,900 & 6,054 & & 2,656 & 2,772 & 2,554 \\
\hline MLP 20-87 & Mesembriornis milneedwardsi & & & & & & & & 2,014 \\
\hline MACN Pv 5944 & Mesembriornis milneedwardsi & 36,132 & & 34,992 & 5,918 & & 2,522 & 2,878 & 2,502 \\
\hline MACN Pv 19170 & Paleopsilopterus itaboraiensis & & & & 2,818 & & & & \\
\hline MLP DGN1418R & Paraphysornis brasiliensis & 30,002 & 28,912 & 28,918 & 9,274 & 9,732 & 5,352 & 2,992 & 5,306 \\
\hline AMNH 9264 & Patagornis marshi & 27,188 & 26,178 & 26,552 & 4,158 & 3,994 & 1,976 & 1,784 & 1,976 \\
\hline MLP 84-III-9-21 & Patagornis marshi & & & & & 3,848 & 2,040 & 2,009 & 1,988 \\
\hline BMNH - A56 & Patagornis marshi & & & & 4,460 & 4,380 & & & \\
\hline MLP 76-V-10-11 & Phorusrhacos longissimus & 39,866 & 39,086 & 38,622 & 8,368 & 8,062 & 3,852 & 2,686 & 3,632 \\
\hline AMNH 9146 & Phorusrhacos longissimus & & & & & & 3,636 & 3,202 & 3,182 \\
\hline MLP 68-I-16-1 & Phorusrhacos longissimus & & & & & 6,358 & & & \\
\hline MLP 20-121 & Phorusrhacos longissimus & & & & 9,570 & & & & \\
\hline MLP 20-120 & Phorusrhacos longissimus & & & & 8,883 & & & & \\
\hline MLP 20-131 & Phorusrhacos longissimus & & & & & & 3,404 & 3,478 & 3,404 \\
\hline MACN Pv 18602 & Phorusrhacos sp. & & & & & 5,032 & & & \\
\hline MACN A 52-185 & Physornis fortis & & & & 10,520 & & & & \\
\hline FM-P14525 & Procariama simplex & 21,577 & 20,902 & 21,043 & 3,022 & 2,748 & 1,238 & 1,378 & 1,290 \\
\hline
\end{tabular}




\begin{tabular}{|c|c|c|c|c|c|c|c|c|c|}
\hline & & & & & & & & & \\
\hline MACN Pv 8225 & Procariama simplex & & & & 2,984 & 2,586 & & & \\
\hline MACN Pv 6939 & Procariama simplex & & & & 2,786 & 2,559 & & & \\
\hline MMP 990 & Procariama simplex & & & & & 3,322 & & & 1,372 \\
\hline MACN Pv 12184 & Psilopterus affinis & & & & 2,094 & 2,194 & 0,954 & 0,976 & \\
\hline YPM-PU15904 & Psilopterus bachmanni & 14,784 & 14,235 & 14,362 & & 2,013 & 0,934 & 1,016 & 0,902 \\
\hline AMNH 9154 & Psilopterus bachmanni & & & & 1,866 & & & & \\
\hline MLP 20-187 & Psilopterus bachmanni & & & & & & & & \\
\hline MLP 20-567 & Psilopterus bachmanni & & & & 2,003 & & & & \\
\hline MLP 20-168 & Psilopterus bachmanni & & & & 2,046 & & & & \\
\hline MPM-PV4243 & Psilopterus bachmanni & & & & & & & & \\
\hline MLP 76-VI-12-2 & Psilopterus colzecus & & & & & 2,620 & 1,088 & 1,295 & 1,078 \\
\hline MPM-PV3650 & Psilopterus lemoinei & 18,422 & 17,818 & 17,962 & 2,814 & 2,694 & 1,222 & 1,272 & 1,222 \\
\hline PA-5 & Psilopterus lemoinei & & & & & 2,704 & & & \\
\hline PA-6 & Psilopterus lemoinei & & & & 2,252 & & & & \\
\hline PA-7 & Psilopterus lemoinei & & & & 2,452 & & & & \\
\hline PA-8 & Psilopterus lemoinei & 17,282 & 16,766 & 16,966 & 2,378 & 2,184 & 1,030 & 1,188 & 1,030 \\
\hline FM-P13260 & Psilopterus lemoinei & & & & & 2,708 & & & \\
\hline YPM-PU15477 & Psilopterus lemoinei & & & & 2,782 & & & & \\
\hline YPM-PU15479 & Psilopterus lemoinei & & & & & & 1,306 & 1,368 & 1,306 \\
\hline YPM-PU15402 & Psilopterus lemoinei & & & & & 2,376 & 1,064 & 1,120 & 1,042 \\
\hline AMNH 7008 & Psilopterus lemoinei & & & & & 2,614 & & & \\
\hline AMNH 9257 & Psilopterus lemoinei & 17,858 & 17,214 & 17,426 & 2,616 & 2,574 & 1,198 & 1,234 & 1,134 \\
\hline AMNH 9157 & Psilopterus lemoinei & 18,006 & & 17,712 & 2,444 & & & & \\
\hline MLP 20-188 & Psilopterus lemoinei & & & & & & & & \\
\hline MMP 5050 & Taxón nuevo A & 29,434 & 28,571 & 28,941 & 3,982 & 3,406 & 1,529 & 1,922 & 1,477 \\
\hline
\end{tabular}




\begin{tabular}{|c|c|c|c|c|c|c|c|}
\hline Catálogo & Especie & $\mathrm{AI}$ & AJ & $\mathrm{AK}$ & $\mathrm{AL}$ & $\mathrm{AM}$ & AN \\
\hline MACN A 11030-68 & cf. Psilopterus lemoinei & & & & & & \\
\hline MNHN-M-189 & Devincenzia pozzi & & & & & 15 & \\
\hline MACN Pv 6554 & Devincenzia pozzi & & & & & & \\
\hline BAR 3877-11 & Kelenken guillermoi & 4,760 & & & 14,3 & 12,2 & \\
\hline FM-P14422 & Mesembriornis incertus & 1,702 & & 2,754 & 13 & & 3,538 \\
\hline MACN Pv 6737 & Mesembriornis incertus & 2,192 & & & 8 & 9 & \\
\hline MMP 155-5 & Mesembriornis milneedwardsi & 2,658 & & & & 11 & \\
\hline MLP 20-87 & Mesembriornis milneedwardsi & & & & 12 & & \\
\hline MACN Pv 5944 & Mesembriornis milneedwardsi & 2,698 & 3,236 & 3,244 & & 8 & 4,568 \\
\hline MACN Pv 19170 & Paleopsilopterus itaboraiensis & & & & & & \\
\hline MLP DGN1418R & Paraphysornis brasiliensis & 2,618 & 4,886 & 4,826 & 16 & 17 & 6,128 \\
\hline AMNH 9264 & Patagornis marshi & 1,784 & 2,178 & 2,230 & 7 & 7,5 & 3,552 \\
\hline MLP 84-III-9-21 & Patagornis marshi & 1,840 & & & & & \\
\hline BMNH - A56 & Patagornis marshi & & 2,470 & 2,670 & & & \\
\hline MLP 76-V-10-11 & Phorusrhacos longissimus & 2,482 & & 4,932 & 13 & 12,5 & \\
\hline AMNH 9146 & Phorusrhacos longissimus & 3,022 & & & & 13 & \\
\hline MLP 68-I-16-1 & Phorusrhacos longissimus & & & & & & \\
\hline MLP 20-121 & Phorusrhacos longissimus & & 4,347 & 5,037 & & & 5,800 \\
\hline MLP 20-120 & Phorusrhacos longissimus & & 3,850 & 5,181 & & & \\
\hline MLP 20-131 & Phorusrhacos longissimus & 3,478 & & & & & \\
\hline MACN Pv 18602 & Phorusrhacos sp. & & & & & & \\
\hline MACN A 52-185 & Physornis fortis & & 4,922 & 4,816 & & & 6,492 \\
\hline FM-P14525 & Procariama simplex & 1,324 & 1,582 & 1,564 & 7,75 & 7,25 & 2,402 \\
\hline MACN Pv 8225 & Procariama simplex & & & 1,367 & & & \\
\hline
\end{tabular}




\begin{tabular}{|c|c|c|c|c|c|c|c|}
\hline MACN Pv 6939 & Procariama simplex & & & & & & \\
\hline MMP 990 & Procariama simplex & 1,412 & & & 7 & 9 & \\
\hline MACN Pv 12184 & Psilopterus affinis & & & 1,156 & & & 1,762 \\
\hline YPM-PU15904 & Psilopterus bachmanni & 0,997 & 1,252 & 1,044 & 6,75 & 7,25 & 1,668 \\
\hline AMNH 9154 & Psilopterus bachmanni & & 1,112 & 1,042 & & & 1,572 \\
\hline MLP 20-187 & Psilopterus bachmanni & & & & & & \\
\hline MLP 20-567 & Psilopterus bachmanni & & 1,144 & 1,044 & & & 1,635 \\
\hline MLP 20-168 & Psilopterus bachmanni & & & & & & \\
\hline MPM-PV4243 & Psilopterus bachmanni & & 1,260 & 1,344 & & & \\
\hline MLP 76-VI-12-2 & Psilopterus colzecus & 1,147 & & & & & \\
\hline MPM-PV3650 & Psilopterus lemoinei & 1,112 & 1,618 & 1,646 & 8 & 9 & 2,140 \\
\hline PA-5 & Psilopterus lemoinei & & & & & & \\
\hline PA-6 & Psilopterus lemoinei & & 1,304 & 0,946 & & & 1,758 \\
\hline PA-7 & Psilopterus lemoinei & & 1,300 & 1,332 & & & 1,936 \\
\hline PA-8 & Psilopterus lemoinei & 1,000 & 1,210 & 1,342 & 9 & 7 & 1,882 \\
\hline FM-P13260 & Psilopterus lemoinei & & & & & & \\
\hline YPM-PU15477 & Psilopterus lemoinei & & & 1,588 & & & 2,116 \\
\hline YPM-PU15479 & Psilopterus lemoinei & 1,368 & & & & 6,5 & \\
\hline YPM-PU15402 & Psilopterus lemoinei & 1,066 & & & 10 & 7 & \\
\hline AMNH 7008 & Psilopterus lemoinei & & & & & & \\
\hline AMNH 9257 & Psilopterus lemoinei & 1,068 & 1,608 & 1,324 & 9 & 8 & 2,022 \\
\hline AMNH 9157 & Psilopterus lemoinei & & 1,204 & 1,138 & & & 1,638 \\
\hline MLP 20-188 & Psilopterus lemoinei & & & & & & \\
\hline MMP 5050 & Taxón nuevo A & 1,499 & 1,916 & 1,961 & 7,5 & 8,5 & 3,063 \\
\hline
\end{tabular}


Tabla 9.9. Individuos promedio para cada especie de fororraco en base a las medidas del tarsometatarso (cm.). Las medidas angulares AL y AM se expresan en grados.

\begin{tabular}{lccccccccccc}
\hline Especie & AA & AB & AC & AD & AE & AF & AG & AH & AI & AJ & AK \\
\hline $\begin{array}{l}\text { Andalgalornis steulleti } \\
\text { Andrewsornis abbotti }\end{array}$ & & & & & & & & & & \\
Devincenzia pozzi & 40,980 & & 39,380 & & & 5,380 & & 5,310 & \\
Kelenken guillermoi & 48,520 & 45,140 & 46,480 & 10,850 & 9,900 & 5,900 & 5,170 & 5,700 & 4,760 & \\
Mesembriornis incertus & 30,976 & 30,464 & & 4,454 & 3,896 & 1,818 & 2,552 & 1,716 & 1,947 & \\
Mesembriornis milneedwardsi & 36,132 & & 35,946 & 5,986 & & 2,589 & 2,825 & 2,357 & 2,678 & 3,236 & 3,244 \\
Paraphysornis brasiliensis & 30,002 & 28,912 & 28,918 & 9,274 & 9,732 & 5,352 & 2,992 & 5,306 & 2,618 & 4,886 & 4,826 \\
Patagornis marshi & 27,188 & 26,178 & 26,552 & 4,309 & 4,074 & 2,008 & 1,897 & 1,982 & 1,812 & 2,324 & 2,450 \\
Phorusrhacos longissimus & 39,866 & 39,086 & 38,622 & 8,940 & 6,484 & 3,631 & 3,122 & 3,406 & 2,994 & 4,099 & 5,050 \\
Physornis fortis & & & & 10,520 & & & & & & 4,922 & 4,816 \\
Procariama simplex & 21,577 & 20,902 & 21,043 & 2,931 & 2,804 & 1,238 & 1,378 & 1,331 & 1,368 & 1,582 & 1,466 \\
Psilopterus affinis & & & & 2,094 & 2,194 & 0,954 & 0,976 & & & & 1,156 \\
Psilopterus bachmanni & 14,784 & 14,235 & 14,362 & 1,972 & 2,013 & 0,934 & 1,016 & 0,902 & 0,997 & 1,192 & 1,119 \\
Psilopterus colzecus & & & & & 2,620 & 1,088 & 1,295 & 1,078 & 1,147 & \\
Psilopterus lemoinei & 17,892 & 17,266 & 17,517 & 2,534 & 2,551 & 1,164 & 1,236 & 1,147 & 1,123 & 1,374 & 1,331 \\
Taxón nuevo A & 29,434 & 28,571 & 28,941 & 3,982 & 3,406 & 1,529 & 1,922 & 1,477 & 1,499 & 1,916 & 1,961 \\
\hline \hline
\end{tabular}




\begin{tabular}{|c|c|c|c|}
\hline Especie & $\mathrm{AL}$ & $\mathrm{AM}$ & AN \\
\hline \multicolumn{4}{|l|}{ Andalgalornis steulleti } \\
\hline \multicolumn{4}{|l|}{ Andrewsornis abbotti } \\
\hline Devincenzia pozzi & & 15 & \\
\hline Kelenken guillermoi & 14,3 & 12,2 & \\
\hline Mesembriornis incertus & 10,5 & 9 & 3,538 \\
\hline Mesembriornis milneedwardsi & 12 & 9,5 & 4,568 \\
\hline Paraphysornis brasiliensis & 16 & 17 & 6,128 \\
\hline Patagornis marshi & 7 & 7,5 & 3,552 \\
\hline Phorusrhacos longissimus & 13 & 12,75 & 5,800 \\
\hline \multicolumn{4}{|l|}{ Physornis fortis } \\
\hline Procariama simplex & 7,375 & 8,125 & 2,402 \\
\hline \multicolumn{4}{|l|}{ Psilopterus affinis } \\
\hline Psilopterus bachmanni & 6,75 & 7,25 & 1,625 \\
\hline \multicolumn{4}{|l|}{ Psilopterus colzecus } \\
\hline Psilopterus lemoinei & 9 & 7,5 & 1,927 \\
\hline Taxón nuevo A & 7,5 & 8,5 & 3,063 \\
\hline
\end{tabular}


Tabla 9.10. Análisis de componentes principales para el conjunto de aves actuales y fororracos analizados mediante el fémur.

\begin{tabular}{lccc}
\hline \hline Componente & Eigenvalue & Varianza $\%$ & Var. acumulada \\
\hline 1 & 0,841961 & 98,48884 & 98,4888 \\
2 & 0,005015 & 0,58660 & 99,0754 \\
3 & 0,003353 & 0,39217 & 99,4676 \\
4 & 0,001421 & 0,16627 & 99,6339 \\
5 & 0,001130 & 0,13220 & 99,7661 \\
6 & 0,000969 & 0,11333 & 99,8794 \\
7 & 0,000653 & 0,07635 & 99,9558 \\
8 & 0,000342 & 0,04005 & 99,9958 \\
9 & 0,000036 & 0,00417 & 100,0000 \\
\hline \hline
\end{tabular}


Tabla 9.11. Análisis de componentes principales para el conjunto de aves actuales y fororracos analizados mediante el tibiotarso.

\begin{tabular}{lccc}
\hline Componente & Eigenvalue & Varianza\% & Var. acumulada \\
\hline 1 & 0,856116 & 97,08505 & 97,0851 \\
2 & 0,011359 & 1,28818 & 98,3732 \\
3 & 0,006753 & 0,76577 & 99,1390 \\
4 & 0,002727 & 0,30929 & 99,4483 \\
5 & 0,001555 & 0,17639 & 99,6247 \\
6 & 0,001415 & 0,16044 & 99,7851 \\
7 & 0,000785 & 0,08898 & 99,8741 \\
8 & 0,000660 & 0,07487 & 99,9490 \\
9 & 0,000343 & 0,03885 & 99,9878 \\
10 & 0,000107 & 0,01216 & 100,0000 \\
\hline \hline
\end{tabular}


Tabla 9.12. Análisis de componentes principales para el conjunto de aves actuales y fororracos analizados mediante el tarsometatarso.

\begin{tabular}{lccc}
\hline Componente & Eigenvalue & Varianza\% & Var. acumulada \\
\hline 1 & 1,264172 & 88,01315 & 88,0131 \\
2 & 0,112203 & 7,81172 & 95,8249 \\
3 & 0,018022 & 1,25472 & 97,0796 \\
4 & 0,015659 & 1,09017 & 98,1698 \\
5 & 0,008243 & 0,57389 & 98,7436 \\
6 & 0,006048 & 0,42109 & 99,1647 \\
7 & 0,005284 & 0,36788 & 99,5326 \\
8 & 0,002435 & 0,16953 & 99,7021 \\
9 & 0,001986 & 0,13827 & 99,8404 \\
10 & 0,001412 & 0,09832 & 99,9387 \\
11 & 0,000516 & 0,03594 & 99,9747 \\
12 & 0,000241 & 0,01677 & 99,9914 \\
13 & 0,000100 & 0,00696 & 99,9984 \\
14 & 0,000023 & 0,00161 & 100,0000 \\
\hline \hline
\end{tabular}


Tabla 9.13. Análisis de componentes principales para el conjunto de aves actuales y fororracos analizados mediante el miembro posterior completo.

\begin{tabular}{lccc}
\hline \hline Componente & Eigenvalue & Varianza $\%$ & Var. acumulada \\
\hline 1 & 2,681229 & 92,44654 & 92,4465 \\
2 & 0,118536 & 4,08701 & 96,5336 \\
3 & 0,019340 & 0,66684 & 97,2004 \\
4 & 0,017614 & 0,60732 & 97,8077 \\
5 & 0,012625 & 0,43531 & 98,2430 \\
6 & 0,009775 & 0,33702 & 98,5800 \\
7 & 0,008023 & 0,27662 & 98,8567 \\
8 & 0,005883 & 0,20284 & 99,0595 \\
9 & 0,004040 & 0,13928 & 99,1988 \\
10 & 0,003687 & 0,12713 & 99,3259 \\
11 & 0,003185 & 0,10981 & 99,4357 \\
12 & 0,002866 & 0,09882 & 99,5346 \\
13 & 0,002425 & 0,08361 & 99,6182 \\
14 & 0,001888 & 0,06509 & 99,6833 \\
15 & 0,001472 & 0,05074 & 99,7340 \\
16 & 0,001201 & 0,04141 & 99,7754 \\
17 & 0,001124 & 0,03877 & 99,8142 \\
18 & 0,000959 & 0,03305 & 99,8472 \\
19 & 0,000882 & 0,03041 & 99,8776 \\
20 & 0,000793 & 0,02734 & 99,9050 \\
21 & 0,000651 & 0,02243 & 99,9274 \\
22 & 0,000470 & 0,01619 & 99,9436 \\
23 & 0,000331 & 0,01141 & 99,9550 \\
24 & 0,000281 & 0,00969 & 99,9647 \\
25 & 0,000259 & 0,00892 & 99,9736 \\
26 & 0,000216 & 0,00745 & 99,9811 \\
27 & 0,000193 & 0,00665 & 99,9877 \\
28 & 0,000168 & 0,00578 & 99,9935 \\
29 & 0,000101 & 0,00350 & 99,9970 \\
30 & 0,000035 & 0,00122 & 99,9982 \\
31 & 0,000024 & 0,00083 & 99,9990 \\
32 & 0,000020 & 0,00069 & 99,9997 \\
33 & 0,000008 & 0,00026 & 100,0000 \\
\hline \hline & & & \\
\hline
\end{tabular}


Tabla 9.14. Análisis de componentes principales para el conjunto de aves actuales y fororracos analizados mediante los índices del miembro posterior.

\begin{tabular}{lccc}
\hline \hline Componente & Eigenvalue & Varianza $\%$ & Var. acumulada \\
\hline 1 & 0,530733 & 51,21692 & 51,2169 \\
2 & 0,128818 & 12,43124 & 63,6482 \\
3 & 0,099694 & 9,62069 & 73,2689 \\
4 & 0,064833 & 6,25655 & 79,5254 \\
5 & 0,053793 & 5,19118 & 84,7166 \\
6 & 0,042441 & 4,09563 & 88,8122 \\
7 & 0,022671 & 2,18782 & 91,0000 \\
8 & 0,018054 & 1,74221 & 92,7423 \\
9 & 0,015812 & 1,52589 & 94,2681 \\
10 & 0,014059 & 1,35676 & 95,6249 \\
11 & 0,011456 & 1,10550 & 96,7304 \\
12 & 0,010018 & 0,96679 & 97,6972 \\
13 & 0,007404 & 0,71451 & 98,4117 \\
14 & 0,006175 & 0,59589 & 99,0076 \\
15 & 0,003212 & 0,30992 & 99,3175 \\
16 & 0,002801 & 0,27027 & 99,5878 \\
17 & 0,002382 & 0,22990 & 99,8177 \\
18 & 0,000816 & 0,07875 & 99,8964 \\
19 & 0,000359 & 0,03464 & 99,9311 \\
20 & 0,000321 & 0,03100 & 99,9621 \\
21 & 0,000237 & 0,02290 & 99,9850 \\
22 & 0,000156 & 0,01503 & 100,0000 \\
\hline \hline
\end{tabular}


Tabla 9.15. Análisis de componentes principales del neurocráneo de los fororracos en vista dorsal. Se analizaron 14 individuos (cinco Cariamidae y nueve Phorusrhacidae) mediante 11 landmarks. Se muestran solo los primeros 10 componentes.

\begin{tabular}{lccc}
\hline \hline Componente & Eigenvalue & Varianza $\%$ & Var. acumulada \\
\hline 1 & 0,40207 & 49,70 & 49,70 \\
2 & 0,30607 & 28,80 & 78,49 \\
3 & 0,16412 & 8,28 & 86,77 \\
4 & 0,12644 & 4,92 & 91,69 \\
5 & 0,09468 & 2,76 & 94,45 \\
6 & 0,08258 & 2,10 & 96,54 \\
7 & 0,07418 & 1,69 & 98,23 \\
8 & 0,04599 & $0,65 \%$ & 98,88 \\
9 & 0,0377 & 0,44 & 99,32 \\
10 & 0,0304 & 0,28 & 99,60 \\
\hline \hline
\end{tabular}


Tabla 9.16. Análisis de componentes principales del neurocráneo de los fororracos en vista lateral. Se incluyeron 12 individuos (cinco Cariamidae y siete Phorusrhacidae), analizados mediante 10 landmarks.

\begin{tabular}{lccc}
\hline Componente & Eigenvalue & Varianza $\%$ & Var. acumulada \\
\hline 1 & 0,44618 & 72,16 & 72,16 \\
2 & 0,17573 & 11,19 & 83,35 \\
3 & 0,11224 & 4,57 & 87,92 \\
4 & 0,10264 & 3,82 & $91,74 \%$ \\
5 & 0,09132 & 3,02 & 94,7 \\
6 & 0,06877 & 1,71 & 96,48 \\
7 & 0,06200 & 1,39 & 97,87 \\
8 & 0,05369 & 1,04 & 98,92 \\
9 & 0,03957 & 0,57 & 99,48 \\
10 & 0,03551 & 0,46 & 99,94 \\
\hline \hline
\end{tabular}


Tabla 9.17. Análisis de componentes principales del cráneo de las aves en vista dorsal. Se utilizaron 77 individuos (cinco fororracos) aplicando 12 landmarks y 9 semilandmarks. Se muestran solo los primeros 10 componentes.

\begin{tabular}{lccc}
\hline \hline Componente & Eigenvalue & Varianza & Var. acumulada \\
\hline 1 & 1,45520 & 72,49 & 72,49 \\
2 & 0,56272 & 10,84 & 83,33 \\
3 & 0,34388 & 4,05 & 87,38 \\
4 & 0,27555 & 2,60 & 89,98 \\
5 & 0,24607 & 2,07 & 92,05 \\
6 & 0,22249 & 1,69 & 93,74 \\
7 & 0,20455 & 1,43 & 95,17 \\
8 & 0,18173 & 1,13 & 96,31 \\
9 & 0,15871 & 0,86 & 97,17 \\
10 & 0,15045 & 0,77 & 97,94 \\
\hline \hline
\end{tabular}


Tabla 9.18. Análisis de componentes principales del cráneo de las aves en vista lateral. Se analizaron 74 individuos (dos fororracos) mediante 16 landmarks y 21 semilandmarks. Se muestran solo los primeros 10 componentes.

\begin{tabular}{lccc}
\hline \hline Componente & Eigenvalue & Varianza & Var. acumulada \\
\hline 1 & 1,60523 & 64,94 & 64,94 \\
2 & 0,72458 & 13,23 & 78,17 \\
3 & 0,48757 & 5,99 & 84,16 \\
4 & 0,37779 & 3,60 & 87,76 \\
5 & 0,31413 & 2,49 & 90,25 \\
6 & 0,26015 & 1,71 & 91,95 \\
7 & 0,24167 & 1,47 & 93,42 \\
8 & 0,2052 & 1,06 & 94,49 \\
9 & 0,18783 & 0,89 & 95,37 \\
10 & 0,16294 & 0,67 & 96,04 \\
10 & 0,16294 & 0,67 & 96,04 \\
\hline \hline
\end{tabular}


Tabla 9.19. Análisis de componentes principales del cráneo de las aves carnívoras en vista lateral. Se analizaron 26 individuos (dos fororracos) mediante 16 landmarks y 21 semilandmarks. Se muestran solo los primeros 10 componentes.

\begin{tabular}{lccc}
\hline \hline Componente & Eigenvalue & Varianza & Var. acumulada \\
\hline 1 & 0,77461 & 61,34 & 61,34 \\
2 & 0,39782 & 16,18 & 77,52 \\
3 & 0,26062 & 6,94 & 84,47 \\
4 & 0,20672 & 4,37 & 88,84 \\
5 & 0,18115 & 3,36 & 92,19 \\
6 & 0,1334 & 1,82 & 94,01 \\
7 & 0,12296 & 1,55 & 95,56 \\
8 & 0,10749 & 1,18 & 96,74 \\
9 & 0,08606 & 0,76 & 97,50 \\
10 & 0,08163 & 0,68 & 98,18 \\
\hline \hline
\end{tabular}


Tabla 9.20. Análisis de componentes principales del cráneo del esplacnocráneo en vista lateral. Se analizaron 74 individuos (dos fororracos) mediante 9 landmarks y 21 semilandmarks. Se muestran solo los primeros 10 componentes.

\begin{tabular}{lccc}
\hline \hline Componente & Eigenvalue & Varianza & Var. acumulada \\
\hline 1 & 0,03290537 & 56,527 & 56,527 \\
2 & 0,01252514 & 21,516 & 78,043 \\
3 & 0,00359155 & 6,170 & 84,213 \\
4 & 0,00224456 & 3,856 & 88,069 \\
5 & 0,00180697 & 3,104 & 91,173 \\
6 & 0,00137898 & 2,369 & 93,542 \\
7 & 0,00089034 & 1,529 & 95,071 \\
8 & 0,00076487 & 1,314 & 96,385 \\
9 & 0,00053099 & 0,912 & 97,297 \\
10 & 0,00043812 & 0,753 & 98,05 \\
\hline \hline
\end{tabular}


Tabla 9.21. Análisis de componentes principales del cráneo del pico en vista lateral. Se incluyeron 74 individuos (dos fororracos), analizados mediante 8 landmarks y 18 semilandmarks. Se muestran solo los primeros 10 componentes.

\begin{tabular}{lccc}
\hline Componente & Eigenvalue & Varianza & Var. acumulada \\
\hline 1 & 0,03044379 & 51,385 & 51,385 \\
2 & 0,01485722 & 25,077 & 76,462 \\
3 & 0,00412814 & 6,968 & 83,43 \\
4 & 0,00313870 & 5,298 & 88,727 \\
5 & 0,00187541 & 3,165 & 91,893 \\
6 & 0,00127480 & 2,152 & 94,045 \\
7 & 0,00110902 & 1,872 & 95,916 \\
8 & 0,00054074 & 0,913 & 96,829 \\
9 & 0,00036453 & 0,615 & 97,444 \\
10 & 0,00034432 & 0,581 & 98,026 \\
\hline \hline
\end{tabular}


Tabla 9.22. Análisis de componentes principales de la pelvis en vista dorsal. Se analizaron 69 individuos (cinco fororracos) mediante 9 landmarks. Se muestran solo los primeros 10 componentes.

\begin{tabular}{lccc}
\hline Componente & Eigenvalue & Varianza & Var. acumulada \\
\hline 1 & 1,23315 & 65,98 & 65,98 \\
2 & 0,57298 & 14,24 & 80,22 \\
3 & 0,38892 & 6,56 & 86,78 \\
4 & 0,32193 & 4,50 & 91,28 \\
5 & 0,2876 & 3,59 & 94,87 \\
6 & 0,18711 & 1,52 & 96,39 \\
7 & 0,16165 & 1,13 & 97,52 \\
8 & 0,14708 & 0,94 & 98,46 \\
9 & 0,12821 & 0,71 & 99,17 \\
10 & 0,09126 & 0,36 & 99,54 \\
\hline \hline
\end{tabular}


Tabla 9.23. Análisis de componentes principales de la pelvis en vista lateral. Se incluyeron 69 individuos (cinco fororracos) analizados mediante 13 landmarks y 18 semilandmarks. Se muestran solo los primeros 10 componentes.

\begin{tabular}{lccc}
\hline \hline Componente & Eigenvalue & Varianza & Var. acumulada \\
\hline 1 & 0,80533 & 41,83 & 41,83 \\
2 & 0,55563 & 19,91 & 61,74 \\
3 & 0,39779 & 10,20 & 71,94 \\
4 & 0,3277 & 6,93 & 78,87 \\
5 & 0,297 & 5,69 & 84,56 \\
6 & 0,22792 & 3,35 & 87,91 \\
7 & 0,1913 & 2,36 & 90,27 \\
8 & 0,18025 & 2,10 & 92,36 \\
9 & 0,14756 & 1,40 & 93,77 \\
10 & 0,12529 & 1,01 & 94,78 \\
\hline \hline
\end{tabular}


Tabla 10.1. Medidas del miembro anterior $(\mathrm{cm})$, proporciones e índice braquial $(\mathrm{BI}=$ longitud del húmero/longitud de la ulna) de las especies seleccionadas para su comparación con Psilopterus lemoinei. $\mathrm{Cmc}=$ carpometacarpo.

\begin{tabular}{lccccccccc}
\hline \hline \multicolumn{1}{c}{ Species } & Húmero & Ulna & Cmc & $\begin{array}{c}\text { Long. } \\
\text { total }\end{array}$ & \%húmero & \%ulna & $\% \mathrm{cmc}$ & BI \\
\hline Aramus guarauna & 11,56 & 12,16 & 6,50 & 30,22 & 38,24 & 40,24 & 21,51 & 0,95 \\
Ardea cocoi & 19,17 & 22,27 & 9,57 & 51,01 & 37,57 & 43,66 & 18,77 & 0,86 \\
Cariama cristata & 10,62 & 10,00 & 4,90 & 25,52 & 41,60 & 39,18 & 19,22 & 1,06 \\
Chunga burmeisteri & 7,83 & 7,41 & 4,05 & 19,29 & 40,58 & 38,44 & 20,98 & 1,06 \\
Fratercula corniculata & 6,79 & 5,57 & 3,68 & 16,03 & 42,34 & 34,72 & 22,94 & 1,22 \\
Geranoaetus melanoleucus & 15,95 & 18,11 & 8,91 & 42,97 & 37,11 & 42,15 & 20,74 & 0,88 \\
Otis tarda* & 17,30 & 18,70 & 8,60 & 44,60 & 38,79 & 41,93 & 19,28 & 0,93 \\
Penelope purpurascens & 9,57 & 10,27 & 5,23 & 25,06 & 38,17 & 40,97 & 20,85 & 0,93 \\
Phoenicopterus chilensis & 19,66 & 20,91 & 9,09 & 49,66 & 39,59 & 42,11 & 18,31 & 0,94 \\
Pitangus sulphuratus & 2,91 & 3,54 & 1,80 & 8,25 & 35,31 & 42,85 & 21,83 & 0,82 \\
Psilopterus lemoinei & 10,80 & 8,08 & 4,80 & 23,68 & 45,61 & 34,12 & 20,27 & 1,34 \\
Psophia crepitans & 8,13 & 8,07 & 3,54 & 19,74 & 41,19 & 40,88 & 17,93 & 1,01 \\
Turdus rufiventris & 3,02 & 3,68 & 2,02 & 8,71 & 34,60 & 42,18 & 23,22 & 0,82 \\
Uria aalge** & 0,87 & 0,63 & -- & -- & -- & -- & -- & 1,38 \\
\hline \hline
\end{tabular}

* Información proporcionada por G. Mayr.

** de Nudds et al. (2006) 
Apendice 5.1. Matriz de 148 caracteres morfológicos para los cuatro Phorusrhacidae y el Anseriformes Brontornis incluidos en este estudio (matriz tomada de Mayr y Clarke, 2003)

\begin{tabular}{lcccccccccccccccccccccccc}
\hline \hline & 1 & 2 & 3 & 4 & 5 & 6 & 7 & 8 & 9 & 10 & 11 & 12 & 13 & 14 & 15 & 16 & 17 & 18 & 19 & 20 & 21 & 22 \\
\hline Psilopterus lemoinei & 1 & 1 & 0 & 0 & 0 & 0 & 0 & 0 & $?$ & 0 & 1 & 1 & 1 & $?$ & 0 & 1 & 0 & $?$ & $?$ & $?$ & $?$ & 1 \\
Patagornis marshi & 1 & 1 & 0 & 0 & 0 & 0 & 0 & 0 & $?$ & $?$ & $?$ & 0 & 1 & $?$ & 0 & 1 & 0 & $?$ & $?$ & $?$ & $?$ & 1 \\
Mesembriornis milneedwardsi & 1 & $?$ & 0 & 0 & $?$ & 0 & 0 & $?$ & $?$ & $?$ & $?$ & $?$ & 1 & $?$ & $?$ & $?$ & 0 & $?$ & $?$ & $?$ & $?$ & 1 \\
Taxón nuevo A & 1 & 1 & 0 & 0 & 0 & 0 & 0 & $?$ & $?$ & 1 & 1 & 1 & 1 & $?$ & 0 & 1 & 0 & 0 & 1 & 1 & 1 & 1 \\
Brontornis burmeisteri & $?$ & $?$ & $?$ & $?$ & $?$ & $?$ & $?$ & $?$ & $?$ & $?$ & $?$ & $?$ & $?$ & $?$ & $?$ & $?$ & $?$ & $?$ & $?$ & $?$ & $?$ & $?$ \\
\hline \hline
\end{tabular}

\begin{tabular}{lccccccccccccccccccccccc}
\hline \hline & 23 & 24 & 25 & 26 & 27 & 28 & 29 & 30 & 31 & 32 & 33 & 34 & 35 & 36 & 37 & 38 & 39 & 40 & 41 & 42 & 43 & 44 \\
\hline Psilopterus lemoinei & 0 & 1 & 0 & 0 & 0 & 0 & 1 & 0 & 0 & 1 & 0 & 1 & 0 & 1 & 0 & 0 & $?$ & 0 & 1 & 1 & 0 & 0 \\
Patagornis marshi & 0 & 1 & 0 & 0 & 0 & 0 & 1 & 1 & 0 & 1 & 0 & 1 & 0 & 1 & 0 & 0 & $?$ & 0 & 1 & 1 & 0 & 0 \\
Mesembriornis milneedwardsi & $?$ & $?$ & $?$ & $?$ & $?$ & $?$ & $?$ & $?$ & $?$ & 1 & 0 & $?$ & $?$ & $?$ & $?$ & $?$ & $?$ & 0 & $?$ & 1 & 0 & $?$ \\
Taxón nuevo A & 0 & 1 & 0 & 0 & 1 & $?$ & $?$ & 1 & $?$ & 1 & 0 & 1 & 0 & 1 & 0 & 0 & $?$ & 0 & 1 & 1 & 0 & 0 \\
Brontornis burmeisteri & $?$ & $?$ & $?$ & $?$ & $?$ & $?$ & $?$ & $?$ & $?$ & $?$ & $?$ & $?$ & $?$ & $?$ & 0 & 1 & $?$ & 0 & $?$ & 1 & 0 & $?$ \\
\hline \hline
\end{tabular}

\begin{tabular}{lccccccccccccccccccccccc}
\hline \hline & 45 & 46 & 47 & 48 & 49 & 50 & 51 & 52 & 53 & 54 & 55 & 56 & 57 & 58 & 59 & 60 & 61 & 62 & 63 & 64 & 65 & 66 \\
\hline Psilopterus lemoinei & 0 & 0 & 0 & 1 & 0 & 1 & 0 & 1 & 1 & 0 & $?$ & 0 & 1 & 0 & 1 & 0 & $?$ & $?$ & $?$ & 0 & 1 & 0 \\
Patagornis marshi & 1 & $?$ & $?$ & $?$ & $?$ & $?$ & $?$ & 1 & $?$ & 0 & $?$ & 0 & 1 & 0 & $?$ & $?$ & $?$ & $?$ & $?$ & 0 & 1 & 0 \\
Mesembriornis milneedwardsi & 0 & 0 & 0 & 1 & 0 & 0 & 0 & 1 & 1 & 0 & 0 & 0 & 1 & 0 & $?$ & $?$ & $?$ & $?$ & $?$ & $?$ & $?$ & $?$ \\
Taxón nuevo A & 0 & 0 & 0 & 1 & 0 & 0 & 0 & 1 & 1 & 0 & 0 & 0 & 1 & 0 & 1 & $?$ & $?$ & 0 & 0 & 0 & 1 & 0 \\
Brontornis burmeisteri & $?$ & $?$ & $?$ & $?$ & $?$ & $?$ & $?$ & $?$ & $?$ & $?$ & $?$ & $?$ & $?$ & $?$ & $?$ & $?$ & $?$ & $?$ & $?$ & $?$ & $?$ & $?$ \\
\hline \hline
\end{tabular}




\begin{tabular}{lcccccccccccccccccccccccccc}
\hline \hline & 67 & 68 & 69 & 70 & 71 & 72 & 73 & 74 & 75 & 76 & 77 & 78 & 79 & 80 & 81 & 82 & 83 & 84 & 85 & 86 & 87 & 88 \\
\hline Psilopterus lemoinei & 0 & 0 & 0 & $?$ & $?$ & $?$ & 2 & 2 & 0 & 0 & 1 & 0 & 1 & 1 & 0 & 0 & 0 & 1 & 1 & 1 & 0 & 0 & \\
Patagornis marshi & 0 & 0 & $?$ & $?$ & $?$ & $?$ & $?$ & 2 & $?$ & $?$ & $?$ & $?$ & 1 & 1 & $?$ & $?$ & 0 & 0 & 1 & 1 & $?$ & $?$ \\
Mesembriornis milneedwardsi & $?$ & $?$ & $?$ & $?$ & $?$ & $?$ & $?$ & $?$ & $?$ & $?$ & $?$ & $?$ & $?$ & $?$ & $?$ & $?$ & $?$ & 1 & $?$ & $?$ & $?$ & $?$ & \\
Taxón nuevo A & 0 & 0 & 0 & 1 & 1 & 0 & 2 & 2 & 0 & 0 & 1 & 0 & 1 & 1 & 0 & 0 & 0 & 1 & $?$ & $?$ & 0 & 0 & \\
Brontornis burmeisteri & $?$ & $?$ & $?$ & $?$ & $?$ & $?$ & $?$ & $?$ & $?$ & $?$ & $?$ & $?$ & $?$ & $?$ & $?$ & $?$ & $?$ & $?$ & $?$ & $?$ & $?$ & $?$ \\
\hline \hline
\end{tabular}

\begin{tabular}{|c|c|c|c|c|c|c|c|c|c|c|c|c|c|c|c|c|c|c|c|c|c|c|}
\hline & 89 & 90 & 91 & 92 & 93 & 94 & 95 & 96 & 97 & 98 & 99 & 100 & 101 & 102 & 103 & 104 & 105 & 106 & 107 & 108 & 109 & 110 \\
\hline Psilc & $?$ & 1 & 2 & 1 & 0 & 1 & 1 & 0 & 0 & 0 & 0 & 1 & 1 & 1 & 0 & 0 & 0 & 0 & 0 & 1 & 0 & 1 \\
\hline Patą & $?$ & 1 & $?$ & 1 & $?$ & 1 & 1 & 1 & 0 & 0 & 0 & 1 & 0 & 1 & 0 & 0 & 0 & 0 & 0 & 1 & 0 & 1 \\
\hline milneedwardsi & 0 & 1 & $?$ & 1 & 0 & $?$ & 1 & 1 & 0 & 0 & 0 & 1 & 1 & 1 & 0 & 0 & 0 & 0 & 0 & 1 & 0 & $?$ \\
\hline Taxón nuevo A & $?$ & 1 & 2 & 1 & $?$ & 1 & 1 & 0 & 0 & 0 & 0 & 1 & 1 & 0 & 0 & 0 & 0 & 0 & 0 & 1 & 0 & 1 \\
\hline Brontornis burmeisteri & $?$ & $?$ & $?$ & $?$ & $?$ & $?$ & $?$ & 1 & $?$ & $?$ & $?$ & 0 & 0 & 1 & 0 & 0 & 0 & 0 & 0 & 0 & 0 & 1 \\
\hline
\end{tabular}

\begin{tabular}{|c|c|c|c|c|c|c|c|c|c|c|c|c|c|c|c|c|c|c|c|c|c|c|}
\hline & $\begin{array}{c}11 \\
1\end{array}$ & $\begin{array}{c}11 \\
2\end{array}$ & $\begin{array}{c}11 \\
3\end{array}$ & $\begin{array}{c}11 \\
4\end{array}$ & $\begin{array}{c}11 \\
5\end{array}$ & $\begin{array}{c}11 \\
6\end{array}$ & $\begin{array}{c}11 \\
7\end{array}$ & $\begin{array}{c}11 \\
8\end{array}$ & $\begin{array}{c}11 \\
9\end{array}$ & $\begin{array}{c}12 \\
0\end{array}$ & $\begin{array}{c}12 \\
1\end{array}$ & $\begin{array}{c}12 \\
2\end{array}$ & $\begin{array}{c}12 \\
3\end{array}$ & $\begin{array}{c}12 \\
4\end{array}$ & $\begin{array}{c}12 \\
5\end{array}$ & $\begin{array}{c}12 \\
6\end{array}$ & $\begin{array}{c}12 \\
7\end{array}$ & $\begin{array}{c}12 \\
8\end{array}$ & $\begin{array}{c}12 \\
9\end{array}$ & $\begin{array}{c}13 \\
0\end{array}$ & $\begin{array}{c}13 \\
1\end{array}$ & $\begin{array}{c}13 \\
2\end{array}$ \\
\hline Psilopterus lemoinei & $?$ & $?$ & 0 & $?$ & $?$ & $?$ & $?$ & $?$ & $?$ & $?$ & $?$ & $?$ & $?$ & $?$ & $?$ & $?$ & $?$ & $?$ & $?$ & $?$ & $?$ & $?$ \\
\hline Patagornis marshi & $?$ & $?$ & 0 & $?$ & $?$ & $?$ & $?$ & $?$ & $?$ & $?$ & $?$ & $?$ & $?$ & $?$ & $?$ & $?$ & $?$ & $?$ & $?$ & $?$ & $?$ & $?$ \\
\hline $\begin{array}{l}\text { Mesembriornis } \\
\text { milneedwardsi }\end{array}$ & $?$ & $?$ & 0 & $?$ & $?$ & $?$ & $?$ & $?$ & $?$ & $?$ & $?$ & $?$ & $?$ & ? & $?$ & $?$ & $?$ & $?$ & $?$ & $?$ & $?$ & $?$ \\
\hline Taxón nuevo A & $?$ & $?$ & 0 & $?$ & $?$ & $?$ & $?$ & $?$ & $?$ & $?$ & $?$ & $?$ & $?$ & $?$ & $?$ & $?$ & $?$ & $?$ & $?$ & $?$ & $?$ & $?$ \\
\hline Brontornis burmeisteri & $?$ & $?$ & $?$ & $?$ & $?$ & $?$ & $?$ & $?$ & $?$ & $?$ & $?$ & $?$ & $?$ & $?$ & $?$ & $?$ & $?$ & $?$ & $?$ & $?$ & $?$ & $?$ \\
\hline
\end{tabular}




\begin{tabular}{lcccccccccccccccc}
\hline \hline & 133 & 134 & 135 & 136 & 137 & 138 & 139 & 140 & 141 & 142 & 143 & 144 & 145 & 146 & 147 & 148 \\
\hline Psilopterus lemoinei & $?$ & $?$ & $?$ & $?$ & $?$ & $?$ & $?$ & $?$ & $?$ & $?$ & $?$ & $?$ & $?$ & $?$ & $?$ & $?$ \\
Patagornis marshi & $?$ & $?$ & $?$ & $?$ & $?$ & $?$ & $?$ & $?$ & $?$ & $?$ & $?$ & $?$ & $?$ & $?$ & $?$ & $?$ \\
Mesembriornis milneedwardsi & $?$ & $?$ & $?$ & $?$ & $?$ & $?$ & $?$ & $?$ & $?$ & $?$ & $?$ & $?$ & $?$ & $?$ & $?$ & $?$ \\
Taxón nuevo A & $?$ & $?$ & $?$ & $?$ & $?$ & $?$ & $?$ & $?$ & $?$ & $?$ & $?$ & $?$ & $?$ & $?$ & $?$ & $?$ \\
Brontornis burmeisteri & $?$ & $?$ & $?$ & $?$ & $?$ & $?$ & $?$ & $?$ & $?$ & $?$ & $?$ & $?$ & $?$ & $?$ & $?$ & $?$ \\
\hline \hline
\end{tabular}


Apéndice 6.1. Datos de masa corporal en kg. y fuerza de mordida en Newtons $(\mathrm{N})$ utilizados para estimar la fuerza de mordida.

\begin{tabular}{|c|c|c|c|c|c|}
\hline Especie & Orden & Familia & $\begin{array}{l}\text { Masa } \\
\text { Corporal } \\
\end{array}$ & $\begin{array}{l}\text { Fuerza de } \\
\text { Mordida }\end{array}$ & Referencia \\
\hline Rhea americana & Rheiformes & Rheidae & 23 & 48,59 & Carril, 2010 \\
\hline Geranoaetus melanoleucus & Falconiformes & Accipitridae & 3,1 & 50 & Degrange et al., 2010 \\
\hline Geranoaetus melanoleucus & Falconiformes & Accipitridae & 2,445 & 33,25 & Carril, 2010 \\
\hline Accipiter cooperii & Falconiformes & Accipitridae & 0,4504 & 3,1 & Sustaita y Hertel, 2010 \\
\hline Accipiter striatus & Falconiformes & Accipitridae & 0,1655 & 1,42 & Sustaita y Hertel, 2010 \\
\hline Falco peregrinus & Falconiformes & Falconidae & 0,7738 & 12,96 & Sustaita y Hertel, 2010 \\
\hline Falco sparverius & Falconiformes & Falconidae & 0,1109 & 3,99 & Sustaita y Hertel, 2010 \\
\hline Falco columbarius & Falconiformes & Falconidae & 0,2147 & 4,74 & Sustaita y Hertel, 2010 \\
\hline Falco mexicanus & Falconiformes & Falconidae & 0,5037 & 13,79 & Sustaita y Hertel, 2010 \\
\hline Sarcoramphus papa & Ciconiformes & Cahartidae & 3,375 & 110 & Carril, 2010 \\
\hline Anser anser & Anseriformes & Anatidae & 3,308 & 50,32 & Carril, 2010 \\
\hline Ramphastos toco & Piciformes & Ramphastidae & 0,618 & 25,14 & Carril, 2010 \\
\hline Cariama cristata & Cariamiformes & Cariamidae & 1,5 & 19,42 & Degrange et al., 2010 \\
\hline Chunga burmeisteri & Cariamiformes & Cariamidae & 1,3 & 19,42 & Degrange et al., 2010 \\
\hline Amadina erythrocephala & Passeriformes & Estrildidae & 0,0227 & 4 & van der Meij y Bout, 2004 \\
\hline Amadina fasciata & Passeriformes & Estrildidae & 0,0185 & 5,2 & van der Meij y Bout, 2004 \\
\hline Chloebia gouldia & Passeriformes & Estrildidae & 0,0152 & 4,1 & van der Meij y Bout, 2004 \\
\hline Erythrura trichroa & Passeriformes & Estrildidae & 0,0131 & 5,3 & van der Meij y Bout, 2004 \\
\hline Estrilda troglodytes & Passeriformes & Estrildidae & 0,0074 & 1,1 & van der Meij y Bout, 2004 \\
\hline Hypargos niveoguttatus & Passeriformes & Estrildidae & 0,0161 & 3,1 & van der Meij y Bout, 2004 \\
\hline Lagonosticta senegala & Passeriformes & Estrildidae & 0,0069 & 1,2 & van der Meij y Bout, 2004 \\
\hline Lonchura fringilloides & Passeriformes & Estrildidae & 0,0162 & 5 & van der Meij y Bout, 2004 \\
\hline Lonchura pallida & Passeriformes & Estrildidae & 0,0132 & 3,3 & van der Meij y Bout, 2004 \\
\hline Lonchura punctulata & Passeriformes & Estrildidae & 0,0124 & 3,7 & van der Meij y Bout, 2004 \\
\hline Neochima modesta & Passeriformes & Estrildidae & 0,0132 & 2 & van der Meij y Bout, 2004 \\
\hline Neochmia ruficauda & Passeriformes & Estrildidae & 0,012 & 2,1 & van der Meij y Bout, 2004 \\
\hline Padda oryzivora & Passeriformes & Estrildidae & 0,0304 & 9,6 & van der Meij y Bout, 2004 \\
\hline Phoephila acuticauda & Passeriformes & Estrildidae & 0,0183 & 2,6 & van der Meij y Bout, 2004 \\
\hline Taeniopygia bichenovi & Passeriformes & Estrildidae & 0,0097 & 1,9 & van der Meij y Bout, 2004 \\
\hline Poephila cincta & Passeriformes & Estrildidae & 0,0157 & 2,5 & van der Meij y Bout, 2004 \\
\hline Pytilia hypogrammica & Passeriformes & Estrildidae & 0,0153 & 3,1 & van der Meij y Bout, 2004 \\
\hline Taenopygia guttata & Passeriformes & Estrildidae & 0,0227 & 3,9 & van der Meij y Bout, 2004 \\
\hline Uraeginthus bengalus & Passeriformes & Estrildidae & 0,01 & 1,3 & van der Meij y Bout, 2004 \\
\hline Carduelis chloris & Passeriformes & Fringillidae & 0,0283 & 13,6 & van der Meij y Bout, 2004 \\
\hline Carduelis flammea & Passeriformes & Fringillidae & 0,0126 & 2,9 & van der Meij y Bout, 2004 \\
\hline Carduelis sinica & Passeriformes & Fringillidae & 0,02 & 8,1 & van der Meij y Bout, 2004 \\
\hline Carduelis spinus & Passeriformes & Fringillidae & 0,013 & 3,1 & van der Meij y Bout, 2004 \\
\hline Carpodactus erythrinus & Passeriformes & Fringillidae & 0,0216 & 6,3 & van der Meij y Bout, 2004 \\
\hline Eophona migratoria & Passeriformes & Fringillidae & 0,052 & 36,1 & van der Meij y Bout, 2004 \\
\hline Mycerobas affinis & Passeriformes & Fringillidae & 0,07 & 38,4 & van der Meij y Bout, 2004 \\
\hline Pyrrhula pyrrhula & Passeriformes & Fringillidae & 0,0209 & 4,9 & van der Meij y Bout, 2004 \\
\hline Rhodopechys obsoleta & Passeriformes & Fringillidae & 0,0225 & 6,4 & van der Meij y Bout, 2004 \\
\hline
\end{tabular}




\begin{tabular}{lllccc} 
Serinus leucopygius & Passeriformes & Fringillidae & 0,0095 & 2,1 & van der Meij y Bout, 2004 \\
Serinus mozambicus & Passeriformes & Fringillidae & 0,012 & 2,9 & van der Meij y Bout, 2004 \\
Serinus sulphuratus & Passeriformes & Fringillidae & 0,0182 & 11,8 & van der Meij y Bout, 2004 \\
\hline \hline
\end{tabular}


Apéndice 9.1. Correlación variable-componente (Factor Loading) de los tres primeros componentes principales del análisis del fémur.

\begin{tabular}{lccc}
\hline Variable & Componente 1 & Componente 2 & Componente 3 \\
\hline $\log _{10}$ EA & $-0,985530$ & 0,147940 & 0,057522 \\
$\log _{10}$ EB & $-0,990120$ & 0,126664 & 0,044081 \\
$\log _{10}$ EC & $-0,995509$ & $-0,046974$ & 0,025910 \\
$\log _{10}$ ED & $-0,988467$ & $-0,022741$ & $-0,142257$ \\
$\log _{10}$ EE & $-0,995604$ & $-0,052180$ & 0,004224 \\
$\log _{10}$ EF & $-0,992791$ & $-0,071736$ & 0,052872 \\
$\log _{10}$ EG & $-0,992040$ & $-0,089747$ & 0,051280 \\
$\log _{10}$ EH & $-0,992681$ & 0,073565 & $-0,040007$ \\
$\log _{10}$ EI & $-0,996276$ & 0,008467 & 0,002761 \\
\hline \hline
\end{tabular}


Apéndice 9.2. Correlación variable-componente (Factor Loading) de los tres primeros componentes principales del análisis del tibiotarso.

\begin{tabular}{lccc}
\hline Variable & Componente 1 & Componente 2 & Componente 3 \\
\hline $\log _{10}$ ZA & $-0,974596$ & 0,220652 & 0,008033 \\
$\log _{10}$ ZB & $-0,974516$ & 0,221372 & 0,003767 \\
$\log _{10}$ ZC & $-0,993325$ & $-0,077889$ & 0,002029 \\
$\log _{10}$ ZD & $-0,980264$ & $-0,052710$ & $-0,139314$ \\
$\log _{10}$ ZE & $-0,983132$ & $-0,119729$ & 0,081259 \\
$\log _{10}$ ZF & $-0,992210$ & $-0,080653$ & 0,027323 \\
$\log _{10}$ ZG & $-0,992940$ & $-0,041788$ & 0,051346 \\
$\log _{10}$ ZH & $-0,991277$ & $-0,002612$ & 0,101429 \\
$\log _{10}$ ZI & $-0,991348$ & $-0,020670$ & 0,070607 \\
$\log _{10}$ ZJ & $-0,980483$ & $-0,030397$ & $-0,166582$ \\
\hline \hline
\end{tabular}


Apéndice 9.3. Correlación variable-componente (Factor Loading) de los tres primeros componentes principales del análisis del tarsometatarso.

\begin{tabular}{lccc}
\hline \hline Variable & Componente 1 & Componente 2 & Componente 3 \\
\hline $\log _{10}$ AA & 0,933883 & 0,344292 & $-0,026926$ \\
$\log _{10}$ AB & 0,929108 & 0,354416 & $-0,027480$ \\
$\log _{10}$ AC & 0,928455 & 0,358533 & $-0,027118$ \\
$\log _{10}$ AD & 0,986367 & $-0,134627$ & 0,003583 \\
$\log _{10}$ AE & 0,972056 & $-0,188578$ & 0,002003 \\
$\log _{10}$ AF & 0,950171 & $-0,287705$ & 0,017450 \\
$\log _{10}$ AG & 0,982908 & $-0,053933$ & 0,046226 \\
$\log _{10}$ AH & 0,943001 & $-0,304081$ & 0,049256 \\
$\log _{10}$ AI & 0,974144 & $-0,109495$ & 0,085714 \\
$\log _{10}$ AJ & 0,944045 & $-0,148206$ & 0,192803 \\
$\log _{10}$ AK & 0,934251 & $-0,028929$ & $-0,287925$ \\
$\log _{10}$ AN & $-0,111609$ & $-0,799396$ & $-0,279223$ \\
$\log _{10}$ AO & $-0,129891$ & $-0,825875$ & $-0,213294$ \\
$\log _{10}$ AP & 0,986907 & $-0,049973$ & $-0,037390$ \\
\hline \hline
\end{tabular}


Apéndice 9.4. Correlación variable-componente (Factor Loading) de los tres primeros componentes principales del análisis del miembro posterior.

\begin{tabular}{lccc}
\hline \hline $\operatorname{Variable}_{10}$ & Componente 1 & Componente 2 & Componente 3 \\
\hline $\log _{10}$ EA & 0,980742 & $-0,065499$ & 0,036446 \\
$\log _{10}$ EB & 0,986336 & $-0,052924$ & 0,028570 \\
$\log _{10}$ EC & 0,988237 & $-0,109420$ & 0,000512 \\
$\log _{10}$ ED & 0,979324 & $-0,101659$ & $-0,000131$ \\
$\log _{10}$ EE & 0,990313 & $-0,082125$ & 0,015930 \\
$\log _{10}$ EF & 0,987269 & $-0,088030$ & 0,032087 \\
$\log _{10}$ EG & 0,985771 & $-0,111244$ & 0,014887 \\
$\log _{10}$ EH & 0,986539 & $-0,060602$ & 0,003660 \\
$\log _{10}$ EI & 0,994776 & $-0,033293$ & 0,001485 \\
$\log _{10}$ ZA & 0,971388 & 0,177814 & 0,010072 \\
$\log _{10}$ ZB & 0,971830 & 0,176097 & 0,012323 \\
$\log _{10}$ ZC & 0,993970 & $-0,047058$ & 0,017376 \\
$\log _{10}$ ZD & 0,978365 & 0,030217 & 0,058926 \\
$\log _{10}$ ZE & 0,984964 & $-0,115256$ & $-0,031016$ \\
$\log _{10}$ ZF & 0,991543 & $-0,064144$ & 0,033112 \\
$\log _{10}$ ZG & 0,993250 & $-0,039546$ & 0,003548 \\
$\log _{10}$ ZH & 0,991767 & $-0,034084$ & $-0,032657$ \\
$\log _{10}$ ZI & 0,990222 & $-0,058777$ & $-0,014634$ \\
$\log _{10}$ ZJ & 0,975767 & 0,019571 & 0,053690 \\
$\log _{10}$ AA & 0,919746 & 0,380594 & $-0,002335$ \\
$\log _{10}$ AB & 0,917403 & 0,383714 & $-0,003263$ \\
$\log _{10}$ AC & 0,914318 & 0,393381 & $-0,001570$ \\
$\log _{10}$ AD & 0,990527 & $-0,097197$ & $-0,018908$ \\
$\log _{10}$ AE & 0,972984 & $-0,167045$ & $-0,011963$ \\
$\log _{10}$ AF & 0,948754 & $-0,267913$ & $-0,003978$ \\
$\log _{10}$ AG & 0,980749 & $-0,013063$ & 0,018443 \\
$\log _{10}$ AH & 0,940183 & $-0,292334$ & 0,024285 \\
$\log _{10}$ AI & 0,971496 & $-0,093905$ & 0,023227 \\
$\log _{10}$ AJ & 0,930776 & $-0,107920$ & 0,182684 \\
$\log _{10}$ AK & 0,908912 & 0,025729 & $-0,392775$ \\
$\log _{10}$ AN & $-0,157315$ & $-0,781012$ & $-0,109678$ \\
$\log _{10}$ AO & $-0,211291$ & $-0,798304$ & $-0,068400$ \\
$\log _{10}$ AP & 0,982585 & $-0,006600$ & $-0,078531$ \\
\hline \hline
\end{tabular}


Apéndice 9.5. Correlación variable-componente (Factor Loading) de los tres primeros componentes principales del análisis de los índices del miembro posterior.

\begin{tabular}{lccc}
\hline \hline Variable & Componente 1 & Componente 2 & Componente 3 \\
\hline EA/EB & $-0,471218$ & $-0,034904$ & 0,206271 \\
EC/ED & $-0,176388$ & $-0,186711$ & 0,657679 \\
EC/EE & $-0,366726$ & $-0,361277$ & 0,316726 \\
EF/EG & 0,138868 & 0,022250 & 0,067758 \\
EI/EH & 0,125612 & $-0,038338$ & 0,281557 \\
ZB/ZA & $-0,178406$ & $-0,053170$ & $-0,225944$ \\
ZD/ZC & 0,374706 & 0,197886 & 0,217298 \\
ZJ/ZD & 0,011700 & 0,044001 & $-0,700861$ \\
ZC/ZE & 0,300274 & 0,098452 & 0,069826 \\
ZF/ZG & 0,016809 & 0,314282 & $-0,273805$ \\
ZH/ZI & 0,202413 & $-0,040420$ & 0,213972 \\
AA/AB & $-0,100461$ & $-0,054431$ & 0,004083 \\
AA/AC & $-0,585034$ & $-0,052676$ & $-0,139949$ \\
AD/AP & $-0,374695$ & 0,424243 & $-0,264325$ \\
AD/AE & 0,427844 & 0,016645 & 0,309516 \\
AJ/AK & $-0,373353$ & 0,915534 & 0,093245 \\
AF/AG & $-0,879071$ & $-0,074779$ & $-0,363023$ \\
AH/AI & $-0,801439$ & $-0,067055$ & $-0,397899$ \\
AN/AO & $-0,050027$ & $-0,141577$ & 0,102053 \\
EB/ZB & $-0,551999$ & $-0,039778$ & 0,230906 \\
ZB/AA & $-0,960714$ & $-0,091793$ & 0,135027 \\
EB/AA & $-0,942313$ & $-0,085467$ & 0,198807 \\
\hline \hline
\end{tabular}

